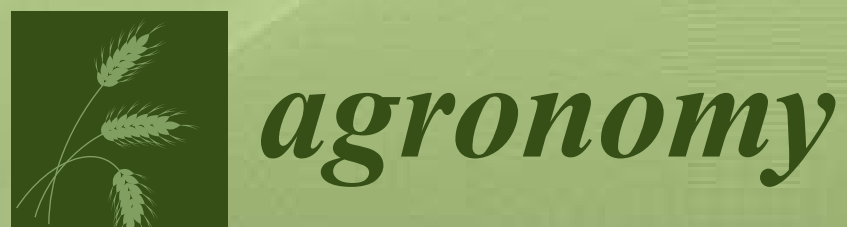

\title{
Fertilizer \\ Application on Crop Yield
}

Edited by Jagadish Timsina Printed Edition of the Special Issue Published in Agronomy 
Fertilizer Application on Crop Yield 



\section{Fertilizer Application on Crop Yield}

Special Issue Editor

Jagadish Timsina

MDPI • Basel • Beijing • Wuhan • Barcelona • Belgrade

\section{MDPI}


Special Issue Editor

Jagadish Timsina

University of Melbourne

Australia

Editorial Office

MDPI

St. Alban-Anlage 66

4052 Basel, Switzerland

This is a reprint of articles from the Special Issue published online in the open access journal Agronomy (ISSN 2073-4395) from 2018 to 2019 (available at: https://www.mdpi.com/journal/agronomy/ special_issues/Fertilizer_Crop_Yield)

For citation purposes, cite each article independently as indicated on the article page online and as indicated below:

LastName, A.A.; LastName, B.B.; LastName, C.C. Article Title. Journal Name Year, Article Number, Page Range.

ISBN 978-3-03897-654-7 (Pbk)

ISBN 978-3-03897-655-4 (PDF)

(C) 2019 by the authors. Articles in this book are Open Access and distributed under the Creative Commons Attribution (CC BY) license, which allows users to download, copy and build upon published articles, as long as the author and publisher are properly credited, which ensures maximum dissemination and a wider impact of our publications.

The book as a whole is distributed by MDPI under the terms and conditions of the Creative Commons license CC BY-NC-ND. 


\section{Contents}

About the Special Issue Editor $\ldots \ldots \ldots \ldots \ldots \ldots \ldots$ vii

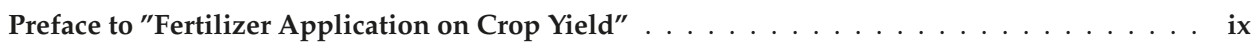

Jagadish Timsina

Can Organic Sources of Nutrients Increase Crop Yields to Meet Global Food Demand?

Reprinted from: Agronomy 2018, 8, 214, doi:10.3390/agronomy8100214 . . . . . . . . . . 1

Bijay- Singh

Are Nitrogen Fertilizers Deleterious to Soil Health?

Reprinted from: Agronomy 2018, 8, 48, doi:10.3390/agronomy8040048 . . . . . . . . . . . . 21

Sheetal Sharma, Rajeev Padbhushan and Upendra Kumar

Integrated Nutrient Management in Rice-Wheat Cropping System: An Evidence on Sustainability in the Indian Subcontinent through Meta-Analysis

Reprinted from: Agronomy 2019, 9, 71, doi:10.3390/agronomy9020071 . . . . . . . . . . . 40

Vinod K. Singh, Brahma S. Dwivedi, Rajendra P. Mishra, Arvind K. Shukla, Jagadish Timsina, Pravin K. Upadhyay, Kapila Shekhawat, Kaushik Majumdar and Azad S. Panwar Yields, Soil Health and Farm Profits under a Rice-Wheat System: Long-Term Effect of Fertilizers and Organic Manures Applied Alone and in Combination

Reprinted from: Agronomy 2019, 9, 1, doi:10.3390/agronomy9010001

Ruth Njoroge, Abigael N. Otinga, John R. Okalebo, Mary Pepela and Roel Merckx

Maize (Zea mays L.) Response to Secondary and Micronutrients for Profitable N, P and K Fertilizer Use in Poorly Responsive Soils

Reprinted from: Agronomy 2018, 8, 49, doi:10.3390/agronomy8040049 _ . . . . . . . . . . . 77

Dale Loussaert, Josh Clapp, Nick Mongar, Dennis P. O'Neill and Bo Shen

Nitrate Assimilation Limits Nitrogen Use Efficiency (NUE) in Maize (Zea mays L.)

Reprinted from: Agronomy 2018, 8, 110, doi:10.3390/agronomy8070110 . . . . . . . . . . . 97

Saiful Islam, Jagadish Timsina, Muhammad Salim, Kaushik Majumdar and Mahesh K Gathala

Potassium Supplying Capacity of Diverse Soils and K-Use Efficiency of Maize in South Asia

Reprinted from: Agronomy 2018, 8, 121, doi:10.3390/agronomy8070121 . . . . . . . . . . 120

Francesco Rossini, Maria Elena Provenzano, Francesco Sestili and Roberto Ruggeri

Synergistic Effect of Sulfur and Nitrogen in the Organic and Mineral Fertilization of Durum

Wheat: Grain Yield and Quality Traits in the Mediterranean Environment

Reprinted from: Agronomy 2018, 8, 189, doi:10.3390/agronomy8090189 . . . . . . . . . . . 142

Timothy J. Boring, Kurt D. Thelen, James E. Board, Jason L. De Bruin, Chad D. Lee,

Seth L. Naeve, William J. Ross, Wade A. Kent and Landon L. Ries

Phosphorus and Potassium Fertilizer Application Strategies in Corn-Soybean Rotations

Reprinted from: Agronomy 2018, 8, 195, doi:10.3390/agronomy8090195 . . . . . . . . . . . 159

Khin Thuzar Win, Aung Zaw Oo, Naoko Ohkama-Ohtsu and Tadashi Yokoyama

Bacillus Pumilus Strain TUAT-1 and Nitrogen Application in Nursery Phase Promote Growth of Rice Plants under Field Conditions

Reprinted from: Agronomy 2018, 8, 216, doi:10.3390/agronomy8100216 . . . . . . . . . . . 171 
Lu Yang, Jinshun Bai, Jia Liu, Naohua Zeng and Weidong Cao

Green Manuring Effect on Changes of Soil Nitrogen Fractions, Maize Growth, and Nutrient Uptake

Reprinted from: Agronomy 2018, 8, 261, doi:10.3390/agronomy8110261 . . . . . . . . . . . . . 183

Hirak Banerjee, Krishnendu Ray, Sudarshan Kumar Dutta, Kaushik Majumdar,

Talatam Satyanarayana and Jagadish Timsina

Optimizing Potassium Application for Hybrid Rice (Oryza sativa L.) in Coastal Saline Soils of West Bengal, India

Reprinted from: Agronomy 2018, 8, 292, doi:10.3390/agronomy8120292 . . . . . . . . . . . . . . . 196

Marta Aranguren, Ana Aizpurua, Ander Castellón, Gerardo Besga and Nerea Villar

Soil Properties for Predicting Soil Mineral Nitrogen Dynamics Throughout a Wheat Growing Cycle in Calcareous Soils

Reprinted from: Agronomy 2018, 8, 303, doi:10.3390/agronomy8120303 . . . . . . . . . . . . 210

Jes ús Santillano-Cázares, Fidel Núñez-Ramírez, Cristina Ruíz-Alvarado, María Elena Cárdenas-Castañeda and Iván Ortiz-Monasterio

Assessment of Fertilizer Management Strategies Aiming to Increase Nitrogen Use Efficiency of Wheat Grown Under Conservation Agriculture

Reprinted from: Agronomy 2018, 8, 304, doi:10.3390/agronomy8120304 


\section{About the Special Issue Editor}

Jagadish Timsina (Prof. Dr.) is a globally respected agricultural scientist specializing in agronomy, plant and soil nutrient management, conservation agriculture, crop and systems modeling, farming systems, and agroecosystems sustainability. He has a wide range of research and development experiences in Australia and several countries in Asia. He started his career as a Lecturer at the Institute of Agriculture and Animal Sciences, Tribhuvan University, Nepal, where he worked for about 15 years. He then moved to Australia where he worked as a Senior Research Scientist with CSIRO Land and Water Division and as a Senior Research Fellow at the University of Melbourne, where he continues to be associated as an Honorary Principal Research Fellow. In addition, he has worked with some of the world's most respected agriculture research institutes such as the International Rice Research Institute (IRRI) and International Maize and Wheat Research Centre (CIMMYT). He now holds an Adjunct Professor position with the Agriculture and Forestry University in Nepal. He is currently the Director of Agricultural Research and Development to the Institute for Studies and Development Worldwide (IFSD), Sydney and Senior Adviser to the International Institute for Sustainable Mountain Development (IISUMOD) in Rome, Italy. He has led several research projects on water, plant and soil nutrient management, crop and systems modeling, food security, and farming systems and sustainable agricultural intensification, to name a few. He has published over 140 scientific papers and sits on the editorial boards of Agricultural Systems, Global Journal of Agriculture and Allied Sciences, and EC Nutrition. He is an active academic contributing to higher and vocational education sectors in Australia, Bangladesh, and Nepal. 



\section{Preface to "Fertilizer Application on Crop Yield"}

Inorganic fertilizers consume at least one-third of the total energy used by agriculture globally. Increased fertilizer application can increase crop yields and improve global food security, and has the potential to eliminate hunger and poverty. The excessive application of fertilizer, however, can contribute to groundwater pollution, greenhouse gas emissions, eutrophication, deposition and disruptions to natural ecosystems, and soil acidification over time. In contrast, insufficient application can decrease crop yields. Both extremes have raised broader concerns regarding soil and environmental degradation, nutrient deficiencies, increased fertilizer costs, and decreased profits. To develop practical recommendations for farmers, yield responses to applied fertilizers from inorganic and organic sources, indigenous nutrient supply from soil, and nutrient use efficiency (NUE) require consideration. These factors form the basis of precision or field-specific nutrient management approaches, which could aid in the development of more precise and spatially appropriate fertilizer recommendations. Inadequate knowledge of these factors has constrained efforts to develop precision nutrient management recommendations that aim to rationalize input costs, increase yield and profits, and reduce environmental externalities.

Over the years, advances have been made in understanding the crop yield response to fertilizers and NUE in varying farmers' management practices. However, small farmers in many countries still think inorganic fertilizers are expensive inputs and degrade soils, and, thus, policymakers want to promote organic fertilizers instead of inorganic fertilizers. There is a lack of sufficient scientific understanding regarding the need and benefit of inorganic fertilizers to meet the nutrient demand of high-yielding crops. A balanced application of inorganic and organic fertilizers maybe be advocated to increase yields and profits, and reduce soil and environmental degradation.

This Special Issue of the journal provided some evidence of the usefulness of integrated nutrient management (i.e., with inorganic and organic sources of nutrients) to sustain soil and supply nutrients to crops grown with major cereal and legume crops in some developing countries. The Special Issue has 3 critical reviews and 11 papers focusing on the management of inorganic and organic fertilizer application, NUE and crop yield response, and policy advice. The topic is, however, quite broad and requires more knowledge to be generated across crops and cropping systems, soil types, and geographies. I would like to thank everyone who has contributed to it and who is open to further discussion and contribution in the future.

Jagadish Timsina Special Issue Editor 



\title{
Can Organic Sources of Nutrients Increase Crop Yields to Meet Global Food Demand?
}

\author{
Jagadish Timsina ${ }^{1,2}$ \\ 1 Soil and Environment Research Group, Faculty of Veterinary \& Agricultural Sciences, \\ University of Melbourne, Victoria 3010, Australia; jtimsina@unimelb.edu.au; Tel.: +61-420-231-211 \\ 2 Agriculture \& Forestry University, Rampur, Chitwan 44209, Nepal
}

Received: 27 August 2018; Accepted: 1 October 2018; Published: 3 October 2018

\begin{abstract}
Meeting global demand of safe and healthy food for the ever-increasing population now and into the future is currently a crucial challenge. Increasing crop production by preserving environment and mitigating climate change should thus be the main goal of today's agriculture. Conventional farming is characterized by use of high-yielding varieties, irrigation water, chemical fertilizers and synthetic pesticides to increase yields. However, due to either over- or misuse of chemical fertilizers or pesticides in many agro-ecosystems, such farming is often blamed for land degradation and environmental pollution and for adversely affecting the health of humans, plants, animals and aquatic ecosystems. Of all inputs required for increased agricultural production, nutrients are considered to be the most important ones. Organic farming, with use of organic sources of nutrients, is proposed as a sustainable strategy for producing safe, healthy and cheaper food and for restoring soil fertility and mitigating climate change. However, there are several myths and controversies surrounding the use of organic versus inorganic sources of nutrients. The objectives of this paper are: (i) to clarify some of the myths or misconceptions about organic versus inorganic sources of nutrients and (ii) to propose alternative solutions to increase on-farm biomass production for use as organic inputs for improving soil fertility and increasing crop yields. Common myths identified by this review include that organic materials/fertilizers can: (i) supply all required macro- and micro-nutrients for plants; (ii) improve physical, chemical and microbiological properties of soils; (iii) be applied universally on all soils; (iv) always produce quality products; (v) be cheaper and affordable; and (vi) build-up of large amount of soil organic matter. Other related myths are: "legumes can use entire amount of $\mathrm{N}_{2}$ fixed from atmosphere" and "bio-fertilizers increase nutrient content of soil." Common myths regarding chemical fertilizers are that they: (i) are not easily available and affordable, (ii) degrade land, (iii) pollute environment and (iv) adversely affect health of humans, animals and agro-ecosystems. The review reveals that, except in some cases where higher yields (and higher profits) can be found from organic farming, their yields are generally $20-50 \%$ lower than that from conventional farming. The paper demonstrates that considering the current organic sources of nutrients in the developing countries, organic nutrients alone are not enough to increase crop yields to meet global food demand and that nutrients from inorganic and organic sources should preferably be applied at 75:25 ratio. The review identifies a new and alternative concept of Evergreen Agriculture (an extension of Agroforestry System), which has potential to supply organic nutrients in much higher amounts, improve on-farm soil fertility and meet nutrient demand of high-yielding crops, sequester carbon and mitigate greenhouse gas emissions, provide fodder for livestock and fuelwood for farmers and has potential to meet global food demand. Evergreen Agriculture has been widely adapted by tens of millions of farmers in several African countries and the review proposes for evaluation and scaling-up of such technology in Asian and Latin American countries too.
\end{abstract}

Keywords: organic farming; conventional farming; organic nutrients; chemical fertilizers; global food demand; agroforestry system; evergreen agriculture 


\section{Introduction}

Providing enough, safe and healthy food to their citizens by avoiding environmental degradation under current and the projected climate change are the most important issues that all countries are facing in the world. Global food production increased by 70\% from 1970 to 1995 in developing countries, largely due to the green revolution technologies (also called conventional agriculture) which uses high-yielding inputs such as improved and high-yielding varieties (HYVs), irrigation, chemical fertilizers and synthetic pesticides $[1,2]$ and the production has been increasing after that period too. As per FAO's revised projection, global food production should be $60 \%$ higher in 2050 than in 2005/2007 to feed the projected global population of 10 billion [3,4]. To close this gap, total crop production needs to be increased even more from 2006 to 2050 than it did in the same number of years from 1962 to 2006 [5]. Though in the past green revolution technologies have increased crop yields and produced food to meet caloric requirements of the global population [6], there are also increasing concerns about the environmental costs, such as increased soil erosion, surface and groundwater contamination, greenhouse gas emissions, increased pest resistance and reduced biodiversity and so forth, with use of such technologies $[7,8]$. These concerns suggest that more sustainable methods of food production are essential to meet the food requirements of ever-increasing population now and into the future but at the same time such methods must maintain natural resource base by avoiding land degradation and mitigating climate change. The challenge now is to fine-tune the existing technologies or develop alternative technologies that can increase crop yields to meet global food demand of increasing population but without compromising with the natural resources or the environment.

Over the past 2-3 decades organic agriculture has been advocated as an alternative form of farming to produce food sustainably by reducing the impact of agriculture on the environment [9-12]. All these authors believe that a widespread shift from conventional to organic farming could feed the world with safe and healthy food now and into the future and also could avoid environmental degradation. Their claims however have been widely criticized by many authors [13-18], as they all argue that organic farming without the use of synthetic fertilizers, pesticides, or genetically-engineered crops simply cannot feed the projected 10 billion people for 2050 and that extra lands and water would be required for organic farming to produce similar amount of food to that from conventional farming. Kirchmann et al. $[2,19,20]$ warned that expansion of areas for organic farming into forests or natural lands to feed the projected global population would lead to loss of biodiversity or natural habitats, increase of greenhouse gas emissions and depletion of ecosystem services. Ammann [21] and Ronald and Adamchak [22] however proposed a mid-way or a balanced view suggesting that a combination of high technology and organic techniques (i.e., a hybrid of organic and conventional farming) may provide more realistic and sustainable solutions.

Although many production factors (nutrients, water, pest and diseases, labour, prices of inputs and outputs, etc.) contribute to crop yield, it seems from various debates and arguments surrounding the use of conventional and organic farming that availability of required amounts of plant nutrients and the practicality of their use to produce enough food to feed 10 billion people remain the central issues of all these debates. While role of nutrients, whether organic or inorganic, for increased crop production is universally and unequivocally recognised, there seem to be several myths or misconceptions of using organic farming and/or organic sources of nutrients. Some sectors of the society, particularly those activists or advocates influenced by International Non-governmental Organizations (INGOs) or Non-governmental Organizations (NGOs), some researchers and extensions workers and even the government policy makers in many developing countries claim that use of the chemical fertilizers adversely affects soil quality and decreases the soil and crop productivity, whereas the use of organic farming or organic nutrients unquestionably and universally increases soil and crop productivity. These claims however have very little scientific basis and any decline in soil or crop productivity due to the use of chemical fertilizers could be due to their either over- or misuse. 
This paper focuses on the discussion on nutrient sources for crops grown under organic and conventional farming and tries to argue whether existing sources of organic materials can supply enough nutrients to increase crop yields so as to meet the food demand of the growing population. The specific objectives are: (i) to clarify some of the myths or misconceptions regarding organic nutrients/fertilizers and chemical fertilizers by providing scientific facts and realities so that the applications of appropriate amounts of inorganic or organic fertilizers either alone or in their combination can be advised to farmers and (ii) to propose alternative solutions to increase on-farm biomass production for use as organic inputs for maintaining or improving on-farm soil fertility and increasing crop yields. Such clarifications and alternative solutions could help planners and policy makers of any country to develop policies and programs to promote for the rationale use of inorganic and/or organic nutrient inputs to achieve food security and get rid of poverty. The paper is organised into the following sections: (i) Differences between organic and conventional agriculture (iii) Sources of inorganic and organic nutrients for crops (ii) Myths and realities of use of organic materials/fertilizers and chemical fertilizers (iii) Nutrient requirements and supply for organically- and conventionally-grown crops (iv) Need for site-specific nutrient management (v) Alternative approaches to increase on-farm soil fertility and nutrient supply (vi) Conclusions and research and policy implications.

\section{Organic Agriculture: Concepts, Principles and Global Performance against Conventional Agriculture}

FAO has defined organic agriculture as a holistic production management system which promotes and enhances agro-ecosystem health, including biodiversity, biological cycles and soil biological activity. It emphasizes the use of management practices in preference to the use of off-farm inputs, considering that regional conditions require locally adapted systems (http:/ /www.fao.org/ docrep/meeting/x0075e.html). This is accomplished by using, where possible, agronomic, biological and mechanical methods, as opposed to using synthetic materials, to fulfil any specific function within the system. International Federation of Organic Agriculture Movement (IFOAM) has defined organic agriculture as a production system that sustains the health of soils, ecosystems and people and relies on ecological processes, biodiversity and cycles adapted to local conditions, rather than the use of external inputs with adverse effects and such agriculture combines tradition, innovation and science to benefit the shared environment and promote fair relationships and a good quality of life for all involved [23]. IFOAM stresses that organic agriculture is based on the principles of health, ecology, fairness and care. It can sustain and enhance the health of soil, plant, animal, human and planet; sustain living ecological systems and cycles; build on relationships that ensure fairness about the common environment and life opportunities; and manage in a precautionary and responsible manner to protect the health and well-being of current and future generations and the environment. National Research Council (NRC) from USA [24] has also identified organic methods as one of several innovative systems that can meet production, environmental and socio-economic objectives and sustainability goals. Despite the heavy emphasis on, and importance given to organic agriculture by various national and international entities it is now practised only on about 50.9 Mha (1.1\% of total agricultural land) by 2.4 million farmers globally, with about 87 countries having some sort of organic regulations or certifications [25].

Organic farming is a form of agriculture that deliberately follows a set of management practices, which exclude the use of chemical fertilizers and other chemical inputs such as synthetic pesticides and genetically-engineered crops. Organic agriculture uses organic materials to supply nutrients and to control pests and diseases. There are contrasting results from both developed and developing countries regarding the performance of organic versus conventional agriculture. In one of the earliest reviews, Stanhill [26], using data from developed countries and mostly from prior to 1985, reported 9\% lower yield for organic crops compared to conventional ones. Penning de Vries et al. [27], based on results from a crop simulation model, concluded that organic agriculture can only produce enough 
food to feed 9 billion people assuming moderate amounts of diet and with animal proteins. Lotter [28] reported that large scale conversion from conventional to organic agriculture is possible only if meat consumption is reduced. Subsequently, Badgley et al. [9], comparing yield data between organic and conventional agriculture from 293 studies reported about $8 \%$ lower yield for organic agriculture. Kirchmann et al. $[19,20]$, however reported that organic crop yields are 25-50\% lower than conventional ones, which were mainly attributed to lower nutrient availability, poorer weed control and limited possibility to improve the soil nutrient status.

Ponti et al. [29], using a meta-dataset of 362 studies globally, concluded that individual yields of organic crops, on an average, were $20 \%$ lower than conventional crops. In their study, the organic yield gaps varied significantly between crop groups and regions and the gaps increased as yields of conventional crops increased. The results of Ponti et al. however are not surprising because potential yield of any crop is climate-derived and not limited by water or nutrients, with pests and diseases fully controlled [30]. Yield potential of any crop can be increased with increasing amounts of nutrients and water and by fully controlling weeds, pests and diseases so that crop will not be stressed by any biotic and abiotic factors [30-32]. On the other hand, even the well-managed organic crops generally do not receive adequate amounts of nutrients and pests and diseases are not fully controlled. Also from a meta-analysis of 316 yield comparisons in 66 studies, Seufert et al. [12] concluded that organic crops in developed countries yielded $20 \%$ lower but when developed and developing countries were combined, they yielded $25 \%$ lower than their conventional counterparts. However, they also found that for certain crops and for certain growing conditions and management practices, yields of organic crops matched their conventional counterparts. Results from Badgely et al. [9], Ponti et al. [29] and Seufert et al. [12] suggest that adoption of organic agriculture under conditions in which it performs well might close the yield gap between organic and conventional crops.

The results and conclusions of these three studies $[9,12,29]$ were heavily disputed by Cassman [33], Connor [16], Goulding et al. [15] and Dobermann [34], who all argued that their yield data and assumptions made on nutrient availability from organic sources were quite unrealistic. Connor [16] and Dobermann [34] questioned about the analysis methods of Badgely et al. owing to their reliance on yield ratios as in many cases they represented large differences in crop management. Due to flaws and criteria for design and evaluation of comparisons between organic and conventional agriculture, Kirchmann et al. [2] proposed three stringency criteria to ensure scientific quality of data: requirements of similar initial soil fertility, comparable crop production type and quantification of off-farm organic nutrient inputs. Based on the review of above studies, crop yields from organic farming are generally about $20-50 \%$ lower although in some cases their yields and economic returns are higher than from conventional farming.

\section{Sources of Organic Nutrients}

Several terms (e.g., organic farming, natural farming, alternative farming, regenerative farming, low-input agriculture, sustainable agriculture, etc.) are used in literature, sometime interchangeably, to describe organic farming. Likewise, many other terms (e.g., organic materials, organic fertilizers, organic nutrients and bio-fertilizers, etc.) are used to describe sources of nutrients. Crop plants require nutrients derived from organic as well as inorganic sources. Common inorganic sources of nutrients include fossil-fuel derived chemical fertilizers while organic sources include decomposed or undecomposed plant and animal materials. Many different types of chemical fertilizers in various formulations are available in markets in all countries. Chemical fertilizers, especially the nitrogenous fertilizers, are prone to losses from soil-plant systems. Hence, smart and innovative fertilizers such as controlled-release or slow-release fertilizers (e.g., poly-coated urea), deep placement (e.g., urea super granules), or nitrification inhibitors are being developed and used to reduce losses and increase the efficiency of fertilizers [35]. Precision nutrient management such as site-specific nutrient management (SSNM) can help reduce and/or optimize the fertilizer use considering the field, soil or site history and characteristics and resulting nutrient needs. This will be discussed in Section 6 . 
Some of the organic materials used as organic sources of fertilizers in Asia include (i) agricultural wastes such as crop residues (including rice and wheat straw, maize stover, legume leaves and residues, etc.), rice hulls, wheat chaffs, weeds and grasses in farms, homesteads and farmsteads, biochars, biogas slurry, oilcakes and so forth, (ii) biodegradable wastes, including kitchen and market wastes, fruits and vegetables peelings and biosolids and so forth, (iii) farmyard manure (FYM) and litters such as cattle manure, poultry manure, composts, vermicomposts and so forth, from on-farm and off-farm sources and (iv) forest and grasslands wastes, such as tree leaves, branches and twigs, shrubs and herbs underneath trees, roadside and community grasses and weeds and so forth. Other common sources of organic nutrients include growing food and non-food legumes as intercrops or rotational crops for current or residual $\mathrm{N}$ contribution, surface or residue recycling and in situ or ex-situ $\mathrm{N}_{2}$-fixing green manure crops and so forth $[36,37]$. Organic fertilizers refer only to decomposed or partially-decomposed plant or animal materials used as a source of nutrients for crops. These also refer to small-sized pellets or granules (for example, granules made from cattle or poultry manure) developed from processing of organic materials. Finally, bio-fertilizers refer to microbial amendments of organisms such as Rhizobia or Azospirilium, bacteria promoted to stimulate biological $\mathrm{N}_{2}$ fixation, or Trichoderma, a fungus promoted to hasten decomposition of organic materials [36].

In recent years, many kinds and formulations of organic fertilizers and bio-fertilizers are produced in many countries in South and SE Asia as well as imported from other countries and are floated in the markets as organic fertilizers. Some of such fertilizers, for example in Nepal, are bio-organic fertilizers, Jaibik Superphosphate (P), Jaibik dhulo (N), Jhol mal, HB 101, Bonsoon Super Prangarik Mal, Green Gold Super Prangarik Mal (Nepal), Chao Nang granules, Super Green plus, Super Green plant, Super Green mix and Premium Azosp, Premium Phospofix and Premium Azotoplus (India) [38]. Likewise, some common organic fertilizers in the Philippines are coco-composts, vermicomposts, Kalikasan Organic, Norfarco Bioorganic, Bio-green Compost, Foundation LCF Organic, Green Harvest Organic, Bio-earth Organic and so forth [36].

\section{Organic versus Inorganic Materials/Fertilizers: Myths and Realities}

Organic materials are widely used, albeit in small quantities, especially in subsistence farming systems in Asia, Africa and Latin America. Organic materials can improve soil's physical properties such as structure and aggregation and water holding capacity and drainage, biological properties such as increased microbial populations for biological activity and chemical properties such as nutrient holding capacity through increased cation exchange capacity and increased ability to resist changes in soil pH [39]. Improvement in soil physical properties can improve the medium for plant growth especially under well-drained, aerobic condition but less so under submerged paddy field soils, which during land preparation are typically puddled resulting in the breakdown of soil structure [40]. Submergence or flooding tends to buffer $\mathrm{pH}$ near neutrality and reduces the decomposition of native soil organic matter (SOM) or mineralization of soil organic nitrogen (SON) as compared to aerobic soils. In addition, puddling of rice soils reduces downward movement of water thereby reducing the need for greater nutrient-holding capacity of soil to reduce loss of nutrients by leaching [40]. Organic materials can also stimulate the activity of aerobic bacteria found in well-drained soils and, to some extent that of anaerobic bacteria found in submerged soils [36].

There are several myths about organic materials/fertilizers and inorganic fertilizers [36,41]. Many of the myths, however, seem to be mostly based on guesses, perceptions, or prejudices, or for political motives, without enough scientific evidences. Some of such myths and associated facts are discussed below:

\subsection{Chemical Fertilizers Deteriorate Soil Physical Properties and Degrade Lands}

A common myth among the advocates of organic farming is that the chemical fertilizers destroy the soil physical and chemical properties while organic materials or organic fertilizers improve the soil structure and water holding capacity of all soils [36]. Chemical fertilizers are also blamed for soil 
deterioration through alteration of soil physical properties and making soils acidic [37]. Some policy makers, politicians and even researchers and extension workers perceive that inorganic fertilizers, whether applied in small or large quantities, can degrade soils (structural change and acidification, etc.) and decline soil or crop productivity. There are, however, no scientific evidences demonstrating that the chemical fertilizers, when applied in optimum rates for high yield, destroy soil structure or reduce soil water holding capacity. The reality is that chemical fertilizers per se do not deteriorate soils by changing soil texture or making them acidic. Until and unless fertilizer $\mathrm{N}$ acidifies the soil to $\mathrm{pH}<5$, the application of $\mathrm{N}$ fertilizers at optimal rate generally has a positive effect on soil biota. It is only when they are applied in excessive amounts they may change soil texture, acidify soil and reduce microbial communities. In most subsistence farming systems practiced in Asia, Africa and Latin America, the use of chemical fertilizers is too low and thus above issues might not be quite important.

Although organic materials, when used as soil cover or mulch, can improve the soil physical properties, such benefits are mostly limited to aerobic soils through improved water retention, reduced soil crusting, increased soil porosity and reduced erosion. In contrast, flooded rice fields are puddled during land preparation destroying the soil structure and hence improvements of soil physical properties are of little significance to such fields. Improvements in soil physical properties however may be of importance for direct-seeded rice established without puddling, or for non-puddled transplanted rice which are now being promoted through conservation agriculture (CA) in South Asia $[42,43]$. In CA, soil is tilled to a minimum extent and crop residues are retained in the soil to help build up of SOM $[43,44]$.

\subsection{Organic Materials Are Available in Adequate Amounts and Have High Nutrient Contents}

Advocates of organic fertilizers generally claim that there is enormous amount of organic materials (manures, crop residues, green manures, bio fertilizers, etc.) which contain high amount of essential nutrients to supply the amounts as per the crop demand for high yield. The reality, however, is that organic materials are not universally available in large quantities and contain very minimal macroand micro-nutrients compared to inorganic fertilizers (Tables 1 and 2).

Table 1. Nutrient contents (\%) of some commonly used organic materials in South and SE Asia (adapted from BARC, 2012 and Timsina, 2018, with permission from BARC, Bangladesh, 2012 and Agriculture \& Forestry University, Nepal, 2018).

\begin{tabular}{ccccc}
\hline Organic Materials & \multicolumn{4}{c}{ Nutrient Content (\%) } \\
\cline { 2 - 5 } & $\mathbf{N}$ & $\mathbf{P}_{2} \mathbf{O}_{5}$ & $\mathbf{K}_{2} \mathbf{O}$ & $\mathbf{S}$ \\
\hline Cow dung (Fresh 60\% MC *) & 0.50 & 0.34 & 0.6 & - \\
Cow dung (Decomposed 30\% MC) & 2.06 & 2.29 & 1.92 & 0.13 \\
Farm yard manure (70\% MC) & 1.00 & 1.90 & 2.04 & 0.56 \\
Poultry manure (55\% MC) & 2.50 & 1.28 & 0.9 & 1.10 \\
Duck manure & 2.15 & 2.59 & 1.38 & - \\
Goat manure & 2.00 & 3.41 & 2.94 & - \\
Swine manure & 2.76 & 6.05 & 1.764 & - \\
Compost (rural 40\% MC) & 0.75 & 1.37 & 1.2 & - \\
Compost (urban 40\% MC) & 1.50 & 1.37 & 1.8 & - \\
Mustard oilcake (15\% MC) & 5.00 & 4.12 & 1.44 & - \\
Linseed oilcake (15\% MC) & 5.50 & 3.21 & 1.44 & - \\
Sesame oilcake (15\% MC) & 6.20 & 4.58 & 1.44 & - \\
Groundnut oilcake & 7.00 & 3.44 & 1.56 & - \\
Bone meal (raw, 8\% MC) & 3.50 & 20.61 & - & - \\
Bone meal (steamed, 7\% MC) & 1.50 & 22.90 & - & - \\
Dried blood (10\% MC) & 11.00 & 1.10 & 0.70 & - \\
Fishmeal (10\% MC) & 7.00 & 3.50 & 1.00 & - \\
\hline
\end{tabular}

Source: [41,45]; ${ }^{*} \mathrm{MC}=$ Moisture content; - indicates data not available. 
Table 2. Nutrient contents (\%) of some commonly used green manure crops and crop residues in South and SE Asia (adapted from BARC, 2012 and Timsina, 2018, with permission from BARC, Bangladesh, 2012 and Agriculture \& Forestry University, Nepal, 2018).

\begin{tabular}{|c|c|c|c|c|c|c|}
\hline \multirow{2}{*}{$\begin{array}{l}\text { Green Manure Crops/ } \\
\text { Crop Residues }\end{array}$} & \multirow{2}{*}{ Scientific Name } & \multirow{2}{*}{ Moisture (\%) } & \multicolumn{4}{|c|}{ Nutrient Content (\%) } \\
\hline & & & $\mathbf{N}$ & $\mathrm{P}_{2} \mathrm{O}_{5}$ & $\mathrm{~K}_{2} \mathrm{O}$ & $\mathrm{S}$ \\
\hline Dhaincha & Sesbania sp. & 80 & 2.51 & 0.92 & 0.92 & 0.20 \\
\hline Mung bean & Vigna radiata & 70 & 0.80 & 0.46 & 1.15 & 0.30 \\
\hline Black gram & $\overline{\text { Vigna mungo }}$ & 70 & 0.80 & 0.46 & 1.15 & 0.30 \\
\hline Cowpea & Vigna unguiculata & 70 & 0.70 & 0.34 & 1.15 & - \\
\hline Pea & $\overline{\text { Pisum sativum }}$ & - & 1.97 & - & - & - \\
\hline Sun hemp & $\overline{\text { Crotolaria juncea }}$ & 70 & 0.70 & 0.27 & 1.15 & - \\
\hline Rice straw & $\overline{\text { Oryza sativa }}$ & 30 & 0.58 & 0.23 & 3.16 & - \\
\hline Wheat straw & Triticum aestivum & 20 & 0.50 & 0.69 & 2.06 & - \\
\hline Maize stover & Zea mays & 15.5 & 0.59 & 0.71 & 3.00 & - \\
\hline Sugarcane leaves & Saccharum officinarum & 20 & 1.00 & 1.15 & 3.21 & - \\
\hline Rice hull & Oryza sativa & 15 & 0.31 & 0.16 & 0.85 & - \\
\hline Coconut husk & $\overline{\text { Cocos nucefer } a}$ & - & 1.75 & 0.27 & 2.06 & - \\
\hline Banana stem & Musa sp. & - & 1.00 & 1.05 & 19.42 & - \\
\hline Leucaena & Leucaena leucocephala & - & 4.29 & 0.44 & 3.14 & - \\
\hline Azolla & Azolla sp. & - & 3.68 & 0.46 & 0.34 & - \\
\hline Acacia & Acacia Arabica (leaves) & - & 2.61 & 0.39 & 2.75 & - \\
\hline
\end{tabular}

Source: [41,45]. - indicates data not available.

Further, nutrient value of organic materials, particularly that of FYM and composts, is highly variable and often more variable, than that of crop by-products such as residues (rice straw or maize stover/hulls/husks, etc.). The animal's diet, the use and type of bedding material, manure age and how it was stored are factors that affect nutrient value of manures. These factors can vary seasonally on and among farms and regionally or on a larger geographic scale. Thus, if different nutrients required for high yields are to be supplied solely through the organic sources, excessively large amounts and volumes of organic materials would be required (Table 3). The exception is that organic materials, especially crop residues (e.g., rice residues), can supply (recycle) considerable potassium $(\mathrm{K})$, sometime even more than crop needs [46,47].

There is poor synchronicity between crop demand and $\mathrm{N}$ release from organic manures as $\mathrm{N}$ from organic sources could be released during periods without a crop and thus such $\mathrm{N}$ could be exposed to leaching when precipitation occurs. Bergstrom and Kirchmann $[48,49]$ demonstrated through two lysimeter studies that leaching of $\mathrm{N}$ through $\mathrm{NH}_{4} \mathrm{NO}_{3}$ was lower compared with animal manures or green manures. Likewise, Aronsson et al. [50] and Torstensson et al. [51] also demonstrated from long-term field studies in Sweden that $\mathrm{N}$ losses through leaching were higher in organic than in conventional systems. These results demonstrate that organic $\mathrm{N}$ sources are more vulnerable to leaching than inorganic fertilizers because $\mathrm{N}$ from organic sources maybe released during periods when there is no crop uptake of $\mathrm{N}$. 
Table 3. Quantities of chemical fertilizers, farmyard manure (FYM) and crop residues required $\left(\mathrm{kg} \mathrm{ha}^{-1}\right)$ to attain yield targets of rice, wheat and maize (5, 5 and $10 \mathrm{t} \mathrm{ha}^{-1}$, respectively) for various scenarios of nutrient application (adapted from Timsina, 2018, Agriculture \& Forestry University, Nepal, 2018).

\begin{tabular}{|c|c|c|c|}
\hline Source & Rice & Wheat & Maize \\
\hline \multicolumn{4}{|c|}{ Scenario 1: $100 \%$ through chemical fertilizers $\left(\mathrm{kg} \mathrm{ha}^{-1}\right)$} \\
\hline Urea & 159 & 196 & 485 \\
\hline TSP & 68 & 64 & 200 \\
\hline $\mathrm{MoP}$ & 159 & 174 & 400 \\
\hline \multicolumn{4}{|c|}{ Scenario 2: $50 \%$ through chemical fertilizers; $25 \%$ each from FYM and crop residues $\left(\mathrm{kg} \mathrm{ha}^{-1}\right)$} \\
\hline Urea & 79 & 98 & 242 \\
\hline TSP & 34 & 32 & 100 \\
\hline MoP & 80 & 87 & 200 \\
\hline FYM & 1821 & 2250 & 5575 \\
\hline Crop residues & 1310 & 1263 & 3948 \\
\hline \multicolumn{4}{|c|}{ Scenario 3: $75 \%$ through chemical fertilizers; $12.5 \%$ each from FYM and crop residues $\left(\mathrm{kg} \mathrm{ha}^{-1}\right)$} \\
\hline Urea & 119 & 147 & 364 \\
\hline TSP & 51 & 48 & 150 \\
\hline MoP & 119 & 131 & 300 \\
\hline FYM & 913 & 1125 & 2788 \\
\hline Crop residues & 1547 & 1940 & 4806 \\
\hline \multicolumn{4}{|c|}{ Scenario 4: $50 \%$ each from FYM and crop residues $\left(\mathrm{kg} \mathrm{ha}^{-1}\right)$} \\
\hline FYM & 3650 & 4500 & 11150 \\
\hline Crop residues & 6186 & 7759 & 19224 \\
\hline
\end{tabular}

${ }^{1}$ Author's calculations; Source: [41].

\subsection{Organic Fertilizers Undoubtedly Can Produce Quality Products}

Promoters of organic farming commonly claim that organic farming or organic fertilizers produce better quality products compared to conventional farming or chemical fertilizers [36]. In fact, a review of multiple studies shows that organic varieties do provide significantly greater levels of vitamin C, iron, magnesium and phosphorus than non-organic varieties of the same foods [52]. Crinnion [53] also reported that organic varieties, while being higher in all these nutrients, are also significantly lower in nitrates and pesticide residues. Meta-analyses based on 343 peer-reviewed publications also indicated that the concentrations of a range of antioxidants were substantially higher in organic crops/crop-based foods than non-organic ones, with higher percentage of phenolic acids, flavanones, stilbenes, flavones, flavanols and anthocyanins [54]. There is also consistent evidence that, in general, organic plant-based foods contain a higher amount of beneficial, health-promoting secondary plant compounds than non-organic plant-based foods. For example, tomatoes grown on fields that have been organically managed for 10 years exhibited respectively 79 and $97 \%$ higher quercetin and kaempferol aglycones (i.e., the flavonoid concentrations) than their conventional counterparts [55]. Likewise, a long-term biannual rotation with cauliflower coupled with legume cover crop in an organic system optimized the nutrient fluxes of globe artichoke, suggesting as the most promising approach to foster long-term sustainability for the Mediterranean climate [56]. In a follow-up study in the same environment, polyphenol and $\mathrm{Fe}$ and $\mathrm{K}$ contents and dihydroxycinnamic and dicaffeoylquinic acids of globe artichoke were higher in organic system than in conventional system [57]. Willer et al. [23] also reported that organically processed products do not contain hydrogenated fats and other additives whose negative health impacts are widely acknowledged. Organic foods are more potent suppressors of the mutagenic action of toxic compounds and inhibit the proliferation of certain cancer cell lines. Clear health benefits from consuming organic dairy products have also been demonstrated regarding allergic dermatitis [53]. Finally, Parrott and Marsden [58] reported an improvement in taste and nutritional content of products by the farmers converted into organic system. Due to high quality of organic products, farmers practicing organic farming can receive higher economic returns due to higher premiums of the products. 
While many studies such as above show increase in anti-oxidants and polyphenolics in organically-grown crops or foods, there are also evidences that it is not the application of organic farming alone that results in increase of anti-oxidants, it is when sustainable use of chemical fertilizers but without the use of chemical pesticides can also result in high anti-oxidants.

In fact, some studies have shown that the polyphenol content could be even higher in plants applied with inorganic fertilizers for as long as no pesticides are applied [37]. In the most extreme case, Miller [18] argued that organic foods are less healthy because of the presence of fungi, bacteria and animal manure and provided several examples of organic foods that had dangerous amounts of these substances on them. Thus, it seems unclear from these studies regarding the superiority of organic products over the non-organic ones. More research would be required comparing the performance of organic versus conventional farming or organic versus inorganic fertilizers as the benefits of organic farming/nutrients in terms of product quality or presence of antioxidants is not yet universally accepted. Further, research has shown two important concerns in using organic materials or organic fertilizers. One is that raw organic materials may contain pathogens especially when these are from manures, including human faeces. Another is the level of heavy metals especially when the raw materials are industrial or urban wastes and even household wastes [36]. Hence, bags containing organic materials or organic fertilizers should be properly labelled providing guarantee that these are free of pathogens and that the contents of the heavy metals are within the acceptable levels.

\subsection{Organic Fertilizers Are Cheaper and Affordable}

One of the widely spread misconceptions by the advocates of organic fertilizers is that organic sources of nutrients are cheaper than the inorganic fertilizers. Research has however shown that, on per unit of nutrient content basis, inorganic fertilizers are cheaper than the organic fertilizers [36]. Inorganic fertilizers contain substantially higher amounts of nutrients, especially macro-nutrients than organic manures. Nutrients from chemical fertilizers are also readily available to plants than that from organic sources. Thus, compared to chemical fertilizers, it can be cost ineffective to purchase, transport and apply organic materials such as FYM and composts with high-moisture and low-nutrient contents.

\subsection{Legumes Can Use All $N_{2}$ Fixed from Atmosphere}

Leguminous plants can fix atmospheric $\mathrm{N}_{2}$ in the root nodules with the help of aerobic and anaerobic $\mathrm{N}_{2}$-fixing organisms (Table 4). One of the common misconceptions about green manures, leguminous crops and cover crops and residues and so forth is that all their $\mathrm{N}$ content is fixed from the atmosphere and all $\mathrm{N}$ is utilized easily by the crops [36]. The reality, however is that the $\mathrm{N}$ in green manures and leguminous crops is not necessarily fixed from the atmosphere as a good portion is absorbed from the soil. Also, when green manures or legume residues are incorporated into the soil, not all their $\mathrm{N}$ contents are used by the crops as some $\mathrm{N}$ is lost during decomposition or mineralization. However, there are exceptions when crops grown in rotation with crops capture nutrient unavailable to crops and recycle the otherwise lost nutrients back to crops. One such case is when crops, weeds, or green manures (grown in rotation with lowland rice) can assimilate nitrate and then recycle the $\mathrm{N}$ back to future rice crops through retained biomass. Another case is deep rooting shrubs (such as in agroforestry systems) grown on deep soils, which can capture nutrient from below the rooting depth of crops and recycle them back to future crops (see details about agroforestry systems in a later section below). 
Table 4. Amount of $\mathrm{N}_{2}$ fixed $\left(\mathrm{kg} \mathrm{ha}^{-1}\right)$ by some common aerobic and anaerobic $\mathrm{N}_{2}$-fixing organisms and tree legumes (adapted from Akinnifesi et al., 2010, Canadian Center of Science and Education, 2010).

\begin{tabular}{|c|c|c|}
\hline Group & $\mathrm{N}_{2}$-Fixing Organisms/Legumes & Amount of $\mathrm{N}_{2}$ Fixed $\left(\mathrm{kg} \mathrm{ha}^{-1}\right)$ \\
\hline \multirow{8}{*}{ Aerobic } & Azospirillium sp. & $20-40$ season $^{-1}$ \\
\hline & Klebsiella & 32 year $^{-1}$ \\
\hline & $\overline{\text { Anabaena }}$ (Cyanobacter/Blue green algae) & $15-45$ crop $^{-1}$ \\
\hline & Nostoc (Cyanobacter/Blue green algae) & $15-45$ crop $^{-1}$ \\
\hline & Enterobacter & 32 year $^{-1}$ \\
\hline & Achromobacter & 32 year $^{-1}$ \\
\hline & Klebsiella & 32 year $^{-1}$ \\
\hline & Cyanobacteria/Blue green algae & $15-45$ crop $^{-1}$ \\
\hline \multirow{5}{*}{ Tree and perennial legumes } & Gliricidia sepium & 212 year $^{-1}$ \\
\hline & $\overline{\text { Acacia anguistissima }}$ & 122 year $^{-1}$ \\
\hline & $\overline{\text { Leucaena collinsi }}$ & 300 year $^{-1}$ \\
\hline & $\overline{\text { Cajanus cajan }}$ & $34-85 \mathrm{crop}^{-1}$ \\
\hline & Sesbania sesban & 84 season $^{-1}$ \\
\hline
\end{tabular}

Source: [59].

Even though legumes or cover crops can fix $\mathrm{N}_{2}$ from atmosphere they use lands for them to grow at the cost of cropping of main staple crops. In developed countries where mostly monoculture is practiced, inclusion of legumes as a second crop may not be a great issue but in developing countries with small holder farming systems, double or multiple cropping with $200-300 \%$ annual cropping intensity is a common phenomenon. For example, rice-wheat or rice-maize systems are practiced often as double cropping and on many occasions by including a third crop in large areas of South and SE Asia [35,60]. Meeting food security of their people through staple crops (rice, wheat, maize, etc.) is high priority of the governments. Thus, they cannot sacrifice their lands to grow non-staple crops such as legumes instead of staple ones unless replacement of the latter by the former is economically viable without much reduction in total system productivity. Even for the developed countries, there are not enough $\mathrm{N}_{2}$-fixing cover or legume crops that could fertilize all their crops. Many studies have overestimated the contribution of biological nitrogen fixation (BNF) by legumes. One of such studies is that of Badgley et al. [9] who grossly overestimated the global N supply through BNF, which was immediately disputed by Connor [16] and Dobermann [34].

\subsection{Chemical Fertilizers Cannot Supply Micro-Nutrients}

One popular misconception about chemical fertilizers is that they provide only a few macro-nutrients and not micro-nutrients. The reality is that while most organic fertilizers contain some micro-nutrients by nature, there are now several commercially-available inorganic fertilizers containing micro-nutrients [36]. Thus, soils deficient in micro-nutrients can now be supplied with smaller amount of inorganic fertilizers containing micro-nutrients rather than large amount of organic materials to supply the same quantity of micro-nutrients required by plants.

\subsection{Organic Materials Can Build-Up Large Amount of SOM}

Organic crop production has been proposed as a strategy for soil organic carbon (SOC) sequestration. Thus, advocates of organic fertilizers believe that organic materials build up SOM irrespective of the amounts they are applied to the soil. Organic materials no doubt supply nutrients and energy for soil micro-organisms that help in accumulating SOM in soils, their contribution to SOM build-up within a short period of time (e.g., one or two years) is widely misperceived or over-exaggerated [36], as large quantities of organic materials as well as a long time would be required to build up SOM. Moreover, the amount of SOM formed with addition of organic materials depends on the carbon nitrogen ratio ( $\mathrm{C}: \mathrm{N}$ ratio) of the original materials and conditions during decomposition. 
Annual carbon input into the soil is the most important factor responsible to build and sequester SOC and crop production practices that result in higher biomass and yields can add more carbon to soil through above- and below-ground crop residues [61]. Since the above-mentioned evidences indicate that crop yields are generally lower in organic farming, it can be hypothesized that the carbon input through crop residues to soil would also be lower resulting in lower SOC sequestration and consequently lower SOM build-up in organic farming. This hypothesis has been proved to be true in many cases. For example, Lutzow and Ottow [62] and Petersen et al. [63] reported lower SOC in organically- than conventionally-managed farms while Burkitt et al. [64] and Leifeld and Fuhrer [65] demonstrated no difference in SOC between organically- and conventionally-managed farms. Thus, it seems clear from these studies that the magnitudes of increases in SOM due to addition of organic materials or organic fertilizers would be far less than what many advocates of organic fertilizers claim.

\subsection{Chemical Fertilizers Cannot Build Up SOM}

The critics of chemical fertilizers believe that such fertilizers cannot build up organic matter in soil. Some evidences however indicate that inorganic fertilizers, when applied at rates at which maximum yields are achieved, can also result in SOM build-up and microbial biomass by promoting plant growth and increasing the amount of litter and root biomass added to soil. Bijay-Singh [66] reported that only when fertilizer $\mathrm{N}$ is applied at rates more than the optimum, it can increase the residual inorganic $\mathrm{N}$ accelerating the loss of SOM through mineralization. Fertilizer N application can affect SOM in two ways: (i) it may increase SOM by promoting plant growth and increasing the amount of litter and root biomass added to soil compared with the soil not receiving fertilizer N; and (ii) it may accelerate SOM loss through decay or microbial transformation of litter (leaves, straw, manures) and indigenous forms of organic C already present in the soil [67]. High fertilizer rates however can adversely affect soil microbial biomass (see later).

\subsection{Organic Materials Can Be Universally Applied}

Advocates of organic fertilizers claim that it is always safe to apply organic materials on every soil, irrespective of amounts and SOM status, including the anaerobic flooded soils. The reality is that excess organic matter could cause zinc and sulphur deficiency especially when the field is continuously flooded [37,40]. In addition, toxicity from products of anaerobic decomposition (such as organic acids and hydrogen sulphide) could also be a concern. Hence, when the SOM in soils is relatively high $(>4.0 \%)$, organic materials should preferably be applied in dry season or aerobic conditions $[36,39]$.

\subsection{Bio-Fertilizers Can Increase Nutrient Content of Soil}

Soil organisms (bacteria, fungi, algae, actinomycetes, earthworms, etc.) are essential components of the soil, contributing to soil productivity. There are aerobic and anaerobic $\mathrm{N}_{2}$-fixing bacteria (e.g., Rhizobia) and some other bacteria and fungi (e.g., Trichoderma), which are effective in decomposing or mineralizing SOM. These microorganisms can be used to dispose farm wastes and to improve soil productivity. Bio fertilizers, which are applied to seeds, soils in seedbed, or to composting materials can increase the number of microorganisms and accelerate certain microbial processes such as atmospheric $\mathrm{N}_{2}$ fixation, phosphate solubilisation, or cellulose degradation [37]. Advocates of organic fertilizers claim that microbial fertilizers or bio fertilizers, containing organisms such as bacteria, fungi, algae, actinomycetes and so forth, contribute significant amount of nutrients to the crop and can be used to any crop or any type of ecosystems [36]. The fact is that bio fertilizers do not directly contribute nutrients but merely make nutrients available from other sources like atmospheric $\mathrm{N}_{2}$ or SOM [37].

While the role of the bio fertilizers has been recognised, there are evidences regarding their inconsistent effects on crop growth or yield, or not as dramatic as claimed by the advocates of organic fertilizers. Moreover, since most of the microorganisms in bio fertilizers work under aerobic conditions, they may not be effective under anaerobic conditions. Conditions where bio fertilizers are effective 
are not defined properly to guide extension workers and farmers. Hence, it is important that the bio fertilizer developers indicate the species or strains of organisms present (whether aerobic or anaerobic) and the conditions where the product is effective.

\section{Nutrient Supply from Inorganic and Organic Sources}

It is a widely recognised fact that small and poor farmers in almost all countries of the world lack resources to purchase high-yielding inputs such as chemical fertilizers and hence rely on the organic inputs in whatever quantities already available in their farm. Organic nutrients are available in varying amounts (from low to high) in soil (i.e., indigenous nutrients) and/or through external sources (i.e., either inorganic or organic). In most cases (except some lowland rice fields), organic nutrients must be supplemented with inorganic fertilizers. Small farmers practising subsistence farming system and with limited income to purchase fertilizers can rely on organic inputs such as FYM, composts, or crop wastes and residues that are available in their farm [68]. However, such inputs contain very low amounts of nutrients which can only support very low-yielding crops. For transitioning from subsistence to commercial agriculture and to achieve high yields and high income, application of inorganic fertilizers is unavoidable.

Erisman et al. [69] reported that over $48 \%$ of more than 7 billion people are living today because of increased crop production made possible by applying fertilizer N. Hence, if sufficient amounts of nutrients, especially $\mathrm{N}$, are not applied to plants, high yields will not be possible and transitioning to commercialization of agriculture will be a dream only. However, fertilizers being chemicals can potentially disturb the natural functioning of the soil and may also affect the output of other ecosystem services. The challenge ahead is to manage fertilizers (inorganic and organic) and soil in such a way that not only food demands are continuously met but soil also remains healthy to support adequate food production with minimal environmental impact. As stated earlier, while inorganic fertilizers are crucial to increase crop yields, they ae generally not affordable by small-scale subsistence farmers of developing world. On the other hand, the soil-derived as well as the externally-supplied organic sources of nutrients will not be sufficient to achieve high yield. Hence, depending on their relative availability, nutrients need to be supplied in an integrated manner and in balanced proportions through both inorganic and organic sources.

For illustration purpose, nutrient supply through chemical fertilizers and most common organic sources (FYM and crop residues) for various scenarios involving various combinations of inorganic fertilizers and organic materials to achieve target yields of rice, wheat and maize $\left(5,5\right.$ and $10 \mathrm{tha}^{-1}$, respectively) is shown in Table 3. Rice, wheat and maize are chosen because these are the crops grown predominantly in all regions of the world and are globally important especially for achieving the food security of the growing population of the developing countries [32,35,60]. Their sustainable production is necessary in all countries where these are the principal crops. Four scenarios are considered: Scenario 1 is when all nutrients are supplied through $100 \%$ chemical fertilizers and with no organic sources; Scenario 2 is when $50 \%$ nutrients are applied through chemical fertilizers and $25 \%$ each from FYM and crop residues; Scenario 3 is when $75 \%$ nutrients are applied through chemical fertilizers and $12.5 \%$ each from FYM and crop residues; and finally Scenario 4 is when all nutrients are applied through organic sources (50\% each from FYM and crop residues) and with no application of chemical fertilizers. FYM and crop residues are chosen because these are the main sources of organic nutrients in the smallholder crop-livestock or crop-tree-livestock farming systems in tropics and subtropics and contribute to nutrient cycling [68,70-72]. In the example, rice residues are applied to wheat and maize crops and maize residues are applied to the rice crop. The concentrations of $\mathrm{N}_{2} \mathrm{P}_{2} \mathrm{O}_{5}$ and $\mathrm{K}_{2} \mathrm{O}$ in urea, TSP and MoP are $46.0 \%, 46 \%$ and $60 \%$, respectively. As stated earlier, the nutrient contents in organic manures are variable and hence the mean values for FYM and crop residues, as shown in Tables 1 and 2, were used for the calculations. Nutrient requirements, predicted by the QUEFTS (Quantitative Evaluation of the Fertility of Tropical Soils) model shows that for rice, wheat and maize, $14.6,18.0$ and $22.3 \mathrm{~kg} \mathrm{~N}$, respectively, would be required to obtain $1 \mathrm{t}$ of grain yield. 
The respective values are 6.2, 5.9 and $9.2 \mathrm{~kg} \mathrm{P}_{2} \mathrm{O}_{5}$ and 19.1, 20.9 and $24.0 \mathrm{~K}_{2} \mathrm{O}$ per t grain yield of above crops $[67,73-76]$.

Data in Table 3 reveal that when only chemical fertilizers are used to meet the requirements of high-yielding crops (Scenario 1), only small volumes of chemical fertilizers would be required and hence the handling, storing, transporting and applying the fertilizers in the fields would not be a big issue. This is in contrast to Scenario 4, where very large volumes or amounts of FYM and crop residues would be required to meet crop nutrient requirements and hence all the above issues would be significantly greater. In Scenario 2 and 3, where some fractions of the nutrients are used through organic sources, these issues would still be there but to the much lesser extent than in Scenario 4 . The extremely large amounts of organic materials (FYM or other sources of animal manures or crop residues) as required for Scenario 4 and to the lesser extent for Scenario 2, simply would not be available in sufficient amount for organic farming in any country, also due to their multiple uses [68]. Miller [18] also reported that there is simply not enough cow manure in any country to fertilize the organic crops for high yield. Avery [13] also stressed that sewage sources of $\mathrm{N}$ would be only about $2 \%$ of the synthetic $\mathrm{N}$ used to fertilize the crops. The above calculations and the literature review clearly suggest that most countries would need extra lands and water to grow and produce organic materials and feed animals to produce enough quantities of plant biomass and manures to fertilise the soils for achieving high yields if the nutrients were to be supplied through organic sources only.

Our conclusions also agree with many previous workers $[2,13,16,19,20,77,78]$, who all reported that huge amount of extra land would be needed if such sources of $\mathrm{N}$ were to be promoted. Except for some countries in Africa, extra lands would not be available in any other countries due to the ever-increasing population and need for housing, industry and other infrastructures. Even if lands would be made available to produce organic inputs, using only organic sources will be highly laborious, costly and impractical unless some novel or innovative practices are developed and used to build on-farm soil fertility and in-situ nutrient application. Further, as mentioned above, nutrient contents in organic materials are highly variable and release nutrients at variable rates. Hence, any assumptions on nutrient contents and release patterns lead to uncertainties in calculations of nutrient recommendations from organic sources. In most developing countries, information on period of nutrient release and on the rates by which nutrients are mineralized are not provided to farmers, further leading to uncertainties in calculations of nutrients supplied through such sources.

\section{Need for Site-Specific Nutrient Management}

Existing nutrient management recommendations for most crops in most developing countries often consist of one predetermined rate of nutrients for vast areas of production. Such recommendations assume that the need of a crop for nutrients is constant over time and space. However, the nutrient needs for supplemental nutrients for any crop can vary greatly among fields, seasons and years, because of differences in crop-growing conditions, water, nutrient and soil management and climate, resulting in large spatial and temporal variability in soil $\mathrm{N}$ supply. Hence, the nutrient management for crops aimed at high yields requires an approach that enables adjustments in nutrient application to accommodate the site- or soil-specific needs of the crop for supplemental nutrients. Site-specific nutrient management (SSNM), a plant-based approach and a form of precision nutrient management, is used to address nutrient differences which exist within and between fields by adjusting the nutrient application through chemical fertilizers or organic sources to match the site, soil, or season differences. SSNM approach for irrigated rice systems for South and SE Asia was developed by International Rice Research Institute (IRRI) in collaboration with National Agricultural Research and Extension Systems (NARES) partners in 1990s [79-81] to address serious limitations arising from blanket fertilizer recommendation for large areas. The approach focused on managing field-specific spatial variation in indigenous $\mathrm{N}, \mathrm{P}$ and $\mathrm{K}$ supply and considering nutrient losses from soil, recovery efficiency of a given fertilizer and nutrient uptake and use efficiencies, 
temporal variability in plant $\mathrm{N}$ status occurring within a growing season and medium-term changes in soil $\mathrm{P}$ and $\mathrm{K}$ supply resulting from actual nutrient balance.

SSNM or precision nutrient management strategies, based on principles of synchronization of crop demand of nutrients with supply from all sources, including soil, fertilizer and organics, hold great potential for ensuring high yields of crops along with maintenance or improvement in soil health $[39,60]$. SSNM approaches have the potential to optimize nutrient management for cropping systems as farmers replace crops in their crop rotations. Based on the scientific principles, SSNM recommends nutrients for optimally supplying to crops as and when needed for specific field/soil and cropping season. Scaling-up of nutrient management technologies can be faster if simple computer-based decision support system (DSS) tools can be developed for use by farmers and extension workers from governmental and non-governmental organizations and from the private sector. One of such tools is Crop Manager for rice, maize and wheat developed by International Rice Research Institute (IRRI) (http:/ / cropmanager.irri.org/) and similar other tool is Nutrient Expert for rice, maize, wheat soybean developed by International Plant Nutrition Institute (IPNI) (http://software.ipni.net/article/nutrient-expert). Both tools have been widely evaluated and promoted by IRRI and IPNI in partnership and collaboration with International Centre for Maize and Wheat (CIMMYT) and NARES of several countries in South and SE Asia and Sub-Saharan Africa [82-87]. These tools are available both on-line and off-line in mobile phones and laptops and are interactive and easy-to-use that can rapidly provide nutrient recommendations for an individual farmer's field in the presence or absence of soil testing data. Future approach should give priority for further refinements of simple DSS tools for integration and widespread delivery of improved and integrated nutrient management strategies for diverse agro-ecosystems of Asia, Africa and Latin America.

\section{New and Alternative Approaches to Increase On-Farm Soil Fertility and Nutrient Supply}

An important question in soil fertility management globally and especially in South and SE Asia and Sub-Saharan Africa, where very low amounts of fertilizers are used, is how crop biomass production can be increased. This is important to enhance surface cover and generate greater quantities of organic nutrients to complement or supplement whatever amounts of inorganic fertilizers a smallholder farmer can afford to apply. The calculations presented in previous section reveal that organic materials (or organic fertilizers) obtained from traditional crop or crop-livestock systems are not enough to improve soil fertility and meet nutrient demand of high-yielding crops. Alternative techniques (or some radical approaches) would be required if the aim was to supply larger proportion of nutrients from organic sources to restore and maintain on-farm soil fertility, obtain high yields and achieve food security for the ever-increasing global population. One of such approaches could be agroforestry system, which is defined as the integration of trees into annual food crop systems, using both perennial and annual species (trees, food and vegetable crops, etc.). In this system, farmers can grow crops and trees in right proportions so that crop residues and tree leaves can provide enough nutrients to build and maintain soil fertility, supply nutrients to plants and can provide green fodder to livestock [88,89]. Sanchez [89] called agroforestry system as "second soil fertility paradigm" which mainly focuses on improved fallow as well as biomass transfer technologies using trees and shrub legumes capable of fixing $\mathrm{N}_{2}$ through their roots and from the biomass from their leaves and build and maintain soil fertility.

In recent years, more attention has been given to agroforestry system as a possible and sustainable solution to maintain soil fertility. Thus, to promote agroforestry system, a global alliance called Evergreen Agriculture Partnership, has been formed (http://evergreenagriculture.net/). Evergreen Agriculture, an advanced form of agroforestry system, is an approach for maintenance of a green cover on the land throughout the year in the tropical and sub-tropical climate. Such an approach of producing enormous amounts of biomass on-farm does not require extra lands for growing trees as they can be planted in same land together with crops. Depending upon which woody species are used and how they are managed, their cultivation in crop fields can bolster nutrient supply through 
$\mathrm{N}_{2}$ fixation and nutrient cycling, can build-up on-farm soil fertility and provide nutrients to plants as per their demand, enhance suppression of insect pests and weeds, improve soil structure and water infiltration, produce greater amount of food, fodder, fuelwood and fibre and obtain higher income directly from products produced by the intercropped trees and crops [90,91]. Authors suggest that such an intercropped system can enhance carbon storage both above- and below-ground, produce greater quantities of organic matter in soil surface residues, result in more effective conservation of aboveand below-ground biodiversity, sequester carbon in trees and soil and thus can mitigate $\mathrm{CO}_{2}$ emissions and tackle climate change [90,91]. Evergreen Agriculture thus has potential to contribute to integrated soil fertility management and the knowledge to adapt these to local conditions that maximize use efficiencies of chemical fertilizers and organic resources and increase crop productivity. In this respect, the authors $[90,91]$ suggest that the types of intercropped trees can include species whose primary purpose is to provide products or benefits other than soil fertility replenishment alone, such as fodder, fruits, timber and fuel wood. In such cases, the trees are expected to provide an overall value greater than that of the annual crops within the area that they occupy per unit area in the field.

The principles of Evergreen Agriculture have now been widely applied in sub-Saharan Africa where they have been adapted to a diversity of situations, often building successfully on proven indigenous farming technologies and where diversity and polyculture are a common feature of the agricultural systems [91]. For example, in several countries in sub-Saharan Africa, Evergreen Agriculture is practised with conservation farming with Acacia albida (or Faidherbia albida (Delile) A.Chev.), an indigenous $\mathrm{N}_{2}$-fixing tree species. Faidherbia remains dormant and sheds its foliage during the early rainy season at the time when field crops are being established and re-growing at the end of the wet season, thus exhibiting minimal competition while enhancing yields and soil health. This unique growth habit, known as 'reverse leaf phenology' makes it highly compatible with food crops, since it does not compete with them significantly for light, nutrients or water during the growing season. In contrast, annual crops near Faidherbia trees tend to exhibit improved performance and yield [59,92]. Other potential options for sub-Saharan Africa include intercropping maize with Gliricidia sepium (Jacq.) Kunth ex Walp., Tephrosia candida (Roxb.) DC., Cajanas cajan (L.) Millsp., or Sesbania sesban (L.) Merr. [59] but can also be recommended for South and SE Asia. For example, research in Africa has revealed that several tons of additional biomass $\mathrm{ha}^{-1}$ can be generated annually to accelerate soil fertility replenishment and provide additional livestock fodder and that such systems can result in dramatic increases in maize yield when grown in association with Faidherbia of varying age and density, agronomic practices and the weather conditions [92,93]. Akinifessi et al. [59] concluded that fertilizer trees such as Faidherbia, Gliricidia and Leucaena sp. can add 34-300 $\mathrm{kg} \mathrm{N} \mathrm{ha}^{-1}$ year $^{-1}$ through BNF and that, depending on crops, nutrient contributions from fertilizer tree biomass can reduce the mineral $\mathrm{N}$ requirement by up to $75 \%$. This broadens the concept of crop rotations to incorporate the role of fertilizer/fodder trees to more effectively enhance soil fertility and provide needed organic materials to increase crop yield, increase income and achieve food security.

Evergreen Agriculture could also be compatible with crop-tree-livestock integration which is practiced for decades by smallholder farmers in South and SE Asia (for e.g., for example, see Timsina et al., 1991 [68] for a description of crop-livestock and crop-tree-livestock integration for Nepal). This could also be compatible with the three principles of conservation agriculture (CA) (i.e., reduced or no tillage, residue retention on the soil surface and profitable and sustainable rotations) in situations where these are feasible and appropriate [42]. Although some implementation-related issues of CA remain to be addressed, it has now been adapted to many crops and areas in countries of South Asia [42-44] and Africa [94]. Research in Africa has also demonstrated that Evergreen Agriculture by integrating fertilizer trees and shrubs into CA can dramatically enhance both fodder production and soil fertility [91]. 


\section{Conclusions and Research and Policy Implications}

A brief review of organic and conventional farming and sources of nutrients in this paper demonstrates that yields of organic agriculture are much less than conventional agriculture and that the current organic sources of nutrients are not enough to increase crop yields required to feed global population. The review also identifies the fact that unless novel and innovative approaches are developed and promoted to build on-farm soil fertility, organic nutrients in the current state of global agriculture are not enough to provide same amount of food that can be produced from conventional agriculture. Integrated and/or site-specific precision nutrient management of inorganic and organic sources is crucial for sustainable soil fertility management and to achieve food security. The application of nutrients in a balanced proportion through organic and inorganic sources and based on SSNM principles can lead to further improvements in soil health and soil fertility and productivity. Based on the available scientific evidences and considering the non-availability of organic materials in sufficient amount in most countries, nutrients from inorganic and organic sources should preferably be applied at 75:25 ratio but the new and alternative concept of Evergreen Agriculture, as discussed in this review, has potential to supply inorganic and organic sources of nutrients at 50:50 or 25:75 ratio.

It is recommended that appropriately-designed field experiments in any country must be conducted to determine the soils and environmental conditions where the organic fertilizers can be effective to better guide and benefit farmers before promoting or spreading the use of organic materials or organic fertilizers. There is also a need to document the long-term fate of organic materials in different cropping systems. Finally, the review strongly recommends that a well-designed agroforestry system for sustainable intensification would be the most effective strategy for integrated soil fertility management and the Evergreen Agriculture, which has been adopted in many countries of Africa, could be introduced and promoted in countries of Asia and Latin America too. Evergreen Agriculture seems to be a sustainable strategy to improve on-farm soil fertility, increase crop yields, provide fodder to livestock and fuel wood to smallholding farmers residing in countries with tropical and sub-tropical climate and finally meet global food demand. In areas where trees are sparse, government policies should aim to increase tree plantation and promote agroforestry and Evergreen Agriculture in those countries. This will encourage farmers to plant trees and will also promote the use of organic materials for sustainable soil fertility management, increase crop yields and feed the ever-increasing global population.

Author Contributions: The author solely conceptualized and wrote the paper.

funding: No funding was provided from any source for this research.

Acknowledgments: The author is grateful to Saiful Islam, CIMMYT, Bangladesh, for assisting him in the preparation of tables and in reviewing the paper prior to submission.

Conflicts of Interest: The author declares no conflict of interest.

\section{References}

1. Cassman, K.G.; Döbermann, A.D.; Walters, D.T.; Yang, H. Meeting cereal demand while protecting natural resources and improving environmental quality. Ann. Rev. Environ. Resour. 2003, 28, 315-358. [CrossRef]

2. Kirchmann, H.; Katterer, T.; Bergstrom, L.; Borjesson, G.; Bolinder, M.A. Flaws and criteria for design and evaluation of comparative organic and conventional cropping systems. Field Crop. Res. 2016, 186, 99-106. [CrossRef]

3. Bruinsma, J. The Resource Outlook to 2050. By How Much Do Land, Water and Crop Yields Need to Increase by 2050? FAO Expert Meeting on How to Feed the World in 2050; FAO: Rome, Italy, 2009; p. 33.

4. Alexandratos, N.; Bruinsma, J. World Agriculture towards 2030/2050: The 2012 Revision; ESA Working Paper No. 12-03; Food and Agriculture Organization of the United Nations: Rome, Italy, 2012.

5. Searchinger, T.; Hanson, C.; Ranganathan, J.; Lipinski, B.; Waite, R.; Winterbottom, R.; Dinshaw, A.; Heimlich, R. Creating a Sustainable Food Future. A Menu of Solutions to Sustainably Feed More Than 9 Billion People by 2050. World Resources Report 2013-14: Interim Findings; World Resources Institute: Washington, DC, USA, 2014. 
6. Smil, V. Feeding the World-A Challenge for the 21st Century; MIT Press: Cambridge, MA, USA, 2000.

7. Pimentel, D. Green revolution agriculture and chemical hazards. Sci. Total. Environ. 1996, 188, S86-S98. [CrossRef]

8. Tilman, D.; Cassman, K.G.; Matson, P.A.; Naylor, R.; Polasky, S. Agricultural sustainability and intensive production practices. Nature 2002, 418, 671-677. [CrossRef] [PubMed]

9. Badgley, C.; Moghtader, J.; Quintero, E.; Zakern, E.; Chappell, J.; Avilés-Vázquez, K.; Samulon, A.; Perfecto, I. Organic agriculture and the global food supply. Renew. Agric. Food Syst. 2007, 22, 86-108. [CrossRef]

10. Hamer, E.; Anslow, M. 10 reasons why organic farming can feed the world. The Ecologist. 1 March 2008. Available online: http:/ / / www.theecologist.org/trial_investigations/268287/10_reasons_why_organic_ can_feed_the_world.html (accessed on 25 August 2018).

11. Woese, K.; Lange, D.; Boess, C.; Bogl, K.W. A comparison of organically and conventionally grown foods: Results of a review of the relevant literature. J. Sci. Food Agric. 1997, 74, 281-293. [CrossRef]

12. Seufert, V.; Ramankutty, N.; Foley, A.E. Comparing the yields of organic and conventional agriculture. Nature 2012, 485, 229-232. [CrossRef] [PubMed]

13. Avery, D. From saving the planet with pesticides. In The True State of the Planet; Baley, R., Ed.; The Free Press: New York, NY, USA, 1995.

14. Borlaug, N.E. Feeding a world of 10 billion people: The miracle ahead. In Vitro Cell. Dev. Biol. Plant 2002, 38, 221-228. [CrossRef]

15. Goulding, K.W.T.; Trewavas, A.J.; Giller, K.E. Can Organic Farming Feed the World? A Contribution to the Debate on the Ability or Organic Farming Systems to Provide Sustainable Supplies of Food; International Fertiliser Society: York, UK, 2009; p. 633.

16. Connor, D.J. Organic agriculture cannot feed the world. Field Crop. Res. 2008, 106, 187-190. [CrossRef]

17. Connor, D.J. Organically grown crops do not a cropping system make and nor can organic agriculture nearly feed the world. Field Crop Res. 2013, 144, 145-147. [CrossRef]

18. Miller, J.J. The organic myth. Natl. Rev. 2006, 56, 35-37.

19. Kirchmann, H.; Kätterer, T.; Bergström, L. Nutrient supply in organic agriculture-Plant availability, sources and recycling. In Organic Crop Production-Ambitions and Limitations; Kirchmann, H., Bergström, L., Eds.; Springer: Doordrecht, The Netherlands, 2008.

20. Kirchmann, H.; Bergström, L.; Kätterer, T.; Andrén, O.; Andersson, R. Can organic crop production feed the world? In Organic Crop Production-Ambitions and Limitations; Kirchmann, H., Bergström, L., Eds.; Springer: Doordrecht, The Netherlands, 2008; pp. 39-74.

21. Ammann, K. Why farming with high tech methods should integrate elements of organic agriculture. New Biotech. 2009, 25, 378-388. [CrossRef] [PubMed]

22. Ronald, P.C.; Adamchak, R.W. Tomorrow's Table: Organic Farming, Genetics and the Future of Food; Oxford University Press: New York, NY, USA, 2008.

23. Willer, H.; Yussefi-Menzler, M.; Sorensen, N. The World of Organic Agriculture—Statistics and Emerging Trends 2008; IFOAM: Bonn, Germany; FiBL: Frick, Switzerland, 2008.

24. NRC. Toward Sustainable Agricultural Systems in the 21st Century; The National Academies Press: Washington, DC, USA, 2010; p. 4.

25. Willer, H.; Lernoud, J. (Eds.) The World of Organic Agriculture: Statistics and Emerging Trends 2017. Research Institute of Organic Agriculture (FIBL); Frick; IFOAM-Organic International: Bonn, Germany, 2017.

26. Stanhill, G. The comparative productivity of organic agriculture. Agric. Ecosys. Environ. 1990, 30, 1-26. [CrossRef]

27. Penning de Vries, F.W.T.; Rabbinge, R.; de Groot, J.J.R. Potential and attainable food production and food security in different regions. Philos. Trans. R. Soc. Lond B. Biol. Sci. 1997, 352, 917-928. [CrossRef]

28. Lotter, D.W. Organic agriculture. J. Sustain. Agric. 2003, 21, 59-128. [CrossRef]

29. Ponti, T.D.; Rijk, B.; Ittersum, M.V. The crop yield gap between organic and conventional agriculture. Agric. Syst. 2012, 108, 1-9. [CrossRef]

30. De Vries, P.; Jansen, D.M.; ten Berge, H.F.M.; Bakema, A. Simulation of Eco-physiological Processes of Growth in Several Annual Crops; Simulation monographs 29; Pudoc: Wageningen, The Netherlands, 1989; p. 271, ISSN 0924-8439.

31. Van Ittersum, M.K.; Cassman, K.G.; Grassini, P.; Wolf, J.; Tittonell, P.; Hochman, Z. Yield gap analysis with local to global relevance-A review. Field Crop. Res. 2013, 143, 4-17. [CrossRef] 
32. Timsina, J.; Wolf, J.; Guilpart, N.; van Bussel, L.; Grassini, P.; van Wart, J.; Hossain, A.; Rashid, H.; Islam, S.; van Ittersum, M. Can Bangladesh produce enough cereals to meet future demand? Agric. Syst. 2018, 163, 36-44. [CrossRef] [PubMed]

33. Cassman, K.G. Editorial response by Kenneth Cassman: Can organic agriculture feed the world-Science to the rescue? Renew. Agric. Food Syst. 2007, 22, 83-84.

34. Dobermann, A. Getting back to the Field. Nature 2012, 485, 176-177.

35. Timsina, J.; Connor, D.J. The productivity and management of rice-wheat cropping systems: Issues and challenges. Field Crop. Res. 2001, 69, 93-132. [CrossRef]

36. Mamaril, C.P.; Castillo, M.B.; Sebastian, L.S. Facts and Myths about Organic Fertilizers; Philippine Rice Research Institute (PhilRice): Muñoz, Nueva Ecija, Philippines, 2009.

37. Mamaril, C.P. Organic Fertilizers in Rice: Myths and Facts. FAO: Rome, Italy; Los Banos, Laguna, Philippines, 2004.

38. Dahal, K.R.; Sharma, K.P.; Bhandari, D.R.; Regmi, B.D.; Nandwani, D. Organic Agriculture: A Viable Option for Food Security and Livelihood Sustainability in Nepal. In Organic Farming for Sustainable Agriculture. Sustainable Development and Biodiversity; Nandwani, D., Ed.; Springer: Cham, Switzerland, 2016; p. 9.

39. Buresh, R.J.; Dobermann, A. Organic materials and rice. In Annual Rice Forum 2009: Revisiting the Organic Fertilizer Issue in Rice; Asia Rice Foundation: College, Laguna, Philippines, 2010; pp. 17-33.

40. Ponnamperuma, F.N. The chemistry of submerged soils. Adv. Agron. 1972, 24, 29-96.

41. Timsina, J. Can organic materials supply enough nutrients to achieve food security? J. Agric. Forest. Univ. 2018, 2, 9-21.

42. Hobbs, P.; Gupta, R.; Jat, R.K.; Malik, R.K. Conservation agriculture in the indo-gangetic plains of India: Past, present and future. Exp. Agric. 2017, 1-19. [CrossRef]

43. Gathala, M.K.; Timsina, J.; Islam, S.; Rahman, M.; Hossain, I.; Harun-Ar-Rashid; Ghosh, A.K.; Krupnik, T.J.; Tiwari, T.P.; McDonald, A. Conservation agriculture-based tillage and crop establishment options can maintain farmers' yields and increase profits in South Asia's rice-maize systems: Evidence from Bangladesh. Field Crop. Res. 2015, 172, 85-98. [CrossRef]

44. Gathala, M.K.; Timsina, J.; Islam, S.; Krupnik, T.J.; Bose, T.R.; Islam, N.; Rahman, M.M.; Hossain, M.I.; Harun-Ar-Rashid; Ghosh, A.K.; et al. Productivity, profitability and energetics: A multi-criteria and multi-location assessment of farmers' tillage and crop establishment options in intensively cultivated environments of South Asia. Field Crop Res. 2016, 186, 32-46. [CrossRef]

45. BARC. Fertilizer Recommendation Guide-2012. Farmgate, Dhaka-1215; BARC: Dhaka, Bangladesh, 2012.

46. Timsina, J.; Singh, V.K.; Majumdar, K. Potassium management in Rice-maize systems in South Asia. J. Soil Sci. Plant Nutr. 2013, 176, 317-330. [CrossRef]

47. Singh, V.K.; Dwivedi, B.S.; Yadvinder-Singh; Singh, S.K.; Mishra, R.P.; Shukla, A.K.; Rathore, S.S.; Shekhawat, K.; Majumdar, K.; Jat, M.L. Effect of Tillage and Crop Establishment, Residue Management and K Fertilization on Yield, K Use Efficiency and Apparent K Balance under Rice-Maize System in North-Western India. Field Crop Res. 2018, 224, 1-12. [CrossRef]

48. Bergström, L.F.; Kirchmann, H. Leaching of total nitrogen fromnitrogen-15-labeled poultry manure and inorganic nitrogen fertilizer. J. Environ. Qual. 1999, 28, 1283-1290. [CrossRef]

49. Bergström, L.F.; Kirchmann, H. Leaching of total nitrogen from 15-N-labeledgreen manures and15NH415NO3. J. Environ. Qual. 2004, 33, 1786-1792. [CrossRef] [PubMed]

50. Aronsson, H.; Torstensson, G.; Bergström, L. Leaching and crop uptake of N, P and K in a clay soil with organic and conventional cropping systems on a clay soil. Soil Use Manag. 2007, 23, 71-81. [CrossRef]

51. Torstensson, G.; Aronsson, H.; Bergström, L. Nutrient use efficiencies andleaching of organic and conventional cropping systems in Sweden. Agron. J. 2006, 98, 603-615. [CrossRef]

52. Worthington, V. Nutritional quality of organic versus conventional fruits, vegetables and grains. J. Altern. Complement. Med. 2001, 7, 161-73. [CrossRef] [PubMed]

53. Crinnion, W.J. Organic foods contain higher levels of certain nutrients, lower levels of pesticides and may provide health benefits for the consumer. Altern. Med. Rev. 2010, 15, 4-12. [PubMed]

54. Barański, M.; Srednicka-Tober, D.; Volakakis, N.; Seal, C.; Sanderson, R.; Stewart, G.B.; Benbrook, C.; Biavati, B.; Markellou, E.; Giotis, C.; et al. Higher antioxidant and lower cadmium concentrations and lower incidence of pesticide residues in organically grown crops: A systematic literature review and meta-analyses. Br. J. Nutr. 2014. [CrossRef] [PubMed] 
55. Mitchell, A.E.; Hong, Y.J.; Koh, E.; Barret, D.M.; Bryant, D.E. Ten-year comparison of the influence of organic and conventional crop management practices on the content of flavonoids in tomatoes. J. Agric. Food Chem. 2007, 55, 6154-6159. [CrossRef] [PubMed]

56. Deligios, P.A.; Tiloca, M.T.; Sulas, L.; Buffa, M.; Caraffini, S.; Doro, L.; Sana, G.; Spanu, E.; Spissu, E.; Urraci, G.R.; et al. Stable nutrient flows in sustainable and alternative cropping systems of globe artichoke. Agron. Sustain. Dev. 2017, 37, 54. [CrossRef]

57. Spanu, E.; Deligios, P.A.; Azara, E.; Delogu, G.; Ledda, L. Effects of alternative cropping systems on globe artichoke qualitative traits. J. Sci. Food Agric. 2018, 98, 1079-1087. [CrossRef] [PubMed]

58. Parrott, N.; Marsden, T. The Real Green Revolution: Organic and Agro-Ecological Farming in the South; Greenpeace Environmental Trust: London, UK, 2002; p. 153.

59. Akinnifesi, F.K.; Ajayi, O.C.; Sileshi, G.; Chirwa, P.W.; Chianu, J. Fertilizer tree systems for sustainable food security in the maize-based production systems of East and Southern Africa Region: A review. J. Sustain. Dev. 2010, 30, 615-629.

60. Timsina, J.; Jat, M.L.; Majumdar, K. Rice-maize systems of South Asia: Current status, future prospects and research priorities for nutrient management. Pant Soil 2010, 335, 65-82. [CrossRef]

61. Bolinder, M.A.; Janzen, H.H.; Gregorich, E.G.; Angers, D.A.; Vanden Bygaart, A.J. An approach for estimating net primary productivity and annual carbon inputs to soil for common agricultural crops in Canada. Agric. Ecosyst. Environ. 2007, 118, 29-42. [CrossRef]

62. Lützow, M.; Ottow, J.C.G. Effect of conventional and biological farming on microbial biomass and its nitrogen turnover in agriculturally used Luvisols of the Friedberg plains. Z. Pflanzenernähr. Bodenk 1994, 157, 359-367.

63. Petersen, C.; Drinkwater, L.; Wagoner, P. The Rodale Institute Farming 750 Systems Trial: The First 15 Years; Rodale Institute: Kutztown, PA, USA, 1999.

64. Burkitt, L.L.; Small, D.R.; McDonald, J.W.; Wales, W.J.; Jenkin, M.L. Comparing irrigated biodynamic and conventionally managed dairy farms. 1. Soil and pasture properties. Aust. J. Exp. Agric. 2007, 47, 479-488. [CrossRef]

65. Leifeld, J.; Fuhrer, J. Organic farming and soil carbon sequestration: What do we really know about the benefits? Ambio 2010, 39, 585-599. [CrossRef] [PubMed]

66. Bijay-Singh. Are nitrogenous fertilizers deleterious to soil health? Agronomy 2018, 8, 48. [CrossRef]

67. Recous, S.; Robin, D.; Darwis, D.; Mary, B. Soil inorganic nitrogen availability: Effect on maize residue decomposition. Soil Biol. Biochem. 1995, 27, 1529-1538. [CrossRef]

68. Timsina, J.; Singh, S.B.; Timsina, D. Integration of crop, animal and tree in rice-based farming systems of hills and Terai of Nepal: Some successful cases. In Proceeding of Crop-Livestock Integration Workshop, Asian Rice Farming Systems Network; IRRI: Los Banos, Philippines, 1991.

69. Erisman, J.W.; Sutton, M.A.; Galloway, J.N.; Klimont, Z.; Winiwarter, W. How a century of ammonia synthesis changed the world? Nat. Geosci. 2008, 1, 636-639. [CrossRef]

70. Bijay-Singh; Shan, Y.H.; Johnson-Beebout, S.E.; Yadvinder-Singh; Buresh, R.J. Crop residue management for lowland rice-based cropping systems in Asia. Adv. Agron. 2008, 98, 117-199.

71. Thuy, N.H.; Shan, Y.; Bijay, S.; Wang, K.; Cai, Z.; Yadvinder, S.; Buresh, R.J. Nitrogen supply in rice-based cropping systems as affected by crop residue management. Soil Sci. Soc. Am. J. 2008, 72, 514-523. [CrossRef]

72. Yadvinder-Singh; Bijay-Singh; Timsina, J. Crop residue management for nutrient cycling and improving soil productivity in rice-based cropping systems in the tropics. Adv. Agron. 2005, 85, 269-407.

73. Chuan, L.; He, P.; Jin, J.; Li, S.; Grant, C.; Xu, X.; Qui, S.; Zhao, S.; Zhou, W. Estimating nutrient requirements for wheat in China. Field Crop. Res. 2013, 146, 96-104. [CrossRef]

74. Janssen, B.H.; Guiking, F.C.T.; Van der Eijk, D.; Smaling, E.M.A.; Wolf, J.; Van Reuier, H.A. System for quantitative evaluation of the fertility of tropical soils (QUEFTS). Geoderma 1990, 46, 299-318. [CrossRef]

75. Jiang, W.T.; Liu, X.H.; Qi, W.; Xu, X.N.; Zhu, Y.C. Using QUEFTS model for estimating nutrient requirements of maize in the Northeast China. Plant Soil Environ. 2017, 63. [CrossRef]

76. Setiyono, T.D.; Walters, D.T.; Cassman, K.G.; Witt, C.; Dobermann, A. Estimating maize nutrient uptake requirements. Field Crop. Res. 2010, 118, 158-168. [CrossRef]

77. Halberg, N.; Kristensen, I.S. Expected crop yield loss when converting to organic dairy farming in Denmark. Biol. Agric. Hort. 1997, 14, 25-41. [CrossRef] 
78. Quinones, N.A.; Borlaug, N.E.; Dowswell, C.R. A fertilizer-based green revolution for Africa. In Replenishing Soil Fertility in Africa; Buresh, R.J., Sanchez, P.A., Calhourn, F., Eds.; SSSA Special Publications No. 51: Madison, WI, USA, 1997; pp. 81-95.

79. Fairhurst, T.H.; Witt, C.; Buresh, R.J.; Dobermann, A. (Eds.) Rice: A Practical Guide to Nutrient Management, 2nd ed.; International Rice Research Institute (IRRI): Laguna, Philippines; International Plant Nutrition Institute (IPNI); International Potash Institute (IPI): Singapore, 2007.

80. Witt, C.; Dobermann, A.; Abdulrachman, S.; Gines, H.C.; Wang, G.; Nagarajan, R.; Satawatananont, S.; Son, T.T.; Tan, P.S.; Tiem, L.V.; et al. Internal nutrient efficiencies of irrigated lowland rice and in tropical and sub-tropical Asia. Field Crop. Res. 1999, 63, 113-138. [CrossRef]

81. Witt, C.; Buresh, R.J.; Peng, S.; Balasubramanian, V.; Dobermann, A. Nutrient management. In Rice: A Practical Guide to Nutrient Management; Fairhurst, T.H., Witt, C., Buresh, R., Dobermann, A., Eds.; International Rice Research Institute (IRRI): Laguna, Philippines; International Plant Nutrition Institute (IPNI); International Potash Institute (IPI): Singapore, 2007; pp. 1-45.

82. Banayo, N.P.M.C.; Haefele, S.M.; Desamero, N.V.; Kato, Y. On-farm assessment of site-specific nutrient management for rainfed lowland rice in the Philippines. Field Crop. Res. 2018, 220, 88-96. [CrossRef]

83. Gupta, S.K.; Ghosh, M.; Kohli, A.; Sharma, S.; Singh, Y.K.; Kumar, S.; Kumar, U.; Lakshman, K. Site-Specific Nutrient Management with Rice-Wheat Crop Manager in South Bihar Alluvial Plain Zone of India. Int. J. Pure App. Biosci. 2017, 5, 1070-1074. [CrossRef]

84. Islam, S.; Timsina, J.; Salim, M.; Majumdar, K.; Gathala, M.K. Potassium Supplying Capacity of Diverse Soils and K-Use Efficiency of Maize in South Asia. Agronomy 2018, 8, 121. [CrossRef]

85. Pampolino, M.F.; Witt, C.; Pasuquin, J.M.; Johnston, A.; Fisher, M.J. Development approach and evaluation of the Nutrient Expert software for cereal crops. Comput. Electron. Agric. 2012, 88, 103-110. [CrossRef]

86. Saito, K.; Sharma, S. Improving Smallholder Rice Farmers' Yields and Income in Asia and Sub-Saharan Africa. Framework of the 2017 e-Agriculture Call for Good and Promising Practices on the use of ICTs for Agriculture and Rural Development; FAO: Rome, Italy, 2018.

87. Xu, X.; He, P.; Qiu, S.; Pampolino, M.F.; Zhao, S.; Johnston, A.M.; Zhou, W. Estimating a new approach of fertilizer recommendation across small-holder farms in China. Field Crop. Res. 2014, 163, 10-17. [CrossRef]

88. Mango, N.; Hebinck, P. Agroforestry: A second soil fertility paradigm? A case of soil fertility management in Western Kenya. Cogent Soc. Sci. 2016, 2, 121577. [CrossRef]

89. Sanchez, P. Improved fallows come of age in the tropics. Agrofor. Syst. 1999, 47, 3-12. [CrossRef]

90. Garrity, D.P. Agroforestry and the achievement of the millennium development goals. Agrofor. Syst. 2004, 61, 5-17. [CrossRef]

91. Garrity, D.; Akinnifesi, F.; Ajayi, O.; Sileshi, G.W.; Mowo, J.G.; Kalinganire, A.; Larwanou, M.; Bayala, J. Evergreen Agriculture: A robust approach to sustainable food security in Africa. Food Secur. 2010, 2, 197-214. [CrossRef]

92. Barnes, R.D.; Fagg, C.W. Faidherbia Albida: Monograph and Annotated Bibliography; Tropical Forestry Papers No 41; Oxford Forestry Institute: Oxford, UK, 2003; p. 281.

93. Kang, B.T.; Akinifessi, F.K. Agroforestry as an alternative land-use production system for the tropics. Nat. Res. 2000, 24, 137-151. [CrossRef]

94. Pittelkow, C.M.; Liang, X.; Linquist, B.A.; van Groenigen, K.J.; Lee, J.; Lundy, M.E.; van Gestel, N.; Six, J.; Venterea, R.T.; van Kessel, C. Productivity limits and potentials of the principles of conservation agriculture. Nature 2014. [CrossRef] [PubMed] 


\title{
Are Nitrogen Fertilizers Deleterious to Soil Health?
}

\author{
Bijay- Singh \\ Department of Soil Science, Punjab Agricultural University, Ludhiana 141 004, India; bijaysingh20@hotmail.com; \\ Tel.: +919815569369
}

Received: 5 March 2018; Accepted: 12 April 2018; Published: 14 April 2018

\begin{abstract}
Soil is one of the most important natural resources and medium for plant growth Anthropogenic interventions such as tillage, irrigation, and fertilizer application can affect the health of the soil. Use of fertilizer nitrogen $(\mathrm{N})$ for crop production influences soil health primarily through changes in organic matter content, microbial life, and acidity in the soil. Soil organic matter (SOM) constitutes the storehouse of soil $\mathrm{N}$. Studies with ${ }^{15} \mathrm{~N}$-labelled fertilizers show that in a cropping season, plants take more $\mathrm{N}$ from the soil than from the fertilizer. A large number of long-term field experiments prove that optimum fertilizer $\mathrm{N}$ application to crops neither resulted in loss of organic matter nor adversely affected microbial activity in the soil. Fertilizer N, when applied at or below the level at which maximum yields are achieved, resulted in the build-up of SOM and microbial biomass by promoting plant growth and increasing the amount of litter and root biomass added to soil. Only when fertilizer $\mathrm{N}$ was applied at rates more than the optimum, increased residual inorganic $\mathrm{N}$ accelerated the loss of SOM through its mineralization. Soil microbial life was also adversely affected at very high fertilizers rates. Optimum fertilizer use on agricultural crops reduces soil erosion but repeated application of high fertilizer $\mathrm{N}$ doses may lead to soil acidity, a negative soil health trait. Site-specific management strategies based on principles of synchronization of $\mathrm{N}$ demand by crops with $\mathrm{N}$ supply from all sources including soil and fertilizer could ensure high yields, along with maintenance of soil health. Balanced application of different nutrients and integrated nutrient management based on organic manures and mineral fertilizers also contributed to soil health maintenance and improvement. Thus, fertilizer $\mathrm{N}$, when applied as per the need of the field crops in a balanced proportion with other nutrients and along with organic manures, if available with the farmer, maintains or improves soil health rather than being deleterious.
\end{abstract}

Keywords: soil organic matter; soil biota; soil acidity; soil erosion; fertilizer management; site-specific nutrient management; balanced use of fertilizers; integrated nutrient management

\section{Introduction}

Soil is fundamental to crop production and constitutes a natural resource that provides humans with most of their food and nutrients. However, it is finite and fragile, and requires special care and conservation so that it can be used indefinitely by future generations. Doran and Parkin [1] defined soil quality or soil health as its capacity to function within ecosystem and land-use boundaries, sustain biological productivity, maintain environmental quality, and promote plant and animal health. Soil as a medium for plant growth constitutes a living system and a habitat for many organisms and is characterized mainly by its biological functions, which operate through complex interactions with the abiotic, physical, and chemical environment. Soil health often reflects the condition of the soil in terms of management-sensitive properties and provides an idea of its overall fitness for carrying out ecosystem functions and responding to environmental stresses [2]. According to Kibblewhite et al. [3], a healthy agricultural soil is one that is capable of supporting the production of food and fiber to a level, and with regard to quality, it is sufficient to meet human requirements and can continue to sustain those functions that are essential to maintaining the quality of life for humans and the conservation of 
biodiversity. This definition implies that soil health is an integrative property that reflects the capacity of the soil to respond to agricultural interventions and circumvent processes that degrade it.

The main driver for anthropogenic interventions in the functioning of soils over the past century has been the quadrupling of the world's population, which has demanded a fundamental change in soil and crop management in order to produce more food from land already in cultivation [4]. Cultivation of soil to prepare the seed bed possibly constituted the first human intervention. In regions receiving little rainfall, irrigation represented another major external influence on the soil. Additionally, during the last 70 years or so, the application of mineral fertilizers has constituted an important human intervention that has influenced the functioning of agricultural soils, although the widespread use of mineral fertilizers has been one of the major factors in ensuring global food security. Every human intervention invariably represents major and sometimes irrevocable change in the nature and properties of the original soil. The key issue is to minimize the negative effects of such changes. Otherwise, the history of agriculture is replete with examples in which civilizations waned or disappeared because of failure to minimize the impact of human interventions on the soil resource.

Mineral fertilizers are applied to the soil to supplement or substitute for biological functions that are considered inadequate or inefficient for achieving the required levels of production. As per FAO's revised projection regarding world agriculture, global agricultural production in 2050 should be $60 \%$ higher than in 2005/2007 [5]. To close this gap through agricultural production increases alone, total crop production would need to increase even more from 2006 to 2050 than it did in the same number of years from 1962 to 2006 - an 11\% larger increase [6]. The bulk of the projected increases in crop production will come from high yields, which normally demand high fertilizer application rates, and will lead to an increase in fertilizer use [5]. According to Erisman et al. [7], over $48 \%$ of the more than 7 billion people alive today are living because of increased crop production made possible by applying fertilizer nitrogen $(\mathrm{N})$. However, fertilizers being chemicals can potentially disturb the natural functioning of the soil and may also affect the output of other ecosystem services.

The challenge ahead is to manage fertilizers and soil in such a way that not only food demands are continuously met, but soil also remains healthy to support adequate food production with minimal environmental impact. The objective of this paper is to examine how fertilizer $\mathrm{N}$ use affects important and crucial soil health parameters such as soil organic matter (SOM), carbon (C), N, soil microorganisms, and soil acidity. As mineral fertilizers can potentially affect normal functioning of the soil, important management aspects of fertilizer $\mathrm{N}$ have also been discussed in terms of supplying adequate amounts of nutrients to crop plants, as well as maintenance of soil health.

\section{Fertilizer Use-Soil Health Linkages}

The major impact of fertilizers on the soil health and ecosystem functions is regulated through their effect on primary productivity. There are hardly any direct toxic effects even when fertilizers are applied in somewhat excessive quantities; the effects are on rates of different processes in the soil. Prior to the development of Haber-Bosch process in the early 1900s and introduction of $\mathrm{N}$ fertilizers around middle of the last century, organic manures (mainly animal manures) containing large amount of organic materials and legume crops used to be the major source of $\mathrm{N}$ for crops. An important indirect consequence of the increasing use of $\mathrm{N}$ fertilizers was a reduction in the use of organic manures; decoupling of animal farming from arable farming and availability of sewage sludges were also factors in the reduced use of organic manures. Subsequently, after a couple of decades, there was a revival of interest in organic manures due to their increasing supplies and their perceived role in soil health and nutrient recycling. Nevertheless, in several developing countries, particularly in Asia, crop production still relies more on fertilizers because of limited availability of animal manures and crop residues. For example, in South Asia, which accounted for more than $18 \%$ of the global fertilizer consumption in 2015 [8], a significant proportion of animal excreta are used as household fuel rather than for making organic manure for crops. 
Soil organic matter is a relatively small component of the soil in terms of volume, but it constitutes the single most important soil property in relation to soil health. It exerts profound influence on the chemical, physical, and biological properties of the soil. Rate of decomposition of 'low quality' or high C:N ratio organic inputs and SOM increases when fertilizers, particularly $\mathrm{N}$, are applied to the soil [9]. Fertilizer application increases microbial decomposer activity, which has been limited due to low nutrient concentrations in the organic materials. Thus, application of fertilizer $\mathrm{N}$ may lead to accelerated decomposition of organic matter in the soil and adversely affect the soil health.

Soil microbial life and associated microbial transformations constitute another important soil health parameter that may be affected by application of fertilizers. While net primary production in agricultural ecosystems is generally $\mathrm{N}$ limited, activity of soil microorganisms may be $\mathrm{C}$ and/or $\mathrm{N}$ limited [10]. The response of soil microbes to fertilizer $\mathrm{N}$ application may, therefore, differ from the response of the plants. That the soil biota are adversely affected due to application of $\mathrm{N}$ fertilizers is one of the notions that has been put forth many times to support the argument against fertilizers. However, $\mathrm{N}$ fertilizers may lead to increased acidity and adversely affect many soil functions. On the other hand, fertilizer use may reduce soil erosion and may have a positive impact on soil health.

\section{Fertilizer Use Effects on Soil Organic Matter}

Soil organic matter is a key indicator of soil health because of its vital functions that affect soil fertility, productivity, and the environment. In low-fertility ecosystems, application of nutrients through fertilizers regulates net primary productivity and SOM cycling [11,12]. Build-up of SOM definitely leads to improvement in soil health. However, over time, if the SOM level declines by soil microbial mineralization and/or other losses such as leaching and soil erosion, the soil health deteriorates not only in terms of many benefits including improvement in soil structure, increased soil $\mathrm{C}$ storage, and water holding capacity but also $\mathrm{N}$ nutrition of crop plants. Because of the fundamental coupling of microbial $\mathrm{C}$ and $\mathrm{N}$ cycling and the close correlation between soil $\mathrm{C}$ and $\mathrm{N}$ mineralization, the management practices that lead to loss of soil organic C (SOC) also have serious implications for the storage of $\mathrm{N}$ in soil. Thus loss of SOM can be inherently detrimental to crop productivity.

Dourado-Neto et al. [13] conducted a ${ }^{15} \mathrm{~N}$-recovery experiment in 13 diverse tropical agro-ecosystems and estimated the total recovery of one single ${ }^{15} \mathrm{~N}$ application of inorganic $\mathrm{N}$ during three to six growing seasons. Between 7 and 58\% (average of 21\%) of crop N uptake (mean $147 \pm 6 \mathrm{~kg} \mathrm{~N} \mathrm{ha}^{-1}$ ) during the first growing season was derived from fertilizer. On average, $79 \%$ of crop $\mathrm{N}$ was derived from the soil (Table 1). Average recoveries of ${ }^{15} \mathrm{~N}$-labeled fertilizer and residue in crops after the first growing season were 33 and $7 \%$, respectively. Corresponding recoveries in the soil were 38 and $71 \%$. After five growing seasons, more residue $\mathrm{N}(40 \%)$ than fertilizer $\mathrm{N}(18 \%)$ was recovered in the soil, better sustaining the $\mathrm{N}$ content in SOM. Making a worldwide evaluation of fertilizer N use efficiency in cereals, Ladha et al. [14] used data from 93 published studies and concluded that average ${ }^{15} \mathrm{~N}$ fertilizer recovery in the grain and straw in maize, rice, and wheat in the first growing season was 40,44, and 45\%, respectively. Overall recovery based on ${ }^{15} \mathrm{~N}$ dilution method among regions and crops was $44 \%$ (572 data points). The International Atomic Energy Agency [15] reported that the average percentage of single applications of ${ }^{15} \mathrm{~N}$ fertilizer recovered in above-ground portion of the crop plants in the subsequent five growing seasons (excluding the crop to which ${ }^{15} \mathrm{~N}$ fertilizer was applied) across all locations was 5.7 to $7.1 \%$. Thus, with an average ${ }^{15} \mathrm{~N}$ fertilizer recovery of $44 \%$ in the first crop of a cropping system [14], the total recovery of ${ }^{15} \mathrm{~N}$ fertilizer in the first and the five subsequent crops is approximately $50 \%$. Assuming that amount of ${ }^{15} \mathrm{~N}$ in the roots becomes negligible in the sixth growing season, large portion of remaining $50 \%$ of the ${ }^{15} \mathrm{~N}$ fertilizer will become part of the large soil $\mathrm{N}$ pool and some portion may get lost from the cropping system [16]. Thus, $\mathrm{N}$ bound to $\mathrm{C}$ in the SOM is not only the largest source of $\mathrm{N}$ for the crop plants but also the largest sink of $\mathrm{N}$ fertilizer inputs in modern cereal cropping systems, so that SOC impacts both crop yield and $\mathrm{N}$ losses to the environment. 
Table 1. Total above-ground $\mathrm{N}$ accumulation and contribution of fertilizer $\mathrm{N}$ and soil $\mathrm{N}$ as estimated by applying ${ }^{15} \mathrm{~N}$ labelled fertilizers for crops grown under diverse soil and climatic conditions.

\begin{tabular}{|c|c|c|c|c|c|c|}
\hline Country & Soil Order & Crop & $\begin{array}{l}\text { Fertilizer N Applied } \\
\quad\left(\mathrm{kg} \mathrm{N} \mathrm{ha}^{-1}\right)\end{array}$ & $\begin{array}{c}\text { Total Crop N } \\
\left(\mathrm{kg} \mathrm{N} \mathrm{ha}^{-1}\right)\end{array}$ & $\begin{array}{c}\text { Derived from } \\
\text { Fertilizer N (\%) }\end{array}$ & $\begin{array}{l}\text { Derived from } \\
\text { Soil N (\%) }\end{array}$ \\
\hline Bangladesh & Haplaquepts & Wheat & 60 & $60 \pm 3$ & $43 \pm 1$ & $57 \pm 1$ \\
\hline Brazil & Ultisol & Sugarcane & 63 & $251 \pm 7$ & $16 \pm 1$ & $84 \pm 1$ \\
\hline Chile & Andisol & Maize & 300 & $178 \pm 7$ & $31 \pm 2$ & $69 \pm 2$ \\
\hline Chile & Andisol & Wheat & 160 & $124 \pm 4$ & $16 \pm 2$ & $84 \pm 2$ \\
\hline China & Inceptisol & Rice & 60 & $292 \pm 7$ & $7 \pm<1$ & $93 \pm<1$ \\
\hline Egypt & Entisol & Wheat & 60 & $80 \pm 6$ & $20 \pm 1$ & $80 \pm 1$ \\
\hline Malaysia & Ultisol & Maize & 60 & $53 \pm 2$ & $23 \pm 1$ & $77 \pm 1$ \\
\hline Morocco & Aridisol & Wheat & 42 & $161 \pm 7$ & $18 \pm 1$ & $82 \pm 1$ \\
\hline Morocco & Inceptisol & Sunflower & 35 & $129 \pm 7$ & $7 \pm<1$ & $93 \pm<1$ \\
\hline Morocco & Inceptisol & Bean & 85 & $225 \pm 6$ & $7 \pm<1$ & $93 \pm<1$ \\
\hline Sri Lanka & Ultisol & Maize & 60 & $139 \pm 6$ & $11 \pm<1$ & $89 \pm<1$ \\
\hline Sri Lanka & Ultisol & Maize & 60 & $139 \pm 6$ & $18 \pm 1$ & $82 \pm 1$ \\
\hline \multirow[t]{2}{*}{ Vietnam } & Ultisol & Maize & 120 & $92 \pm 3$ & $58 \pm 1$ & $42 \pm 1$ \\
\hline & & Mean & & $147 \pm 6$ & $21 \pm 1$ & $79 \pm 1$ \\
\hline
\end{tabular}

Modified from Dourado-Neto et al. [13].

Plant uptake of native soil $\mathrm{N}$ is boosted either through increase in mineralization of soil $\mathrm{N}$ or by plant-mediated processes such as increased root growth and rhizosphere $\mathrm{N}$ priming $[17,18]$. Native soil $\mathrm{N}$ priming dynamics are influenced by soil type, fertilizer type, and environmental factors [19-21]. Using a meta-analysis based on $43{ }^{15} \mathrm{~N}$ studies from all over the globe, Liu et al. [22] revealed fertilizer $\mathrm{N}$ effects on mineralization and plant uptake of native soil $\mathrm{N}$ were not influenced by study type (laboratory or field), location and duration, soil texture, $\mathrm{C}$ and $\mathrm{N}$ content, and $\mathrm{pH}$. Although fertilizer tended to increase $\mathrm{N}$ priming through variable effects on native soil $\mathrm{N}$ mineralization, plant uptake of native soil $\mathrm{N}$ increased consistently. This inconsistency suggested that there exists a complex interaction between fertilizer $\mathrm{N}$ addition and microbial immobilization-mineralization of $\mathrm{N}$ and $\mathrm{C}$, but not that fertilizer $\mathrm{N}$ application results in loss of SOM.

Potentially, fertilizer N application can affect SOM in two ways: (i) it may increase SOM by promoting plant growth and increasing the amount of litter and root biomass added to soil compared with the soil not receiving fertilizer N; and (ii) it may accelerate SOM loss through decay or microbial transformation of litter (leaves, straw, manures) and indigenous forms of organic $\mathrm{C}$ already present in the soil [9]. The first mechanism is widely accepted, but the second mechanism has not been demonstrated indisputably. Normally, SOM decreases with cultivation $[3,23,24]$ when no $\mathrm{N}$ fertilizer is applied. Application of fertilizer $\mathrm{N}$ often increases $\mathrm{SOM}$ level and $\mathrm{C}$ sequestration in soils of intensively managed multiple cropping systems [25-30]. Ghimire et al. [26] have cited a number of long-term fertility experiments from India and Nepal in which SOC in control plots after 20 years ranged from 1.9 to $7.3 \mathrm{~g} \mathrm{~kg}^{-1}$, but in all the experiments application of optimum N, P and $\mathrm{K}$ fertilizers registered an increase in SOC over control ranging from 0.2 to $3.5 \mathrm{~g} \mathrm{~kg}^{-1}$. Also, fertilizer use could promote aggregate formation [31] and stabilization [32], and enhance the spatial inaccessibility for decomposing organisms [33].

Poffenbarger et al. [34] evaluated changes in surface SOC over 14 to 16 years by applying fertilizer $\mathrm{N}$ rates empirically determined to be insufficient, optimum, or excessive for maximum maize yield. It was observed that SOC balances were negative when no $\mathrm{N}$ was applied. For continuous maize, the rate of SOC storage increased with increasing $\mathrm{N}$ rate, reaching a maximum at the optimum $\mathrm{N}$ rate but decreasing above the optimum $\mathrm{N}$ rate. When fertilizer $\mathrm{N}$ application rate was below the optimum, applied $\mathrm{N}$ stimulated crop growth, leading to increasing crop residue inputs to the soil and, in turn, increasing the rate of soil organic storage. However, when the $\mathrm{N}$ application rate was above the optimum, added $\mathrm{N}$ did not increase crop residue production beyond that observed at the optimum level but increased residual inorganic N, which enhanced SOC mineralization leading to loss of SOC. Green et al. [35] also observed that annual additions of more $N$ than needed to maximize yields of maize could cause losses of SOM and suggested that reducing unnecessary fertilization could help conserve 
SOM. Conceptual understanding of the SOC response to N fertilization is illustrated in Figure 1 [34]. Residual soil inorganic $\mathrm{N}$ produced due to application of fertilizer $\mathrm{N}$ beyond the optimum level may enhance mineralization of SOC by eliminating $\mathrm{N}$ limitation on microbial growth $[35,36]$ or by adversely affecting soil aggregation $[37,38]$, which makes previously protected SOM more susceptible to decay. Excessive $\mathrm{N}$ fertilization may also decrease the C:N ratio of crop residues [39] and enhance their decomposition rate. There may be multiple processes controlling the SOC response to N fertilization, but the extent of increased C inputs vis-à-vis SOC mineralization depends on the N sufficiency level.

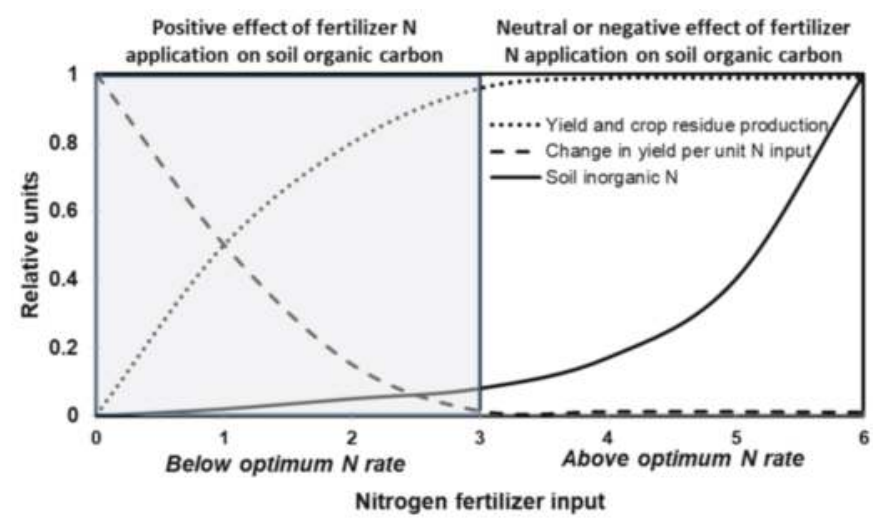

Figure 1. Conceptual diagram showing possible effects of fertilizer application to crops on SOC as defined by relationships between increasing fertilizer $\mathrm{N}$ application levels and (i) yield and crop residue production, (ii) change in yield per unit $\mathrm{N}$ input, and (iii) residual soil inorganic N. Maximum yield of the crop is obtained at the optimum $\mathrm{N}$ rate. Expected SOC responses to fertilizer $\mathrm{N}$ application below and above optimum $\mathrm{N}$ rate are shown above the grey and white areas of the plots, respectively (Modified from Poffenbarger et al. [34]).

Glendining and Powlson [40] found that in 84\% comparisons in 45 long-term experiments in temperate regions, applications of fertilizer $\mathrm{N}$ on long-term basis increased total soil organic $\mathrm{N}$ (SON) as compared to in the treatments receiving no fertilizer. However, Khan et al. [41] and Mulvaney et al. [36] reported that in long-term experiments located in both temperate and tropical regions, continuous application of fertilizer $\mathrm{N}$ induced a net loss of SOC in 73\% sites and reduction in soil $\mathrm{N}$ at $92 \%$ of the sites examined. Powlson et al. [42] argued that data sets used by these authors were not comprehensive enough, and long-term changes in soil $\mathrm{N}$ and $\mathrm{C}$ in the zero- $\mathrm{N}$ control plots were not taken into consideration. Ladha et al. [43] resolved this controversy using data from 135 studies of 114 long-term experiments located at 100 sites located all over the world. The data pertaining to SOC and SON were analyzed following time-response ratio and time by fertilizer $\mathrm{N}$ response ratio. The time-response ratio is a percentage change in total SOC or N compared with the initial amount, and it was calculated separately for both zero-N and N-fertilized treatments. Khan et al. [41] and Mulvaney [36] used this approach, and like them Ladha [43] also observed an average decline in SOC to the tune of $16 \%$ and $10 \%$ in zero- $\mathrm{N}$ and fertilizer $\mathrm{N}$ amended plots; corresponding decline in SON was $11 \%$ and $4 \%$ (Table 2). These decreases were confounded with decrease in SOM content occurring independently of the use of fertilizer N. Ladha et al. [43] separated the two processes by following the change over time in SOM content with or without fertilizer, and this was done by analyzing the data using time by fertilizer $\mathrm{N}$ response ratio. While the time-response ratio addressed the impact of the whole system (tillage, residue management, erosion, fertilizer amendment) on changes in SOC or $\mathrm{SON}$, the time by fertilizer $\mathrm{N}$ response ratio specifically assessed the impact of fertilizer $\mathrm{N}$ amendment, and it is defined as the percentage difference between the change in SOC or N in the N-fertilized 
treatments compared with the changes in zero-N treatment. Using the time by fertilizer ratio, which is based on changes in the paired comparisons at the initiation of the long-term experiments and final sampling period, Ladha et al. [43] observed overall averages of $8 \%$ higher SOC and $10 \%$ higher SON with fertilizer $\mathrm{N}$ than with zero-N (Table 2). Furthermore, the positive effect of fertilizer $\mathrm{N}$ in tropical, humid subtropical, and temperate soils ranged from 3 to $16 \%$ for SOC and 8 to $15 \%$ for SON, with the highest increases observed in the tropical environment (Table 2). Due to inherently lower status of SOC and $\mathrm{N}$ than in temperate soils, the relatively higher positive effect of fertilizer $\mathrm{N}$ application is expected in tropical soils. Recently, Geiseller and Scow [44] and Körschens et al. [45] also observed that in long-term experiments from all over the world, application of mineral fertilizers leads to increase in SOM as compared to in no-fertilizer plots (Table 3). Using total organic $C$ and natural ${ }^{13} \mathrm{C}$ abundance measurements in a long-term experiment under continuous maize, Gregorich et al. [46] observed that fertilized soils had more organic $C$ than unfertilized soils; the difference was accounted for by more C4-derived $C$ in the fertilized soils.

Table 2. Changes in SOC and SON in zero-N and $\mathrm{N}$ fertilized plots observed by meta-analysis of data from 114 long-term experiments following time-response ratio (TR) and time by fertilizer $\mathrm{N}$ response ratio (TNR).

\begin{tabular}{ccccc}
\hline & \% Change in SOC & \multicolumn{2}{c}{$\%$ Change in SON } \\
\hline & Zero-N & Fertilizer N & Zero-N & Fertilizer N \\
TR: overall changes & -16 & -10 & -11 & -4 \\
TNR: overall changes & - & 8 & - & 10 \\
TNR: changes in tropical soils & - & 16 & - & 15 \\
TNR: changes in humid tropical soils & - & 11 & - & 11 \\
TNR: changes in temperate soils & - & 3 & - & 8 \\
\hline
\end{tabular}

Data source: Ladha et al. [43].

Table 3. Increase in SOC due to fertilizer application as compared to in the unfertilized controls in meta-analysis conducted on long-term experiments from all over the world.

\begin{tabular}{|c|c|c|c|c|}
\hline Crops & Region & $\begin{array}{c}\text { Duration of Long-Term } \\
\text { Experiments (years) }\end{array}$ & Increase in SOC (\%) & Reference \\
\hline Non-lowland rice crops & World & $5-130$ & 12.8 & Geiseller and Scow [44] \\
\hline Cereal crops & World & $6-158$ & 8 & Ladha et al. [43] \\
\hline $\begin{array}{l}\text { Wheat, barley, oats, sugar } \\
\text { beets, potato, maize, } \\
\text { sorghum, rye }\end{array}$ & Europe & $16-108$ & 10 & Körschens et al. [45] \\
\hline
\end{tabular}

The North Indian state of Punjab is the most intensively cultivated region in India, with a cropping intensity of $190 \%$, predominantly of a rice-wheat cropping system. A study based on 0.319 million soil samples of the 0-20 cm plough layer analyzed during 25 year period between 1981/82 to 2005/06 revealed that as a weighted average for the whole state, SOC increased from $2.9 \mathrm{~g} \mathrm{~kg}^{-1} \mathrm{in} 1981 / 82$ to $4.0 \mathrm{~g} \mathrm{~kg}^{-1}$ in $2005 / 06$, an increase of $38 \%$ [47]. A close relationship $\left(R^{2}=0.79\right)$ between SOC stocks in the plough layer and total rice and wheat grain yield during the 25-year period was observed. Increased productivity of rice and wheat resulted in enhanced $C$ accumulation in the plough layer by $0.8 \mathrm{t} \mathrm{C} \mathrm{ha}^{-1} \mathrm{t}^{-1}$ of increased grain production. The increased productivity of both rice and wheat in the Punjab was achieved through increasing fertilizer (N, P, and K) use from $0.762 \mathrm{Mt}$ in 1980/81 to 1.687 Mt in 2005/06 or from $112.5 \mathrm{~kg} \mathrm{ha}^{-1}$ in $1980 / 81$ to $214.0 \mathrm{~kg} \mathrm{ha}^{-1}$. Soil $\mathrm{pH}$ declined by $0.8 \mathrm{pH}$ units from 8.5 in 1981/82 to 7.7 in 2005/06. This $\mathrm{pH}$ decline has positive implications for availability of $\mathrm{P}$ and micronutrients such as $\mathrm{Zn}, \mathrm{Fe}$, and Mn. Tian et al. [48] conducted a meta-analysis of paired-treatment data from 95 long-term field experiments published from 1980 to 2012 to characterize the changes in SOC in paddy soils in China. While significant increase in the SOC was observed in the optimum fertilizer N, P, and K fertilizer treatment as compared to in the no-fertilizer treatment; the mean difference 
in SOC change rates between the two treatments was measured to be $0.140 \pm 0.023 \mathrm{~g} \mathrm{~kg}^{-1} \mathrm{year}^{-1}$. Using a meta-analysis based on 257 published studies, Lu et al. [49] revealed that despite increased soil respiration, there was a significant $3.5 \%$ increase in $C$ storage in agricultural ecosystems due to application of $\mathrm{N}$. The $\mathrm{N}$-induced change in soil $\mathrm{C}$ storage was related to changes in below-ground production rather than above-ground growth. Russel et al. [39] also observed that quantity of below-ground organic C inputs was the best predictor of long-term soil C storage. Shang et al. [50] conducted a meta-analysis based on published data on crop yields and soil parameters from long-term experiments in maize-wheat, rice-rice, and rice-wheat cropping systems in China. Although conservation of SOC in upland maize-wheat system was conspicuously less than in the rice based cropping systems, application of optimum rate of $\mathrm{N}, \mathrm{P}$, and $\mathrm{K}$ fertilizers resulted in build-up of SOC over no-fertilizer control in all the three cropping systems (Table 4). Decrease in SOC content in the no-fertilizer control from the initial values in the completely aerobic maize-wheat cropping system should be due to cultivation of the soil.

Table 4. Average SOC content at the start (initial) of long-term experiments on maize-wheat, rice-wheat, and rice-rice cropping systems and in no-fertilizer (N, P, and $\mathrm{K}$ ) control and optimum $\mathrm{N}$, $\mathrm{P}$, and $\mathrm{K}$ fertilizer level treatments at the end of the experiments in different locations in China.

\begin{tabular}{|c|c|c|c|c|c|}
\hline \multirow{2}{*}{$\begin{array}{l}\text { Cropping } \\
\text { System }\end{array}$} & \multirow{2}{*}{$\begin{array}{l}\text { Number of } \\
\text { Experiments }\end{array}$} & \multirow{2}{*}{$\begin{array}{c}\text { Duration } \\
\text { (years) }\end{array}$} & \multicolumn{3}{|c|}{$\operatorname{SOC}\left(\mathrm{g} \mathrm{kg}^{-1}\right)$} \\
\hline & & & Initial & $\begin{array}{l}\text { No-Fertilizer } \\
\text { Control }\end{array}$ & $\begin{array}{l}\text { Optimum N, P and } \mathrm{K} \\
\text { Fertilizer Levels }\end{array}$ \\
\hline Maize-wheat & 12 & $6-25$ & 6.4 & 5.8 & 6.8 \\
\hline Rice-wheat & 10 & $9-27$ & 14.3 & 14.9 & 16.3 \\
\hline Rice-rice & 23 & $6-26$ & 16.7 & 18.1 & 19.6 \\
\hline
\end{tabular}

Data Source: Shang et al. [50].

Cultivation invariably reduces SOM levels to an extent that depends on management and inputs. In well managed cultivated soils, SOC fluctuated between a low steady state value of SOM in the heavily cultivated soil and the highest value observed in the uncultivated soil [51]. Cultivation of the soil leads to lower equilibrium soil C levels, but the addition of fertilizers reduces the extent of SOM decline observed with cultivation. Katyal et al. [52] critically analyzed data from several long-term fertility experiments in India and documented such changes. Twenty years after initiation of a long-term experiment in a virgin soil, SOM content in the no-fertilizer control reached $34 \%$ of the initial value and seemed to have stabilized at a lower equilibrium level as defined by Buyanovsky and Wagner [51]. Loss in SOM was obviously due to cultivation of the virgin soil. Buyanovsky and Wagner [51] reported a decline in native organic matter between 20 and 40\% within 5 years after opening of virgin land. However, when optimum level of fertilizers was applied, SOM remained stable over the first decade, but in the next 3 years fell to about $40 \%$ of the initial value. In contrast to a virgin soil, already cultivated soil implies that the soil had already shifted to a new dynamic equilibrium but had probably not yet reached the steady state low value of SOM in the heavily cultivated soil. In long-term experiments initiated in soil already under cultivation, SOM declined without any fertilizer application. However, SOM levels were either maintained or increased when adequate amount of N, P, and K fertilizers was applied [52]. This conclusion was valid, irrespective of the location or the cropping system. That soil health in terms of SOC and SON declines when soil is tilled year after year is now an established fact $[3,23,24]$. Therefore, interaction between tillage and fertilizer use should be taken into account when interpreting changes with time in the SOM in long-term experiments.

\section{Effect of Fertilizer Use on Microbial Life Ion the Soil}

Several ecosystem services or the beneficial functions provided by soil are driven by many interrelated and complex biological processes. The concept of soil health takes into account not only the 
soil biota and the myriad of biotic interactions that occur, but also considers that the soil provides a living space for the biota. Microorganisms and various by-products of their metabolism play an important role in the formation of soil aggregates and in soil structure maintenance. Since soil constitutes an open system, its integrity or health is affected by external environmental and anthropogenic pressures. Recently, Hermans et al. [53] observed that soil bacterial communities and their relative abundances varied more in response to changing soil environments than in response to changes in climate or increasing geographic distance. As microorganisms play an important role in maintaining fertile and productive soils, the effect of fertilizers on microbial communities has potentially important implications for sustainable agriculture. Applied nutrients constitute a controlling input to the soil system and the processes within it, but adequate knowledge is lacking about the impacts of nutrient additions on the condition of different assemblages of soil organisms. According to O'Donnell et al. [54], fertilizers do affect microbial community structure, but the relationship between diversity, community structure, and function remains complex and difficult to interpret using currently available chemical and molecular fingerprinting techniques. Mineral fertilizers interact with microbial communities in the soil in a number of ways and affect the population, composition, and function of soil microorganisms [55]. These may promote growth of microbes directly by providing nutrients and indirectly by stimulating plant growth and enhancing root $\mathrm{C}$ flow [56]. However, fertilizers, particularly N, when applied to soil may result in soil acidification limiting microbial growth and activity in soils [57]. Several studies conducted during last 2-3 decades have revealed that fertilizer application usually favours the accumulation of bacterial residues [58] and increases soil microbial biomass [59-63]. In some studies, fertilizer application increased biomass C and N [64-66]. Significant improvement in soil quality in terms of increased SOC and soil microbial biomass due to long-term application of fertilizers in maize-wheat cropping systems has been reported by Li et al. [67] and Liu et al. [68].

Mbuthia et al. [69] observed that fertilizer $\mathrm{N}$ application to cotton continuously for 31 years significantly increased soil microbial biomass $\mathrm{N}$, mycorrhizae fungi biomarkers, b-glucosaminidase (N-cycling) activity, and basal microbial respiration rates. In a study in which inorganic fertilizers were continuously applied for 13 years to flooded double rice crop, Zhong and Cai [70] found that stimulation of microbial biomass and community functional diversity by fertilizer $\mathrm{N}$ could be achieved only after improvement of the P supply. However, most microbial parameters were correlated with SOC content, indicating that the application of nutrients through fertilizers affected microbial parameters in the soil indirectly by increasing the accumulation of SOM. It is generally considered that the primary limiting factor for microbial activity in soils is the availability of $\mathrm{C}$ substrate. However, soil microbes may frequently be limited by the supply of $\mathrm{N}$ in the soil [71]. When demand for $\mathrm{N}$ exceeds its supply, the functional capacity of the soil system is strongly influenced by $\mathrm{N}$ availability. Under such situations in agro-ecosystems, soil health declines without additional inputs of $\mathrm{N}$ via fertilizers or organic manures, and particularly without due consideration of the associated $\mathrm{C}$ requirements of the biomass [37].

Effect of fertilizer application on the soil biota can be positive or negative and vary in duration, depending upon the type and amount of fertilizer used and mode of application. For example, potential damage to soil microorganisms from high concentration of ammonia fertilizer applied in bands is usually short-term, and only in the zone of application. Angus et al. [72] reported that injection of urea and ammonia in bands generally exhibited a short-term effect on microbial activity in the soil. Total microbial activity was reduced in narrow bands of application for a period of 5 weeks, after which levels returned to normal. However, an $80 \%$ reduction in the number of protozoa did not return to normal after 5 weeks. On the other hand, there was a large increase in the number of nitrifying bacteria in the soil 5 weeks after application of urea/ammonia in bands. Geiseller and Scow [44] carried out a meta-analysis based on 107 data sets from 64 long-term experiments from around the world and revealed that application of mineral fertilizers resulted in a significant increase (15.1\%) in the microbial biomass above levels in the no-fertilizer control treatments. Where soil $\mathrm{pH}$ was 7 or higher, the fertilizer induced increase in microbial biomass averaged $48 \%$, but fertilizer 
application tended to reduce microbial biomass in soils with a pH below 5 (Table 5). Furthermore, the increase in microbial biomass was the highest in experiments that were in place for at least 20 years. Biederbeck et al. [73] also reported little impact on soil microbial populations when urea and anhydrous ammonia were applied continuously for 10 years. The arbuscular mycorrhizal fungi biomass was increased by application of $\mathrm{N}$ and $\mathrm{P}$ fertilizer in the $\mathrm{N}$ - and P-deficient sites, respectively [74].

Table 5. Unweighted averages of soil microbial biomass $C\left(\mathrm{mg} \mathrm{kg}^{-1}\right)$ in fertilizer $\mathrm{N}(+\mathrm{N})$ and no-N treatments in 64 non-lowland rice long-term experiments from all over the world.

\begin{tabular}{|c|c|c|c|}
\hline & \multirow{2}{*}{ Number of Data Sets } & \multicolumn{2}{|c|}{ Soil Microbial Biomass C $\left(\mathrm{mg} \mathrm{kg}^{-1}\right)$} \\
\hline & & no-N & $+\mathrm{N}$ \\
\hline All data sets & 107 & 238 & 268 \\
\hline $\mathrm{pH}$ in $+\mathrm{N}$ treatment: $<5$ & 17 & 240 & 213 \\
\hline $\mathrm{pH}$ in $+\mathrm{N}$ treatment: $5-7$ & 39 & 234 & 253 \\
\hline $\mathrm{pH}$ in $+\mathrm{N}$ treatment: 7 or higher & 17 & 139 & 205 \\
\hline Duration of long-term experiment: $5-10$ years & 18 & 300 & 239 \\
\hline Duration of long-term experiment: $10-20$ years & 34 & 227 & 270 \\
\hline Duration of long-term experiment: 20 years or longer & 55 & 224 & 276 \\
\hline
\end{tabular}

Modified from Geiseller and Scow [44].

That tilling of soil leads to decline of its health is also revealed by changes in microbial community structure assessed using phospholipid fatty acid analysis and automated ribosomal intergenic spacer analysis [75,76]. In a study conducted by Doran [77], microbial biomass and potentially mineralizable $\mathrm{N}$ levels of no-tillage soils averaged $54 \%$ and $37 \%$ higher, respectively, than those in the ploughed soils. In a meta-analysis based on 139 observations from 62 studies, Zuber and Villamil [78] inferred that microbial biomass and enzyme activities were greater under no-till as compared to in the tilled soils. Therefore, in conventionally tilled fertilized soils the reduced microbial activity is due to cultivation of soils rather than the effect of fertilizer application.

Over-use of mineral fertilizers and excessive tillage can affect biological communities in the soil by damaging their habitats and disrupting their functions [37]. Over-use of fertilizer, particularly $\mathrm{N}$, is like enrichment of ecosystems with reactive $\mathrm{N}$. Using a meta-analysis based on 82 published field studies, Treseder [79] reported that microbial biomass declined 15\% on average under heavy $\mathrm{N}$ fertilization, but fungi and bacteria were not significantly altered in studies that examined each group separately. Declines in abundance of microbes and fungi were more evident in studies of longer durations and with higher total amounts of $\mathrm{N}$ added.

\section{Potential Contribution of Nitrogen Fertilizers to Soil Acidity}

Nitrogen fertilizers can exert indirect negative effects on soil health arising through lowering of soil $\mathrm{pH}$ due to natural transformations of $\mathrm{N}$ in the soil. Soil $\mathrm{pH}$ is one of the most influential factors affecting the microbial community in soil. As shown in Table 5, while fertilizer-induced increase in microbial population in long-term experiments was observed at soil $\mathrm{pH} 7$ or higher, a reduction in microbial biomass was observed in soils with a $\mathrm{pH}$ below 5 . In a silt loam soil on which barley has been continuously grown for more than 100 years, Rousk et al. [80] observed a fivefold decrease in bacterial growth and a fivefold increase in fungal growth due to lowering of $\mathrm{pH}$ from 8.3 to 4.0.

Form of fertilizer $\mathrm{N}$ applied $\left(\mathrm{NO}_{3}{ }^{-}, \mathrm{NH}_{4}{ }^{+}\right.$, urea), fertilizer product type (for example, ammonium nitrate, calcium ammonium nitrate), the net balance between proton-producing and consuming processes, and the buffering capacity of the soil dictate the extent of soil acidification due to application of fertilizer N. Buffering capacity of the soil as determined by the presence of solid-phase calcium carbonate resists change in soil $\mathrm{pH}$ due to $\mathrm{N}$ transformations [81]. In arid and semi-arid areas of the world, soils are generally calcareous and thus highly buffered. In temperate regions, soils are generally neutral or slightly acidic in reaction, whereas tropical soils are usually highly weathered and generally acidic with little or no buffering capacity. During the acidification process, base cations 
such as calcium and magnesium are released from the soil. With continued addition of fertilizer $\mathrm{N}$, the base cations get depleted and aluminum $\left(\mathrm{Al}^{3+}\right)$ is released from soil minerals, often reaching toxic levels that induce nutrient disorders in plants. Guo et al. [82] reported severe soil acidification in large crop production areas in China following application of high fertilizer $\mathrm{N}$ rates between the 1980s and 2000s. Based on strictly paired data available from 154 agricultural fields, top soils were significantly acidified with an average $\mathrm{pH}$ decline of 0.50 . Fertilizer $\mathrm{N}$ application released 20 to $221 \mathrm{~kg}$ hydrogen ion $\left(\mathrm{H}^{+}\right) \mathrm{ha}^{-1}$ year ${ }^{-1}$, and base cations uptake contributed a further 15 to $20 \mathrm{~kg} \mathrm{H}^{+} \mathrm{ha}^{-1}$ year ${ }^{-1}$ to soil acidification. In Southern China, Lu et al. [83] observed that after application of ammonium nitrate for 6 years, the site was showing high acidification $\left[\mathrm{pH}\left(\mathrm{H}_{2} \mathrm{O}\right)<4.0\right]$, negative water-extracted acid neutralizing capacity, and low base saturation $(<8 \%)$ throughout soil profiles.

\section{Rational Use of Fertilizers Enhances Soil Health by Reducing Soil Erosion}

Role of anthropogenic activities in causing soil erosion is very well documented [84], but the connection between erodibility of the soil (defined as the susceptibility of a soil to become detached and transported by wind, water, or ice) and crop production practices, especially the use of fertilizers, is not well documented. Soil erosion is a problem when there is insufficient ground cover to protect the soil and reduce the impact of rainfall and wind on the soil surface and when aggregate stability is reduced due to limited SOC. Adequately fertilized crops will have extensive root system and top growth. A well-developed canopy reduces the pounding effect of water drops from rain so that runoff is reduced and erosion is minimized. Also, extensive root system developed in the well fertilized soil helps hold soil in place and decreases the potential for soil loss in runoff water. Bhattacharyya et al. [85] reported reduced loss of soil due to erosion by applying fertilizers to crops as compared to when no fertilizer was applied. At $2 \%$ slope, soil loss by erosion was reduced by $7.2 \%$ and $11.7 \%$ by applying fertilizer to sorghum (Sorghum bicolor) and chickpea (Cicer arietinum), respectively. According to Portch and Jin [86], balanced fertilization of crops in China could reduce soil erosion. They further reported that work conducted by International Board for Soil Research and Management (IBSRAM) in late 1980s in several Asian countries showed that fertilizer use alone could reduce soil erosion from 50 to $15 \mathrm{tha}^{-1}$ year $^{-1}$. Biological $\mathrm{N}$ fixation and manure recycling are the only local nutrient sources that are not always optimally exploited. The inability to match crop harvests with sufficient nutrient inputs leads to depletion of nutrients and SOM, declining soil health, and increased risk of land degradation through erosion.

\section{Optimizing Fertilizer Management to Maintain Soil Health}

A sustainable agricultural production system with good soil health having the capacity to produce high yields with fewer external nutrient inputs can be developed using the correct combination of ecosystem processes and appropriate use of fertilizers. Soils in agro-ecosystems should be able to supply a certain minimum level of plant-available $\mathrm{N}$ and other essential nutrients at different growth stages of crop plants. In principle, the concept of optimum fertilization aims at a dynamic balance between nutrient requirement to obtain high yields and nutrient uptake by crops. This is achieved by maintaining synchrony between nutrient demand of the crop and the supply of nutrients from all sources including fertilizer and soil throughout the growing season of the crop.

Application of optimum doses of all nutrients is important, but due to fundamental coupling of $\mathrm{C}$ and $\mathrm{N}$ cycles, optimization of fertilizer $\mathrm{N}$ management is more closely linked to build-up of SOC and soil health. Concepts emerging from the work of Poffenbarger et al. [34] and depicted in Figure 1 suggest that when $\mathrm{N}$ inputs are below the optimum rate at which maximum yield is obtained, applied $\mathrm{N}$ stimulates crop growth, increasing crop residue inputs to the soil and thereby increasing SOC. Additionally, when fertilizer $\mathrm{N}$ inputs are above the optimum level, added $\mathrm{N}$ imparts no change in crop residue production but increases residual inorganic $\mathrm{N}$, which alleviates microbial $\mathrm{N}$ limitation and thereby enhances mineralization of SOC [35]. However, crop response to $\mathrm{N}$ fertilization is site-specific because there exists large spatial and temporal variability in soil $\mathrm{N}$ supply, which is in part 
due to historical differences in management. Regional blanket fertilization recommendations cannot account for this variability. Thus, site-specific nutrient management strategies based on principles of synchronization of crop $\mathrm{N}$ demand with $\mathrm{N}$ supply from all sources including soil and fertilizer $\mathrm{N}$ can ensure high yields along with maintenance of soil health. These can not only account for site-to-site variability in optimum fertilizer rate but also resolve uncertainty regarding response of SOC build-up to fertilizer application.

In the last two decades, site-specific real-time methods of $\mathrm{N}$ management that utilize crop simulation models, remote sensing, or on-the-go crop sensing/variable-rate $\mathrm{N}$ spreaders to determine the spatially variable needs for $\mathrm{N}$ at critical growth stages are increasingly being used to apply optimum doses of fertilizer $\mathrm{N}$ to crops following synchrony principles. Whether implemented for crops in small fields with little or no mechanization in developing countries or practiced as precision agriculture for variable rate adjustment using on-the-go canopy reflectance spectra in large fields of developed countries [87], the principles and objectives of site-specific $\mathrm{N}$ management are the same.

The first report of the Status of the World's Soil Resources prepared by the Intergovernmental Technical Panel on Soils lists nutrient imbalances (both nutrient deficiency and nutrient excess) as one of the specific threats to soil functions [88]. In a long-term field trial with spring barley, Johnston et al. [89] demonstrated that the grain yield increased by more than $50 \%$ with the same amount of fertilizer N only when the plants were grown on a soil well supplied with K. Similarly, barley cultivated on a P-deficient soil yielded only half of the crop, which was grown on a soil with adequate $\mathrm{P}$, although receiving the same amount of fertilizer N. Haerdter and Fairhurst [90] showed that the recovery of N from fertilizers increased from $16 \%$ at traditional $\mathrm{N}$ and $\mathrm{P}$ fertilization levels to $76 \%$ at balanced application of $\mathrm{N}, \mathrm{P}$, and $\mathrm{K}$ fertilizers. Kumar and Yadav [91] reported higher SOM content in plots in which N, P, and K were applied in a balanced proportion on a long-term basis than in treatments receiving only $\mathrm{N}$ or inadequate amounts of P (Figure 2). Similarly, Belay et al. [92] observed more SOC and soil microbial biomass in the $\mathrm{N}, \mathrm{P}$, and $\mathrm{K}$ fertilizer treatment rather than in $\mathrm{N}, \mathrm{P}$, or $\mathrm{K}$ alone fertilizer treatments in a long-term field experiment on maize-field pea rotation initiated in 1939 in South Africa.

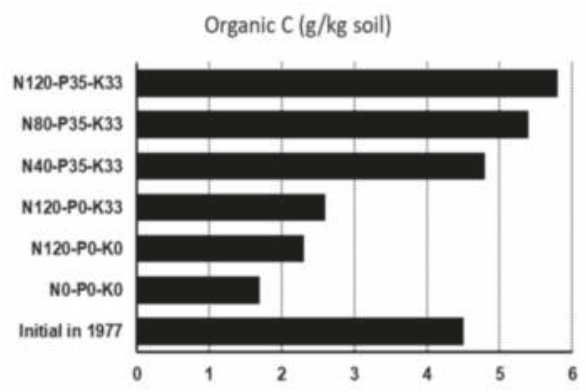

Figure 2. Effect of application of different combinations of N, P, and K fertilizers to rice-wheat cropping system for 20 years on organic $C$ content in the soil in a long-term experiment at Faizabad, India. The numbers after N, P, and $\mathrm{K}$ indicate $\mathrm{kg} \mathrm{ha}^{-1}$. Data source: Kumar and Yadav [91].

In a 16-year long-term field experiment, Chu et al. [93] observed that balanced application of N, P, and $\mathrm{K}$ fertilizers had a higher microbial biomass and activity than in the P- and $\mathrm{N}$-deficient treatments. Balanced fertilization resulted in higher dehydrogenase activity than under nutrient-deficiency fertilization. In a 33-year long-term experiment in a brown soil in China, long-term $\mathrm{N}$ and $\mathrm{P}$, as well as $\mathrm{N}, \mathrm{P}$, and $\mathrm{K}$, fertilizer application treatments exhibited greatly increased soil microbial biomass C and dehydrogenase activity compared to in the only $\mathrm{N}$ treatment [94]. Similarly, in a 21-year long-term experiment, Zhong et al. [95] observed that balanced fertilization with N, P, and K promoted the soil microbial biomass, activity, and diversity and thus enhanced soil health, crop growth, and production. In a wheat-maize cropping system in a fluvo-aquic soil in the North China Plain, Gong et al. [27] reported 
that balanced application of N, P, and K fertilizers for 18 years showed higher $\mathrm{C}$ and $\mathrm{N}$ contents of the light and heavy fractions, as well as more culturable microbial counts, than in unbalanced $\mathrm{N}$ and $\mathrm{P}, \mathrm{P}$ and $\mathrm{K}$, or $\mathrm{N}$ and $\mathrm{K}$ fertilizer treatments.

\section{Integrated Management of Fertilizers and Organic Manures for Improvement of Soil Health}

With increasing awareness about soil health and sustainability in agriculture, organic manures have regained importance, because these can supply precious organic matter, along with many different nutrients, including micronutrients to the soil. Organic manures also influence the availability of plant nutrients in the soil for plants by changing both the physical and biological characteristics of the soil. The concept of integrated management of mineral fertilizers and organic manures became the mainstay of soil fertility management practices at the turn of the 20th century, because it strives to maintain/improve the fertility and health of the soil for sustained crop productivity on a long-term basis [96]. Nutrients supplied through fertilizers are used to supplement those supplied by the different organic sources available to farmers. In Sub-Saharan Africa, where the traditional farming systems depend primarily on mining soil nutrients, the concept of integrated soil fertility management based on the use of mineral fertilizers, organic inputs, and improved germplasm, combined with the knowledge of adapting these practices to local conditions, has been introduced to intensify agriculture. Fertilizers constitute an entry point for practicing integrated soil fertility management, which is a field-specific strategy for increasing productivity, improving soil health, and a sustainable cropping system [97].

In several long-term experiments initiated in 1970s with different cropping systems in various agro-climatic zones in India, along with several other treatments, the two consisted of application of optimum level of N, P, and K fertilizers with and without farmyard manure. Soil organic C in different treatments estimated at the initiation of the experiments and 20 years later is shown in Table 6 . The data convincingly proves that integrated management of mineral fertilizers and farmyard manure resulted in build-up of SOC more than in the fertilizer only treatment. Nevertheless, as already discussed, application of optimum levels of N, P, and $\mathrm{K}$ fertilizers resulted in accumulation of SOC more than in the control treatment to which neither fertilizer nor manure was applied. In recent years, several other workers [27,29,32,98-102] have reported that the application of organic manures along with mineral fertilizers increases SOM and different fractions of SOC more effectively than the application of mineral fertilizers alone. Integrated management of organic manures and mineral fertilizers rather than application of fertilizers alone not only has a positive impact on build-up of SOC but also on soil health related microbial indicators like soil microbial biomass, soil bacterial community diversities, and soil enzyme activities [67,103,104].

Table 6. Changes in SOC due to application of optimum N, P, and K fertilizer levels with and without farmyard manure for 20 years to different cropping systems in long-term experiments established in different soil types in India.

\begin{tabular}{|c|c|c|c|c|c|c|}
\hline \multirow[b]{2}{*}{ Cropping System } & \multirow[b]{2}{*}{ Location } & \multirow[b]{2}{*}{ Soil } & \multirow[b]{2}{*}{$\begin{array}{c}\text { SOC at } \\
\text { Initiation (\%) }\end{array}$} & \multicolumn{3}{|c|}{ SOC after 20 Years (\%) } \\
\hline & & & & Control & $\begin{array}{l}\mathrm{N}, \mathrm{P} \text { and } \mathrm{K} \\
\text { Fertilizers }\end{array}$ & $\begin{array}{c}\mathrm{N}, \mathrm{P} \text { and } \mathrm{K} \\
\text { Fertilizers }+ \\
\text { Farmyard Manure }\end{array}$ \\
\hline Rice-rice & Bhubaneshwar & Inceptisol & 0.27 & 0.41 & 0.59 & 0.76 \\
\hline Rice-wheat & Pantnagar & Mollisol & 1.48 & 0.50 & 0.95 & 1.51 \\
\hline Rice-wheat & Faizabad & Inceptisol & 0.37 & 0.19 & 0.40 & 0.50 \\
\hline Rice-wheat-jute & Barrackpore & Inceptisol & 0.71 & 0.42 & 0.45 & 0.52 \\
\hline Rice-wheat-cowpea & Pantnagar & Mollisol & 1.48 & 0.60 & 0.90 & 1.44 \\
\hline Maize-wheat & Palampur & Alfisol & 0.79 & 0.62 & 0.83 & 1.20 \\
\hline Rice-wheat & Karnal & Alfisol & 0.23 & 0.30 & 0.32 & 0.35 \\
\hline Cassava & Trivandrum & Ultisol & 0.70 & 0.26 & 0.60 & 0.98 \\
\hline
\end{tabular}

Data source: Nambiar [105], Swarup et al. [106]. 
In Sub-Saharan Africa, two types of soils have been recognized in terms of responsiveness to mineral fertilizers. One type of soils are termed as responsive soils, because, due to nutrient mining, crops grown in these soils respond to fertilizer application in a normal way. The other type of soils are referred to as poor, less-responsive soils because these are highly degraded in terms of both extensive nutrient mining and loss of SOM, and crops grown in these respond to fertilizer use minimally or do not respond [107]. The degradation of soil to non-responsive state occurs due to discontinuous, insufficient, or no fertilizer application over a certain period of time. When a certain threshold of soil degradation is exceeded, this condition may not be reversible and soils may not respond immediately to fertilizer or organic manure application so that crop productivity may not return to the level attained before fertilizer use was discontinued. In a study conducted by Zingore et al. [108], response to fertilizer application on less-responsive soils was observed only after application of $17 \mathrm{tha}^{-1}$ year ${ }^{-1}$ of farmyard manure during three consecutive years. Once the soil became responsive to fertilizers, improvement in agronomic efficiency and soil health could be achieved through integrated nutrient management of fertilizers and farmyard manure. This unique interaction of organic manures and fertilizers seems to be very valuable in dealing with soils degraded due to long history of nutrient depletion.

\section{Conclusions and Policy Implications}

Nitrogen fertilizers, when applied at rates less than the optimum at which maximum yields are obtained, stimulate crop growth, leading to increasing crop residue inputs to the soil and, in turn, increasing the rate of soil organic storage. Until and unless fertilizer $\mathrm{N}$ acidifies the soil to $\mathrm{pH}<5$, the application of fertilizer at optimal rate generally has a positive effect on soil biota. The balanced application of N, P, and K fertilizers results in further significant improvement in the soil health in terms of increased SOC and soil microbial biomass. The uptake of $\mathrm{N}$ by crop plants is generally greater from native soil $\mathrm{N}$ than from $\mathrm{N}$ applied as fertilizers. As a decline in SOM following the application of fertilizer $\mathrm{N}$ is not a general phenomenon, a spiral of decline in soil functioning and crop productivity due to fertilizer $\mathrm{N}$ use is not expected. Application of fertilizers more than the optimum level can not only adversely influence biological communities in the soil but may also result in increased residual inorganic $\mathrm{N}$, which can enhance SOC mineralization and loss of SOC. Because there exists large spatial and temporal variability in soil $\mathrm{N}$ supply, crop response to $\mathrm{N}$ fertilization is site-specific. Thus, site-specific nutrient management strategies based on principles of synchronization of crop $\mathrm{N}$ demand with $\mathrm{N}$ supply from all sources including soil and fertilizer $\mathrm{N}$ hold great potential for ensuring high yields of crops along with maintenance or improvement in soil health.

Soil and agronomic research reviewed and analysed in this paper shows that sustainable agricultural intensification through application of fertilizer $\mathrm{N}$ and healthy soils are compatible goals. The extent to which fertilizer $\mathrm{N}$ can contribute to economic and efficient crop production, and concomitantly benefit the soil in terms of quality or health, is dictated by the adoption of management practices that ensure that fertilizer $\mathrm{N}$ is not applied indiscriminately to agricultural crops. Fertilizer $\mathrm{N}$ should never be applied in amounts greater than what is required to obtain optimum yields. Ideally, fertilizer $\mathrm{N}$ should be managed on a site-specific basis, whether based on the nutrient status of soil or plants in a given field, so that $\mathrm{N}$ is applied in the right amount and at a right time according to the needs of the soil-plant system. The application of fertilizer $\mathrm{N}$ in a balanced proportion with other nutrients and integrated nutrient management based on organic manures and fertilizers can lead to further improvements in soil health.

The effect of temperature and moisture on SOM decomposition is very well documented in the literature. However, hardly any studies are available in which the interaction effects of fertilizer $\mathrm{N}$ and temperature and moisture on SOM decomposition are reported. This information is needed to evaluate the effect of fertilizer use on soil health under different temperature and moisture regimes. While studies related to soil health and fertilizer $\mathrm{N}$ are being reported from different climatic regions of the world, models can be usefully employed to define the specific effects of rainfall or soil moisture and soil temperature on fertilizer N-related soil health issues. The response of different microbial 
groups to repeated applications of fertilizer $\mathrm{N}$ varies and depends on environmental and crop management-related factors. As enough data are not available to understand the interactions among environmental factors, fertilizer $\mathrm{N}$ rates and types, and specific groups of soil microorganisms, there is a need to conduct studies to understand these complex interactions. Also, there is a need for adequate documentation of the effect of fertilizer N on the stability of SOM and the fate of organic residues in the long-term in different cropping systems. Long-term agronomic experiments involving the application of fertilizers in different agro-ecological zones across the world can be used to generate information on these lines. Increased soil salinity due to application of mineral fertilizers can deteriorate soil health, but $\mathrm{N}$ fertilizers based on sodium salts are no longer applied to field crops. In the quest to reduce the cost of cultivation and possibly maintain and/or improve soil health, in many parts of the world conservation agriculture systems are being adopted. In these systems, soil is tilled to a minimum extent and crop residues are retained in the soil so as to help build up of SOM. There is a need to establish appropriate fertilizer management strategies in such systems so that soil health is maintained or improved.

Conflicts of Interest: The authors declare no conflicts of interest.

\section{References}

1. Doran, J.W.; Parkin, T.B. Defining and assessing soil quality. In Defining Soil Quality for a Sustainable Environment; SSSA Special Publication 35; Doran, J.W., Coleman, D.C., Bezdicek, D.F., Stewart, B.A., Eds.; Soil Science Society of America: Madison, WI, USA, 1994; pp. 1-21. [CrossRef]

2. Lewandowski, A.; Zumwinkle, M.; Fish, A. Assessing the Soil System: A Review of Soil Quality Literature; Minnesota Department of Agriculture, Energy and Sustainable Agriculture Program: St. Paul, MN, USA, 1999.

3. Kibblewhite, M.G.; Ritz, K.; Swift, M.J. Soil health in agricultural systems. Philos. Trans. R. Soc. B 2008, 363, 685-701. [CrossRef] [PubMed]

4. Lal, R.; Stewart, B.A. Food Security and Soil Quality; CRC Press: Boca Raton, FL, USA, 2010.

5. Alexandratos, N.; Bruinsma, J. World Agriculture towards 2030/2050: The 2012 Revision; ESA Working Paper No. 12-03; Food and Agriculture Organization of the United Nations: Rome, Italy, 2012.

6. Searchinger, T.; Hanson, C.; Ranganathan, J.; Lipinski, B.; Waite, R.; Winterbottom, R.; Dinshaw, A.; Heimlich, R. Creating a Sustainable Food Future. A Menu of Solutions to Sustainably Feed More Than 9 Billion People by 2050; World Resources Report 2013-14: Interim Findings; World Resources Institute: Washington, DC, USA, 2014.

7. Erisman, J.W.; Sutton, M.A.; Galloway, J.N.; Klimont, Z.; Winiwarter, W. How a century of ammonia synthesis changed the world? Nat. Geosci. 2008, 1, 636-639. [CrossRef]

8. IFADATA. Available online: http://ifadata.fertilizer.org/ucSearch.aspx (accessed on 20 February 2018).

9. Recous, S.; Robin, D.; Darwis, D.; Mary, B. Soil inorganic nitrogen availability: Effect on maize residue decomposition. Soil Biol. Biochem. 1995, 27, 1529-1538. [CrossRef]

10. Wardle, D.A. A comparative assessment of factors which influence microbial biomass carbon and nitrogen levels in soil. Biol. Rev. 1992, 67, 321-358. [CrossRef]

11. Kirkby, C.A.; Richardson, A.E.; Wade, L.J.; Batten, G.D.; Blanchard, C.; Kirkegaard, J.A. Carbon-nutrient stoichiometry to increase soil carbon sequestration. Soil Biol. Biochem. 2013, 60,77-86. [CrossRef]

12. Zhang, H.; Ding, W.; Yu, H.; He, X. Linking organic carbon accumulation to microbial community dynamics in a sandy loam soil: Result of 20 years compost and inorganic fertilizers repeated application experiment. Biol. Fertil. Soils 2015, 51, 137-150. [CrossRef]

13. Dourado-Neto, D.; Powlson, D.; Abu Bakar, R.; Bacchi, O.O.S.; Basanta, M.V.; thi Cong, P.; Keerthisinghe, G.; Ismaili, M.; Rahman, S.M.; Reichardt, K.; et al. Multiseason recoveries of organic and inorganic nitrogen-15 in tropical cropping systems. Soil Sci. Soc. Am. J. 2010, 74, 139-152. [CrossRef]

14. Ladha, J.K.; Pathak, H.; Krupnik, T.J.; Six, J.; van Kessel, C. Efficiency of fertilizer nitrogen in cereal production: Retrospects and prospects. Adv. Agron. 2005, 87, 85-156. [CrossRef]

15. IAEA (International Atomic, Energy Agency). Management of Crop Residues for Sustainable Crop Production; IAEA TECHDOC-1354; International Atomic, Energy Agency: Vienna, Austria, 2003. 
16. Jansson, S.L.; Persson, J. Mineralization and immobilization of soil nitrogen. In Nitrogen in Agricultural Soils; Agronomy Monograph 22; Stevenson, F.J., Ed.; ASA, CSSA, and SSSA: Madison, WI, USA, 1982; pp. $229-252$.

17. Jenkinson, D.S.; Fox, R.H.; Rayner, J.H. Interactions between fertilizer nitrogen and soil nitrogen-The so-called priming effect. Eur. J. Soil Sci. 1985, 36, 425-444. [CrossRef]

18. Schimel, J.P.; Bennett, J. Nitrogen mineralization: Challenges of a changing paradigm. Ecology 2004, 85, 591-602. [CrossRef]

19. Glendining, M.J.; Poulton, P.R.; Powlson, D.S.; Jenkinson, D.S. Fate of ${ }^{15}$ N-labelled fertilizer applied to spring barley grown on soils of contrasting nutrient status. Plant Soil 1997, 195, 83-98. [CrossRef]

20. Liu, X.-J.A.; Sun, J.; Mau, R.L.; Finley, B.K.; Compson, Z.G.; van Gestel, N.; Brown, J.R.; Schwartz, E.; Dijkstra, P.; Hungate, B.A. Labile carbon input determines the direction and magnitude of the priming effect. Appl. Soil Ecol. 2017, 109, 7-13. [CrossRef]

21. Recous, S.; Fresneau, C.; Faurie, G.; Mary, B. The fate of labelled ${ }^{15} \mathrm{~N}$ urea and ammonium nitrate applied to a winter wheat crop I. Nitrogen transformations in the soil. Plant Soil 1988, 112, 205-214. [CrossRef]

22. Liu, X.-J.A.; van Groenigen, K.J.; Dijkstra, P.; Hungate, B.A. Increased plant uptake of native soil nitrogen following fertilizer addition-Not a priming effect? Appl. Soil Ecol. 2017, 114, 105-110. [CrossRef]

23. Haddaway, N.R.; Hedlund, K.; Jackson, L.E.; Kätterer, T.; Lugato, E.; Thomsen, I.K.; Jørgensen, H.B.; Isberg, P.E. How does tillage intensity affect soil organic carbon? A systematic review. Environ. Evid. 2017, 6, 30. [CrossRef]

24. Liu, X.; Herbert, S.J.; Hashemi, A.M.; Zhang, X.; Ding, G. Effects of agricultural management on soil organic matter and carbon transformation-A review. Plant Soil Environ. 2006, 52, 531-543. [CrossRef]

25. Cong, R.H.; Xu, M.G.; Wang, X.J.; Zhang, W.J.; Yang, X.Y.; Huang, S.M.; Wang, B.R. An analysis of soil carbon dynamics in long-term soil fertility trials in China. Nutr. Cycl. Agroecosyst. 2012, 93, 201-213. [CrossRef]

26. Ghimire, R.; Lamichhane, S.; Acharya, B.S.; Bista, P.; Sainju, U.M. Tillage, crop residue, and nutrient management effects on soil organic carbon in rice-based cropping systems: A review. J. Integr. Agric. 2017, 16,1-15. [CrossRef]

27. Gong, W.; Yan, X.; Wang, J.; Hu, T.; Gong, Y. Long-term manure and fertilizer effects on soil organic matter fractions and microbes under a wheat-maize cropping system in northern China. Geoderma 2009, 149, 318-324. [CrossRef]

28. Manna, M.C.; Swarup, A.; Wanjari, R.H.; Mishra, B.; Shahi, D.K. Long-term fertilization, manure and liming effects on soil organic matter and crop yields. Soil Tillage Res. 2007, 94, 397-409. [CrossRef]

29. Purakayastha, T.J.; Rudrappa, L.; Singh, D.; Swarup, A.; Bhadraray, S. Long-term impact of fertilizers on soil organic carbon pools and sequestration rates in maize-wheat-cowpea cropping system. Geoderma 2008, 144, 370-378. [CrossRef]

30. Tian, J.; Lou, Y.; Gao, Y.; Fang, H.; Liu, S.; Xu, M.; Blagodatskaya, E.; Kuzyakov, Y. Response of soil organic matter fractions and composition of microbial community to long-term organic and mineral fertilization. Biol. Fertil. Soils 2017, 53, 523-532. [CrossRef]

31. Sleutel, S.; Neve, S.D.; Németh, T.; Tóth, T.; Hofmana, G. Effect of manure and fertilizer application on the distribution of organic carbon in different soil fractions in long-term field experiments. Eur. J. Agron. 2006, 25, 280-288. [CrossRef]

32. Blair, N.; Faulkner, R.D.; Till, A.R.; Poulton, P.R. Long-term management impacts on soil C, N and physical fertility Part I: Broadbalk experiment. Soil Tillage Res. 2006, 91, 30-38. [CrossRef]

33. Kögel-Knabner, I.; Ekschmitt, K.; Flessa, H.; Guggenberger, G.; Matzner, E.; Marschner, B.; Lützow, M. An integrative approach of organic matter stabilization in temperate soils: Linking chemistry, physics, and biology. J. Plant Nutr. Soil Sci. 2008, 171, 5-13. [CrossRef]

34. Poffenbarger, H.J.; Barker, D.W.; Helmers, M.J.; Miguez, F.E.; Olk, D.C.; Sawyer, J.E.; Six, J.; Castellano, M.J. Maximum soil organic carbon storage in Midwest US cropping systems when crops are optimally nitrogen-fertilized. PLoS ONE 2017, 12, e0172293. [CrossRef] [PubMed]

35. Green, C.J.; Blackmer, A.M.; Horton, R. Nitrogen effects on conservation of carbon during corn residue decomposition in soil. Soil Sci. Soc. Am. J. 1995, 59, 453-459. [CrossRef]

36. Mulvaney, R.L.; Khan, S.A.; Ellsworth, T.R. Synthetic nitrogen fertilizers deplete soil nitrogen: A global dilemma for sustainable cereal production. J. Environ. Qual. 2009, 38, 2295-2314. [CrossRef] [PubMed]

37. Chivenge, P.; Vanlauwe, B.; Gentile, R.; Six, J. Comparison of organic versus mineral resource effects on short-term aggregate carbon and nitrogen dynamics in a sandy soil versus a fine textured soil. Agric. Ecosyst. Environ. 2011, 140, 361-371. [CrossRef] 
38. Fonte, S.J.; Quansah, G.W.; Six, J. Fertilizer and residue quality effects on organic matter stabilization in soil aggregates. Soil Sci. Soc. Am. J. 2009, 73, 961-966. [CrossRef]

39. Russell, A.E.; Cambardella, C.A.; Laird, D.A.; Jaynes, D.B.; Meek, D.W. Nitrogen fertilizer effects on soil carbon balances in Midwestern U.S. agricultural systems. Ecol. Appl. 2009, 19, 1102-1113. [CrossRef] [PubMed]

40. Glendining, M.J.; Powlson, D.S. The effects of long-continued applications of inorganic nitrogen fertilizer on soil organic nitrogen-A review. In Soil Management: Experimental Basis for Sustainability and Environmental Quality; Advances in Soil Science Series; Lal, R., Stewart, B.A., Eds.; Lewis: Boca Raton, FL, USA, 1995; pp. 385-446.

41. Khan, S.A.; Mulvaney, R.L.; Ellsworth, T.R.; Boast, C.W. The myth of nitrogen fertilization for soil carbon sequestration. J. Environ. Qual. 2007, 36, 1821-1832. [CrossRef] [PubMed]

42. Powlson, D.S.; Jenkinson, D.S.; Johnston, A.E.; Poulton, P.R.; Glendining, M.J.; Goulding, K.W.T. Comments on "Synthetic nitrogen fertilizers deplete soil nitrogen: A global dilemma for sustainable cereal production," by R.L. Mulvaney, S.A. Khan, and T.R. Ellsworth in the Journal of Environmental Quality (2009, 38:2295-2314). J. Environ. Qual. 2010, 39, 749-752. [CrossRef] [PubMed]

43. Ladha, J.K.; Kesava Reddy, C.; Padre, A.T.; van Kessel, C. Role of nitrogen fertilization in sustaining organic matter in cultivated soils. J. Environ. Qual. 2011, 40, 1756-1766. [CrossRef] [PubMed]

44. Geiseller, D.; Scow, K.M. Long-term effects of mineral fertilizers on soil microorganisms-A review. Soil Biol. Biochem. 2014, 75, 54-63. [CrossRef]

45. Körschens, M.; Albert, E.; Armbruster, M.; Barkusky, D.; Baumecker, M.; Behle-Schalk, L.; Bischoff, R.; Čergan, Z.; Ellmer, F.; Herbst, F.; et al. Effect of mineral and organic fertilization on crop yield, nitrogen uptake, carbon and nitrogen balances, as well as soil organic carbon content and dynamics: Results from 20 European long-term field experiments of the twenty-first century. Arch. Agron. Soil Sci. 2013, 59, 1017-1040. [CrossRef]

46. Gregorich, E.G.; Liang, B.C.; Ellert, B.H.; Drury, C.F. Fertilization effects on soil organic matter turnover and corn residue C storage. Soil Sci. Soc. Am. J. 1996, 60, 472-476. [CrossRef]

47. Benbi, D.K.; Brar, J.S. A 25-year record of carbon sequestration and soil properties in intensive agriculture. Agron. Sustain. Dev. 2009, 29, 257-265. [CrossRef]

48. Tian, K.; Zhao, Y.; Xu, X.; Hai, N.; Huang, B.; Deng, W. Effects of long-term fertilization and residue management on soil organic carbon changes in paddy soils of China: A meta-analysis. Agric. Ecosyst. Environ. 2015, 204, 40-50. [CrossRef]

49. Lu, M.; Zhou, X.; Luo, Y.; Yang, Y.; Fang, C.; Chen, J.; Li, B. Minor stimulation of soil carbon storage by nitrogen addition: A meta-analysis. Agric. Ecosyst. Environ. 2011, 140, 234-244. [CrossRef]

50. Shang, Q.; Ling, N.; Feng, X.; Yang, X.; Wu, P.; Zou, J.; Shen, Q.; Guo, S. Soil fertility and its significance to crop productivity and sustainability in typical agroecosystem: A summary of long-term fertilizer experiments in China. Plant Soil 2014, 381, 13-23. [CrossRef]

51. Buyanovsky, G.A.; Wagner, G.H. Changing role of cultivated land in the global carbon cycle. Biol. Fertil. Soils 1998, 27, 242-245. [CrossRef]

52. Katyal, J.C.; Rao, N.H.; Reddy, M.N. Critical aspects of organic matter management in the Tropics: The example of India. Nutr. Cycl. Agroecosyst. 2001, 61,77-88. [CrossRef]

53. Hermans, S.M.; Buckley, H.L.; Case, B.S.; Curran-Cournane, F.; Taylor, M.; Lear, G. Bacteria as emerging indicators of soil condition. Appl. Environ. Microbiol. 2017, 83, e02826-16. [CrossRef] [PubMed]

54. O'Donnell, A.G.; Seasman, M.; Macrae, A.; Waite, I.; Davies, J.T. Plants and fertilisers as drivers of change in microbial community structure and function in soils. Plant Soil 2001, 232, 135-145. [CrossRef]

55. Marschner, P.; Kandeler, E.; Marschner, B. Structure and function of the soil microbial community in a long-term fertilizer experiment. Soil Biol. Biochem. 2003, 35, 453-461. [CrossRef]

56. Buyanovsky, G.A.; Wagner, G.H. Carbon transfer in a winter wheat (Triticum aestivum) ecosystem. Biol. Fertil. Soils 1987, 5, 76-82. [CrossRef]

57. Khonje, D.J.; Varsa, E.C.; Klubek, B. The acidulation effects of nitrogenous fertilisers on selected chemical and microbiological properties of soil. Commun. Soil Sci. Plant Anal. 1989, 20, 1377-1395. [CrossRef]

58. Murugan, R.; Kumar, S. Influence of long-term fertilisation and crop rotation on changes in fungal and bacterial residues in a tropical rice field soil. Biol. Fertil. Soils 2013, 49, 847-856. [CrossRef]

59. Ge, Y.; Zhang, J.B.; Zhang, L.M.; Yang, M.; He, J.Z. Long-term fertilization regimes affect bacterial community structure and diversity of an agricultural soil in northern China. J. Soils Sediments 2008, 8, 43-50. [CrossRef] 
60. Girvan, M.S.; Bullimore, J.; Ball, A.S.; Pretty, J.N.; Osborn, A.M. Responses of active bacterial and fungal communities in soils under winter wheat to different fertilizer and pesticide regimens. Appl. Environ. Microbiol. 2004, 70, 2692-2701. [CrossRef] [PubMed]

61. Kumar, U.; Shahid, M.; Tripathi, R.; Mohanty, S.; Kumar, A.; Bhattacharyya, P.; Lal, B.; Gautam, P.; Raja, R.; Panda, B.B.; et al. Variation of functional diversity of soil microbial community in sub-humid tropical rice-rice cropping system under long-term organic and inorganic fertilization. Ecol. Indic. 2017, 73, 536-543. [CrossRef]

62. Mandal, A.; Patra, A.K.; Singh, D.; Swarup, A.; Masto, R.E. Effect of long-term application of manure and fertilizer on biological and biochemical activities in soil during crop development stages. Bioresour. Technol. 2007, 98, 3585-3592. [CrossRef] [PubMed]

63. Zhao, J.; Ni, T.; Li, Y.; Xiong, W.; Ran, W.; Shen, B.; Shen, Q.; Zhang, R. Responses of bacterial communities in arable soils in a rice-wheat cropping system to different fertilizer regimes and sampling times. PLoS ONE 2014, 9, e85301. [CrossRef] [PubMed]

64. Goyal, S.; Mishra, M.M.; Hooda, I.S.; Singh, R. Organic matter-microbial biomass relationships in field experiments under tropical conditions: Effects of inorganic fertilization and organic amendments. Soil Biol. Biochem. 1992, 24, 1081-1084. [CrossRef]

65. Kanazawa, S.; Asakawa, S.; Takai, Y. Effect on fertilizer and manure application on microbial numbers, biomass, and enzyme activities in volcanic ash soils. I. Microbial numbers and biomass carbon. Soil Sci. Plant Nutr. 1988, 34, 429-439. [CrossRef]

66. Lynch, J.M.; Panting, L.M. Effects of season, cultivation and nitrogen fertiliser on the size of the soil microbial biomass. J. Sci. Food Agric. 1982, 33, 249-252. [CrossRef]

67. Li, J.; Cooper, J.M.; Lin, Z.A.; Li, Y.; Yang, X.; Zhao, B. Soil microbial community structure and function are significantly affected by long-term organic and mineral fertilization regimes in the North China Plain. Appl. Soil Ecol. 2015, 96, 75-87. [CrossRef]

68. Liu, E.; Yan, C.; Mei, X.; He, W.; Bing, S.H.; Ding, L.; Liu, Q.; Liu, S.; Fan, T. Long-term effect of chemical fertilizer, straw, and manure on soil chemical and biological properties in northwest China. Geoderma 2010, 158, 173-180. [CrossRef]

69. Mbuthia, L.W.; Acosta-Martínez, V.; DeBruyn, J.; Schaeffer, S.; Tyler, D.; Odoi, E.; Mpheshea, M.; Walker, F.; Eash, N. Long term tillage, cover crop, and fertilization effects on microbial community structure, activity: Implications for soil quality. Soil Biol. Biochem. 2015, 89, 24-34. [CrossRef]

70. Zhong, W.H.; Cai, Z.C. Long-term effects of inorganic fertilizers on microbial biomass and community functional diversity in a paddy soil derived from quaternary red clay. Appl. Soil Ecol. 2007, 36, 84-91. [CrossRef]

71. Schimel, J.P.; Bennett, J.; Fierer, N. Microbial community composition and soil nitrogen cycling: Is there really a connection? In Biological Diversity and Function in Soils; Bardgett, R.D., Usher, M.B., Hopkins, D.W., Eds.; Cambridge University Press: Cambridge, UK, 2005; pp. 172-188.

72. Angus, J.J.; Gupta, V.V.S.R.; Good, A.J.; Pitson, G.D. Wheat Yield and Protein Responses to Anhydrous Ammonia (coldflo) and Urea, and their Effects on Soil; Final Report of Project CSP 169 for the Grain Research and Development Corporation; CSIRO: Canberra, Australia, 1999; p. 17.

73. Biederbeck, V.O.; Campbell, C.A.; Ukrainetz, H.; Curtin, D.; Bouman, O.T. Soil microbial and biochemical properties after 10 years of fertilization with urea and anhydrous ammonia. Can. J. Soil Sci. 1996, 76, 7-14. [CrossRef]

74. Treseder, K.K.; Allen, M.F. Direct nitrogen and phosphorus limitation of arbuscular mycorrhizal fungi: A model and field test. New Phytol. 2002, 155, 507-515. [CrossRef]

75. Jackson, L.E.; Calderon, F.J.; Steenwerth, K.L.; Scow, K.M.; Rolston, D.E. Responses of soil microbial processes and community structure to tillage events and implications for soil quality. Geoderma 2003, 114, 305-317. [CrossRef]

76. Mathew, R.P.; Feng, Y.; Githinji, L.; Ankumah, R.; Balkcom, K.S. Impact of no-tillage and conventional tillage systems on soil microbial communities. Appl. Environ. Soil Sci. 2012. [CrossRef]

77. Doran, J.W. Microbial biomass and mineralizable nitrogen distributions in no-tillage and plowed soils. Biol. Fertil. Soils 1987, 5, 68-75. [CrossRef]

78. Zuber, S.M.; Villamil, M.B. Meta-analysis approach to assess effect of tillage on microbial biomass and enzyme activities. Soil Biol. Biochem. 2016, 97, 176-187. [CrossRef] 
79. Treseder, K.K. Nitrogen additions and microbial biomass: A meta-analysis of ecosystem studies. Ecol. Lett. 2008, 11, 1111-1120. [CrossRef] [PubMed]

80. Rousk, J.; Brookes, P.C.; Bååth, E. Contrasting soil pH effects on fungal and bacterial growth suggest functional redundancy in carbon mineralization. Appl. Environ. Microbiol. 2009, 75, 1589-1596. [CrossRef] [PubMed]

81. Bolan, N.S.; Adriano, D.C.; Curtin, D. Soil acidification and liming interactions with nutrient and heavy metal transformation and bioavailability. Adv. Agron. 2003, 78, 215-272. [CrossRef]

82. Guo, J.H.; Liu, X.J.; Zhang, Y.; Shen, J.L.; Han, W.X.; Zhang, W.F.; Christie, P.; Goulding, K.W.T.; Vitousek, P.M.; Zhang, F.S. Significant acidification in major Chinese croplands. Science 2010, 327, 1008-1010. [CrossRef] [PubMed]

83. Lu, X.; Mao, Q.; Gilliam, F.S.; Luo, Y.; Mo, J. Nitrogen deposition contributes to soil acidification in tropical ecosystems. Glob. Chang. Biol. 2014, 20, 3790-3801. [CrossRef] [PubMed]

84. Lal, R. Anthropogenic influences in world soil and implications for global food security. Adv. Agron. 2007, 93, 69-93. [CrossRef]

85. Bhattacharyya, R.; Ghosh, B.N.; Mishra, P.K.; Mandal, B.; Rao, C.S.; Sarkar, D.; Das, K.; Anil, K.S.; Lalitha, M.; Hati, K.M.; et al. Soil degradation in India: Challenges and potential solutions. Sustainability 2015, 7, 3528-3570. [CrossRef]

86. Portch, S.; Jin, J.Y. Fertilizer use in China: Types and amounts. In Encyclopaedia of Life Support Systems, Agricultural Sciences; Lal, R., Ed.; EOLSS Publishers Co. Ltd.: Oxford, UK, 2009; Volume II, pp. 247-256.

87. Buresh, R.J.; Witt, C. Site-specific nutrient management. In Fertilizer Best Management Practices; International Fertilizer Industry Association (IFA): Paris, France, 2007; pp. 47-55.

88. Montanarella, L.; Pennock, D.J.; McKenzie, N.; Badraoui, M.; Chude, V.; Baptista, I.; Mamo, T.; Yemefack, M.; Aulakh, M.S.; Yagi, K.; et al. World's soils are under threat. Soil 2016, 2, 79-82. [CrossRef]

89. Johnston, A.E.; Poulton, P.R.; Syers, J.K. Phosphorus, Potassium and Sulphur Cycles in Agricultural Soils; Proceedings No. 465; The International Fertiliser Society: York, UK, 2001.

90. Haerdter, R.; Fairhurst, T. Nutrient use efficiency in upland cropping systems of Asia. In Proceedings of the IFA Regional Conference, Cheju Island, Korea, 6-8 October 2003.

91. Kumar, A.; Yadav, D.S. Long-term effects of fertilizers on the soil fertility and productivity of a rice-wheat system. J. Agron. Crop Sci. 2001, 186, 47-54. [CrossRef]

92. Belay, A.; Claassens, A.; Wehner, F.C. Effect of direct nitrogen and potassium and residual phosphorus fertilizers on soil chemical properties, microbial components and maize yield under long-term crop rotation. Biol. Fertil. Soils 2002, 35, 420-427. [CrossRef]

93. Chu, H.; Lin, X.; Fujii, T.; Morimoto, S.; Yagi, K.; Hu, J.; Zhang, J. Soil microbial biomass, dehydrogenase activity, bacterial community structure in response to long-term fertilizer management. Soil Biol. Biochem. 2007, 39, 2971-2976. [CrossRef]

94. Luo, P.; Han, X.; Wang, Y.; Han, M.; Shi, H.; Liu, N.; Bai, H. Influence of long-term fertilization on soil microbial biomass, dehydrogenase activity, and bacterial and fungal community structure in a brown soil of northeast China. Ann. Microbiol. 2015, 65, 533-542. [CrossRef] [PubMed]

95. Zhong, W.; Gu, T.; Wang, W.; Zhang, B.; Lin, X.; Huang, Q.; Shen, W. The effects of mineral fertilizer and organic manure on soil microbial community and diversity. Plant Soil 2010, 326, 511-522. [CrossRef]

96. Palm, C.A.; Myers, R.J.K.; Nandwa, S.M. Combined use of organic and inorganic nutrient sources for soil fertility maintenance and replenishment. In Replenishing Soil Fertility in Africa; Buresh, R.J., Sanchez, P.A., Calhoun, F., Eds.; American Society of Agronomy and Soil Science Society of America: Madison, WI, USA, 1997; pp. 193-217. [CrossRef]

97. Vanlauwe, B.; Bationo, A.; Chianu, J.; Giller, K.E.; Merckx, R.; Mokwunye, U.; Ohiokpehai, O.; Pypers, P.; Tabo, R.; Shepherd, K.; et al. Integrated soil fertility management: Operational definition and consequences for implementation and dissemination. Outlook Agric. 2010, 39, 17-24. [CrossRef]

98. Wu, T.Y.; Schoenau, J.J.; Li, F.M.; Qian, P.Y.; Malhi, S.S.; Shi, Y.C.; Xue, F.L. Influence of cultivation and fertilization on total organic carbon and carbon fractions in soils from the Loess Plateau of China. Soil Tillage Res. 2004, 77, 59-68. [CrossRef]

99. Rudrappa, L.; Purakayastha, T.J.; Singh, D.; Bhadraray, S. Long-term manuring and fertilization effects on soil organic carbon pools in a Typic Haplustept of semi-arid sub-tropical India. Soil Tillage Res. 2006, 88, 180-192. [CrossRef] 
100. Brar, B.S.; Kamalbir-Singh; Dheri, G.S.; Balwinder-Kumar. Carbon sequestration and soil carbon pools in a rice-wheat cropping system: Effect of long-term use of inorganic fertilizers and organic manure. Soil Tillage Res. 2013, 128, 30-36. [CrossRef]

101. Manna, M.C.; Swarup, A.; Wanjari, R.H.; Singh, Y.V.; Ghosh, P.K.; Singh, K.N.; Tripathi, A.K.; Saha, M.N. Soil organic matter in a West Bengal Inceptisol after 30 years of multiple cropping and fertilization. Soil Sci. Soc. Am. J. 2006, 70, 121-129. [CrossRef]

102. Yadvinder-Singh; Bijay-Singh; Ladha, J.K.; Khind, C.S.; Gupta, R.K.; Meelu, O.P.; Pasuquin, E. Long-term effects of organic inputs on yield and soil fertility in the rice-wheat rotation. Soil Sci. Soc. Am. J. 2004, 68, 845-853. [CrossRef]

103. Gu, Y.; Zhang, X.; Tu, S.; Lindström, K. Soil microbial biomass, crop yields, and bacterial community structure as affected by long-term fertilizer treatments under wheat-rice cropping. Eur. J. Soil Biol. 2009, 45, 239-246. [CrossRef]

104. Hao, X.H.; Liu, S.L.; Wu, J.S.; Hu, R.G.; Tong, C.L.; Su, Y.Y. Effect of long-term application of inorganic fertilizer and organic amendments on soil organic matter and microbial biomass in three subtropical paddy soils. Nutr. Cycl. Agroecosyst. 2008, 81, 17-24. [CrossRef]

105. Nambiar, K.K.M. Major cropping systems in India. In Agricultural Sustainability-Economic Environment and Statistical Considerations; Barnett, V., Pyne, R., Steiner, R., Eds.; John Wiley and Sons: New York, NY, USA, 1995; pp. 133-168.

106. Swamp, A.; Reddy, D.D.; Prasad, R.N. Proceedings of a National Workshop on Long Term Soil Fertility Management through Integrated Plant Nutrient Supply; Indian Institute of Soil Science: Bhopal, India, 1998.

107. Vanlauwe, B.; Kihara, J.; Chivenge, P.; Pypers, P.; Coe, R.; Six, J. Agronomic use efficiency of N fertilizer in maize-based systems in sub-Saharan Africa within the context of integrated soil fertility management. Plant Soil 2011, 339, 35-50. [CrossRef]

108. Zingore, S.; Murwira, H.K.; Delve, R.J.; Giller, K.E. Soil type, management history and current resource allocation: Three dimensions regulating variability in crop productivity on African smallholder farms. Field Crops Res. 2007, 101, 296-305. [CrossRef]

(c) 2018 by the author. Licensee MDPI, Basel, Switzerland. This article is an open access article distributed under the terms and conditions of the Creative Commons Attribution (CC BY) license (http://creativecommons.org/licenses/by/4.0/). 


\title{
Integrated Nutrient Management in Rice-Wheat Cropping System: An Evidence on Sustainability in the Indian Subcontinent through Meta-Analysis
}

\author{
Sheetal Sharma ${ }^{1, *}$, Rajeev Padbhushan ${ }^{2}$ and Upendra Kumar ${ }^{3}$ \\ 1 International Rice Research Institute-India Office, 1st Floor, CG Block, NASC Complex, DPS Marg, Pusa, \\ New Delhi 110012, India \\ 2 International Rice Research Institute-Odisha Office, Plot no. 340/C, School St., Saheed Nagar, Bhubaneswar, \\ Odisha 751007, India; r.padbhushan@irri.org \\ 3 National Rice Research Institute (NRRI), Bidyadharpur, Cuttack, Odisha 753006, India; \\ ukumarmb@gmail.com \\ * Correspondence: sheetal.sharma@irri.org
}

Received: 21 January 2019; Accepted: 2 February 2019; Published: 7 February 2019

\begin{abstract}
Over years of intensive cultivation and imbalanced fertilizer use, the soils of the Indian subcontinent have become deficient in several nutrients and are impoverished in organic matter. Recently, this region has started emphasizing a shift from inorganic to organic farming to manage soil health. However, owing to the steadily increasing demands for food by the overgrowing populations of this region, a complete shift to an organic farming system is not possible. The rice-wheat cropping system (RWCS) is in crisis because of falling or static yields. The nations of this region have already recognized this problem and have modified farming systems toward integrated nutrient management (INM) practices. The INM concept aims to design farming systems to ensure sustainability by improving soil health, while securing food for the population by improving crop productivity. Therefore, this paper was synthesized to quantify the impact and role of INM in improving crop productivity and sustainability of the RWCS in the context of the Indian subcontinent through meta-analysis using 338 paired data during the period of 1989-2016. The meta-analysis of the whole data for rice and wheat showed a positive increase in the grain yield of both crops with the use of INM over inorganic fertilizers only (IORA), organic fertilizers only (ORA), and control (no fertilizers; CO) treatments. The increase in grain yield was significant at $p<0.05$ for rice in INM over ORA and CO treatments. For wheat, the increase in grain yield was significant at $p<0.05$ in INM over IORA, ORA, and CO treatments. The yield differences in the INM treatment over IORA were 0.05 and $0.13 \mathrm{Mg}$ $\mathrm{ha}^{-1}$, respectively, in rice and wheat crops. The percent yield increases in INM treatment over IORA, ORA, and CO treatments were 2.52, 29.2, and 90.9, respectively, in loamy soil and 0.60, 24.9, and 93.7, respectively, in clayey soil. The net returns increased by $121 \%$ (INM vs. CO) in rice, and $9.34 \%$ (INM vs. IORA) and $127 \%$ (INM vs. CO) in wheat crop. Use of integrated nutrient management had a positive effect on soil properties as compared to other nutrient management options. Overall, the yield gain and maintenance of soil health due to INM practices over other nutrient management practices in RWCS can be a viable nutrient management option in the Indian subcontinent.
\end{abstract}

Keywords: integrated nutrient management; rice; wheat; yield; net returns; soil health; sustainability

\section{Introduction}

Rice (Oryza sativa L.) and wheat (Triticum aestivum L.) crops are major staple foods, contributing a key portion of digestible energy and protein in human intake and occupying a premium position among all food communities [1-3]. The rice-wheat cropping system (RWCS) is one of the most 
prominent cropping systems prevailing on the Indian subcontinent and is considered to be of utmost importance for food security and livelihood [4-7]. The RWCS occupies about 13.5 million hectares spread over the Indian subcontinent, namely, India, Pakistan, Nepal, Bangladesh, Sri Lanka, and Bhutan, and accounting for one-fourth to one-third of total food grain production [8,9]. This cropping system covers about one-third of the total rice cultivation and two-fifths of the total wheat cultivation in the Indian subcontinent. Currently, more than nine-tenths of global rice is produced and consumed in these nations [10].

Natural resources, primarily agricultural lands, are limited globally. To meet the food demand of the ever-increasing population, agriculture must produce more food grains from limited cultivable land [11]. The crop productivity of the region is low and oscillating from $0.5 \mathrm{tha} \mathrm{h}^{-1}$ to $2.5 \mathrm{t} \mathrm{ha}{ }^{-1}$, with a mean of $1.5 \mathrm{t} \mathrm{ha}^{-1}$. The increasing population and food consumption and the decline in existing arable land and other units of supply are placing exceptional pressure on the present farming system to meet the growing food demand. To counteract this problem and obtain higher yields, crop growers are shifting to fertilizer-responsive high-yielding varieties and avoiding the overuse of inputs such as synthetic fertilizers. The soils under the RWCS are now showing signs of fatigue and are no longer showing increased production with an increase in fertilizer use [12]. Even with the use of the recommended rate of fertilizer in the RWCS, a negative balance of primary nutrients has been recorded. To obtain food security in these nations, crop yields must rise considerably while ecological effects must contract significantly [13]. Figures 1 and 2 represent the trends and ratio of rice-wheat production and fertilizer consumption in the Indian subcontinent. These show that, from 1961 to 2016, rice-wheat production increased by four times, whereas fertilizer consumption increased by 67 times, which clearly indicates the slower increase in rice-wheat production even though fertilizer consumption was increasing at an exponential rate. Hence, innovative interventions are required to optimize fertilizer use and sustain the rice-wheat production system in this region.

Intensive cropping systems with continuous imbalanced use of synthetic fertilizers to feed fertilizer-responsive varieties have caused losses in soil organic carbon (SOC) [14] and soil health [15-17], often leading to unsustainability of crop production systems. The use of organic sources of nutrients in agriculture is rapidly gaining favor but, owing to the problems related to the lack of availability of a good quality and quantity of organic materials, the system may not be sufficient to achieve and sustain the production of cereal crops in the amounts required for food security [17].

Integrated nutrient management (INM) or integrated nutrient supply (INS) help to achieve efficient use of synthetic fertilizers integrated with organic sources of nutrients [18]. INM is developed with an understanding of the interactions among crops, soils, and climate, which advocates the integration of inorganic and organic sources of nutrients. This approach is based on the maintenance of plant nutrition supply to attain a certain level of crop production by enhancing the benefits from all potential sources of plant nutrition in a cohesive manner, applicable to each cropping pattern and farming scenario [19]. The inclusion of organic manures regulates the uptake of nutrients, positively affecting production, improving soil quality (physical, chemical, and biological), and producing a synergistic effect on crops [20]. INM integrates traditional and recent practices of nutrient management into an environmentally sound and cost-effective ideal farming system that uses remunerations from all probable sources of nutrition (organic, inorganic, and biological) in a careful, effective, and combined way $[21,22]$. It optimizes the balance between input sources and outputs with the goal of coordinating the nutritional demand of the crop and its discharge in its surroundings (Figure 3). 


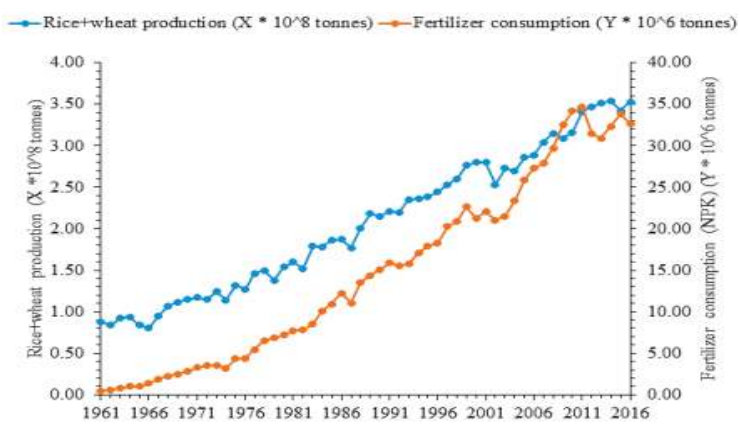

Figure 1. Trends of rice + wheat production and fertilizer consumption during the period 1961-2016 on the Indian subcontinent, Reproduced with permission from FAO (http:/ / faostat.fao.org/).

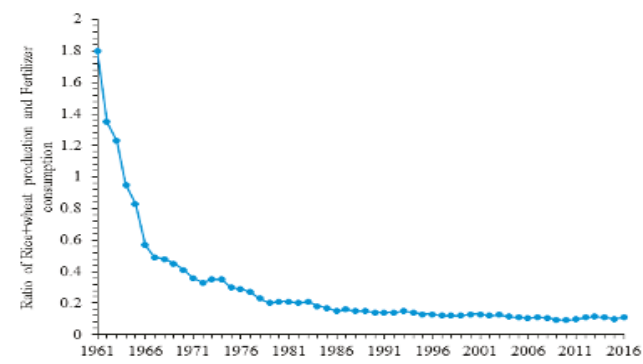

Figure 2. Ratio of rice + wheat production and fertilizer consumption during the period 1961-2016 on the Indian subcontinent, FAO (http: / / faostat.fao.org/).

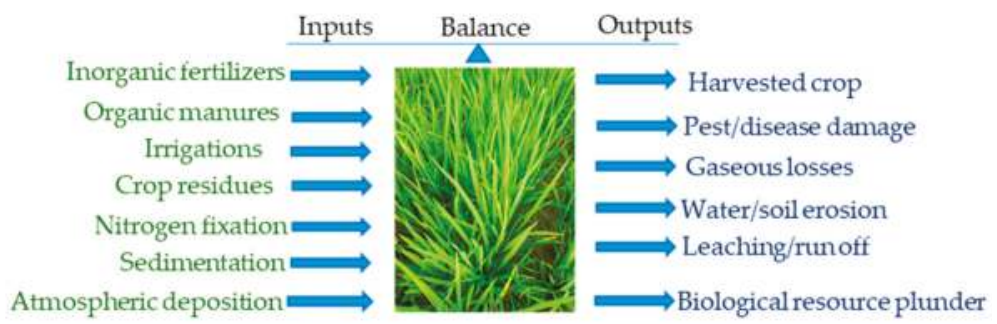

INM method based on inputs and outputs:

- Matching the quantity with demand of the crop

- Synchronizing in terms of time with crop growth

Figure 3. Mean of nutrients for inputs and outputs, and the principles of integrated nutrient management systems [22,23].

The importance of INM practices has been mentioned in several researches in the Indian subcontinent. The INM concept is now being broadened to make it more context-specific for local environmental conditions, increasing mechanization (due to the serious labor shortage as a result of migration), the increasing popularity of conservation agriculture, upcoming rain-harvesting technologies, and the increasing focus on recycling of available organic nutrient flows [22]. The incorporation of these new interventions in an INM system has developed new dimensions in the INM system and thus makes these practices synthesized for the region. An innovative approach 
such as INM can harness natural resources appropriately, bring about food security, and improve the livelihood of the people in the region [24]. The provision of appropriate policies, such as an incentive to adopt INM, will motivate small-holder farmers to adopt INM. Legislation on or the taxing of nutrient inputs should be enforced to minimize the use of inorganic fertilizers and encourage the integration of organic fertilizers for nutrient management.

The RWCS is a fertilizer-responsive cropping system. However, the imbalanced and excessive application of inorganic fertilizers is detrimental to the soil ecosystem and ultimately affects crop yield. Organic farming, a traditional production system relying on the use of only organic sources of nutrients, is supposed to be the production system that causes minimal damage to the ecosystem. However, the organic farming system has become a fundamental topic for discussion in recent times, with concerns about whether it can produce enough food to feed the ever-growing population of the Indian subcontinent $[25,26]$. On the Indian subcontinent, around a half century ago, the population was controlled and technology was not advanced. Organic manures were the only sources of nutrients. Currently, with the increase in the availability of new sources of nutrients, there is a need to recognize them and develop integrated options to increase production which are both ecologically viable and linked to economic growth.

Several researchers showed the impact of INM over other nutrient management options, such as the use of organic fertilizers only (ORA), the use of inorganic fertilizers only (IORA), or the use of no fertilizers as a control (CO), through their studies of the RWCS and undoubtedly, INM has emerged as a viable alternative nutrient management option in the RWCS for the Indian subcontinent. Researchers have compared yield and other performance parameters of nutrient management options, but an attempt to synthesize information in the RWCS, particularly in the Indian subcontinent region, is critically lacking. Such kinds of synthesis can help to prioritize research and development issues, including precise technology targeting, and articulate policy and institutional measures to facilitate large-scale adoption of nutrient management options.

Therefore, the present paper aimed to perform a comprehensive meta-analysis to understand the impacts of INM on crop performance in the RWCS of the Indian subcontinent during the period of 1989-2016. This study also outlines the sustainability of INM, noting that sole dependence on inorganic fertilizers or organic farming could not serve the purpose of the food security of the ever-growing populations in these countries. The role of INM is discussed for resolving those complications and as one of the promising strategies for addressing the current challenges of crop output and sustainability of the RWCS in these nations.

\section{Materials and Methods}

\subsection{Data Collection}

Literatures were reviewed for the period from 1989 to 2016 related to the on-station field experiments using integrated organic and inorganic nutrient sources with an aim of finding the effect of INM on crop productivity, net returns, and different soil parameters in the Indian subcontinent. After general review, they were critically analyzed, and data pertaining to INM along with other treatments (control (no fertilizer applied), organic fertilizer alone, and inorganic fertilizer alone) were selected. The treatment with 100\% NPK (Nitrogen-Phosphorous-Potassium) application was selected as inorganic alone. Meta-analysis was conducted for the selected data (338 paired datasets) from several researchers to show the impact of INM over the other nutrient management options.

Only studies that met the following criteria were included:

1. Rice and wheat as study crops.

2. Nutrient management options include INM-integration of organic and inorganic sources (option 1); ORA—use of organic source of nutrient application only (option 2); or IORA—full dose of inorganic fertilizer application that mean recommended dose fertilizer application (option 3 ).

3. CO: Control treatments where no fertilizers were added. 
4. Two soil textures: Loamy (moderately coarse to medium fine) and clayey (moderately fine to fine).

\subsection{Crop and Soil Performance Parameters and Economic Analysis Used for Meta-Analysis Study}

The following performance parameters were considered in the analysis: (a) Grain yield ( $\left.\mathrm{Mg} \mathrm{ha}^{-1}\right)$, (b) soil parameters: Bulk density (BD; $\mathrm{Mg} \mathrm{m}^{-3}$ ), soil $\mathrm{pH}$ (soil water ratio:1:2), soil organic carbon (SOC; $\%$ ), total nitrogen ( $\mathrm{TN} ; \mathrm{kg} \mathrm{ha}^{-1}$ ), available phosphorus (Av. P; $\left.\mathrm{kg} \mathrm{ha}^{-1}\right)$, available potassium (Av. K; $\mathrm{kg} \mathrm{ha}^{-1}$ ), and soil microbial biomass carbon (SMBC; $\mathrm{mg} \mathrm{kg}^{-1}$ ), and (c) net returns (NR; $\$ \mathrm{ha}^{-1}$ ) (Net returns data from the study points was converted from INR ha ${ }^{-1}$ to US $\$ \mathrm{ha}^{-1}$ for meta-analysis).

\subsection{Meta-Analysis}

All the variables were subjected to meta-analysis separately for rice and wheat and for soil texture. Meta-analysis has attracted considerable attention recently as a powerful statistical tool to analyze the response of treatments (i.e., nutrient management options vs. CO) from diverse individual studies to evolve to a general global trend or pattern. The meta-analysis was performed by using Meta Win 2.1 in two stages [27], in which effect size was calculated using the formula:

$$
\text { Effect size }=\frac{M(\mathrm{NM})}{M(\mathrm{INM})}
$$

where $M(\mathrm{NM})$ is the mean of response variables (Grain yield, NR, soil parameters) of options 2, 3, and $\mathrm{CO}$, and $M$ (INM) is the mean of these variables of option 1 . Since most researchers did not report the variance of the means of response variables, the effect sizes were weighted based on the number of replicates $(N)$ as follows:

$$
\text { Weight }=\frac{N(\mathrm{NM}) \times N(\mathrm{INM})}{N(\mathrm{NM})+N(\mathrm{INM})}
$$

where $N(\mathrm{NM})$ and $N(\mathrm{INM})$ represent the number of replications for each of the nutrient management options, in an individual study. In cases where more than one observation was included in an option, the number of observations from that research was divided by the weights. All the results are discussed as change with INM over other nutrient management options and CO. Unless stated otherwise, differences were considered significant only when $p$ values were $<0.05$. The meta-analyzed value has been presented either in graph or in table to clearly show the effect of INM over the other nutrient management options.

\section{Results}

\subsection{Impact of INM on Rice and Wheat Yield and Net Returns}

The meta-analysis of the data for rice and wheat showed positive increases in the grain yield of both crops with the use of INM over IORA, ORA, and CO treatments (Figure 4). The increase in grain yield was significant at $p<0.05$ for rice in INM over ORA and CO treatments. The data show that some of the study points in INM over IORA for rice crop were negative, but the effect was non-significant. The increases in wheat grain yield were significant in INM over IORA, ORA, and CO treatments. The respective percent yield increases in INM treatment over CO, ORA, and IORA treatments were $86.5,28.1$, and 1.2 in rice crop, and 104.6, 39.2, and 4.5 in wheat crop. On average, the yield differences in the INM treatment over IORA were 0.05 and $0.13 \mathrm{Mg} \mathrm{ha}^{-1}$ in rice and wheat crop, respectively.

The data showed a significant increase in grain yield with INM over IORA, ORA, and CO treatments under loamy soils (Figure 4). Under clayey soils, there was an increase in grain yield in INM over IORA, ORA, and CO treatments, but the effect was non-significant for IORA and ORA treatments (Figure 4). The percent yield increases in INM treatment over CO, ORA and IORA treatments were $90.9,29.2$, and 2.52, respectively, in loamy soil, and 93.7, 24.9, and 0.60, respectively, in clayey soil. The yield gains calculated through meta-analysis of various studies for INM treatment over other 
nutrient management options suggest that INM can be a viable nutrient management option for reversing the yield plateauing in both rice wheat cropping systems of the Indian subcontinent.

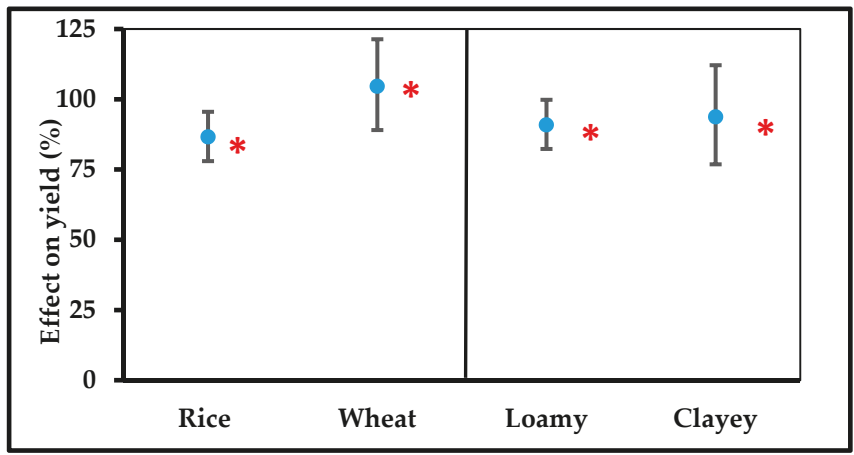

(a) Integrated nutrient management vs. Control

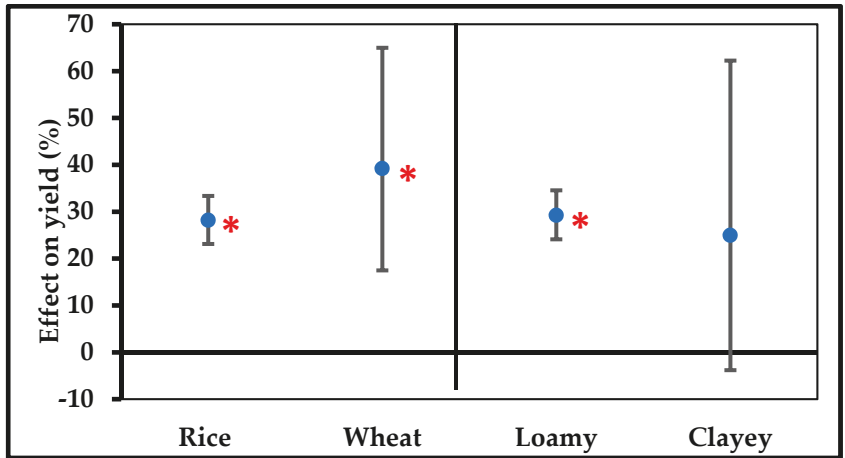

(b) Integrated nutrient management vs. Organic alone

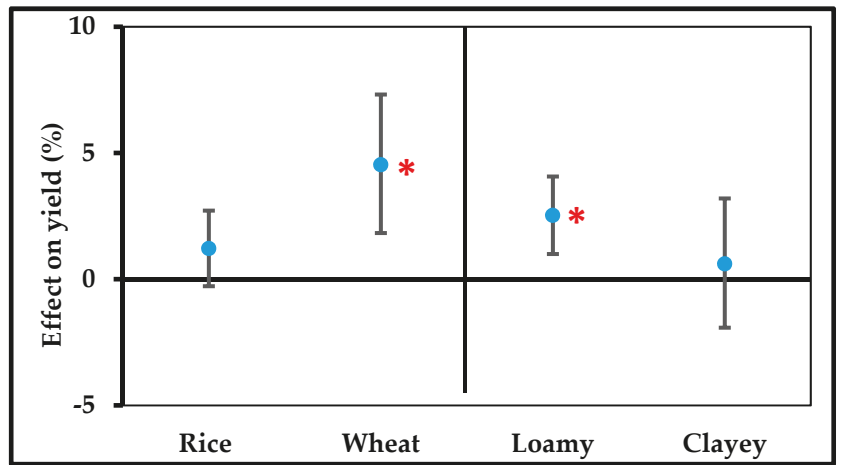

(c) Integrated nutrient management vs. Inorganic alone

Figure 4. Effect of integrated nutrient management on grain yield vis-a vis control (a), organic alone (b), and inorganic alone (c), separated for rice and wheat crops and for soil texture (loamy and clayey). (Note: Error bars in meta-analysis indicate 95\% confidence intervals (CI), where effect of yield was considered significant if $95 \%$ CI does not cover zero. ${ }^{*}$ Indicates significant percent yield at $p<0.05$ ). 
Table 1 represents meta-analysis of the data, showing the effects of nutrient management practices on net returns in rice and wheat crops. The data for rice showed a significant positive increase in net returns with INM over the CO. The effect was significantly positive for INM over CO and IORA in wheat crop. The increases were 121 percent in NM vs. CO for rice, 9.34 and 127 per cent in INM vs. IORA and INM vs. CO, respectively, for wheat crop. The net returns increased by $0.13 \%$ in INM over ORA in wheat, but this was non-significant. Net returns decreased by $2.34 \%$ in INM vs. IORA and $0.27 \%$ in INM vs. ORA for rice crop, but these were non-significant. The negative effect in these cases was due to increased cost of cultivations in some of the studies.

Table 1. Influence on net returns in rice and wheat with integrated nutrient management over inorganic alone, organic alone, and control treatments in percent.

\begin{tabular}{ccc}
\hline \multirow{2}{*}{ Nutrient Management Practices } & \multicolumn{2}{c}{ Crops } \\
\cline { 2 - 3 } & Rice & Wheat \\
\hline INM vs. IORA & $-2.93(-9.48$ to 3.93$)$ & $9.34(4.28$ to 15.07$) *$ \\
INM vs. ORA & $-0.27(-3.78$ to 3.37$)$ & $0.13(-3.85$ to 4.27$)$ \\
INM vs. CO & $121(101$ to 142$) *$ & $127(97$ to 156$){ }^{*}$ \\
\hline
\end{tabular}

Mean values are given with $95 \% \mathrm{CI}$ in parentheses. In bracket the values represent the ranges of percent net return for compared nutrient management practices. * Indicates percent net returns significant at $p<0.05$. Where INM stands for integrated nutrient management, IORA for inorganic alone, ORA for organic alone, and CO for control (No fertilizer applied). CI used for confidence interval.

\subsection{Effect of INM on Soil Characteristics}

Crop- and texture-wise meta-analysis for the effect of INM compared to IORA, ORA, and CO treatments on various soil properties is presented in Table 2. The effect was non-significant for bulk density (BD) for both crops and soil textures. The BD increased by $0.53 \%$ (INM vs. IORA) and $1.15 \%$ (INM vs. CO) in rice crop. In wheat crop, the BD decreased by $0.98 \%$ (INM vs. IORA) and $0.55 \%$ (INM vs. CO). In loamy soil, BD decreased by $0.94 \%$ in INM vs. IORA and increased by $0.19 \%$ in INM vs. CO. In clayey soil, BD increased by $1.85 \%$ in INM vs. IORA and $1.38 \%$ in NM vs. CO.

The data for soil $\mathrm{pH}$ showed a positive effect of INM with an increase of $1.15 \%$ over CO in rice. However, the effect was negative by $0.55 \%$ in wheat crop for INM vs. CO. In clayey soil, pH increased by $1.85 \%$ in INM vs. IORA. The effect on soil $\mathrm{pH}$ was significantly negative for INM vs. CO, decreasing by $0.98 \%$ in wheat crop, and in INM vs. IORA by $0.94 \%$ in loamy soil (Table 2$)$. The effects for all other comparisons were non-significant.

Meta-analysis of SOC showed a significant positive effect for all comparisons with sufficient data points, both crop-wise and texture-wise (Table 2). The SOC increased by $23.2 \%$ in INM vs. IORA and by $34.95 \%$ in INM vs. CO for rice. The increases were $16.2 \%$ in INM vs. IORA and 52.09\% in INM vs. CO for wheat. In loamy soil, the increases were $26.5 \%$ in INM vs. IORA, and $51.21 \%$ in INM vs. CO. In clayey soils, the increases were $12.29 \%$ in INM vs. IORA and $23.4 \%$ in INM. There was no sufficient data for meta-analysis for INM vs. ORA.

For all the compared treatments, the TN, Av. P, Av. K, and SMBC showed significant positive effects for rice and wheat crops, indicating that INM treatment improved these soil properties over lone application of organic and inorganic fertilizers and CO (Table 2). Texture-wise, there was a significantly positive effect of INM over other nutrient management NM practices and CO for Av. P, Av. K, and SMBC. 


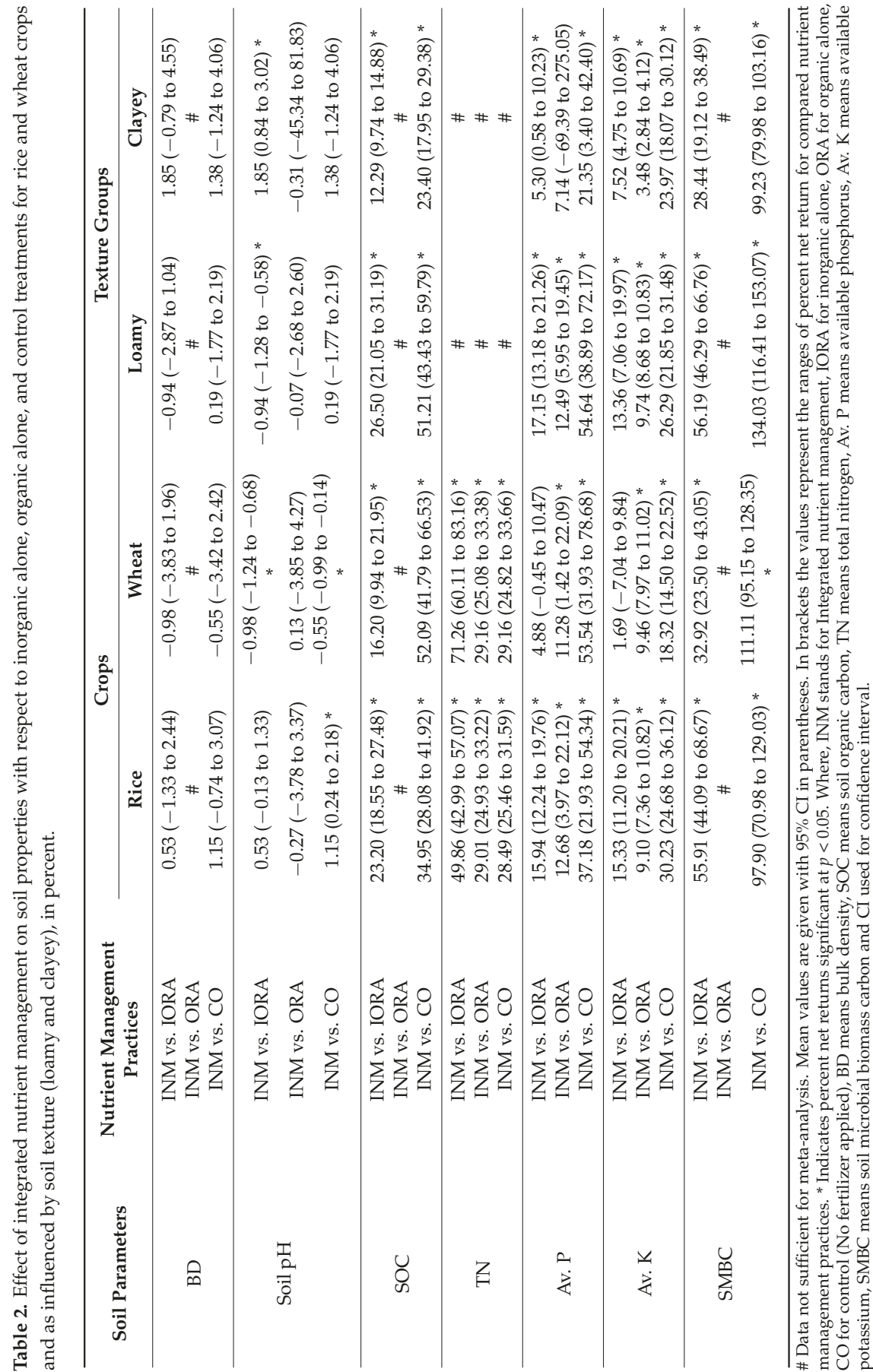




\section{Discussion}

The above results in this article for the period 1989-2016, obtained through meta-analysis, emphasize the importance of INM practices in the Indian subcontinent. The crop-wise and texture-wise analyses show positive effects of INM treatment over IORA and ORA on grain yield. The increase in yield due to the use of INM treatment puts forth that the integration of organic sources of nutrients with inorganic fertilizers could be a viable alternative nutrient management option in RWCS in the Indian subcontinent. Although the yield gains in the INM treatment over the IORA treatment were only $1.2 \%$ in rice and $4.5 \%$ in wheat, considering that the conditions of curtailing the use of inorganic fertilizers prevent the soil quality/health from ill effects of synthetic fertilizers, this would really show the benefits of the use of INM over IORA treatment. From this study, it is clear that the use of the ORA did not serve the purpose of enhancing crop productivity in both crops and hence, complete shifting towards organic farming cannot be a feasible option as far as human food security is concerned. Similar findings were also pointed out by different researchers of the Indian subcontinent. In Bangladesh, researchers reported that integrated use of Sesbania (dhaincha) and mung bean residues with inorganic sources of nutrients improved crop yield by $7.6 \%$ and $9.5 \%$, respectively, over inorganic alone in $T$. aman rice [28]. The application of wheat straw or farm yard manure (FYM) along with inorganic fertilizer in the rice field recorded higher grain and straw yields of rice in comparison to the treatments with only inorganic fertilizer [29]. The grain yields of basmati rice and wheat in the RWCS when $50 \%$ of the recommended dose from chemical fertilizers was substituted with green manure (GM) significantly increased crop productivity by $100 \%$ [30]. The incorporation of green gram residues along with inorganic fertilizers resulted in a significant rice yield increase of $13 \%$ over IORA [31]. The highest yield of $4.68 \mathrm{Mg} \mathrm{ha}^{-1}$ in wheat crop was recorded when $50 \% \mathrm{~N}$ (nitrogen) of the recommended dose of fertilizer treatment was replaced with FYM in the rice crop [32].

The yield response to the soil texture group suggests that INM treatment appears to be more suitable in loamy soil in comparison to clayey soil. The reason is that loamy soils have better drainage than clayey soils, and therefore offer adequate aeration. The better performance in these soils is also because of less cracking of soil in the early state, which is critical for the rice crop. Cracking is high in clayey soil, which directly affects the plant. The plant-available water content is also higher in these soils [33].

The data show that the use of INM increased net returns in several studies over other nutrient management options. Although, increases in the cost of cultivation at a few instances resulted in negative values under meta-analysis. For wheat crop, the effect of INM treatment on net returns was positive over the other nutrient management options. In case of rice, INM vs. IORA showed declines in net returns, but the effect was not significant. This may be due to large variations in effects of treatments for net returns. Proper planning and management can decrease the cost of cultivation for INM in the instances with high cost of cultivation and can bring in a positive effect on net returns for RWCS.

The study clearly indicated the positive effect of INM on soil characteristics over other nutrient management options. The increases in SOC, TN, Av. P, Av. K, and SMBC correlated the INM with enhanced soil quality/health. Continuous use of chemical fertilizers alone affects the soil reaction by increasing hydrogen ions $\left(\mathrm{H}^{+}\right)$in the soil during the formation of ammonia. The soil reaction in turn affects the supply of nutrients in the soil. The use of compost with inorganic fertilizers reduced soil $\mathrm{pH}$ significantly over the IORA treatment [34]. The reduction in soil pH is due to the formation of organic acids by the reactions between compost and the inorganic fertilizers in the presence of microorganisms. The dissolution of salts by formed acids under INM significantly improved the electrical conductivity (EC) of the soil. Thus, the use of INM regulates $\mathrm{pH}$ and EC of the soil due to the presence of organic sources, hence improving nutrient availability in the soil.

The integrated application of organic and inorganic fertilizers for 29 years reduced soil reactions by $0.22 \%$ over the application of inorganic fertilizers alone [32]. In a long-term fertilizer experiment under the RWCS, it was reported that INM reduced BD by $16.6 \%$, whereas the application of IORA 
showed a reduction of $7.3 \%$ compared to the CO treatment [35]. The effects of INM on nutrient dynamics were recorded, and it was concluded that combining FYM with inorganic fertilizers could maintain SOC and available N and P at either equal to or greater than the initial soil nutrient levels, thus maintaining soil fertility even under continuous cultivation [36]. Incorporation of rice straw with green manure along with inorganic fertilizers increased Av. P by $12.7 \%$ and Av. K by $14.3 \%$, as compared to treatments in which only inorganic sources of nutrients were applied [37]. Sesbania green-manuring in rice, integrated with inorganic fertilizers, increased the available $\mathrm{N}$ from 5.8 to $22.0 \mathrm{~kg} \mathrm{ha}^{-1}$, Av. P from 1.4 to $3.8 \mathrm{~kg} \mathrm{ha}^{-1}$, and Av. $\mathrm{K}$ from 2.2 to $17.9 \mathrm{~kg} \mathrm{ha}^{-1}$ in comparison to IORA [38]. The use of INM in the RWCS increased SOC content by 21\% [32] and $45.8 \%$ [39,40] over the application of IORA.

The study [3] analyzed apparent balances of the nutrients N, P, and K in the RWCS for an average of 28 years as influenced by a combination of organic and inorganic sources of nutrients. Apparent $\mathrm{N}$ balance was negative for the $\mathrm{CO}$ and IORA, whereas apparent $\mathrm{N}$ balance was positive for INM ( $50 \%$ recommended dose of fertilizer $+50 \% \mathrm{~N}$ straw). This shows that the nutrient $\mathrm{N}$ was recycled through an organic supplement. Similar positive results for apparent $\mathrm{P}$ balance were observed in the INM treatment over the $\mathrm{CO}$. The positive balance shows more $\mathrm{P}$ accumulation due to an affirmative linear relationship between the available and surplus P. Apparent $\mathrm{K}$ balance was negative for all the treatments (INM, IORA, and CO). INM plays a key role in retaining the balance between demand and supply of nutrients in the soil-plant system. Under the current scenario, sustainable $\mathrm{N}, \mathrm{P}$, and $\mathrm{K}$ management strategies need to be identified for optimal production and nutrient balance. The balances deliver key information about the sustainability of the RWCS and the potential environmental impacts [41,42]. It is worth noting that one-fourth of the $\mathrm{N}$ and four-fifths of the $\mathrm{K}$ removed by the rice and wheat crop remain in the straw and are obtainable after incorporation to the soil. Application of straw residues in the field can thus reduce the recommended dose of chemical fertilizer. At present, it has been assessed that only 33\% to 50\% of the applied $\mathrm{N}$ and P fertilizers are used by crops $[43,44]$. The efficacy of the applied nutrients might be enhanced by the integrated use of inorganic and organic fertilizers, by increasing the availability of these nutrients to the crops [45]. Declining trends in RWCS productivity and the need for higher inputs have been observed due to the depletion of organic matter in the soil, which causes a disturbance in aggregate stability, soil productivity, and soil quality/health $[46,47]$. Thus, there is a need for partial substitution of inorganic fertilizers by locally available organic sources of nutrients for sustainable production [48-50].

Long-term studies conducted at several sites on the Indian subcontinent indicate that the application of required nutrients only by inorganic fertilizers affects soil health [51]. The application of unwarranted nutrients could lead to a decline in nutrient-use efficiency, making fertilizer application uneconomical and resulting in an adverse effect on the environment [52] and groundwater quality [53], causing health hazards and ill effects on the climate. Therefore, there is a need to enhance the nutrient supply system through INM that brings sustainable changes in the soil-plant system and the environment [54,55].

Soil sequesters atmospheric carbon in the soil, which improves the productivity and quality of the ecosystem [56]. The integrated use of organic manure and inorganic fertilizer is an indispensable component to manage soil in an arable crop production system. The application of INM can enhance plant available nutrients, but the amendments can also affect the soil microbial population. The use of organic manures for managing soil quality/health has been well recognized [57]. Soil biodiversity is the population of microbes that manage or enhance soil health. The microbial population enhances nutrient availability. Soil microbes and the mechanisms to control the activities are important for maintaining the long-term sustainability of farming systems [58], and are key factors in nutrient cycling and soil genesis. The activity and biomass of the microbes play a key role in enhancing soil quality/health [59], as these respond to soil and crop management practices [60]. The bacterial and fungal populations are compared in the INM-treated plot compared to the inorganic-treated plot [61]. The bacterial population increased by approximately $60 \%$, whereas the fungal population almost 
doubled in the INM system in comparison with the IORA. The increase in microbial population is due to the conducive soil environment, formed by the organic addition increasing the magnitude of easily degradable carbonaceous compounds in the INM system supporting nutrition for soil inhabitants. The INM application also improves physical components such as porosity, water-holding capacity, and aggregate stability, and decreases surface crusting and soil bulk density. INM also helps in improving structure, air capacity, and water retention in the soil profile [62].

Thus, the INM system improves soil quality by regulating the soil reaction, building up SOC, improving soil physical properties, and improving nutrient solubility/mobility. By integrating organic and inorganic sources, the added SOC can aid in the sustenance of agriculture for a longer period than inorganic sources alone, especially in the tropical climate of the Indian subcontinent where the temperature remains high and organic matter decomposition is rapid. INM is the key to sustaining our soils for improving productivity and preserving soil quality and environmental sustainability. Because the agricultural production system is a combined shared effect of the soil-water-fertilizer-climate continuum (SWFCC), a sensible and methodical management of this multifaceted system is vital for improving crop productivity on a continual basis. Among the several inputs of the nutrient balance, water and nutrients are the critical inputs that contribute the most to crop yield. The use of these inputs in a better manner and interactive effect with other factors is essential for targeting crop yield potential. Practices to manage soil through tillage can improve the efficiency of these input factors. Sustainable agricultural promotion uses the efficient integration of soil, water, soil organic matter, tillage, and nutrients for achieving yield targets of the RWCS. INM aims to promote sustainable production systems by managing soil quality together with improving crop yield through the balanced integration of organic and inorganic sources [63].

The studies reported improvements in yields, net profit, and soil characteristics in the RWCS with the use of INM, and attributed the increases to improvements in the availability of nutrients, increases in resource-use efficiencies, and increases in resistance to environmental stresses with the use of INM [22,64-68]. Farmers of these nations can be benefited with the use of INM through increased productivity and profitability. This will not only reduce the excessive use of inorganic fertilizers but also improve soil quality/health and ensure food security and environmental sustainability on the Indian subcontinent.

\section{Conclusions}

This review paper emphasized the role and importance of an integrated nutrient management system as a management strategy that can bring sustainability to the rice-wheat cropping system of the Indian subcontinent. The meta-analysis data points of rice and wheat during the period of 1989-2016 revealed that INM treatment over inorganic alone, organic alone, and control treatments was positive on grain yield, both crop-wise as well as texture-wise. The present paper also concludes that net returns through integrated nutrient management treatment were increased by $121 \%$ and $127 \%$ in rice and wheat, respectively, compared to control. Finally, the findings of the present review suggested that INM can be one of the viable nutrient management options in the Indian subcontinent, particularly for the rice-wheat cropping system.

Author Contributions: S.S. provided overall leadership, conceived the conceptual framework and was in charge of overall direction and planning. R.P. did literature search. S.S., R.P. and U.K. wrote the manuscript. All authors discussed the results and contributed to the final manuscript.

Acknowledgments: We are grateful to all the researchers whose contributions have been cited in this paper, which have helped us to prepare this review study.

Conflicts of Interest: The authors declare no conflict of interest. 


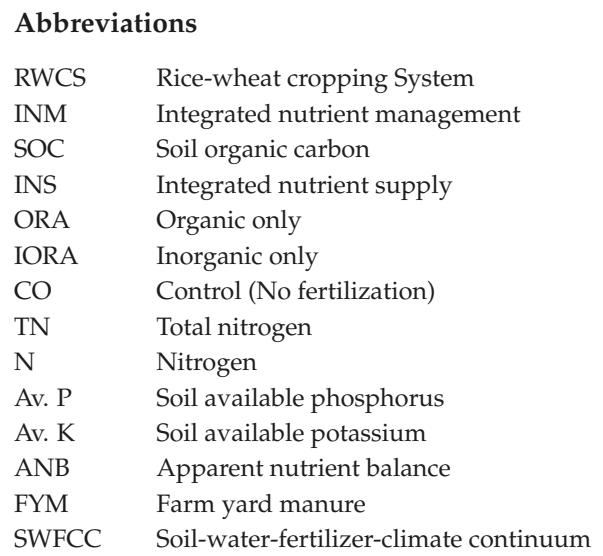

\section{References}

1. Timsina, J.; Connor, D.J. Productivity and management of rice-wheat cropping systems: Issues and challenges. Field Crop. Res. 2001, 69, 93-132. [CrossRef]

2. Singh, R.A.; Singh, J.; Yadav, D.; Singh, H.K.; Singh, J. Integrated nutrient management in rice-wheat cropping system. Int. J. Agric. Sci. 2012, 8, 523-526.

3. Das, A.; Sharma, R.P.; Chattopadhyaya, N.; Rakshit, R. Yield trends and nutrient budgeting under a long-term (28 years) nutrient management in rice-wheat cropping system under subtropical climatic condition. Plant Soil Environ. 2014, 60, 351-357. [CrossRef]

4. Gupta, R.K.; Naresh, R.K.; Hobbs, P.R.; Jiaguo, Z.; Ladha, J.K. Sustainability of post green revolution agriculture: The rice-wheat cropping systems of Indo-Gangetic plains and China. In Improving the Productivity and Sustainability of the Rice-Wheat System: Issues and Impact; Ladha, J.K., Hill, J.E., Duxbury, J.M., Gupta, R.K., Buresh, R.J., Eds.; ASA Special Publication No. 65; American Society Agronomy, Crop Science Society American, Soil Sciien Society American: Madison, WI, USA, 2003; pp. 1-25.

5. Mohanty, S.; Nayak, A.K.; Kumar, A.; Tripathi, R.; Shahid, M.; Bhattacharyya, P.; Raja, R.; Panda, B.B. Carbon and nitrogen mineralization kinetics in soil of rice-rice system under long term application of chemical fertilizers and farmyard manure. Eur. J. Soil Biol. 2013, 58, 113-121. [CrossRef]

6. Kalhapure, A.; Singh, V.P.; Kumar, R.; Pandey, D.S. Tillage and nutrient management in wheat with different plant geometries under rice-wheat cropping system: A review. Basic Res. J. Agric. Sci. Rev. 2015, 4, $296-303$.

7. Zhao, J.T.N.; Lia, J.; Lua, Q.; Fanga, Z.; Huang, Q.; Lia, R.Z.R.; Shen, B.; Shena, Q. Effects of organic-inorganic compound fertilizer with reduced chemical fertilizer application on crop yields, soil biological activity and bacterial community structure in a rice-wheat cropping system. Appl. Soil Ecol. 2016, 99, 1-12. [CrossRef]

8. Abrol, I.P.; Bronson, K.F.; Duxbury, J.M.; Gupta, R.K. Long-term soil fertility experiments in rice-wheat cropping systems. In Long-Term Soil Fertility Experiments with Rice-Wheat Rotations in South Asia; Rice-Wheat Consortium Paper Series No. 1; Abrol, I.P., Ed.; Rice-Wheat Consortium for the Indo-Gangetic Plains: New Delhi, India, 1997; pp. 14-15.

9. Ladha, J.K.; Dawe, D.; Pathak, H.; Padre, A.T.; Yadav, R.L.; Singh, B.; Singh, Y.; Singh, Y.; Singh, P.; Kundu, A.L.; et al. How extensive are yield declines in long-term rice-wheat experiments in Asia? Field Crop. Res. 2003, 81, 159-180. [CrossRef]

10. Dobermann, A.; Cassman, K.G. Precision nutrient management in intensive rice systems: The need for another on-farm revolution. Better Crop. 1996, 10, 20-25.

11. Hobbs, P.R.; Sayre, K.; Gupta, R. The role of conservation agriculture in sustainable agriculture. Philos. Trans. R. Soc. B Biol. Sci. 2008, 363, 543-555. [CrossRef]

12. Benbi, D.K.; Brar, J.S.A. 25-year record of carbon sequestration and soil properties in intensive agriculture. Agron. Sustain. Dev. 2009, 29, 257-265. [CrossRef]

13. Foley, J.A.; Ramankutty, N.; Brauman, K.A.; Cassidy, E.S.; Gerber, J.S.; Johnston, M. Solutions for a cultivated planet. Nature 2011, 478, 337-342. [CrossRef] [PubMed] 
14. Singh, R.P.; Mundra, M.C.; Gupta, S.C.; Agrawal, S.K. Effect of integrated nutrient management on productivity of pearl millet-wheat cropping system. Indian J. Agron. 1999, 44, 250-253.

15. Anwar, M.; Patra, D.D.; Chand, S.; Kumar, A.; Naqvi, A.A.; Khanuja, S.P.S. Effect of organic manures and inorganic fertilizer on growth, herb and oil yield, nutrient accumulation, and oil quality of French basil. Commmun. Soil Sci. Plant Anal. 2005, 36, 1737-1746. [CrossRef]

16. Kumar, U.; Shahid, M.; Tripathi, R.; Mohanty, S.; Kumar, A.; Bhattacharyya, P.; Lal, B.; Gautam, P.; Raja, R.; Panda, B.B.; et al. Variation of functional diversity of soil microbial community in sub-humid tropical rice-rice cropping system under long-term organic and inorganic fertilization. Ecol. Indic. 2017, 73, 536-543. [CrossRef]

17. Kumar, U.; Nayak, A.K.; Shahid, M.; Gupta, V.V.S.R.; Panneerselvam, P.; Mohanty, S.; Kaviraj, M.; Kumar, A.; Chatterjee, D.; Lal, B.; et al. Continuous application of inorganic and organic fertilizers over 47 years in paddy soil alters the bacterial community structure and its influence on rice production. Agric. Ecosyst. Environ. 2018, 262, 65-75. [CrossRef]

18. Mahajan, A.; Bhagat, R.M.; Gupta, R.D. Integrated nutrient management in sustainable rice-wheat cropping system for food security in India. SAARC J. Agric. 2008, 6, 1-13.

19. Mahajan, A.; Sharma, R. Integrated nutrient management (INM) system: Concept, need and future strategy. Agrobios. Newsl. 2005, 4, 29-32.

20. Yadav, D.S.; Kumar, A. Integrated nutrient management in rice-wheat cropping system under eastern Uttar Pradesh. Indian Farm. 2000, 50, 28-30.

21. Janssen, B.H. Integrated nutrient management: The use of organic and mineral fertilizers. In The Role of Plant Nutrients for Sustainable Crop Production in Sub-Saharan Africa; Van Reuler, H., Prins, W.H., Eds.; Ponsen and Looijen: Wageningen, The Netherlands, 1993; pp. 89-105.

22. $\mathrm{Wu}, \mathrm{W}$; $\mathrm{Ma}, \mathrm{B}$. Integrated nutrient management (INM) for sustaining crop productivity and reducing environmental impact: A review. Sci. Total Environ. 2015, 512-513, 415-427. [CrossRef]

23. Gruhn, P.; Goletti, F.; Yudelman, M. Integrated Nutrient Management, Soil Fertility and Sustainable Agriculture: Current Issues and Future Challenges; International Food Policy Research Institute: Washington, DC, USA, 2000.

24. Timsina, J. Can organic sources of nutrients increase crop yields to meet global food demand? Agronomy 2018, 8, 214. [CrossRef]

25. Niggli, U.; Fliebbach, A.; Hepperly, P.; Scialabba, N. Low Greenhouse Gas Agriculture: Mitigation and Adaptation Potential of Sustainable Farming Systems; Food and Agriculture Organization of the United Nations: Rome, Italy, 2009.

26. Padbhushan, R.; Rakshit, R.; Das, A.; Sharma, R.P. Effects of various organic amendments on organic carbon pools and water stable aggregates under a scented rice-potato-onion cropping system. Paddy Water Environ. 2016, 14, 481-489. [CrossRef]

27. Rosenberg, M.S.; Adams, D.C.; Gurevitch, J. MetaWin: Statistical Software for Meta-Analysis, Version 2.0; Sinauer Associates: Sunderland, MA, USA, 2000.

28. Zaman, S.K.; Jahiruddin, M.; Panaullah, G.M.; Mian, M.H.; Islam, M.R. Integrated nutrient management for sustainable yield in rice-rice cropping system. In Proceedings of the 17th WCSS, Bangkok, Thailand, 14-21 August 2002.

29. Kumar, M.; Singh, R.P.; Rana, N.S. Effect of organic and inorganic sources of nutrition on productivity of rice. Ind. J. Agron. 2003, 48, 175-177.

30. Bhoite, S.V. Integrated nutrient management in basmati rice (Oryza sativa)-wheat (Triticum aestivum) cropping system. Indian J. Agron. 2005, 50, 98-101.

31. Surekha, K.; Rao, K.V. Direct and residual effects of organic sources on rice productivity and soil quality of vertisols. J. Indian Soc. Soil Sci. 2009, 57, 53-57.

32. Kumari, R.; Kumar, S.; Kumar, R.; Das, A.; Kumari, R.; Choudhary, C.D.; Sharma, R.P. Effect of long-term integrated nutrient management on crop yield, nutrition and soil fertility under rice-wheat system. J. Appl. Nat. Sci. 2017, 9, 1801-1807. [CrossRef]

33. Chakraborty, D.; Ladha, J.K.; Rana, D.S.; Jat, M.L.; Gathala, M.K.; Yadav, S.; Rao, A.N.; Ramesha, M.S.; Raman, A. A global analysis of alternative tillage and crop establishment practices for economically and environmentally efficient rice production. Sci. Rep. 2017, 7, 9342. [CrossRef] [PubMed]

34. Reddy, K.R.; Khaleel, R.; Overcash, M.R. Behavior and transport of microbial pathogens and indicator organism in soils treated with organic wastes. J. Environ. Qual. 1981, 10, 255-266. [CrossRef] 
35. Mehdi, S.M.; Sarfraz, M.; Abbas, S.T.; Shabbir, G.; Akhtar, A. Integrated nutrient management for rice-wheat cropping system in a recently reclaimed soil. Soil Environ. 2011, 30, 36-44.

36. Chaudhary, S.; Dheri, G.S.; Brar, B.S. Long-term effects of NPK fertilizers and organic manures on carbon stabilization and management index under rice-wheat cropping system. Soil Tillage Res. 2017, 166, 59-66. [CrossRef]

37. Kharub, A.S.; Sharma, R.K.; Mongia, A.D.; Chhokar, R.S.; Tripathi, S.C.; Sharma, V.K. Effect of rice (Oryza sativa) straw removal, burning and incorporation on soil properties and crop productivity under rice-wheat (Triticum aestivum) system. Indian J. Agric. Sci. 2004, 74, 295-299.

38. Paikaray, R.K.; Mahapatra, B.S.; Sharma, G.L. Effect of organic and inorganic sources of nitrogen on productivity and soil fertility under rice (Oryza sativa)-wheat (Triticum aestivum) crop sequence. Indian J. Agric. Sci. 2002, 72, 445-448.

39. Ghuman, B.S.; Sur, H.S. Effect of manuring on soil properties and yield of rainfed wheat. J. Indian Soc. Soil Sci. 2006, 54, 6-11.

40. Bhattacharya, R.; Chandra, S.; Singh, R.D.; Kundu, S.; Srivastva, A.K.; Gupta, H.S. Long-term farmyard manure application effects on properties of a silty clay loam soil under irrigated wheat-soybean rotation. Soil Tillage Res. 2007, 94, 386-396. [CrossRef]

41. Oborn, I.; Edwards, A.C.; Witter, E.; Oenema, O.; Ivarsson, K.; Withers, P.J.A.; Nilsson, S.I.; Stinzing, A.R. Element balances as a tool for sustainable nutrient management: A critical appraisal of their merits and limitations within an agronomic and environmental context. Eur. J. Agron. 2003, 20, 211-225. [CrossRef]

42. Janssen, B.H.; de Willigen, P. Ideal and saturated soil fertility as bench marks in nutrient management. II. Interpretation of chemical soil tests in relation to ideal and saturated soil fertility. Agric. Ecosyst. Environ. 2006, 116, 147-155. [CrossRef]

43. Ladha, J.K.; Pathak, H.; Krupnik, T.J.; Six, J.; Kessel, C.V. Efficiency of fertilizer nitrogen in cereal production: Retrospect and prospects. Adv. Agron. 2005, 87, 85-156.

44. Ghosh, B.N.; Singh, R.J.; Mishra, P.K. Soil and input management options for increasing nutrient use efficiency. In Nutrient Use Efficiency: From Basics to Advances; Rakshit, A., Ed.; Springer: New Delhi, India, 2015.

45. Abrol, I.P.; Gill, M.S. Regional office for Asia and Pacific (FAO) Publication; FAO: Roma, Italy, 1994; Volume 11, pp. 172-183.

46. Modgal, S.C.; Singh, Y.; Gupta, P.C. Nutrient management in rice-wheat cropping system. Fert. News 1995, 40, 49-54.

47. Patro, H.; Dash, D.; Parida, D.; Panda, P.K.; Kumar, A.; Tiwari, R.C.; Shahid, M. Effect of organic and inorganic sources of nitrogen on yield attributes, grain yield and straw yield of rice (Oryza sativa). Int. J. Pharma Biol. Sci. 2011, 2,1-8.

48. Acharya, D.; Mandal, S.S. Effect of integrated nutrient management on the growth, productivity and quality of crops in rice (Oryza sativa L.) —Cabbage (Brassica oleracea)—Greengram (Vigna radiata) cropping system. Ind. J. Agron. 2010, 55, 1-5.

49. Brahmachari, K.; Choudhury, S.R.; Karmakar, S.; Dutta, S.; Ghosh, P. Sustainable nutrient management in rice (Oryza sativa)—Paira chickling pea (Lathyrus sativus)—Green gram (Vigna radiata) sequence to improve total productivity of land under coastal zone of West Bengal. Rajshahi Univ. J. Environ. Sci. 2011, 1, 51-61.

50. Yadav, G.S.; Datta, M.; Basu, S.; Debnath, C.; Sarkar, P.K. Growth and productivity of lowland rice (Oryza sativa) as influenced by substitution of nitrogenous fertilizer by organic sources. Indian J. Agric. Sci. 2013, 83, 1038-1042.

51. Jaga, P.K. Effect of integrated nutrient management on wheat-A review. Innovare J. Agric. Sci. 2013, 1, 185-191.

52. Aulakh, M.S.; Adhya, T.K. Impact of agricultural activities on emission of greenhouse gases-Indian perspective. In Proceedings of the International Conference on Soil, Water and Environmental Quality—Issues and Strategies; Indian Society of Soil Science: New Delhi, India, 2005; pp. 319-335.

53. Aulakh, M.S.; Khurana, M.P.S.; Singh, D. Water pollution related to agricultural, industrial and urban activities, and its effects on food chain: Case studies from Punjab. J. New Seeds 2009, 10, 112-137. [CrossRef]

54. Prasad, B.; Prasad, J.; Prasad, R. Nutrient management for sustainable rice and wheat production in calcareous soil amended with green manures, organic manures and zinc. Fert. News. 1995, 40, 39-45. 
55. Aulakh, M.S. Integrated nutrient management for sustainable crop production, improving crop quality and soil health, and minimizing environmental pollution. In Proceedings of the 19th World Congress of Soil Science, Soil Solutions for a Changing World, Brisbane, Australia, 1-6 August 2010.

56. Kundu, S.; Bhattacharyya, R.; Prakash, V.; Ghosh, B.N.; Gupta, H.S. Carbon sequestration and relationship between carbon addition and storage under rainfed soybean-wheat rotation in a sandy loam soil of the Indian Himalayas. Soil Tillage Res. 2007, 92, 87-95. [CrossRef]

57. Chander, K.; Goyal, S.; Mundra, M.C.; Kapoor, K.K. Organic matter, microbial biomass and enzyme activity of soils under different crop rotations in the tropics. Biol. Fert. Soils 1977, 24, 306-310. [CrossRef]

58. Wardle, D.A.; Yeates, G.W.; Nicholson, K.S.; Bonner, K.I.; Watson, R.N. Response of soil microbial biomass dynamics, activity and plant litter decomposition to agricultural intensification over a seven-year period. Soil Biol. Biochem. 1999, 31, 1707-1720. [CrossRef]

59. Schloter, M.; Dilly, O.; Munch, J.K. Indicators for evaluating soil quality. Agric. Ecosyst. Environ. 2003, 98, 255-262. [CrossRef]

60. Livia, B.; Uwe, L.; Frank, B. Microbial biomass, enzyme activities and microbial community structure in two European long-term field experiments. Agric. Ecosyst. Environ. 2005, 109, 141-152.

61. Kuttimani, R.; Somasundaram, E.; Velayudham, K. Effect of integrated nutrient management on soil microorganisms under irrigated banana. Int. J. Curr. Microbiol. Appl. Sci. 2017, 6, 2342-2350. [CrossRef]

62. Pernes-Debuyser, A.; Tessier, D. Soil physical properties affected by long-term fertilization. Eur. J. Soil Sci. 2004, 55, 505-512. [CrossRef]

63. Singh, G.; Singh, O.P.; Singh, S.; Prasad, K. Weed management in late sown wheat (Triticum aestivum) after rice (Oryza sativa) in rice-wheat system in rainfed lowland. Indian J. Agron. 2010, 55, 83-88.

64. Prasad, P.; Satyanarayana, V.; Murthy, V.; Boote, K.J. Maximizing yields in rice- groundnut cropping sequence through integrated nutrient management. Field Crop. Res. 2002, 75, 9-21. [CrossRef]

65. Parkinson, R. System based integrated nutrient management. Soil Use Manag. 2013, 29, 608. [CrossRef]

66. Zhang, F.; Cui, Z.; Chen, X.; Ju, X.; Shen, J.; Chen, Q.; Liu, X.; Zhang, W.; Mi, G.; Fan, M.; et al. Integrated nutrient management for food security and environmental quality in China. Adv. Agron. 2012, 116, 1-40.

67. Das, B.; Chakraborty, D.; Singh, V.; Aggarwal, P.; Singh, R.; Dwivedi, B.; Mishra, R. Effect of integrated nutrient management practice on soil aggregate properties, its stability and aggregate-associated carbon content in an intensive rice-wheat system. Soil Tillage Res. 2014, 136, 9-18. [CrossRef]

68. Khan, M.U.; Qasim, M.; Sarhad, I.U.K. Effect of integrated nutrient management on crop yields in rice-wheat cropping system. J. Agric. 2007, 23, 4.

(C) 2019 by the authors. Licensee MDPI, Basel, Switzerland. This article is an open access article distributed under the terms and conditions of the Creative Commons Attribution (CC BY) license (http:/ / creativecommons.org/licenses/by/4.0/). 


\title{
Yields, Soil Health and Farm Profits under a Rice-Wheat System: Long-Term Effect of Fertilizers and Organic Manures Applied Alone and in Combination
}

\author{
Vinod K. Singh ${ }^{1}$, Brahma S. Dwivedi ${ }^{1, *}$, Rajendra P. Mishra ${ }^{2}$, Arvind K. Shukla ${ }^{3}$, \\ Jagadish Timsina ${ }^{4}$, Pravin K. Upadhyay ${ }^{1}$, Kapila Shekhawat ${ }^{1}$, Kaushik Majumdar ${ }^{5}$ \\ and Azad S. Panwar ${ }^{2}$ \\ 1 ICAR-Indian Agricultural Research Institute, New Delhi-110 012, India; \\ vkumarsingh_01@yahoo.com (V.K.S.); pravin.ndu@gmail.com (P.K.U.); drrathorekapila@gmail.com (K.S.) \\ 2 ICAR-Indian Institute of Farming Systems Research, Modipuram-250 110, India; \\ rp_min@yahoo.co.in (R.P.M.); director.iifsr@icar.gov.in (A.S.P.) \\ 3 ICAR-Indian Institute of Soil Science, Bhopal-462 038, India; arvindshukla2k3@yahoo.co.in \\ 4 Soils and Environment Research Group, Faculty of Veterinary and Agricultural Sciences, \\ University of Melbourne, Victoria 3010, Australia; timsinaj@hotmail.com \\ 5 International Plant Nutrition Institute, Gurgaon-122001, India; kmajumdar@ipni.net \\ * Correspondence: bsdwivedi@yahoo.com
}

Received: 21 October 2018; Accepted: 12 December 2018; Published: 20 December 2018

\begin{abstract}
The rice-wheat system (RWS), managed over 10.5 Mha in the Indo-Gangetic Plains of India suffers from production fatigue caused by declining soil organic matter, multi-nutrient deficiencies and diminishing factor productivity. We, therefore, conducted a long-term field experiment (1998-1999 to 2017-2018) in Modipuram, India to study the effect of continuous use of farmyard manure (FYM) as an organic fertilizer (OF), mineral fertilizers applied alone (RDF) and their combination (IPNS), as well as the inclusion of forage berseem (IPNS+B) or forage cowpea $($ IPNS+C) on crop yield, soil health and profits. The long-term yield trends were positive $(p<0.05)$ in all treatments except the control (unfertilized) in rice, and the control and RDF in wheat. Although the yields of rice, wheat and RWS were highest under IPNS treatments (IPNS, IPNS+B, IPNS+C), the maximum annual yield increase in rice $(9.2 \%)$ and wheat $(13.7 \%)$ was obtained under OF. A linear regression fitted to the yield data under different IPNS options revealed a highly significant $(p<0.001)$ annual yield increase in rice (5.1 to $6.6 \%$ ) and wheat (6.8 to $7.7 \%$ ) crops. Continuous rice-wheat cropping with RDF brought an increase in soil bulk density $(\mathrm{Db})$ over the initial $\mathrm{Db}$ at different soil profile depths, more so at depths of $30-45 \mathrm{~cm}$, but inclusion of forage cowpea or berseem in every third year (IPNS+B or C) helped to decrease $\mathrm{Db}$, not only in surface $(0-15 \mathrm{~cm})$ but also in sub-surface (15-30 and 30-45 cm depth) soil. Whereas soil organic carbon (SOC) increased under OF, IPNS and IPNS + legume (B or C) treatments, it remained unaffected under RDF after 20 RW cycles. The inclusion of legumes along with IPNS not only helped to trap the $\mathrm{NO}_{3}-\mathrm{N}$ from soil layers below $45 \mathrm{~cm}$ but also increased its retention in the upper soil ( $0-15 \mathrm{~cm}$ depth). On the other hand, $\mathrm{RDF}$ had a higher $\mathrm{NO}_{3}-\mathrm{N}$ content in the lower layers (beyond $45 \mathrm{~cm}$ depth), indicating downward $\mathrm{NO}_{3}-\mathrm{N}$ leaching beyond the root zone. A build-up of Olsen-P was noticed under RDF at different time intervals. The soil exchangeable $\mathrm{K}$ and available $\mathrm{S}$ contents were maximal under OF and IPNS options, whereas a decline in DTPA extractable-Zn was recorded under OF. Overall, RWS economics revealed that OF treatment involved the maximum cost of cultivation (US\$1174 ha ${ }^{-1}$ ) with the least economic net return (US\$1211 ha ${ }^{-1}$ ). Conversely, IPNS + legume (B or C) had lowest cost of cultivation (US\$707 to $765 \mathrm{ha}^{-1}$ ) and a significantly higher $(p<0.05)$ net return (US\$2233 to $2260 \mathrm{ha}^{-1}$ ). The study, thus, underlines the superiority of IPNS over RDF or OF; the inclusion of legumes gives an added advantage in terms of production sustainability and soil health. Further studies involving IPNS ingredients other than FYM is needed to develop location-specific IPNS recommendations.
\end{abstract}


Keywords: rice-wheat system; organic farming; forage legume; long-term productivity; soil health; economics

\section{Introduction}

The rice (Oryza sativa L.)-wheat (Triticum aestivum L.) system (RWS) occupying around 13.5 million hectares area in South Asia is the spine of social and economic growth of millions of people [1,2]. The RWS remains the mainstay of cereal production by contributing $23 \%$ of food grains [3]. However, the system has begun to show signs of fatigue with yield plateau and soil health decline. Moreover, the differential ecological requirement for more than 10 Mha of agricultural area in India [4], where these crops are grown in sequence, makes the system complex, and the maintenance of sustainability remains a challenge as well as a necessity [5]. The sustainability of the system has been questioned due to yield stagnation, soil health deterioration and poor carbon and water footprints in the environment for more than two decades now [6,7]. Further, the low system diversity results in the associated problems of multi-nutrient deficiencies, higher insect-pest and disease insurgence, and infestation of some noxious weeds. The input-intensive nature of this system makes it less profitable under the ever-diminishing natural resources such as the declining water table and poor soil fertility [8]. Although there are limited options for the diversification of RWS, its productivity ought to rise with the increasing demographic pressure.

Ladha et al., (2003) [9] reviewed 33 years of long-term experiments (LTEs) and observed yield stagnation in rice and wheat in $72 \%$ and $85 \%$ of the LTEs, respectively, with the application of recommended rates of $\mathrm{N}, \mathrm{P}$ and $\mathrm{K}$, whereas $22 \%$ and $6 \%$ of the LTEs showed significant declining trends for rice and wheat yields, respectively. The decadal yield trend analysis also revealed that the RWS have not only suffered productivity stagnation but have also undergone a depletion of inherent nutrients and a reduction in the quantity and quality of organic matter [10]. The soil organic C (SOC) content in LTEs in the major RWS growing areas of Northwestern India decreased sharply under unbalanced fertilizer input [11].

In an intensive RWS, nutrient removal often exceeds replenishment through fertilizers [12-16]. LTEs continuing under diverse agro-ecologies in India underlined that neither the fertilizers nor the organic sources in isolation can achieve sustainable production. The superiority of the combined use of these nutrient sources over their sole application is well-documented [6,17]. Nutrient management strategies thus have an over-riding impact on RWS production through alterations of soil resilience, responsiveness and receptiveness. The nutrient management strategies for this economically and socially important cropping system should ensure optimum plant nutrient supply and desired crop productivity while sustaining or improving soil fertility. The benefits of the use of fertilizers have been documented [18,19], yet the timely availability of cheaper or subsidised fertilizers and lack of options for providing all the limiting nutrients in the right proportions and in the right amounts often prevents their use as a complete nutrient package [20]. The integrated plant nutrient supply system (IPNS), which involves applying the traditionally used organic nutrient sources in conjunction with fertilizers, provides a plant-demand synchronized and slow-release nutrient input to maintain a continuous nutrient supply, preventing losses and ensuring efficient utilization of the applied nutrients [21]. With IPNS, organic manures along with fertilizers serve as a labile source and an immediate sink of C, N, P and $\mathrm{S}$ in the soils which improves crop productivity, organic carbon, and soil fertility status [22]. The long-term application of organic manures alone in the form of well-rotten and good quality farmyard manure (FYM) has been reported to make nutrients available gradually, in synchrony with plant needs. Besides improving the physico-chemical properties of soil, the application of organic manures can also increase productivity while maintaining a better energy and environmental balance [23]. Nonetheless, low and variable nutrient contents, scarce availability and problems associated with handling and storage of organic manures are the major constraints in their large-scale usage [19]. 
However, the inclusion of legumes, especially forage legumes, as a break crop during the third or fourth cycle can benefit RWS without impairing the food security [14]. Besides providing the green fodder for cattle, there is evidence that a forage legume crop can fix $35-120 \mathrm{~kg} \mathrm{~N} \mathrm{ha}^{-1}$ in the current season with a carryover effect ranging between $35-60 \mathrm{~kg} \mathrm{~N} \mathrm{ha}^{-1}$ for the succeeding crop $[16,24,25]$. The inclusion of a legume crop in RWS adds $\mathrm{N}$ through biological $\mathrm{N}$ fixation, recycles nutrients from the deeper soil layers, minimizes soil compaction, increases soil organic matter, breaks weed and pest cycles and minimizes harmful allelopathic effects [26,27]. However, the effects of fertilizers and IPNS vis-à-vis sole organic input and the substitution of main crop with a forage legume as a break crop at 2-3 year intervals, have rarely been studied in intensively cultivated RWS. Also, the limited information on the use of sole organics in RWS makes it difficult to compare different nutrient management options. Such comparisons are, however, essentially required to aid in the understanding of the effects of different nutrient supply options on soil health and crop productivity and to formulate optimum recommendations to attain sustainability of this important cropping system.

Against this background, the present long-term experiment was conducted to study the effects of continuous application of distinct nutrient supply and crop diversification options viz. organics and fertilizers applied alone or in combination as well as the effect of the inclusion of forage legumes on crop yield, soil health and farm profits under RWS.

\section{Materials and Methods}

\subsection{The Experimental Site}

A long-term field experiment was established during the monsoon season of 1998-1999 and continued for twenty consecutive years, i.e., up until 2017-2018, on Typic Ustocrept soil of the Research Farm of the Indian Institute of Farming Systems Research, Modipuram, Meerut to study the changes in yield, soil health and farm profits of rice and wheat grown in sequence with different nutrient management and crop diversification options. Modipuram $\left(29^{\circ} 4^{\prime} \mathrm{N}, 77^{\circ} 46^{\prime} \mathrm{E}, 237 \mathrm{~m}\right.$ above sea level), located in the Western part of Uttar Pradesh, represents an irrigated, mechanised and input-intensive cropping area of the Upper Gangetic Plain (UGP) transect of the Indo-Gangetic Plain (IGP). The climate of the experimental site is semi-arid sub-tropical, with dry hot summers and cold winters. The long-term average annual rainfall is $807 \mathrm{~mm}$, and nearly $80 \%$ of the total rainfall is received through northwest monsoons from July to September. The year-wise variations in temperature and rainfall are illustrated in Figure 1. Apparently, there were no remarkable changes in these weather parameters over the years of experimentation.

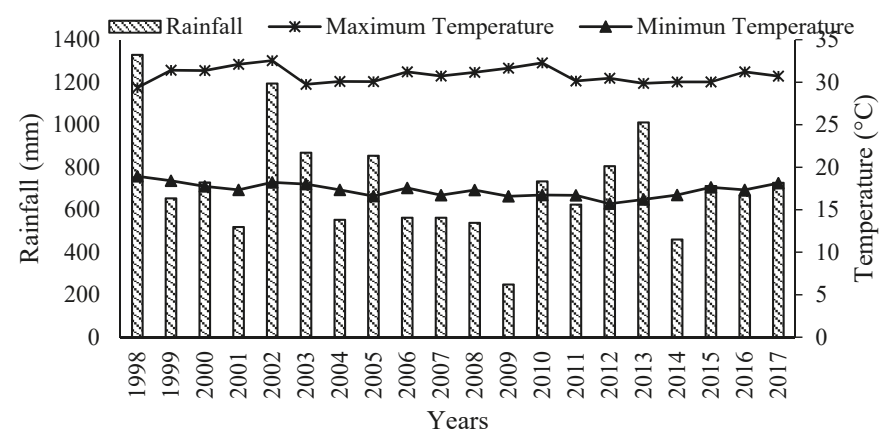

Figure 1. Average yearly temperature (minimum and maximum) and total annual rainfall during the study period.

Nonetheless, the average monthly minimum temperatures fluctuated from 4.5 to $7.8^{\circ} \mathrm{C}$ in January (the coolest month) and from 23.7 to $25.4^{\circ} \mathrm{C}$ in May (the hottest month). The respective maximum 
temperatures ranged from 15.7 to $23.4{ }^{\circ} \mathrm{C}$ in January and 37.1 to $42.9{ }^{\circ} \mathrm{C}$ in May. The soil at the long-term experimental site was sandy loam (17.8\% clay, $19.3 \%$ silt and $62.9 \%$ sand) of Gangetic alluvial origin, which was very deep (>20 m), well-drained, and flat (about 1\% slope), representing one of the most extensive soil series, i.e., the Sobhapur series of northwest India.

Data on the initial soil characteristics of the surface soil (0-15 cm depth) measured at the onset of the experiment in 1998-1999 revealed that the soil was mildly alkaline ( $\mathrm{pH}$ 8.1) and non-saline (electrical conductivity (EC) $0.11 \mathrm{dSm}^{-1}$ ) and contained $5.1 \mathrm{~g} \mathrm{~kg}^{-1}$ Walkley and Black carbon (WBC), $8.3 \mathrm{mg} \mathrm{kg}^{-1}$ Olsen (0.05 M NaHCO 3 -extractable) $\mathrm{P}, 74.1 \mathrm{mg} \mathrm{kg}^{-1}$ exchangeable (1 M ammonium acetate-extractable) $\mathrm{K}, 14.3 \mathrm{mg} \mathrm{kg}^{-1}$ available (0.15\% $\mathrm{CaCl}_{2}$-extractable) $\mathrm{S}$ and $0.54 \mathrm{mg} \mathrm{kg}^{-1} \mathrm{of}$ DTPA-extractable $\mathrm{Zn}$. The important physico-chemical characteristics of the soil at commencement of the experiment are presented in Table 1. Prior to establishment of the long-term experiment, the site was managed under a sugarcane-ratoon-wheat cropping system, with an intermittent rice (puddled-transplanted)-wheat system.

Table 1. Physico-chemical characteristics of the soil measured at commencement of the field experiment in 1998.

\begin{tabular}{|c|c|c|c|c|c|c|c|c|c|c|}
\hline $\begin{array}{l}\text { Soil } \\
\text { Profile-Depth } \\
\text { (cm) }\end{array}$ & $\begin{array}{c}\text { Bulk } \\
\text { Density } \\
\left(\mathrm{Mgm}^{-3}\right)\end{array}$ & $\mathrm{pH}$ & $\begin{array}{c}\mathrm{EC}(\mathrm{dS} \\
\left.\mathrm{m}^{-1}\right)\end{array}$ & $\begin{array}{l}\text { Organic } \\
\text { Carbon } \\
\left(\mathrm{g} \mathrm{kg}^{-1}\right)\end{array}$ & $\begin{array}{c}\mathrm{NO}_{3}-\mathrm{N} \\
(\mathrm{mg} \\
\left.\mathrm{kg}^{-1}\right)\end{array}$ & $\begin{array}{c}\mathrm{NH}_{4}-\mathrm{N} \\
(\mathrm{mg} \\
\left.\mathrm{kg}^{-1}\right)\end{array}$ & $\begin{array}{c}\text { Olsen } \\
\text { Available P } \\
\left(\mathrm{mg} \mathrm{kg}^{-1}\right)\end{array}$ & $\begin{array}{l}\text { Available } \\
\mathrm{K}_{(\mathrm{mg}} \\
\left.\mathrm{kg}^{-1}\right)\end{array}$ & $\begin{array}{l}\text { Available } \\
\mathrm{S}(\mathrm{mg} \\
\left.\mathrm{kg}^{-1}\right)\end{array}$ & $\begin{array}{c}\text { DTPA-Zn } \\
(\mathrm{mg} \\
\left.\mathrm{kg}^{-1}\right)\end{array}$ \\
\hline $0-15$ & 1.49 & 8.01 & 0.11 & 5.1 & 6.9 & 11.3 & 8.3 & 74.1 & 14.3 & 0.54 \\
\hline $15-30$ & 1.52 & 7.89 & 0.12 & 3.6 & 6.8 & 11.6 & 6.1 & 66.3 & 9.1 & 0.46 \\
\hline $30-45$ & 1.58 & - & - & - & 6.1 & 11.64 & - & - & - & - \\
\hline $45-60$ & 1.60 & - & - & - & 5.42 & 10.8 & - & - & - & - \\
\hline $60-75$ & 1.61 & - & - & - & 5.2 & 10.4 & - & - & - & - \\
\hline
\end{tabular}

\subsection{Treatments and Crop Culture}

The long-term experiment comprised six treatments involving the following nutrient management options: control (no-fertilizer), FYM as the sole organic fertilizer (OF), recommended doses of fertilizers (RDF) alone, combination of FYM and fertilizers (IPNS), and IPNS with cowpea (Vigna ungiculata L.) $($ IPNS + C) and berseem (Trifolium alexandrinum L.) (IPNS+B) as a break crop introduced every third year. These were evaluated on a permanent (undisturbed) layout with a randomised block design (Table 2). The experiment was established as a randomised block design with four replications.

Table 2. Treatment details of the long-term experiment chosen for different nutrient management options.

\begin{tabular}{|c|c|c|}
\hline Treatment Code & \multicolumn{2}{|c|}{ Treatment Details } \\
\hline Control & No chemical fertilizer or organic manure & No chemical fertilizer or organic manure \\
\hline IPNS & $\begin{array}{c}\text { fertilizers }+25 \% \text { substitution of recommended } N \\
\text { through FYM }\end{array}$ & Recommended N, P and K through fertilizers \\
\hline $\mathrm{IPNS}+\mathrm{B}$ & $\begin{array}{c}75 \% \text { of recommended } \mathrm{N}, \mathrm{P} \text { and } \mathrm{K} \text { through } \\
\text { fertilizers }+25 \% \text { substitution of recommended } \mathrm{N} \\
\text { through FYM }+ \text { every third wheat substituted } \\
\text { with berseem }\end{array}$ & Recommended N, P and $\mathrm{K}$ through fertilizers \\
\hline
\end{tabular}


The plot size was $25 \mathrm{~m} \times 10 \mathrm{~m}$. The recommended NPK rates of $120 \mathrm{~kg} \mathrm{ha}^{-1} \mathrm{~N}, 26 \mathrm{~kg} \mathrm{ha}^{-1} \mathrm{P}$ and $33 \mathrm{~kg} \mathrm{ha}^{-1} \mathrm{~K}$ for both rice and wheat crops were applied through urea $(46.4 \% \mathrm{~N})$, diammonium phosphate (DAP, $18 \% \mathrm{~N}$ and $20.09 \% \mathrm{P}$ ) and muriate of potash (MOP, $49.6 \% \mathrm{~K}$ ), respectively. Apart from the control and OF plots, $5 \mathrm{~kg} \mathrm{ha}^{-1} \mathrm{Zn}$ was applied through zinc sulfate ( $33 \% \mathrm{Zn}$ ) to rice in all treatments. One-third of the $\mathrm{N}$ and the entire quantity of $\mathrm{P}, \mathrm{K}$ and $\mathrm{Zn}$ were applied as basal doses to each treatment, except OF at the time of transplanting or sowing, and the remaining $\mathrm{N}$ was top-dressed in two equal portions at the maximum tillering stage and at panicle or ear emergence. The quantity of FYM was predetermined on the basis of the $\mathrm{N}$ content. The average composition of FYM was $\mathrm{C}$ (\%) $29.8 \pm 6.2, \mathrm{~N}(\%) 0.72 \pm 0.13, \mathrm{P}(\%) 0.26 \pm 0.08, \mathrm{~K}(\%) 0.51 \pm 0.18, \mathrm{~S}(\%) 0.16 \pm 0.05$ and a C: $\mathrm{N}$ ratio of 6.2. Thus, the quantity of FYM used annually in the IPNS and OF treatments averaged 4.2 and $16.8 \mathrm{t} \mathrm{ha}^{-1}$, respectively. FYM was incorporated into the soil 1 week before the transplantation or sowing of crops.

Each year, 25-day-old rice seedlings (cv. PD 4/PR 106/PR112) were transplanted manually at intervals of $15 \mathrm{~cm}$ in rows spaced at $20 \mathrm{~cm}$ in puddled plots during the first week of July. After rice harvesting, wheat (cv. UP 2338/ PBW 343/ HD 2967) was sown in rows spaced at $20 \mathrm{~cm}$ intervals during the third week of November. All crops were grown under assured irrigated conditions, and chemical weed control was used to maintain almost completely weed-free conditions in the different treatments, except for the OF plots wherein weeds were managed through manual weeding. Need-based spot-weeding was also done in other treatments at 60 days after rice transplantation/wheat sowing depending on weed intensity, despite chemical weed control. Crops were harvested manually using sickle just above the ground level, and the above ground biomass was removed from the plots. The treatments involving cowpea in place of rice (IPNS+C) and berseem in place of wheat (IPNS+B) were sown during first week of July and second week of November during every third rice-wheat cycle. Forage cowpea was harvested manually at the maximum vegetative growth stage, whereas four cuttings of berseem were taken, and green biomass was removed from the plots.

\subsection{Soil Sampling and Analysis}

Soil samples were collected from a profile depth of $0-75 \mathrm{~cm}$ at $15-\mathrm{cm}$ depth intervals from four places in the experimental field using a core sampler of $8 \mathrm{~cm}$ diameter before commencement of the experiment in 1998-1999. The post-wheat harvest soil samples (profile depth of 0-105 cm at 15-cm depth intervals) were drawn following the same procedure after completion of every fifth crop cycle at wheat harvest (2002-2003, 2007-2008, 2012-2013 and 2017-2018) in each treatment. The sub-samples obtained were mixed and bulked, and representative soil samples for each depth were drawn for chemical analysis. The initial and post-harvest soil samples were pulverized using a wooden pestle-mortar and sieved through a $2 \mathrm{~mm}$ sieve. The processed samples were analysed for mineral $\mathrm{N}$ content [28] at all sampled depths and organic carbon [29], Olsen P (0.5 $\mathrm{M} \mathrm{NaHCO}$, pH 8.5 extractable) [30], exchangeable $\mathrm{K}$ (1 M NH $4 \mathrm{OAc}$, pH 7.0 extract) [31], available $\mathrm{S}(0.15 \%$ $\mathrm{CaCl}_{2}$ extraction) [32], and DTPA-extractable $\mathrm{Zn}$ (DTPA-CaCl $2-\mathrm{TEA}, \mathrm{pH} 7.3$ extraction) [33] at depths of 0-15 and 15-30 cm. During 2012-2013, soils from a depth of 0-15 cm were also analysed for extractable $\mathrm{N}$ by the alkaline $\mathrm{KMNO}_{4}$ method [34] at 15-day intervals starting from 15 days after transplantation/sowing in rice and wheat up until 120 days into the crop period. The initial samples were also analysed for $\mathrm{pH}$ and electrical conductivity (1:2 soil:water suspensions) and mechanical composition (international pipette method), following standard analytical procedures [35].

\subsection{Soil Bulk Density}

The soil bulk density (Db) at 0-15, 15-30, 30-45, 45-60, 60-75, 75-90 and 90-105 cm depths was measured using undisturbed soil cores [36] drawn just before start of the study (1998-1999) and in the terminal year (post-wheat 2017-2018). Two cores were collected at random in each plot by placing metal cores (5 cm inner diameter) in the middle of each soil layer (i.e., 6-9, 21-24, 36-39, 51-54, 66-69, $\mathrm{cm}$ depth in $0-15,15-30,30-45,45-60$ and $60-75 \mathrm{~cm}$ soil layers). Bulk density was obtained from the 
gravimetric weights of cores and from the core volume $\left(58.9 \mathrm{~cm}^{3}\right)$ after oven drying for $48 \mathrm{~h}$ at $105{ }^{\circ} \mathrm{C}$. The average $\mathrm{Db}$ of two cores collected for each layer was reported for each plot.

\subsection{Economic Analysis}

Partial economics based on averaged data for the final three years (2015-2016, 2016-2017 and 2017-2018) was computed by using variable costs and income from the sale of grains and straw of rice and wheat as well as berseem and cowpea fodder. The variable cost of cultivation (VCC) of rice and wheat crops included the costs involved in different operations (e.g., rice nursery raising, tillage for seed bed preparation, seeding, insect-pest and weed management, harvesting, threshing) and the inputs (seed, irrigation, fertilizers and agrochemicals and labour) used for raising the crops. The economic analysis, however, did not include the value of the land. The market price considered for different inputs was US $\$ 0.5 \mathrm{~kg}^{-1}$ of rice and wheat seed, US $\$ 1.5 \mathrm{~kg}^{-1}$ of berseem and US $\$ 0.8 \mathrm{~kg}^{-1}$ of cowpea (1US\$ = Indian rupees, INR $=70.00$ ). The cost of fertilizers was calculated on nutrient basis as, $\mathrm{N}=\mathrm{US} \$ 0.17 \mathrm{~kg}^{-1}, \mathrm{P}=\mathrm{US} \$ 1.99 \mathrm{~kg}^{-1}, \mathrm{~K}=\mathrm{US} \$ 0.46 \mathrm{~kg}^{-1}, \mathrm{Zn}=\mathrm{US} \$ 1.21 \mathrm{~kg}^{-1}$. The cost of FYM, herbicide/insecticide and bio-pesticides use was US $\$ 14.28 \mathrm{t}^{-1}$, US $\$ 10 \mathrm{ha}^{-1}$ and US\$ 8ha ${ }^{-1}$ application ${ }^{-1}$, respectively. Among the field operations, the cost of nursery raising was taken as US $\$ 0.035 \mathrm{~m}^{-2}$, plowing/harrowing was US $\$ 8.5 \mathrm{ha}^{-1}$, puddling was US $\$ 20.00 \mathrm{ha}^{-1}$, dry planking was US $\$ 10.00 \mathrm{ha}^{-1}$, wet planking was US $\$ 17.00 \mathrm{ha}^{-1}$, sowing of wheat using seed drill was US $\$ 25.00 \mathrm{ha}^{-1}$ and transplantation of rice was US $\$ 45.00 \mathrm{ha}^{-1}$. The cost of irrigation was taken as US\$7 ha ${ }^{-1}$, hand weeding was US $\$ 50 \mathrm{ha}^{-1}$, spot weeding was US $\$ 25 \mathrm{ha}^{-1}$ insecticide/ herbicide spraying was US $\$ 8.5 \mathrm{ha}^{-1}$ and labour was US\$5.0 unit $^{-1}$ day $^{-1}$.

Gross returns (GR) were calculated by multiplying the grain, straw yield and green fodder by their prices. The minimum support prices (MSPs) fixed by the government for rice (US\$0.18 kg-1) and wheat grain (US\$0.21 kg-1) were used, whereas the price of rice straw (US\$0.016 kg-1) and wheat straw (US $\$ 0.05 \mathrm{~kg}^{-1}$ ), respectively, and green fodder of cowpea and berseem (US $\$=0.71$ ) were taken as the prevailing prices in local markets at the time of harvest. The net return (NR) for each crop was calculated as the GR minus the VCC. The NR of rice/cowpea was added to the NR of wheat/berseem to compute the cropping system's net returns for each treatment in respective years. Here, we report data based on the average of the three terminal years (2015-2016, 2017-2018, 2018-2019) for economic analysis.

\subsection{Statistical Analysis and Computations}

In Figures 2-4, the standard error ( $\mathrm{SE} \pm$ ) of the treatment means was computed as

$$
\mathrm{SE}=\mathrm{SD}(\sqrt{ } \mathrm{N})^{-1}
$$

where $\mathrm{SD}$ is the standard deviation of the mean, and $\mathrm{N}$ is the number of observations on which the mean is based.

For comparison of treatment means in the field experiments, a multivariate analysis was adapted for multiple comparison of the means, following the procedures of randomized block design [37], as shown in Tables 4-9 and Figure 5. In order to compare the treatments over the years, the yield data of the initial years (1998-1999 and 1999-2000) and final years (2016-2017 and 2017-2018) were pooled, and an analysis of variance (ANOVA) was performed (Table 4).

A least-squares linear regression of yield versus time (years) was computed for all treatments to test the hypothesis that yield trends throughout the experimentation period are not significantly different from zero. In order to understand the yield stability in rice and wheat over time, the yields of 20 years from the start of the experiment were analysed against time using a least-squares linear regression:

$$
\mathrm{Y}=\mathrm{a}+\mathrm{bt}
$$


where $\mathrm{Y}$ is the grain yield ( $\mathrm{t} \mathrm{ha}{ }^{-1}$ ) of rice or wheat, $\mathrm{a}$ is a constant, $\mathrm{b}$ is the slope or magnitude of the annual yield change, and $t$ is the time (experimentation period in years).

\section{Results}

\subsection{Effect on Rice and Wheat Yields}

The application of RDF either alone or in combination with FYM (IPNS, i.e., $75 \%$ RDF $+25 \% \mathrm{~N}$ through FYM in rice and 100\% RDF in wheat) significantly $(p<0.05)$ increased the yield of rice over the control (unfertilized) or OF during the initial years (1998-1999 and 1999-2000). The yields of rice under RDF were, however, on par $(p>0.05)$ with the IPNS and IPNS+B or IPNS+C (Table 3). The differences between $\mathrm{OF}$ and the control were not significant during the initial years (Table 3). On the other hand, yield reductions under OF as compared with RDF, IPNS, IPNS+B, IPNS+C were in the range of 2.36 to $2.53 \mathrm{tha}^{-1}$, during the initial years.

Table 3. Trends in the yields of rice and wheat in a long-term rice-wheat system under different nutrient management options.

\begin{tabular}{|c|c|c|c|c|c|}
\hline \multirow{2}{*}{ Particulars } & \multicolumn{4}{|c|}{ Annual Yield Changes a } & \multirow{2}{*}{ Initial Yield ${ }^{b}\left(t h^{-1}\right)$} \\
\hline & $b$-Value & $t$-Statistics & $p$-Value & $R^{2}$-Value & \\
\hline \multicolumn{6}{|c|}{ Rice } \\
\hline Control & -0.06 & -6.98 & $* * *$ & 0.83 & 1.84 \\
\hline RDF & 0.01 & -4.34 & $* * *$ & 0.07 & 4.62 \\
\hline IPNS & 0.07 & -3.72 & $* * *$ & 0.65 & 5.01 \\
\hline IPNS+B & 0.05 & -3.78 & $* * *$ & 0.58 & 4.99 \\
\hline $\mathrm{OF}$ & 0.09 & -5.05 & $* * *$ & 0.81 & 2.90 \\
\hline \multicolumn{6}{|c|}{ Wheat } \\
\hline Control & -0.06 & -7.11 & $* * *$ & 0.78 & 1.58 \\
\hline RDF & -0.05 & -4.85 & $* * *$ & 0.57 & 4.42 \\
\hline IPNS & 0.07 & -3.91 & $* * *$ & 0.72 & 4.54 \\
\hline IPNS+C & 0.08 & -4.04 & $* * *$ & 0.72 & 4.49 \\
\hline OF & 0.14 & -5.08 & $* * *$ & 0.91 & 2.33 \\
\hline
\end{tabular}

${ }^{\mathrm{a}}$ computed from linear regression; ${ }^{\mathrm{b}}$ the intercept (a value) of the linear regression; ${ }^{* * *}$ significant at $p<0.001$.

The average rice yields for the terminal years (2016-2017 and 2017-2018) revealed that the treatments receiving conjoint use of fertilizers and FYM, with or without inclusion of a legume, i.e., IPNS, IPNS+B or IPNS+C had significantly $(p<0.05)$ greater yields than those receiving RDF (Table 3 ). The magnitude of increase in rice yield in IPNS or IPNS+B or IPNS+C over RDF was in the range of $26 \%$ to $29 \%$ during the terminal years. Rice yield under OF was also significantly $(p<0.05)$ lower as compared with RDF during the terminal years.

Although the residual effects of FYM application to rice on the succeeding wheat yields were not significant $(p<0.01)$ over RDF during the initial years, this varied based on the use of IPNS and different organic and legume combinations during the terminal years (2016-2017 and 2017-2018). Compared with RDF, wheat yields under IPNS, IPNS+B and IPNS+C during the terminal years were greater by $64 \%, 72 \%$ and $73 \%$, respectively (Table 3 ). Wheat yields under OF also increased with the passage of time and gave significantly $(p<0.05)$ higher yield gains over RDF and the control. Nonetheless, the yields under OF remained 21\% to $25 \%$ lower than those of IPNS after two decades of experimentation (Table 3).

Further, a comparison of yields during the terminal years vis-à-vis the initial years (2-year average) revealed that OF had the maximum yield gain (63\% in rice and $108 \%$ in wheat). This yield gain under different IPNS options during the terminal years as compared with the initial years ranged from $20 \%$ to $23 \%$ in rice and $27 \%$ to $34 \%$ in wheat in the following order: IPNS > IPNS+C > IPNS+B. After 20 years 
of RW cropping, changes in the system productivity under the control and RDF showed negative trends $(58.1 \%$ and $9.43 \%$ decline over the initial years) whereas, system productivity gains of $83.4 \%$, $28.2 \%, 27.2 \%$ and $23.6 \%$ were noticed under OF, IPNS+C, IPNS+B and IPNS, respectively (Table 4).

Table 4. Changes in rice, wheat and RWS productivity under different long-term nutrient management options during the initial and terminal years.

\begin{tabular}{|c|c|c|c|c|c|c|c|c|c|}
\hline \multirow{2}{*}{ Treatments } & \multicolumn{2}{|c|}{ Rice Yield (t ha ${ }^{-1}$ ) } & \multirow{2}{*}{$\begin{array}{c}\% \\
\text { Change }\end{array}$} & \multicolumn{2}{|c|}{ Wheat Yield (t ha ${ }^{-1}$ ) } & \multirow{2}{*}{$\begin{array}{c}\% \\
\text { Change }\end{array}$} & \multicolumn{2}{|c|}{$\begin{array}{c}\text { RW System Yield } \\
\left(\mathrm{t} \mathrm{ha}^{-1}\right)\end{array}$} & \multirow{2}{*}{$\begin{array}{c}\% \\
\text { Change }\end{array}$} \\
\hline & $\begin{array}{l}\text { Initial } \\
\text { Years }^{a}\end{array}$ & $\begin{array}{l}\text { Terminal } \\
\text { Years }^{b}\end{array}$ & & $\begin{array}{l}\text { Initial } \\
\text { Years }\end{array}$ & $\begin{array}{l}\text { Terminal } \\
\text { Years }\end{array}$ & & $\begin{array}{l}\text { Initial } \\
\text { Years }\end{array}$ & $\begin{array}{l}\text { Terminal } \\
\text { Years }\end{array}$ & \\
\hline Control & $2.01^{c}$ & $0.83^{\mathrm{d}}$ & -58.7 & $1.81^{\mathrm{d}}$ & $0.77^{\mathrm{d}}$ & -57.5 & $3.82^{c}$ & $1.60^{c}$ & -58.1 \\
\hline RDF & $4.96^{\mathrm{a}}$ & $4.88^{b}$ & -1.6 & $4.37^{b}$ & $3.57^{c}$ & -18.35 & $9.33^{\mathrm{a}}$ & $8.45^{b}$ & -9.4 \\
\hline IPNS & $5.09^{\mathrm{a}}$ & $6.13^{a}$ & 20.4 & $4.60^{\mathrm{ab}}$ & $5.85^{\mathrm{a}}$ & 27.2 & $9.69^{a}$ & $11.98^{\mathrm{a}}$ & 23.6 \\
\hline $\mathrm{IPNS}+\mathrm{C}$ & $5.09^{\mathrm{a}}$ & $6.27^{\mathrm{a}}$ & 23.2 & $4.59^{a b}$ & $6.14^{\mathrm{a}}$ & 33.8 & $9.68^{\mathrm{a}}$ & $12.41^{\mathrm{a}}$ & 28.2 \\
\hline OF & $2.60^{b}$ & $4.23^{c}$ & 62.7 & $2.15^{c}$ & $4.48^{\mathrm{b}}$ & 108.4 & $4.75^{b}$ & $8.71^{b}$ & 83.4 \\
\hline
\end{tabular}

\subsection{Yield Trends in Rice and Wheat}

In rice, the trends in yield were positive $(p<0.001)$ in all treatments except for the control (Table 4 , Figure 2). The annual increase was 9.2\% under OF, 6.6\% in IPNS, 5.1\% in IPNS+B and $1.4 \%$ under RDF, which was statistically significantly different from zero $(p<0.001)$. Skipping fertilizer application caused a significant $(p<0.001)$ annual yield decline $(-6.1 \%)$ during the study.
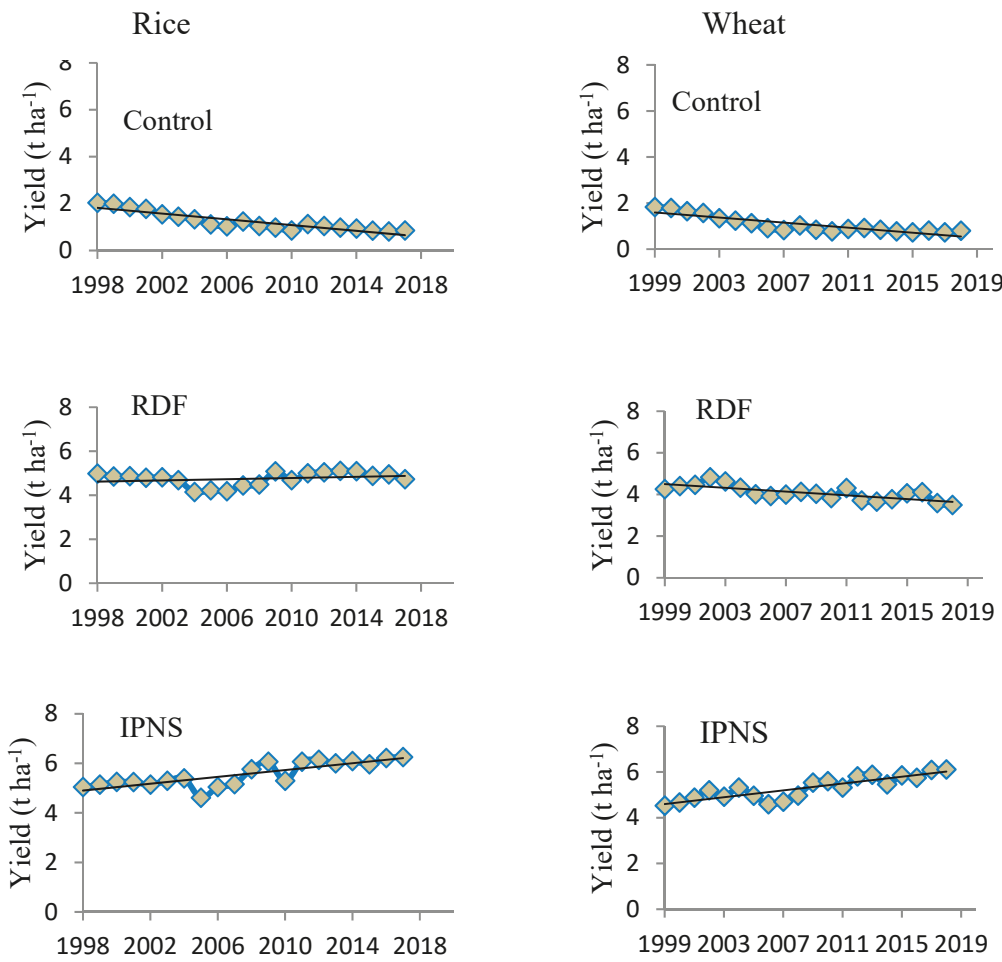

Figure 2. Cont. 

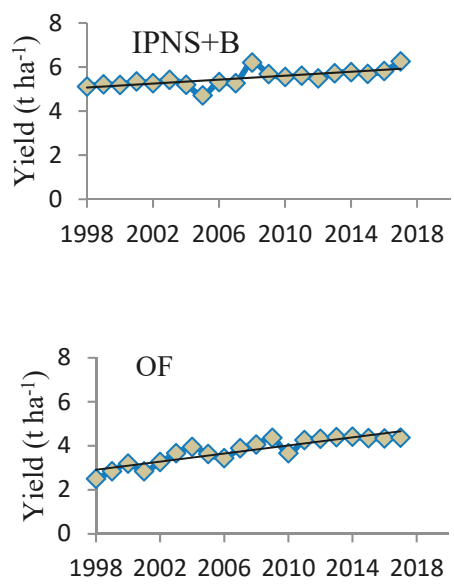

Years
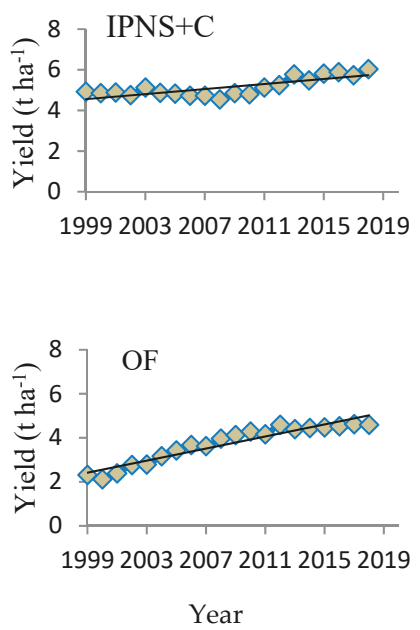

Figure 2. Trends in yields of rice and wheat in a long-term RWS under different nutrient management options. Measured mean yields of the treatments (symbols) and the trend line fitted by linear regression (Table 3) are shown.

The trends in wheat yield in the control as well as RDF were negative $(p<0.001)$, with annual yield declines of $-5.5 \%$ and $-4.5 \%$, respectively (Table 4 , Figure 1 ). In contrast, yield trends were positive and significant $(p<0.001)$ in all other treatments. The maximum annual wheat yield gain $(13.7 \%)$ was noticed under OF, followed by IPNS+C (7.7\%) and IPNS (6.8\%).

\subsection{Effect on Soil Health}

\subsubsection{Soil Bulk Density}

The soil bulk density $(\mathrm{Db})$ of the surface layer $(0-15 \mathrm{~cm})$, was $1.49 \pm 0.013 \mathrm{Mg} \mathrm{m}^{-3}$ at the onset of the experiment. It, however, increased with an increasing soil profile depth, measuring $1.61 \pm 0.010 \mathrm{Mg} \mathrm{m}^{-3}$ at a depth of 60-75 $\mathrm{cm}$ (Figure 3). At the end of experimentation in 2017-2018, the RDF treatment did not influence the soil $\mathrm{Db}$ in the upper soil depths $(0-15 \mathrm{~cm}$ and $15-30 \mathrm{~cm})$, but the $\mathrm{Db}$ values at the $30-45 \mathrm{~cm}$ soil depth were greater $\left(1.74 \pm 0.012 \mathrm{Mg} \mathrm{m}^{-3}\right)$ compared with the initial $\mathrm{Db}\left(1.58 \pm 0.016 \mathrm{Mg} \mathrm{m}^{-3}\right)$ at this depth, thereby indicating ta tendency towards sub-surface soil compaction. In the plots having IPNS with legumes as a break crop during every third year, no such compaction was noticed. The Db of soil at a profile depth of $30-45 \mathrm{~cm}$ was much smaller $\left(1.36 \pm 0.16 \mathrm{Mg} \mathrm{m}^{-2}\right.$ and $1.34 \pm 0.014 \mathrm{Mg} \mathrm{m}^{-2}$ in IPNS+B and IPNS+C plots, respectively) compared with the $\mathrm{Db}$ in RDF plots $\left(1.74 \pm 0.013 \mathrm{Mg} \mathrm{m}^{-2}\right)$. Although the Db values under IPNS and OF treatments were much smaller (1.42 \pm 0.018 and $1.38 \pm 0.024)$ at the $0-15 \mathrm{~cm}$ depth as compared with the $\mathrm{Db}$ at the onset of the experiment, this did not influence values at the other soil profile depths. 


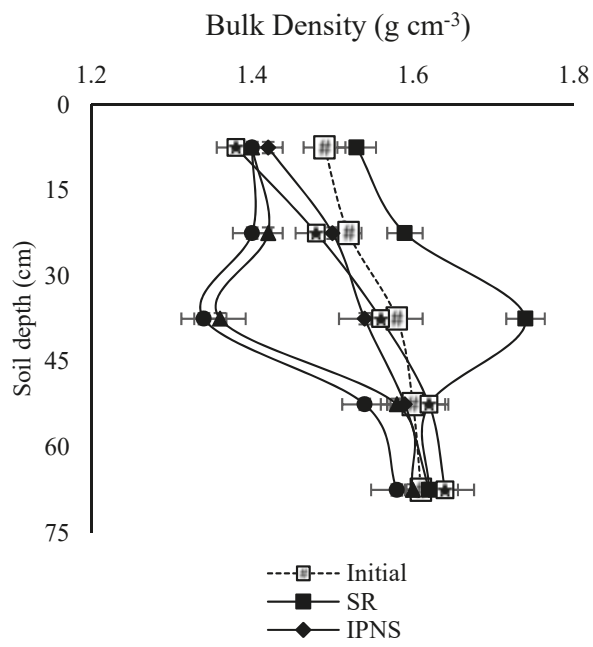

Figure 3. Changes in the bulk density of soil at different profile depths after 20 RWS cycles under the influence of different nutrient management options. Bars indicate the standard error of the mean, $n=4$.

\subsubsection{Soil OC Content}

The soil organic carbon (SOC) content measured at profile depths of 0-15 and 15-30 cm during 2002-2003, 2007-2008, 2012-2013 and 2017-2018 varied in accordance with the soil depth and with the passage of time (Table 5). In surface soil (0-15 cm depth), during 2002-2003, the SOC content was highest $\left(5.3 \mathrm{~g} \mathrm{~kg}^{-1}\right)$ under OF which was on par with IPNS $\left(5.6 \mathrm{~g} \mathrm{~kg}^{-1}\right)$ and IPNS+C or IPNS+B $\left(5.8 \mathrm{~g} \mathrm{~kg}^{-1}\right)$, though statistically higher $(p<0.05)$ than $\operatorname{RDF}\left(5.2 \mathrm{~g} \mathrm{~kg}^{-1}\right)$. The SOC content increased $(p<0.05)$ under OF, IPNS and IPNS+B or C over the years but declined in the control plots. The SOC remained unaffected under RDF during the different years of study. During the terminal year (2017-2018), the maximum SOC $\left(6.9 \mathrm{~g} \mathrm{~kg}^{-1}\right)$ was noticed under OF which was significantly higher $(p<0.05)$ than that under IPNS $\left(6.2 \mathrm{~g} \mathrm{~kg}^{-1}\right)$ and IPNS+B or IPNS+C $\left(6.4 \mathrm{~g} \mathrm{~kg}^{-1}\right)$. The RDF and control plots had significantly $(p<0.05)$ lower SOC contents than the different IPNS options.

Table 5. Effects of different nutrient management options on the soil organic carbon (SOC) content $\left(\mathrm{g} \mathrm{kg}^{-1}\right.$ ) at soil depths of $0-15$ and $15-30 \mathrm{~cm}$ after 5 RWS cycle intervals.

\begin{tabular}{ccccccccccc}
\hline \multirow{2}{*}{ Treatment } & 2002-2003 & 2007-2008 & 2012-2013 & 2017-2018 & Mean & 2002-2003 & 2007-2008 & 2012-2013 & 2017-2018 & Mean \\
\cline { 2 - 9 } & \multicolumn{9}{c}{ 0-15 cm Depth } \\
\hline Control & $4.7^{\mathrm{cA}}$ & $4.3^{\mathrm{cAB}}$ & $3.9^{\mathrm{cB}}$ & $3.3^{\mathrm{dC}}$ & $4.1^{\mathrm{c}}$ & $3.0^{\mathrm{cA}}$ & $2.8^{\mathrm{bA}}$ & $2.8^{\mathrm{eA}}$ & $2.6^{\mathrm{dA}}$ & $2.8^{\mathrm{d}}$ \\
RDF & $5.2^{\mathrm{bA}}$ & $5.1^{\mathrm{bA}}$ & $5.3^{\mathrm{bA}}$ & $5.4^{\mathrm{cA}}$ & $5.3^{\mathrm{b}}$ & $3.2^{\mathrm{aA}}$ & $3.4^{\mathrm{aA}}$ & $3.5^{\mathrm{cA}}$ & $3.7^{\mathrm{bcA}}$ & $3.5^{\mathrm{c}}$ \\
IPNS & $5.6^{\mathrm{abB}}$ & $5.8^{\mathrm{aAB}}$ & $6.0^{\mathrm{aAB}}$ & $6.2^{\mathrm{bA}}$ & $5.9^{\mathrm{a}}$ & $3.6^{\mathrm{aA}}$ & $4^{\mathrm{aB}}$ & $4.2^{\mathrm{dB}}$ & $4.4^{\mathrm{cB}}$ & $4.1^{\mathrm{b}}$ \\
IPNS+B & $5.5^{\mathrm{abC}}$ & $5.9^{\mathrm{aBC}}$ & $6.2^{\mathrm{aAB}}$ & $6.4^{\mathrm{bA}}$ & $6.0^{\mathrm{a}}$ & $3.9^{\mathrm{b}}$ & $4.7^{\mathrm{aB}}$ & $5.0^{\mathrm{aA}}$ & $5.3^{\mathrm{aAB}}$ & $4.7^{\mathrm{a}}$ \\
IPNS+C & $5.5^{\mathrm{abB}}$ & $5.8^{\mathrm{aB}}$ & $6.4^{\mathrm{aA}}$ & $6.4^{\mathrm{bA}}$ & $6.0^{\mathrm{a}}$ & $4.0^{\mathrm{a}}$ & $4^{\mathrm{aB}}$ & $5.1^{\mathrm{aA}}$ & $5.4^{\mathrm{aA}}$ & $4.8^{\mathrm{a}}$ \\
OF & $5.8^{\mathrm{aC}}$ & $6.4^{\mathrm{aBC}}$ & $6.9^{\mathrm{aB}}$ & $7.1^{\mathrm{aA}}$ & $6.6^{\mathrm{a}}$ & $3.3^{\mathrm{c}}$ & $3^{\mathrm{aA}}$ & $4.0^{\mathrm{bcA}}$ & $4.2^{\mathrm{bA}}$ & $3.8^{\mathrm{bc}}$ \\
\hline
\end{tabular}

Values followed by different lower case letter(s) within a column are significant at $p<0.05$. Values followed by different capital letter(s) within a row are significant at $p<0.05$.

The SOC content also varied with soil depth, and a relatively lower SOC was noticed at the 15-30 cm depth (Table 5). At this soil depth, IPNS combined with legumes had a significant edge over OF in different years of the study. The SOC, measured after 20 annual RW cycles vis-à-vis the onset of the experiment, showed improvements of $6-39 \%$ and $19-74 \%$ at the $0-15$ and $15-30 \mathrm{~cm}$ soil depths, respectively, in all treatments except for the control, wherein the SOC declined by $14-35 \%$ from its initial value. 


\subsubsection{Soil Mineral N Content}

The nitrate $\left(\mathrm{NO}_{3}\right)-\mathrm{N}$ content of surface soil $(0-15 \mathrm{~cm})$ was greater under IPNS+B and IPNS+C compared with the other nutrient management options; the differences were more prominent during 2012-2013 and 2017-2018 (Figure 4). The $\mathrm{NO}_{3}-\mathrm{N}$ content in the surface soil layer after wheat harvest in the IPNS+B treatment was greater than that in the RDF by 103\% in 2002-2003, 173\% in 2007-2008, $213 \%$ in $2012-2013$ and $268 \%$ in $2017-2018$. The corresponding increases with the inclusion of cowpea as a break crop (IPNS+C) were $93 \%, 159 \%, 204 \%$ and $255 \%$, respectively.

$\mathrm{NO}_{3}(\mathrm{ppm})$

$2 \quad 4 \quad 6 \quad 8 \quad 101214161820$

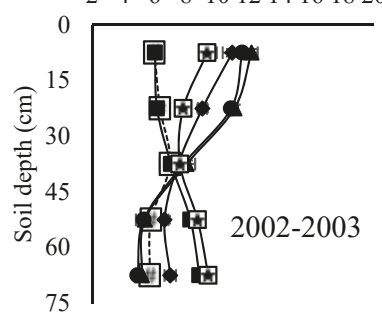

$\mathrm{NO}_{3}(\mathrm{ppm})$

$\begin{array}{lllllllll}2 & 4 & 6 & 8 & 101214 & 161820\end{array}$

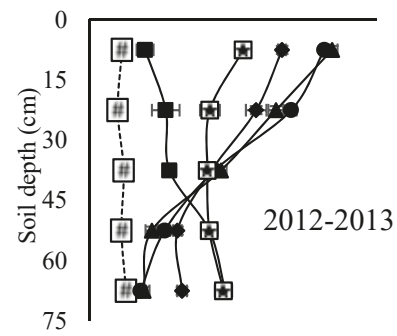

$\mathrm{NO}_{3}(\mathrm{ppm})$

24668101214161820

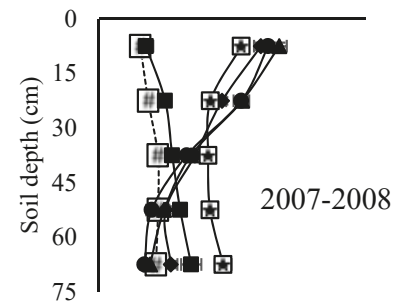

$\mathrm{NO}_{3}(\mathrm{ppm})$

$24 \quad 6 \quad 8 \quad 101214161820$

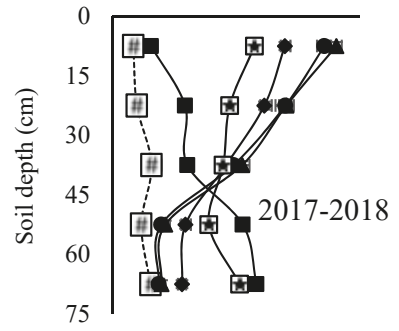

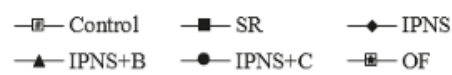

Figure 4. Effects of the nutrient management options on the distribution of nitrate-N in different soil profiles after wheat harvest at five-year intervals of the RWS cycle. Bars indicate the standard error of the mean, $n=4$.

Compared with the initial $\mathrm{NO}_{3}-\mathrm{N}$ content of the surface soil layer $\left(6.9 \mathrm{mg} \mathrm{kg}^{-1}\right)$, the $\mathrm{NO}_{3}-\mathrm{N}$ content in IPNS, IPNS+B, IPNS+C, and OF treatments was greater by 7.76, 7.76, 11.5 and $10.6 \mathrm{mg} \mathrm{kg}^{-1}$, respectively, during the terminal year. On the other hand, no application of fertilizer or the application of FYM (control) and RDF led to depletion of $\mathrm{NO}_{3}-\mathrm{N}$ by $3.25 \mathrm{mg} \mathrm{kg}^{-1}$ and $1.96 \mathrm{mg} \mathrm{kg}^{-1}$, respectively, over the initial status (Figure 4).

Different nutrient management options markedly influenced the distribution of $\mathrm{NO}_{3}-\mathrm{N}$ in the soil profile. Whereas the $\mathrm{NO}_{3}-\mathrm{N}$ content increased over the initial content up to a profile depth of $75 \mathrm{~cm}$ in the RDF and OF plots, a constant decrease in the $\mathrm{NO}_{3}-\mathrm{N}$ content was observed under the IPNS + legume options (Figure 4). The inclusion of legumes in every third RW cycle (IPNS+B or IPNS+C) not only favoured a greater $\mathrm{NO}_{3}-\mathrm{N}$ content in the surface layer as compared with $\mathrm{RDF}$, but also resulted in 
a lower $\mathrm{NO}_{3}-\mathrm{N}$ content in the deeper soil layers, as was evident from a decrease in the $\mathrm{NO}_{3}-\mathrm{N}$ content with an increasing soil profile depth. This advantage (greater retention of $\mathrm{NO}_{3}-\mathrm{N}$ in the surface soil) of the inclusion of legumes in RWS as a break crop was, however, more spectacular during the terminal year (2017-2018).

The nutrient supply through fertilizers, organic compounds, or both increased the $\mathrm{NH}_{4}-\mathrm{N}$ content as compared with no fertilizer application in the surface soil layer; the magnitude of such increase was greater under OF, followed by IPNS+C, IPNS+B, IPNS and RDF during 2002-2003 (Figure 5).
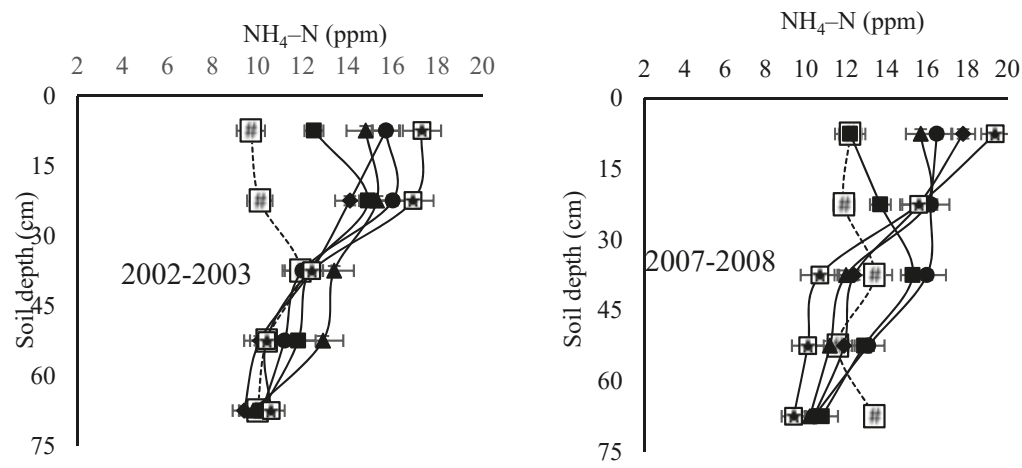

$\mathrm{NH}_{4}-\mathrm{N}(\mathrm{ppm})$

$\mathrm{NH}_{4}-\mathrm{N}(\mathrm{ppm})$

$\begin{array}{llllllllllll}2 & 4 & 6 & 8 & 10 & 12 & 14 & 16 & 18 & 20 & 22 & 24\end{array}$
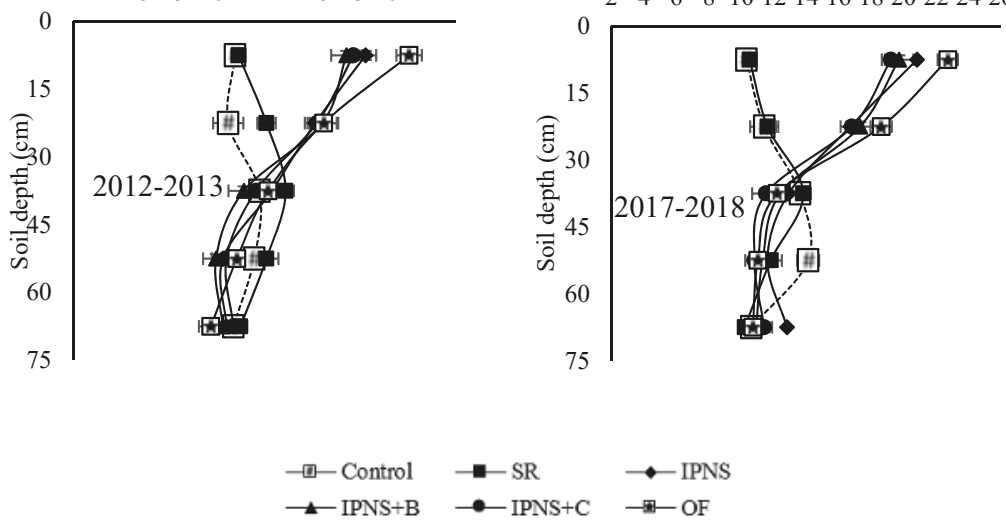

Figure 5. Effect of nutrient management options on the distribution of the ammonium-N content in different soil profiles after wheat harvest at five-year intervals of the RWS cycle. Bars indicate the standard error of the mean, $n=4$.

Compared with the initial $\mathrm{NH}_{4}-\mathrm{N}$ content $\left(11.3 \mathrm{mg} \mathrm{kg}^{-1}\right)$, OF and different IPNS options had a 31-53\% higher $\mathrm{NH}_{4}-\mathrm{N}$ content in the surface soil layer during 2002-2003 (Figure 5). A similar pattern of increase in $\mathrm{NH}_{4}-\mathrm{N}$ content as the consequence of different fertilizer options was also observed after wheat harvest during 2007-2008, 2012-2013 and 2017-2018. The $\mathrm{NH}_{4}-\mathrm{N}$ content profile at different depths under OF and IPNS was almost uniformly distributed up to a depth of $0-45 \mathrm{~cm}$, and was relatively greater than the initial $\mathrm{NH}_{4}-\mathrm{N}$ concentration. Values beyond a soil depth of $45 \mathrm{~cm}$ did not show any consistent trend among different sampling intervals. 


\subsubsection{Soil Olsen-P Content}

The Olsen-P content of the surface soil $(0-15 \mathrm{~cm})$ increased compared with the initial content $\left(8.3 \mathrm{mg} \mathrm{kg}^{-1}\right)$ under different nutrient management options and with the passage of time (Table 6). After the 20th RWS cycle (2017-2018), the maximum P build-up in the surface soil was noticed under RDF (21.8 $\left.\mathrm{mg} \mathrm{kg}^{-1}\right)$, followed by OF $\left(18.2 \mathrm{mg} \mathrm{kg}^{-1}\right)$, whereas a relatively lower P content $\left(16.0 \mathrm{mg} \mathrm{kg}^{-1}\right)$ was recorded under the IPNS treatments. The effect of fertilizer options was relatively smaller in the sub-surface soil (15-30 cm soil depth). Nonetheless, fertilizer input at the recommended rate increased Olsen-P over the initial content $\left(6.1 \mathrm{mg} \mathrm{kg}^{-1}\right)$ in the sub-surface layer by $122 \%$ during the terminal crop cycle (2017-2018). Relatively smaller P accumulations over the initial content in the sub-surface soil (15-30 cm depth) were noticed under IPNS (51\%) and OF (11\%). On the other hand, a $20-23 \%$ decline in Olsen-P over the initial content was noticed under IPNS+B and IPNS+C (Table 6).

Table 6. Effects of different nutrient management options on soil Olsen-P $\left(\mathrm{mg} \mathrm{kg}^{-1}\right)$ at soil depths of 0-15 and 15-30 cm after 5 RWS cycle intervals.

\begin{tabular}{ccccccccccc}
\hline \multirow{2}{*}{ Treatment } & 2002-2003 & 2007-2008 & 2012-2013 & 2017-2018 & Mean & 2002-2003 & 2007-2008 & 2012-2013 2017-2018 & Mean \\
\cline { 2 - 9 } & \multicolumn{9}{c}{ 0-15 cm Depth } \\
\hline Control & $8.0^{\mathrm{eA}}$ & $7.6^{\mathrm{dAB}}$ & $7.1^{\mathrm{eAB}}$ & $6.9^{\mathrm{dB}}$ & $7.4^{\mathrm{d}}$ & $5.6^{\mathrm{cA}}$ & $4.9^{\mathrm{eB}}$ & $4.9^{\mathrm{dB}}$ & $3.9^{\mathrm{eC}}$ & $4.8^{\mathrm{eB}}$ \\
RDF & $13.0^{\mathrm{aD}}$ & $15.9^{\mathrm{aC}}$ & $19.7^{\mathrm{aB}}$ & $21.9^{\mathrm{aA}}$ & $17.6^{\mathrm{a}}$ & $6.3^{\mathrm{bD}}$ & $8^{\mathrm{aC}}$ & $10.9^{\mathrm{aB}}$ & $13.6^{\mathrm{aA}}$ & $9.8^{\mathrm{aC}}$ \\
IPNS & $11.7^{\mathrm{bD}}$ & $13.9^{\mathrm{bC}}$ & $15.9^{\mathrm{bB}}$ & $17.7^{\mathrm{bA}}$ & $14.8^{\mathrm{b}}$ & $7.3^{\mathrm{aC}}$ & $7^{\mathrm{bC}}$ & $8.4^{\mathrm{bB}}$ & $9.2^{\mathrm{bA}}$ & $8.1^{\mathrm{bB}}$ \\
IPNS+B & $8.9^{\mathrm{deD}}$ & $11.3^{\mathrm{cC}}$ & $13.7^{\mathrm{dB}}$ & $15.9^{\mathrm{cA}}$ & $12.5^{\mathrm{c}}$ & $5.3^{\mathrm{cAB}}$ & $5.7^{\mathrm{dA}}$ & $4.8^{\mathrm{dBC}}$ & $4.7^{\mathrm{dC}}$ & $5.1^{\mathrm{deB}}$ \\
IPNS+C & $10.0^{\mathrm{cdD}}$ & $12.1^{\mathrm{cC}}$ & $14.3^{\mathrm{cdB}}$ & $16.0^{\mathrm{cA}}$ & $13.1^{\mathrm{c}}$ & $6.0^{\mathrm{bcA}}$ & $6.0^{\mathrm{cdA}}$ & $5.1^{\mathrm{dB}}$ & $4.9^{\mathrm{dB}}$ & $5.5^{\mathrm{dA}}$ \\
OF & $12.7^{\mathrm{aD}}$ & $14.1^{\mathrm{aC}}$ & $17.2^{\mathrm{bcB}}$ & $18.2^{\mathrm{bA}}$ & $15.6^{\mathrm{b}}$ & $6.5^{\mathrm{bAB}}$ & $6.4^{\mathrm{cB}}$ & $6.9^{\mathrm{cA}}$ & $6.8^{\mathrm{cAB}}$ & $6.6^{\mathrm{cAB}}$ \\
\hline
\end{tabular}

Values followed by different lower case letter(s) within a column are significant at $p<0.05$. Values followed by different capital letter(s) within a row are significant at $p<0.05$.

\subsubsection{Soil Exchangeable K Content}

Over the years, a consistent increase in soil exchangeable K was noticed under IPNS as well as OF (Table 7). At soil depths of $0-15$ and $15-30 \mathrm{~cm}$, the highest exchangeable $\mathrm{K}$ contents were recorded under OF (110 and $90 \mathrm{mg} \mathrm{kg}^{-1}$, respectively) and these were on par with the values under the different IPNS options during 2017-2018. When compared with the initial K contents $\left(74.1\right.$ and $66.3 \mathrm{mg} \mathrm{kg}^{-1}$ at $0-15$ and $15-30 \mathrm{~cm}$ soil depth, respectively), the exchangeable $\mathrm{K}$ content of the soil after $20 \mathrm{RW}$ cycles increased by $48 \%, 43 \%, 42 \%$ and $36 \%$ at the $0-15 \mathrm{~cm}$ depth and by $36 \%, 30 \%, 29 \%$ and $28 \%$ at the 15-30 cm depth under OF, IPNS, IPNS+B and IPNS+C, respectively (Table 7). On the contrary, a consistent depletion of exchangeable $\mathrm{K}$ was observed in the RDF and unfertilized plots, wherein it remained significantly lower $(p<0.05)$ than that in the other treatments at different soil sampling intervals at both soil profile depths $(0-15$ and $15-30 \mathrm{~cm})$.

Table 7. Effects of different nutrient management options on the soil exchangeable $\mathrm{K}$ content $\left(\mathrm{mg} \mathrm{kg}^{-1}\right)$ in at soil depths of $0-15$ and $15-30 \mathrm{~cm}$ after 5 RWS cycle intervals.

\begin{tabular}{ccccccccccc}
\hline \multirow{2}{*}{ Treatment } & 2002-2003 & 2007-2008 & 2012-2013 & 2017-2018 & Mean & 2002-2003 & 2007-2008 & 2012-2013 & 2017-2018 & Mean \\
\cline { 2 - 9 } & \multicolumn{9}{c}{ 0-15 cm Depth } \\
\hline Control & $69.1^{\mathrm{bA}}$ & $67.1^{\mathrm{bA}}$ & $64.7^{\mathrm{bA}}$ & $61.9^{\mathrm{dA}}$ & $65.7^{\mathrm{b}}$ & $64.7^{\mathrm{bAB}}$ & $62.5^{\mathrm{bA}}$ & $60.6^{\mathrm{cAB}}$ & $58.1^{\mathrm{cB}}$ & $61.5^{\mathrm{b}}$ \\
RDF & $70.5^{\mathrm{bA}}$ & $65.2^{\mathrm{bA}}$ & $61.2^{\mathrm{bA}}$ & $58.9^{\mathrm{dA}}$ & $64.0^{\mathrm{b}}$ & $65.8^{\mathrm{bA}}$ & $62.2^{\mathrm{bAB}}$ & $59.9^{\mathrm{cAB}}$ & $56.2^{\mathrm{cB}}$ & $61.0^{\mathrm{b}}$ \\
IPNS & $83.0^{\mathrm{aC}}$ & $91.3^{\mathrm{aAB}}$ & $96.5^{\mathrm{aAB}}$ & $106.4^{\mathrm{bcA}}$ & $94.3^{\mathrm{a}}$ & $69.9^{\mathrm{abC}}$ & $76.0^{\mathrm{aB}}$ & $79.3^{\mathrm{bAB}}$ & $86.2^{\mathrm{bA}}$ & $77.9^{\mathrm{a}}$ \\
IPNS+B & $82.3^{\mathrm{aC}}$ & $92.0^{\mathrm{aB}}$ & $98.2^{\mathrm{aB}}$ & $104.5^{\mathrm{abA}}$ & $94.3^{\mathrm{a}}$ & $67.5^{\mathrm{abC}}$ & $75.9^{\mathrm{aB}}$ & $79.9^{\mathrm{abB}}$ & $85.7^{\mathrm{abA}}$ & $77.3^{\mathrm{a}}$ \\
IPNS+C & $82.4^{\mathrm{aB}}$ & $92.6^{\mathrm{aA}}$ & $96.7^{\mathrm{aA}}$ & $101.4^{\mathrm{cA}}$ & $93.3^{\mathrm{a}}$ & $69.5^{\mathrm{abB}}$ & $76.8^{\mathrm{aA}}$ & $80.6^{\mathrm{abA}}$ & $84.0^{\mathrm{bA}}$ & $77.7^{\mathrm{a}}$ \\
OF & $87.3^{\mathrm{aC}}$ & $94.6^{\mathrm{aB}}$ & $99.4^{\mathrm{aB}}$ & $109.6^{\mathrm{aA}}$ & $97.7^{\mathrm{a}}$ & $72.0^{\mathrm{aC}}$ & $79.8^{\mathrm{aB}}$ & $84.7^{\mathrm{aB}}$ & $90.4^{\mathrm{aA}}$ & $81.7^{\mathrm{a}}$ \\
\hline
\end{tabular}

Values followed by different lower case letter(s) within a column are significant at $p<0.05$. Values followed by different capital letter(s) within a row are significant at $p<0.05$.

\subsubsection{Soil Available S Content}

After 20 RW cycles, the soil available S content increased considerably over the initial content (14.3 and $9.0 \mathrm{mg} \mathrm{kg}^{-1}$ ) at soil profile depths of 0-15 and 15-30 $\mathrm{cm}$ under the OF and IPNS options 
(Table 8). Compared with the initial S status, OF had a $114 \%$ and $89 \%$ higher available S content at the 0-15 and 15-30 cm profile depths during 2017-2018. The increases under IPNS, IPNS+B and IPNS+C were $76 \%$ and $70 \%, 59 \%$ and $57 \%$ and $62 \%$ and $67 \%$, respectively during the terminal years. On the other hand, RDF could not prevent a decline in S content, as depletions of $42 \%$ and $31 \%$ over the initial soil $S$ content were noticed at soil depths of 0-15 and 15-30 cm, respectively, during 2017-2018 (Table 8). A depletion of available $S$ over the initial S content was also noticed in the control, but the magnitude was smaller than that under the RDF plots.

Table 8. Effects of different nutrient management options on the soil available $S$ content $\left(\mathrm{mg} \mathrm{kg}^{-1}\right)$ at soil depths of $0-15$ and $15-30 \mathrm{~cm}$ after 5 RWS cycle intervals.

\begin{tabular}{ccccccccccc}
\hline \multirow{2}{*}{ Treatment } & 2002-2003 & 2007-2008 & 2012-2013 & 2017-2018 & Mean & 2002-2003 & 2007-2008 & 2012-2013 2017-2018 & Mean \\
\cline { 2 - 9 } & \multicolumn{9}{c}{ 0-15 cm Depth } \\
\hline Control & $11.0^{\mathrm{dA}}$ & $10.4^{\mathrm{eAB}}$ & $9.6^{\mathrm{dBC}}$ & $8.7^{\mathrm{dC}}$ & $9.9^{\mathrm{d}}$ & $8.1^{\mathrm{cA}}$ & $7.8^{\mathrm{dA}}$ & $7.9^{\mathrm{dA}}$ & $7.5^{\mathrm{dA}}$ & $7.8^{\mathrm{d}}$ \\
RDF & $10.9^{\mathrm{dA}}$ & $9.8^{\mathrm{eAB}}$ & $9.1^{\mathrm{dBC}}$ & $8.3^{\mathrm{dC}}$ & $9.5^{\mathrm{d}}$ & $7.7^{\mathrm{cA}}$ & $7.1^{\mathrm{dAB}}$ & $6.9^{\mathrm{dB}}$ & $6.3^{\mathrm{dB}}$ & $7.0^{\mathrm{d}}$ \\
IPNS & $16.0^{\mathrm{bD}}$ & $19.2^{\mathrm{bA}}$ & $22.9^{\mathrm{bB}}$ & $25.2^{\mathrm{bA}}$ & $20.8^{\mathrm{b}}$ & $10.3^{\mathrm{bD}}$ & $12.9^{\mathrm{abC}}$ & $14.0^{\mathrm{bB}}$ & $15.4^{\mathrm{bA}}$ & $13.2^{\mathrm{b}}$ \\
IPNS+B & $14.5^{\mathrm{cD}}$ & $16.4^{\mathrm{dA}}$ & $19.7^{\mathrm{cB}}$ & $22.7^{\mathrm{cA}}$ & $18.3^{\mathrm{c}}$ & $9.9^{\mathrm{bD}}$ & $11.6^{\mathrm{cC}}$ & $12.6^{\mathrm{cB}}$ & $14.3^{\mathrm{cA}}$ & $12.1^{\mathrm{c}}$ \\
IPNS+C & $15.1^{\mathrm{bcC}}$ & $17.8^{\mathrm{B}}$ & $22.0^{\mathrm{bA}}$ & $23.1^{\mathrm{cA}}$ & $19.5^{\mathrm{c}}$ & $10.4^{\mathrm{bD}}$ & $12.1^{\mathrm{bcC}}$ & $13.5^{\mathrm{bB}}$ & $14.6^{\mathrm{bcA}}$ & $12.7^{\mathrm{bc}}$ \\
OF & $18.2^{\mathrm{aD}}$ & $22.1^{\mathrm{aC}}$ & $28.3^{\mathrm{aB}}$ & $30.6^{\mathrm{aA}}$ & $24.8^{\mathrm{a}}$ & $11.5^{\mathrm{aD}}$ & $13.7^{\mathrm{aC}}$ & $15.0^{\mathrm{aB}}$ & $17.2^{\mathrm{aA}}$ & $14.4^{\mathrm{a}}$ \\
\hline
\end{tabular}

Values followed by different lower case letter(s) within a column are significant at $p<0.05$. Values followed by different capital letter(s) within a row are significant at $p<0.05$.

\subsubsection{Soil DTPA-Zn Content}

The DTPA-Zn content varied among the different nutrient management options, soil profile depths and years of experimentation (Table 9). Whereas DTPA-Zn increased significantly over the initial content $\left(0.54\right.$ and $0.46 \mathrm{mg} \mathrm{kg}^{-1}$ in the $0-15$ and $15-30$ soil depths, respectively, under RDF, IPNS, IPNS+C and IPNS+B, a continuous decline in DTPA-Zn was noticed under OF and control over the years at both profile depths. After $20 \mathrm{RW}$ cycles, an additional $\mathrm{Zn}$ accumulation of 0.30 to $0.39 \mathrm{mg}$ $\mathrm{kg}^{-1}$ at $0-15 \mathrm{~cm}$ and 0.14 to $0.18 \mathrm{mg} \mathrm{kg}^{-1}$ at the $15-30 \mathrm{~cm}$ soil profile depth was noticed over its initial status under RDF and in the different IPNS options. Conversely, declines of 0.18 and $0.12 \mathrm{mg} \mathrm{kg}^{-1}$ in DTPA-Zn were noticed under OF treatment at the 0-15 and 15-30 cm profile depths, respectively, during 2017-2018.

Table 9. Effects of different nutrient management options on soil DTPA extractable Zn content $\left(\mathrm{mg} \mathrm{kg}^{-1}\right)$ at soil depths of $0-15$ and $15-30 \mathrm{~cm}$ after 5 RWS cycle intervals.

\begin{tabular}{ccccccccccc}
\hline \multirow{2}{*}{ Treatment } & 2002-2003 & 2007-2008 & 2012-2013 & 2017-2018 & Mean & 2002-2003 & 2007-2008 & 2012-2013 2017-2018 & Mean \\
\cline { 2 - 9 } & \multicolumn{9}{c}{ 0-15 cm Depth } \\
\hline Control & $0.48^{\mathrm{bA}}$ & $0.43^{\mathrm{bAB}}$ & $0.40^{\mathrm{cBC}}$ & $0.37^{\mathrm{cC}}$ & $0.42^{\mathrm{b}}$ & $0.41^{\mathrm{bA}}$ & $0.39^{\mathrm{bA}}$ & $0.37^{\mathrm{cAB}}$ & $0.34^{\mathrm{bB}}$ & $0.38^{\mathrm{b}}$ \\
RDF & $0.67^{\mathrm{aB}}$ & $0.70^{\mathrm{aB}}$ & $0.83^{\mathrm{abA}}$ & $0.87^{\mathrm{bA}}$ & $0.77^{\mathrm{a}}$ & $0.51^{\mathrm{aB}}$ & $0.54^{\mathrm{aB}}$ & $0.60^{\mathrm{abA}}$ & $0.62^{\mathrm{aA}}$ & $0.57^{\mathrm{a}}$ \\
IPNS & $0.65^{\mathrm{aB}}$ & $0.70^{\mathrm{aB}}$ & $0.80^{\mathrm{bA}}$ & $0.84^{\mathrm{bA}}$ & $0.75^{\mathrm{a}}$ & $0.48^{\mathrm{aB}}$ & $0.51^{\mathrm{aB}}$ & $0.56^{\mathrm{bA}}$ & $0.60^{\mathrm{aA}}$ & $0.54^{\mathrm{a}}$ \\
IPNS+B & $0.67^{\mathrm{aD}}$ & $0.73^{\mathrm{aC}}$ & $0.87^{\mathrm{aB}}$ & $0.93^{\mathrm{aA}}$ & $0.80^{\mathrm{a}}$ & $0.49^{\mathrm{aB}}$ & $0.53^{\mathrm{aB}}$ & $0.58^{\mathrm{abA}}$ & $0.61^{\mathrm{aA}}$ & $0.55^{\mathrm{a}}$ \\
IPNS+C & $0.69^{\mathrm{aB}}$ & $0.72^{\mathrm{aB}}$ & $0.88^{\mathrm{aA}}$ & $0.88^{\mathrm{abA}}$ & $0.79^{\mathrm{a}}$ & $0.50^{\mathrm{aC}}$ & $0.55^{\mathrm{aB}}$ & $0.61^{\mathrm{aA}}$ & $0.64^{\mathrm{aA}}$ & $0.57^{\mathrm{a}}$ \\
OF & $0.51^{\mathrm{bA}}$ & $0.44^{\mathrm{bB}}$ & $0.40^{\mathrm{cBC}}$ & $0.36^{\mathrm{cC}}$ & $0.43^{\mathrm{bB}}$ & $0.43^{\mathrm{bA}}$ & $0.40^{\mathrm{bA}}$ & $0.35^{\mathrm{cB}}$ & $0.34^{\mathrm{bB}}$ & $0.38^{\mathrm{b}}$ \\
\hline
\end{tabular}

Values followed by different lower case letter(s) within a column are significant at $p<0.05$. Values followed by different capital letter(s) within a row are significant at $p<0.05$.

\subsection{Effect on Economics}

The average cost of cultivation in rice over the terminal three years was US\$644 ha ${ }^{-1}$ under OF, US\$481 ha ${ }^{-1}$ under RDF, US\$489 ha ${ }^{-1}$ under IPNS, US\$464 ha ${ }^{-1}$ under IPNS+B and US\$356 ha ${ }^{-1}$ under IPNS+C. The net returns from the rice produce (grain + straw) ranged between US\$361 ha ${ }^{-1}$ to US\$931 ha ${ }^{-1}$ and were lowest under OF and highest under IPNS.

The cost of wheat was US\$530 ha ${ }^{-1}$, US\$368 ha $\mathrm{ha}^{-1}$, US\$375 ha $\mathrm{ha}^{-1}$, US\$303 ha $\mathrm{ha}^{-1}$ and US\$351 $\mathrm{ha}^{-1}$, under the different treatments (Figure 6). The net returns for wheat were highest under IPNS (US\$1436 ha ${ }^{-1}$ ), closely followed by IPNS+C (US\$1414 ha ${ }^{-1}$ ) and IPNS+B (US\$1355 ha-1). Also, the net returns for wheat under OF (US\$850 ha ${ }^{-1}$ ) were greater than those under RDF (US\$763 ha ${ }^{-1}$ ) 
(Figure 6). Apparently, the net returns under OF were greater than those under rice. For the RWS, OF had the highest cost of cultivation (US\$1174 ha ${ }^{-1}$ ) followed by the IPNS options (US\$864) and RDF (US $\$ 849 \mathrm{ha}^{-1}$ ) and the cultivation costs were lowest under IPNS+C or B (US\$707 ha ${ }^{-1}$ to US\$767 ha ${ }^{-1}$ ). Considering RWS as whole, the economics favoured the integrated use of organics and fertilizers, as the net returns were higher under IPNS (US\$2367 ha ${ }^{-1}$ ) followed by IPNS+B (US\$2260 ha ${ }^{-1}$ ) and IPNS+C (US\$2233 ha ${ }^{-1}$ ). The continuous use of fertilizers (RDF) gave a net return of US\$1406 ha ${ }^{-1}$ which was significantly $(p<0.001)$ lower than the IPNS options. The net return for RWS under OF was

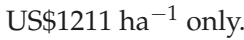

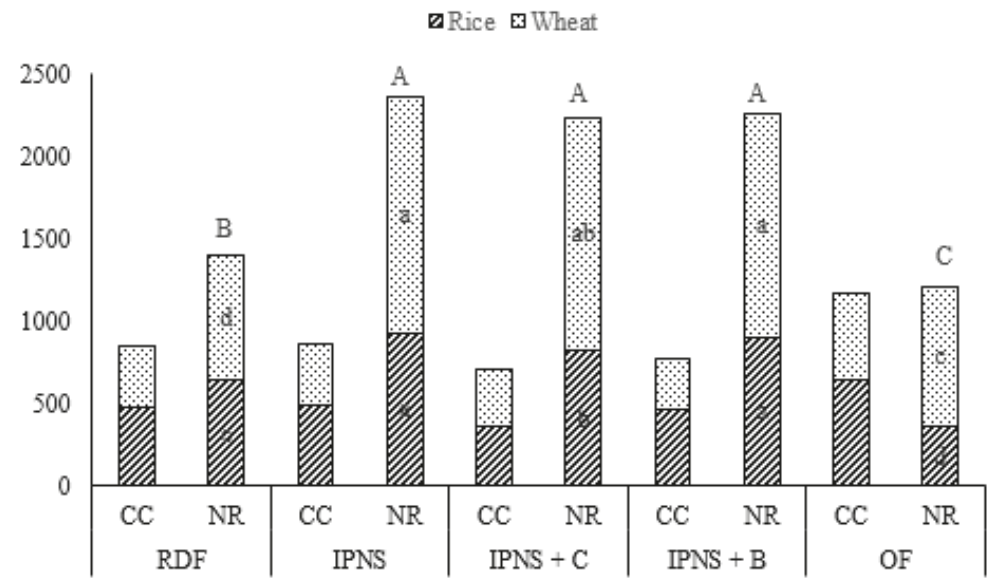

Figure 6. Economics (US\$ha ${ }^{-1}$ ) of different nutrient management practices in rice and wheat under long-term RWS. CC and NR denote the cost of cultivation and the net returns, respectively. Values followed by different lower case letter(s) within rice or wheat for the net returns are statistically significant $(p<0.05)$. Values followed by different capital letter(s) within RWS for net return are statistically significant $(p<0.05)$.

\section{Discussion}

\subsection{RWS Productivity}

In the present investigation, yields of both rice and wheat declined over the years under the RDF plots that received $120 \mathrm{~kg} \mathrm{~N}, 26 \mathrm{~kg} \mathrm{P}$ and $33 \mathrm{~kg} \mathrm{~K}$ to each crop along with $5 \mathrm{~kg} \mathrm{Zn} \mathrm{ha}^{-1}$ to rice. On the other hand, the literature suggests that the soils in the RWS growing area of the IGP are inherently low in organic matter, and suffer from widespread multi-nutrient deficiencies including $N, P, K, S$, Zn and B [7,17,38,39]. Sustainable high productivity of RWS on these soils is obviously possible with adequate supply of these limiting nutrients through fertilizers and organics. In the present case, the RDF plot exhibited marginal changes in SOC (Table 5), and a decline in mineral N, exchangeable $\mathrm{K}$ and available $\mathrm{S}$ in the effective root zone (0-45 $\mathrm{cm}$ depth) compared with their initial contents at different time intervals (Figures 4 and 5, Tables 7 and 8), thus suggesting a depletion in the native nutrient supply due to continuous RW cropping. Further, changes in soil physico-chemical properties due to continuous flooding and drying under a puddled transplanted rice-conventional till wheat system [40,41] also had adverse effects on the soil nutrient supply [42]. The relatively greater yield reduction in wheat as compared with rice under RDF (Table 3) could, therefore, be explained in two ways: (i) the post-rice drying of soil promoted fixation of $\mathrm{P}$ and decreased its availability to subsequent wheat crops; and (ii) the restricted root growth of wheat $[7,24,27]$ caused by increased soil Db (Figure 3) after puddled rice hindered nutrient access in the root zone $[7,41]$. On the other hand, the superiority 
of IPNS involving the concurrent use of FYM and fertilizers (75\% RDF) vis-à-vis RDF is ascribed to improvements in soil physico-chemical properties due to the organic input and addition of significant quantities of P, K, S and other micro-nutrients through FYM. The manure (FYM) applied to substitute $25 \%$ of the recommended $\mathrm{N}$ in rice contributed greater amounts of $\mathrm{P}$ and $\mathrm{K}$ than those curtailed due to the $25 \%$ reduction of RDF in the IPNS treatments, as well as supplying an additional $6.7 \mathrm{~kg} \mathrm{~S} \mathrm{ha}^{-1}$ annually. Also, the continuous and slow release of nutrients from manure would have enabled their efficient utilization by the crops [22,43].

Among the different IPNS options, the maximum yield gain recorded with the inclusion of legumes as a break crop may be ascribed to a reduction in sub-soil compaction as indicated by the lower $\mathrm{Db}$ values beyond the $30 \mathrm{~cm}$ soil depth (Figure 3) which improved the root proliferation of both rice and wheat $[24,27,44]$, thus facilitating nutrient absorption from lower soil profiles. The lower $\mathrm{NO}_{3}-\mathrm{N}$ concentration below the $30 \mathrm{~cm}$ soil depth and its relatively higher content in the surface soil $(0-15 \mathrm{~cm})$ under legume inclusion plots supports this contention. The sustainable high yield under the IPNS+B or IPNS+C treatments may also be associated with a reduction in prominent weeds like Echinochloa sp. in rice and Phalaris minor in wheat under the legume-included plots (data not presented).

The significantly lower yields of rice and wheat under OF plots compared with under RDF and IPNS may be visualized in two possible ways: (i) the FYM equivalent to $120 \mathrm{~kg} \mathrm{~N} \mathrm{ha}^{-1}$ applied at the time of sowing/transplanting was unable to supply the nutrients (especially, N) in adequate quantities up to the reproductive stages of crop (data not reported) causing yield reduction; and (ii) the micronutrient content of soil, especially soil Zn, declined over the period (Table 9) as FYM alone could not ensure a sufficient Zn supply. Widespread Zn deficiency is one of major soil fertility constraints in RW growing areas of the IGP [17], and its inclusion in the fertilization schedule is essential to achieve a sustainable high yield. The study, therefore, underlines that the OF nutrient management protocols that ensure adequate supplies of macro- and micro-nutrients (especially $\mathrm{Zn}$ ) throughout the cropping seasons can hardly sustain high yields of RWS in the IGP [19].

The annual change in the yield of rice under RDF was meagre, whereas the yield of wheat declined significantly over the years. Such yield trends may be ascribed to the high yield level $\left(4.62 \mathrm{t} \mathrm{ha}^{-1}\right)$ in the initial years. An analysis of long-term experiments conducted in the IGP suggested earlier that the magnitude of yield decline in rice-based systems is negatively related to the level of initial yield $[45,46]$. In the present investigation, the decline in crop productivity under RDF may also explained in terms of greater $\mathrm{NO}_{3}-\mathrm{N}$ leaching beyond the root zone (beyond a soil depth of $45 \mathrm{~cm}$ ) (Figure 4), and depletion of soil exchangeable $\mathrm{K}$ and available $\mathrm{S}$ contents (Tables 7 and 8 ). These results are corroborated by earlier reports of other long-term experiments wherein the emergence of multi-nutrient deficiencies [11] led to a yield decline over the passage of time, and the supply of different nutrients in adequate amounts helped to attain yield stability [16,47].

Conversely, initial rice and wheat yield levels under OF plots were lower (2.9 and $2.33 \mathrm{t} \mathrm{ha}^{-1}$ respectively) than those under RDF but showed a significant $(p<0.001)$ positive annual yield increase $\left(9.2 \%\right.$ annum $\left.^{-1}\right)$ (Table 4$)$. Further, the significantly $(p<0.05)$ higher annual yield increases in both rice and wheat under IPNS and IPNS+B or IPNS+C, even over their initial high yields, is ascribed to the balanced and continuous nutrient supply owing to the improved soil structure (lower Db, Figure 3), SOC and other soil fertility parameters (Tables 5-9 and Figures 2-4). Thus, our study indicates that integrated use of organics and fertilizers can sustain higher productivity of RWS in the IGP [19].

\subsection{Soil Health}

\subsubsection{Bulk Density and Organic Carbon}

Continuous RWS under RDF showed an increase in the Db value at soil depths of $30-45 \mathrm{~cm}$ (Figure 3). The sub-surface compaction below the puddled zone owing to aggregate disruption [48] is one of the important constraints for sustainable RWS productivity in the IGP [1]. The migration of clay towards a lower profile consequent to puddling increases soil strength rapidly upon drying [41], 
which restricts the root growth of the subsequent crop $[7,24,27]$. On the other hand, a decrease in $\mathrm{Db}$, particularly in the sub-soil ( $30-45 \mathrm{~cm}$ depth) under the IPNS+B or IPNS $+C$ plots, consequent to the inclusion of tap rooted legumes and subsequent decomposition of roots increased SOC and helped to improve soil porosity $[17,27,49]$, in turn, facilitating root proliferation. The reduction in $\mathrm{Db}$ under IPNS was due to the fibrous nature of added organic matter, which prevents closer packing of soil separates [50]. Also, the use of organic matter input results in better soil aeration and improved soil aggregation, which leads to decreased soil $\mathrm{Db}$ [51]. In fact, changes in organic matter not only have a direct bearing on soil $\mathrm{Db}$ due to its lower particle density vis-à-vis mineral soil, they also increase soil aggregation and permanent pore development due to the increased soil biological activity [51,52].

The soil organic carbon concentration in the surface layer $(0-15 \mathrm{~cm})$ increased significantly under the IPNS options and OF plots (Table 5). In fact, the SOC at any given location largely depends on the annual turnover of organics, root + shoot stubbles and root exudates, and their recycling $[17,21,27]$. Thus, the use of organics in the IPNS treatments including those with legumes brought further improvement in SOC over sole fertilizers. The relatively higher increase in SOC under OF may be attributed to greater recycling of organic matter compared to under the other nutrient management options. The maintenance of SOC at its initial status may be corroborated with the findings of soil fertility delineation studies in similar agro-ecologies of the IGP (Singh et al., 2015) wherein SOC under balanced fertilization either remained unaffected or even increased depending upon the initial SOC content. The higher SOC in sub-soil under the IPNS treatments involving legumes (cowpea/berseem) is apparently due to the recycling of legume roots in the deeper soil layer, which has created a further conducive environment for the root growth of rice and wheat over the years $[24,53]$.

\subsubsection{Soil N, P and K Contents}

The $\mathrm{NO}_{3}-\mathrm{N}$ content in the upper soil (0-15 cm depth) increased sizeably under the OF and IPNS treatments. The favourable effects of organic manures and legume inclusion on soil $\mathrm{N}$ supply have already been documented [14,25], underlining the slow release of nutrients bound in aggregates $[43,54]$ and the addition of $\mathrm{N}$ through BNF [55].On the other hand, control (unfertilized) and RDF plots underwent a depletion of $\mathrm{NO}_{3}-\mathrm{N}$ by $3.25 \mathrm{mg} \mathrm{kg}^{-1}$ and $1.96 \mathrm{mg} \mathrm{kg}^{-1}$, respectively, over the initial status, which suggests excessive nutrient mining due to an inadequate supply of nutrients under high yielding RWS $[15,56]$. The relatively lower $\mathrm{NO}_{3}-\mathrm{N}$ content in the deeper soil profile under IPNS $+\mathrm{C}$ or IPNS+B compared with RDF or IPNS was obviously due to greater root proliferation in the deeper soil profile $[15,57]$ leading ultimately to greater $\mathrm{NO}_{3}-\mathrm{N}$ uptake by rice and wheat from the deeper layers under treatments involving legumes $[24,27,44]$. In view of the lower $\mathrm{NO}_{3}-\mathrm{N}$ content further down the soil profile, the inclusion of legumes as a break crop at certain interval in RWS could be considered a potential option to overcome the groundwater pollution through curbing $\mathrm{NO}_{3}-\mathrm{N}$ leaching in the RWS dominated areas of the IGP [58].

In the present study, the build-up of P highest under RDF (Table 6) was very much expected under regular $\mathrm{P}$ addition through fertilizer as cereal crops utilize only a fraction of the applied P [13]. The relatively greater Olsen-P content in soil under OF and IPNS compared with control (unfertilized) may be ascribed to the fact that FYM and legume litter/stubbles supply sizeable amounts of $\mathrm{P}$ to the soil. A reduction in the fixation/sorption of applied $\mathrm{P}$ in the soil consequent to the enhanced competition of organic molecules with $\mathrm{PO}_{4}{ }^{3-}$ ions for P retention sites [59] under OF/IPNS could be another explanation for these findings. Further, an increased SOC from $5.1 \mathrm{~g} \mathrm{~kg}^{-1}$ to $6.9 \mathrm{~g} \mathrm{~kg}^{-1}$ under OF increased the negative charges that contributed to decreased P sorption by the repulsion of forces between orthophosphate ions and the negatively-charged surface [60]. On the contrary, the Olsen-P content of surface soil $(0-15 \mathrm{~cm})$ under the control declined from the initial content by $17 \%$ at the end of the 2017-2018 RW cycle. This decline in P content is associated with the lack of addition of P despite continuous removal by rice and wheat crops (data not reported) and a gradual decline in SOC under the control (Table 5). Further, the depletion of soil P content in the soil sub-surface and the relatively 
lower P content in the surface layer observed with legume inclusion as a break crop is explained by the fact that legumes have higher P demands and better P utilization efficiency $[17,57]$.

The depletion of exchangeable $\mathrm{K}$ under RDF despite the regular addition of $\mathrm{K}$ through fertilizers can be explained in light of the higher $\mathrm{K}$ demands of the constituent crops of RWS. Being exhaustive $\mathrm{K}$ feeders, these crops may require $20.5-22.0 \mathrm{~kg} \mathrm{~K} \mathrm{t}^{-1}$ of grain production (24). At high productivity levels, the net balance of $K$ in the soil generally remains negative, even with the application of the recommended $\mathrm{K}$ content $[14,61,62]$. Besides, leaching loss of $\mathrm{K}$ with percolating water is one of the most significant methods of $\mathrm{K}$ removal from the rhizosphere, especially under irrigated ecology. The higher K fixing capacity of the illite-dominant soil minerology of IGP is also one of the major reasons for the depletion of exchangeable $\mathrm{K}$ in soil $[12,63]$. On the other hand, the higher exchangeable $\mathrm{K}$ content under OF or IPNS may be ascribed to the release of organic acids during the decomposition which generates negative electric charges in the soil with a preference for di-or-tri-valent cations, such as $\mathrm{Al}^{3+}, \mathrm{Ca}^{2+}$ and $\mathrm{Mg}^{2+}$, leaving $\mathrm{K}^{+}$to be adsorbed by the negatively-charged soil colloids [64]. This phenomenon might have helped to reduce the $\mathrm{K}$ fixation and enhance its availability in soil.

\subsubsection{Secondary and Micro-Nutrients}

The greater S availability under the OF and IPNS options was associated with the greater S addition through FYM in these plots. Since the organic $S$ fraction in the soil is positively related to the organic matter status [65] and is generally considered an important pool of available S [17], lesser deficiencies are expected in soils containing high SOC (Table 5) or those receiving organic manure regularly. On the other hand, the depletion of available $S$ under RDF plots may be explained as (i) the RDF treatments did not include $S$ application, (ii) there was substantial $S$ removal by the crops grown under RDF owing to higher yield levels (data not reported), or (iii) there was reduced $\mathrm{SO}_{4}{ }^{2-}$ retention due to higher available $\mathrm{P}$ under the RDF plots (Table 6) [17,56]. Since $\mathrm{H}_{2} \mathrm{PO}_{4}{ }^{-}$is a strong competitor of $\mathrm{SO}_{4}{ }^{2-}$ for anion exchange sites, its high availability in the exchange complex can cause concurrent desorption of $\mathrm{SO}_{4}{ }^{2-}$ from colloidal surfaces and subsequent leaching with irrigation and rain water $[66,67]$. The smaller depletion of available $S$ in the control (unfertilized) over the initial $S$ content compared to that in the RDF plots might be due to the smaller $S$ uptake by crops grown under the control.

A gradual accumulation of DTPA-Zn in soil was noticed under RDF and IPNS, whereas a declining trend was noticed under OF. It is pertinent to mention that $5 \mathrm{~kg} \mathrm{Zn} \mathrm{ha}^{-1}$ was applied annually to RDF as well as in the different IPNS options (IPNS, IPNS+B and IPNS+C). The increase in DTPA-Zn reflected the application of zinc in excess of its removal in harvested grain and straw [39]. On the other hand, the addition of $\mathrm{Zn}$ in meagre quantities through FYM under OF led to the mining of soil native $\mathrm{Zn}$, resulting in a lower soil $\mathrm{Zn}$ content.

\subsection{Economics of RWS}

The cost of cultivation (CC) for rice, wheat and RWS was maximum under the OF treatments. The higher CC (US\$310 to 467) under OF compared with that under the RDF and IPNS options was attributed to the greater cost of FYM and the excess expenditure on hand-weeding. On the other hand, the lower CC of RWS under the IPNS + legume treatments (US\$707 and 767) vis-à-vis RDF or IPNS may be ascribed to the lower investment on fertilizer nutrients, irrigation, weed/pest management and laborers under legume fodder grown at every third cycle in place of rice or wheat. Further, the higher economic net returns of RWS under different IPNS options over the RDF and OF treatments was mainly due to improved yields (grain + straw) over time. Although the cost of cultivation under the IPNS+B or IPNS $+C$ treatments was lower than that of the IPNS, the net returns under these treatments remained on par, as the cost of legume fodder produced was much smaller (US $\$ 14.3 \mathrm{t}^{-1}$ of fodder) than the cost of grain + straw of rice and wheat. The low returns under OF may be associated with higher CC involved in rice and wheat, and the relatively lower annual productivity as compared with 
the RDF or IPNS treatments. The economics of RWS thus favour the adoption of IPNS with or without inclusion of legumes.

\section{Conclusions}

The foregoing results of the present long-term study underline the fact that the sustainable high productivity of RWS in the intensively-cropped IGP cannot be achieved through a single nutrient source, be it fertilizer or organic manure. Conjoint use of both, on the other hand, proved superior in terms of crop productivity, soil health and economic returns. The inclusion of forage legumes as a break crop in the RWS had an added advantage vis-à-vis IPNS alone, as was evident from the improvement in yield and different soil parameters. In view of scarcity of conventional manure (FYM), there is a need to conduct well planned studies involving other locally available organics to develop rational IPNS prescriptions for large-scale adoption. Also, the environmental impacts of continuous use of organic inputs in sizeable amounts under OF need to be studied in a holistic manner.

Author Contributions: In this study, Drs. Vinod K. Singh, Brahma S. Dwivedi, Arvind K Shukla and Rajendra P. Mishra were involve in research conceptualization, data curation, field investigation, project administration and writing original draft for publication. Dr Azad. S. Panwar helped in funding acquisition and general project administration. Drs. Pravin K. Upadhyay, Kapila Shekhawat, Kaushik Majumdar and Jagadish Timsina supported for evolving methodology, formal data analysis, writing and editing of draft at different stages.

funding: Authors are thankful to Indian Council of Agricultural Research for needful funding support to conduct the study.

Acknowledgments: The authors thank the directors of ICAR—Indian Institute of Farming Systems Research, Modipuram for providing the necessary facilities for field experimentation and laboratory analyses.

Conflicts of Interest: The authors declare no conflict of interest.

\section{References}

1. Chauhan, B.S.; Mahajan, G.; Sardana, V.; Timsina, J.; Jat, M.L. Productivity and Sustainability of the Rice-Wheat Cropping System in the Indo-Gangetic Plains of the Indian subcontinent: Problems, Opportunities, and Strategies. Adv. Agron. 2012, 117, 316-369.

2. Ladha, J.K.; Pathak, H.; Padre, A.T.; Dawe, D.; Gupta, R.K. Productivity trends in intensive rice-wheat cropping systems in Asia. In Improving the Productivity and Sustainability of Rice-Wheat Systems: Issues and Impacts; Ladha, J.K., Hill, J., Gupta, R.K., Duxbury, J., Buresh, R.J., Eds.; ASA Special Publication 65; ASA-CSSA-SSSA: Madison, WI, USA, 2003; pp. 45-76.

3. Verma, B.C.; Datta, S.P.; Rattan, R.K.; Singh, A.K. Long-Term Effect of Tillage, Water and Nutrient Management Practices on Mineral Nitrogen, Available Phosphorus and Sulphur Content under Rice-Wheat Cropping System. J. Indian Soc. Soil Sci. 2016, 64, 71-77. [CrossRef]

4. FAOSTAT; Food and Agriculture Organization of the United Nations: Rome, Italy, 2017.

5. Yadvinder-Singh; Gupta, R.K.; Gurpreet-Singh; Jagmohan-Singh; Sidhu, H.S.; Bijay-Singh. Nitrogen and residue management effects on agronomic productivity and nitrogen use efficiency in rice-wheat system in Indian Punjab. Nutr. Cycl. Agroecosyst. 2009, 84, 141-154. [CrossRef]

6. Das, D.; Dwivedi, B.S.; Singh, V.K.; Datta, S.P.; Meena, M.C.; Chakraborty, D.; Bandyopadhyay, K.K.; Kumar, R.; Mishra, R.P. Long-term effects of fertilizers and organic sources on soil organic carbon fractions under a rice-wheat system in the Indo-Gangetic Plains of north-west India. Soil Res. 2017, 55, 296-308. [CrossRef]

7. Timsina, J.; Connor, D.J. Productivity and management of rice-wheat cropping systems: Issues and challenges. Field Crops Res. 2001, 69, 93-132. [CrossRef]

8. Bhatt, R.; Kukal, S.S.; Busari, M.A.; Arora, S.; Yadav, M. Sustainability issues on rice-wheat cropping system. International Soil and Water Conservation Research. Int. Soil Water Conserv. Res. 2016, 4, 64-74. [CrossRef]

9. Ladha, J.K.; Yadvinder-Singh; Erenstein, O.; Hardy, B. Integrated Crop and Resource Management in the Rice? Wheat System of South Asia; International Rice Research Institute: Los Banos, Philippines, 2009. 
10. Majumder, B.; Mandal, B.; Bandyopadhyay, P.K. Soil organic carbon pools and productivity in relation to nutrient management in a 20-year old rice-berseem agroecosystem. Biol. Fertil. Soils 2008, 44, 451-464. [CrossRef]

11. Singh, M.; Reddy, K.S.; Singh, V.P.; Rupa, T.R. phosphorus availability to rice (Oryza sativa L.)-wheat (Triticum aestivum L.) in a vertical soil after eight years of inorganic and organic fertilizer addition. Bioresource. Technol. 2007, 98, 1474-1481. [CrossRef]

12. Panaullah, G.M.; Timsina, J.; Saleque, M.A.; Ishaque, M.; Pathan, A.B.M.B.U.; Connor, D.J.; Saha, P.K.; Quayyum, M.A.; Humphreys, E.; Meisner, C.A. Nutrient Uptake and Apparent Balances for Rice-Wheat Sequences. III. Potassium. J. Plant Nutr. 2006, 29, 173-187. [CrossRef]

13. Saleque, M.A.; Timsina, J.; Panaullah, G.M.; Ishaque, M.; Pathan, A.B.M.B.U.; Connor, D.J.; Saha, P.K.; Quayyum, M.A.; Humphreys, E.; Meisner, C.A. Nutrient Uptake and Apparent Balances for Rice-Wheat Sequences. II. Phosphorus. J. Plant Nutr. 2006, 29, 157-172. [CrossRef]

14. Singh, V.K.; Sharma, B.B.; Dwivedi, B.S. The impact of diversification of a rice-wheat cropping system on crop productivity and soil fertility. J. Agric. Sci. 2002, 139, 405-412. [CrossRef]

15. Timsina, J.; Panaullah, G.M.; Saleque, M.A.; Ishaque, M.; Pathan, A.B.M.B.U.; Quayyum, M.A.; Connor, D.J.; Saha, P.K.; Humphreys, E.; Meisner, C.A. Nutrient Uptake and Apparent Balances for Rice-Wheat Sequences. J. Plant Nutr. 2006, 29, 137-155. [CrossRef]

16. Dwivedi, B.S.; Singh, V.K.; Dwivedi, V. Application of phosphate rock, with or without Aspergillus awamori inoculation, to meet P demands of rice-wheat systems in the Indo-Gangetic plains of India. Aust. J. Exp. Agric. 2014, 44, 1041-1050. [CrossRef]

17. Singh, V.K.; Dwivedi, B.S.; Shukla, A.K.; Kumar, V.; Gangwar, B.; Rani, M.; Singh, S.K.; Mishra, R.P. Status of available sulphur in soils of north-west Indo-Gangetic Plain and Western Himalayan Region and response of rice and wheat to applied sulphur in farmers' fields. Agric. Res. 2015, 4, 76-92. [CrossRef]

18. Bijay-Singh. Are Nitrogen Fertilizers Deleterious to Soil Health? Agron. J. 2018, 8, 48. [CrossRef]

19. Timsina, J. Review Can Organic Sources of Nutrients Increase Crop Yields to Meet Global Food Demand? Agron. J. 2018, 8, 214. [CrossRef]

20. Bandyopadhyay, K.K.; Misra, A.K.; Ghosh, P.K.; Hati, K.M. Effect of integrated use of farmyard manure and chemical fertilizers on soil physical properties and productivity of soybean. Soil Tillage Res. 2010, 110, 115-125. [CrossRef]

21. Numbiar, K.K.M. Soil Fertility and Crop Production under Long-Term Fertilizer Use in India; ICAR: New Delhi, India, 1994.

22. Dwivedi, B.S.; Singh, V.K.; Meena, M.C.; Dey, A.; Datta, S.P. Integrated nutrient management for enhanced nutrient use efficiency. Indian J. Fertil. 2016, 12, 62-71.

23. Singh, V.K.; Dwivedi, B.S.; Tiwari, K.N.; Majumdar, K.; Rani, M.; Singh, S.K.; Timsina, J. Optimizing nutrient management strategies for rice-wheat system in the Indo-Gangetic Plains and adjacent region for higher productivity, nutrient use efficiency and profits. Field Crops Res. 2014, 164, 30-44. [CrossRef]

24. Dwivedi, B.S.; Shukla, A.K.; Singh, V.K.; Yadav, R.L. Improving nitrogen and phosphorus use efficiencies through inclusion of forage cowpea in the rice-wheat system in the Indo-Gangetic plains of India. Field Crops Res. 2003, 84, 399-418. [CrossRef]

25. Yadav, S.K.; Babu, S.; Yadav, M.K.; Singh, K.; Yadav, G.S.; Suresh, P. A Review of Organic Farming for Sustainable Agriculture in Northern India. Int. J. Agron. 2003, 2013, 718145. [CrossRef]

26. Wani, S.P.; Rego, T.J.; Rajeswari, S.; Lee, K.K. Effect of legume-based cropping systems on nitrogen mineralization potential of Vertisol. Plant Soil. 1995, 175, 265-274. [CrossRef]

27. Singh, V.K.; Dwivedi, B.S.; Shukla, A.K.; Chauhan, Y.S.; Yadav, R.L. Diversification of rice with pigeonpea in a rice-wheat cropping system on a Typic Ustochrept: Effect on soil fertility, yield and nutrient use efficiency. Field Crops Res. 2005, 92, 85-105. [CrossRef]

28. Bremner, J.M.; Keeney, D.R. Steam distillation methods for determination of ammonium, nitrate and nitrite. Anal. Chem. Acta 1965, 32, 485-495. [CrossRef]

29. Walkley, A.; Black, C.A. An examination of the Degitjareff method for determining soil organic matter, and a proposed modification of the chromic acid titration method. Soil Sci. 1934, 37, 29-38. [CrossRef]

30. Olsen, S.R.; Cole, C.V.; Watanabe, F.S.; Dean, L.A. Estimation of Available Phosphorus in Soils by Extraction with Sodium Bicarbonate; United States Department of Agriculture: Washington, DC, USA, 1954. 
31. Washington, D.C.; Helmke, P.A.; Sparks, D.L. Lithium, sodium, potassium, rubidium, and cesium. In Methods of Soil Analysis. Part 3; Sparks, D.L., Ed.; Chemical Methods-Soil Science Society of America Book Series No. 5; SSSA and ASA: Madison, WI, USA, 1996; pp. 551-574.

32. Williams, C.H.; Steinbergs, H. Soil sulphur fractions as chemical indices of available sulphur in some Australian soils. Aust. J. Agric. Res. 1995, 10, 340-352. [CrossRef]

33. Lindsay, W.L.; Norvell, WA. Development of a DTPA Soil Test for Zinc, Iron, Manganese, and Copper. Soil Sci. Soc. Am. J. 1978, 42, 421-428. [CrossRef]

34. Subbiah, B.V.; Asija, G.L. A rapid procedure for the determination of available nitrogen in soils. Curr. Sci. 1956, 25, 259-260.

35. Page, A.L.; Millar, R.H.; Keeney, D.R. (Eds.) Methods of Soil Analysis. Part-2; American Society of Agronomy and Soil Science Society of America: Madison, WI, USA, 1982.

36. Blake, G.R.; Hartge, K.H. Bulk density. In Methods of Soil Analysis, Part 1; Klute, A., Ed.; Physical and Mineralogical Properties, Monograph 9; ASA: Madison, WI, USA, 1986; pp. 363-376.

37. Cochran, W.G.; Cox, G.M. Experimental Designs; Wiley: New York, NY, USA, 1957.

38. Dwivedi, B.S.; Singh, V.K.; Shekhawat, K.; Meena, M.C.; Dey, A. Enhancing Use Efficiency of Phosphorus and Potassium under Different Cropping Systems of India. Indian J. Fertil. 2017, 13, 20-41.

39. Cassman, K.G.; Peng, S.; Olk, D.C.; Ladha, J.K.; Reichardt, W.; Dobermann, A.; Singh, U. Opportunities for increasing nitrogen use effciency from improved resource management in irrigated rice systems. Field Crops Res. 1998, 56, 7-39. [CrossRef]

40. Dwivedi, B.S.; Singh, V.K.; Shukla Arvind, K.; Meena, M.C. Optimizing dry and wet tillage for rice on a Gangetic alluvial soil: Effect on soil characteristics: Water use efficiency and productivity of the rice-wheat system. Eur. J. Agron. 2012, 43, 155-165. [CrossRef]

41. Cassman, K.G.; Pingali, P.L. Extrapolating trends from long-term experiments on farmers' felds: The case study of irrigated rice-systems in Asia. In Agricultural Sustainability: Economic, Environmental and Statistical Considerations; Barnet, V., Payre, R., Steiner, R., Eds.; Wiley: Chichester, UK, 1995; pp. 63-84.

42. Mahajan, A.; Gupta, R.D. Integrated Nutrient Management (INM) in a Sustainable Rice-Wheat System; Springer: Dordrecht, The Netherlands, 2017.

43. Singh, V.K.; Dwivedi, B.S.; Shukla, A.K. Yields, and nitrogen and phosphorus use efficiency as influenced by fertilizer NP additions in wheat (Triticum aestivum) under rice (Oryza sativa)-wheat and pigeonpea (Cajanus cajan)-wheat system on a Typic Ustochrept soil. Indian J. Agric. Sci. 2000, 76, 92-97.

44. Dawe, D.; Dobermann, A.; Moya, P.; Abdulrachman, S.; Singh, B.; Lal, P.; Li, S.Y.; Lin, B.; Panaullah, G.; Sariam, O.; et al. How widespread are yield declines in long-term rice experiments in Asia? Field Crops Res. 2000, 66, 175-193. [CrossRef]

45. Yadav, R.L.; Dwivedi, B.S.; Pandey, P.S. Rice-wheat cropping system: Assessment of sustainability under green manuring and chemical fertilizer input. Field Crops Res. 2000, 65, 15-30. [CrossRef]

46. Swarup, A.; Wanjari, R.H. Three Decades of All India Coordinated Research Project on Long-Term Fertilizer Experiments to Study Changes in Soil Quality, Crop Productivity and Sustainability; IISS: Bhopal, India, 2000.

47. Six, J.; Elliott, E.T.; Paustian, K. Soil macroaggregate turnover and microaggregate formation: A mechanism for C sequestration under no-tillage agriculture. Soil Biol. Biochem. 2000, 32, 2099-2103. [CrossRef]

48. Sharma, P.K.; Ladha, J.K.; Bhushan, L. Soil physical effects of puddling in rice-wheat cropping system. In Improving the Productivity and Sustainability of Rice-Wheat Systems: Issues and Impacts; Ladha, J.K., Hill, J., Gupta, R.K., Duxbury, J., Buresh, R.J., Eds.; ASA Special Publication 65; ASA, CSSA and SSSA: Madison, WI, USA, 2003; pp. 97-114.

49. Adams, W.A. The effect of organic matter on the bulk and true densities of some uncultivated podzolic soils. Eur. J. Soil Sci. 2006, 24, 10-17. [CrossRef]

50. Halvorson, A.D.; Reule, C.A.; Follet, R. Nitrogen Fertilization Effects on Soil Carbon and Nitrogen in a dryland cropping system. Soil Sci. Soc. Am. J. 1999, 63, 912-917. [CrossRef]

51. Franzluebbers, A.J.; Stuedemann, J.A.; Schomberg, H.H.; Wilkinson, S.R. Soil organic C and N pools under long-term pasture management in the Southern Piedmont USA. Soil Biol. Biochem. 2000, 32, 469-478. [CrossRef]

52. Oussible, M.; Crookston, R.K.; Larson, W.E. Subsurface Compaction Reduces the Root and Shoot Growth and Grain Yield of Wheat. Agron. J. 1992, 84, 34-38. [CrossRef] 
53. Das, B.; Chakraborty, D.; Singh, V.K.; Aggarwal, P.; Singh, R.; Dwivedi, B.S. Effect of organic inputs on strength and stability of soil aggregates under rice-wheat rotation. Int. Agrophys. 2014, 8, 163-168. [CrossRef]

54. Awonaike, K.O.; Kumarsinghe, K.S.; Danso, S.K.A. Nitrogen fixation and yield of cowpea as influenced by cultivar and Bradyrhizobium strain. Field Crop Res. 1990, 24, 163-171. [CrossRef]

55. Dwivedi, B.S.; Shukla, A.K.; Singh, V.K.; Yadav, R.L. Response of wheat (Triticum aestivum), potato (Solanum tuberosum) and mustard (Brassica juncea) to potassium applied through muriate of potash of varying particle size. Indian J. Agric. Sci. 2001, 71, 634-638.

56. Dwivedi, B.S.; Shukla, A.K.; Singh, V.K.; Yadav, R.L. Results of participatory diagnosis of constraints and opportunities (PDCO) based trials from the state of Uttar Pradesh. In Development of Farmers' Resource-Based Integrated Plant Nutrient Supply Systems: Experience of a FAO-ICAR-IFFCO Collaborative Project and AICRP on Soil Test Crop Response Correlation; Subba Rao, A., Srivastava, S., Eds.; IISS: Bhopal, India, 2001; pp. 50-75.

57. Singh, V.K.; Dwivedi, B.S.; Shukla, A.K.; Mishra, R.P. Permanent raised bed planting of the pigeonpea-wheat system on a Typic Ustochrept: Effects on soil fertility, yield, and water and nutrient use efficiencies. Field Crops Res. 2010, 116, 127-139. [CrossRef]

58. Aulakh, M.S.; Singh, B. Nitrogen losses and fertilizer N use efficiency in irrigated porous soils. Nutr. Cycl. Agroecosyst. 1997, 147, 197-212. [CrossRef]

59. Xie, R.J.; Fyles, J.W.; Mckenzie, A.F.; O'Hollaran, I.P. Ligno-sulphate retention in a clay soil: Casual modeling. Soil Sci. Soc. Am. J. 1991, 55, 711-716. [CrossRef]

60. Moshi, A.O.; Wild, A.M.; Greenland, D.J. Effect of organic matter on the charge and phosphate adsorption characteristics of Kikuyu red clay from Kenya. Geoderma 1974, 11, 275-285. [CrossRef]

61. Nayak, A.K.; Gangwar, B.; Shukla, A.K.; Mazumdar, S.P.; Kumar, A.; Raja, R.; Kumar, A.; Kumar, V.; Rai, P.K.; Mohan, U. Long-term effect of different integrated nutrient management on soil organic carbon and its fractions and sustainability of rice-wheat system in Indo Gangetic Plains of India. Field Crop Res. 2012, 127, 129-139. [CrossRef]

62. Singh, V.K.; Dwivedi, B.S.; Yadvinder-Singh; Singh, S.K.; Mishra, R.P.; Shukla, A.K.; Rathore, S.; Shekhawat, K.; Majumdar, K.; Jat, M.L. Effect of tillage and crop establishment, residue management and $\mathrm{K}$ fertilization on yield, $\mathrm{K}$ use efficiency and apparent $\mathrm{K}$ balance under ricemaize system in north-western India. Field Crop Res. 2018, 224, 1-12.

63. Tandon, H.L.S.; Sekhon, G.S. Potassium Research and Agricultural Production in India; Fertilizer Development and Consultation Organization: New Delhi, India, 1988.

64. Timsina, J.; Singh, V.K.; Majumdar, K. Potassium management in rice-maize systems in South Asia. J. Plant Nutr. Soil Sci. 2013, 176, 317-330. [CrossRef]

65. Pasricha, N.S.; Sarkar, A.K. Secondary nutrients. In Fundamentals of Soil Science, 2nd ed.; Goswami, N.N., Rattan, R.K., Dev, G., Narayanasamy, G., Das, D.K., Pal, D.K., Rao, D.L.N., Eds.; Indian Society of Soil Science: New Delhi, India, 2009; pp. 449-460.

66. Pasricha, N.S.; Aulakh, M.S. Twenty Years of Sulphur Research and Oilseed Production in Punjab, India; Sulphur in Agriculture; TSI: Washington, DC, USA, 1991.

67. Tandon, H.L.S. Biofertilizers and Organic Farming: A Source-Cum-Directory; Fertilizer Development and Consultation Organisation: New Delhi, India, 2011.

(C) 2018 by the authors. Licensee MDPI, Basel, Switzerland. This article is an open access article distributed under the terms and conditions of the Creative Commons Attribution (CC BY) license (http:/ / creativecommons.org/licenses/by/4.0/). 
Article

\title{
Maize (Zea mays L.) Response to Secondary and Micronutrients for Profitable N, P and K Fertilizer Use in Poorly Responsive Soils
}

\author{
Ruth Njoroge ${ }^{1,2, *}$, Abigael N. Otinga ${ }^{2}$, John R. Okalebo ${ }^{2}$, Mary Pepela ${ }^{2}$ and Roel Merckx ${ }^{1}$ \\ 1 Division of Soil and Water Management, KU Leuven, Kasteelpark, Arenberg 20 box 2459, \\ 3001 Leuven, Belgium; roel.merckx@kuleuven.be \\ 2 Department of Soil Science, University of Eldoret, box 30100-1125 Eldoret, Kenya; \\ amarishas@yahoo.com (A.N.O.); jookalebo@gmail.com (J.R.O.); marynekesa87@yahoo.com (M.P.) \\ * Correspondence: ruth.njoroge@kuleuven.be
}

Received: 23 January 2018; Accepted: 9 April 2018; Published: 15 April 2018

\begin{abstract}
Deficiencies of secondary and micronutrients (SMNs) are major causes of low maize yields in poorly responsive soils. This phenomenon minimizes the agronomic efficiency of $\mathrm{N}$, $\mathrm{P}$ and $\mathrm{K}$ fertilizers and consequently result in a dwindling economic benefit associated with their use. Therefore, 18 on-farm trials were conducted in western Kenya during two cropping seasons to assess maize response to three NPK amendments; (i) N, P, K, Ca, Zn and $\mathrm{Cu}$ (inorganic and organic); (ii) N, P, K, Ca, Zn and $\mathrm{Cu}$ (inorganic) and (iii) N, P K, Zn and $\mathrm{Cu}$ (inorganic) and evaluate the profitability of their use compared to additions of only $\mathrm{N}, \mathrm{P}$ and $\mathrm{K}$ fertilizers. In this set of experiments, maize response to any amendment refers to a yield increase of $\geq 2 \mathrm{tha} \mathrm{e}^{-1}$ above control and could be categorized in three clusters. Cluster 1, comprising of nine sites, maize responded to all amendments. Cluster 2, holding six sites, maize responded only to one amendment, N, P, K, Ca, $\mathrm{Zn}$ and $\mathrm{Cu}$ (inorganic). In this cluster, (2), emerging $\mathrm{S}, \mathrm{Mg}$ and $\mathrm{Cu}$ deficiencies may still limit maize production. Cluster 3; consisting of three sites, maize responded poorly to all amendments due to relatively high soil fertility $\left(\geq 17 \mathrm{mg} \mathrm{P} \mathrm{kg}^{-1}\right)$. Profitability of using NPK amendments is limited to Cluster 1 and 2 and the largest Value Cost Ratio (VCR) of 3.1 is attainable only when soil available $\mathrm{P}$ is below $4.72 \mathrm{mg} \mathrm{kg}^{-1}$. These variable responses indicate the need for developing site-specific fertilizer recommendations for improved maize production and profitability of fertilizer use in poorly responsive soils.
\end{abstract}

Keywords: agronomic response; calcium; Copper; NPK amendments; Value Cost Ratio; Zinc

\section{Introduction}

Mineral fertilizers contribute to $40-60 \%$ of the world's food production. However, their unbalanced use is obvious at the global scale [1]. Optimal and sometimes excessive mineral fertilizer use has resulted in food sufficiency in some parts of the developed world including North America, Western Europe, and China [2,3]. In contrast, quantities of fertilizer applied by farmers in Sub-Saharan Africa (SSA) are still below the $50 \mathrm{~kg} \mathrm{ha}^{-1}$ target set by the African Heads of State at the 2006-Africa fertilizer summit [4]. Consequently, food insecurity remains the main developmental challenge in SSA [5-7]. Inadequate and unequal allocation of fertilizer within farm fields has been cited as one of the attributes to this unsustainable food production in the region [8]. High fertilizer costs, inaccessibility and/or limited availability and relatively low cereal grain prices are some of the major impediments to increased fertilizer use in the region [9]. Furthermore, food production in the SSA is dominated by the $70-80 \%$ resource-poor smallholder farmers [10]. Because of the above-mentioned challenges, crop production in the region is done mainly with limited inputs resulting in inevitable nutrient 
mining [11,12]. Nevertheless, some governments in West, East and South Africa have facilitated an increase in fertilizer use through subsidy programs $[13,14]$. However, fertilizer use in such cases is often based on blanket recommendations ("standard") that ignore the importance of site and crop-specific requirements for its efficient use [15-17]. Moreover, research in SSA has overemphasized the most limiting nutrients $\mathrm{N}, \mathrm{P}$ and sometimes $\mathrm{K}$ with little attention for the other essential nutrients. Consequently, the commonly available and most frequently applied fertilizers in the region are obviously N, P and K based. Therefore, there is need to stimulate awareness among farmers to supply all essential nutrients for sustainable crop production.

This unbalanced soil fertilization results in poor responses to fertilizers in some soils and consequently small crop yields [18-20]. These so-called 'poor/ non-responsive' soils are defined as those with small to no yield increases after fertilizer use and hence negligible economic returns [21]. The value cost ratio (VCR) of 2 is the acceptable profitability level of fertilizer use by farmers in SSA [22]. In poorly responsive soils that profitability criterion is hardly achieved and, therefore, this phenomena threatens fertilizer use in the region. Consensus grows that in SSA, on top of the well-known deficiencies in N, P and K, the occurrence of secondary macro- and micronutrients deficiencies constitute a major constraint for crop production in poorly responsive soils [16,19,23]. Jones et al. [24] also highlight that depletion of soil micronutrients is increasing in most developing countries especially through the high crop yield targets.

Hence our main research question at the outset is whether the addition of secondary (Ca) and micronutrients $(\mathrm{Zn}, \mathrm{Cu})(\mathrm{SMNs})$ increases the yields of maize and eliminates a possible lack of response to the standard N, P and K fertilizer application. Underlying issues relate to whether the responses can be understood based on leaf and/or soil analyses and whether the intervention of adding SMN's lifts the N, P and K addition to (large) profitability.

\section{Materials and Methods}

\subsection{Characteristics of the Study Area}

The study was conducted in two regions of western Kenya: Bungoma-Southwest (latitudes and longitudes ranges from $0.49^{\circ}$ to $0.55^{\circ}$ North and $34.43^{\circ}$ to $34.51^{\circ}$ East, respectively) and Busia-North (latitudes and longitudes ranges from $0.65^{\circ}$ to $0.70^{\circ}$ North and $34.32^{\circ}$ to $34.39^{\circ}$ East, respectively), during two cropping seasons, i.e., the long (LR) and short (SR) rains of 2015 (Figure 1). The study areas are situated on "lower-middle-level uplands" which are gently undulating to undulated; slopes are 2-8\% and altitudes range between 1200 to 1900 masl [25]. The common soil types in those regions are Acrisols, Ferralsols and Cambisols characterized by low soil fertility [26]. Temperature variations in the region are insignificant, monthly means range between $21^{\circ} \mathrm{C}$ and $22{ }^{\circ} \mathrm{C}$. The area has an average annual rainfall of $1400 \mathrm{~mm}$ with a probability of $66 \%$ [25]. The annual rainfall has a bimodal distribution pattern comprised of an initial long to medium season between March and July (LR) followed by a moderately weak season between September and December (SR). Maize growing period ranges between 100 and 150 days and hence, the two rainfall seasons are adequate for its production. In fact, the western region is considered as a medium production area for maize with potential yields of $5.0 \mathrm{t} \mathrm{ha}^{-1}$ [25]. However, yield gaps between farmer-led and research-led production remain wide in the region. While the actual production at farm level is as low as $1.1 \mathrm{tha}^{-1}$, some scientists have recorded yields as high as $4 \mathrm{tha}^{-1}[20]$. 


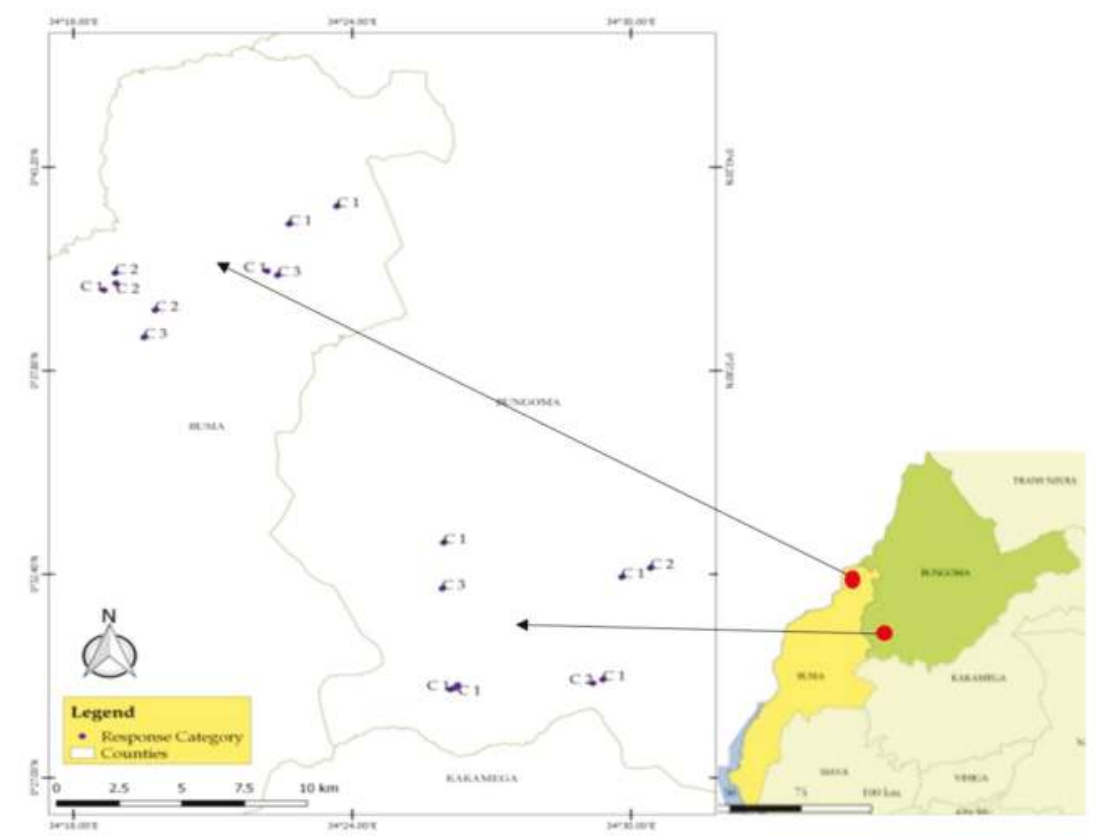

Figure 1. Distributions of the study sites according to their respective response clusters to the NPK amendments in Bungoma-Southwest and Busia-North regions of western Kenya. C1 = Cluster 1 indicating a site that responded well to all the three amendments (NPK2, NPK3 and NPK4) C2 = Cluster 2 indicating a site that responded well to only NPK3 amendment. C3 = Cluster 3 indicating a site that poorly responded to all the three amendments. NPK2 = N, P, K, Ca, Cu and $\mathrm{Zn}$ (inorganic and organic), NPK3 $=$ N, P, K, Ca, Cu and Zn (inorganic), NPK4 = N, P, K, Cu and Zn (inorganic).

\subsection{Description of Experimental Sites}

The trials comprised 18 sites, (nine sites in each region) as shown in Table 1. Selection of those sites was based on a previous multi-locational diagnostic study that sought to identify the extent of poorly responsive soils and their characteristics from the study area [27]. For that study, a poorly responsive soil was defined by economic values below the value cost ratio (VCR) of 2 after N, P and $\mathrm{K}$ fertilizer use for maize production. Further, using the compositional nutrient diagnosis (CND) tool for the same study, $\mathrm{Ca}, \mathrm{Zn}$ and $\mathrm{Cu}$ were found to also limit maize production in such soils.

Soil types for the selected sites in Bungoma-Southwest mainly consisted of Acrisols and Cambisols (Table1) with subtypes ranging from deep, moderately deep to shallow overlying petroplinthite [26,28]. Arenosols were widespread in Busia-North (Table1) with two main subtypes; gleyic and luvic. Other soil types found in the two study areas include Alisols, Luvisols, Lixisols and Planosols. Around $80 \%$ of the total sites had a gentle slope $(<5 \%)$ while the rest were slightly undulating. In addition, it was observed that three of the sites had soil depth $\leq 50 \mathrm{~cm}$, two of which had a plinthic subsurface (Table 1). Majority of the soils are coarse-textured, with an average sand content above $50 \%$. In general, the three primary nutrients $\mathrm{N}, \mathrm{P}$ and $\mathrm{K}$ are low in most of the soils except in some cases where $P$ is relatively large. 
Agronomy 2018, 8, 49

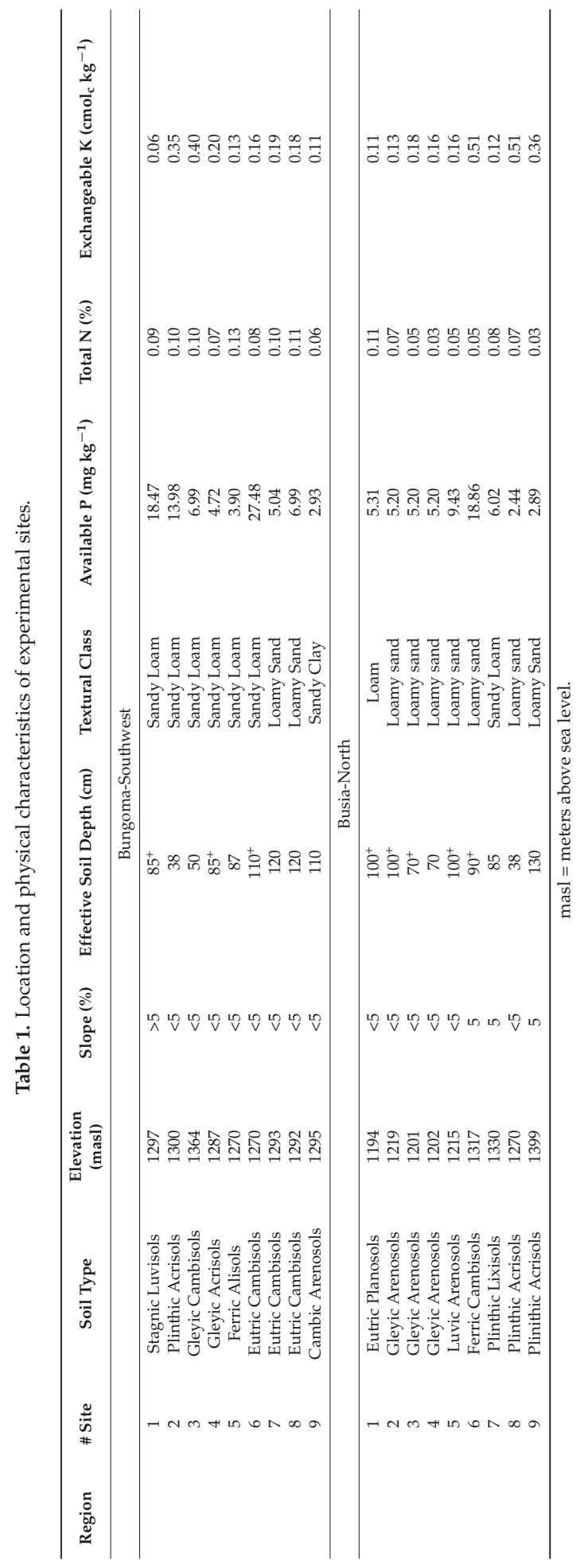




\subsection{Crop Variety and Treatment Structure}

Two medium maturing, Hybrid maize seed varieties, H516 and H513 from Kenya Seed Company were planted during the subsequent seasons; LR and SR, respectively. Each of the nine sites from the two regions had five fertilizer treatments laid out in a Randomized Complete Block Design (RCBD) and replicated three times. Besides the application of N, P and K nutrients at 100, 30 and $60 \mathrm{~kg} \mathrm{ha}^{-1}$, respectively [27], we added three other nutrients $(\mathrm{Ca}, \mathrm{Zn}$ and $\mathrm{Cu}$ ) due to prevalent deficiencies observed in the poorly responsive soils within the study area. Therefore, the treatment structure consisted of an absolute control (without fertilizer), the standard N, P, and K fertilizer (NPK1) and three NPK amendments (i) N, P, K, Ca, Zn and Cu (inorganic and organic); NPK2 (ii) N, P, K, Ca, $\mathrm{Zn}$ and $\mathrm{Cu}$ (inorganic); NPK3 and (iii) N, P, K, Zn and Cu (inorganic), NPK4 (Table 2). We consider the latter three treatments as 'pilot nutrient packages' for rehabilitating the poorly responsive soils in western Kenya. The N, P and K nutrients sources for treatment NPK1 and NPK4 were from Urea, Triple Superphosphate (TSP) and Muriate of Potash (MOP). Mavuno, a blended fertilizer (10\% N, 26\% $\mathrm{P}_{2} \mathrm{O}_{5}, 10 \% \mathrm{~K}_{2} \mathrm{O}, 4 \% \mathrm{~S}, 8 \% \mathrm{CaO}, 4 \% \mathrm{MgO}$ and traces of $\mathrm{B}, \mathrm{Zn}, \mathrm{Mo}, \mathrm{Cu}, \mathrm{Mn}$ ) supplied N. P, K and Ca for NPK3. Application of $\mathrm{Zn}$ and $\mathrm{Cu}$ at $3 \mathrm{~kg} \mathrm{ha}^{-1}$, respectively through amendments, NPK3 and NPK4 followed recent recommendations by National Accelerated Agricultural Input Access Programme (NAAIAP) and Kenya Agricultural Research Institute (KARI) [29]. The NPK2 treatment mainly consisted of farmyard manure (FYM) $\left(0.27 \% \mathrm{~N}, 0.4 \% \mathrm{P}, 2.1 \% \mathrm{~K}, 0.28 \% \mathrm{Ca}, 0.2 \% \mathrm{Mg}, 51.66 \mathrm{mg} \mathrm{kg}^{-1}\right.$ $\mathrm{Zn}, 30.66 \mathrm{mg} \mathrm{kg}^{-1} \mathrm{Cu}$ and $0.03 \mathrm{mg} \mathrm{kg}^{-1} \mathrm{Mn}$ ) with only $\mathrm{N}$ and $\mathrm{P}$ supplements (Table 2). In other words, six tons of FYM were applied together with $84 \mathrm{~kg} \mathrm{~N} \mathrm{ha}^{-1}$ and $6 \mathrm{~kg} \mathrm{P}^{-1}$ from urea and TSP, respectively to match the total amounts of $\mathrm{N}$ and $\mathrm{P}$ added given their small contents in the FYM. The large K-content of $2.1 \%$ analyzed in FYM was considered sufficient to supply $60 \mathrm{~kg} \mathrm{ha}^{-1}$ and hence did not need to be supplemented like was the case for $\mathrm{N}$ and P. A correction to supplement the negligible $\mathrm{Zn}\left(51.66 \mathrm{mg} \mathrm{kg}^{-1}\right)$ and $\mathrm{Cu}\left(30.66 \mathrm{mg} \mathrm{kg}^{-1}\right)$ concentrations in FYM were intentionally ignored. This aimed at evaluating the potential of FYM to supply adequate amounts of micronutrients for maize.

Table 2. Fertilizer treatments implemented for rehabilitating poorly responsive soils in western Kenya during the long (LR) and short (SR) rains of 2015.

\begin{tabular}{|c|c|c|c|c|c|c|c|}
\hline \multirow{2}{*}{ Treatment } & \multicolumn{7}{|c|}{ Nutrient Added (kg ha $\left.{ }^{-1}\right)$} \\
\hline & $\mathbf{N}$ & $\mathbf{P}$ & $\mathbf{K}$ & $\mathrm{Ca}$ & Zn & $\mathrm{Cu}$ & Source \\
\hline Control & - & - & - & - & - & - & No nutrient added \\
\hline NPK1 & 100 & 30 & 60 & - & - & - & Urea, TSP, MOP \\
\hline NPK2 & 100 & 30 & 60 & 16 & 0.3 & 0.2 & FYM, Urea, TSP \\
\hline NPK3 & 100 & 30 & 60 & 16 & 3 & 3 & Mavuno, $\mathrm{Zn}$ and $\mathrm{Cu}$ oxides \\
\hline NPK4 & 100 & 30 & 60 & - & 3 & 3 & Urea, TSP, MOP, $\mathrm{Zn}$ and $\mathrm{Cu}$ oxides \\
\hline
\end{tabular}

TSP = Triple superphosphate, $\mathrm{MOP}=$ Muriate of potash, $\mathrm{FYM}=$ Farmyard manure, Mavuno = blended fertilizer used to provide N, P, K and Ca for treatment NPK3. NPK1 = N, P and K (inorganic), NPK2 = N, P, K, Ca, Cu and Zn (inorganic and organic), NPK3 = N, P, K, Ca, Cu and $\mathrm{Zn}$ (inorganic), NPK4 = N, P, K, Cu and Zn (inorganic).

\subsection{Trial Establishment and Maintenance}

The 15 plots in each site measured $4.5 \mathrm{~m} \times 5 \mathrm{~m}$ individually with six planting rows spaced at $75 \mathrm{~cm}$ apart and intra-row spacing of $25 \mathrm{~cm}$. During the planting period for both seasons, the various fertilizer treatments were assigned to their respective plots. For each treatment, the entire fertilizer components except $\mathrm{N}$ were in bands next to planting rows and thoroughly mixed with soil. The latter eliminates a possible risk of poor seed germination due to high salinity or excess acidity near the fertilizer granules when dissolving. The $100 \mathrm{~kg} \mathrm{~N}^{-1}$ derived from urea was applied in two splits. Half of it was banded together with the other fertilizers at planting. The other half was applied in small furrow (5 cm deep) next to the planting rows and was thoroughly mixed with soil six weeks after seedling emergence. Two maize seeds were planted per hill and two weeks after emergence, 
seedlings were thinned to one. Three weeding using a hand hoe ensured weed-free plots throughout the crop growing seasons. The first weeding was done three weeks after maize seeds were planted while the second and third weedings were done after every four consecutive weeks.

\subsection{Soil and Leaf Tissue Analysis and Grain Yield}

A composite soil sample for each site was analyzed for selected physiochemical parameters. Soil pH, Available P, organic carbon and textural analysis [30] was conducted at the Soil Science laboratory, University of Eldoret, Kenya while total N [31] and cation exchange capacity [32] were analyzed at the Soil and Water laboratory in KU Leuven, Belgium. Maize ear leaf tissues

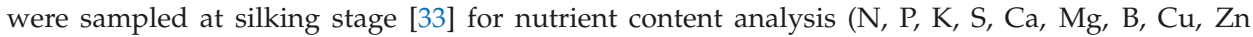
and $\mathrm{Mn}$ ) at KU Leuven, Belgium. All the leaf nutrient analysis except $\mathrm{N}$ followed an acid dissolution procedure [34] and measurements were taken by ICP-MS (Agilent7700X). N analysis was conducted by dry combustion [35] using a Flash Elemental Analyzer 1112HT (Thermo Fisher Scientific Bremen, Germany).

At the onset of physiological maturity, grain harvesting was confined within a net plot of $3 \times 3 \mathrm{~m}^{2}$, comprising of four inner rows while leaving $1 \mathrm{~m}$ from the row edge. The total fresh weight of maize ears was recorded after which eight ears were randomly sampled for grain dry weight analysis.

\subsection{Field Observations}

Farmers were trained and facilitated on how to collect daily rainfall data from their respective sites. From this data, on-farm mean monthly rainfall distribution within the two cropping seasons was recorded and is presented in Figure 2. The rainfall data are cross-checked with long-term data from the closest meteorological stations within each region to determine deviations from the norm. The long-term rainfall data set (1984-2008) for Bungoma-Southwest were sourced from Mungatsi and Sangalo. A 20-year (1990-2010) rainfall data set was acquired from Kwamangor, Amagoro Division Commissioner's (D.C) offices, Angurai and Kolanya meteorological stations for Busia-North. Although we acknowledge the spatial variations in rainfall amount and distribution over time, an overall trend of higher rainfall during the long rains in comparison to the short rains can be inferred from both data sets. A noticeable difference in the rainfall pattern in the farmers' data, however, cannot be ignored. During the long rains, a decrease in rainfall is observed in Busia-North in the months of April and May while it increased during mid-season (November) and at the end of the short rains (December) compared to long-term averages. Rainfall in Bungoma-Southwest increased in June, November and December above the long-term averages.

\subsection{Economic Analysis}

This section seeks to find the most profitable fertilizer treatment to rehabilitate the poorly responsive soils. According to Townsend [36], the profitability of fertilizer use is one of the key factors that determine their adoption and hence the quantity of fertilizer used in SSA. In this context, the value cost ratio (VCR) of fertilizer is used to determine the economic benefit of each treatment for maize grain production. The VCR denotes the value of extra yield produced per unit of money invested in fertilizer as shown in Equation (1).

$\mathrm{VCR}=\left(\right.$ additional maize yield due to fertilizer use $\left(\mathrm{kg} \mathrm{ha}^{-1}\right) \times$ price of grain $(\$$

$\left.\left.\mathrm{kg}^{-1}\right)\right) /\left(\right.$ amount of fertilizer applied $\times$ cost of fertilizer $\left.\left(\$ \mathrm{~kg}^{-1}\right)\right) \ldots \ldots \ldots \ldots \ldots \ldots$

where VCR is the value cost ratio of fertilizer use and $\$$ is US dollar. 


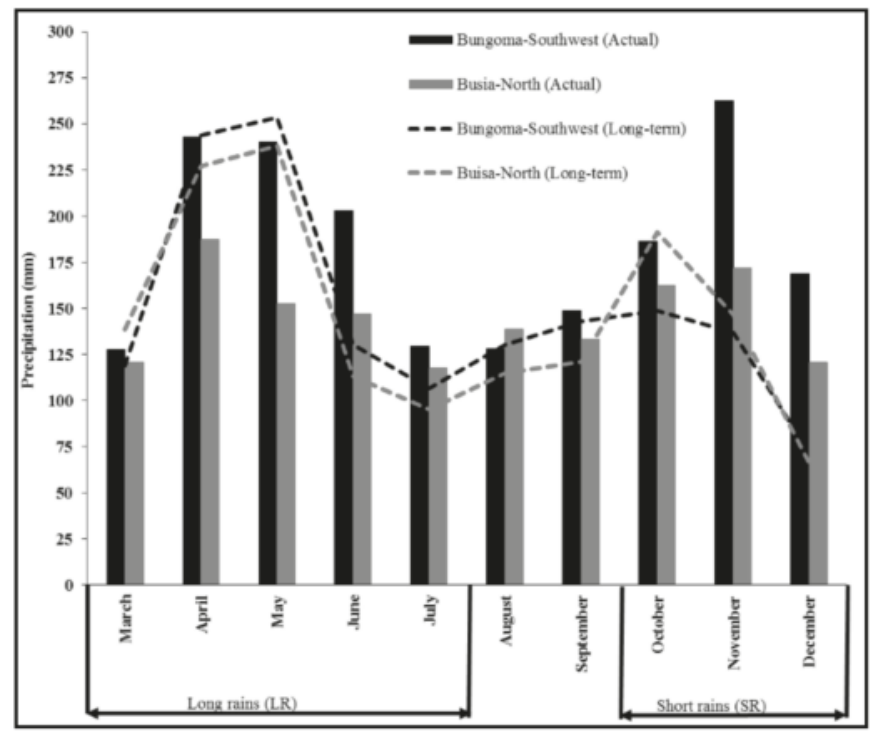

Figure 2. Actual (bars) and a long-term mean monthly rainfall (dotted lines) for each region. A rainy season indicates a time period between crop planting and harvesting. Long rains start in March and end in July while the short rains spread between September and December. Actual = rainfall data recorded during the study period. Long-term = data acquired from the nearest meteorological station.

A VCR value $>1$ means a net profit whereas $<1$ denote a net loss as long as other production inputs such as labor, the cost of seeds are not altered as a result of fertilizer application. Obviously, the larger the VCR value the more worthwhile it is to invest in that particular fertilizer. A VCR value of 2 is considered as the critical threshold to adopt fertilizer use [22]. It implies that for every US dollar (\$1) spent on fertilizer, a return of additional crop yield worth US\$2 is obtained.

To compute VCR values for the two seasons, both the fertilizer cost and grain prices at the local market were taken into account as shown in Table 3. In addition, an average of 100 Kenya Shilling (KES) to 1 USD \$ exchange was factored in for the two seasons to account for inflation effects. Maize grain sold at USD \$0.4 during the LR increased by $10 \%$ in the SR.

Table 3. Fertilizer cost for maize grain production during the long and short rains of 2015

\begin{tabular}{cccc}
\hline \multicolumn{4}{c}{ Fertilizer Cost $\left(\mathbf{~} \mathbf{~ g ~}^{-1}\right)$} \\
\hline Treatment & LR & SR & Average Cost \\
\hline Control & 0.00 & 0.00 & 0.00 \\
NPK1 & 1.76 & 1.50 & 1.63 \\
NPK2 & 2.64 & 2.31 & 2.48 \\
NPK3 & 2.24 & 1.96 & 2.10 \\
NPK4 & 2.11 & 1.81 & 1.96 \\
\hline
\end{tabular}

Control = without fertilizer, NPK1 = N, P and K (inorganic), NPK2 = N, P, K, Ca, Cu and Zn (inorganic and organic), $\mathrm{NPK} 3=\mathrm{N}, \mathrm{P}, \mathrm{K}, \mathrm{Ca}, \mathrm{Cu}$ and $\mathrm{Zn}$ (inorganic), NPK4 = N, P, K, Cu and Zn (inorganic), LR = long rains and SR = short rains. Average cost $=$ mean fertilizer cost of the two seasons. During the long rains (LR), a kilo of each nutrient source costed \$0.78 (TSP), \$0.62 (Urea), \$0.77(MOP), \$0.75 (Mavuno), \$3.8 (Zinc oxide), \$14 (Copper oxide) and $\$ 0.06$ (FYM). For short rains (SR), a kilo of each nutrient source costed \$0.63 (TSP), \$0.51 (Urea), \$0.67 (MOP), \$0.67 (Mavuno), \$3.4 (Zinc oxide), \$12.5 (Copper oxide) and \$0.05 (FYM). 
Further, profitability of fertilizer use for maize was stratified using the decision tree partitioning model [37,38]. The aim of this analysis was to classify the economic benefits of fertilizer use in relation to soil conditions. A proper identification of those soil characteristics that predict profitability of fertilizer use is important to farmers in making sound decisions of fertilizer use. In the model, average VCR value of each treatment in a particular site was considered as the response variable while clusters, fertilizer treatments and selected soil parameters were the predictors explaining the profitability of fertilizer use. The model splits the data into two nodes recursively until a maximum number of nodes is obtained as defined by the maximum $\mathrm{R}$ square value. Each split maximizes the differences in responses between the 2 homogeneous nodes.

\subsection{Statistical Analysis}

All statistical analyses were conducted using JMP Pro statistical software version 12, SAS Institute Inc. SAS [39]. A mixed linear model was adapted to evaluate overall effects of various factors on maize grain yields. In the model, fertilizer treatments, seasons, study area and their interactions were considered as fixed factors while treatment replicates and sites nested within study area taken as random factors. Those factors were compared using the least square means and standard errors of difference (SED). Significant differences between, among the factors and their interactions were evaluated at $p \leq 0.05, p \leq 0.01$ and $p \leq 0.001$.

We further conducted multivariate K-means cluster analysis to reveal meaningful patterns of maize agronomic response to the different fertilizer treatments [23]. The analysis aimed at grouping the experimental sites into sets (cluster) of defined responses to particular fertilizer treatment(s). Maize yield differences of each fertilizer treatment from the control were used for the analysis. Three out of five clusters deemed appropriate for the analysis since they explained the largest variations of the yield differences. We distinguish an agronomic response from a poor response if the yield difference from any of the amendments is $2 \mathrm{t} \mathrm{ha}^{-1}$ above control. This discriminating response value 2 $\mathrm{t} \mathrm{ha}^{-1}$ is based on the fact that most of the smallholder farmers in western Kenya obtain an average yield of $1 \mathrm{t} \mathrm{ha}^{-1}$ without fertilizer application (control) [20]. Therefore, obtaining $2 \mathrm{t} \mathrm{ha}^{-1}$ of maize yields above control corresponds to the green revolution yield target of $3 \mathrm{t} \mathrm{ha}^{-1}$ after fertilizer use for tropical Africa as suggested by Sanchez [40].

To identify the ear leaf nutrient(s) influencing allocation of a given site to a specific cluster, we regressed the response clusters against corresponding nutrient contents using a multinomial logit model. The cluster whose sites responded well to all the three NPK amendments (maize yield of $2 \mathrm{tha}^{-1}$ above control) was taken as the reference (base) cluster for the analysis.

In addition, significant soil parameters among the response clusters were identified using one-way analysis of variance where the cluster is the only fixed factor while replication for each fertilizer treatment is taken as the random factor. Further, a correlation analysis between the significant soil parameters among the response clusters and the influential ear leaf nutrients for site allocation to a given cluster shows the magnitude and direction of the soil-maize nutrient relationship.

\section{Results}

\subsection{Effect of Fertilizer Treatments on Maize Yield}

Effect of fertilizer treatments on maize yield is shown in Table 4. As expected, the control treatment (without fertilizer) had the smallest grain yield on average of $1.65 \mathrm{tha}^{-1}$ which was significantly different from the $2.79 \mathrm{t} \mathrm{ha}^{-1}$ obtained from the standard $\mathrm{N}, \mathrm{P}$ and $\mathrm{K}$ treatment (NPK1). Application of NPK amendments (NPK2, NPK3 and NPK4) more than doubled the control yields, with average yields ranging between 3.38 and $3.56 \mathrm{t} \mathrm{ha}^{-1}$. Nevertheless, yields from those amendments were not significantly different $(p \leq 0.05)$.

Beyond the averages, a clear cropping season effect on maize grain yield was also obvious for both regions (Table 4$)$. The long rains (LR) resulted in significantly $(p \leq 0.05)$ larger yields compared 
to the short rains (SR), irrespective the treatments. Interestingly, both regions had similar average grain yields of $3.6 \mathrm{t} \mathrm{ha}^{-1}$ during the LR. However, during the SR, Busia-North had the smaller yields, on average $0.9 \mathrm{t} \mathrm{ha}^{-1}$ below the $2.8 \mathrm{t} \mathrm{ha}^{-1}$ obtained in Bungoma-Southwest.

Further, Figure 3 shows the variability of maize yields obtained from each treatment for the two regions. A large variability is observed between the minim and maximum yield values for the control, NPK2 and NPK3 treatments compared to their counterparts in NPK1 and NKP4. Moreover, this variability is conspicuous in Bungoma-Southwest compared to Busia-North for the control plots. For the NPK2 and NPK3, the variability is larger in Busia-North compared to Bungoma-Southwest. In addition, Bungoma-Southwest had significantly $(p \leq 0.05)$ larger mean yields than Busia-North in all treatments except for NPK4. Maize control yields obtained in Bungoma-Southwest were $0.2 \mathrm{t} \mathrm{ha}^{-1}$ larger than the $1.55 \mathrm{t} \mathrm{ha}^{-1}$ obtained in Busia-North. Likewise, the standard N, P and $\mathrm{K}$ fertilizer (NPK1) application resulted in a yield of $3.1 \mathrm{t} \mathrm{ha}^{-1}$ in Bungoma-Southwest, $0.6 \mathrm{t} \mathrm{ha}^{-1}$ larger than the $2.5 \mathrm{t} \mathrm{ha}^{-1}$ obtained in Busia-North. In contrast, application of the inorganic/organic-based amendment (NPK2) in Bungoma-Southwest resulted in a yield only $5 \%$ above the $3.36 \mathrm{t} \mathrm{ha}^{-1}$ obtained in Busia-North with the same treatment. The amendment, NPK3 (standard N, P and K plus Ca, Cu and Zn) resulted in the largest yield difference between the two regions. Actually, the amendment yielded $4 \mathrm{t} \mathrm{ha}^{-1}$ of maize grain in Bungoma-Southwest compared to the $3 \mathrm{t} \mathrm{ha}^{-1}$ obtained in Busia-North. Applying the standard $\mathrm{N}, \mathrm{P}$ and $\mathrm{K}$ fertilizer plus micronutrients $\mathrm{Zn}$ and $\mathrm{Cu}(\mathrm{NPK} 4)$ had insignificant $(p \leq 0.05)$ yields between the regions.

Table 4. Maize grain yield as affected by fertilizer application and season for two regions in western Kenya.

\begin{tabular}{|c|c|c|c|c|c|c|c|}
\hline & \multicolumn{3}{|c|}{ Bungoma-Southwest } & \multicolumn{3}{|c|}{ Busia North } & \multirow[b]{2}{*}{ Mean (Season and Site) } \\
\hline & LR & SR & Mean (Site) & LR & SR & Mean (Site) & \\
\hline Treatment & & & & & tha ${ }^{-1}$ & & \\
\hline Control & 2.22 & 1.27 & 1.75 & 2.31 & 0.78 & 1.55 & 1.65 \\
\hline NPK1 & 3.58 & 2.62 & 3.10 & 3.24 & 1.73 & 2.49 & 2.79 \\
\hline NPK2 & 3.72 & 3.24 & 3.46 & 4.26 & 2.31 & 3.29 & 3.38 \\
\hline NPK3 & 4.49 & 3.58 & 4.04 & 3.86 & 2.29 & 3.08 & 3.56 \\
\hline NPK4 & 3.82 & 3.32 & 3.57 & 4.18 & 2.21 & 3.20 & 3.38 \\
\hline Mean (Season) & 3.57 & 2.80 & 3.18 & 3.57 & 1.86 & 2.72 & 2.95 \\
\hline SED Treatment & & & & & $0.13^{* *}$ & & \\
\hline SED Season & & & & & $0.08^{* *}$ & & \\
\hline SED Region & & & & & ns & & \\
\hline SED Treatment $\times$ Region & & & & & $0.32 *$ & & \\
\hline SED Season $\times$ Region & & & & & $0.29 * *$ & & \\
\hline SED Treatment $\times$ Season & & & & & ns & & \\
\hline SED Season $\times$ Region $\times$ site & & & & & ns & & \\
\hline
\end{tabular}

Control = without fertilizer application, NPK1 = N, P and K (Inorganic), NPK2 = N, P, K, Ca, Cu (Inorganic and Organic), NPK3 = N, P, K, Ca, Cu and Zn (Inorganic), NPK4 = N, P, K, Cu and Zn (Inorganic), LR = long rains, $\mathrm{SR}=$ short rains, $\mathrm{SED}=$ standard error of difference, ${ }^{*}$ significant at $p \leq 0.05,{ }^{* *}$ significant at $p \leq 0.01$, ns = not significant.

\subsection{Maize Agronomic Response Clusters}

Three clusters reveal a detailed variability in maize response to fertilizer treatments across all the experimental sites as shown in Figure 4. Cluster 1 represents sites in which maize responds well to all NPK amendments (NPK2, NPK3 and NPK4) compared to standard N, P and K fertilizer (NPK1). This cluster contains $50 \%$ of all sites. In this cluster, application of any of the NPK amendments increase maize yields by $40 \%$ above the $1.6 \mathrm{tha}^{-1}$ increase obtained after use of the standard $\mathrm{N}, \mathrm{P}$ and $\mathrm{K}$ fertilizer (NPK1). Therefore, for the same cluster, additional nutrients (SMNs) beside N, P and K may be either sourced from organic (FYM) or inorganic without a significant $(p \leq 0.05)$ yield reduction. Cluster 2 holds sites with major limitations of micronutrients. Thirty-three percent of all sites are in this cluster and show a significant $(p \leq 0.05)$ maize response to NPK3 compared to the other amendments and NPK1. Maize yields in those sites increase significantly $(p \leq 0.05)$ only when $\mathrm{Ca}$ is added together with relatively large doses of $\mathrm{Cu}$ and $\mathrm{Zn}\left(3 \mathrm{~kg} \mathrm{ha}^{-1}\right)$ above the standard $\mathrm{N}, \mathrm{P}$ and 
K fertilizer. Maize responds poorly to fertilizer treatments in sites belonging to Cluster 3 . The $17 \%$ of all sites belonging to this cluster are relatively fertile based on the large yields observed from control plots of $3 \mathrm{t} \mathrm{ha}^{-1}$ on average. For the same cluster, application of standard $\mathrm{N}, \mathrm{P}$ and $\mathrm{K}$ fertilizer results in a yield decline of $0.7 \mathrm{t} \mathrm{ha}^{-1}$ below control while the use of the amendments barely improved maize yields by $0.3 \mathrm{t} \mathrm{ha}^{-1}$ above control.

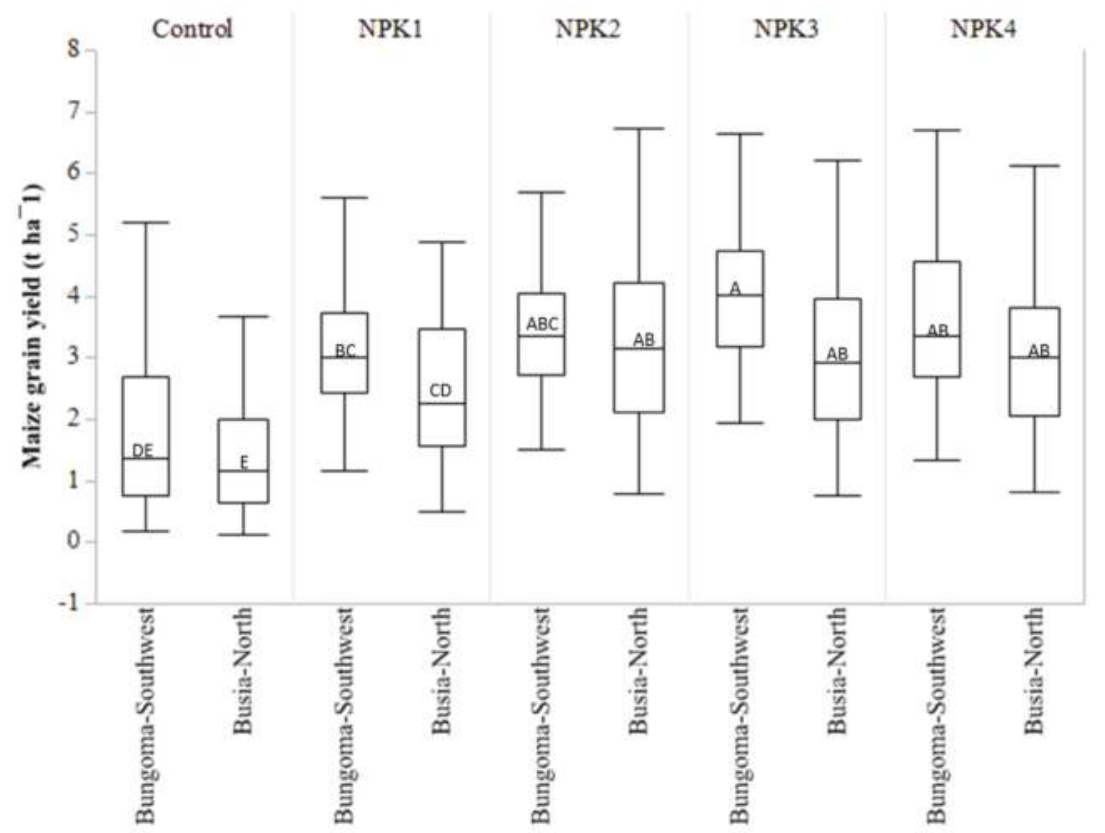

Figure 3. Variability of maize response to the different fertilizer treatments in Bungoma-Southwest and Busia-North. Control = without fertilizer application, NPK1 = N, P and K (Inorganic), NPK2 = N, P, K, $\mathrm{Ca}, \mathrm{Cu}$ (Inorganic and Organic), NPK3 = N, P, K, Ca, Cu and Zn (Inorganic), NPK4 = N, P, K, Cu and $\mathrm{Zn}$ (Inorganic). Different letters indicate significant differences $(p \leq 0.05)$ among the treatments while same letters indicate the opposite.

3.2.1. Relationship between Nutrient Content in Maize Ear Leaf and Type of Maize Response to NPK Amendments

Using Cluster 1 as the reference category in multinomial logit shows that reducing $\mathrm{P}, \mathrm{K}$ and $\mathrm{Zn}$ content and increasing S, Mg and $\mathrm{Cu}$ would transfer a site from, Cluster 2 into Cluster 1 (Table 5). Ear leaves from sites in Cluster 2 were slightly larger in leaf P content and smaller in S and Mg content compared to their counterparts in Cluster 1.

Decreasing $\mathrm{N}$ and $\mathrm{Ca}$ and increasing $\mathrm{S}, \mathrm{Mg}, \mathrm{B}$ and $\mathrm{Cu}$ contents would ultimately transfer an individual site from the poorly responsive, Cluster 3 to Cluster 1 (Table 5). Similar to the plants in Cluster 2, contents of S, Mg, B and Cu were relatively smaller in maize ear leaves of Cluster 3 than in those of Cluster 1 . 


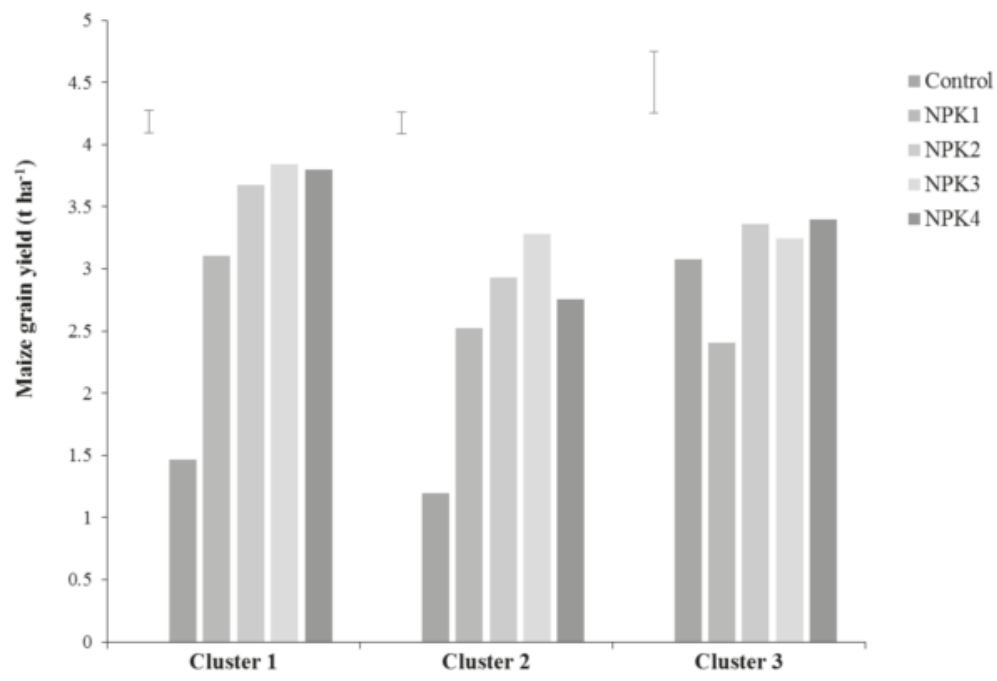

Figure 4. Maize response to various N, P and $\mathrm{K}$ fertilizer treatments as categorized in different clusters following the K-means clustering criterion. A response is defined by $\geq 2 \mathrm{tha}^{-1}$ yield increase above control. Error bars represent standard errors of differences between the means for each cluster. Control = without fertilizer application, NPK1 $=\mathrm{N}, \mathrm{P}$ and $\mathrm{K}$ (Inorganic), NPK2 = N, P, K, Ca, Cu and Zn (Inorganic and Organic), NPK3 = N, P, K, Ca, Cu and Zn (Inorganic), NPK4 = N, P, K, Cu and Zn (Inorganic). Cluster $1=$ response to all the three NPK amendments (NPK2, NPK3, NPK4), Cluster 2 = response to only one NPK amendment (NPK3), Cluster $3=$ poor responsive response to all three NPK amendments.

Table 5. Ear leaf nutrients influencing allocation of various sites to specific agronomic response cluster.

\begin{tabular}{cccc}
\hline & Cluster 1 & Cluster 2 & Cluster 3 \\
\hline \multicolumn{4}{c}{ Macronutrient $(\%)$} \\
\hline $\mathrm{N}$ & $2.37(1.82,2.91)$ & $2.27(1.82,2.91)$ & $2.32(2.07,2.59) \mathrm{a}$ \\
$\mathrm{P}$ & $0.22(0.18,0.26)$ & $0.23(0.18,0.30) \mathrm{a}$ & $0.22(0.18,0.25)$ \\
$\mathrm{K}$ & $1.88(1.50,2.17)$ & $1.88(1.54,2.21) \mathrm{a}$ & $1.75(1.56,1.88)$ \\
$\mathrm{S}$ & $0.15(0.12,0.17)$ & $0.14(0.11,0.16) \mathrm{b}$ & $0.13(0.11,0.15) \mathrm{b}$ \\
$\mathrm{Ca}$ & $0.46(0.33,0.61)$ & $0.44(0.34,0.56)$ & $0.48(0.38,0.54) \mathrm{a}$ \\
$\mathrm{Mg}$ & $0.13(0.09,0.16)$ & $0.11(0.08,0.14) \mathrm{b}$ & $0.12(0.10,0.15) \mathrm{b}$ \\
\hline \multicolumn{4}{c}{ Micronutrient $\left(\mathrm{mg} \mathrm{kg}^{-1}\right)$} \\
\hline $\mathrm{B}$ & $4.90(3.86,6.85)$ & $4.93(3.86,6.85)$ & $4.51(3.85,5.01) \mathrm{b}$ \\
$\mathrm{Cu}$ & $9.19(6.68,13.23)$ & $8.11(5.97,10.39) \mathrm{b}$ & $7.86(5.86,9.98) \mathrm{b}$ \\
$\mathrm{Zn}$ & $15.91(12.35,20.52)$ & $16.22(13.28,20.58) \mathrm{a}$ & $15.67(12.95,17.94)$. \\
\hline
\end{tabular}

Numbers are mean nutrient contents with the corresponding minimum and maximum values in brackets to indicate the range. Based on multinomial logit analysis, letter ' $a$ ' indicates that the corresponding nutrient content should be decreased, while letter ' $b$ ' show those that should be increased in order to move a site from clusters 2 and 3 to Cluster 1. Cluster $1=$ response to all the three NPK amendments, Cluster $2=$ response to one of three NPK amendments and Cluster $3=$ poor response to all the three NPK amendments.

\subsubsection{Soil Characteristics Corresponding to Maize Response Clusters}

Table 6 shows the variation in soil characteristics among various maize response clusters. None of the soil parameters except $\mathrm{P}$ were significantly different $(p \leq 0.05)$ among clusters. Available $\mathrm{P}$ was smallest with $6.45 \mathrm{mg} \mathrm{P} \mathrm{kg}^{-1}$ on average for soils in Cluster 1 while it was largest in Cluster 3 with an average content of $17.2 \mathrm{mg} \cdot \mathrm{kg}^{-1}$ and ranging between 5 and $27 \mathrm{mg} \mathrm{kg}^{-1}$. 
Table 6. Selected soil characteristics of the derived maize response clusters.

\begin{tabular}{ccccc}
\hline & Units & Cluster 1 & Cluster 2 & Cluster 3 \\
\hline $\mathrm{pH}\left(\mathrm{H}_{2} \mathrm{O}\right)$ & & $5.59(5.15,6.01)$ & $5.69(5.50,6.06)$ & $5.56(5.30,5.90)$ \\
Available P & $\mathrm{mg} \mathrm{kg}^{-1}$ & $6.45(2.44,18.37)$ & $6.91(2.93,13.98) *$ & $17.18(5.20,27.48)$ \\
Total N & $\%$ & $0.09(0.03,0.13)$ & $0.07(0.05,0.10)$ & $0.05(0.03,0.08)$ \\
Organic C & $\%$ & $0.80(0.04,1.72)$ & $0.95(0.50,1.60)$ & $1.02(0.48,1.98)$ \\
Effective CEC & $\mathrm{cmol}_{\mathrm{c}} \mathrm{kg}^{-1}$ & $4.10(-0.37,8.53)$ & $3.52(1.31,7.19)$ & $1.42(-0.49,3.07)$ \\
Exch. K & $\mathrm{cmol}_{\mathrm{c}} \mathrm{kg}^{-1}$ & $0.23(0.06,0.51)$ & $0.19(0.11,0.35)$ & $0.28(0.16,0.51)$ \\
Exch. Ca & $\mathrm{cmol}_{\mathrm{c}} \mathrm{kg}^{-1}$ & $2.80(0.81,5.75)$ & $2.43(1.43,3,7)$ & $1.61(0.77,2.36)$ \\
Exch. Mg & $\mathrm{cmol}_{\mathrm{c}} \mathrm{kg}^{-1}$ & $0.58(0.14,1.25)$ & $0.74(0.26,1.72)$ & $0.49(0.13,0.88)$ \\
Sand & $\%$ & $71(46,87)$ & $71 .(52,83)$ & $82(79,85)$ \\
Clay & $\%$ & $11(4,21)$ & $13(3,37)$ & $7(3,12)$ \\
\hline
\end{tabular}

Numbers are means with minimum and maximum values in brackets. ${ }^{*}$ significant at $p \leq 0.05$. All others are not significant. Cluster $1=$ response to all the three NPK amendments, Cluster $2=$ response to one of three NPK amendments and Cluster $3=$ poor response to all the three NPK amendments.

3.2.3. Relationship between Significant Soil Parameters and Influential Ear Leaf Nutrients for Maize Response Clusters

The relationship between soil available $\mathrm{P}$ and ear leaf nutrients that influenced site allocation to clusters, 2 and 3 is shown in Table 7. The larger soil available P for sites in Cluster 2, the larger the P, $\mathrm{K}$ and $\mathrm{S}$ contents in maize ear leaves. However, soil available $\mathrm{P}$ did not have a significant $(p \leq 0.05)$ effect on both $\mathrm{Mg}$ and $\mathrm{Cu}$ ear leaf content in this same cluster. For the poorly responsive, Cluster 3, large soil available P significantly ( $p \leq 0.05)$ enhanced uptake of N, Ca and Cu. Similar effect of soil available $\mathrm{P}$ to $\mathrm{Mg}$ ear leaf content for sites in Cluster 2 is also observed for sites in Cluster 3. Although not significant, soil available $\mathrm{P}$ for Cluster 3 had a negative effect on $\mathrm{S}$ and $\mathrm{B}$ ear leaf content.

Table 7. Correlation of soil available $\mathrm{P}$ and ear leaf nutrients influencing allocation of sites to clusters, 2 and 3.

\begin{tabular}{ccc}
\hline & \multicolumn{2}{c}{ Soil Available P } \\
\hline Ear Leaf Nutrient & Cluster 2 & Cluster 3 \\
\hline $\mathrm{N}$ & 0.39 & $0.59^{*}$ \\
$\mathrm{P}$ & $0.79^{* * *}$ & 0.19 \\
$\mathrm{~K}$ & $0.57^{* *}$ & -0.08 \\
$\mathrm{~S}$ & $0.56^{* *}$ & -0.39 \\
$\mathrm{Ca}$ & -0.06 & $0.62^{*}$ \\
$\mathrm{Mg}$ & -0.01 & -0.01 \\
$\mathrm{~B}$ & 0.25 & -0.32 \\
$\mathrm{Cu}$ & 0.16 & $0.91^{* * *}$ \\
$\mathrm{Zn}$ & 0.23 & 0.07 \\
\hline
\end{tabular}

Numbers are correlation coefficients, ${ }^{*}$ significant at $p \leq 0.05,{ }^{* *}$ significant at $p \leq 0.01,{ }^{* * *}$ significant at $p \leq 0.001$. All others are not significant. Cluster $2=$ response to one of three NPK amendments and Cluster $3=$ poor response to all the three NPK amendments.

\subsection{Economic Benefit from NPK Amendments for Maize Grain Production}

In general, initial investments for the three NPK amendments; NPK2, NPK3 and NPK4 are costly compared to the standard N, P and K fertilizer, NPK1 (Table 3). However, the net profit of using those amendments after grain sales is worth the investment. On average, investing a kilogram of the NPK1 at $\$ 1.6$ (Table 3) during planting results in $50 \%$ net profit. The largest net profit of $160 \%$ is obtained after investing $\$ 2.1$ (Table 3) for a kilogram of NPK3. A similar net profit at $130 \%$ is obtained after investing \$2.5 and \$2.0 for NPK2 and NPK4 (Table 3), respectively.

Figure 5 illustrates profitability of using NPK amendments for maize production in poorly responsive soils of western Kenya. The mean values of VCR partition different levels of profitability. 
Returns on investment directly relate to the agronomic response clusters. This notwithstanding, it is the soil available $\mathrm{P}$ which ultimately determines the extent of the profitability. The first split with mean VCR value of 2.2 shows that use of amendments (NPK2, NPK3, and NPK4) is profitable compared to the standard N, P and K fertilizer, NPK1, irrespective of the response clusters. The mean VCR value of 2.4 obtained after using those amendments is $20 \%$ above the acceptable profitability threshold value of 2. In contrast, the profitability of using the standard N, P and K fertilizer for maize production is on average $25 \%$ less than the acceptable threshold. On average, lowest benefits of using the standard N, $\mathrm{P}$ and $\mathrm{K}$ fertilizer, NPK1 (VCR = 1.3) are observed in 13 of the total sites. Such sites had more than $5.04 \mathrm{mg} \mathrm{P} \mathrm{kg}^{-1}$ of soil. Nevertheless, five of the total sites with less than $5.04 \mathrm{mg} \mathrm{P} \mathrm{kg}^{-1}$ soil attained the profitability threshold, VCR value of 2.0 after application of the standard N, P and K fertilizer.

The average VCR value of 0.4 for all amendments is $80 \%$ below the acceptable threshold value of 2 for sites belonging to the poorly responsive, Cluster 3 irrespective of the amount of available $\mathrm{P}$ in the soil. Farmers with sites belonging to both clusters 1 and 2 satisfactorily benefit from using NPK amendments. However, on average, sites in Cluster 1 result in $25 \%$ larger VCR values above the 2.4 obtained in Cluster 2 when soils have more than $4.72 \mathrm{mg} \mathrm{P} \mathrm{kg}^{-1}$. Use of NPK amendments, for both Clusters 1 and 2, is 15\% more beneficial in sites where soils had less than $4.72 \mathrm{mg} \mathrm{P} \mathrm{kg}^{-1}$. The mean VCR value of 3.3 indicates the largest economic benefits of using the NPK amendments. Sites with the lowest available $\mathrm{P}$ in the soil $\left(2.93 \mathrm{mg} \mathrm{P} \mathrm{kg}^{-1}\right)$ are observed with such economic benefits.

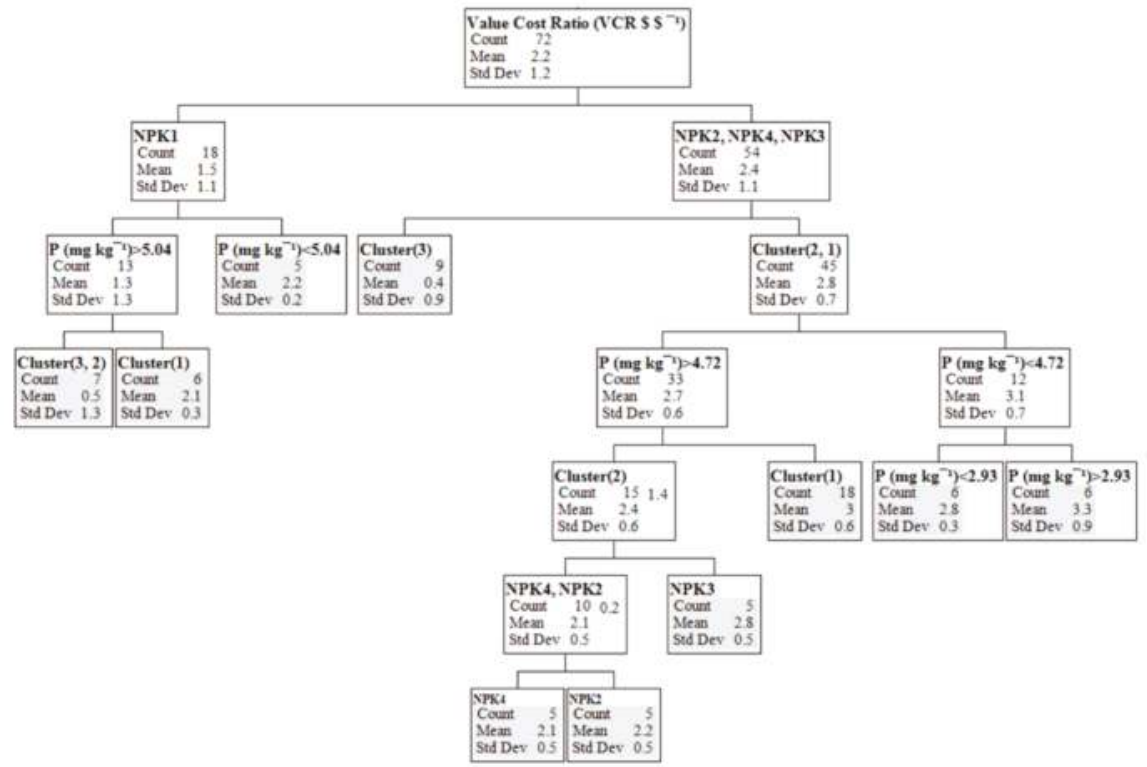

Figure 5. Classification and regression tree (CART) model showing the effect of soil available P and maize agronomic responses (clusters) on profitability of N, P and K fertilizer use. White boxes are splitting nodes while the VCR means are splitting values. Gray shaded boxes are terminal nodes. NPK1 = standard N, P and K fertilizer, NPK2, NPK3, NPK4 = NPK amendments, Cluster 1 = response to all the three NPK amendments, Cluster 2 = response to only NPK3 amendment and Cluster $3=$ poor response to all the three NPK amendments. 


\section{Discussion}

\subsection{Effect of Fertilizer Treatments on Maize Yield}

The overall maize yield increase after additions of selected secondary macro- and micronutrients (SMNs) above the standard N, P and K fertilizer confirms that the closure of maize yield gaps in poorly responsive soils requires more than the 3 primary nutrients [19]. On average, the smallest yield increase above the control was obtained after using the standard N, P and K fertilizer compared with using the NPK amendments for both regions. In Bungoma-Southwest, the largest yield increase of $2.3 \mathrm{t} \mathrm{ha}^{-1}$ was obtained after using NPK3. This implies that, beyond the supply of N, P and K, sites in that region require both $\mathrm{Ca}, \mathrm{Zn}$ and $\mathrm{Cu}$ at optimal rates. It is observed that sites in Bungoma-Southwest had strongly acidic soils (mean $\mathrm{pH}=5.2$ ) compared to those in Busia-North (mean pH = 5.5) (Table 2) using the criterion documented by Kanyanjua, et al. [41]. Neutralization of acidity by $\mathrm{CO}_{3}{ }^{2-}, \mathrm{OH}^{-}$, and $\mathrm{HCO}_{3}{ }^{-}$derived from limestone in Mavuno fertilizer (NPK3) may have resulted in more nutrient availability for maize crop uptake in such soils [42,43]. For sites in Busia-North, application of FYM with $\mathrm{N}$ and $\mathrm{P}$ inorganic supplements performs better than the other amendments. This is an indication that, combining N, P, K and Ca with small rates of $\mathrm{Zn}$ and $\mathrm{Cu}$ is adequate to restore the productivity of poorly responsive soils in that region. Nearly of all sites in Busia-North had more than $75 \%$ sand and, therefore, the NPK2 deems important for nutrient and water retention.

The conspicuous seasonal effect on yield also confirms weather pattern as a major constraint to maize production beyond nutrient deficiencies for the rain-fed agriculture [44]. In general, during the short rains, maize yields reduced by $28 \%$ below the $3.6 \mathrm{t} \mathrm{ha}^{-1}$ obtained during the long rains. Although a comparison between the yields at region level showed no significant differences, yields obtained during the second cropping seasons differed. Sites from Bungoma-Southwest produced larger yields after addressing the SMN deficiencies compared to Busia-North. It was observed that Bungoma-Southwest received a substantial amount of rainfall during the SR (cumulative rainfall of $482 \mathrm{~mm}$ between September and November) compared to the average of precipitation recorded over several years (Figure 2). The rainfall increase was largest in the month of November which coincides with grain filling [45] and consequently may have contributed to the yield difference between the sites

\subsection{Maize Agronomic Response Clusters}

Beyond the yield averages, the clusters reveal diverse maize response patterns across the study sites. Sites in Cluster 1 showed a response to all three NPK amendments. Soils from sites belonging to this cluster were not only deficient in primary nutrients, $\mathrm{P}\left(<10 \mathrm{mg} \mathrm{kg}^{-1}\right)$ and $\mathrm{N}(<0.2 \%)$ (Table 6) but also in SMNs ( $\mathrm{Ca}, \mathrm{Zn}$ and $\mathrm{Cu})$ and hence the response to all NPK amendments. Therefore, these results indicate the need of supplying together all nutrients that limit maize production in poorly responsive soils. In agreement with earlier reports $[23,24,46]$, on the contribution of SMNs in closing the yield gaps in SSA, it is also obvious in these soils. In addition, supplying small amounts of micronutrients, like $\mathrm{Zn}$ and $\mathrm{Cu}$ through FYM may be adequate for maize production in soils such as those found in this cluster. Negligible differences in yield improvement were observed from the application of FYM compared to the relatively high micronutrient rates supplied through the inorganic amendments. Soils for this cluster mainly comprised of Luvisols, Lixisols, Cambisols and Planosols. Those soils are commonly known for their relatively large base saturation and hence, can hold a larger amount of nutrients [28]. Alongside the supply of nutrients, FYM may have further increased the nutrient storage capacity of these soils considering their average low organic carbon content and a large sand content of 71\% [40,47]. A similar observation by Zingore, et al. [48] also highlights the need of FYM for restoring productivity in nutrient depleted sandy soils.

Sites in Cluster 2 showed a selective response to the NPK3 amendment. Sites in this cluster also had low $\mathrm{P}\left(6.9 \mathrm{mg} \mathrm{P} \mathrm{kg}^{-1}\right)$ - while slightly higher- compared to those in Cluster $1\left(6.5 \mathrm{mg} \mathrm{P} \mathrm{kg}^{-1}\right)$. Soil $\mathrm{N}$ was also low in sites belonging to Cluster 2 (Table 6). Although the restricted response to NPK3 indicates a larger demand of micronutrients compared to sites belonging to other clusters, 
it also demonstrates the need of $\mathrm{Ca}$ application in such soils. In addition, the small $\mathrm{S}, \mathrm{Mg}$ and $\mathrm{Cu}$ contents measured in maize ear leaves from sites in this cluster may account for the relatively low yield improvement (Table 5). With reference to the $S$ sufficiency ranges between $0.16-0.2 \%$ given by Reuters and Robinson [49], S was clearly deficient for optimal maize production in sites belonging to this cluster. With reference to Table 5, N and S play a significant role in allocating sites in this cluster, Cluster 2. The content of $\mathrm{N}$ requires being reduced while $\mathrm{S}$ requires being increased for those sites to move to Cluster 1. This implies an imbalance between N and S. According to FAO [50], and in line with first principles, some nutrient deficiencies may be aggravated by application of another. Other studies in SSA also indicate that soils become deficient in nutrients like $\mathrm{S}$ once the macronutrient status has been optimized [51]. The severity of $\mathrm{S}$ deficiency is usually aggregated by high rates of $\mathrm{N}$ application ([52]), probably as those applied in our study.

In recent past, crop deficiencies of $S$ have been reported in cropping systems that have reduced anthropogenic $S$ input and failure to replenishment $S$ through fertilizer input to compensate exportation [53]. In line with this, continuous application of Sulphur-free fertilizers may also induce S deficiency [54] such as the case in this study. All the nutrient sources were S-free except for the negligible content contained in FYM (NPK2) and Mavuno fertilizer, used in the NPK3 treatment [55]. The consequence of S-deficient conditions is an inefficient utilization of N, P and K fertilizers and the resulting poor profitability [56].

Similar to S, Mg was not addressed in this study since it had not been diagnosed as a major problem limiting maize production in poorly responsive soils [27]. However, based on the sufficiency ranges between 0.21 and $0.5 \%$ given by Reuters and Robinson [49], the measured average content of $0.11 \%$ for sites in Cluster 2, indicates deficiency. According to Gransee and Führs [57], Mg deficiency principally occurs due to an absolute small content in the soil or due to cation competition. Using the criterion given by Okalebo, Gathua and Woomer [30], soils in this cluster had moderate exchangeable $\mathrm{Mg}$ content on average of $0.74 \mathrm{cmol}_{\mathrm{c}} \mathrm{kg}^{-1}$ and hence not limiting. Application of $\mathrm{K}$ may have therefore accentuated $\mathrm{Mg}$ deficiency through cation competition [58,59]. In addition, low Mg content in ear leaves from sites in Cluster 2 confirms such possibility.

Likewise, while we did address $\mathrm{Cu}$ deficiencies in this study, ear leaf contents of this nutrient were still relatively small in samples from sites belonging to Cluster 2. On average, the $\mathrm{Cu}$ content for the latter was $1 \mathrm{mg} \mathrm{kg}^{-1}$ below the $9.19 \mathrm{mg} \mathrm{kg}^{-1}$ obtained from sites in Cluster 1 (Table 5). However, those $\mathrm{Cu}$ contents for Cluster 2 may not be regarded as deficient as such since their values are still within the sufficiency ranges between 6 and $20 \mathrm{mg} \mathrm{kg}^{-1}$ specified by Reuters and Robinson [49]. Nevertheless, ion competition may still explain a scenario of deficiency. Both $\mathrm{Cu}$ and $\mathrm{Zn}$ are bivalent cations known to compete for adsorption, i.e., $\mathrm{Zn}$ may have inhibited $\mathrm{Cu}$ adsorption at the root surface [60]. This can be derived from the slightly larger Zn contents for sites in Cluster 2 (16.22 $\mathrm{mg} \mathrm{kg}^{-1}$ ) compared to $15.9 \mathrm{mg} \mathrm{kg}^{-1}$ measured for those in Cluster 1 (Table 5).

Poor responses to SMNs interventions was observed for sites in Cluster 3. This implies that application of NPK amendments had an insignificant effect on yield increase above control for Cluster 3. The average maize yield of $3 \mathrm{tha}^{-1}$ obtained from control plots is indicative of relatively fertile sites in this cluster and hence may be considered as 'fertile poor responsive cluster'. The soils in this cluster comprised Eutric Cambisols and Gleyic Arenosols with adequate levels of available P at an average of $17 \mathrm{mg} \cdot \mathrm{kg}^{-1}$ [30,61]. Nevertheless, ear leaf content of several micronutrients (S, Mg, B and Cu) for this cluster were small compared to those measured in Cluster 1. Out of the four micronutrients, only $\mathrm{Cu}$ was added in the NPK amendments. Although the correlation between soil available P and ear leaf $\mathrm{Cu}$ content indicate a synergistic relationship (Table 7), $\mathrm{Cu}$ content still seems inadequate to result in a significant maize yield increase. In addition, the emerging $S$ and $\mathrm{Mg}$ deficiencies for the same cluster may have also occurred due to similar conditions as those explained for Cluster 2. Furthermore, the marginal B deficiency at $4.5 \mathrm{mg} \mathrm{kg}^{-1}$ in maize ear leaves [62] for Cluster 3 significantly relates to the negligible yield increase above the control. As shown from multinomial logit analysis, $\mathrm{N}$ and $\mathrm{Ca}$ ear leaf content has an antagonistic effect on B content for the same cluster. Application of $\mathrm{N}$ 
may, therefore, have offset the N: B ratio in soil resulting in low B uptake [63]. Boron is also known to have a close relationship with $\mathrm{Ca}$. Application of $\mathrm{Ca}$ to sites belonging to Cluster 3 may have reduced the availability of $B$ resulting in its low uptake [64,65]. A dilution effect is also another possibility of the observed small B ear leaf concentration for Cluster 3 . This mostly occurs when large Ca concentration in plant tissue increases B demand due to close similarity in function [66]. In addition, Ca may also influence uptake of B indirectly. Application of Ca in soils for sites belonging the poor responsive Cluster 3 may have increased the uptake of $P$ as observed in Table 5. Both B and Pare anions that have an antagonistic effect. Increase in P uptake reduces B uptake [67] and hence the small content measured.

\subsection{Economic Benefit from NPK Amendments for Maize Grain Production}

The Economic benefit of fertilizer use is affected by fertilizer cost, grain prices and ultimately how maize responds to fertilizer application [22]. Investing on any of the NPK amendments at an average $\$ 0.5$ extra above the $\$ 1.6$ (Table 3) already used to purchase the standard N. P and K fertilizer results in 3 times net profits. Such profits would be satisfactory incentives for investing in fertilizer use in SSA $[68,69]$. Moreover, it is important to identify the most profitable and suitable fertilizer intervention that fits a local context. In this case, results indicate that NPK3 (Mavuno based amendment) was more profitable in Bungoma-Southwest compared to the other amendments while the FYM based amendment was the most profitable in Busia-North. Further, delineating the type of maize responses clearly separates sites where NPK amendments can be recommended from those that still require further attention. In agreement with Kihara, et al. [70] substantiating the highly variable profitability of fertilizer use helps farmers to make well-informed decisions on fertilizer use.

Application of the CART tool reveals the underlying soil characteristics that would predict the profitability of fertilizer use. The tool, therefore, provides a simple method of determining which would the most profitable fertilizer interventions under specific soil conditions. Use of the standard $\mathrm{N}, \mathrm{P}$ and $\mathrm{K}$ fertilizer can be profitable only to farmers whose sites have less than $5.04 \mathrm{mg} \mathrm{P} \mathrm{kg} \mathrm{g}^{-1}$ irrespective of the response clusters. Only $28 \%$ of the total sites are in this category; confirming the diagnosis of poorly responsive soils in an earlier study [27]. Obviously, the use of NPK amendments remains a risky intervention for farmers with sites that belong to the poorly responsive, Cluster 3 . Therefore, recommending the NPK amendments would also not be appropriate to farmers whose sites belong that cluster. However, determination of judicious and balanced nutrient combinations for maintaining soil productivity in such sites is indispensable [71,72]. For example, applying lower $\mathrm{N}$ and Ca rates may not only reduce the fertilizer cost but would maintain the desired nutrient balance ratio in maize ear leaf tissue. Application of NPK amendments can be beneficial to farmers whose sites belong to clusters 1 and 2, respectively. Furthermore, the smaller the available P $(<4.72 \mathrm{mg}$ $\mathrm{kg}^{-1}$ ) in such soils, the more financial benefits may be realized. However, if the soils have more than $4.72 \mathrm{mg} \mathrm{P} \mathrm{kg}^{-1}$ of soil, supplying of both macro and micronutrients at optimum levels is critical for sites in Cluster 2. For maximum benefit of the NPK amendments, sites should have less than $2.93 \mathrm{mg}$ $\mathrm{P} \mathrm{kg}^{-1}$ of soil. In such case, not only $\mathrm{P}$ would be limiting maize production but also the secondary and micronutrients.

\section{Conclusions}

This study has demonstrated the need for going beyond the application of the standard N, P and $\mathrm{K}$ fertilizers in rehabilitating the poorly responsive soils. Specifically, we demonstrated that (i) maize grain yields increased following inclusion of SMNs in specific cases; (ii) maize response patterns to the interventions relate to specific leaf nutrient content and soil properties and (iii) the addition of the selected nutrients to the standard N, P and $\mathrm{K}$ fertilizer renders the interventions profitable in some cases. In general, the results indicate that application of $\mathrm{Ca}$ is important for all the poor responsive soils irrespective of the source and region. In addition, the optimal rates of $\mathrm{Zn}$ and $\mathrm{Cu}$ at $3 \mathrm{~kg} \mathrm{ha}^{-1}$ are necessary for sites in Bungoma-Southwest compared to those in Busia-North. For the 
latter region, amendment of those nutrients through FYM is adequate. Further, varied crop responses to the NPK amendments irrespective of the regions were observed: (i) response to all three NPK amendments, Cluster 1 (ii) response to only one amendment, Cluster 2 and (iii) poor response to all the three NPK amendments, Cluster 3. Emerging deficiencies of both S, Mg and B were observed while $\mathrm{Cu}$ amendment was not still sufficient for optimal maize production in some of the sites. This study was also able to delineate those sites in which the NPK amendments may be profitable from those that require further attention. Beyond the maize response clusters, available $\mathrm{P}$ in soil determines the profitability of NPK amendments. This is an indication that farmers may have fertilizer options that guide them in decision making for management of poorly responsive soils. The persistent poor responses call for further research to understand the underlying factors such as soil mineralogy and after modifying the NPK amendments for improved crop productivity with a balanced nutrition.

Acknowledgments: We acknowledge the funding of this study by the VLIR-IUC-MUK Programme (Vlaamse Interuniversitaire Raad, Institutional University Cooperation between Flanders (Belgium) and Moi University, Kenya) of which the project was part. The 'CONNESSA' project ERAfrica_IC-080, ERA-NET FP7 partly also funded this study. We are grateful for the farmers' cooperation and participation across Bungoma-Southwest and Busia-North sites throughout the stud period. We also appreciate the provision of long-term rainfall data from Kenya meteorology department, Nairobi, Kenya. Finally, yet importantly, we acknowledge the technical support accorded by experts from both the University of Eldoret, Kenya and KU Leuven, Belgium.

Author Contributions: Ruth Njoroge designed and conducted all field trials, analyzed data and wrote the manuscript. Roel Merckx conceived the research and revised the manuscript. Abigael N. Otinga and John R. Okalebo revised the manuscript. Mary Emongole assisted in the maintenance of field trials and data collection.

Conflicts of Interest: The authors declare no conflicts of interest.

\section{References}

1. Bindraban, P.S.; Dimkpa, C.; Nagarajan, L.; Roy, A.; Rabbinge, R. Revisiting fertilisers and fertilisation strategies for improved nutrient uptake by plants. Biol. Fertil. Soils 2015, 51, 897-911. [CrossRef]

2. Hossain, M.; Singh, V.P. Fertilizer use in asian agriculture: Implications for sustaining food security and the environment. Nutr. Cycl. Agroecosyst. 2000, 57, 155-169. [CrossRef]

3. FAO (Food and Agriculture Organization of the United Nations). Regional Overview of Food Insecurity: African Food Security Prospects Brighter than Ever; FAO: Accra, Ghana, 2015.

4. IFDC (International Fertilizer Development Center). Proceedings of the Africa Fertilizer Summit, Fertilizer Africa Congress. Abuja, Nigeria, 9-13 June 2006; Thigpen, L.L., Hargrove, T.R., Eds.; IFDC: Abuja, Nigeria.

5. Sasson, A. Food security for africa: An urgent global challenge. Agric. Food Secur. 2012, 1, 1-16. [CrossRef]

6. Ozor, N.; Umunnakwe, C.P.; Acheampong, E. Challenges of food security in africa and the way forward. Development 2013, 56, 404-411. [CrossRef]

7. Diriye, M.; Nur, A.; Khalif, A. Food aid and the challenge of food security in africa. Development 2013, 56, 396-403. [CrossRef]

8. Marenya, P.P.; Barrett, C.B. State-conditional fertilizer yield response on western kenyan farms. Am. J. Agric. Econ. 2009, 91, 991-1006. [CrossRef]

9. Vanlauwe, B.; Giller, K.E. Popular myths around soil fertility management in sub-saharan africa. Agric. Ecosyst. Environ. 2006, 116, 34-46. [CrossRef]

10. Tamene, L.; Mponela, P.; Ndengu, G.; Kihara, J. Assessment of maize yield gap and major determinant factors between smallholder farmers in the dedza district of malawi. Nutr. Cycl. Agroecosyst. 2016, 105, 291-308. [CrossRef]

11. Drechsel, P.; Kunze, D.; de Vries, F.P. Soil nutrient depletion and population growth in sub-saharan africa: A malthusian nexus? Popul. Environ. 2001, 22, 411-423. [CrossRef]

12. Stoorvogel, J.J.; Smaling, E.M.A.; Janssen, B.H. Calculating soil nutrient balances in africa at different scales. Fertil. Res. 1993, 35, 227-235. [CrossRef]

13. Ricker-Gilbert, J.; Mason, N.M.; Darko, F.A.; Tembo, S.T. What are the effects of input subsidy programs on maize prices? Evidence from malawi and zambia. Agric. Econ. 2013, 44, 671-686. [CrossRef]

14. Druilhe, Z.; Barreiro-Hurlé, J. Fertilizer Subsidies in Sub-Saharan Africa; FAO: Rome, Italy, 2012. 
15. Vanlauwe, B.; Kihara, J.; Chivenge, P.; Pypers, P.; Coe, R.; Six, J. Agronomic use efficiency of $\mathrm{n}$ fertilizer in maize-based systems in sub-saharan africa within the context of integrated soil fertility management. Plant Soil 2011, 339, 35-50. [CrossRef]

16. Nziguheba, G.; Tossah, B.K.; Diels, J.; Franke, A.C.; Aihou, K.; Iwuafor, E.N.O.; Nwoke, C.; Merckx, R. Assessment of nutrient deficiencies in maize in nutrient omission trials and long-term field experiments in the west african savanna. Plant Soil 2008, 314, 143-157. [CrossRef]

17. Nziguheba, G.; Zingore, S.; Kihara, J.; Merckx, R.; Njoroge, S.; Otinga, A.; Vandamme, E.; Vanlauwe, B. Phosphorus in smallholder farming systems of sub-saharan africa: Implications for agricultural intensification. Nutr. Cycl. Agroecosyst. 2016, 104, 321-340. [CrossRef]

18. Vanlauwe, B.; Coe, R.I.C.; Giller, K.E. Beyond averages: New approaches to understand heterogeneity and risk of technology success or failure in smallholder farming. Exp. Agric. 2016, 1-23. [CrossRef]

19. Vanlauwe, B.; Descheemaeker, K.; Giller, K.E.; Huising, J.; Merckx, R.; Nziguheba, G.; Wendt, J.; Zingore, S. Integrated soil fertility management in sub-saharan africa: Unravelling local adaptation. Soil 2015, 1, 491-508. [CrossRef]

20. Tittonell, P.; Vanlauwe, B.; Corbeels, M.; Giller, K.E. Yield gaps, nutrient use efficiencies and response to fertilisers by maize across heterogeneous smallholder farms of western kenya. Plant Soil 2008, 313, $19-37$. [CrossRef]

21. Vanlauwe, B.; Bationo, A.; Chianu, J.; Giller, K.E.; Merckx, R.; Mokwunye, U.; Ohiokpehai, O.; Pypers, P.; Tabo, R.; Shepherd, K.D.; et al. Integrated soil fertility management: Operational definition and consequences for implementation and dissemination. Outlook Agric. 2010, 39, 17-24. [CrossRef]

22. Kelly, A.V. Factors affecting demand for fertilizer in sub-Saharan Africa. In Discussion Paper; World Bank: Washington, DC, USA, 2006.

23. Kihara, J.; Nziguheba, G.; Zingore, S.; Coulibaly, A.; Esilaba, A.; Kabambe, V.; Njoroge, S.; Palm, C.; Huising, J. Understanding variability in crop response to fertilizer and amendments in sub-saharan africa. Agric. Ecosyst. Environ. 2016, 229, 1-12. [CrossRef] [PubMed]

24. Jones, D.L.; Cross, P.; Withers, P.J.A.; DeLuca, T.H.; Robinson, D.A.; Quilliam, R.S.; Harris, I.M.; Chadwick, D.R.; Edwards-Jones, G.; Kardol, P. Review: Nutrient stripping: The global disparity between food security and soil nutrient stocks. J. Appl. Ecol. 2013, 50, 851-862. [CrossRef]

25. Jaetzold, R.; Schmidt, H.; Hornetz, B.; Shisanya, C. Farm Management Handbook of Kenya: Natural Conditions and Farm Management Information. Part A: West Kenya, Subpart a1, Western Province, 2nd ed.; Ministry of Agriculture and German Agency for Technical Cooperation: Nairobi, Kenya, 2005; Volume 2.

26. Sombroek, W.G.; Braun, H.M.H.; Pouw, B.J.A.V.D. Exploratory Soil Map and Agro-Climatic Zone Map of Kenya, 1980, Scale 1:1,000,000; 9789032701628; Kenya Soil Survey: Nairobi, Kenya, 1982.

27. Njoroge, R.; Otinga, A.N.; Okalebo, J.R.; Pepela, M.; Merckx, R. Occurrence of poorly responsive soils in western kenya and associated nutrient imbalances in maize (zea mays l.). Field Crop. Res. 2017, 210, 162-174. [CrossRef]

28. IUSS Working Group WRB. World reference base for soil resources 2014, update 2015. International soil classification system for naming soils and creating legends for soil maps. In World Soil Resources Reports; FAO: Rome, Italy, 2015.

29. NAAIAP (National Accelerated Agricultural Inputs Access Programme); KARI (Kenya Agricultural Research Institute). Soil Suitability Evaluation for Maize Production in Kenya, Agriculture, Ed.; Ministry of Agriculture Livestock \& Fisheries: Nairobi, Kenya, 2014.

30. Okalebo, J.R.; Gathua, K.W.; Woomer, P.L. Laboratory Methods of Soil and Plant Analysis. A Working Manual, 2nd ed.; TSBF-CIAT and SACRED AFRICA: Nairobi, Kenya, 2002.

31. Dumas, J.B.A. Procedes de l'analyse organic. Ann. Chim. Phys. 1931, 247, 198-213.

32. Ciesielski, H.; Sterckeman, T.; Santerne, M.; Willery, J.P. Determination of cation exchange capacity and exchangeable cations in soils by means of cobalt hexamine trichloride. Effects of experimental conditions. Agronomie 1997, 17, 1-7. [CrossRef]

33. Jones, J.B. Field sampling procedures for conducting a plant analysis. In Handbook of Reference Methods for Plant Analysis; CRC Press: Boca Raton, FL, USA, 1997.

34. Havlin, J.L.; Soltanpour, P.N. A nitric acid plant tissue digest method for use with inductively coupled plasma spectrometry. Commun. Soil Sci. Plant Anal. 1980, 11, 969-980. [CrossRef] 
35. Bremner, J.; Tabatabai, M. Use of automated combustion techniques for total carbon, total nitrogen, and total sulfur analysis of soils. In Instrumental Methods for Analysis of Soils and Plant Tissue; Soil Science Society of America: Madison, WI, USA, 1971; pp. 1-15.

36. Townsend, R.F. Agricultural Incentives in Sub-Saharan Africa: Policy Challenges; World Bank: Washington, DC, USA, 1999; Volume 23.

37. Tittonell, P.; Shepherd, K.D.; Vanlauwe, B.; Giller, K.E. Unravelling the effects of soil and crop management on maize productivity in smallholder agricultural systems of western Kenya-An application of classification and regression tree analysis. Agric. Ecosyst. Environ. 2008, 123, 137-150. [CrossRef]

38. Breiman, L.; Friedman, J.H.; Olshen, R.A.; Stone, C.J. Classification and Regression Trees; Wadsworth \& Brooks: Monterey, CA, USA, 1984.

39. SAS Institute. Discovering Jmp $12^{\circledR}$; SAS Institute: Cary, NC, USA, 2015.

40. Sanchez, P.A. Tripling crop yields in tropical africa. Nat. Geosci. 2010, 3, 299-300. [CrossRef]

41. Kanyanjua, S.M.; Ireri, L.; Wambua, S.; Nandwa, S.M. Acidic soils in Kenya: Constraints and remedial options. In KARI Technical Note Series; Mugah, J.O.E.A., Ed.; KARI Headquarters, Nairobi, Kenya: Nairobi, $2002 ;$ p. 27.

42. Otinga, A.N.; Pypers, P.; Okalebo, J.R.; Njoroge, R.; Emong'ole, M.; Six, L.; Vanlauwe, B.; Merckx, R. Partial substitution of phosphorus fertiliser by farmyard manure and its localised application increases agronomic efficiency and profitability of maize production. Field Crops Res. 2013, 140, 32-43. [CrossRef]

43. Opala, P.; Okalebo, J.; Othieno, C. Effects of organic and inorganic materials on soil acidity and phosphorus availability in a soil incubation study. ISRN Agron. 2012, 2012. [CrossRef]

44. Cooper, P.J.M.; Dimes, J.; Rao, K.P.C.; Shapiro, B.; Shiferaw, B.; Twomlow, S. Coping better with current climatic variability in the rain-fed farming systems of sub-Saharan Africa: An essential first step in adapting to future climate change? Agric. Ecosyst. Environ. 2008, 126, 24-35. [CrossRef]

45. Saini, H.S.; Westgate, M.E. Reproductive development in grain crops during drought. Adv. Agron. 1999, 68, 59-96.

46. Kihara, J.; Njoroge, S. Phosphorus agronomic efficiency in maize-based cropping systems: A focus on western Kenya. Field Crops Res. 2013, 150, 1-8. [CrossRef]

47. Palm, C.A.; Gachengo, C.N.; Delve, R.J.; Cadisch, G.; Giller, K.E. Organic inputs for soil fertility management in tropical agroecosystems: Application of an organic resource database. Agric. Ecosyst. Environ. 2001, 83, 27-42. [CrossRef]

48. Zingore, S.; Delve, R.J.; Nyamangara, J.; Giller, K.E. Multiple benefits of manure: The key to maintenance of soil fertility and restoration of depleted sandy soils on African smallholder farms. Nutr. Cycl. Agroecosyst. 2008, 80, 267-282. [CrossRef]

49. Reuters, D.J.; Robinson, J.B. Plant Analysis: An Interpretation Manual, 2nd ed.; CSIRO: Collinwood, Australia, 1997.

50. FAO. Fertilizer and Plant Nutrition Guide; FAO: Rome, Italy, 1984; Volume M-52, pp. 2-14.

51. Sillanpää, M. Micronutrient assessment at the country level: An international study. In FAO Soils Bulletin; FAO: Rome, Italy, 1990; Volume 63.

52. Kopriva, S.; Koprivova, A. Plant adenosine $5^{\prime}$-phosphosulphate reductase: The past, the present, and the future. J. Exp. Bot. 2004, 55, 1775-1783. [CrossRef] [PubMed]

53. Scherer, H.W. Sulphur in crop production. Eur. J. Agron. 2001, 14, 81-111. [CrossRef]

54. Van Biljon, J.; Fouche, D.; Botha, A. Threshold values for sulphur in soils of the main maize-producing areas of South Africa. South Afr. J. Plant Soil 2004, 21, 152-156. [CrossRef]

55. Poulton, C.; Kydd, J.; Dorward, A. Increasing fertilizer use in Africa: What have we learned? In Discussion Paper; World Bank: Washington, DC, USA, 2006; Volume 25.

56. Channabasamma, A.; Habsur, N.S.; Bangaremma, S.W.; Akshaya, M.C. Effect of nitrogen and sulphur levels and ratios on growth and yield of maize. Mol. Plant Breed. 2013, 4, 292-296.

57. Gransee, A.; Führs, H. Magnesium mobility in soils as a challenge for soil and plant analysis, magnesium fertilization and root uptake under adverse growth conditions. Plant Soil 2013, 368, 5-21. [CrossRef]

58. Walsh, T.; O'Donohoe, T.F. Magnesium deficiency in some crop plants in relation to the level of potassium nutrition. J. Agric. Sci. 2009, 35, 254-263. [CrossRef]

59. Cai, J.; Chen, L.; Qu, H.; Lian, J.; Liu, W.; Hu, Y.; Xu, G. Alteration of nutrient allocation and transporter genes expression in rice under N, P, K, and Mg deficiencies. Acta Physiol. Plant. 2012, 34, 939-946. [CrossRef] 
60. Bowen, J.E. Absorption of copper, zinc, and manganese by sugarcane leaf tissue. Plant Physiol. 1969, 44, 255-261. [CrossRef] [PubMed]

61. Okalebo, J.; Simpson, J.; Probert, M. A search for strategies for sustainable dryland cropping in semi-arid Eastern Kenya, Nairobi. In Phosphorus Status of Cropland Soils in the Semi-Arid Areas of Machakos and Kitui Districts, Kenya; Probert, M., Ed.; Australian Centre for International Agricultura1 Research: Nairobi, Kenya, 1990; pp. 50-54.

62. Lordkaew, S.; Dell, B.; Jamjod, S.; Rerkasem, B. Boron deficiency in maize. Plant Soil 2011, 342, 207-220. [CrossRef]

63. Woodruf, J.R.; Moore, F.W.; Musen, H.L. Potassium, boron, nitrogen, and lime effects on corn yield and earleaf nutrient concentrations1. Agron. J. 1987, 79, 520-524. [CrossRef]

64. Kanwal, S.; Rahmatullah; Aziz, T.; Maqsood, M.A.; Abbas, N. Critical ratio of calcium and boron in maize shoot for optimum growth. J. Plant Nutr. 2008, 31, 1535-1542. [CrossRef]

65. Gupta, U.C. Boron nutrition of crops. Adv. Agron. 1980, 31, 273-307.

66. Chatterjee, C.; Sinha, P.; Nautiyal, N.; Agarwala, S.C.; Sharma, C.P. Metabolic changes associated with boron-calcium interaction in maize. Soil Sci. Plant Nutr. 1987, 33, 607-617. [CrossRef]

67. Günes, A.; Alpaslan, M. Boron uptake and toxicity in maize genotypes in relation to boron and phosphorus supply. J. Plant Nutr. 2000, 23, 541-550. [CrossRef]

68. Suri, T. Selection and comparative advantage in technology adoption. Econometrica 2011, 79, 159-209.

69. Koussoubé, E.; Nauges, C. Returns to fertiliser use: Does it pay enough? Some new evidence from sub-Saharan Africa. Eur. Rev. Agric. Econ. 2017, 44, 183-210. [CrossRef]

70. Kihara, J.; Huising, J.; Nziguheba, G.; Waswa, B.S.; Njoroge, S.; Kabambe, V.; Iwuafor, E.; Kibunja, C.; Esilaba, A.O.; Coulibaly, A. Maize response to macronutrients and potential for profitability in sub-Saharan Africa. Nutr. Cycl. Agroecosyst. 2016, 105, 171-181. [CrossRef]

71. Zingore, S. Maize productivity and response to fertilizer use as affected by soil fertility variability, manure application, and cropping system. Better Crops 2011, 95, 4-6.

72. Ngetich, F.K.; Shisanya, C.A.; Mugwe, J.; Mucheru-Muna, M.; Mugendi, D. The potential of organic and inorganic nutrient sources in sub-Saharan African crop farming systems. In Soil Fertility Improvement and Integrated Nutrient Management-A Global Perspective; Intech: Rijeka, Croatia, 2011; p. 135.

(c) 2018 by the authors. Licensee MDPI, Basel, Switzerland. This article is an open access article distributed under the terms and conditions of the Creative Commons Attribution (CC BY) license (http:/ / creativecommons.org/licenses/by/4.0/). 
Article

\title{
Nitrate Assimilation Limits Nitrogen Use Efficiency (NUE) in Maize (Zea mays L.)
}

\author{
Dale Loussaert *, Josh Clapp, Nick Mongar, Dennis P. O'Neill and Bo Shen \\ DuPont Pioneer, 7250 NW 62nd Ave, Johnston, IA 50113, USA; joshuaclapp76@gmail.com (J.C.); \\ nick.mongar@pioneer.com (N.M.); dennis.oneill@pioneer.com (D.P.O.); bo.shen@pioneer.com (B.S.) \\ * Correspondence: dale.loussaert@gmail.com; Tel.: +1-515-720-3965
}

Received: 31 May 2018; Accepted: 27 June 2018; Published: 1 July 2018

\begin{abstract}
Grain yield in maize responds to $\mathrm{N}$ fertility in a linear-plateau fashion with nitrogen use efficiency (NUE) higher under lower $\mathrm{N}$ fertilities and less as grain yield plateaus. Field experiments were used to identify plant parameters relative for improved NUE in maize and then experiments were performed under controlled conditions to elucidate metabolism controlling these parameters. Field experiments showed reproductive parameters, including R1 ear-weight, predictive of $\mathrm{N}$ response under both high and low NUE conditions. R1 ear-weight could be changed by varying nitrate concentrations early during reproductive development but from V12 onward R1 ear-weight could be changed little by increasing or decreasing nitrate fertility. Ammonia, on the other hand, could rescue R1 ear-weight as late as V15 suggesting nitrate assimilation (NA) limits ear development response to $\mathrm{N}$ fertility since bypassing NA can rescue R1 ear-weight. Nitrate reductase activity (NRA (in vitro)) increases linearly with nitrate fertility but in vivo nitrate reductase activity (NRA (in vivo)) follows organic $\mathrm{N}$ accumulation, peaking at sufficient levels of nitrate fertility. The bulk of the increase in total plant $\mathrm{N}$ at high levels of nitrate fertility is due to increased plant nitrate concentration. Increasing NADH levels by selective co-suppression of ubiquinone oxidoreductase $51 \mathrm{kDa}$ subunit (Complex I) was associated with improved grain yield by increasing ear size, as judged by increased kernel number plant $^{-1}(\mathrm{KNP})$, and increased NRA (in vivo) without a change in NRA (in vitro). These results support NUE is limited in maize by NA but not by nitrate uptake or NRA (in vitro).
\end{abstract}

Keywords: nitrogen use efficiency (NUE); nitrate assimilation; nitrate reductase activity; maize; nitrate; ammonia; NADH; NADH-dehydrogenase; Complex I

\section{Introduction}

NUE in maize is defined as an incremental increase in grain yield with incremental increases in $\mathrm{N}$ fertilizer [1,2]. Grain yield responds to $\mathrm{N}$ fertility in a linear-plateau fashion [3]. NUE is greater at lower inputs of $\mathrm{N}[1,4,5]$ where grain yield responses approach linearity, and NUE is very low past the inflexion point where little grain yield increases result from increased $\mathrm{N}$ fertility. NUE in maize ranges from $50-10 \%$ [6-8] but field sources of $\mathrm{N}$ are not limited to fertilizer input. Field environments may provide up to $185 \mathrm{~kg} \mathrm{ha}^{-1}$ of non-fertilizer $\mathrm{N}$ [9] with $\mathrm{N}$ mineralization and $\mathrm{N}$ carryover as sources of non-fertilizer $\mathrm{N}$ input. These additional sources of $\mathrm{N}$ vary from season to season based on soil temperature and moisture, organic matter, and performance of the previous crop. Precise control of $\mathrm{N}$ input in a field environment is difficult and only 50-65\% of applied fertilizer is taken up by the plant the same year it is applied [9,10]. Applied $\mathrm{N}$ fertilizer can be incorporated into soil organic matter, lost due to ammonia volatility, leached, and lost due to denitrification [11-14]. Precise control of $\mathrm{N}$ in field environments required to develop transgenic improvements in NUE is very difficult and requires controlled environments to complement field experimentation to bridge the gap between what is known biochemically, required to make transgenic modifications, and field performance. 
Nitrate uptake and assimilation have been studied in controlled environments using the model system, Arabidopsis thaliana (L.) Heynh. $[8,15,16]$, but A. thaliana is a rather poor model for maize both genetically [17] and physiologically. Not only is photosynthetic carbon metabolism different between maize (C4) and A. thaliana (C3) but nitrogen metabolism is dissimilar [18,19].

Recently, Fan et al. [20] showed transgenic expression of a high affinity nitrate transporter significantly improves NUE in rice. It is difficult to conceive that increasing nitrate uptake would have a significant effect on maize, especially under high $\mathrm{N}$ fertility, since maize accumulates significant amounts of nitrate under these conditions. As much as $70 \%$ of stalk $\mathrm{N}$ is nitrate [21]. Cliquet et al. [22] showed that $47 \%$ of the $\mathrm{N}$ applied after pollination accumulated in the stalk as nitrate. Currently, the main interest in stalk nitrate is in predicting $\mathrm{N}$ carryover and overall plant health when soil nitrate is limited by poor fertilization or nitrate leaching $[4,23,24]$ but stalk nitrate is also associated with reduced NUE. Brouder et al. [25] showed that stalk nitrate and agronomic efficiency, defined identically as NUE, were inversely related. Binford et al. [4] showed, using 900 crop years of data, that stalk nitrate is linearly related to grain yield up to the linear regression plateau (LRP) inflection point. This would suggest that accumulation of stalk nitrate is symptomatic of reduced NUE as demonstrated by Varvel et al. [26] and Brouder et al. [25]. Varvel et al. [26] showed stalk nitrate linearly increased with increased $\mathrm{N}$ fertility past the LRP inflection point while grain yields were unchanged. With no additional grain yield with increased $\mathrm{N}$ fertility, NUE dropped as stalk nitrate dramatically increased. Under normal or high $\mathrm{N}$ fertility, maize will concentrate nitrate in the stalk 20-100 times the soil nitrate concentration [24] which would argue that $\mathrm{N}$ uptake is not limiting under high $\mathrm{N}$ fertility (low NUE).

Linking physiological/biochemical information to relevant field performance is critical in developing transgenic improvements in maize NUE. Though nitrate transporter research is more recent than NA research, NA is likely more relevant in improving NUE in maize. Beevers and Hageman [27] proposed that NRA (in vitro) is the limiting step in N metabolism in plants. Though grain yields in maize can be significantly improved by $\mathrm{N}$ fertility, a direct correlation between NRA (in vitro) and grain yield has never been established. Blackmer et al. [28] showed $>80 \%$ of grain yield was related to spring soil nitrate concentrations. Klepper et al. [29] showed in vivo nitrate reductase activity, NRA (in vivo), or the ability of leaf tissue to generate nitrite from nitrate in the dark, was enhanced by respiratory metabolites. Klepper et al. [29] also demonstrated that NRA (in vitro) could be supported by the addition of glyceraldehyde-3-phosphate and $\mathrm{NAD}^{+}$to cell free plant extracts suggesting glyceraldehyde-3-phosphate dehydrogenase (GA3PDH-EC 1.2.1.12) the source of NADH for nitrate reduction. Later, Gowri and Campbell [30] showed that NRA (in vitro) and GA3PDH are coincidentally induced by nitrate in etiolated maize. Though extractable levels of GA3PDH are high enough to provide sufficient NADH to support NRA (in vitro) and NRA (in vitro) and GA3PDH are co-induced by nitrate, this is not a proof of in vivo metabolism. Klepper et al. [29] also noted that NRA (in vitro) was 2.5-20 times higher than the rate of NRA (in vivo) which would suggest that extractable NRA (in vitro), per se, is far in excess of what is required to support NA. Also, since extractable levels of GA3PDH are high enough to support NRA (in vitro) it would follow that GA3PDH is in excess of that required to support NA. Later, Neyra and Hageman [31] suggested malate could be a substrate for generating NADH to support NA. Neither Klepper et al. [29] nor Neyra and Hageman [31] were able to demonstrate enhanced NRA (in vivo), by the addition of malate to the NRA (in vivo) assay medium. Rathnam [32] showed NA, measured by the disappearance of nitrate, in spinach protoplast could be supported by the addition of phospho-3-glyceric acid and oxaloacetic acid (OAA) in the light and/or by glyceraldehyde-3-phosphate and malate in either light or dark showing GA3PDH and/or malate dehydrogenase (MDH-EC 1.1.1.37) capable of supporting NA. Similar to the observation made by Klepper et al. [29], Kaiser et al. [33] also observed higher extractable levels of NRA (in vitro) than NRA (in vivo) and concluded that NADH levels, and not NRA (in vitro), limits NA. Later, increased leaf NADH levels were also reported [33] to be associated with NA.

In order to complete the nitrogen assimilation pathway from nitrate to the formation of glutamate, NADH, ATP, reduced ferredoxin, and $\alpha$-ketoglutarate $(\alpha \mathrm{KG})$ are required. Mitochondrial 
or cytoplasmic isocitrate dehydrogenase (ICDH-EC 1.1.1.41, EC 1.1.1.42) produce $\alpha$ KG. Reducing the expression of mitochondrial citrate synthase (CS-EC 2.3.3.1) [34] or ICDH [35] in tomato resulted in elevated levels of lamina nitrate. This suggests a direct link between $\alpha \mathrm{KG}$ and nitrate reduction. When isocitrate or $\alpha$ KG moves out of the mitochondria, NADH levels drop in the mitochondria and since NADH does not pass through the mitochondrial membrane it cannot be replenished directly. Reestablishing the mitochondrial NADH concentration may be done by importing malate from the cytoplasm. Assuming malate provides significant reduction power for NA the loss of malate from the cytoplasm results in NA becoming limited by low cytoplasmic NADH. Thus, the pathway becomes self-regulated. Cytoplasmic male sterile (CMS) tobacco [36] and CMS cucumber [37] have improved NUE under lower $\mathrm{N}$ fertility. These CMS mutants with defective Complex I (NADH dehydrogenase-EC 1.6.5.3) have reduced capacity to oxidize mitochondrial NADH which results in increased mitochondrial NADH concentrations, reducing the need to import malate to balance the mitochondrial NADH levels due to the transport of $\alpha \mathrm{KG}$ out of the mitochondria. Based on these observations, Foyer et al. [38] predicted over-expression of ICDH or co-suppression of Complex I would improve NUE. CMS tobacco [36] and CMS cucumber [37] might be examples of improved NUE through diminished Complex I activity but these have associated deleterious attributes (slow growth, male sterility) which makes these agronomically unsuitable. The mutant NCS2 in maize also has defective Complex I and expresses undesirable traits [39] but has not, specifically, been shown to have improved NUE.

In this report, multi-year field experiments of maize grown at different levels of NUE showed reproductive plant parameters are associated with improved NUE under both low and high NUE conditions. The response of these parameters to different forms of $\mathrm{N}$ applied at different times of development were used, under controlled environments, to elucidate key physiological factors related to improved NUE. The accumulation of nitrate in lower internodes was investigated between plants grown under high and low NUE conditions and shown to be inversely related to improved NUE. Finally, increasing cytoplasmic NADH using a transgenic co-suppression of Complex I under the control of a tissue preferred promoter increased kernel number plant ${ }^{-1}(\mathrm{KNP})$ and grain yield under low NUE (high N fertility) conditions. In all, these results suggest that NA limits NUE in maize via reduced availability of cytoplasmic $\mathrm{NADH}$.

\section{Materials and Methods}

\subsection{Field NUE Analyses under Normal and Depleted N Conditions}

Field plots depleted of $\mathrm{N}$ for a minimum of two years were used in NUE experiments over a period of three years in Johnston, Iowa. Non-depleted plots were plots in previous cropping seasons fertilized with $\mathrm{N}$ to obtain maximum economic grain yield of maize. In the depleted plots $\mathrm{N}$ treatments consisted of $0,22,45,67 \mathrm{~kg} \mathrm{ha}^{-1} \mathrm{~N}$ applied as urea and in the non-depleted plots $\mathrm{N}$ treatments were 0 , $34,67,101,135$, and $168 \mathrm{~kg} \mathrm{ha}^{-1} \mathrm{~N}$ applied as urea. All $\mathrm{N}$ applications were made at V3. The three DuPont-Pioneer hybrids (33K42, 33W84, and 33T56) used in these studies were selected based on a range of yield responses to $\mathrm{N}$ fertility when grown under depleted $\mathrm{N}$ conditions in multi-environment trials. The experiments were arranged in a split, split plot experimental design with season as the main plot, $\mathrm{N}$ fertility as the subplot and cultivar as the sub, subplot. Sampling dates, R1 and maturity (black layer), were blocked as separate experiments to avoid contamination of the maturity sampling by the R1 sampling. Planting density was 75,000 plants ha ${ }^{-1}$, each plot consisted of two $5.1 \mathrm{~m}$ rows spaced $0.75 \mathrm{~m}$ apart. There were five replicates of all treatments. Soluble leaf amino acids at V9 was the first parameter measured. At R1 chlorophyll measurements (Minolta SPAD, Minolta Camera Co., Ramsey, NJ, USA) were made by averaging five samplings taken down the ear leaf of 10 plants in each plot. Chlorophyll measurements were made in a similar manner at R2 and R3. At R1 10 plants were sampled from each plot and the ears removed and dried $\left(70^{\circ} \mathrm{C}, 72 \mathrm{~h}\right)$. Ear shoots of plants sampled for R1 ear measurements were bagged prior to silk emergence to avoid pollination. Ear length, ear 
width and ear dry weight were determined. Total fresh weight of the remaining chopped plants was measured and vegetative biomass was determined by weighing and drying $\left(70^{\circ} \mathrm{C}, 72 \mathrm{~h}\right)$ a subsample. Samples were ground and total $\mathrm{N}$ determined. At maturity, 10 plants were sampled, the ears removed and dried $\left(70{ }^{\circ} \mathrm{C}, 72 \mathrm{~h}\right)$. Ear weight, grain weight, and kernel density were determined of the dried ears. Vegetative biomass and total $\mathrm{N}$ were determined similarly as at R1. Statistical analysis was performed as previously described [40].

\subsection{Field Stalk Nitrate Experiments}

The DuPont-Pioneer cultivar 33W84 was grown in field plots in Johnston, IA either fertilized for optimum grain yield $\left(224 \mathrm{~kg} \mathrm{~N}^{-1}\right)$ or in plots depleted for $\mathrm{N}$ for at least two years and fertilized with $77 \mathrm{~kg} \mathrm{~N} \mathrm{ha}^{-1}$ immediately after planting. Plants were sampled for stalk nitrate at V11, VT, R1, $\mathrm{R} 2$ and R3. Leaves associated with each internode were punched (10, $5 \mathrm{~mm}$ diameter) and used for metabolic analysis. Leaves, including leaf sheath, were removed and stalk internodes were numbered and cut at the top of each node, dried $\left(70^{\circ} \mathrm{C}, 72 \mathrm{~h}\right)$, then ground to a fine powder. When physiological measurements were made, plants were cut at ground level and transported to the laboratory in buckets filled with water.

\subsection{Controlled Environment Experiments}

A Conviron PGR15 growth chamber set at $30^{\circ} \mathrm{C}, 60 \% \mathrm{RH}, 16 \mathrm{~h}$ light $/ 25^{\circ} \mathrm{C}, 50 \% \mathrm{RH}, 8 \mathrm{~h}$ dark was used to grow the maize model system plant, Gaspe Flint-3 (GF3) (manufacturer, city, state, country) [41] under controlled environmental conditions. A semi-hydroponics irrigation system [41], similar to that described [42], was used in growth chamber and field hydroponics to attain a high level of control of $\mathrm{N}$ input. When ammonia was used as an $\mathrm{N}$ source $1 \mathrm{mM} \mathrm{NH}_{4} \mathrm{Cl}$ was substituted for $\mathrm{KNO}_{3}$ but $\mathrm{KCl}$ was maintained at $4 \mathrm{mM}$. GF3 was grown in $1.74 \mathrm{~L}$ pots and field hydroponics plants were grown in 15.14 L pots.

\subsection{Controlled Environment Plant Samplings}

When plants were sampled, the Turface ${ }^{\mathrm{TM}}$ (Turface/Profile Products, LLC, Buffalo Grove, IL, USA) was washed off the roots and the plant separated into shoot, roots, leaves, midribs, tassel, tillers, husk, and ear. Plant parts were dried $\left(70{ }^{\circ} \mathrm{C}, 72 \mathrm{~h}\right)$ but when metabolic profiling was performed, plant parts were frozen in dry ice and lyophilized. Individual plant parts were weighed, ground to a fine powder, and a sample $(30-60 \mathrm{mg})$ weighed for extraction. Fresh tissue was also extracted as leaf punches (10, $5 \mathrm{~mm}$ diameter). In either case, duplicate samples were extracted by Genogrinder (SPEX SamplePrep, Metuchen, NJ, USAin $500 \mu \mathrm{L}$ acid and $500 \mu \mathrm{L}$ base as described by Queval and Noctor [43]. When $\mathrm{NAD}^{+} / \mathrm{NADH}$ was quantified a small aliquot of the acid extract was heat-treated for the quantification of NADH and the remaining acid extract was quenched and used for metabolic analysis.

\section{5. $\mathrm{NAD}^{+} / \mathrm{NADH}$ Measurements}

The method of Queval and Noctor [43] was used.

\subsection{Total Amino Acids}

An aliquot of each tissue extract was suspended in a total volume of $100 \mu \mathrm{L}$ water and $50 \mu \mathrm{L}$ of a solution containing $350 \mathrm{mM}$ Borate buffer $\mathrm{pH} 9.5,1 \% \mathrm{SDS}, 0.5 \% \beta$-mercaptoethanol (ME), and $200 \mu \mathrm{g}$ o-phthadialdehyde was added to each well. Blank samples were treated similarly but without o-phthadialdehyde. Fluorescence (Excitation (Ex) $360 \mathrm{~nm}$ Emission (Em) $520 \mathrm{~nm}$ ) was determined immediately and each complete sample was corrected with the respective blank sample. Alanine from 0 to 5 nmole in 0.5 nmole increments, were used as standards. 


\subsection{Total $N$}

$\mathrm{N}$ of ground plant samples was converted to $(\mathrm{NO})^{\mathrm{n}}$ equivalents by oxidation using a FlashEA 1112 series combustion analyzer (Thermo Fisher Scientific, Waltham, MA, USA) applying Association of Official Analytical Chemists (AOCS) method Ba 4e-93

\subsection{Nitrate Quantification}

The method of Miranda et al. [44] was used with slight modification to correct for background anthocyanins that absorb at $540 \mathrm{~nm}$ in acid, and for nitrite. An equal volume of $1 \%$ sulfanilamide, $0.01 \%$ naphthalene ethylene diamine in $2 \mathrm{M} \mathrm{H}_{3} \mathrm{PO}_{4}$ was added and optical density at $540 \mathrm{~nm}\left(\mathrm{OD}^{540}\right)$ was determined followed by the addition of a sample volume of saturated $\mathrm{VCl}_{2}$ in $1 \mathrm{M} \mathrm{HCl}$ then incubated at $37^{\circ} \mathrm{C}$ for $1 \mathrm{~h}$. The $\mathrm{OD}^{540}$ was again measured and the previous absorption readings used to correct for anthocyanin and nitrite after correction for differences in path lengths.

\subsection{Malate Quantification}

An aliquot was suspended in a total volume of $100 \mu \mathrm{L}$ with water. $10 \mu \mathrm{L}$ of $10 \mathrm{mM}$ NADP, $5 \mathrm{mM} \mathrm{MgCl} 2,1 \mathrm{M}$ Tris- $\mathrm{HCl} \mathrm{pH} 7.5$ was added to each well followed by $10 \mu \mathrm{L}$ containing 0.05 units of malic enzyme (EC 1.1.1.40). Blank plates were prepared in the same fashion but $10 \mu \mathrm{L}$ of water was added instead of malic enzyme. These were incubated for $1 \mathrm{~h}$ at room temperature and fluorescence (Ex 345, Em 460) was measured subtracting the blank from the sample plate. Malate standards from 0 to 5 nmoles, in 0.5 nmole increments, were used.

\subsection{In Vivo Nitrate Reductase Activity-NRA (In Vivo)}

In vivo nitrate reductase activity was measured similar to the method of Reed and Hageman [45]. Leaf punches (10, $5 \mathrm{~mm}$ diameter) were submerged in $400 \mu \mathrm{L} 50 \mathrm{mM} \mathrm{KH} \mathrm{PO}_{4}-\mathrm{KHPO}_{4} \mathrm{pH}$ 6.0, $300 \mathrm{mM}$ sorbitol, $0.04 \%$ Trition $\mathrm{X}-100$ then vacuum infiltrated. A $100 \mu \mathrm{L}$ aliquot of a $100 \mathrm{mM} \mathrm{KNO}, 50 \mathrm{mM}$ $\mathrm{KHCO}_{3}, 300 \mathrm{mM}$ sorbitol, $50 \mathrm{mM} \mathrm{KH} \mathrm{PO}_{4}-\mathrm{KHPO}_{4} \mathrm{pH}$ 6.0, 0.04\% Trition X-100 solution was added to each tube so the final assay concentration was $300 \mathrm{mM}$ sorbitol, $50 \mathrm{mM} \mathrm{KH} \mathrm{PO}_{4}-\mathrm{KHPO}_{4} \mathrm{pH}$ 6.0, $0.04 \%$ Trition $\mathrm{X}-100,20 \mathrm{mM} \mathrm{KNO}_{3}$, and $10 \mathrm{mM} \mathrm{KHCO}_{3}$. Tubes were incubated in the dark at $30{ }^{\circ} \mathrm{C}$ and $50 \mu \mathrm{L}$ aliquots were remove every $30 \mathrm{~min}$ for $2 \mathrm{~h}$. The production of nitrite was determined by adding $100 \mu \mathrm{L}$ of $1 \%$ sulfanilamide, $2 \mathrm{M} \mathrm{H}_{3} \mathrm{PO}_{4}, 0.02 \%$ naphthalene ethylene diamine, and $50 \mu \mathrm{L}$ acetonitrile and measuring $\mathrm{OD}^{540}$. The assay was linear for at least $3 \mathrm{~h}$.

\subsection{In Vivo Nitrite Reductase Activity-NiRA (In Vivo)}

In vivo nitrite reductase activity was measure by the loss of nitrite from the medium. Leaf punches (5, $5 \mathrm{~mm}$ diameter) were submerged in $200 \mu \mathrm{L} 50 \mathrm{mM} \mathrm{KH} \mathrm{PO}_{4}-\mathrm{KHPO}_{4} \mathrm{pH}$ 6.0, $300 \mathrm{mM}$ sorbitol, $0.04 \%$ Trition $\mathrm{X}-100$ then vacuum infiltrated. A $50 \mu \mathrm{L}$ aliquot of a $1 \mathrm{mM} \mathrm{KNO}, 50 \mathrm{mM} \mathrm{KHCO}$, $300 \mathrm{mM}$ sorbitol, $50 \mathrm{mM} \mathrm{KH} \mathrm{PO}_{4}-\mathrm{KHPO}_{4} \mathrm{pH}$ 6.0, 0.04\% Trition X-100 solution was added to each tube so the final assay concentration was $300 \mathrm{mM}$ sorbitol, $50 \mathrm{mM} \mathrm{KH} \mathrm{PO}_{4}-\mathrm{KHPO}_{4} \mathrm{pH} 6.0,0.04 \%$ Trition X-100, $200 \mu \mathrm{M} \mathrm{KNO}_{2}$, and $10 \mathrm{mM} \mathrm{KHCO}_{3}$. Tubes were incubated at $30{ }^{\circ} \mathrm{C}$ under a bank of light emitting diodes of photosynthetic quality (Quantum Devices, Model \# SL1515-470-670, manufacturer, Barneveld, WI, USA). Duplicate $10 \mu \mathrm{L}$ aliquots were removed every $30 \mathrm{~min}$ for $2 \mathrm{~h}$ and treated with $150 \mu \mathrm{L}$ of $1 \%$ sulfanilamide, $2 \mathrm{M} \mathrm{H}_{3} \mathrm{PO}_{4}, 0.02 \%$ naphthalene ethylene diamine, and $50 \mu \mathrm{L}$ acetonitrile and $\mathrm{OD}^{540}$ determined. The assay was linear for at least $3 \mathrm{~h}$.

\subsection{Enzyme (In Vitro) Extraction}

Extraction tubes (1.2) $\mathrm{mL}$ were filled with $500 \mu \mathrm{L}$ of a $1 \%$ slurry of insoluble polyvinyl polypyrrolidone (PVPP), reduced to dryness by Speedvac (SPD131DDA-115 Thermo Fisher Scientific, Waltham, MA, USA), then stored at room temperature until use. Extraction tubes were filled with $500 \mu \mathrm{L}$ extraction medium (100 mM Tris- $\mathrm{HCl} \mathrm{pH} 8,10 \mathrm{mM}$ cysteine, $10 \mu \mathrm{M}$ leupeptin, $\left.4^{\circ} \mathrm{C}\right)$ and 
leaf punches (10, $5 \mathrm{~mm}$ diameter) were delivered to the tubes. The tubes were arranged in a 96-well plate such that surrounding tubes contained ice and were vacuum infiltrated. Tubes were ground by Genogrinder for 2, 1 min intervals. Plates were centrifuged $4000 \times g$ for $20 \mathrm{~min}$ at $4{ }^{\circ} \mathrm{C}$ and a $200 \mu \mathrm{L}$ aliquot removed and place on a $2 \mathrm{~mL}$ bed of Sephadex G-25 previously equilibrated with $50 \mathrm{mM}$ Tris- $\mathrm{HCl} \mathrm{pH} 7.5$ with the void volume removed by a $1 \mathrm{~min} 500 \times g$ centrifugation. Small molecular weight metabolites were removed from the plant extract without dilution by a second low speed centrifugation with the receiving wells containing concentrated cysteine and leupeptin to maintain $10 \mathrm{mM}$ and $10 \mu \mathrm{M}$ concentrations, respectively.

\subsection{Nitrate Reductase Activity (NRA (In Vitro)) EC 1.6.6.1}

Cyclic renewal of NADH was used to avoid excess NADH from interfering with color development. The assay was performed in a $20 \mu \mathrm{L}$ volume in 384-well plates with the following component concentrations: enzyme extract; $100 \mathrm{mM}$ Tris- $\mathrm{HCl} \mathrm{pH} \mathrm{7.5;} 10 \mathrm{mM}$ cysteine; $10 \mathrm{mM} \mathrm{KNO}_{3}$; $20 \mu \mathrm{M} \mathrm{NAD}^{+}$; 1 mM glucose-6-phosphate; and, 1 unit glucose-6-phosphate dehydrogenase-NAD ${ }^{+}$ (EC 1.1.1.388). The reaction was started by the addition of enzyme extract and stopped at $30 \mathrm{~min}$ intervals by adding two volumes of $1 \%$ sulfanilamide, $2 \mathrm{M} \mathrm{H}_{3} \mathrm{PO}_{4}, 0.02 \%$ naphthalene ethylene diamine. Activation state of NRA (in vitro) was estimated by including either $5 \mathrm{mM}$ EDTA or $10 \mathrm{mM}$ $\mathrm{MgCl}_{2}$ in the assay. The ratio of $\mathrm{MgCl}_{2}$ to EDTA enzyme activities was used as estimate of the activation state of NRA (in vitro) [46].

Since the concentration of NADH was maintained at $20 \mu \mathrm{M}$, inhibition of color development was not statistically $(p \leq 0.05)$ significant, relative to the inherent variability of the experiments. If there was interference of color development it would be constant across all samples since the concentration of NADH was maintained constant. In an assay development experiment where the concentration of $\mathrm{NAD}^{+}$was varied $0,20,50,100$, and $200 \mu \mathrm{M}$ in the assay media across a range of nitrite concentrations from 0 to $100 \mu \mathrm{M}$, in $10 \mu \mathrm{M}$ increments, $\mathrm{NAD}^{+}(\mathrm{NADH})$ significantly $(p \leq 0.05)$ inhibited color development starting at $50 \mu \mathrm{M} \mathrm{NAD}{ }^{+}$but the absorption of varying $\mathrm{NAD}^{+}$concentrations across nitrite concentrations were parallel (equal slopes $(p \leq 0.05)$ ), demonstrating equal levels of inhibition of color development across nitrite concentrations. This would negate the effect of variable leftover concentrations NADH on the assay since color reduction would be equal at the end of the assay irrespective of the intensity of NRA (in vitro). Also, since $\mathrm{NAD}(\mathrm{P}) \mathrm{H}$ inhibits color development by reducing the diazonium salt formed between sulfanilamide and nitrite to a hydrazone such that the azo-compound is not formed, combining sulfanilamide and naphthalene ethylene diamine increases the chance the diazonium salt reacts with the diamine rather than with $\mathrm{NAD}(\mathrm{P}) \mathrm{H}$. Finally, the assay was further improved by removing small molecular weight molecules including oxaloacetic acid (OAA) which reduces the level of detectable nitrite over time (not shown), presumably by forming an oxime.

\subsection{Nitrite Reductase Activity (NiRA (In Vitro)) EC 1.7.7.1}

NiRA (in vitro) was assayed in a $200 \mu \mathrm{L}$ volume containing enzyme extract, $100 \mathrm{mM} \mathrm{KH}_{2} \mathrm{PO}_{4}-\mathrm{KHPO}_{4}$ $\mathrm{pH} 6.9,400 \mu \mathrm{M} \mathrm{KNO}{ }_{2}, 10 \mathrm{mM}$ methyl viologen, $30 \mathrm{mM} \mathrm{Na}_{2} \mathrm{~S}_{2} \mathrm{O}_{4}$ and $30 \mathrm{mM} \mathrm{KHCO}_{3}$. The assay was started by addition of $\mathrm{Na}_{2} \mathrm{~S}_{2} \mathrm{O}_{4}+\mathrm{KHCO}_{3}$ and incubated at $30^{\circ} \mathrm{C}$. Aliquots $(50 \mu \mathrm{L})$ were removed after 0,10 and $20 \mathrm{~min}$ and methyl viologen oxidized by shaking. The loss of nitrite was determined after methyl viologen oxidation by adding $150 \mu \mathrm{L}$ of $1 \%$ sulfanilamide, $2 \mathrm{M} \mathrm{H}_{3} \mathrm{PO}_{4}, 0.02 \%$ naphthalene ethylene diamine and $50 \mu \mathrm{L}$ acetonitrile and determining $\mathrm{OD}^{540}$.

\subsection{Phosphoenolpyruvate Carboxylase (PEP Carboxylase) EC 4.1.1.31}

PEP carboxylase activity was measured by the loss of NADH coupled to the conversion of OAA, formed, to malate via malate dehydrogenase (EC 1.1.1.37). The extract was diluted $10 \times$ with water and $10 \mu \mathrm{L}$ was used in a $200 \mu \mathrm{L}$ assay volume which was $25 \mathrm{mM}$ HEPES pH 7.5, 20\% ethylene glycol, $5 \mathrm{mM} \mathrm{MgCl}_{2}, 10 \mathrm{mM} \mathrm{KHCO}_{3}, 2 \mathrm{mM}$ phosphoenolpyruvate (PEP), $40 \mu \mathrm{M} \mathrm{NADH}$, and 1 unit malate 
dehydrogenase (EC 1.1.1.37). Blanks contained water instead of PEP. The reaction was started by the addition of PEP and fluorescence (Ex 345, Em 440) was measure every minute for $10 \mathrm{~min}$. The linear portion of the reduction in fluorescence was used to determine enzyme activity. Removal of OAA from the enzyme extract was crucial to maintain a constant baseline for this assay.

\subsection{Malate Enzyme (ME) EC 1.1.1.40}

Malate enzyme activity was determined by measuring NADPH formed as a result of malate conversion to pyruvate and $\mathrm{HCO}_{3}{ }^{-}$. The extract was diluted $10 \times$ with water and $10 \mu \mathrm{L}$ was used in a $200 \mu \mathrm{L}$ assay volume which was $50 \mathrm{mM}$ HEPES $\mathrm{pH} 7.0,1 \mathrm{mM} \mathrm{NADP}^{+}, 5 \mathrm{mM} \mathrm{MgCl}_{2}$ and $2 \mathrm{mM}$ malate. The reaction was started by adding malate; the blanks had water instead of malate. Fluorescence (Ex 345, Em 440) was measured every minute for $10 \mathrm{~min}$. The linear portion of the increase in fluorescence was used to determine enzyme activity.

\subsection{Protein}

The method of Bradford [47] was used.

\subsection{Ear Growth Response to Switching Nitrate Concentrations at Different Stages of Development}

The DuPont-Pioneer hybrid, 33W84, was grown in a field semi-hydroponics system previously described. Plants were grown in either 1 or $3 \mathrm{mM} \mathrm{KNO}_{3}$ as the $\mathrm{N}$ source and at $\mathrm{V0}$ (control), V3, V6, V9, $\mathrm{V} 12, \mathrm{~V} 15$, and V18 (tassel emergence) plants growing in $1 \mathrm{mM} \mathrm{KNO}_{3}$ were switched to $3 \mathrm{mM} \mathrm{KNO}_{3}$ and plants growing in $3 \mathrm{mM} \mathrm{KNO}_{3}$ switched to $1 \mathrm{mM} \mathrm{KNO}_{3}$. Ear shoots were bagged as the shoots emerged to avoid seed set. Plants were sampled at $\mathrm{R} 1$ and separated into ear and remaining vegetative plant then dried $\left(70^{\circ} \mathrm{C}, 72 \mathrm{~h}\right)$. There were 10 replicates of each treatment combination. The experiment was repeated a second season but the concentrations of $\mathrm{KNO}_{3}$ used were 1 and $4 \mathrm{mM} \mathrm{KNO}$.

\subsection{Response to Nitrate and Ammonia Nutrition during Later Stages of Ear Development}

The DuPont-Pioneer hybrid, 33W84, was grown in a field semi-hydroponics system and ear dry weight response to ammonia tested for two consecutive growing seasons. In the first season plants were grown in nutrient medium containing 1 and $3 \mathrm{mM} \mathrm{KNO}_{3}$ and converted to $1 \mathrm{mM} \mathrm{NH}_{4} \mathrm{Cl}$ at V12 and V15 or maintained at 1 and $3 \mathrm{mM} \mathrm{KNO}_{3}$. The plants were treated similarly in the subsequent year, except the $3 \mathrm{mM} \mathrm{KNO}_{3}$ treatments were replaced by $4 \mathrm{mM} \mathrm{KNO}_{3}$ treatments. Ear shoots were bagged as the shoots emerged to avoid seed set. Plants were harvested at R1 and separated into ear and remaining vegetative plant then dried $\left(70^{\circ} \mathrm{C}, 72 \mathrm{~h}\right)$. There were 10 replicates of each treatment combination.

GF3 was grown semi-hydroponically in either 1 or $2 \mathrm{mM} \mathrm{KNO}_{3}$ as the sole $\mathrm{N}$ source. At 23 days after emergence (DAE), plants growing in $1 \mathrm{mM} \mathrm{KNO}_{3}$ fertility were switched to $2 \mathrm{mM} \mathrm{KNO}_{3}$, to $1 \mathrm{mM}$ $\mathrm{NH}_{4} \mathrm{Cl}$, or maintained at $1 \mathrm{mM} \mathrm{KNO}_{3}$. Plants growing in $2 \mathrm{mM} \mathrm{KNO}_{3}$ were switched to $1 \mathrm{mM} \mathrm{KNO}_{3}$, to $1 \mathrm{mM} \mathrm{NH}_{4} \mathrm{Cl}$, or maintained at $2 \mathrm{mM} \mathrm{KNO}_{3}$. At $30 \mathrm{DAE}$ (R1) plants were separated into ears and remaining plant biomass then dried by lyophilization. Ear weight, remaining plant biomass, and total $\mathrm{N}$ were determined.

GF3 was grown semi-hydroponically under controlled environment in $1 \mathrm{mM} \mathrm{KNO}_{3}$ up to $22 \mathrm{DAE}$ and the plants were switched to $1 \mathrm{mM} \mathrm{NH}_{4} \mathrm{Cl}, 10 \mathrm{mM} \mathrm{KNO}_{3}$, or maintained at $1 \mathrm{mM} \mathrm{KNO}_{3}$. Ear and plant biomass was determined of all treatments at 23, 25, and $27 \mathrm{DAE}$ along with total $\mathrm{N}$.

\subsection{Vector Construction, Plant Transformation and Transgene Expression Analysis}

A 230-base pair (bp) fragment of maize NADH ubiquinone oxidoreductase (GRMZM2G024484) including the 5'-untranslated region (UTR) and part of the coding sequence was PCR-cloned to make an RNAi construct. An intron from ST-LS1 was added between the two inverted repeats of NADH ubiquinone oxidoreductase. Maize PEP carboxylase gene promoter and sorghum actin gene terminator 
were used to silence NADH ubiquinone oxidoreductase in mesophyll cells. This cassette was linked to LTP2:DS-RED2:PIN II TERM as a seed marker for transgenic seed as described [48]. The vector construction and maize transformation were carried out as described previously [48,49]. Multiple lines were generated. Single-copy T-DNA integration lines that expressed the transgene were selected for advancement to greenhouse or field test.

\subsection{NADH-Ubiquinone Oxidoreductase $51 \mathrm{kDa}$ Subunit (Complex I) Expression}

RNA was isolated using a Qiagen RNeasy kit followed by Invitrogen Turbo DNA free kit to remove contaminating DNA. Transcript quantification was performed using Biorad's iTaq ${ }^{\mathrm{TM}}$ Universal One-Step RT-qPCR (Bio-Rad, Hercules, CA. USA) on a Biorad CFX96 Touch Real-Time PCR Detection System (Bio-Rad, Hercules, CA. USA). NADH-ubiquinone oxidoreductase $51 \mathrm{kDa}$ subunit (Complex I) was quantified using the forward primer CAACTCTGGAACCAAGCTCTAT and the reverse primer GAGCAACTCCTTCAGAGGTATG. Transcriptional corepressor LEUNIG was used as a reference using CATCGACACCTTCCACTCATAC as the forward and TCCGTCAGAGCCAAACATTAC as the reverse primer.

\subsection{Multi-Location Field Yield Trails}

Transgenic Complex I RNAi events and the corresponding null were tested in 5 locations managed for optimal grain yields with four replicates at Johnston IA, Woodland CA, Plainview TX, and Corning $\mathrm{AR}$, and three replicates in Garden City, KS. The field trial and statistical analysis were conducted as described previously [48]. Grain yield was calculated and adjusted to a standard moisture of $155 \mathrm{~g} \mathrm{~kg}^{-1}$. Yield was predicted using Best Linear Unbiased Predictor (BLUP).

\section{Results}

\subsection{Field NUE Analyses under Normal and Depleted N Conditions}

During the 2009-2010 growing seasons, experiments were conducted to identify yield parameters responsive to $\mathrm{N}$ input and those that were also related to grain yield under conditions of high and low $\mathrm{N}$ fertility. These experiments were conducted in fields with corn on corn cropping systems with normal $\mathrm{N}$ inputs and in fields depleted of $\mathrm{N}$ for at least two years at the start of the experiment. There were significant $(F \leq 0.1)$ effects of experimental year and significant $(F \leq 0.05)$ effects of $\mathrm{N}$ fertility on grain yield but there were no significant $(F \leq 0.1)$ effects of cultivar and no significant interactions of experimental year $\times$ cultivar, experimental year $\times \mathrm{N}$ fertility, or cultivar $\times \mathrm{N}$ fertility, so means were pooled across experimental years and cultivars. Grain yields were linearly related to $\mathrm{N}$ fertility in both years under both low $\mathrm{N}$ fertility (depleted $\mathrm{N}$ ) and high $\mathrm{N}$ fertility (non-depleted $\mathrm{N}$ ) ranges. Since grain yields were linearly related to $\mathrm{N}$ fertility, NUE was constant in both environments but NUE was $52 \%$ efficient $\left(15.132 \mathrm{~kg} \mathrm{ha}^{-1} \mathrm{~kg} \mathrm{~N}^{-1}\right)$ in the low $\mathrm{N}$ fertility range and $23 \%$ efficient $\left(4.764 \mathrm{~kg} \mathrm{ha}^{-1} \mathrm{~kg} \mathrm{~N}^{-1}\right)$ in the high $\mathrm{N}$ fertility range. Response parameters measured are shown in Table 1. Leaf total amino acid-V9 was very responsive to $\mathrm{N}$ fertility under both low and high ranges of $\mathrm{N}$ fertility. However, the relationship to grain yield was much greater under low $\mathrm{N}$ range than under high $\mathrm{N}$ range (Table 1). R1 biomass was not responsive to $\mathrm{N}$ fertility in either low or high $\mathrm{N}$ ranges, but R1 biomass was highly related to grain yield in the high $\mathrm{N}$ range. Total vegetative $\mathrm{N}$ at $\mathrm{R} 1$ was responsive to $\mathrm{N}$ fertility in the high $\mathrm{N}$ range and moderately related to grain yield. Ear length and ear-weight at R1, but not ear-width, were responsive to $\mathrm{N}$ and were highly correlated to grain yield in both high and low $\mathrm{N}$ ranges. SPAD chlorophyll measured at R1, R2, and R3 all responded to N fertility under both high and low $\mathrm{N}$ ranges, but the relationship to grain yield in the high $\mathrm{N}$ range was poor. Mature biomass was very responsive to $\mathrm{N}$ fertility in the low $\mathrm{N}$ range and poorly responsive in the high $\mathrm{N}$ range. Plant total $\mathrm{N}$ at maturity was non-responsive to $\mathrm{N}$ fertility and poorly correlated to grain yield. Ear-weight, $\mathrm{KNP}$, and grain total $\mathrm{N}$ were all highly responsive to $\mathrm{N}$ fertility and closely related to grain yield under both $\mathrm{N}$ fertility ranges. Kernel weight was moderately responsive to $\mathrm{N}$ fertility in 
the high $\mathrm{N}$ range but slightly negatively responsive to $\mathrm{N}$ fertility in the low $\mathrm{N}$ range. Kernel weight was highly correlated to grain yield in the high $\mathrm{N}$ fertility range but poorly related to grain yield in the lower $\mathrm{N}$ fertility range.

Table 1. Maize parameters responsive to $\mathrm{N}$ input and correlated to grain yield.

\begin{tabular}{|c|c|c|c|c|}
\hline \multirow{3}{*}{ Parameter } & \multicolumn{2}{|c|}{ Response to $\mathrm{N}$} & \multicolumn{2}{|c|}{ Relation to Grain Yield } \\
\hline & \multicolumn{2}{|c|}{$p>F$} & \multicolumn{2}{|c|}{$r^{2}$} \\
\hline & High $\mathbf{N}$ & Low $\mathbf{N}$ & High $\mathbf{N}$ & Low $\mathbf{N}$ \\
\hline Total Amino Acids (V9) & $<0.01$ & $<0.01$ & 0.77 & 0.99 \\
\hline Biomass, R1 & 0.638 & 0.828 & 0.96 & 0.85 \\
\hline Total N, R1 & 0.018 & 0.119 & 0.88 & 0.91 \\
\hline Ear Length, R1 & 0.028 & $<0.01$ & 0.99 & 0.97 \\
\hline Ear Weight, R1 & 0.072 & $<0.01$ & 0.95 & 0.93 \\
\hline Ear Width, R1 & 0.476 & 0.134 & 0.12 & 0.78 \\
\hline SPAD, R1 & $<0.01$ & $<0.01$ & 0.87 & 0.96 \\
\hline SPAD, R2 & $<0.01$ & $<0.01$ & 0.62 & 0.91 \\
\hline SPAD, R3 & 0.012 & 0.017 & 0.77 & 0.91 \\
\hline Biomass-Maturity & 0.302 & 0.038 & 0.68 & 0.84 \\
\hline Plant Total N-Maturity & 0.15 & 0.84 & 0.23 & 0.31 \\
\hline Ear Weight-Maturity & 0.027 & 0.01 & 0.99 & 0.99 \\
\hline Kernel Weight & 0.1 & $0.048(-)$ & 0.98 & $0.56(-)$ \\
\hline Kernel Number & 0.038 & 0.013 & 0.99 & 0.99 \\
\hline Grain Total N & $<0.01$ & 0.061 & 0.97 & 0.95 \\
\hline
\end{tabular}

During the 2009 and 2010 growing seasons, three DuPont-Pioneer hybrids (33K42, 33W84, 33T56) were grown in fields not depleted for $\mathrm{N}$ ( High N) and were treated with six N fertilities $\left(0,34,67,101,134\right.$, and $\left.167 \mathrm{~kg} \mathrm{ha}^{-1}\right)$. In a similar fashion, 33W84 was planted in an $\mathrm{N}$ depleted field (Low $\mathrm{N})$ and treated with four $\mathrm{N}$ fertilities $(0,22,45$, and $67 \mathrm{~kg} \mathrm{ha}^{-1}$ ). Various parameters were measured and their response to $\mathrm{N}$-fertility determined along with their relationship to grain yield.

\subsection{Stalk Nitrate}

Nitrate accumulates in maize lower stalk internodes as early as V11 (11th fully expanded leaf) in high $\mathrm{N}$ fertilized plots but little detectable nitrate was found in stalks of plants grown under low $\mathrm{N}$ fertility (Figure 1). V11 was the earliest all of the stalk internodes could be sampled and stalk nitrate was maximum at R3 but not significantly different $(p \leq 0.1)$ between sampling dates.

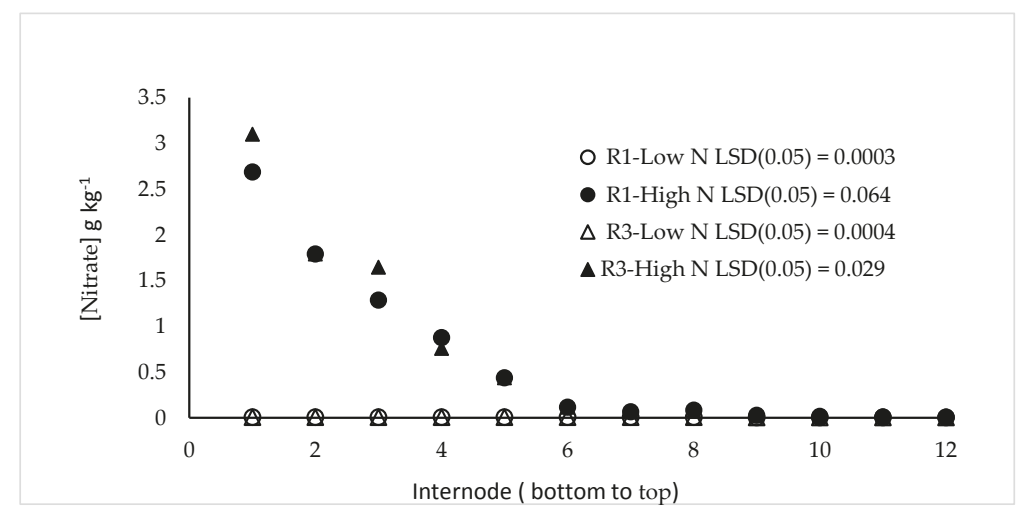

Figure 1. Stalk nitrate, by internode, of plants grown under high $\mathrm{N}$ and low $\mathrm{N}$ fertility. The DuPont-Pioneer hybrid 33W84 was grown in field plots depleted in $\mathrm{N}$ then fertilized with $77 \mathrm{~kg} \mathrm{ha}^{-1} \mathrm{~N}$ (Low N), or in plots not $\mathrm{N}$ depleted and fertilized with $224 \mathrm{~kg} \mathrm{ha}^{-1} \mathrm{~N}$ (High N). At V11, R1, R2, and R3 plants were sampled, leaves and leaf sheaths removed and the stalks separated into segments by internode. Samples were dried, ground to a fine powder and nitrate quantified. 
Though generally low, lamina nitrate levels were not different irrespective of $\mathrm{N}$ fertility (Table 2). Lower leaves accumulated malate (Table 2) in both high and low $\mathrm{N}$ fertility grown plants at all sampling dates from V11 to R3. Lower leaves had less capacity to assimilate nitrate (NRA (in vivo)), (Figure 2) but nitrite assimilation (NiRA (in vivo)) was not significantly different in any leaf. Plants grown in lower $\mathrm{N}$ fertility also showed this response in lower leaves but the overall NRA (in vivo) and NiRA (in vivo) capacities were reduced by $70 \%$ (not shown) diminishing the ability to make statistically significant $(p \leq 0.1)$ inferences. The extractable levels of enzymes followed the same pattern from lower to upper leaves with extractable nitrate reductase activity (NRA (in vitro)—EC 1.6.6.1) significantly less in the lower leaves whereas nitrite reductase activity (NiRA (in vitro)—EC 1.7.7.1) was not different (Figure 3). The ratio of NRA (in vitro) $\left(\mathrm{MgCl}_{2}\right)$ to NRA (in vitro) (EDTA) showed no signs of change in NRA (in vitro) activation [46]. The data presented is the NRA (in vitro) with EDTA in the assay medium, or maximum in vitro activity. Interestingly, the extractable PEP-carboxylase (EC 4.1.1.31) activity showed the same pattern as NRA (in vitro) with lower activity in lower leaves whereas malic enzyme (EC 1.1.1.40) activity was not different in lower verses upper leaves similarly as NiRA (in vitro) (Figure 3).

Table 2. Leaf metabolites by internode of plants grown under non-depleted N (High N) and depleted $\mathrm{N}($ Low $\mathrm{N})$ conditions of $\mathrm{N}$ fertility.

\begin{tabular}{ccccc}
\hline \multirow{2}{*}{ Internode } & \multicolumn{2}{c}{ Leaf Nitrate } & \multicolumn{2}{c}{ Leaf Malate } \\
\cline { 2 - 5 } & \multicolumn{2}{c}{$\left(\mu \mathrm{g} \mathrm{g}^{-\mathbf{1}}\right)$} & \multicolumn{2}{c}{$\left(\mu\right.$ mole $\left.^{-\mathbf{1}}\right)$} \\
\cline { 2 - 5 } & Low N & High N & Low N & High N \\
\hline 1 & 0.96 & 1.18 & 16.28 & 38.89 \\
2 & 1.01 & 1.16 & 22.43 & 28.83 \\
3 & 1.23 & 1.28 & 14.73 & 16.98 \\
4 & 1.26 & 1.36 & 10.91 & 17.64 \\
5 & 1.06 & 1.14 & 11.67 & 11.93 \\
6 & 1.47 & 1.56 & 8.89 & 11.87 \\
7 & 1.19 & 1.11 & 10.27 & 9.31 \\
8 & 1.44 & 1.14 & 9.49 & 9.76 \\
9 & 1.14 & 1.12 & 8.41 & 8.80 \\
10 & 0.97 & 1.27 & 9.68 & 9.17 \\
11 & 0.91 & 1.05 & 9.68 & 9.72 \\
12 & 1.48 & 1.26 & 10.07 & 9.94 \\
\hline LSD (0.05) & \multicolumn{3}{c}{1.177} \\
\hline
\end{tabular}

DuPont-Pioneer hybrid 33W84 was planted in Johnston, IA under high N fertility $\left(224 \mathrm{~kg} \mathrm{~N} \mathrm{ha}^{-1}\right)$ and in a field depleted of $\mathrm{N}$ for at least 2 years (Low N) and fertilized with $77 \mathrm{~kg} \mathrm{~N} \mathrm{ha}^{-1}$. Sampling occurred at V11 and R1. Subtending leaves of each internode were sampled by leaf punching. Samples were dried and metabolites quantified at each sampling date but analyzed together with sampling time included in the replicate term. Leaf 1 is at the base of the plant and leaf 12 is at the top.

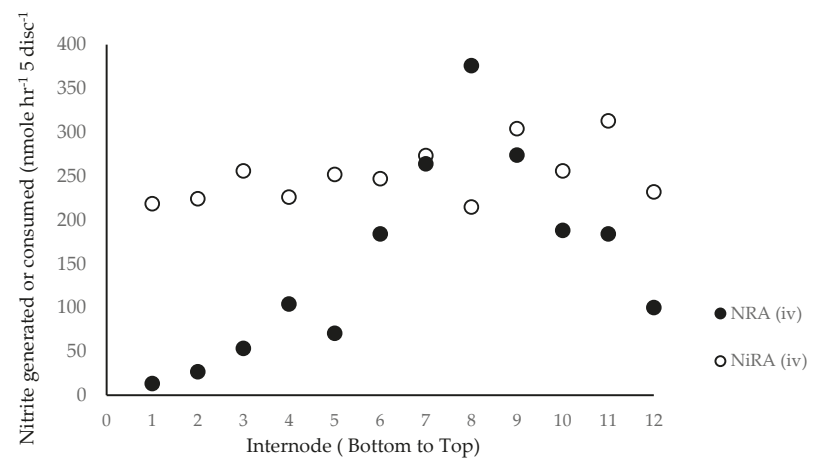

Figure 2. In vivo nitrate assimilation-NRA (in vivo) and in vivo nitrite assimilation-NiR (in vivo) by leaf position. The DuPont-Pioneer hybrid 33W84 was grown in non-depleted field plots and fertilized with $224 \mathrm{Kg} \mathrm{N}{ }^{-1}$. At R1 each leaf was sampled for nitrate assimilation (NRA (in vivo)) and nitrite assimilation (NiRA (in vivo)). 


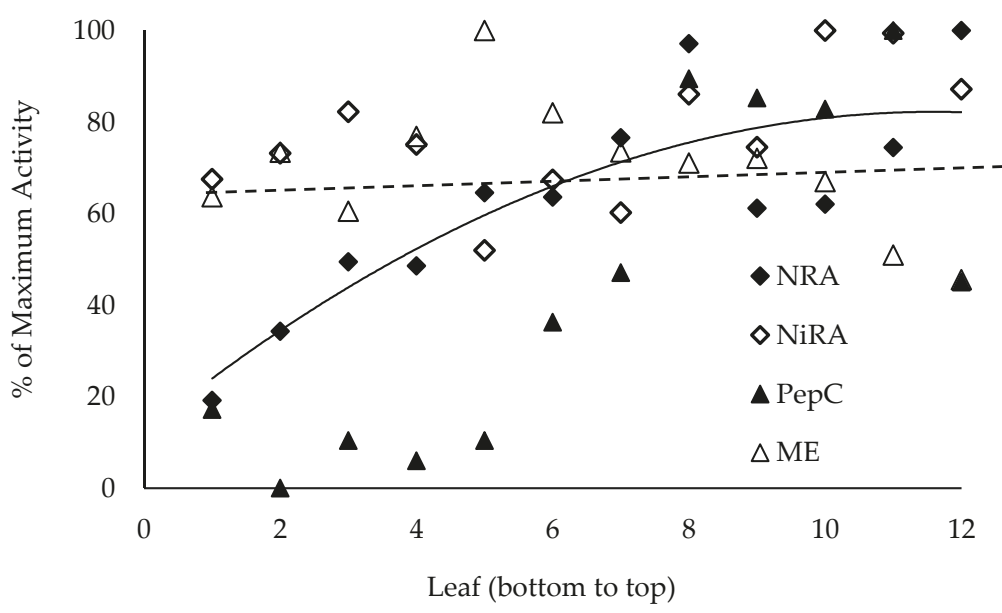

Figure 3. Extractable enzyme activities by internode. The DuPont-Pioneer hybrid 33W84 was grown in non-depleted field plots and fertilized with $224 \mathrm{Kg} \mathrm{N}_{\mathrm{g}}{ }^{-1}$. Cell free extracts were produced from leaf punches (10, $5 \mathrm{~mm}$ ) of each leaf, small molecular weight molecules removed, and enzymes assayed. Nitrate reductase activity (NRA (in vitro)) had a quadradic fit with leaf position whereas nitrite reductase activity (NiRA (in vitro)) and malic enzyme (ME) did not change with leaf position (slopes not different from 0). PEP-carboxylase activity follows a similar trend as NRA (in vitro) with lower activity in lower leaves.

\subsection{Ear Dry Weight Response to Switching Nitrate Concentrations}

In these experiments what effect reducing or increasing nitrate concentration has on R1 ear-weight was investigated. These experiments were conducted during two sequential growing seasons. The first season plants were grown in either $1 \mathrm{mM} \mathrm{KNO}_{3}$ as insufficient levels of $\mathrm{N}$ fertility and at specific developmental stages switched to $3 \mathrm{mM} \mathrm{KNO}_{3}$, considered a luxurious level of $\mathrm{N}$ fertility, for the remaining time. Concurrently, plants grown in $3 \mathrm{mM} \mathrm{KNO}_{3}$ were switched to $1 \mathrm{mM} \mathrm{KNO}_{3}$ and the effect of reducing nitrate for the remaining time had on $\mathrm{R} 1$ ear-weight was determined. In the second year the higher $\mathrm{KNO}_{3}$ concentration was switched from $3 \mathrm{mM}$ to $4 \mathrm{mM} \mathrm{KNO}_{3}$. The results were similar for both years so means were summed across years. In Figure 4 plants switched at $\mathrm{V} 0$ (planting) would be considered controls; maintained at either 1 or $3-4 \mathrm{mM} \mathrm{KNO}_{3}$ the entire time. Predictably, reducing nitrate levels at $\mathrm{V} 3$ (switching from $3-4 \mathrm{mM} \mathrm{KNO}_{3}$ to $1 \mathrm{mM} \mathrm{KNO}_{3}$ ) resulted in significant loss in R1 ear-weight. Likewise, increasing nitrate levels at $\mathrm{V} 3$ (switching from $1 \mathrm{mM} \mathrm{KNO}_{3}$ to $3-4 \mathrm{mM}$ $\mathrm{KNO}_{3}$ ) improved R1 ear-weight but R1 ear-weight could not be completely restored when switched at V3. Recovery of R1 ear-weight was much less when nitrate levels were increased at V6 (switching from $1 \mathrm{mM} \mathrm{KNO}_{3}$ to 3-4 $\mathrm{mM} \mathrm{KNO}_{3}$ ) and reducing nitrate at $\mathrm{V} 6$ (switching from 3-4 mM KNO 3 to $1 \mathrm{mM} \mathrm{KNO}_{3}$ ) was much less effective on reducing R1 ear-weight. Switching at V12, or later, had very little effect on R1 ear-weight, neither increasing (switching from $1 \mathrm{mM} \mathrm{KNO}_{3}$ to $3-4 \mathrm{mM} \mathrm{KNO}_{3}$ ) nor decreasing (switching from $3-4 \mathrm{mM} \mathrm{KNO}_{3}$ to $1 \mathrm{mM} \mathrm{KNO}_{3}$ ) nitrate levels.

\subsection{The Effect of Ammonia on Ear Development}

Though R1 ear-weight could not be changed by increasing or decreasing nitrate levels after V12, ammonia (1 mM) could significantly change R1 ear-weight as late as V15. These experiments were conducted during sequential growing years. In the first year, plants were grown in either 1 or 3 $\mathrm{mM} \mathrm{KNO}_{3}$ as the insufficient and sufficient $\mathrm{N}$ levels, respectively, and in the second year, the $3 \mathrm{mM}$ $\mathrm{KNO}_{3}$ treatment was replaced with $4 \mathrm{mM} \mathrm{KNO}_{3}$. There was no significant effect of year so the years 
were combined in analysis. Switching to $1 \mathrm{mM} \mathrm{NH}_{4} \mathrm{Cl}$ significantly increased the ear number at both starting nitrate concentrations (Table 3). There was a significant effect of ammonia on R1 ear-weight when 3-4 $\mathrm{mM} \mathrm{KNO}_{3}$ grown plants were switched to $1 \mathrm{mM} \mathrm{NH}_{4} \mathrm{Cl}$ (Table 3) at $\mathrm{V} 12-\mathrm{V} 15$, stages when nitrate was ineffective in influencing $\mathrm{R} 1$ ear-weight. There was no significant effect of $\mathrm{NH}_{4} \mathrm{Cl}$ on vegetative biomass.

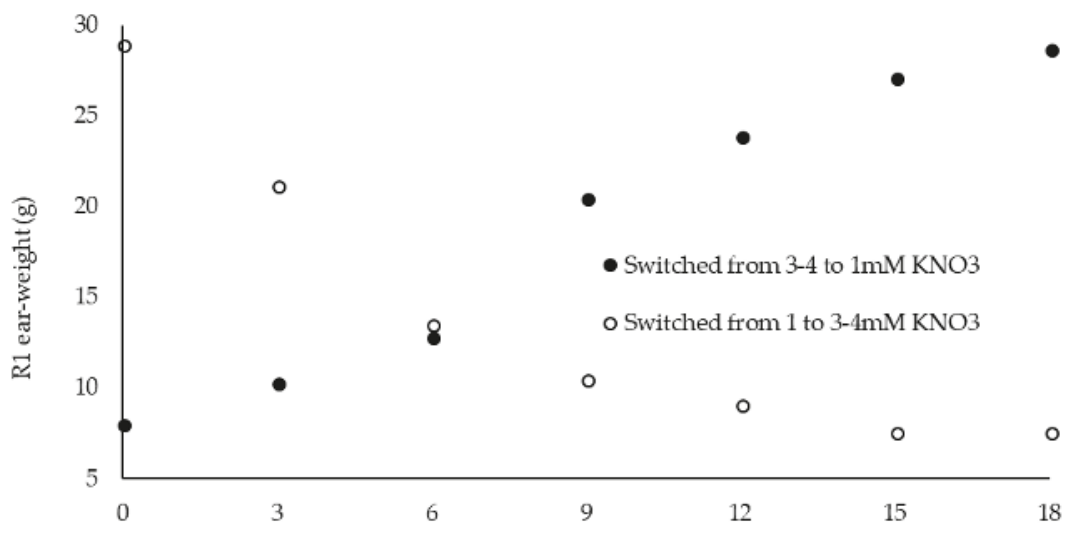

$\mathrm{V}$ stage in which $\mathrm{N}$ fertility switch was made

$$
\operatorname{LSD}(0.05)=1.28
$$

Figure 4. The DuPont-Pioneer 33W84 was grown in field hydroponics during two successive growing seasons. The first season plants were grown in nutrient media containing 1 and $3 \mathrm{mM} \mathrm{KNO}_{3}$ as the sole $\mathrm{N}$ source and the second season grown in nutrient media containing 1 and $4 \mathrm{mM} \mathrm{KNO}_{3}$ as the sole $\mathrm{N}$ source. Starting at emergence (V0), plants growing in $1 \mathrm{mM} \mathrm{KNO}_{3}$ were switched to either 3 or $4 \mathrm{mM} \mathrm{KNO}_{3}$ and plants growing in 3 or $4 \mathrm{mM} \mathrm{KNO}_{3}$ switched to $1 \mathrm{mM} \mathrm{KNO}$ every third developmental stage.

Table 3. The effect of V12-15 nutrient replacement with $\mathrm{NH}_{4} \mathrm{Cl}$ on $\mathrm{R} 1$ ear-weight.

\begin{tabular}{|c|c|c|c|}
\hline \multirow{2}{*}{ Treatment } & Ear Dwt & Plant Biomass & Ear Number \\
\hline & (g) & (g) & $(\%)$ \\
\hline $1 \mathrm{mM} \mathrm{KNO}_{3}$ (No Change) & $7.3 \mathrm{c}$ & $97.9 \mathrm{~b}$ & $86 \mathrm{~b}$ \\
\hline Switched from $1 \mathrm{mM} \mathrm{KNO}_{3}$ to $1 \mathrm{mM} \mathrm{NH}_{4} \mathrm{Cl}$ & $8.3 \mathrm{c}$ & $97.9 \mathrm{~b}$ & $97 \mathrm{a}$ \\
\hline 3-4 $\mathrm{mM} \mathrm{KNO}_{3}$ (No Change) & $28.2 \mathrm{~b}$ & $152.6 \mathrm{a}$ & 93 a \\
\hline Switched from 3-4 mM KNO 3 to $1 \mathrm{mM} \mathrm{NH}_{4} \mathrm{Cl}$ & $36.0 \mathrm{a}$ & $154.8 \mathrm{a}$ & $100 \mathrm{a}$ \\
\hline
\end{tabular}

DuPont-Pioneer hybrid 33W84 was grown in nutrient media containing 1 or $3 \mathrm{mM} \mathrm{KNO}_{3}$ as the sole nitrogen source up to V12 and V15 and then switched to media containing $1 \mathrm{mM} \mathrm{NH}_{4} \mathrm{Cl}$. Controls were unchanged. At R1, plants were harvested and ear and plant dry weights were determined along with the proportion of the plants that had a visible ear with emerging silks. The experiment was repeated in the following growing season except the upper $\mathrm{KNO}_{3}$ concentration was $4 \mathrm{mM}$. Data were summed across treatment stages (V12 and V15) and experimental seasons. Means with different letters were significantly different by protected LSD (0.05).

Subsequent experiments were performed with Gaspe Flint-3 (GF3) under controlled environmental conditions. In these experiments, switching from insufficient levels of nitrate to sufficient levels of nitrate, and vice-versa, showed a similar R1 ear-weight response (data not shown) as the full season hybrids. GF3 R1 ear-weight was not responsive to changes in nitrate levels 20 days after emergence (DAE), or later. R1 in GF3 occurs from 29-31 DAE so, as in the case of a full season hybrids, GF3 R1 ear-weight was unresponsive to changes in nitrate for a significant amount of time prior to R1, 
or approximately for the last third of the time required to reach R1. Switching GF3 plants grown on either 1 or $2 \mathrm{mM} \mathrm{KNO}_{3}$ to 2 or $1 \mathrm{mM} \mathrm{KNO}_{3}$, respectively, had no significant effect on ear dry weight, vegetative biomass or total vegetative biomass (Table 4) compared to plants maintained at 1 or $2 \mathrm{mM}$ $\mathrm{KNO}_{3}$ the entire time. Switching to $1 \mathrm{mM} \mathrm{NH}_{4} \mathrm{Cl}$ from both nitrate sources significantly increased ear dry weight and ear total $\mathrm{N}$. There were some non-significant $(\mathrm{F} \leq 0.1)$ reductions in biomass in plants switched to $1 \mathrm{mM} \mathrm{NH}_{4} \mathrm{Cl}$ but there were no significant effects of $\mathrm{NH}_{4} \mathrm{Cl}$ on vegetative $\mathrm{N}$.

Table 4. R1 ear-weight, ear N, R1 vegetative biomass, and vegetative N of GF3 switch from $1 \mathrm{mM}$ nitrate $\mathrm{N}$ nutrition 23DAE.

\begin{tabular}{|c|c|c|c|c|}
\hline \multirow{2}{*}{ Treatment } & Veg Dwt & Veg $\mathbf{N}$ & Ear Dwt & Ear $\mathbf{N}$ \\
\hline & (g) & (mg) & (mg) & (mg) \\
\hline $1 \mathrm{mM} \mathrm{KNO} 3$ (No Change) & 4.11 & 175.5 & $193 \mathrm{~b}$ & $14.4 \mathrm{~b}$ \\
\hline Switched from $1 \mathrm{mM} \mathrm{KNO}_{3}$ to $2 \mathrm{mM} \mathrm{KNO}_{3}$ & 4.02 & 160.6 & $212 b$ & $14.7 \mathrm{~b}$ \\
\hline Switched from $1 \mathrm{mM} \mathrm{KNO}_{3}$ to $1 \mathrm{mM} \mathrm{NH}_{4} \mathrm{Cl}$ & 3.83 & 190.7 & $265 \mathrm{a}$ & $22.4 \mathrm{a}$ \\
\hline Significance level & NS & NS & 0.05 & 0.05 \\
\hline $2 \mathrm{mM} \mathrm{KNO}_{3}$ (No Change) & 4.32 & 197.0 & $208 \mathrm{~b}$ & $13.5 \mathrm{~b}$ \\
\hline Switched from $2 \mathrm{mM} \mathrm{KNO}_{3}$ to $1 \mathrm{mM} \mathrm{KNO}_{3}$ & 4.21 & 187.9 & $193 \mathrm{~b}$ & $12.1 \mathrm{~b}$ \\
\hline Switched from $2 \mathrm{mM} \mathrm{KNO}_{3}$ to $1 \mathrm{mM} \mathrm{NH}_{4} \mathrm{Cl}$ & 3.79 & 229.9 & $297 \mathrm{a}$ & $24.7 \mathrm{a}$ \\
\hline Significance level & NS & NS & 0.05 & 0.05 \\
\hline
\end{tabular}

GF3 was grown in nutrient media containing 1 or $2 \mathrm{mM} \mathrm{KNO}_{3}$ as the sole nitrogen source up to 23-DAE. Plants grown in $1 \mathrm{mM} \mathrm{KNO}_{3}$ were switched to $2 \mathrm{mM} \mathrm{KNO}_{3}$, switched $1 \mathrm{mM} \mathrm{NH}_{4} \mathrm{Cl}$ or maintained in $1 \mathrm{mM} \mathrm{KNO}_{3}$. Likewise, plants grown in $2 \mathrm{mM} \mathrm{KNO}_{3}$ were switched to $1 \mathrm{mM} \mathrm{KNO}_{3}$, switched to $1 \mathrm{mM} \mathrm{NH}_{4} \mathrm{Cl}$ or maintained in 2 $\mathrm{mM} \mathrm{KNO}_{3}$. Plants were harvested 29-DAE and ear and plant dry weights along with total-N were determined. Means with different letters were significantly different by protected LSD $(0.05)$.

In companion experiments, GF3 was grown in $1 \mathrm{mM} \mathrm{KNO}_{3}$ and at $22 \mathrm{DAE}$ were either maintained in $1 \mathrm{mM} \mathrm{KNO}_{3}$, switched to $1 \mathrm{mM} \mathrm{NH}_{4} \mathrm{Cl}$, or switched to $10 \mathrm{mM} \mathrm{KNO}_{3}$. Switching to ammonia $(1 \mathrm{mM})$ doubled the rate of ear growth within $24 \mathrm{~h}$. Nitrate concentration of $10 \mathrm{mM}$ nitrate was much less affective (Table 5).

Table 5. The effect of ammonia fertility on ear growth rate of GF3 when applied 22DAE.

\begin{tabular}{ccccc}
\hline \multirow{2}{*}{ Treatment } & \multicolumn{3}{c}{ Ear Dry Weight (mg) } \\
\cline { 2 - 5 } & 22 DAE & 23 DAE & 25 DAE & 27 DAE \\
\hline 1 $\mathrm{mM} \mathrm{KNO}_{3}$ (No Change) & 34 & $51 \mathrm{f}$ & $110 \mathrm{~d}$ & $195 \mathrm{c}$ \\
Switched from 1 $\mathrm{mM} \mathrm{KNO}_{3}$ to $10 \mathrm{mM} \mathrm{KNO}_{3}$ & 34 & $47 \mathrm{f}$ & $101 \mathrm{~d}$ & 284 b \\
Switched from $1 \mathrm{mM} \mathrm{KNO}_{3}$ to $1 \mathrm{mM} \mathrm{NH}_{4} \mathrm{Cl}$ & 34 & $87 \mathrm{e}$ & $244 \mathrm{~b}$ & $420 \mathrm{a}$ \\
\hline
\end{tabular}

GF3 was grown in medium containing $1 \mathrm{mM} \mathrm{KNO}_{3}$ as the sole $\mathrm{N}$ source. At 22-DAE plants were either maintained in $1 \mathrm{mM} \mathrm{KNO}_{3}$ medium, switched to $10 \mathrm{mM} \mathrm{KNO}_{3}$ or switched to $1 \mathrm{mM} \mathrm{NH}_{4} \mathrm{Cl}$. Ear dry weight was determined at every sampling date. Each mean represents 9 replicates and means with a similar letter are not different by protected LSD (0.05).

\subsection{Total-N, Nitrate-N, and Organic-N Accumulation}

Nitrogen balance experiments, both quantitatively and qualitatively, in response to nitrate fertility were conducted using GF3 under controlled environment. These experiments would be very difficult to conduct under field conditions, especially, since root:shoot ratios drop with increased N fertility [50] and access to the entire plant is required to quantify whole plant $\mathrm{N}$ levels. As in full season maize cultivars, $\mathrm{N}$ fertility of $2 \mathrm{mM} \mathrm{KNO}_{3}$ is sufficient to support R1 ear-weight in GF3 [43]. Above $2 \mathrm{mM}$ $\mathrm{KNO}_{3}$ no further increase in R1 ear-weight can be observed so $\mathrm{N}$ fertilities of 3 and $4 \mathrm{mM} \mathrm{KNO}_{3}$ would be considered more than sufficient. This range of $\mathrm{N}$ fertility was shown to accumulate nitrate in lower leaf midribs and stalk internodes especially when $\mathrm{KNO}_{3}$ was provided in excess. NRA (in vitro) increases linearly with increased nitrate fertility (Figure 5), whereas NRA (in vivo) does not change above $2 \mathrm{mM} \mathrm{KNO}_{3}$ fertility (Figure 5). When the accumulation of total plant $\mathrm{N}$ is compared to 
increasing $\mathrm{N}$ fertility, organic- $\mathrm{N}$ accumulation is not significantly $(F \leq 0.1)$ increased from $2 \mathrm{mM} \mathrm{KNO}$ or above, similarly as NRA (in vivo). With increased $\mathrm{N}$ fertility, the proportion of the total plant $\mathrm{N}$ that is nitrate increases (Figure 6). Though there is a numeric difference in organic-N between 2 and $3 \mathrm{mM}$ $\mathrm{KNO}_{3}$ grown plants, organic-N levels were not significantly changed with increased $\mathrm{N}$ fertility.

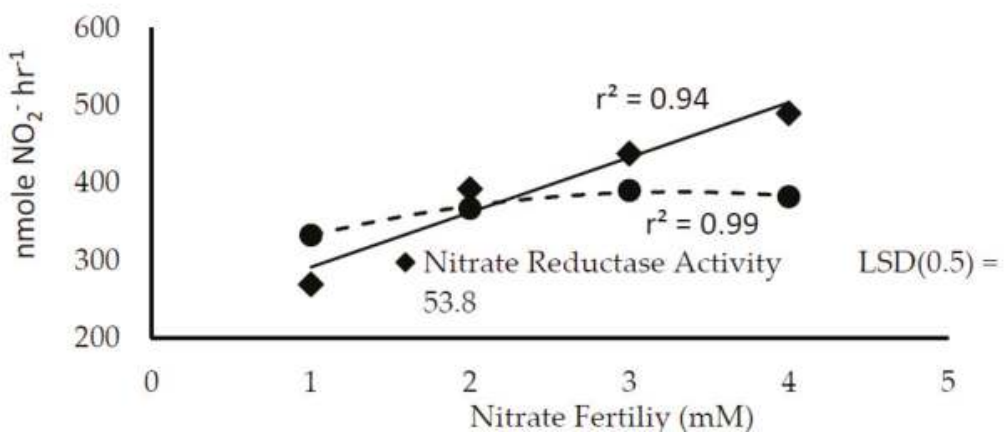

Figure 5. Change in nitrate reductase activity (NRA (in vitro)) and nitrate reductase activity, in vivo, (NRA (in vivo)) with increased nitrate fertility. GF3 was grown under controlled conditions with nitrate fertility varied from 1 to $4 \mathrm{mM} \mathrm{KNO}_{3}$. The penultimate leaf was sampled 28-DAE for both Nitrate Assimilation (NRA (in vivo) and Nitrate Reductase Activity (NRA (in vitro)).

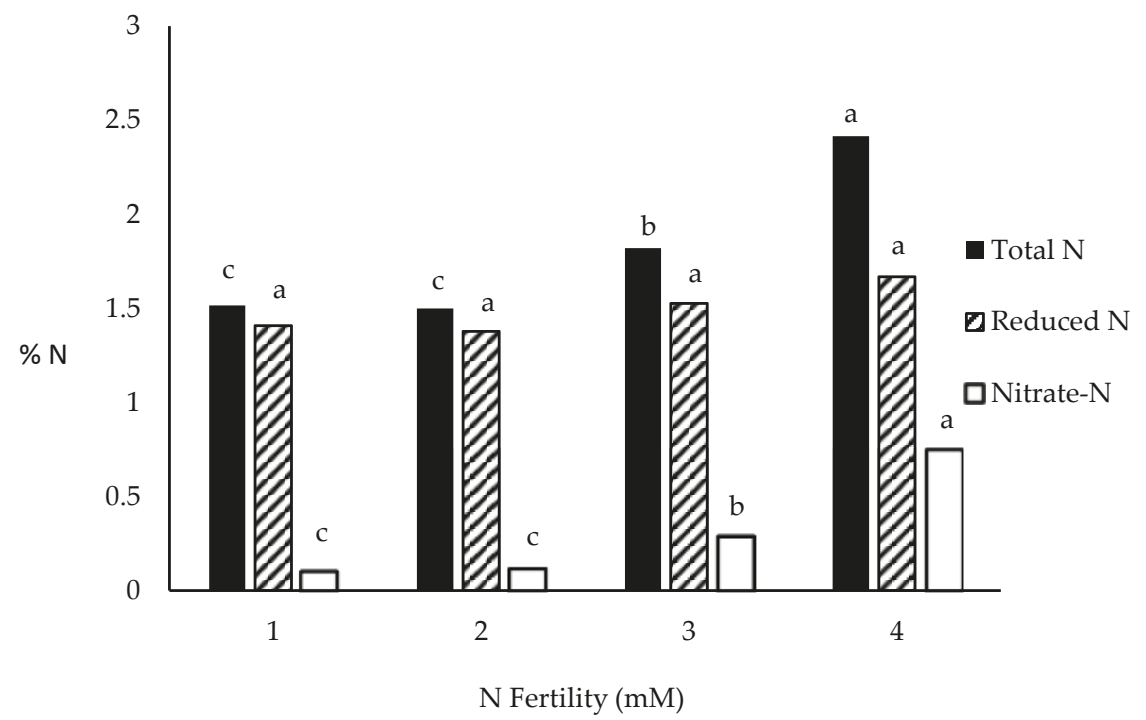

Figure 6. Plant $\mathrm{N}$ with increasing nitrate fertility. GF3 was grown under controlled conditions with nitrate fertility varied from 1 to $4 \mathrm{mM} \mathrm{KNO}_{3}$. At 26-DAE the entire plant was removed from the potting media, dried, and ground to a fine power. Total-N and nitrate-N were determined. Organic-N was determined by subtracting nitrate-N from total-N. Means with similar letters are not different by protected LSD (0.05).

\subsection{Transgenic Co-Suppression of NADH-Ubiquinone Oxidoreductase $51 \mathrm{kDa}$ Subunit (Complex I)}

Eight events of NADH-ubiquinone oxidoreductase $51 \mathrm{kDa}$ subunit co-suppression driven by PEP-carboxylase promoter were generated and yield tested in multi-location environments managed 
for maximum yields (high $\mathrm{N}$ fertility). Only one event had a statistically significant $(p<0.1)$ grain yield increase of $230.37 \mathrm{~kg} \mathrm{ha}^{-1}$ across all locations (Table 6), relative to the null hybrid. The positive event was selected for a second-year grain yield test along with physiological/biochemical evaluation. In the second-year field evaluation the positive event showed significant improvements in grain yield that was primarily associated with increased KNP (Table 7). The positive event had significantly lower levels of leaf NADH-ubiquinone oxidoreductase $51 \mathrm{kDa}$ subunit (Complex I) expression, greater extractable NADH, higher NRA (in vivo) but no difference in extractable NRA (in vitro) (Table 7). Complex I expression in root, a non-targeted tissue, was not different between transgene and non-transgene. Though the statistic cannot be used to determine a null effect, since non-significance may be due to higher variability, the numeric difference between transgenic and non-transgenic root expression was small suggesting selective co-suppression of Complex I.

Table 6. NADH-ubiquinone oxidoreductase $51 \mathrm{kDa}$ subunit (Complex I) co-suppression multi-location yield trial (2013).

\begin{tabular}{cc}
\hline Event & Grain Yield Increase over Transgenic Null $\left(\mathbf{k g ~ h a}^{\mathbf{- 1}}\right)$ \\
\hline 1.2 & 72.18 \\
1.4 & 162.57 \\
1.5 & -23.22 \\
1.8 & 87.25 \\
1.12 & 91.64 \\
1.14 & 6.28 \\
1.18 & 80.97 \\
1.19 & $230.37^{*}$ \\
\hline
\end{tabular}

NADH-ubiquinone oxidoreductase $51 \mathrm{kDa}$ subunit (Complex I) inverted repeat co-suppression gene driven by PEP-carboxylase promoter was transformed into an elite inbred. Eight transgenic progenies were produced and crossed pollinated to form a commercial hybrid. Transgenic hybrid seed was separated from null hybrid seed using the color marker associated with the transgene. The hybrid was tested for grain yield in multiple locations managed for maximum yield and a multi-location yield analysis performed. Transgenic null hybrid grain yield across locations-12,384 $\mathrm{kg} \mathrm{ha}^{-1}$. * - Best Linear Unbiased Predictor (BLUP) $(p \leq 0.1)$.

Table 7. The effect of selective NADH-ubiquinone oxidoreductase $51 \mathrm{kDa}$ subunit (Complex I) co-suppression on maize $\mathrm{N}$ metabolism and grain yield.

\begin{tabular}{|c|c|c|c|c|c|c|c|c|}
\hline & \multicolumn{2}{|c|}{$\begin{array}{l}\text { Complex I } \\
\text { Expression }\end{array}$} & \multirow{2}{*}{$\begin{array}{c}\text { NADH } \\
\text { nmole 10 } \\
\text { Punches }^{-1}\end{array}$} & \multicolumn{2}{|c|}{ Nitrate Metabolism } & \multicolumn{3}{|c|}{ Yield Parameters } \\
\hline & $\begin{array}{l}\text { Leaf } \\
\text { (V9) }\end{array}$ & $\begin{array}{l}\text { Root } \\
\text { (V2) }\end{array}$ & & $\begin{array}{c}\text { NRA (in vitro) } \\
\text { nmole }^{-1} 5 \text { disc }^{-1}\end{array}$ & 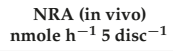 & $\begin{array}{c}\text { Kernel } \\
\text { Wt (mg) }\end{array}$ & $\begin{array}{l}\text { Kernel Number } \\
\text { Plant }^{-1}\end{array}$ & $\begin{array}{c}\text { Grain Yield } \\
\mathrm{kg} \mathrm{ha}^{-1}\end{array}$ \\
\hline Transgene & $0.63 \mathrm{~b}$ & 2.09 & $1.27 \mathrm{a}$ & 578.6 & $677 \mathrm{a}$ & 250.9 & $559 \mathrm{a}$ & $4886.0 \mathrm{a}$ \\
\hline Null & $1.04 \mathrm{a}$ & 2.06 & $1.01 \mathrm{~b}$ & 603.2 & $552 \mathrm{~b}$ & 248.9 & $526 \mathrm{~b}$ & $4581.5 \mathrm{~b}$ \\
\hline$P>F$ & $<0.01$ & NS & $<0.01$ & NS & $<0.01$ & NS & $<0.01$ & $<0.01$ \\
\hline
\end{tabular}

Hybrid containing NADH-ubiquinone oxidoreductase $51 \mathrm{kDa}$ subunit (Complex I) co-suppression transgene event, 1.19, was compared to the null (non-transgenic) hybrid. Means with a different letter are significantly $($ LSD $<0.01)$ different.

\section{Discussion}

\subsection{Field NUE Analyses under Normal and Depleted N Conditions}

Improving NUE under low N fertility is very difficult due to the inherently high NUE under these conditions and the unwillingness of farmers to accept lower grain yields in order to attain higher NUE. Identification of parameters associated with $\mathrm{N}$ input, especially under conditions of low NUE (high $\mathrm{N}$ fertility), is highly desirable for identifying plant parameters that might lead to increased NUE and higher grain yields. Useful parameters for study are those parameters that respond to $\mathrm{N}$ input that are also highly correlated to changes in grain yield. R1-biomass was closely related to grain yield but poorly responsive to $\mathrm{N}$ fertility (Table 1 ) which might suggest R1-biomass and grain yield are related but R1-biomass may not necessarily be vectored by N input. Pearson and Jacobs [51] found no relationship between plant biomass at anthesis and KNP. Andrade et al. [52] and Paponov et al. [53] 
proposed increase in KNP was associated with plant growth rate around anthesis. Ciampitti et al. [54] observed a similar relationship between biomass and grain yield, though no direct correlation with $\mathrm{N}$ fertility was made. Loussaert et al. [41] showed the developing ear competes for $\mathrm{N}$ with the developing tassel, with the tassel having priority; increased R1 ear-weight in male sterile plants was independent of R1-biomass but associated with reduced tassel biomass. Ear length and ear-weight at R1, but not ear-width, were responsive to $\mathrm{N}$ and were highly correlated to grain yield in both high and low $\mathrm{N}$ ranges. Lemcoff and Loomis [55] showed the effect of $N$ deprivation, verses population stress, was on KNP and not on kernel abortion suggesting the effect of $\mathrm{N}$ fertility is primarily on ear development. Poor SPAD chlorophyll relationship to grain yield in high $\mathrm{N}$ fertility make these measurements less useful since improvements in NUE are more desirable in high $\mathrm{N}$ fertilities. These are similar to results obtained by Blackmer and Schepers [56], in that SPAD measurements were not related to grain yield at higher $\mathrm{N}$ fertilities. Grain total $\mathrm{N}$ and ear weight would be expected to be highly related to grain yield since ear weight is nearly identical to grain yield and, since there were no significant differences in grain $\% \mathrm{~N}$, grain total $\mathrm{N}$ would also be nearly identical to grain yield. KNP has been routinely associated with improved grain yield in maize [3,51-53] and these data (Table 1) show KNP is highly responsive to $\mathrm{N}$ fertility. Somewhat surprising was the effect of $\mathrm{N}$ fertility on kernel weight. In the low $\mathrm{N}$ range, KNP was reduced such that kernel weight compensated for poor seed set by making larger kernels under conditions which also produced lower grain yields resulting in a negative relationship between kernel weight and grain yield at lower $\mathrm{N}$ fertility. Though kernel weight was only moderately responsive to $\mathrm{N}$ fertility in the high $\mathrm{N}$ range, kernel weight was highly correlated to grain yield in the high $\mathrm{N}$ range but not in the lower $\mathrm{N}$ range. $\mathrm{N}$ fertility, especially in the high $\mathrm{N}$ range where NUE is lower, affects ear development that can have a lasting effect on increased KNP. Pearson and Jacobs [51] showed that $\mathrm{N}$ fertility manipulations during ear development had a lasting effect on KNP. Kernel weight seems only to be a factor in the higher $\mathrm{N}$ fertility when KNP has been optimized and added $\mathrm{N}$ may have an effect on increasing kernel weight. Biomass, measured at R1 or maturity, especially in the higher $\mathrm{N}$ range, was poorly responsive to $\mathrm{N}$ input.

These data would suggest that the prime effect of $\mathrm{N}$ under higher $\mathrm{N}$ fertility (low NUE) is on reproductive development since under higher $\mathrm{N}$ fertility, biomass was not affected by $\mathrm{N}$ fertility and SPAD was poorly associated with grain yield. N fertility increases KNP under higher N fertility and this is manifested at R1 by longer, more massive ears. R1 ear-weight, R1 ear-length, KNP, and kernel density are parameters responsive to $\mathrm{N}$ fertility and related to grain yield, especially under higher $\mathrm{N}$ fertility (low NUE). Ear-weight at R1 is particularly useful since it is a reproductive trait that can be determined early during plant development.

\subsection{Stalk Nitrate Accumulation}

Another important difference between plants grown under $\mathrm{N}$ deficient and $\mathrm{N}$ sufficient conditions is the accumulation of nitrate in the lower stalk internodes (Figure 1). Warner and Huffaker [57] and later Espen et al. [58] showed nitrate uptake is not dependent upon NA, so reduction in NRA (in vivo) would have little effect on the uptake of nitrate, but with NRA (in vivo) reduced in the lower leaves (Figure 2), nitrate would accumulate in the lower stalk internodes. Reduced NRA (in vivo) in the lower leaves could be explained by reduced NRA (in vitro) (Figure 3). Maize, being a C4 plant, generates OAA via PEP-carboxylase which is reduced to malate and transported to bundle sheath cells where $\mathrm{CO}_{2}$ is concentrated. Reduced OAA production and thus reduced malate would be expected with reduced PEP-carboxylase activity in lower leaves (Figure 3). No change in malic enzyme activity between leaves coupled to reduced PEP-carboxylate activity in the lower leaves should result in lower malate levels in the lower leaves unless some other mechanism is responsible for increased malate in lower leaves. If malate is a main source of cytoplasmic NADH supporting NA [31,32], reduced NA capacity might be partially responsible for malate accumulation in lower leaves (Table 2). Thus, accumulation of malate in the lower leaves may be due to reduced NA resulting in the accumulation of reductant, malate. 


\subsection{Ear Dry Weight Response to Nitrate and Ammonia}

Soil nitrate concentration sampled when plants are $20-30 \mathrm{~cm}$ tall has been shown to be related to maize grain yield [28] and the pre-sidedress nitrate test (PSNT_-[59]) is a soil test used to determine whether supplemental $\mathrm{N}$ fertilizer is required. According to the PSNT, soil nitrate concentrations greater than $25 \mathrm{mg} \mathrm{N} \mathrm{L}^{-1}(1.78 \mathrm{mM})$ require no supplemental $\mathrm{N}$ fertility, suggesting this level of soil nitrate is sufficient for optimum economic maize yield. R1 ear-weight response to nitrate concentrations from 1 to $4 \mathrm{mM} \mathrm{KNO}_{3}$ is consistent with the PSNT with $1 \mathrm{mM} \mathrm{KNO}_{3}$ being insufficient to support $\mathrm{R} 1$ ear-weight whereas $2 \mathrm{mM} \mathrm{KNO}_{3}$ is sufficient and $3 \mathrm{mM} \mathrm{KNO}_{3}$, and above, being luxurious levels of fertilizer $\mathrm{N}$ [41]. In the results shown in Figure 4, R1 ear-weight was established by V12 and increasing or decreasing $\mathrm{KNO}_{3}$ levels from $\mathrm{V} 12$, on, had little effect on $\mathrm{R} 1$ ear-weight. This is consistent with Binder et al. [60] who showed delaying side dressing $\mathrm{N}$ till V6 resulted in $12 \%$ yield decreases. da Silva et al. [61] showed that grain yields could be increased by N side dressing at silking only when sufficient $\mathrm{N}$ was applied during vegetative development. In the studies of da Silval et al. [61] NUE of vegetative $\mathrm{N}$ application was twice that of $\mathrm{N}$ applied at silking and the main yield component improved by $\mathrm{N}$ applied at silking was kernel weight not KNP. R1 ear-weight is largely established by V12 and only moderate changes in R1 ear-weight can be obtained by changes in nitrate fertility after V12.

Unlike nitrate applications, moderate levels of ammonia improve ear development applied at a time (V12-V15) when much higher levels of nitrate are ineffective (Table 3). Ammonia improves ear development of plants grown in insufficient $(1 \mathrm{mM})$ levels of nitrate but is even more efficacious in improving R1 ear-weight of plants grown in sufficient (3-4 mM) levels of nitrate (Table 3). R1 ear-weight improvements induced by ammonia were not due to biomass increases since no change in biomass was observed (Table 3). In controlled experiments with GF3, switching $\mathrm{N}$ fertility from nitrate to $1 \mathrm{mM}$ $\mathrm{NH}_{4} \mathrm{Cl}$ at a time when higher concentrations of nitrate are ineffective (23DAE) increases R1 ear-weight and ear total $\mathrm{N}$ without significantly changing vegetative biomass (Table 4). Changes in R1 ear-weight appear to be due to an increase in ear growth rate in response to ammonia (Table 5) with a doubling of the ear dry weight within $24 \mathrm{~h}$ of ammonia application. Ten times the concentration of nitrate is not as effective as ammonia at this developmental stage. These results suggest that NA, the conversion of nitrate to ammonia, limits R1 ear-weight and NUE in maize. These data show that bypassing NA by supplying ammonia rescues ear development when nitrate is ineffective. If R1 ear-weight is predictive of improved NUE then improvements in R1 ear-weight by by-passing NA would suggest NA limits NUE in maize.

Few studies have shown differential effects of ammonia, versus nitrate, on ear development. Jung et al. [62] showed that supplemental application of urea or $\mathrm{NH}_{4} \mathrm{NO}_{3}$ was much more efficacious than $\mathrm{KNO}_{3}$ when applied 5 to 8 weeks after emergence. $\mathrm{KNO}_{3}$ applications after 8 weeks were ineffective. Though the developmental stage was not specified in these experiments, a 5-8 week after emergence time frame would be roughly from V8-V15. Pan et al. [63] showed that urea fertilization fortified with a nitrification inhibitor produced more ears than comparable nitrate fertilities. Below and Gentry [64] showed that maize produced more kernels ear ${ }^{-1}$ and more grain yield when supplied with a mixture of nitrate and ammonium than when supplied nitrate alone. Smiciklas and Below [65] showed improved grain yield and increased kernels ear ${ }^{-1}$ were associated with a mixture of ammonia and nitrate verses nitrate alone but related the effect to cytokinin balance. Yasir et al. [66] showed foliar feeding of urea was most effective in improving grain yield, KNP and stover biomass when applied at V12. All of these observations are in agreement with ammonia induced increase in ear growth rate shown in these experiments (Tables 3-5). These results, combined with the observations that maize accumulates nitrate in the stalk under higher N fertilities, Figure 1, [4,23,24], would suggest NA limits ear development since stalk nitrate accumulation at high $\mathrm{N}$ fertility would suggest nitrate uptake is not limiting and by-passing NA by providing ammonia stimulates R1 ear-weight, raising NUE. This inference is different from those of Chen et al. [67] and Fan et al. [20] who showed transgenic expression of high affinity nitrate transporters in rice significantly improved grain yield and NUE 
in rice, implying the results are due to improved nitrate uptake. It is not surprising that maize and rice have different mechanisms limiting NUE since maize is a C4 plant and rice is a C3 plant; rice can grow submerged in water and maize cannot. In the field experiments of Fan et al. [20] rice was grown submerged in water, as is the custom for rice, and fertilized with urea [20]. Under these conditions, the main source of $\mathrm{N}$ would be ammonia [68]. Fan et al. [20] showed that when ${ }^{15} \mathrm{~N}$ was supplied as $\mathrm{Ca}\left({ }^{15} \mathrm{NO}_{3}\right)_{2}$ transgenic rice expressing OsNrt2.1 had significantly higher rates of ${ }^{15} \mathrm{~N}$ uptake but when ${ }^{15} \mathrm{~N}$ was supplied as $\mathrm{NH}_{4}{ }^{15} \mathrm{NO}_{3}$ there was a significant reduction in ${ }^{15} \mathrm{~N}$ uptake in transgenic plants compared to controls. When ${ }^{15} \mathrm{NH}_{4} \mathrm{NO}_{3}$ was used as a substrate not only was the background ${ }^{15} \mathrm{~N}$ uptake rate 10-20× higher than when $\mathrm{NH}_{4}{ }^{15} \mathrm{NO}_{3}$ was supplied but there was significantly more ${ }^{15} \mathrm{~N}$ taken up by the transgenic plants. The rate of ${ }^{15} \mathrm{~N}$ uptake when ${ }^{15} \mathrm{NH}_{4}{ }^{15} \mathrm{NO}_{3}$ was used as a substrate was not significantly different from ${ }^{15} \mathrm{~N}$ uptake from the ${ }^{15} \mathrm{NH}_{4} \mathrm{NO}_{3}$ treatment suggesting the effect of the transgene was on the uptake of ammonia, not nitrate. This would make our current inference of NA limiting NUE in congruence with those of Chen et al. [67] and Fan et al. [20] since improved ammonia uptake would bypass NA, the limiting step, resulting in improved NUE.

\subsection{Total N, Organic- $N$, Nitrate- $N$, and NA}

When GF3 was provided a range of fertilities that spans the range of insufficient to greater than sufficient levels of nitrate, NRA (in vitro) increased linearly with increased nitrate fertility, whereas NRA (in vivo) leveled off at the point in which nitrate fertility reached sufficiency to support R1 ear-weight (Figure 5). Organic-N accumulation mirrored NRA (in vivo) reaching maximum organic-N at $2 \mathrm{~mm}$ nitrate fertility (Figure 6). These results show that uptake of nitrate, the predominant form of $\mathrm{N}$ in aerobic soils, nor the extractable level of NRA (in vitro) do not limit NUE but the conversion of nitrate-N to organic-N (ammonia) limits NUE, especially, under conditions of high $\mathrm{N}$ fertility. Ciampitti et al. [54] concluded NUE in maize is limited by N uptake. The methodology used by Ciampitti et al. [54] was not capable of distinguishing between nitrate- $\mathrm{N}$ and organic-N which could significantly bias any inference made. Uncoupling of NRA (in vitro) with NRA (in vivo) (Figure 5) has been previously shown by Klepper et al. [29] and again by Kaiser et al. [33]. NRA (in vitro) does not reflect NA and is in excess of that required for NA which might suggest some other factor other than NRA (in vitro) limits NA. The increase in total $\mathrm{N}$ was primarily due to an increase in nitrate- $\mathrm{N}$ at higher $\mathrm{N}$ fertilities with $30 \%$ of the total plant $\mathrm{N}$ of plants grown in $4 \mathrm{M} \mathrm{KNO}_{3}$ being nitrate (Figure 6). With both nitrate and NRA (in vitro) in excess under high nitrate fertility and NiR (in vivo) not limiting (Figure 2), the only other factor affecting NA would be the availability of reductant, NADH, to drive NA. The availability of cytoplasmic NADH as the limiting step in NA as proposed $[33,36,38]$ would be a logical alternative.

\subsection{Transgenic NADH-Ubiquinone Oxidoreductase 51 kDa Subunit (Complex I) Co-Suppression}

NA is a complex biochemical process both supported and inhibited by respiratory metabolism [38]. The tricarboxylic acid cycle contributes $\alpha$ KG for NA but in the process robs the tricarboxylic acid cycle's ability to generate NADH within the mitochondria, resulting in lower mitochondrial NADH concentrations. NA may become self-regulated when mitochondrial NADH levels are restored by absorbing cytoplasmic malate which lowers the level of reductant available to generate NADH for nitrate reduction. Tobacco [36] and cucumber [37] have cytoplasmic mutants deficient in mitochondrial $\mathrm{NADH}$ dehydrogenase (Complex I) which inhibits the oxidation of NADH, artificially increasing the concentration of NADH inside the mitochondria. These mutants have improved capacity to utilize nitrate, but because the trait is constitutively expressed, also have undesirable traits associated with reduced capacity to generate reduction power in non-photosynthetic tissues. NCS2, a Complex I mutant in maize, has striped leaves, reduced growth rate and other deleterious traits [39]. A constitutive co-suppression of Complex I would likely be similarly compromised. Since NA occurs exclusively in the mesophyll cells in maize leaves, selective Complex I co-suppression in the mesophyll cells might minimize deleterious effects not related to NA. Also, since mitochondrial respiration shifts 
toward providing carbon skeletons for NA in the light when nitrate is the N source [69], generation of leaf mitochondrial energy might not be important in the light. The promoter of PEP-carboxylase, preferentially expressed in the mesophyll cells [70], was selected to drive Complex I co-suppression with the aim to maximize the expression of Complex I co-suppression in mesophyll cells while minimizing non-targeted effects.

One transgenic event showed positive grain yield responses when maintained in high $\mathrm{N}$ fertility (low NUE) in two years, one year in a multi-environment experiment (Tables 6 and 7). In the second-year field evaluation, the positive event showed significant improvements in grain yield that was primarily associated with increased KNP (Table 7). The positive event had significantly lower levels of leaf NADH-ubiquinone oxidoreductase $51 \mathrm{kDa}$ subunit (Complex I) expression, greater extractable NADH, higher NRA (in vivo) but no difference in extractable NRA (in vitro) (Table 7). NADH-ubiquinone oxidoreductase $51 \mathrm{kDa}$ subunit (Complex I) expression in root, a non-targeted tissue, was not different between transgene and non-transgene. These results are expected if NA is limited by NADH rather than by NRA (in vitro). Since the transgenic hybrid showed higher NADH levels associated with improved NRA (in vivo) without increase in NRA (in vitro) it would follow that increases in KNP associated with increased grain yields under high $\mathrm{N}$ fertility could have been brokered by improved NA during ear development. It may be suggested that increased reductant (NADH) limits NA, which limits NUE. A disturbing issue is the low frequency of positive events. The difference in transgene and non-transgene expression of NADH-ubiquinone oxidoreductase $51 \mathrm{kDa}$ subunit (Complex I) was greater with plant maturity, with the greatest difference in leaf expression at R2. This is similar to PEP-carboxylase expression shown by Cho et al. [70], increasing with plant maturity with maximum expression at R3. The PEP-carboxylase promoter may be sufficiently tissue specific but not have sufficient strength to drive gene co-suppression during the critical time of ear development between V9-V15. If maximum expression of the promoter gene (PEP-carboxylase) is R2-R3 [70] not all of the transgene events may have had sufficient expression levels from V9-V15 when ear development would require maximum NADH to support NA. These data demonstrate the potential of increasing leaf NADH levels to improve maize NUE.

\section{Conclusions}

R1 ear-weight is a good estimate of maize NUE under both high N fertility (low NUE) and low $\mathrm{N}$ fertility (high NUE) conditions. The assimilation of nitrate to ammonia limits ear development and NUE in maize. This is concluded by observation that nitrate cannot rescue ear development at later stages of reproductive growth but ammonia can. Nitrate uptake is not limiting under high $\mathrm{N}$ fertility and accumulates in the stalk to much higher concentrations than soil nitrate concentrations. Stalk nitrate accumulation is associated with reduced leaf NRA (in vivo) and increased leaf malate concentrations. At higher nitrate fertilities, NRA (in vitro) increases linearly but NRA (in vivo) levels off at higher nitrate fertilities. Organic-N follows NRA (in vivo), not NRA (in vitro) with increasing nitrate fertility, with the bulk of increased total-N due to nitrate accumulation at higher nitrate fertilities. Improved NUE in maize is associated with improved NA which may be brokered by increased NADH levels available for nitrate reduction.

Author Contributions: Conceptualization, D.L., N.M.; Methodology, D.L.; Validation, B.S.; Investigation, N.M., J.C., D.P.O.; Writing-Original Draft Preparation, D.L.; Writing-Review \& Editing, D.L.; Funding Acquisition, B.S.

funding: This research received no external funding.

Acknowledgments: David Sevenich for total N analyses. Renee Lafitte for supervising the multi-environment field yield trial.

Conflicts of Interest: The authors declare no conflict of interest. 


\section{References}

1. Uriberlarrea, M.; Moose, S.P.; Below, F.E. Divergent selection for grain protein affects nitrogen use in maize hybrids. Field Crops Res. 2007, 100, 82-90. [CrossRef]

2. Ciampitti, I.A.; Vyn, T.J. A comprehensive study of plant density consequences on nitrogen uptake dynamics of maize plants from vegetative to reproductive stages. Field Crops Res. 2011, 12, 2-18. [CrossRef]

3. Uhart, S.A.; Andrade, F.H. Nitrogen Deficiency in Maize: II. Carbon-Nitrogen Interaction Effects on Kernel Number and Grain Yield. Crop Sci. 1995, 35, 1384-1389. [CrossRef]

4. Binford, G.D.; Blackmer, A.M.; El-Hout, N.M. Tissue Test for Excess Nitrogen during Corn Production. Agron. J. 1990, 82, 124-129. [CrossRef]

5. Rutto, E.; Bossenkemper, J.P.; Kelly, J.; Chim, B.K.; Raun, W.R. Maize grain yield response to the distance nitrogen is placed away from the row. Exp. Agric. 2013, 49, 3-18. [CrossRef]

6. Raun, W.R.; Johnson, G.V. Improving nitrogen use efficiency for cereal production. Agron. J. 1999, 91, 357-363. [CrossRef]

7. Xu, G.; Fan, X.; Miller, A.J. Plant nitrogen assimilation and use efficiency. Annu. Rev. Plant Biol. 2012, 63, 153-182. [CrossRef] [PubMed]

8. McAllister, C.H.; Beatty, P.H.; Good, A.G. Engineering nitrogen use efficiency crop plants: The current status. Plant Biotechnol. J. 2012, 10, 1011-1025. [CrossRef] [PubMed]

9. Sawyer, J.; Nafziger, E.; Randall, G.; Bundy, L.; Rehm, G.; Joern, B. Concepts and Rational for Regional Nitrogen Rate Guidelines for Corn. Iowa State University Extension: Ames, IA, USA, 2006. Available online: http:/ / publications.iowa.gov/id/eprint/3847 (accessed on 2 June 2010).

10. Kohl, D.H.; Shearer, G.B.; Commoner, B. Variation of ${ }^{15} \mathrm{~N}$ in Corn and Soil Following Application of Fertilizer Nitrogen. Soil Sci. Soc. Am. J. 1973, 37, 888-892. [CrossRef]

11. Sogbedji, J.M.; van Es, H.M.; Yang, C.L.; Geohring, L.D.; Magdoff, F.R. Nitrate Leaching and Nitrogen Budget as Affected by Maize Nitrogen Rate and Soil Type. J. Environ. Qual. 2000, 29, 1813-1820. [CrossRef]

12. Nelson, K.A.; Scharf, P.C.; Stevens, W.E.; Burdick, B.A. Rescue Nitrogen Applications for Corn. Soil Sci. Soc. Am. J. 2010, 75, 143-151. [CrossRef]

13. Wang, Z.-H.; Liu, X.-J.; Ju, X.-T.; Zhang, F.-S.; Malhi, S.S. Ammonia Volatilization Loss from Surface-Broadcast Urea: Comparison of Vented- and Closed-Chamber Methods and Loss in Winter Wheat-Summer Maize Rotation in North China Plain. Commun. Soil Sci. Plant Anal. 2011, 35, 2917-2939. [CrossRef]

14. Pelstera, D.E.; Larouche, F.; Rochette, P. Nitrogen fertilization but not soil tillage affects nitrous oxide emissions from a clay loam soil under a maize-soybean rotation. Soil Tillage Res. 2011, 115-116, 16-26. [CrossRef]

15. Good, A.G.; Shrawat, A.K.; Muench, D.G. Can less yield more? Is reducing nutrient input into the environment compatible with maintaining crop production? Trends Plant Sci. 2004, 9, 597-605. [CrossRef] [PubMed]

16. Kant, S.; Bi, Y.-M.; Rothstein, S.J. Understanding plant response to nitrogen limitation for the improvement of crop nitrogen use efficiency. J Exp. Bot. 2011, 62, 1499-1509. [CrossRef] [PubMed]

17. Brendel, V.; Kurtz, S.; Walbot, V. Comparative genomics of Arabidopsis and maize: Prospects and limitations. Genome Biol. 2002, 3. [CrossRef]

18. Basra, A.S.; Dhawan, A.K.; Goyal, S.S. DCMU inhibits in vivo nitrate reduction in illuminated barley (C3) leaves but not in maize (C4): A new mechanism for the role of light? Planta 2002, 215, 855-861. [CrossRef] [PubMed]

19. Bloom, A.J.; Burger, M.; Asensio, J.S.R.; Cousins, A.B. Carbon Dioxide Enrichment Inhibits Nitrate Assimilation in Wheat and Arabidopsis. Science 2010, 328, 899-903. [CrossRef] [PubMed]

20. Fan, X.; Tang, Z.; Tan, Y.; Zhang, Y.; Luo, B.; Yang, M.; Lian, X.; Shen, Q.; Miller, A.J.; Xu, G. Overexpression of a pH-sensitive nitrate transporter in rice increases crop yields. Proc. Natl. Acad. Sci. USA 2017, 113, 7118-7123. [CrossRef] [PubMed]

21. Rizzi, E.; Balconi, B.C.; Manusardi, C.; Gentinetta, E.; Motto, M. Genetic variation for traits relating to nitrogen content of maize stalks. Euphytica 1991, 52, 91-98.

22. Cliquet, J.-B.; Deléens, E.; Bousser, A.; Martin, M.; Lescure, J.-C.; Prioul, J.-L.; Mariotti, A.; Morot-Gaudry, J.-F. Estimation of Carbon and Nitrogen Allocation during Stalk Elongation by ${ }^{13} \mathrm{C}$ and ${ }^{15} \mathrm{~N}$ Tracing in Zea mays L. Plant Physiol. 1990, 92, 79-87. [CrossRef] [PubMed] 
23. Binford, G.D.; Blackmer, A.M.; Meese, E.G. Optimal Concentrations of Nitrate in Cornstalks at Maturity. Agron. J. 1992, 84, 881-887. [CrossRef]

24. Sawyer, J. Corn Stalk Nitrate Interpretation. 2010. Available online: http://www.extension.iastate.edu/ CropNews/2010/0914sawyer.htm (accessed on 5 September 2012).

25. Brouder, S.M.; Mengel, D.B.; Hofmann, B.S. Diagnostic Efficiency of the Blacklayer Stalk Nitrate and Grain Nitrogen Tests for Corn. Agron. J. 2000, 92, 1236-1247. [CrossRef]

26. Varvel, G.E.; Schepers, J.S.; Francis, D.D. Chlorophyll Meter and Stalk Nitrate Techniques as Complementary Indices for Residual Nitrogen. J. Prod. Agric. 1997, 10, 147-151. [CrossRef]

27. Beevers, L.; Hageman, R.H. Nitrate Reduction in Higher Plants. Annu. Rev. Plant Physiol. 1969, 20, 495-522. [CrossRef]

28. Blackmer, A.M.; Pottker, D.; Cerrato, M.E.; Webb, J. Correlations between Soil Nitrate Concentrations in Late Spring and Corn Yields in Iowa. J. Prod. Agric. 1988, 2, 103-109. [CrossRef]

29. Klepper, L.; Flesher, D.; Hageman, R.H. Generation of Reduced Nicotinamide Adenine Dinucleotide for Nitrate Reduction in Green Leaves. Plant Physiol. 1971, 48, 580-590. [CrossRef] [PubMed]

30. Gowri, G.; Campbell, W.H. Communication cDNA Clones for Corn Leaf NADH:Nitrate Reductase and Chloroplast $\mathrm{NAD}(\mathrm{P})^{+}$:GlyceraIdehyde-3-Phosphate Dehydrogenase; Characterization of the Clones and Analysis of the Expression of the Genes in Leaves as Influenced by Nitrate in the Light and Dark. Plant Physiol. 1989, 90, 792-798. [PubMed]

31. Neyra, C.A.; Hageman, R.H. Relationships between Carbon Dioxide, Malate, and Nitrate Accumulation and Reduction in Corn (Zea mays L.) Seedlings. Plant Physiol. 1976, 58, 726-730. [CrossRef] [PubMed]

32. Rathnam, C.K.M. Malate and Dihydroxacetone Phosphate-dependent Nitrate Reduction in Spinach Leaf Protoplasts. Plant Physiol. 1978, 62, 220-223. [CrossRef] [PubMed]

33. Kaiser, W.M.; Kandlbinder, A.; Stoimenova, M.; Glaab, J. Discrepancy between nitrate reduction rates in intact leaves and nitrate reductase activity in leaf extracts: What limits nitrate reduction in situ? Planta 2000, 210, 801-807. [CrossRef] [PubMed]

34. Sienkiewicz-Porzucek, A.; Nunes-Nesi, A.; Sulpice, R.; Lisec, J.; Centeno, D.C.; Carillo, P.; Leissea, A.; Urbanczyk-Wochniak, E.; Fernie, A.R. Mild Reductions in Mitochondrial Citrate Synthase Activity Result in a Compromised Nitrate Assimilation and Reduced Leaf Pigmentation But Have No Effect on Photosynthetic Performance or Growth. Plant Physiol. 2008, 147, 115-127. [CrossRef] [PubMed]

35. Sienkiewicz-Porzuceka, A.; Sulpicea, R.; Osorioa, S.; Krahnerta, I.; Leissea, A.; Urbanczyk-Wochniaka, E.; Hodges, M.; Ferniea, A.R.; Nunes-Nesia, A. Mild Reductions in Mitochondrial NAD Dependent Isocitrate Dehydrogenase Activity Result in Altered Nitrate Assimilation and Pigmentation But Do Not Impact Growth. Mol. Plant 2010, 3, 156-173. [CrossRef] [PubMed]

36. Hager, J.; Pellny, T.K.; Mauve, C.; Lelarge-Troverie, C.; DePaepe, R.; Foyer, C.H.; Noctor, G. Conditional modulation of NAD levels and metabolite profiles in Nicotiana sylvestris by mitochondrial electron transport and carbon/nitrogen supply. Planta 2010, 231, 1145-1157. [CrossRef] [PubMed]

37. Szal, B.; Jastrzebska, A.; Kulka, M.; Lesniak, K.; Podgórska, A.; Pärnik, T.; Ivanova, H.; Keerberg, O.; Gardeström, P.; Rychter, A.M. Influence of mitochondrial genome rearrangement on cucumber leaf carbon and nitrogen metabolism. Planta 2010, 232, 1371-1382. [CrossRef] [PubMed]

38. Foyer, C.H.; Noctor, G.; Hodges, M. Respiration and nitrogen assimilation: Targeting mitochondria-associated metabolism as a means to enhance nitrogen use efficiency. J. Exp. Bot. 2011, 62, 1467-1482. [CrossRef] [PubMed]

39. Marienfeld, J.R.; Newton, K.J. The maize NCS2 abnormal growth mutant has a chimeric nad4-nad7 mitochondrial gene and is associated with reduced complex I function. Genetics 1994, 138, 855-863. [PubMed]

40. Loussaert, D. Microcomputer-based experiment management system: II. Data analysis. Agron. J. 1992, 84, 256-259. [CrossRef]

41. Loussaert, D.; DeBruin, J.; San Martin, J.P.; Schussler, J.; Pape, R.; Clapp, J.; Mongar, N.; Fox, T.; Albertsen, M.; Trimnell, M.; et al. Genetic Male Sterility (Ms44) Increases Maize Grain Yield. Crop Sci. 2017, 57, 2718-2728. [CrossRef]

42. Tollenaar, M.; Migus, W. Dry matter accumulation of maize grown hydroponically under controlled-environment and field conditions. Can. J. Plant Sci. 1984, 64, 475-485. [CrossRef] 
43. Queval, G.; Noctor, G. A plate reader method for the measurement of NAD, NADP, glutathione, and ascorbate in tissue extracts: Application to redox profiling during Arabidopsis rosette development. Anal. Biochem. 2007, 363, 58-69. [CrossRef] [PubMed]

44. Miranda, K.M.; Espey, M.G.; Wink, D.A. A rapid, simple spectrophotometric method for simultaneous detection of nitrate and nitrite. Nitric Oxide 2001, 5, 62-71. [CrossRef] [PubMed]

45. Reed, A.J.; Hageman, R.H. The relationship between nitrate uptake, nitrate flux and nitrate reductase in four maize (Zea mays L.) genotypes. I. Genotypic variation. Plant Physiol. 1980, 66, 1179-1183. [CrossRef] [PubMed]

46. Kaiser, W.M.; Huber, S.C. Correlation between apparent activation state of nitrate reductase (NR), NR hysteresis and degradation of NR protein. J. Exp. Bot. 1997, 48, 1367-1374. [CrossRef]

47. Bradford, M.M. A rapid and sensitive method for the quantitation of microgram quantities of protein utilizing the principle of protein-dye binding. Anal. Biochem. 1976, 72, 248-254. [CrossRef]

48. Fox, T.; DeBruin, J.; Haug-Collet, K.; Trimnell, M.; Clapp, J.; Leonard, A.; Li, B.; Scolaro, E.; Collinson, S.; Glassman, K.; et al. A single point mutation in Ms44 results in dominant male sterility and improves nitrogen use efficiency in maize. Plant Biotechnol. J. 2017, 15, 942-952. [CrossRef] [PubMed]

49. Unger, E.; Betz, S.; Xu, R.; Cigan, A.M. Selection and orientation of adjacent genes influences DAM-mediated male sterility in transformed maize. Transgenic Res. 2001, 10, 409-422. [CrossRef] [PubMed]

50. Bonifas, K.D.; Walters, D.T.; Cassman, K.G.; Lindquist, J.L. Nitrogen supply affects root:shoot ratio in corn and velvetleaf (Abutilon theophrasti). Weed Sci. 2005, 53, 670-675. [CrossRef]

51. Pearson, C.J.; Jacobs, B.C. Yield components and nitrogen partitioning of maize in response to nitrogen before and after anthesis. Aust. J. Agric. Res. 1987, 38, 1001-1009. [CrossRef]

52. Andrade, F.H.; Echarte, L.; Rizzalli, R.; Della Maggiora, A.; Casanovas, M. Kernel Number Prediction in Maize under Nitrogen or Water Stress. Crop Sci. 2002, 42, 1173-1179. [CrossRef]

53. Paponov, J.A.; Sambo, P.; Presterl, T.; Geiger, H.H.; Engels, C. Kernel set in maize genotype differing in nitrogen use efficiency in response to resource availability around flowering. Plant Soil 2005, 272, 101-110. [CrossRef]

54. Ciampitti, I.A.; Zhang, H.; Friedemannc, P.; Vyn, T.J. Potential Physiological Frameworks for Mid-Season Field Phenotyping of Final Plant Nitrogen Uptake, Nitrogen Use Efficiency, and Grain Yield in Maize. Crop Sci. 2012, 52, 2728-2742. [CrossRef]

55. Lemcoff, J.H.; Loomis, R.S. Nitrogen and density influences on silk emergence, endosperm development, and grain yield in maize (Zea mays L.). Field Crop Res. 1994, 38, 63-72. [CrossRef]

56. Blackmer, T.M.; Schepers, J.S. Aerial Photography to Detect Nitrogen Stress in Corn. J. Plant Physiol. 1996, 148, 440-444. [CrossRef]

57. Warner, R.L.; Huffaker, R.C. Nitrate Transport Is Independent of NADH and NAD(P)H Nitrate Reductases in Barley Seedlings. Plant Physiol. 1989, 91, 947-953. [CrossRef] [PubMed]

58. Espen, L.; Nocito, F.F.; Cocucci, M. Effect of $\mathrm{NO}_{3}{ }^{-}$transport and reduction on intracellular pH: An in vivo NMR study in maize roots. J. Exp. Bot. 2004, 55, 2053-2061. [CrossRef] [PubMed]

59. Magdoff, F.R. Understanding the Magdoff pre-sidedress nitrate test for corn. J. Prod. Agric. 1991, 4, $297-305$. [CrossRef]

60. Binder, D.L.; Sander, D.H.; Walters, D.T. Maize Response to Time of Nitrogen Application as Affected by Level of Nitrogen Deficiency. Agron. J. 2000, 92, 1228-1236. [CrossRef]

61. Da Silval, F.P.R.; Striederl, M.L.; da Silva Coserl, R.P.; Rambol, L.; Sangoill, L.; Argentalll, G.; Forsthoferlll, E.L.; da Silval, A.A. Grain yield and kernel crude protein content increases of maize hybrids with late nitrogen side-dressing. Sci. Agric. 2005, 62, 487-492. [CrossRef]

62. Jung, P.E., Jr.; Peterson, L.A.; Schader, L.E. Response of Irrigated Corn to Time, Rate and Source of Applied N on Sandy Soils. Agron. J. 1972, 64, 668-670. [CrossRef]

63. Pan, W.L.; Kamprath, E.J.; Moll, R.H.; Jackson, W.A. Prolificacy in Corn: Its Effects on Nitrate and Ammonium Uptake and Utilization. Soil Sci. Soc. Am. J. 1984, 48, 1101-1106. [CrossRef]

64. Below, F.E.; Gentry, L.E. Maize Productivity as Influenced by Mixed Nitrogen Supplied before or after Anthesis. Crop Sci. 1992, 32, 163-168. [CrossRef]

65. Smiciklas, K.D.; Below, F.E. Role of cytokinin in enhanced productivity of maize supplied with $\mathrm{NH}_{4}{ }^{+}$and $\mathrm{NO}_{3}{ }^{-}$. Plant Soil 1992, 142, 307-313. [CrossRef] 
66. Yasir, A.M.; Khlil, S.K.; Jan, M.T.; Khan, A.Z. Phenology, growth, and grain yield of maize as influenced by foliar applied urea at different growth stages. J. Plant Nutr. 2010, 33, 71-79.

67. Chen, J.; Fan, X.; Qian, K.; Zhang, Y.; Song, M.; Liu, Y.; Xu, G.; Fan, X. pOsNAR2.1:OsNAR2.1 expression enhances nitrogen uptake efficiency and grain yield in transgenic rice plants. Plant Biotechnol. J. 2017, 15, 1273-1283. [CrossRef] [PubMed]

68. Yu, T.-R. Soil and plants. In Physical Chemistry of Paddy Soils; Yu, T.-R., Ed.; Science Press: Beijing, China, 1985; pp. 197-217.

69. Gardeström, P.; Igamberdiev, A.U.; Raghavendra, A.S. Mitochondrial Functions in the Light and Significance to Carbon-Nitrogen Interactions. In Photosynthetic Nitrogen Assimilation and Associated Carbon and Respiratory Metabolism; Foyer, C.H., Noctor, G., Eds.; Springer: Dordrecht, The Netherlands, 2002; Chapter 12; pp. 151-172.

70. Cho, Y.; Fernandes, J.; Kim, S.-H.; Walbot, V. Gene-expression profile comparisons distinguish seven organs of maize. Genome Biol. 2002, 3. [CrossRef]

(c) 2018 by the authors. Licensee MDPI, Basel, Switzerland. This article is an open access article distributed under the terms and conditions of the Creative Commons Attribution (CC BY) license (http:/ / creativecommons.org/licenses/by/4.0/). 
Article

\title{
Potassium Supplying Capacity of Diverse Soils and K-Use Efficiency of Maize in South Asia
}

\author{
Saiful Islam ${ }^{1, *}$, Jagadish Timsina ${ }^{2}$, Muhammad Salim ${ }^{3}$, Kaushik Majumdar ${ }^{4}$ \\ and Mahesh K Gathala ${ }^{1}$ \\ 1 International Maize and Wheat Improvement Centre, Bangladesh Office, House-10/B, Road-53, Gulshan-2, \\ Dhaka 1212, Bangladesh; ms.islam@cgiar.org \\ 2 Soil Research Group, Faculty of Veterinary and Agricultural Sciences, University of Melbourne, \\ Victoria 3010, Australia; jtimsina@unimelb.edu.au \\ 3 Department of Agronomy, Bangladesh Agricultural University, Mymensingh 2022, Bangladesh; \\ msalimafa@yahoo.com \\ 4 International Plant Nutrition Institute, South Asia Office, Palm Drive, B-1602, Golf Course Ext Road, \\ Sector-66, Gurgaon 122001, Haryana, India; kmajumdar@ipni.net \\ * Correspondence: ms.islam@cgiar.org; Tel.: +880-179-666-3778
}

Received: 13 June 2018; Accepted: 12 July 2018; Published: 16 July 2018

\begin{abstract}
Increased nutrient withdrawal by rapidly expanding intensive cropping systems, in combination with imbalanced fertilization, is leading to potassium (K) depletion from agricultural soils in Asia. There is an urgent need to better understand the soil K-supplying capacity and $\mathrm{K}$-use efficiency of crops to address this issue. Maize is increasingly being grown in rice-based systems in South Asia, particularly in Bangladesh and North East India. The high nutrient extraction, especially $\mathrm{K}$, however, causes concerns for the sustainability of maize production systems in the region. The present study was designed to estimate, through a plant-based method, the magnitude, and variation in K-supplying capacity of a range of soils from the maize-growing areas and the K-use efficiency of maize in Bangladesh. Eighteen diverse soils were collected from several upazillas (or sub-districts) under 11 agro-ecological zones to examine their K-supplying capacity from the soil reserves and from $\mathrm{K}$ fertilization (100 $\mathrm{mg} \mathrm{K} \mathrm{kg}^{-1}$ soil) for successive seven maize crops grown up to V10-V12 in pots inside a net house. A validation field experiment was conducted with five levels of $\mathrm{K}\left(0,40,80,120\right.$ and $\left.160 \mathrm{~kg} \mathrm{ha}^{-1}\right)$ and two fertilizer recommendations based on "Nutrient Expert for Maize-NEM" and "Maize Crop Manager-MCM" decision support tools (DSSs) in 12 farmers' fields in Rangpur, Rajshahi and Comilla districts in Bangladesh. Grain yield and yield attributes of maize responded significantly $(p<0.001)$ to $\mathrm{K}$ fertilizer, with grain yield increase from 18 to $79 \%$ over control in all locations. Total K uptake by plants not receiving $\mathrm{K}$ fertilizer, considered as potential K-supplying capacity of the soil in the pot experiment, followed the order: Modhukhali $>$ Mithapukur $>$ Rangpur Sadar $>$ Dinajpur Sadar $>$ Jhinaidah Sadar $>$ Gangachara $>$ Binerpota $>$ Tarash $>$ Gopalpur $>$ Daudkandi $>$ Paba $>$ Modhupur $>$ Nawabganj Sadar $>$ Shibganj $>$ Birganj $>$ Godagari > Barura > Durgapur. Likewise, in the validation field experiment, the K-supplying capacity of soils was 83.5, 60.5 and $57.2 \mathrm{~kg} \mathrm{ha}^{-1}$ in Rangpur, Rajshahi, and Comilla, respectively. Further, the order of K-supplying capacity for three sites was similar to the results from pot study confirming the applicability of results to other soils and maize-growing areas in Bangladesh and similar soils and areas across South Asia. Based on the results from pot and field experiments, we conclude that the site-specific K management using the fertilizer DSSs can be the better and more efficient K management strategy for maize.
\end{abstract}

Keywords: site-specific K management; soil K supply; maize yield response to K; maize crop manager; nutrient expert for maize 


\section{Introduction}

Maize is the second most important cereal crop after rice in Asia and provides approximately $30 \%$ of the food calories to more than 4.5 billion people in 94 developing countries [1]. The world population is increasing and will continue to increase from 7.2 to 8.1 billion by 2025 , reaching 9.6 billion by 2050 and 10.9 billion by 2100 , with most growth occurring in the developing countries [2,3]. Maize was grown in 0.43 million hectares during 2016-2017 in Bangladesh [4].

Available soil $\mathrm{K}$ is deficient in many soils of Bangladesh, and crops are showing $\mathrm{K}$ deficiency symptoms. It is well known that the availability of $\mathrm{K}$ to plants does not only depend on the size of the available pool in the soil but also on the transport of $\mathrm{K}$ from soil solution to the root zone and from the root zone into plant roots [5]. Many plant factors (variety, root system, and antagonistic and synergistic mechanisms in ion uptake), soil factors ( $\mathrm{pH}$, organic matter content, texture, complementary cations, etc.) and environmental factors (rainfall, temperature, etc.) may affect these processes. However, when plant available soil $\mathrm{K}$ is sufficient, these factors tend to become less important. Therefore, soil $\mathrm{K}$-supplying capacity is a key factor to sustain and increase crop yields.

Recent soil-test results have shown that many soils of the Indo-Gangetic Plains (IGP) of South Asia, with available $\mathrm{K}$ concentration of less than $0.1 \mathrm{cmol} \mathrm{kg}^{-1}$, are becoming deficient in $\mathrm{K}$ despite their original high $\mathrm{K}$ contents [6-10]. The introduction and prevalence of high yielding varieties of rice, hybrid maize and wheat since the green revolution accelerated the removal of $\mathrm{K}$ from the soil than the traditional varieties did. At the same time, the application of $\mathrm{K}$ fertilizers, on the other hand, was limited, leading to negative input-output balance of $\mathrm{K}$ that depleted soil $\mathrm{K}$ status in most of the Asian countries [10,11]. Scientists reported 31\% decline in soil K status in Bangladesh over the past 30 years, which is an alarming figure [12]. Despite this, studies in soil K received less attention than other major nutrients, because the application of $\mathrm{K}$ fertilizer doesn't frequently bring about a dramatic improvement in the vegetative growth of crop as is observed with nitrogen $(\mathrm{N})$ fertilizer, or does not have the environmental concerns associated with its use as in N. Besides, the general perception that the South Asian soils are rich in K-bearing minerals also led to the complacency that crops may not require external $\mathrm{K}$ application to perform adequately. Therefore, most of the farmers, who can afford to apply fertilizers to their crops, apply only urea and phosphate fertilizers, while K application is often neglected. As a result, soils which were not deficient in $\mathrm{K}$ in the past have either become deficient or are likely to become deficient in the near future [13].

Of the three main macronutrients ( $\mathrm{N}$, phosphorus- $\mathrm{P}$, and potassium-K), much work has been done in the past about $\mathrm{N}$ management in cropping systems [14,15]. The focus now, however in the context of maize production has been shifted to $\mathrm{K}$ nutrition, as the $\mathrm{K}$ dynamics of maize-growing soils dictate how well the $\mathrm{K}$ demand for high-yielding maize crops can be met. It is hypothesized that soils of maize-growing areas in Bangladesh differ in terms of mineralogy, soil K reserves, allowable drawdown, and K-supplying capacity. Thus, some soils would require more while others would require less $\mathrm{K}$ to grow profitable maize crops. Carefully-conducted pot and field experiments using a plant-based assay are expected to help estimate the magnitude and variation in K-supplying capacity of soils. The information generated from such experiments would help develop soil-based coefficients on allowable draw down of soil $\mathrm{K}$ reserves, which can be used for the determination of fertilizer K requirements of maize for Bangladesh, as well as for other maize-growing areas in South Asia.

Soil indigenous K supply, K-use efficiency, and crop yield vary spatially and temporally in the diverse irrigated maize fields in Bangladesh and South Asia. At present, however, blanket fertilizer recommendations are often applied over large areas without taking into account the wide variability in site- and season-specific crop nutrient requirements, which explains the reasons for low K-use efficiency. Further, the use of $\mathrm{K}$ fertilizers is often not based on crop requirements and are not balanced with other nutrients. As a result, the profitability is not optimized [6,16]. A rational and profitable K fertilizer management strategy needs to be based on better understanding of the soil K-supplying capacity. The efficiency of applied $\mathrm{K}$ fertilizer, in terms of agronomic efficiency of $\mathrm{K}\left(\mathrm{AE}_{\mathrm{K}}, \mathrm{kg}\right.$ yield increase per $\mathrm{kg}$ nutrient applied) and apparent $\mathrm{K}$ recovery efficiency $\left(\mathrm{RE}_{\mathrm{K}}, \mathrm{kg} \mathrm{K}\right.$ uptake per $\mathrm{kg} \mathrm{K}$ applied) are 
commonly used as performance indicators for K management strategies [17-19]. The K-use efficiency is generally affected by yield levels, soil indigenous K-supplying capacity, amount of K fertilizer applied, and the quality of crop management operations [18]. Keeping the above points in view, the present study was undertaken to (i) determine the indigenous K-supplying capacity of major maize-growing soils in Bangladesh, and (ii) evaluate the grain yield and the K-use efficiency for maize under different $\mathrm{K}$ fertilizer recommendation strategies in the diverse soils of Bangladesh.

\section{Materials and Methods}

\subsection{Pot Experiment}

\subsubsection{Experimental Soils}

Soil samples $(0-20 \mathrm{~cm})$ were collected from farmers' fields of 18 upazillas or sub-districts (representing 18 diverse soils) located in the North, North-west, East, and South parts of Bangladesh. The 18 upazillas were: Birganj, Dinajpur Sadar, Gangachara, Rangpur Sadar, Mithapukur, Shibganj, Godagari, Paba, Durgapur, Tarash, Gopalpur, Modhupur, Daudkandi, and Barura (Figure 1). The soil samples were air-dried, ground and sieved through $2 \mathrm{~mm}$ sieve, and subject to test for their properties. Soil $\mathrm{pH}$ was determined in 1:1 soil/water paste by a $\mathrm{pH}$ meter. Exchangeable $\mathrm{K}$ was extracted by 1 mol L ${ }^{-1}$ Ammonium acetate $\left(\mathrm{NH}_{4} \mathrm{OAc}\right)$, non-exchangeable $\mathrm{K}$ by boiling Nitric acid $\left(\mathrm{HNO}_{3}\right)$ method, and total K by Hydrogen fluoride (HF) digestion [20]. Particle size analysis was done by Hydrometer method [21] and the textural class was determined from Marshall's triangular co-ordinate following USDA system. The physical and chemical properties of the tested soils from the various upazillas used for pot study are presented in Table 1, while that for field experiment are presented in Table 2.

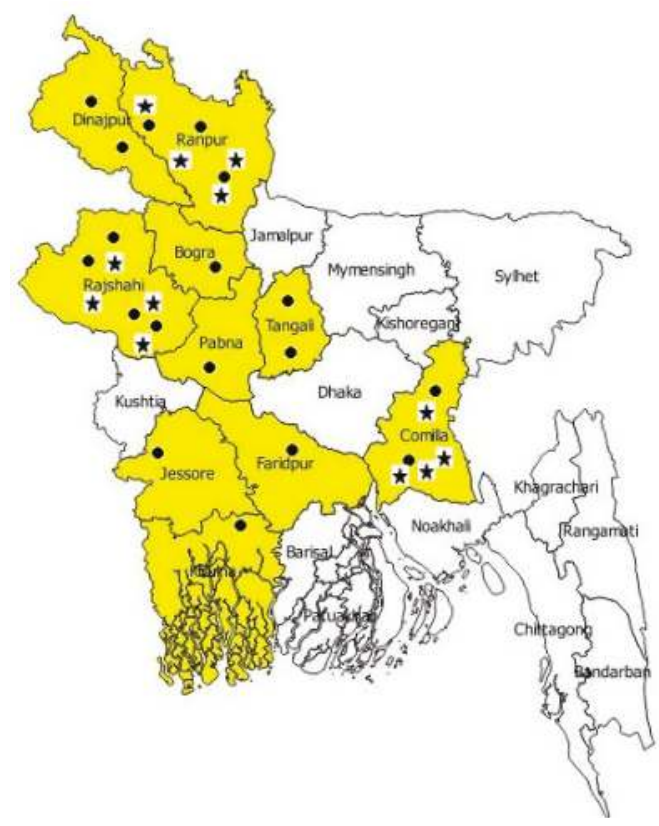

Figure 1. Dots showing the locations for 18 soil samples collected from various districts for pot experiment and stars showing the field experimental sites in Bangladesh. 


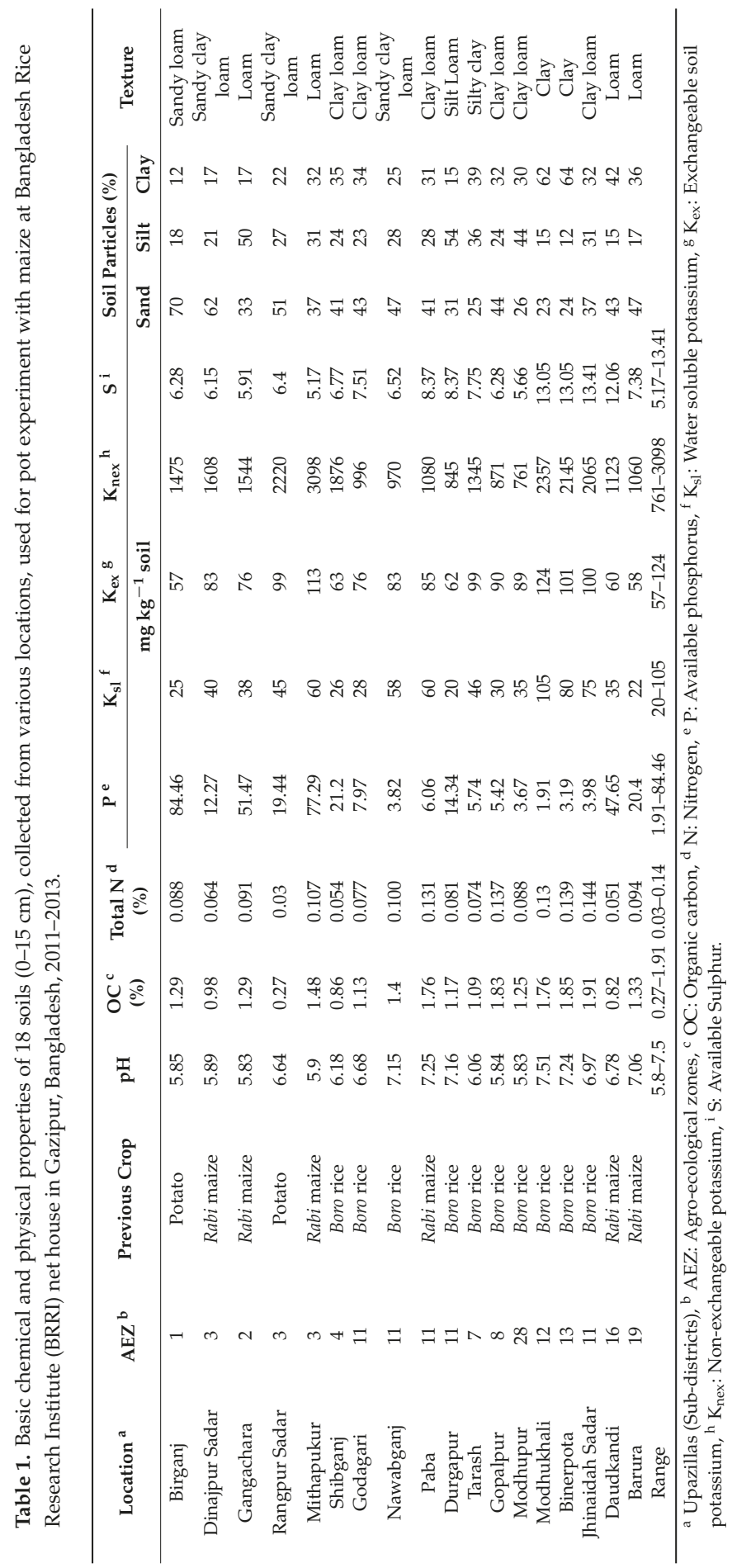




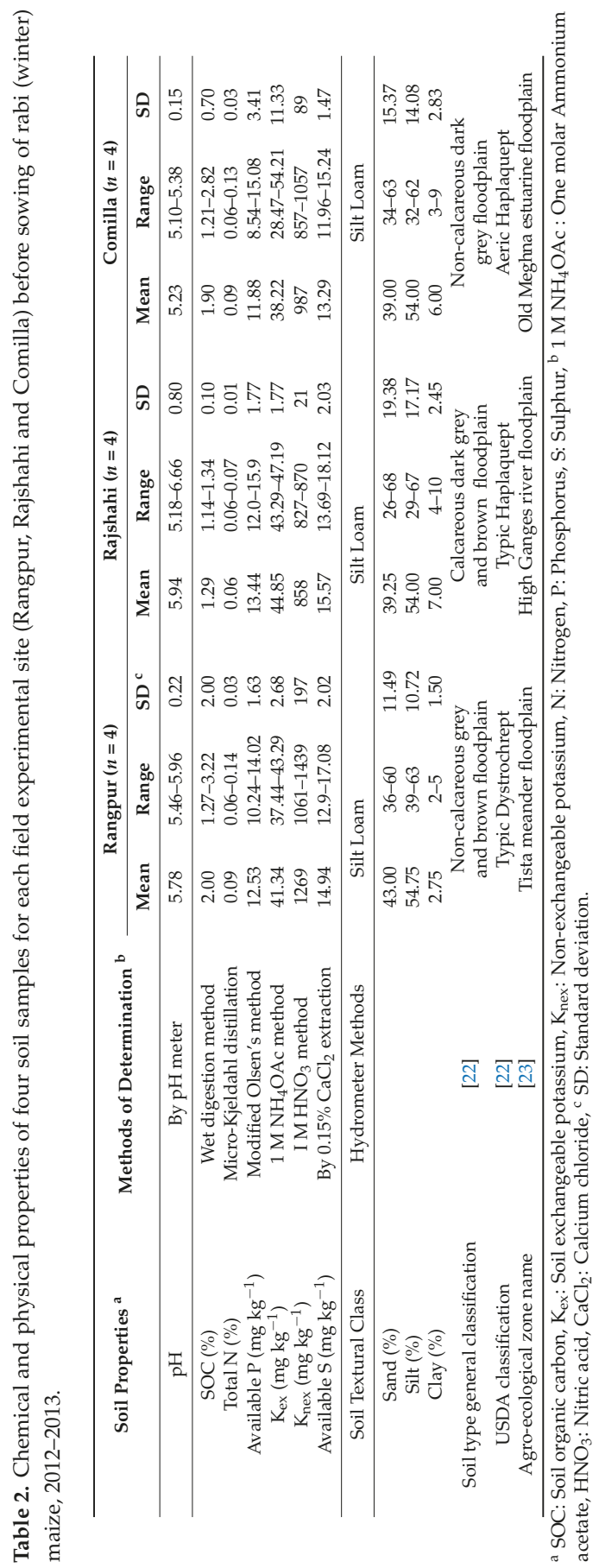




\subsubsection{Description of Pot Experiment}

A repeated pot experiment was conducted with the eighteen soils using a randomized complete block experimental design that consisted of a no-K fertilizer (K0) and a $100 \mathrm{mg} \mathrm{K} \mathrm{kg}^{-1}$ soil (K100) treatments in four replications in a net house of BRRI, Gazipur. Soils were air dried and ground to pass a 2-mm sieve, and $7 \mathrm{~kg}$ of each soil was weighed into each pot. Other fertilizers such as urea, Triple Super Phosphate (TSP), gypsum, and zinc sulfate were used in every pot to supply N, P, S and $\mathrm{Zn}$ at the rate of 200,50,10, and $5 \mathrm{mg} \mathrm{pot}^{-1}$, respectively. All nutrients except $\mathrm{N}$ were applied before sowing of maize while $\mathrm{N}$ was applied in two splits. After application of fertilizers, the soil was gently irrigated allowing smooth mixing of fertilizer materials with soils. After basal fertilizer application, five healthy seeds of hybrid maize (cv. BARI Hybrid Maize-8) were sown two cm below soil surface in each pot. Seeds were germinated after 6-11 days of sowing. Emergence was delayed in winter due to low temperature. Thinning was done 5-7 days after emergence, keeping 4 healthy plants per pot. After thinning, half $\mathrm{N}$ was top dressed, while the remaining 1/2 was applied at V6 stage (when 6 leaves appeared). The soils in pots were irrigated with tap water once every 3-5 days to replenish $100 \%$ soil moisture and to ensure that plants were not drought stressed. The aboveground part of the maize plant was cut at the soil surface at V10-V12 stage (55-65 days after emergence) because $>90 \%$ of the total $\mathrm{K}$ uptake is usually accumulated by that stage [24]. The maize tissue was dried at $70{ }^{\circ} \mathrm{C}$ for 48 hours, crushed, and ground to pass a $0.5-\mathrm{mm}$ sieve. A 0.5 -g sub-sample was digested by an $\mathrm{HNO}_{3}-\mathrm{HClO}_{42}$ mixture at 180 to $200{ }^{\circ} \mathrm{C}$ [25] and $\mathrm{K}$ concentration was determined. Soil samples were collected before and after cropping for NHOAc-extractable K determination [20]. Seven maize crops were grown successively in each pot. Climate during the seven maize-growing periods together with crop duration for each period are presented in Figure 2.

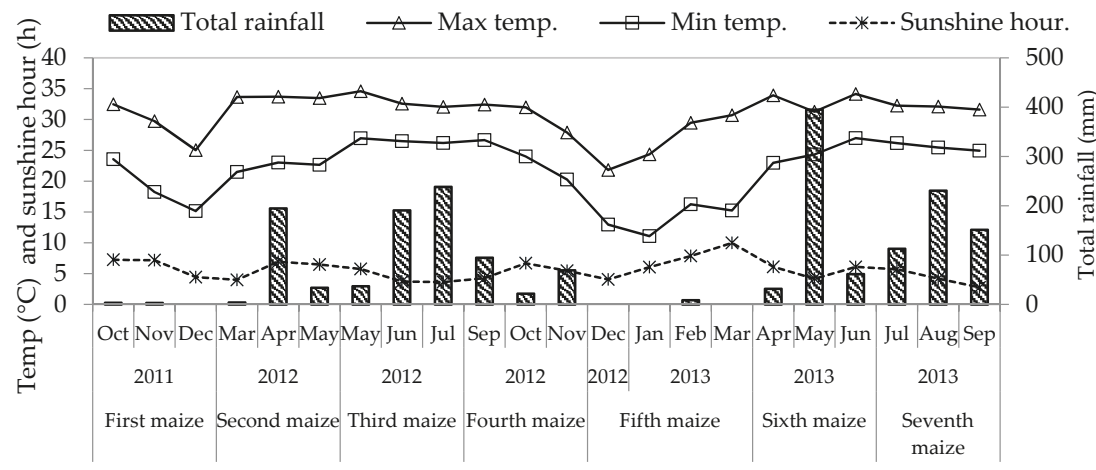

Figure 2. Mean monthly sunshine hour (h), minimum and maximum temperatures $\left({ }^{\circ} \mathrm{C}\right)$, and total rainfall (mm) during successive cropping of rabi maize in pots from 2011 to 2013 in Gazipur, Bangladesh.

\subsection{Field Experiment}

\subsubsection{Experimental Sites}

A field experiment was conducted in 12 farmers' fields in three districts in Bangladesh, with 4 fields each in Rangpur $\left(25.74^{\circ} \mathrm{N}, 89.28^{\circ} \mathrm{E}\right)$, Rajshahi $\left(24.36^{\circ} \mathrm{N}, 88.62^{\circ} \mathrm{E}\right)$ and Comilla $\left(23.46^{\circ} \mathrm{N}\right.$, $91.19^{\circ} \mathrm{E}$ ) (Figure 1). Rajshahi is situated in the Active Ganges Floodplain (agro-ecological zone-AEZ, AEZ 11); Comilla is in the Old Meghna Estuarine Floodplain (AEZ 19); while Rangpur is spread over both the Active Tista Floodplain (AEZ 2) and Tista Meander Floodplain (AEZ 3). According to USDA Taxonomy, the soils are classified as Typic Haplaquept, Aeric Haplaquept and Typic Dystrochrept, respectively [22]. Experimental fields in Rangpur were located in AEZ 3 only. 
The four farmers' fields in each district (two upazillas per district) were selected based on soil $\mathrm{K}$ (ranging from very low to high) across Bangladesh and from the literature review of $\mathrm{K}$ status in Bangladesh soils. The selected farmers' fields represented the diverse agro-ecosystems with variations in the cropping system, soil, and climate within each district.

\subsubsection{Climatic Condition during the Experimental Period}

The experimental fields were located in sub-tropical to the tropical climate, and the weather data for the three districts during the experimental period are shown in Figure 3. Most of the rainfall at all the sites occurred during the monsoon season (June-October). There was no rain from November 2012 to January 2013 in Rangpur, but Rajshahi and Comilla received $\sim 100 \mathrm{~mm}$ rain in November. The total rainfall during the maize season was 532, 373, and $611 \mathrm{~mm}$ in Rangpur, Rajshahi, and Comilla, respectively. The mean minimum and maximum temperatures during the maize season were $9{ }^{\circ} \mathrm{C}$ and $32{ }^{\circ} \mathrm{C}, 9^{\circ} \mathrm{C}$ and $36^{\circ} \mathrm{C}, 11^{\circ} \mathrm{C}$ and $33^{\circ} \mathrm{C}$ in Rangpur, Comilla, and Rajshahi, respectively. The mean minimum and maximum temperatures were $9{ }^{\circ} \mathrm{C}$ and $25^{\circ} \mathrm{C}$ respectively at the beginning of the experiment in January, with lower temperatures in Rangpur than the other two districts. The temperatures increased steadily to mean a minimum of $22{ }^{\circ} \mathrm{C}$ and mean maximum of $36^{\circ} \mathrm{C}$ in April and May 2013. Mean sunshine hours across districts ranged from 5.8 to $6.8 \mathrm{~h}^{\text {day }}{ }^{-1}$, with lowest sunshine hours recorded in Rangpur and highest in Comilla. At the beginning of the experiment, the sunshine hour was much lower in Rangpur $\left(2.8 \mathrm{~h} \mathrm{day}^{-1}\right)$ than the other two districts, and as the season progressed, the sunshine hour in all districts increased steadily to maximum of 10.9, 10.6, and $10.3 \mathrm{~h} \mathrm{day}^{-1}$ in Rangpur, Rajshahi and Comilla, respectively (Figure 3).

\subsubsection{Fertilizer Decision Support Tools}

Based on the principles of site-specific nutrient management (SSNM) and experiences drawn from several years of on-farm research on maize in several Asian countries [26-31], the International Rice Research Institute (IRRI) and International Plant Nutrition Institute (IPNI) developed the fertilizer decision support system (DSS) tools, Maize Crop Manager (MCM) and Nutrient Expert for Maize (NEM), respectively, in collaboration with the International Maize and Wheat Improvement Centre (CIMMYT) and National Agricultural Research and Extension Systems (NARES) partners in South and Southeast Asia. The $\mathrm{K}$ fertilizer recommendation rates based on these two fertilizer DSS tools were compared against five levels of K (Table 3).

Table 3. Fertilizer recommendations for three field experimental sites in Bangladesh based on Maize Crop Manager (MCM) and Nutrient Expert for Maize (NEM).

\begin{tabular}{|c|c|c|c|c|c|c|}
\hline \multirow{2}{*}{ Nutrient $^{a}$} & \multicolumn{2}{|c|}{ Rangpur (kg ha ${ }^{-1}$ ) } & \multicolumn{2}{|c|}{ Rajshahi (Kg ha $\left.{ }^{-1}\right)$} & \multicolumn{2}{|c|}{ Comilla (kg ha $\left.{ }^{-1}\right)$} \\
\hline & $\mathrm{MCM}^{\mathrm{b}}$ & NEM $^{\mathrm{c}}$ & MCM & NEM & MCM & NEM \\
\hline $\mathrm{N}$ & 184 & $164-173$ & $184-190$ & $162-173$ & $115-150$ & $141-152$ \\
\hline $\mathrm{P}$ & 20 & $22-23$ & $15-20$ & $19-25$ & 15-20 & 19-20 \\
\hline K & 75-100 & $109-125$ & $75-100$ & 93-105 & 75-100 & 93-103 \\
\hline $\mathrm{S}$ & 7 & 7 & 7 & 7 & 7 & 7 \\
\hline $\mathrm{Zn}$ & 3 & 3 & 3 & 3 & 3 & 3 \\
\hline B & 1 & 1 & 1 & 1 & 1 & 1 \\
\hline
\end{tabular}

${ }^{a} \mathrm{~N}$ : Nitrogen supplied from urea, P: Phosphorus supplied from Triple super phosphate (TSP), K: Potassium supplied from Muriate of potash (MoP), S: Sulphur supplied from Gypsum, Zn: Zinc supplied from Zinc sulphate, B: Boron supplied from Boric acid. b MCM: Maize crop manager, an online fertilizer decision tool based on SSNM,

${ }^{c}$ NEM: Nutrient expert for maize, an offline computer-based fertilizer decisions tool based on SSNM.

\subsubsection{Experimental Design and Treatments}

The experiment was laid out in a Randomized Complete Block Design in 12 farmers' fields (serving as replicates) with five $\mathrm{K}$ levels $\left(\mathrm{K}_{1}=0, \mathrm{~K}_{2}=40, \mathrm{~K}_{3}=80, \mathrm{~K}_{4}=120, \mathrm{~K}_{5}=160\right)$, and two $\mathrm{K}$ fertilizer 
recommendations based on SSNM (DSS) tools $\left(\mathrm{K}_{6}=\right.$ Nutrient Expert based recommendation for maize $(\mathrm{NEM}) ; \mathrm{K}_{7}=$ Maize Crop Manager based recommendation (MCM)) in three districts. To determine the SSNM-based recommendations using two DSS tools: MCM (http:/ / webapps.irri.org/bd/mcm/; IRRI, Philippines) and (NEM, an offline computer-based software; IPNI Offices, Delhi and Singapore), the participant farmers were asked 20 questions based on their agronomic and nutrient management practices of last (previous) year along with their field or soil characteristics. The answers to these questions were used as inputs to the MCM and NEM for generating fertilizer recommendations for each farmer (Table 3). Each treatment plot was $50 \mathrm{~m}^{2}$ in area. Bunds of $0.5 \mathrm{~m}$ width were prepared between plots, and a border of $1 \mathrm{~m}$ width was kept around the experimental area. A medium-statured hybrid maize NK40, popularly grown in Rabi (winter) season was used. NK40 is tolerant of lodging and has a high yield potential of up to $20 \mathrm{tha}^{-1}$.

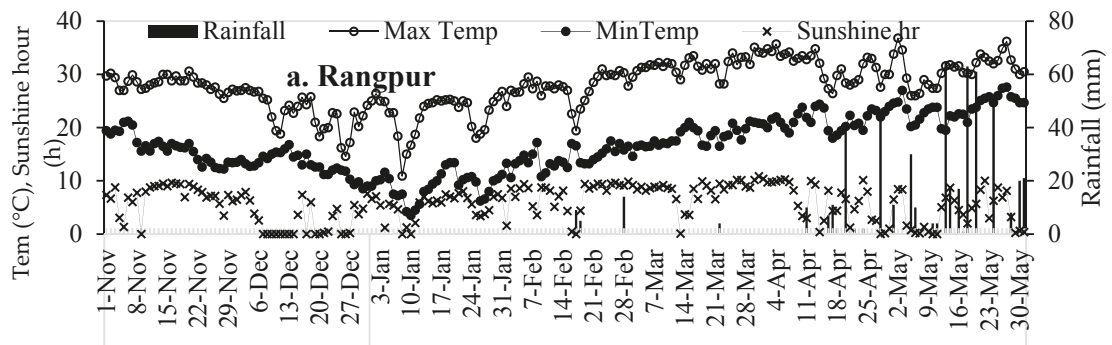

2012

2013

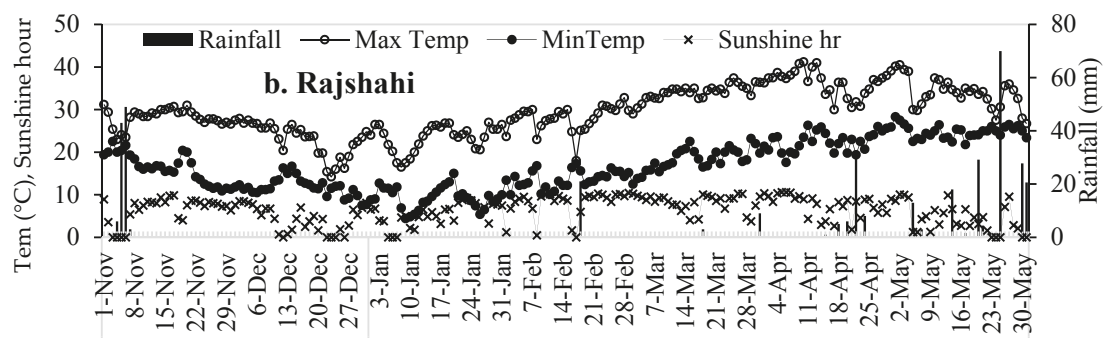

2012

2013

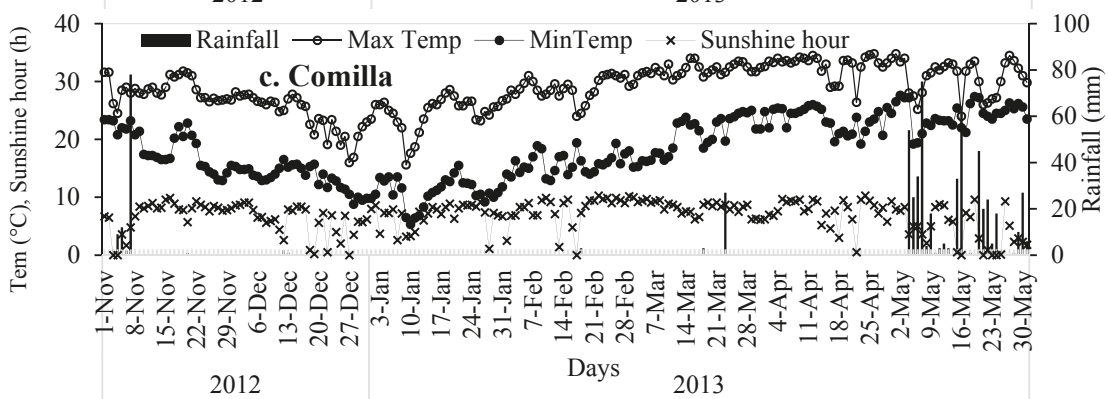

Figure 3. Daily maximum and minimum temperatures $\left({ }^{\circ} \mathrm{C}\right)$, sunshine hour $(\mathrm{h})$ and total rainfall (mm) during the rabi maize season from November 2012 to May 2013 in experimental sites (a. Rangpur, b. Rajshahi, c. Comilla) in Bangladesh.

\subsubsection{Crop Management Practices}

The experimental fields in all districts were irrigated with about $10 \mathrm{~cm}$ of water and allowed to reach proper moisture condition conducive for tillage. The fields were then prepared by $3-4$ tillage 
with a 2-wheel operated power tiller to a depth of 8-10 $\mathrm{cm}$ followed by planking. Seeds in all districts were sown manually (with sowing dates ranging from 26 November 2012 to 6 January 2013) on shallow holes by dibbling and maintaining row to row and seed to seed distances of 60 and $20 \mathrm{~cm}$ respectively. Gap filling was done after emergence to maintain the 85,000 plant population ha ${ }^{-1}$. N, P, K, S, and Zn were applied through urea, TSP, MoP, gypsum and zinc sulfate, respectively. Rates for different nutrients, including $\mathrm{K}$, applied through the recommendations of MCM and NEM are presented in Table 3. $\mathrm{N}$ fertilizer was applied as three splits: as basal and top-dressed twice at V6 and V10; while K was applied as two splits: as basal and at V6. All other fertilizers were applied as basal.

The crops were manually weeded twice: the first weeding was done just before the first top dressing while the second was before the second top dressing, thus allowing the weeds to be removed from the fields before each top-dressing. As rainfall was not enough, four irrigations were applied in each site to avoid drought stress to the crops. First irrigation was applied at V2-V4 (2-3 leaves stage) while the second irrigation was applied after first weeding and before first top dressing at V6-V8 (6-8 leaves stage). Likewise, third irrigation was applied after second weeding and before second top-dressing at V10-V12 (10-12 leaf stage) and fourth irrigation during grain formation stage. The amount of water for each irrigation at each site was about $7.5 \mathrm{~cm}$. Carbofuran 10G @ 100g per 100 -meter rows was applied at planting for controlling cutworms and nematode infestation.

\subsection{Data Analysis and Measurements}

The crops were harvested at maturity from a $10.08 \mathrm{~m}^{2}$ ( $4.2 \mathrm{~m}$ row length by 4 rows) area in the center of each treatment plot, excluding the two outer border rows. After harvesting, the crops were threshed with a hand thresher. The grain and stover yields and the growth and yield attributing characters (plant height, cobs plant ${ }^{-1}$, cob length and girth, grains cob ${ }^{-1}, 1000$-grain weight) were measured. The grain and stover samples from each plot were analyzed for total K content. For the post-harvest soil analysis for $\mathrm{K}_{\mathrm{ex}}$ and $\mathrm{K}_{\text {nex }}$, composite soil samples were taken from each treatment of each farmer immediately after crop harvest by using the methods as described in Table 2 [25].

Indigenous K supply (IKS) is defined as the amount of soil $\mathrm{K}$ that is available to maize from the soil during its growing period when other nutrients are non-limiting [31], and the IKS can be measured as the $\mathrm{K}$ accumulation in the above ground dry matter at harvest in the K omission plots [32]. Yield response (YR) is an effective index of soil fertility, and YR to $\mathrm{K}$ is defined as the yield difference between the attainable yield (measured as $85-90 \%$ of yield potential) and yield from the K omission plots $[25,26]$. YR to $\mathrm{K}$ can also be used to evaluate the soil K-supplying capacity [33]. The K concentration (\%) of plant samples (stover and grain) was determined by a flame photometer [34].

The data from the K exhaustion study from the pot experiment as well as the field experiments were used to quantify the K-supplying capacity of the 18 soils to maize crops, and was calculated as follows:

Total plant $\mathrm{K}$ uptake $=$ above ground biomass $\times \mathrm{K}$ concentration in plant tissue

Agronomic efficiency ( $\mathrm{AE}_{\mathrm{K}} ; \mathrm{kg}$ grain yield increase $\mathrm{kg}^{-1}$ applied $\mathrm{K}$ ) was calculated using the equation:

$$
A E_{K}=\left(G Y_{+K}-G Y_{0 K}\right) \div F_{K}
$$

where $\mathrm{GY}_{+\mathrm{K}}$ is the grain yield in the treatment with $\mathrm{K}$ application $\left(\mathrm{kg} \mathrm{ha}^{-1}\right), \mathrm{GY}_{0 \mathrm{~K}}$ is the grain yield in the treatment without $\mathrm{K}$ application $\left(\mathrm{kg} \mathrm{ha}^{-1}\right)$, and $\mathrm{F}_{\mathrm{K}}$ is the quantity of $\mathrm{K}$ applied $\left(\mathrm{kg} \mathrm{ha}^{-1}\right)$.

Recovery efficiency $\left(\mathrm{RE}_{\mathrm{K}} ; \mathrm{kg} \mathrm{K}\right.$ taken up $\mathrm{kg}^{-1} \mathrm{~K}$ applied) was calculated using the equation:

$$
R E_{K}=\left(U K_{+K}-U K_{0 K}\right) \div F_{K}
$$


where $\mathrm{UK}_{+\mathrm{K}}$ is the total plant $\mathrm{K}$ uptake $\left(\mathrm{kg} \mathrm{ha}^{-1}\right)$ of the above-ground biomass (stover + grain) in plots that received $\mathrm{K}, \mathrm{UK}_{0 \mathrm{~K}}$ is total $\mathrm{K}$ uptake without the addition of $\mathrm{K}$, and $\mathrm{F}_{\mathrm{K}}$ is the quantity of $\mathrm{K}$ applied $\left(\mathrm{kg} \mathrm{ha}^{-1}\right)$.

The R software [35,36] was used to analyze the means of grain and stover yields, growth and yield components, total $\mathrm{K}$ uptake, agronomic efficiency and recovery efficiency of $\mathrm{K}$ between different soils and treatments by using the least significant difference at 0.05 probability level. The Duncan's New Multiple Range Test, a mean separation technique, was applied to detect significant differences between treatment [37].

\section{Results}

\subsection{Pot Experiment}

\subsubsection{Mean Shoot Dry Matter Yield and Yield Response to K Fertilizer}

The mean shoot dry matter yield of maize over seven successive cropping across 18 soils varied widely from 14.52 to $39.37 \mathrm{~g} \mathrm{pot}^{-1}$ in $\mathrm{K}$ control pots while it was from 38.83 to $47.81 \mathrm{~g} \mathrm{pot}^{-1}$ in $\mathrm{K}$ applied pots. The lowest and highest dry matter yield with no added K soils were found in Durgapur and Mithapukur soils, respectively. While the lowest and highest dry matter yield with $\mathrm{K}$ fertilizer added soils were found in Modhupur and Gopalpur soils, respectively (Figure 4). The contribution of $\mathrm{K}$ fertilizer to the increment of maize shoot dry matter over $\mathrm{K}$ control was considered as the shoot dry matter response to $\mathrm{K}$. The mean response of shoot dry matter over seven successive cropping ranged from 4 to $16 \mathrm{~g} \mathrm{pot}^{-1}$, with the highest response $(p \leq 0.001)$ in Durgapur soil and the lowest in Modhukhali. The mean response followed the order of: Durgapur $>$ Shibganj $>$ Barura $>$ Godagari $>$ Tarash $>$ Paba $>$ Binerpota $>$ Jhinaidah Sadar $>$ Modhupur $>$ Birganj $>$ Nawbagnj Sadar $>$ Gopalpur $>$ Daudkandi $>$ Gangachara $>$ Rangpur Sadar $>$ Dinajpur Sadar $>$ Mithapukur $>$ Modhukhali. Therefore, Durgapur and Modhukhali soil appeared as the most and least responsive to $\mathrm{K}$ fertilization, respectively (Figure 4). There was significant $(p \leq 0.001)$ negative correlation $\left(r^{2}=0.70, r=-0.84\right.$ ) between yield response to $\mathrm{K}$ fertilizer and soil initial K (Figure 5). The mean shoot dry matter yield in the 18 soils without $\mathrm{K}$ fertilization reduced drastically from 1 st to 3 rd crops, decreased slightly in the 4 th to 5 th crop due to climatic variation, and after that gradually declined up to the 7th crop. The differences in shoot dry matter yield between the $\mathrm{K}$ applied soils and the no added $\mathrm{K}$ fertilizer soils were gradually increased with the successive cropping (Figure 6).

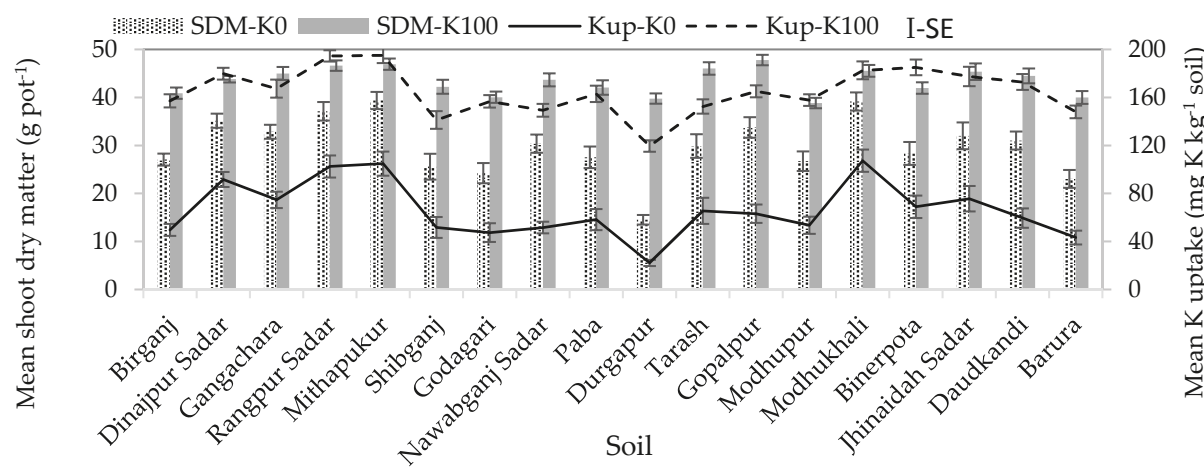

Figure 4. Trends for mean shoot dry matter (SDM) and mean K uptake over successive seven rabi maize crops in pots with $\mathrm{K} 0$ and $\mathrm{K} 100$ for 18 diverse soils of Bangladesh. 


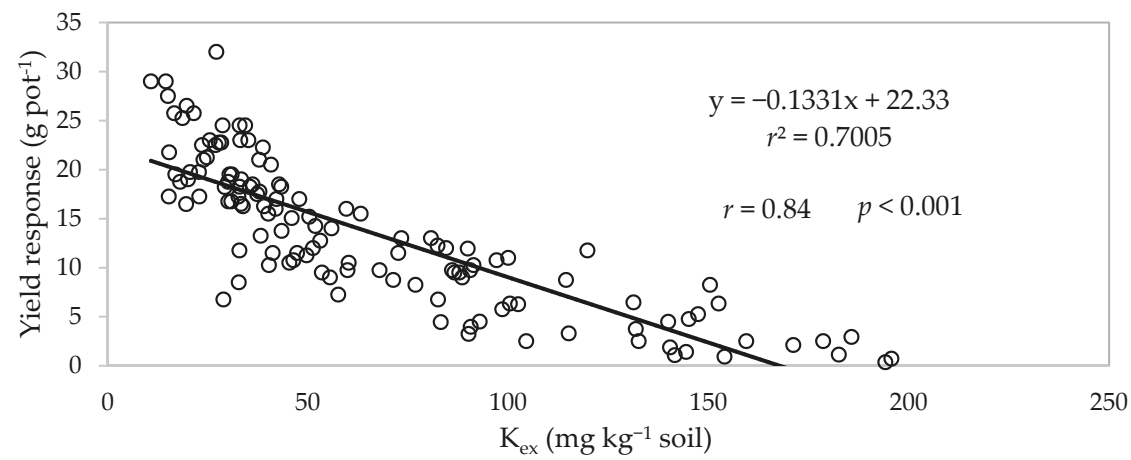

Figure 5. The relationship between initial exchangeable soil $\mathrm{K}\left(\mathrm{K}_{\mathrm{ex}}\right)$ for 18 diverse soils of Bangladesh and yield response of rabi maize grown up to V10-V12 for seven successive crops to K fertilizer in pot experiment, Gazipur, Bangladesh.

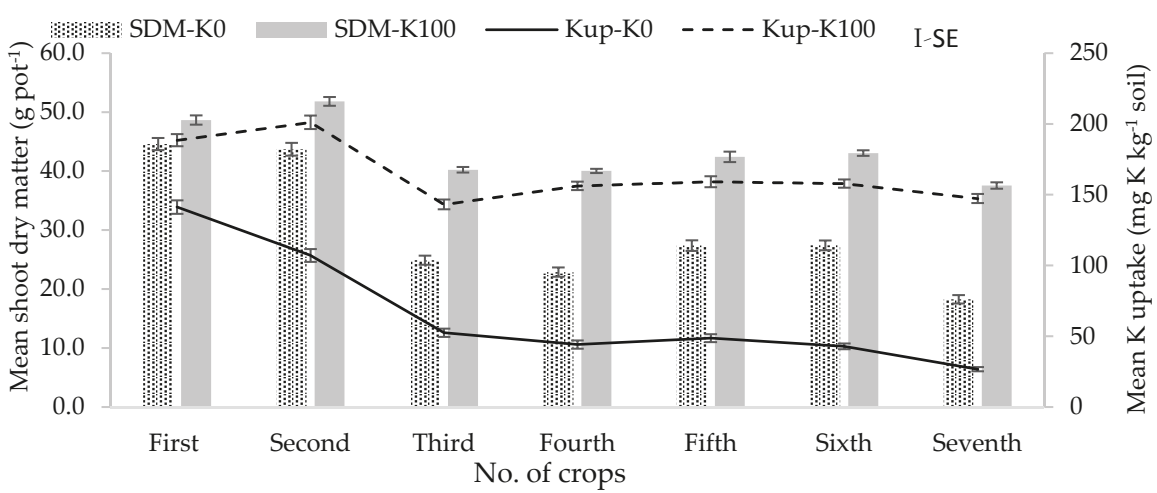

Figure 6. Trends for mean shoot dry matter (SDM) and mean K uptake over 18 diverse soils for seven successive cropping of rabi maize with $\mathrm{K} 0$ and $\mathrm{K} 100$ in pots in Gazipur, Bangladesh.

\subsubsection{Soil K Supplying Capacity and K Depletion over Successive Cropping}

The amount of total $\mathrm{K}$ uptake by plants in different soils without application of $\mathrm{K}$ fertilizer was defined as the potential $\mathrm{K}$-supplying capacity. The $\mathrm{K}$ uptake varied significantly due to the variation of soil $\mathrm{K}$ reserves among the soils. In control pots, average $\mathrm{K}$ uptake over seven successive crops varied from 22.1 to $107.3 \mathrm{mg} \mathrm{kg}^{-1}$ soil (Figure 4). The lowest $\mathrm{K}$ uptake was found in Durgapur and significantly higher K uptake was recorded in Modhukhali and Mithapukur soils. In general, potential K-supplying capacity of these tested soils followed the order: Modhukhali $>$ Mithapukur $>$ Rangpur Sadar $>$ Dinajpur Sadar $>$ Jhinaidah Sadr $>$ Gangachara $>$ Binerpota $>$ Tarash $>$ Gopalpur $>$ Daudkandi $>$ Paba $>$ Modhupur Nawabganj $>$ Shibganj $>$ Birganj $>$ Godagari $>$ Barura $>$ Durgapur (Figure 4). Though the trends were similar for both $+\mathrm{K}$ and $-\mathrm{K}$ soils but the $\mathrm{K}$ uptake was $2-3$ times higher for K-treated soils than the non-treated ones (Figure 4). In control pots mean K uptake over 18 soils drastically reduced from first to the third crop but it was gradually declined from fourth to seventh crops (Figure 6). There was a strong positive relationship in both soil Kex $\left(r^{2}=0.56-0.84\right)$ and $K_{n x}$ $\left(r^{2}=0.48-0.63\right)$ with $\mathrm{K}$ uptake, but it was stronger in soil $\mathrm{K}_{\mathrm{ex}}$ than $\mathrm{K}_{\mathrm{nx}}$. Moreover, the relationship became gradually stronger with increasing the number of successive cropping (Figure 7). And soil $\mathrm{K}_{\mathrm{ex}}$ and $\mathrm{K}_{\text {nex }}$ decreased remarkably in control pots due to the growing of seven successive maize crops (Table 4). 

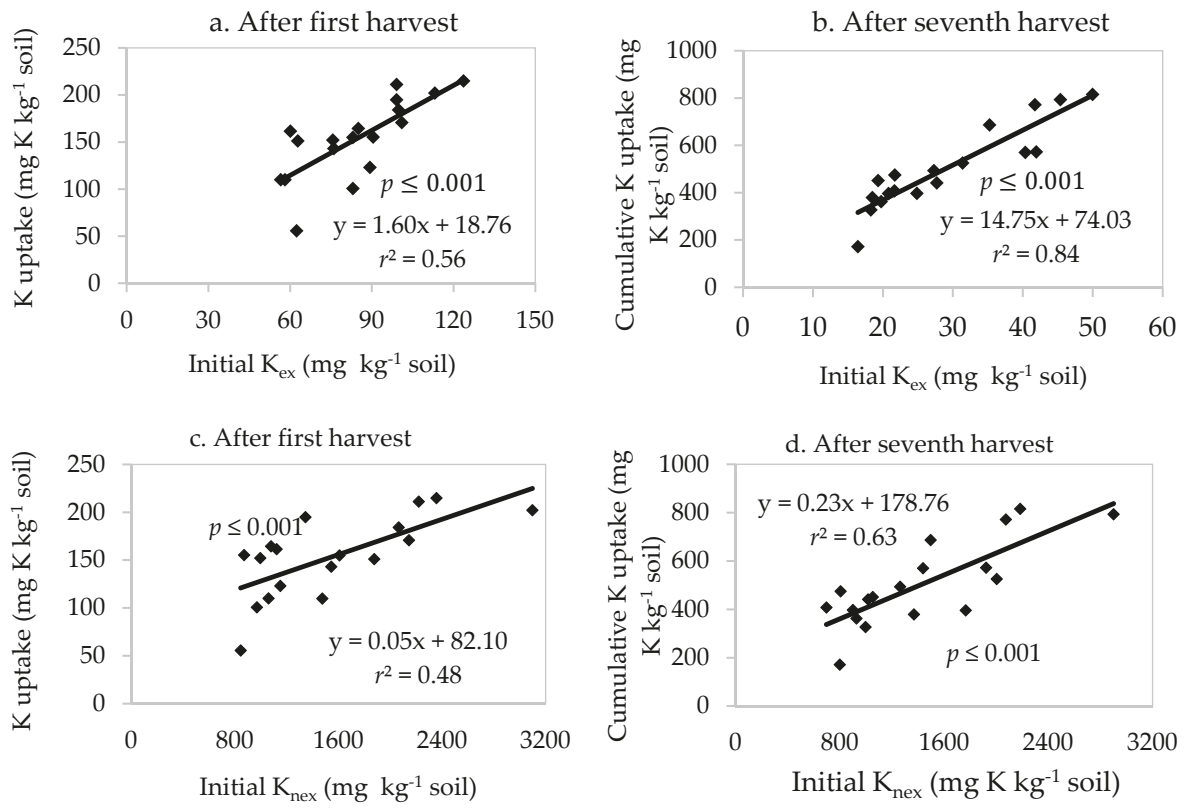

Figure 7. The relationship between exchangeable soil $\mathrm{K}\left(\mathrm{K}_{\mathrm{ex}}\right)$ and $\mathrm{K}$ uptake (a. after first harvest and $\mathbf{b}$. after seventh harvest), and between non-exchangeable $\mathrm{K}\left(\mathrm{K}_{\mathrm{ex}}\right)$ for 18 diverse soils of Bangladesh and $\mathrm{K}$ uptake (c. after first harvest and $\mathbf{d}$. after seventh harvest) in the above ground biomass of rabi maize grown up to V10-V12 in pot as successive crop.

Table 4. Amount of exchangeable and non-exchangeable $\mathrm{K}$ before the start of the experiment (initial) and after seventh harvest (grown up to V10-V12) of maize grown in pots with $\mathrm{K}_{0}$ and $\mathrm{K}_{100}$ with 18 diverse soils, Gazipur, Bangladesh.

\begin{tabular}{|c|c|c|c|c|c|c|}
\hline \multirow{3}{*}{ Location of Soil a } & \multirow{2}{*}{ Pre $K_{e x}{ }^{b}$} & \multicolumn{2}{|c|}{ Post $\mathrm{K}_{\mathrm{ex}}$} & \multirow[t]{2}{*}{ Pre $K_{\text {nex }}{ }^{c}$} & \multicolumn{2}{|c|}{ Post $K_{n e x}$} \\
\hline & & К0 & K100 & & K0 & K100 \\
\hline & \multicolumn{6}{|c|}{$\mathrm{mg} \mathrm{kg}^{-1}$ soil } \\
\hline Birganj & 57 & 16 & 39 & 1475 & 1369 & 1435 \\
\hline Dinajpur Sadar & 83 & 37 & 66 & 1608 & 1498 & 1568 \\
\hline Gangachara & 76 & 35 & 57 & 1544 & 1439 & 1502 \\
\hline Rangpur Sadar & 99 & 36 & 76 & 2220 & 2075 & 2168 \\
\hline Mithapukur & 113 & 39 & 85 & 3098 & 2900 & 3028 \\
\hline Shibganj & 63 & 14 & 42 & 1876 & 1767 & 1849 \\
\hline Godagari & 76 & 18 & 50 & 996 & 928 & 971 \\
\hline Nawabganj & 83 & 20 & 68 & 970 & 901 & 944 \\
\hline Paba & 85 & 23 & 64 & 1080 & 1018 & 1061 \\
\hline Durgapur & 62 & 20 & 40 & 845 & 800 & 831 \\
\hline Tarash & 99 & 21 & 67 & 1345 & 1264 & 1322 \\
\hline Gopalpur & 90 & 20 & 55 & 871 & 807 & 846 \\
\hline Modhupur & 89 & 21 & 67 & 761 & 698 & 733 \\
\hline Modhukhali & 124 & 45 & 113 & 2357 & 2184 & 2360 \\
\hline Binerpota & 101 & 31 & 83 & 2145 & 2005 & 2102 \\
\hline Jhinaidah Sadar & 100 & 35 & 78 & 2065 & 1923 & 2016 \\
\hline Daudkandi & 60 & 18 & 37 & 1123 & 1053 & 1104 \\
\hline Barura & 58 & 14 & 37 & 1060 & 998 & 1045 \\
\hline
\end{tabular}

${ }^{a}$ Upazilas (Sub-districts); ${ }^{\mathrm{b}} \mathrm{K}_{\mathrm{ex}}$ : Exchangeable soil $\mathrm{K} ;{ }^{\mathrm{c}} \mathrm{K}_{\text {nex }}$ : Non-exchangeable $\mathrm{K}$. 


\subsection{Field Experiment}

The ANOVA for the means for all yield and yield attributing characters (except number of cobs plant $^{-1}$ ) in all the farmers' fields across the three districts showed highly significant effects between the treatments $(p \leq 0.001)$ due to farmers' fields being scattered over a large area with variable soils and land types. There was no significant effect $(p \geq 0.05)$ on the interaction among the same treatment of different farmers for most of the measurable variables (except yield increase over control) in the same location due to less variability of soils and maintaining same practices for all farmers.

\subsubsection{Growth and Yield Components}

Plant heights were $237 \pm 1.35,186 \pm 5.10$ and $237 \pm 3.51 \mathrm{~cm}$ in Rangpur, Rajshahi, and Comilla, respectively, while it was $217 \pm 3.20 \mathrm{~cm}$ over all sites (Table 5). In all sites, significantly shortest plants were found in control plots, and the height increased progressively, though not significantly, with an increase of $\mathrm{K}$ rate up to $120 \mathrm{~kg} \mathrm{~K} \mathrm{ha}^{-1}$. In Rangpur and Rajshahi significantly taller plants were found with all K-treated plots except $40 \mathrm{~kg} \mathrm{~K}$ ha $^{-1}$ plots, with slightly taller plants in MCM and NEM plots. In Comilla, however, maize plants in all K-treated plots were significantly taller than in the control plots.

Cob length varied from 15.0 to $17.8 \mathrm{~cm}$ overall sites, ranging from 17.0-20.1, 12.6-15.1 and 15.4-19.3 cm in Rangpur, Rajshahi, and Comilla, respectively (Table 5). Cob length increased progressively with increase of $\mathrm{K}$ fertilizer rate up to $120 \mathrm{~kg} \mathrm{ha}^{-1}$. In all locations, cobs were significantly longer for all levels of K and MCM- and NEM-based recommendations than in control. The longest cob was found with $120 \mathrm{~kg} \mathrm{~K}$ ha $^{-1}$ plots in Rangpur and MCM-based fertilizer recommendation $\left(88 \mathrm{~kg} \mathrm{~K} \mathrm{ha}^{-1}\right)$ in Rajshahi, though it was statically identical with the NEM-based recommendation in all locations (Table 5).

The cob girth was $16.5 \pm 0.27,14.78 \pm 0.10$ and $15.6 \pm 0.22 \mathrm{~cm}$ in Rangpur, Rajshahi, and Comilla, respectively (Table 5). Cob girth increased progressively with the increase of $\mathrm{K}$ rates up to $120 \mathrm{~kg} \mathrm{~K} \mathrm{ha}^{-1}$. Cob girth in control plots was lower than other treatments in all sites though it was only statistically lower to 120 and $160 \mathrm{~kg} \mathrm{~K} \mathrm{ha}^{-1}$ treated plots in Rangpur. The highest cob girth for $120 \mathrm{~kg} \mathrm{~K} \mathrm{ha}^{-1}$ was found in Rangpur and Rajshahi and in NE fertilizer recommended plots in Comilla, though it was statically identical to the MCM fertilizer recommended plots in all locations. In Rajshahi and Comilla, except control, all treatments were statistically identical.

The number of grains $\mathrm{cob}^{-1}$ was $495 \pm 9.82,367 \pm 3.09$ and $442 \pm 17.05$ in Rangpur, Rajshahi, and Comilla, respectively. The number of grains $\mathrm{cob}^{-1}$ increased progressively with the increase of $\mathrm{K}$ rate up to $120 \mathrm{~kg} \mathrm{ha}^{-1}$. It was the highest for the NEM-based recommendation in Rangpur and Comilla, $160 \mathrm{~kg} \mathrm{~K} \mathrm{ha}^{-1}$ treated plots in Rajshahi, though it was statistically identical to all $\mathrm{K}$ levels and MCM- and NEM-based fertilizer recommendations (Table 5).

The weight of 1000-grains varied significantly among the treatments, ranging $314 \pm 7.03$, $3121 \pm 8.61$ and $307 \pm 3.68 \mathrm{~g}$ in Rangpur, Rajshahi, and Comilla, respectively. Across the sites, it varied significantly $(p<0.001)$ from $252 \mathrm{~g}$ in $\mathrm{K} 0$ to $339 \mathrm{~g}$ in NEM based recommendation plot. The results showed that NEM-based fertilizer recommendation resulted in heaviest grains in all locations, followed by all levels of K and MCM-based recommendation (Table 5).

The average grain yields across all treatments were $9.18 \pm 0.33,7.67 \pm 0.25$ and $6.60 \pm 0.26 \mathrm{tha}^{-1}$ in Rangpur, Rajshahi, and Comilla, respectively. Likewise, average biomass was $18.53 \pm 0.67,15.32 \pm 0.49$ and $13.18 \pm 0.52 \mathrm{tha}^{-1}$, respectively, in the three districts. The average grain and biomass yields over all districts were $7.82 \pm 0.20$ and $15.68 \pm 0.40$, respectively (Table 5). Grain and biomass yields progressively increased with the increase of $\mathrm{K}$ rate up to $120 \mathrm{~kg} \mathrm{~K} \mathrm{ha}^{-1}$. Grain and biomass yields in control plots were significantly lower compared to other treatments in Rajshahi, but it was similar to $40 \mathrm{~kg} \mathrm{~K} \mathrm{ha}^{-1}$ plots in Rangpur and Comilla. In all districts, grain and biomass yields were significantly similar for $80,120,160 \mathrm{~kg} \mathrm{~K} \mathrm{ha}^{-1}$, and NEM- and MCM-based fertilizer recommendation. 
Table 5. Effect of $\mathrm{K}$ fertilization on growth, and yield and yield attributes of rabi maize in three field experimental sites in Bangladesh, 2012-2013.

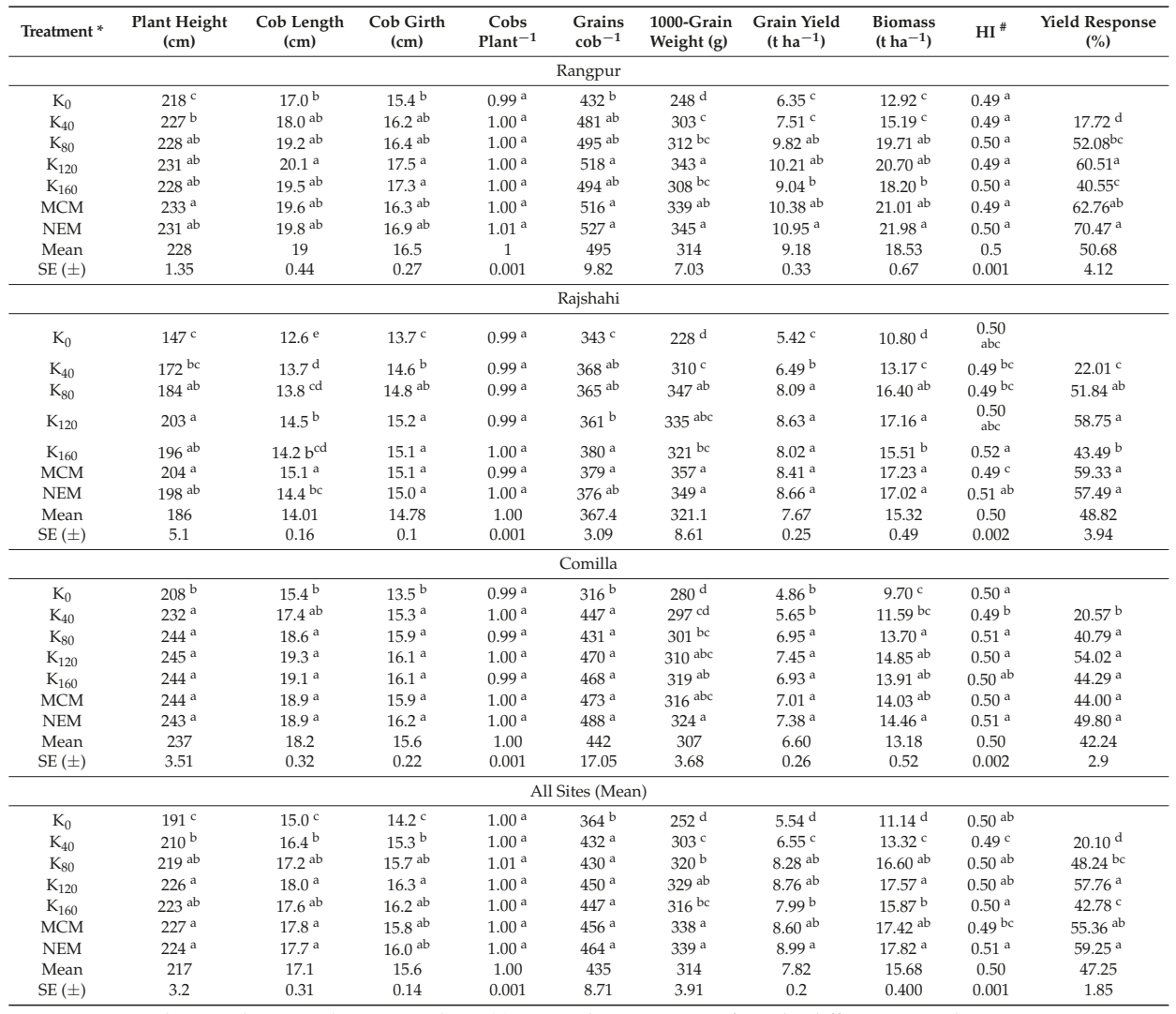

Data not sharing the same lower-case letter(s) in a column are significantly different according to Duncan's New Multiple-Range Test at $5 \%$ level of probability [37]; $\mathrm{K}_{0}, \mathrm{~K}_{40}, \mathrm{~K}_{80}, \mathrm{~K}_{120}, \mathrm{~K}_{160}$ represent control, 40, 80, 120, $160 \mathrm{~kg} \mathrm{~K} \mathrm{ha}^{-1}$, respectively; ${ }^{*}$ MCM: Fertilizer recommendation ranged $75-100 \mathrm{~kg} \mathrm{~K} \mathrm{ha}^{-1}$ across sites based on SSNM through "Maze Crop Manager" developed by IRRI; NEM: Fertilizer recommendations ranged 93-125 kg K ha ${ }^{-1}$ across sites based on SSNM through "Nutrient Expert for Maize"; SE-Standard error of mean, "HI: Harvest index.

Harvest index varied from 0.49 to $0.50,0.49$ to 0.52 , and 0.49 to 0.51 in Rangpur, Rajshahi and Comilla, respectively. It varied significantly across treatments in Rajshahi and Comilla, but not in Rangpur. Yield response to K application across treatments varied from 17.72 to $70.47 \%, 22.01$ to $59.33 \%$, and 20.57 to $54.02 \%$ in Rangpur, Rajshahi, and Comilla, respectively, and when averaged across sites, it varied from 20.10 to $59.25 \%$ (Table 5).

\subsubsection{Estimation of K Supplying Capacity}

The average K concentration in maize grain over treatments were $0.439 \pm 0.013,0.439 \pm 0.012$ and $0.409 \pm 0.014 \%$ in Rangpur, Rajshahi, and Comilla, respectively. Likewise, average K concentration in maize stover were $1.32 \pm 0.05 \%, 1.21 \pm 0.06 \%$ and $1.24 \pm 0.05 \%$, respectively, in the three districts. The average $\mathrm{K}$ concentration in grain and biomass yields over all districts were $0.429 \pm 0.008$ and $1.24 \pm 0.03$, respectively (Table 6). $\mathrm{K}$ concentration in maize grain and stover over sites varied from 0.309 to $0.520 \%$ and from 0.88 to $1.73 \%$, respectively. K concentration in maize grain and stover progressively increased with the increase in $\mathrm{K}$ rate up to the maximum dose $\left(160 \mathrm{~kg} \mathrm{~K} \mathrm{ha}^{-1}\right)$. 
K concentration across locations and treatments was lowest $(0.31 \%$ in grain and $0.88 \%$ in stover) in control plots and highest in $160 \mathrm{~kg} \mathrm{~K}$ ha $^{-1}$ plots $(0.52 \%$ in grain and $1.73 \%$ in stover (Table 6$)$.

The total mean $\mathrm{K}$ uptake by maize (grain + stover) across treatments was from $166 \pm 9.66$, $128 \pm 7.39$, and $106 \pm 6.40 \mathrm{~kg} \mathrm{ha}^{-1}$ in Rangpur, Rajshahi, and Comilla, respectively. Total $\mathrm{K}$ uptake over the sites varied significantly from 67.1 to $178.3 \mathrm{~kg} \mathrm{~K} \mathrm{ha}^{-1}$. Total $\mathrm{K}$ uptake progressively increased with the increase in $\mathrm{K}$ rate up to $160 \mathrm{~kg} \mathrm{~K} \mathrm{ha}^{-1}$. Total $\mathrm{K}$ uptake by maize across treatments and locations was lowest in control plots and highest in $160 \mathrm{~kg} \mathrm{~K} \mathrm{ha}^{-1}$. Across all locations, in both control and K-treated plots, the total K uptake, i.e., the K-supplying capacity of soils, was in the order: Rangpur $>$ Rajshahi > Comilla, and this was similar to the results found in the pot study (Table 6). There was a strong positive linear relationship $\left(r^{2}=0.73, p<0.001\right)$ between indigenous soil $\mathrm{K}$ to $\mathrm{K}$ uptake in without $\mathrm{K}$ fertilized plots (Figure 8a), but no such relationship with indigenous soil $\mathrm{K}$ was observed in high $\mathrm{K}$ fertilized plots (Figure 8b).
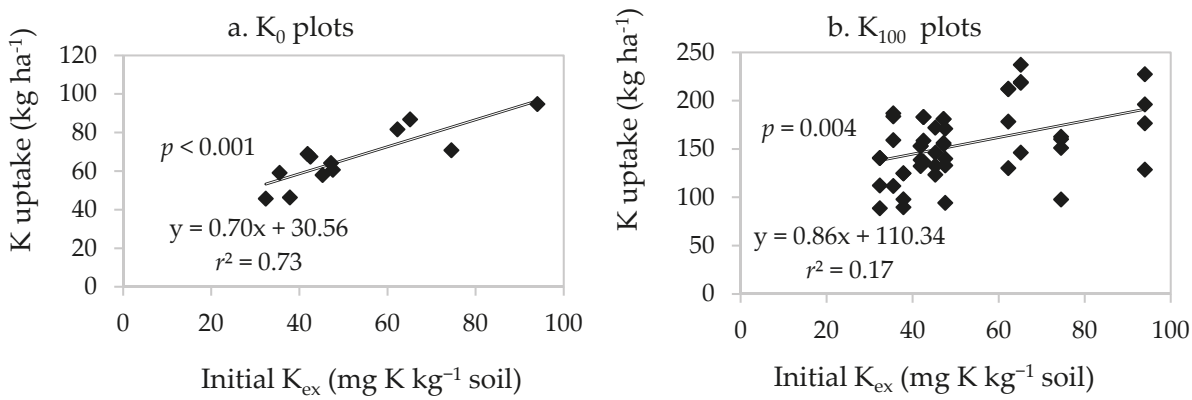

Figure 8. The relationship between initial soil $\mathrm{K}_{\mathrm{ex}}$ and $\mathrm{K}$ uptake in (a) control plots, $\mathrm{K}_{0}(n=12)$ and (b) K-fertilizer applied plots, $\mathrm{K}_{100}(n=48)$ in three field experimental sites in Bangladesh. ' $n$ ' indicates number.

Table 6. Effect of $\mathrm{K}$ fertilization on $\mathrm{K}$ concentration and $\mathrm{K}$ uptake, and agronomic and recovery efficiency of $\mathrm{K}$ by rabi maize in three field experimental sites in Bangladesh, 2012-2013.

\begin{tabular}{|c|c|c|c|c|c|c|c|}
\hline \multirow{2}{*}{ Treatment * } & \multicolumn{2}{|c|}{ K Concentration (\%) } & \multicolumn{3}{|c|}{ K Uptake (kg ha $\left.{ }^{-1}\right)$} & \multirow{2}{*}{$\mathrm{AE}_{\mathrm{K}}{ }^{\alpha}$} & \multirow{2}{*}{$\mathrm{RE}_{\mathrm{K}}{ }^{\beta}$} \\
\hline & Grain & Stover & Grain & Stover & Total & & \\
\hline \multicolumn{8}{|c|}{ Rangpur } \\
\hline $\mathrm{K}_{0}$ & $0.312^{\mathrm{d}}$ & $0.97^{\mathrm{c}}$ & $19.8^{c}$ & $63.8^{c}$ & $83.6^{c}$ & & \\
\hline $\mathrm{K}_{40}$ & $0.404^{c}$ & $1.21^{\mathrm{d}}$ & $30.4^{\mathrm{b}}$ & $93.4^{\mathrm{c}}$ & $123.8^{\mathrm{b}}$ & $29.05^{b}$ & $1.01^{\mathrm{a}}$ \\
\hline $\mathrm{K}_{80}$ & $0.447^{\mathrm{b}}$ & $1.25 \mathrm{bc}$ & $44.1^{\mathrm{a}}$ & $124.7^{\mathrm{b}}$ & $168.8^{\mathrm{a}}$ & $43.41^{\mathrm{a}}$ & $1.06^{\mathrm{a}}$ \\
\hline $\mathrm{K}_{120}$ & $0.455^{b}$ & $1.43^{b}$ & $46.6^{\mathrm{a}}$ & $150.3^{a b}$ & $196.9^{\mathrm{a}}$ & $32.19^{b}$ & $0.94^{\mathrm{a}}$ \\
\hline $\mathrm{K}_{160}$ & $0.527^{\mathrm{a}}$ & $1.73^{\mathrm{a}}$ & $47.6^{\mathrm{a}}$ & $159.6^{\mathrm{a}}$ & $207.2^{\mathrm{a}}$ & $16.80^{\mathrm{c}}$ & $0.77^{\mathrm{a}}$ \\
\hline MCM & $0.452^{b}$ & $1.29 \mathrm{~b}^{\mathrm{c}}$ & $47.0^{\mathrm{a}}$ & $137.4^{\mathrm{ab}}$ & $184.4^{\mathrm{a}}$ & $46.10^{\mathrm{a}}$ & $1.15^{\mathrm{a}}$ \\
\hline NEM & $0.476^{b}$ & $1.37 \mathrm{bc}$ & $52.2^{\mathrm{a}}$ & $151.9^{a b}$ & $204.1^{\mathrm{a}}$ & $39.57^{\mathrm{ab}}$ & $1.04^{\mathrm{a}}$ \\
\hline Mean & 0.439 & 1.32 & 41.1 & 125.87 & 166.97 & 34.52 & 1.00 \\
\hline $\mathrm{SE}( \pm)$ & 0.013 & 0.05 & 2.3 & 7.49 & 9.66 & 2.44 & 0.06 \\
\hline \multicolumn{8}{|c|}{ Rajshahi } \\
\hline $\mathrm{K}_{0}$ & $0.317^{\mathrm{d}}$ & $0.81^{\mathrm{f}}$ & $17.2^{\mathrm{d}}$ & $43.4^{\mathrm{e}}$ & $60.5^{f}$ & & \\
\hline $\mathrm{K}_{40}$ & $0.396^{c}$ & $0.99^{\mathrm{e}}$ & $25.7^{c}$ & $66.0^{\mathrm{d}}$ & $91.7^{\mathrm{e}}$ & $26.58^{a}$ & $0.78^{a b}$ \\
\hline $\mathrm{K}_{80}$ & $0.441^{\mathrm{b}}$ & $1.11^{\mathrm{d}}$ & $35.7^{b}$ & $92.2^{c}$ & $127.9^{\mathrm{d}}$ & $33.30^{\mathrm{a}}$ & $0.84^{\mathrm{ab}}$ \\
\hline $\mathrm{K}_{120}$ & $0.479^{b}$ & $1.33^{b}$ & $41.2^{\mathrm{a}}$ & $114.1^{\mathrm{b}}$ & $155.3^{\mathrm{b}}$ & $26.73^{a}$ & $0.79^{a b}$ \\
\hline $\mathrm{K}_{160}$ & $0.519^{\mathrm{a}}$ & $1.82^{\mathrm{a}}$ & $41.4^{\mathrm{a}}$ & $135.7^{\mathrm{a}}$ & $177.2^{\mathrm{a}}$ & $16.20^{\mathrm{b}}$ & $0.73^{b}$ \\
\hline
\end{tabular}


Table 6. Cont.

\begin{tabular}{|c|c|c|c|c|c|c|c|}
\hline \multirow{2}{*}{ Treatment * } & \multicolumn{2}{|c|}{ K Concentration (\%) } & \multicolumn{3}{|c|}{ K Uptake (kg ha-1) } & \multirow{2}{*}{$\mathrm{AE}_{\mathrm{K}}{ }^{\alpha}$} & \multirow{2}{*}{$\mathrm{RE}_{\mathrm{K}}{ }^{\beta}$} \\
\hline & Grain & Stover & Grain & Stover & Total & & \\
\hline $\mathrm{MCM}$ & $0.466^{\mathrm{b}}$ & $1.23 \mathrm{bc}$ & $39.3^{a b}$ & $107.9^{\mathrm{b}}$ & $147.2^{b c}$ & $34.20^{a}$ & $1.00^{\mathrm{a}}$ \\
\hline NEM & $0.456^{\mathrm{b}}$ & $1.19 \mathrm{~cd}$ & $39.4^{\mathrm{ab}}$ & $99.0 \mathrm{bc}$ & $138.4^{\mathrm{cd}}$ & $32.37^{\mathrm{a}}$ & $0.79^{a b}$ \\
\hline Mean & 0.439 & 1.21 & 34.3 & 94.0 & 128.3 & 28.23 & 0.82 \\
\hline $\mathrm{SE}( \pm)$ & 0.012 & 0.06 & 1.75 & 5.76 & 7.39 & 1.49 & 0.03 \\
\hline \multicolumn{8}{|c|}{ Comilla } \\
\hline $\mathrm{K}_{0}$ & $0.299^{\mathrm{d}}$ & $0.88^{\mathrm{d}}$ & $14.5^{c}$ & $42.7^{\mathrm{d}}$ & $57.2^{\mathrm{d}}$ & & \\
\hline $\mathrm{K}_{40}$ & $0.356^{\mathrm{cd}}$ & $1.04^{\mathrm{c}}$ & $20.1^{b c}$ & $61.5^{\mathrm{cd}}$ & $81.7^{\mathrm{cd}}$ & $19.62^{a b}$ & $0.61^{a}$ \\
\hline $\mathrm{K}_{80}$ & $0.419^{\mathrm{b}}$ & $1.15^{b c}$ & $29.4^{\mathrm{ab}}$ & $77.3^{b c}$ & $106.6^{\mathrm{bc}}$ & $26.02^{\mathrm{a}}$ & $0.62^{\mathrm{a}}$ \\
\hline $\mathrm{K}_{120}$ & $0.447^{\mathrm{b}}$ & $1.24^{\mathrm{b}}$ & $33.6^{\mathrm{a}}$ & $91.8^{\mathrm{b}}$ & $125.4^{\mathrm{ab}}$ & $21.57^{a b}$ & $0.57^{\mathrm{a}}$ \\
\hline $\mathrm{K}_{160}$ & $0.516^{\mathrm{a}}$ & $1.65^{\mathrm{a}}$ & $35.8^{\mathrm{a}}$ & $114.8^{\mathrm{a}}$ & $150.6^{\mathrm{a}}$ & $12.90^{\mathrm{b}}$ & $0.58^{a}$ \\
\hline $\mathrm{MCM}$ & $0.430^{\mathrm{b}}$ & $1.18^{b c}$ & $30.7^{\mathrm{a}}$ & $83.0^{\mathrm{b}}$ & $113.6^{\mathrm{b}}$ & $23.93^{a}$ & $0.64^{a}$ \\
\hline NEM & $0.394^{b c}$ & $1.11^{b c}$ & $29.0^{\mathrm{ab}}$ & $77.9 \mathrm{bc}$ & $106.9^{b c}$ & $25.10^{a}$ & $0.50^{\mathrm{a}}$ \\
\hline Mean & 0.409 & 1.177 & 27.59 & 78.4 & 106 & 21.52 & 0.59 \\
\hline $\mathrm{SE}( \pm)$ & 0.014 & 0.045 & 1.77 & 4.74 & 6.4 & 1.47 & 0.02 \\
\hline \multicolumn{8}{|c|}{ Across Sites } \\
\hline $\mathrm{K}_{0}$ & $0.309^{\mathrm{d}}$ & $0.88^{\mathrm{e}}$ & $17.2^{\mathrm{c}}$ & $49.9^{\mathrm{e}}$ & $67.1^{\mathrm{e}}$ & - & - \\
\hline $\mathrm{K}_{40}$ & $0.385^{c}$ & $1.08^{\mathrm{d}}$ & $25.4^{b}$ & $73.7^{\mathrm{d}}$ & $99.0^{\mathrm{d}}$ & $25.09^{b}$ & $0.80^{a b}$ \\
\hline$K_{80}$ & $0.436^{b}$ & $1.17^{\mathrm{c}}$ & $36.4^{a}$ & $98.0^{\mathrm{c}}$ & $134.4^{c}$ & $34.25^{\mathrm{a}}$ & $0.84^{\mathrm{ab}}$ \\
\hline $\mathrm{K}_{120}$ & $0.460^{b}$ & $1.33^{b}$ & $40.5^{\mathrm{a}}$ & $118.7^{b}$ & $159.2^{b}$ & $26.83^{b}$ & $0.77^{a b}$ \\
\hline $\mathrm{K}_{160}$ & $0.520^{\mathrm{a}}$ & $1.73^{a}$ & $41.6^{\mathrm{a}}$ & $136.7^{a}$ & $178.3^{a}$ & $15.30^{c}$ & $0.70^{\mathrm{b}}$ \\
\hline MCM & $0.449^{b}$ & $1.23^{c}$ & $39.0^{\mathrm{a}}$ & $109.4^{b c}$ & $148.4^{b c}$ & $34.74^{\mathrm{a}}$ & $0.93^{a}$ \\
\hline NEM & $0.442^{b}$ & $1.22^{c}$ & $40.2^{a}$ & $109.6^{b c}$ & $149.8^{b c}$ & $32.35^{\mathrm{a}}$ & $0.78^{a b}$ \\
\hline Mean & 0.429 & 1.24 & 34.3 & 99.4 & 133.8 & 28.1 & 0.8 \\
\hline $\mathrm{SE}( \pm)$ & 0.008 & 0.03 & 1.27 & 4.102 & 5.303 & 1.154 & 0.03 \\
\hline
\end{tabular}

Data not sharing the same lower-case letter(s) in a column are significantly different according to Duncan's New Multiple-Range Test at $5 \%$ level of probability [37]; $\mathrm{K}_{0}, \mathrm{~K}_{40}, \mathrm{~K}_{80}, \mathrm{~K}_{120}, \mathrm{~K}_{160}$ represent control, 40, 80, 120 , $160 \mathrm{~kg} \mathrm{~K} \mathrm{ha}^{-1}$, respectively; * MCM: Fertilizer recommendation ranged $75-100 \mathrm{~kg} \mathrm{~K}^{-1} \mathrm{across}^{-1}$ the sites based on SSNM through "Maze Crop Manager"; NEM: Fertilizer recommendations ranged 93-125 kg K ha ${ }^{-1}$ across sites based on SSNM through "Nutrient Expert for Maize"; SE-Standard error of mean; ${ }^{\alpha} \mathrm{AE}_{\mathrm{k}}$ : agronomic use efficiency of $\mathrm{K}\left(\mathrm{kg}\right.$ grain yield increase $\mathrm{kg}^{-1}$ applied $\left.\mathrm{K}\right) ; \mathrm{RE}_{\mathrm{k}}$ : Recovery efficiency of $\mathrm{K}\left(\mathrm{kg} \mathrm{K}\right.$ taken up $\mathrm{kg}^{-1} \mathrm{~K}$ applied).

\subsubsection{K-Use Efficiency}

There was a significant effect of $\mathrm{K}$ application on agronomic efficiency $\left(\mathrm{AE}_{\mathrm{K}}\right)$ and recovery efficiency $\left(\mathrm{RE}_{\mathrm{K}}\right)$ in each site and across all sites. The $\mathrm{AE}_{\mathrm{K}}$ varied significantly over control from 16.8 to 46.1, 16.2 to 34.2, and 12.9 to 26.0 in Rangpur, Rajshahi, and Comilla, respectively. Likewise, the ranges of $\mathrm{RE}_{\mathrm{K}}$ were from 0.77 to $1.15,0.73$ to 1.00 , and 0.50 to 0.64 , respectively in the three sites. $\mathrm{AE}_{\mathrm{K}}$ and $\mathrm{RE}_{\mathrm{K}}$ over the sites varied from 15.30 to 34.74 and 0.70 to 0.93 , respectively, and decreased progressively with increase of $\mathrm{K}$ rates (Table 6). Both $\mathrm{AE}_{\mathrm{K}}$ and $\mathrm{RE}_{\mathrm{K}}$ were lowest for the highest $\mathrm{K}$ dose $\left(160 \mathrm{~kg} \mathrm{ha}^{-1}\right)$ compared to other rates. Though not significantly different, the MCM-based recommendation generally resulted in higher $\mathrm{AE}_{\mathrm{K}}$ and $\mathrm{RE}_{\mathrm{K}}$ than NEM-based recommendation (Table 6).

\section{Discussion}

Until a few years back, there was a general perception that agricultural soils in South and South East Asia, including those in Bangladesh, were well supplied with $\mathrm{K}$, and hence there was no need to apply K fertilizer to crops. But recently, many investigations, reviews and research results have shown that the intensification of agriculture in the region with little or no $\mathrm{K}$ application caused gradual $\mathrm{K}$ mining, and crop responses to K are observed in many of those countries including Bangladesh [38-44]. Such results suggest the need for application of $\mathrm{K}$ fertilizers for sustaining or increasing the crop yields. Proper application and management of $\mathrm{K}$ require a thorough understanding of soil $\mathrm{K}$ dynamics and its 
uptake by crops at various $\mathrm{K}$ inputs and outputs scenarios and for different cropping systems. It is well known that the $\mathrm{K}$ availability to the plants does not only depend on the size of the available $\mathrm{K}$ pool in the soil but also K release patterns, and its transport from soil solution to the root zone for its uptake by plants $[45,46]$. It is hypothesized that soils $\mathrm{K}$ availability to plants differ in terms of mineralogy, soil K reserves, K-supplying capacity and its allowable drawdown factors $[47,48]$. Thus, some soils would require more while others would require less $\mathrm{K}$ to grow profitable maize crops [40].

Plant available K can be assessed either by plant growth analysis or by simple chemical extraction method or by a combination of both procedures with plants grown in no-K added plots. A robust relationship $\left(r^{2}=0.82\right)$ between $\mathrm{K}$ uptake and grain yield was observed in no-K plots, which was considered as a good measure of soil K supply to crops [49]. When assessed by plant $\mathrm{K}$ uptake, it can be termed as "K-supplying capacity" whereas if assessed by extracting the soil with one or more extractions, a chemical index of available K (K-releasing capacity), can be the true index of plant available K. Consequently, many investigators reported, while "plant available K" can be equated to the K-supplying capacity of the soil, it can only be related to the K-releasing capacity. Thus, both K-releasing and K-supplying capacity can be considered the measures of the ability of a soil to supply $\mathrm{K}$ to plants [50-52]. The amount of total $\mathrm{K}$ uptake by plants from a soil depends on the potential of K-supplying capacity.

The $\mathrm{K}$ depletion pattern in this study was carried out in a pot experiment with the successive planting of maize for seven harvests to understand K-supplying capacity from soil reserves of major soils in Bangladesh. The 18 tested soils varied considerably in supporting $\mathrm{K}$ uptake over seven crops, ranging from $22.1-103.7 \mathrm{mg} \mathrm{K} \mathrm{kg}^{-1}$ soil, and the uptake in control pots was lowest in Durgapur (Rajshahi), and highest in Mithapukur and Modhukhali (Rangpur) soils. Similar trends were observed for K-treated pots with $\mathrm{K}$ uptake ranging from 119.6 to $195.14 \mathrm{mg} \mathrm{K} \mathrm{kg}^{-1}$. The results from this study assisted us to divide the potential K-supplying capacity of 18 soils into three categories: low, medium, and high, and corresponding to average K uptake over seven successive crops of $<50,51-80$ and $>80 \mathrm{mg} \mathrm{K} \mathrm{kg}^{-1}$ soil, respectively (Figure 4). According to the classification, among the tested soils, K uptake (or soil K-supply capacity) by maize was low in Durgapur, Barura, Godagari and Birganj; medium in Nawabganj, Shibganj, Modhupur, Paba, Daudkandi, Gopalpur Tarash, Binerpota, Gangachara and Jhinaidah soils; and high in Dinajpur Sadar, Rangpur Sadar, Mithapukur and Modhukhali soils (Figure 4). In line to our study, similar observations were also recorded in Guinea grass for six successive crop harvests. In that study, the tissue $\mathrm{K}$ concentration and $\mathrm{K}$ uptake in plants, and soil K-supplying capacity varied widely in various soils and was higher for K-treated than for no K-applied soils $[46,53,54]$.

In the multi-location field experiment, growth and yield attributing characteristics of maize, except number of cobs per plant, responded to $\mathrm{K}$ fertilization significantly in all locations. Yield increase over control varied 18-79\%, 22-59\% and 21-54\% in Rangpur, Rajshahi and Comilla, respectively [55]. In all locations, significantly higher grain yield was found with NEM-based fertilizer recommendation followed respectively by MCM-based recommendation, 120,80 and $160 \mathrm{~kg} \mathrm{~K} \mathrm{ha}^{-1}$, and lowest with no $\mathrm{K}$ added and $40 \mathrm{~kg} \mathrm{~K} \mathrm{ha}^{-1}$ treatments. Both NEM- and MCM-based recommendations were based on the SSNM principles which considered previous crop's residues and manures and fertilizers practices, and indigenous soil fertility [28]. Previous results have also shown that the MCM and NEM have great potential to estimate $\mathrm{K}$ fertilizer recommendation for maize, which could help to reduce the cost of production and to increase yield and profit by reducing the over or underuse of fertilizer to the crop $[27,40]$.

$\mathrm{K}$ uptake by maize was governed by $\mathrm{K}$ content in plant tissue and above ground dry matter. The K concentration of the plant tissue was consistent with the $\mathrm{K}$ availability in the soil. Therefore, K uptake by maize in K-omission plots can be a reliable measure of K-supplying capacity of soil [50-52]. In control plots, $\mathrm{K}$ uptake by maize varied from 57.2 to $83.6 \mathrm{~kg} \mathrm{ha}^{-1}$. The order of K-supplying capacity in the field experiment was Rangpur > Rajshahi > Comilla which was similar to the order observed in the pot study. The correlation between $\mathrm{K}$ uptake by maize at harvest and initial $\mathrm{K}_{\mathrm{ex}}$ and $\mathrm{K}_{\text {nex }}$ were 
positive and linear. Plots of cumulative $\mathrm{K}$ uptake by maize from 1 st to 7 th harvest versus initial $\mathrm{K}_{\mathrm{ex}}$ contents showed a progressively higher utilization of $\mathrm{NH}_{4} \mathrm{OAc}-\mathrm{K}$ by maize during the experiment (Figure 7a,b). Moreover, the highly significant $r^{2}$ values (0.56 to 0.84 ) revealed that 56 to $84 \%$ of the $\mathrm{K}$ uptake by maize was governed by the initial $\mathrm{K}_{\mathrm{ex}}$ content. However, the slope $(>1)$ of the linear regression line indicated that the initial $\mathrm{K}_{\mathrm{ex}}$ was not sufficient to meet the entire uptake requirement of maize starting from the 1st crop to the 7th crop. The value of slope (1.6 to 14.8) increased with increase in crop number revealing the gradual depletion in $\mathrm{K}_{\mathrm{ex}}$ pool and therefore, the uptake of $\mathrm{K}$ might have been complimented from other soil $\mathrm{K}$ pools also (Figure $7 \mathrm{a}, \mathrm{b}$ ). In the case of $\mathrm{K}_{\text {nex }}$, the lower value of the slope and $r^{2}$ of a linear relationship for the 1st harvest indicated that the contribution of the $\mathrm{K}_{\text {nex }}$ pool to $\mathrm{K}$ uptake by maize was lower than the $\mathrm{K}_{\mathrm{ex}}$ pool. But the relationship of cumulative $\mathrm{K}$ uptake versus $K_{n e x}$ at 7 th harvest became stronger with a higher value of slope than the $1^{\text {st }}$ harvest. The value of slope and $r^{2}$ increased with successive crops indicating that the K uptake dependency on the $\mathrm{K}_{\text {nex }}$ pools was increased due to reduced $K_{\mathrm{ex}}$ availability in the soil with successive exhaustive cropping in control pots (Figure $7 \mathrm{c}, \mathrm{d}$ ). A significant contribution of $\mathrm{K}_{\text {nex }}$ to crop uptake was reported in other studies also. However, $\mathrm{K}_{\text {nex }}$ is not measured in routine soil $\mathrm{K}$ test in most countries and the depletion of $\mathrm{K}_{\text {nex }}$ often remain unnoticed to the detriment of soil $\mathrm{K}$ fertility.

The amount of $\mathrm{K}$ uptake by maize in the K-applied plots (99.0-178.3 $\mathrm{kg} \mathrm{K} \mathrm{ha}^{-1}$ ) was significantly higher than in control plots $\left(67.1 \mathrm{~kg} \mathrm{~K} \mathrm{ha}^{-1}\right)$ across the sites. The highest $\mathrm{K}$ uptake occurred with $160 \mathrm{~kg} \mathrm{~K} \mathrm{ha}^{-1}$, though MCM (75-100 $\left.\mathrm{kg} \mathrm{K} \mathrm{ha}^{-1}\right)$ resulted in significantly higher agronomic and recovery efficiency of $\mathrm{K}$. The $\mathrm{K}$ requirements vary for different crops, varieties, and locations in which they are grown $[54,56]$. Other studies have also shown that crop $\mathrm{K}$ requirement depends on the $\mathrm{K}$ status and $\mathrm{K}$ dynamics in soils, as well as efficient $\mathrm{K}$ use, which depends also on the rooting pattern of different crops and varieties, and their productivity [46,53]. There is thus essential need for K to be supplied at an optimum dose and maintained to augment production and ensure to improve quality crop $[27,56,57]$. Nevertheless, both the concomitant increase in yield and efficiency improvement with added $\mathrm{K}$ are important considerations for improved $\mathrm{K}$ management. Finally, improving nutrient use efficiency should not be the singular goal of any sustainable nutrient management program as higher efficiencies can be achieved by less and less nutrient application. In this study, the trend is yield and efficiency increase from 40 to $80 \mathrm{~kg} \mathrm{~K}$, but efficiencies drop as 120 or $160 \mathrm{~kg}$ of K are applied, clearly suggesting that yield improvement at these rates are not enough to improve use efficiencies also. In any improved K management programs, decision support system (DSS) tools such as MCM or NEM strategies could be the better options for improved $\mathrm{K}$ fertilizer management, as the current study showed that, these strategies increased $\mathrm{K}$ application but also increased maize yield to keep the efficiencies at higher levels. SSNM strategies, such as MCM and NEM DSS tools, can take care of adequate and balanced application of all nutrients, including $\mathrm{K}$, and hence their adoption in Bangladesh and South Asia would be important not just for K management but for the management of all nutrients.

\section{Conclusions}

In pot study, maize responded to added K in Godagari, Durgapur, and Modhupur soils out of 18 soils from the first crop and 50\% soils responding from the second crop, with remaining soils responding from the third crop onwards. The mean yield response over seven successive crops across 18 soils varied from 20 to $195 \%$, where least and most responsive soils to $\mathrm{K}$ fertilizer were found in Modhukhali and Durgapur soils. In control pots, K-supplying capacity over seven successive crops varied (22.1-107.3 $\left.\mathrm{mg} \mathrm{K} \mathrm{kg} \mathrm{soil}{ }^{-1}\right)$ significantly and there was a significant $(p<0.001)$ negative correlation between yield response and indigenous K-supplying capacity. In the field validation experiment, yield and yield attributes of maize responded to $\mathrm{K}$ fertilizer significantly in all locations. Potassium fertilizer increased grain yield from 18 to $79 \%$.

The current research established that the requirement of $\mathrm{K}$ was $111-122 \mathrm{~kg} \mathrm{~K} \mathrm{ha}^{-1}$ for maize cultivation in Bangladesh. Total $\mathrm{K}$ uptake by the plot that did not receive $\mathrm{K}$ fertilizer in on-farm trials, 
considered as K-supplying capacity of the soils, was in the order: Rangpur > Rajshahi > Comilla, which was similar to the results of pot study. Thus, assessment of K-supplying capacity of major soils in Bangladesh will be useful for managing $\mathrm{K}$ fertility in soils and $\mathrm{K}$ nutrition for maize. The study provides evidence of the essentiality of adequate and balanced $\mathrm{K}$ application in maize in Bangladesh for sustainably improving or maintaining high yields. The results, however, have great implications for South Asia as a whole as maize is replacing rice and wheat in vast areas of the region because of its economic value and climate resilience. Although the results of the pot and field experiments provide sufficient information on the K-supplying capacity of diverse soils of, and the productivity maize for selected sites in, Bangladesh, which helps refine current $\mathrm{K}$ fertilizer recommendation rates to farmers, further study would be required to better understand K-supplying capacity, yield and K-use efficiency in more diverse soils and for robust recommendation to farmers across maize-growing areas of South Asia.

Author Contributions: S.I., J.T., M.S. and K.M conceived and designed the experiments; S.I., J.T and M.S. conducted the experiments; S.I. recorded the data; S.I., J.T and M.K.G. analyzed the data; S.I. and J.T. wrote the paper; S.I., J.T., M.S., K.M. and M.K.G. reviewed, edited, and approved the final manuscript.

funding: This research was funded by International Plant Nutrition Institute (IPNI) for "Assessment of Soil Potassium Supplying Capacity from Soil Nutrient Reserves and Dissemination of Nutrient Management Technologies through Nutrient Manager" project (South Asia Office, New Delhi, India, grant number [IPNI-2010-BGD-6] and Australian Centre for International Agricultural Research (ACIAR) for "Sustainable Intensification of Rice-Maize production systems in Bangladesh" project, grant number [CIM-2007-122].

Acknowledgments: Authors give special thanks to Bangladesh Rice Research Institute (BRRI) for giving the opportunity to conduct pot experiments in their net house. Authors would also like to thank Abu Saleque (BRRI) and Roland Buresh (IRRI) for their constructive suggestions during the conduct of research. We are also grateful to farmers for providing lands for the experiments and actively involved in care and maintenance of the experiments.

Conflicts of Interest: The authors declare no conflict of interest.

\section{References}

1. Shiferaw, B.; Prasanna, B.M.; Hellin, J.; Bänziger, M. Crops that feed the world 6. Past successes and future challenges to the role played by maize in global food security. Food Secur. 2011, 3, 307-327. [CrossRef]

2. Gerland, P.; Raftery, A.E.; Ševčíková, H.; Li, N.; Gu, D.; Spoorenberg, T.; Alkema, L.; Fosdick, B.K.; Chunn, J.; Lalic, N.; et al. World population stabilization unlikely this century. Science 2014, 346, 234-237. [CrossRef] [PubMed]

3. Bank, W. World Development Indicators 2014; World Bank: Washington, DC, USA, 2014; Volume 87, pp. 98-191.

4. DAE. Krishi Diary; Agricultural Information Services, Department of Agriculture Extension (DAE), Ministry of Agriculture, Khamar Bari: Dhaka, Bangladesh, 2018.

5. Barber, S.A. Potassium availability at the soil-root interface and factors influencing potassium uptake. In Potassium in Agriculture; Munson, R.D., Ed.; American Society of Agronomy: Madison, WI, USA, 1985; pp. 309-324.

6. Dobermann, A.; Cassman, K.G.; Mamaril, C.P.; Sheehy, J.E. Management of phosphorus, potassium, and sulfur in intensive, irrigated lowland rice. Field Crop. Res. 1998, 56, 113-138. [CrossRef]

7. Regmi, A.P.; Ladha, J.K.; Pathak, H.; Pasuquin, E.; Bueno, C.; Dawe, D.; Hobbs, P.R.; Joshy, D.; Maskey, S.L.; Pandey, S.P. Yield and Soil Fertility Trends in a 20-Year Rice-Rice-Wheat Experiment in Nepal. Soil Sci. Soc. Am. J. 2002, 66, 857. [CrossRef]

8. Srivastava, S.; Raghavareddy Rupa, T.; Swarup, A.; Singh, D. Effect of long-term fertilization and manuring on potassium release properties in a Typic Ustochrept. J. Plant Nutr. Soil Sci. 2002, 165, 352-356. [CrossRef]

9. Singh, B.; Singh, Y.; Imas, P.; Jian-chang, X. Potassium Nutrition of the Rice-Wheat Cropping System. Adv. Agron. 2001, 81, 203-259.

10. Timsina, J.; Jat, M.L.; Majumdar, K. Rice-maize systems of South Asia: Current status, future prospects and research priorities for nutrient management. Plant Soil 2010, 335, 65-82. [CrossRef]

11. Doboerman, A.; Fairhurst, T.H. Nutrient Disorders \& Nutrient Management, 1st ed.; Potash \& Phosphate Institute (PPI)-Potash \& Phosphate Institute of Canada (PPIC): Norcross, GA, Canada; International Rice Institute (IRRI): Los Baños, Philippines, 2000; ISBN 9810427425. 
12. Ali, M.M.; Saheed, S.M.; Kubota, D.; Masunaga, T.; Wakatsuki, T. Soil degradation during the period 1967-1995 in Bangladesh. Soil Sci. Plant Nutr. 1997, 43, 879-890. [CrossRef]

13. Saleque, M.A.; Saha, P.K.; Panaullah, G.M.; Bhuiyan, N.I. Response of wetland rice to potassium in farmers' fields of the Barind tract of Bangladesh. J. Plant Nutr. 1998, 21, 39-47. [CrossRef]

14. Majumdar, K.; Zingore, S.; Garcia, F.; Johnston, A.M. Improving nutrient management for sustainable intensifi cation of maize. In Achieving Sustainable Cultivation of Maize; Burleigh Dodds Science Publishing: Sawston, UK, 2017; Volume 2, pp. 1-32.

15. Panaullah, G.M.; Timsina, J.M.A.; Saleque, M.A.; Ishaque, M.; Pathan, A.B.M.B.U.; Connor, D.J.; Saha, P.K.; Quayyum, M.A.; Humphreys, E.; Meisner, C.A. Nutrient uptake and apparent balances for rice-wheat sequences. III. Potassium. J. Plant Nutr. 2006, 29, 173-187. [CrossRef]

16. Olk, D.C.; Cassman, K.G.; Simbahan, G.; Sta. Cruz, P.C.; Abdulrachman, S.; Nagarajan, R.; Tan, P.S.; Satawathananont, S. Interpreting fertilizer-use efficiency in relation to soil nutrient-supplying capacity, factor productivity, and agronomic efficiency. Nutr. Cycl. Agro-Ecosyst. 1999, 1621, 35-41. [CrossRef]

17. Cassman, K.G.; Dobermann, A.R.; Walters, D.T. Agroecosystems, Nitrogen-use Efficiency, and Nitrogen Management. Agron. Hortic. 2002, 31, 132-140. [CrossRef]

18. Dobermann, A. Nutrient use efficiency-measurement and management. In Fertilizer Best Management Practices, Proceedings of the IFA International Workshop on Fertilizer Best Management Practices, Brussels, Belgium, 7-9 March 2007; International Fertilizer Industry Association: Paris, France, 2007; p. 28.

19. Liu, X.; He, P.; Jin, J.; Zhou, W.; Sulewski, G.; Phillips, S. Yield gaps, indigenous nutrient supply, and nutrient use efficiency of wheat in China. Agron. J. 2011, 103, 1452-1463. [CrossRef]

20. Sparks, D.L.; Page, A.L.; Helmke, P.A.; Loeppert, R.A.; Soltanpour, P.N.; Tabatabai, M.A.; Johnston, C.T.; Sumner, M.E. Methods of soil analysis: Chemical Methods. In Chemical Methods; Fundación Hondureña de Investigación Agrícola (FHIA): Madison, WI, USA, 1996; p. 1390. ISBN 0891188258.

21. ASTM D422-63(2007)e2. Report of Standard Test Method for Particle-Size Analysis of Soils; ASTM International: West Conshohocken, PA, USA, 2007; Volume D422-63, pp. 1-8.

22. Brammer, H.; Antoine, J.; Kassam, A.H.; Van Velthuizen, H.T. Land Resources Appraisal of Bangladesh for Agricultural Development; FAO of United Nations: Rome, Italy, 1988; Volume II.

23. Fertilizer Recommendation Guide 2012; BARC (Bangladesh Agricultural Research Council): Farmgate, Dhaka, 2012; ISBN 978-984-500-000-0.

24. Ritchie, S.; Hanway, J.; Benson, G. How a Corn Plant Develops; Iowa State University of Science and Technology: Ames, IA, USA, 1989; pp. 1-25.

25. Jones, J.B., Jr. Laboratory Guide for Conducting Soil Tests and Plant Analysis. In Laboratory Guide for Conducting Soil Tests and Plant Analysis, 1st ed.; CRC (Chemical Rubber Company) Press: Boca Raton, FL, USA, 2001; p. 202. ISBN 1420025295.

26. Buresh, R.J.; Pampolino, M.F.; Witt, C. Field-specific potassium and phosphorus balances and fertilizer requirements for irrigated rice-based cropping systems. Plant Soil 2010, 335, 35-64. [CrossRef]

27. Satyanarayana, T.; Kaushik, M.; Biradar, D.P. New approaches and tools for site-specific nutrient management with reference to potassium. Karnataka J. Agric. Sci. 2011, 24, 86-90.

28. Anand, S.R.; Vishwanatha, J.; Rajkumar, R.H. Site Specific Nutrient Management (SSNM) Using " Nutrient Expert " for Hybrid Maize (Zea mays L.) Under Zero Tillage in Thungabhadra Project (TBP) Command Area of Karnataka. Int. J. Curr. Microbiol. Appl. Sci. 2017, 6, 3597-3605. [CrossRef]

29. Witt, C.; Found, M.G. A Site-Specific Nutrient Management Approach for Irrigated, Lowland Rice in Asia. Better Crop. Int. 2016, 16, 20-24.

30. Witt, C.; Pasuquin, J.M.C.A.; Dobermann, A. A Site-Specific Nutrient Management for Maize in Favorable Tropical Environments of Asia. In Proceedings of the 5th International Crop Science Congress, Brisbane, Australia, 26 September-1 October 2004; Better Crops Internationa: Jeju, Korea, April 2008; p. 257.

31. Xu, X.; He, P.; Qiu, S.; Pampolino, M.F.; Zhao, S.; Johnston, A.M.; Zhou, W. Estimating a new approach of fertilizer recommendation across small-holder farms in China. Field Crop. Res. 2014, 163, 10-17. [CrossRef]

32. Dobermann, A.; Witt, C.; Abdulrachman, S.; Gines, H.C.; Nagarajan, R.; Son, T.T.; Tan, P.S.; Wang, G.H.; Chien, N.V.; Thoa, V.T.K.; et al. Estimating indigenous nutrient supplies for site-specific nutrient management in irrigated rice. Agron. J. 2003, 95, 924-935. [CrossRef] 
33. Xu, X.; He, P.; Pampolino, M.; Johnston, A.; Qiu, S.; Zhao, S.; Chuan, L.; Zhou, W. Fertilizer recommendation for maize in China based on yield response and agronomic efficiency. Field Crop. Res. 2014, 157, 27-34. [CrossRef]

34. Cock, J.; Yoshida, S.; Forno, D.A. Laboratory Manual for Physiological Studies of Rice. Int. Rice Res. Inst. 1976, 69-72. [CrossRef]

35. Venables, W.N.; Smith, D.M.; R Development Core Team. R Software; R Foundation for Statistical Computing: Vienna, Austria, 2008; Volume 739, p. 409. Available online: http:/ / www.r-project.org (accessed on 15 July 2018).

36. Chambers, J.M. Software for Data Analysis Programming with R; Springer Science \& Business Media: Berlin/Heidelberg, Germany, 2008; Volume 15, ISBN 9780387759357.

37. Steel, R.G.D.; Torrie, J.H. Principles and Procedures of Statistics: A Biometrical Approach, 3rd ed.; McGraw-Hill: New York, NY, USA, 1997.

38. Dobermann, A.; Sta. CruzK, P.C.; Cassman, K.G. Fertilizer inputs, nutrient balance, and soil nutrient-supplying power in intensive, irrigated rice systems. I. Potassium uptake and K balance. Nutr. Cycl. Agroecosyst. 1996, 46, 1-10. [CrossRef]

39. Miah, M.A.M.; Saha, P.K.; Islam, A.; Hasan, M.N.; Nosov, V. Potassium fertilization in rice-rice and rice-wheat cropping system in Bangladesh. Bangladesh J. Agric. Environ. 2016, 4, 51-67.

40. Timsina, J.; Kumar Singh, V.; Majumdar, K. Potassium management in rice-maize systems in South Asia. J. Plant Nutr. Soil Sci. 2013, 176, 317-330. [CrossRef]

41. Islam, A.; Muttaleb, A. Effect of potassium fertilization on yield and potassium nutrition of Boro rice in a wetland ecosystem of Bangladesh. Arch. Agron. Soil Sci. 2016, 62, 1530-1540. [CrossRef]

42. Srinivasarao, C.; Satyanarayana, T.; Venkateswarlu, B. Potassium mining in Indian agriculture: input and output balance. Karnataka J. Agric. Sci. 2011, 24, 20-28.

43. Rijmpa, J.; Islam, F. Nutrient mining and its effect on crop production and environment. In Seminar on Soil Health Management: DAE-SFFP Experience; DAE-SFFP (Department of Agriculture Extension-Soil Fertility of the Paddy Fields): Dhaka, Bangladesh, 2002.

44. Grzebisz, W.; Szczepaniak, W.; Potarzycki, J.; Łukowiak, R. Sustainable Management of Soil PotassiumA Crop Rotation Oriented Concept. In Soil Fertility; InTech: Rijeka, Croatia, 2012.

45. Barber, S.A. Soil Nutrient Bioavailability: A Mechanistic Approach, 2nd ed.; John Wiley and Sons: New York, NY, USA, 1995; ISBN 978-0-471-58747-7.

46. Darunsontaya, T.; Suddhiprakarn, A.; Kheoruenromne, I.; Prakongkep, N.; Gilkes, R. The forms and availability to plants of soil potassium as related to mineralogy for upland Oxisols and Ultisols from Thailand. Geoderma 2012, 170. [CrossRef]

47. Jagadish, T.; Vinod, K.S.; Kaushik, M. Potassium management in rice-maize systems in South Asia. J. Plant Nutr. Soil Sci. 2013, 176, 317-330. [CrossRef]

48. Islam, A.; Karim, A.J.M.S.; Solaiman, A.R.M.; Islam, M.S.; Saleque, M.A. Eight-year long potassium fertilization effects on quantity/intensity relationship of soil potassium under double rice cropping. Soil Tillage Res. 2017, 169, 99-117. [CrossRef]

49. Pathak, D.S.; Aggarwal, P.K.; Rötter, R.P.; Kalra, N.; Bandyopadhaya, S.K.; Prasad, S.; van keulen, H. Modelling the quantitative evaluation of soil nutrient supply, nutrient use efficiency, and fertilizer requirements of wheat in India. Nutr. Cycl. Agroecosyst. 2003, 65, 105-113. [CrossRef]

50. Fergus, I.F.; Martin, A.E. Studies on potassium. IV. Interspecific differences in the uptake of non-exchangeable potassium. Soil Res. 1974, 12, 147-158. [CrossRef]

51. Memon, Y.M.; Fergus, I.F.; Hughes, J.D.; Page, D.W. Utilization of non-exchangeable soil potassium in relation to soil type, plant species and stage of growth. Soil Res. 1988, 26, 489-496. [CrossRef]

52. Surapaneni, A.; Tillman, R.W.; Kirkman, J.H.; Gregg, P.E.H.; Roberts, A.H.C. Potassium-supplying power of selected Pallic soils of New Zealand 1. Pot trial study. N. Z. J. Agric. Res. 2002, 45, 113-122. [CrossRef]

53. Hussain, A.; Arshad, M.; Ahmad, Z.; Ahmad, H.T.; Afzal, M.; Ahmad, M. Potassium Fertilization and Maize Physiology Potassium Fertilization Influences Growth, Physiology and Nutrients Uptake of Maize (Zea mays L.). Cercet. Agron. Mold. 2015, XLVIII, 37-50. [CrossRef]

54. Askegaard, M.; Eriksen, J.; Johnson, A.E. Sustainable management of potassium. In Managing Soil Quality: Challenges in Modern Agriculture; Schjønning, P., Elmholt, S., Christensen, B.T., Eds.; CABI (The Centre for Agriculture and Bioscience International) Publishing: Wallingford, Oxfordshire, UK, 2004; pp. 85-102. 
55. Huang, S.W.; Jin, J.Y.; Tan, D.S. Crop Response to Long-Term Potassium application as affected by Potassium Supplying Power of the Selected Soils in Northern China. Commun. Soil Sci. Plant Anal. 2009, 2833-2854. [CrossRef]

56. Sadanandan, A.K.; Peter, K.V; Hamza, S. Role of Potassium Nutrition in Improving Yield and Quality of Spice Crops in India. In Potassium for Sustainable Crop Production; Haryana and International Potash Institute: Zug, Switzerland, 2002; pp. 445-466.

57. Singh, V.K.; Dwivedi, B.S.; Buresh, R.J.; Jat, M.L.; Majumdar, K.; Gangwar, B.; Govil, V.; Singh, S.K. Potassium fertilization in rice-wheat system across northern India: Crop performance and soil nutrients. Agron. J. 2013, 105, 471-481. [CrossRef]

(C) 2018 by the authors. Licensee MDPI, Basel, Switzerland. This article is an open access article distributed under the terms and conditions of the Creative Commons Attribution (CC BY) license (http://creativecommons.org/licenses/by/4.0/). 
Article

\title{
Synergistic Effect of Sulfur and Nitrogen in the Organic and Mineral Fertilization of Durum Wheat: Grain Yield and Quality Traits in the Mediterranean Environment
}

\author{
Francesco Rossini, Maria Elena Provenzano, Francesco Sestili and Roberto Ruggeri * \\ Department of Agriculture and Forestry Science (DAFNE), University of Tuscia, via San Camillo de Lellis, \\ 01100 Viterbo, Italy; rossini@unitus.it (F.R.); provenzano.mariaelena@gmail.com (M.E.P.); \\ francescosestili@unitus.it (F.S.) \\ * Correspondence: r.ruggeri@unitus.it; Tel.: +39-0761-357561
}

Received: 20 July 2018; Accepted: 12 September 2018; Published: 14 September 2018

\begin{abstract}
In recent years, awareness on sustainable land use has increased. Optimizing the practice of nitrogen fertilization has become crucially imperative in cropping management as a result of this current trend. The effort to improve the availability of organic nitrogen has incurred a bottleneck while seeking to achieve a high yield and quality performance for organic winter cereals. Field experiments were conducted, under rainfed Mediterranean conditions, over a period of two subsequent growing seasons. The objective was to investigate the effect of soil and foliar $\mathrm{S}$ application on the performance of three durum wheat cultivars fertilized with either organic or inorganic N. The hypothesis to be verified was if different $S$ fertilization strategies could improve grain yield and quality when coupled with mineral or organic $\mathrm{N}$ fertilizer. There were three levels of treatment with mineral $\mathrm{N}$ fertilizer (120, 160 and $\left.200 \mathrm{~kg} \mathrm{ha}^{-1}\right)$, two levels of organic $\mathrm{N}$ fertilizer $\left(160\right.$ and $\left.200 \mathrm{~kg} \mathrm{ha}^{-1}\right)$, two levels of $S$ fertilizer applied to the soil $\left(0\right.$ and $\left.70 \mathrm{~kg} \mathrm{ha}^{-1}\right)$, and two levels of foliar $\mathrm{S}$ application at flag leaf stage $\left(0\right.$ and $\left.5 \mathrm{~kg} \mathrm{ha}^{-1}\right)$. Cultivars were Dylan, Iride and Saragolla. Analyzed traits were grain yield, yield components and quality features of grain. Overall, at the same $\mathrm{N}$ rate, grain yield and quality were markedly higher for mineral than organic $\mathrm{N}$ source. Cultivar $\times$ Year $\times \mathrm{N}$ treatment interactions significantly affected grain yield and quality indices. Iride showed a high yield stability throughout the mineral N rates in the most favorable year (2011) and, in the same year, was the top performing cultivar in organic $\mathrm{N}$ treatments. Dylan was the top performing cultivar for protein content, while Saragolla for the SDS sedimentation test. Soil S fertilization had no effect on grain quality, whereas it significantly increased grain yield $\left(+300 \mathrm{~kg} \mathrm{ha}^{-1}\right)$ when coupled with organic rather than a mineral $\mathrm{N}$ source. However, foliar $\mathrm{S}$ application at flag leaf stage did not affect grain yield, but it significantly enhanced quality indices such as test weight $\left(81 \mathrm{vs} .79 .9 \mathrm{~kg} \mathrm{hL}^{-1}\right)$, protein content (13.7\% vs. $12.9 \%$ ) and SDS value (72.5 vs. $70.5 \mathrm{~mm})$. A rate of $160 \mathrm{~kg} \mathrm{ha}^{-1}$ of $\mathrm{N}$ (both mineral and organic) determined the optimal response for both grain yield and quality. Finally, soil and foliar application of $S$ may help to contain the large yield and quality gap that still exists between mineral and organic fertilization of durum wheat.
\end{abstract}

Keywords: durum wheat; mineral N; organic N; S fertilization; grain quality; grain yield

\section{Introduction}

Durum wheat (Triticum turgidum L. subsp. durum (Desf.) Husn.) is an economically important crop cultivated worldwide. Europe-28 is by far the largest world durum wheat producer. In 2017, it was grown on 2.7 million hectares only in the European Union (EU), providing an output of about 9 million tons. The cultivation area of durum wheat in Europe is mostly concentrated in the 
Mediterranean region: Italy, Spain and France together account for $80 \%$ of total EU production [1]. Italy is the top EU producer country and a traditional durum wheat growing region as it dedicates half of the total EU durum wheat area to this crop, thus accounting for $45 \%$ of the entire EU production, with a yield of about $3.2 \mathrm{tha}^{-1}$.

Grain quality has become one of the most important goals for the breeders and growers [2,3], because it is essential in obtaining premium prices and meeting markets needs for high-quality end-products of durum wheat such as pasta, couscous and burghul [4].

There is no simple and complete definition for the quality of durum wheat $[4,5]$. Grain protein content, color and gluten strength are considered the most important features needed for use in pasta and bread production. Grain protein content is known to be influenced by climatic parameters, genetic factors, nitrogen fertilizer rate, time of nitrogen application, residual soil nitrogen and available moisture during grain filling [6-9]. The yellow color is due to the carotenoid pigment content in the whole kernel, and it is commercially identified as the yellow index in semolina. Besides their role as an important aesthetic parameter, the carotenoids have important nutritional and health characteristics [10]. While yellow index was found to be affected by weather conditions, cultivar and $\mathrm{N}$ rate and timing [10-12], less is known about the effect of $\mathrm{N}$ source and $\mathrm{S}$ fertilization on this quality index.

Gluten strength contributes to the ability of dough to rise and maintain its shape as it is baked. Gluten strength is commonly estimated using the sodium dodecyl sulfate (SDS) sedimentation test that, depending on the protein quality, provides a good indicator of pasta cooking quality [13-15]. Ercoli et al. (2011) [15] found that SDS value increases with the increase of inorganic N (from 120 to $180 \mathrm{~kg} \mathrm{ha}^{-1}$ ) and $\mathrm{S}$ (from 0 to $60 \mathrm{~kg} \mathrm{ha}^{-1}$ ) rate.

The use of nitrogen is normally considered a key factor in cereal crops and numerous studies on the best $\mathrm{N}$ fertilization rates and timing have been conducted. In fact, if on the one hand it has been proved that nitrogen positively affects grain yield and quality, on the other hand $\mathrm{N}$ fertilizer management is pivotal to avoiding $\mathrm{N}$ losses caused by leaching, runoff, denitrification or volatilization $[11,16,17]$.

After taking all this into account, the use of organic $\mathrm{N}$ fertilizers may be a further option, together with other cropping management and practices, to reduce nitrate pollution and improve the environmental sustainability of conventional farming systems [12]. Thus, another feature can be added to the definition of the quality of wheat products [18].

Moreover, fertility management was the identified key factor in limiting both yield and grain protein content in the organic wheat management $[12,19,20]$. The results on common wheat (Triticum aestivum L.) emphasize the importance of a sufficient supply of soils with organic fertilizers as well as the need to improve the availability of organic nitrogen $[19,21]$. This latter option might be accomplished by trying to regulate the degradation and mineralization of organic matter $(\mathrm{OM})$ in the soils, which is the traditional role assigned to heterotrophic microbes [22]. The number of these microorganisms, and in particular those which oxidize sulfur (S), was found to be: (i) greater in some rizospheres (e.g., canola and wheat) than in bulk soil controls [23]; and (ii) stimulated by $\mathrm{S}$ fertilization and soil OM [24]. A recent study conducted in the Canadian prairie showed that common wheat biomass production in organic systems was positively related (among other factors) to the plant tissue $\mathrm{S}$ concentration [21]. Thus, $\mathrm{S}$ application to the soil might have a synergistic effect with organic $\mathrm{N}$ fertilization of durum wheat, determining higher yields and better quality. This hypothesis could be particularly verified in those agroecosystems that extend along the Mediterranean coast, in which soil temperature and water availability during the winter season do not drastically reduce mineralization capacity by the soil biota.

Sulfur is an essential element for all organisms since it is present in many molecules (amino acids, oligopeptides, vitamins and many secondary metabolites) and it is involved in several biochemical processes. Plants absorb $\mathrm{S}$ as sulfate ion $\left(\mathrm{SO}_{4}{ }^{2-}\right)$ from soil solution and use it in key steps of their metabolism [25]. Furthermore, findings provide evidence for the uptake and metabolization of elemental $\mathrm{S}$ also at the leaf level $[26,27]$. However, the fact that symptoms of deficiency appear earlier 
in young leaves than mature ones suggests that $S$ is relatively immobile in mature leaves and that the re-distribution from vegetative tissues to wheat kernels is noticeably less than that of $\mathrm{N}$ and $\mathrm{P}$ [28]. These are significant findings when considering foliar S application from flag leaf emergence to anthesis, aiming to reach greater efficiency in the $S$ fertilization $[29,30]$.

The importance of $S$ in plant nutrition is highlighted by the fact that a limited availability of this element causes both direct (biomass reduction) and indirect production loss [28,31-33]. The indirect effects on plants productivity are attributable to the role that $S$ plays in the synthesis of several metabolites such as Sulfur-containing Defense Compounds (SDC) involved in the physiological response to biotic and abiotic stresses [34-36]. Such considerations have led to studying grain yield and quality responses to $\mathrm{S}$ fertilizer and thus developing improved $\mathrm{N}$ and $\mathrm{S}$ fertilization strategies $[11,16,37,38]$.

Although many studies have been conducted on the influence of $\mathrm{N}$ and $\mathrm{S}$ fertilization on common wheat characteristics such as growth, yield, quality and technological properties [28-30,38-40], still very little is known about the effect of $\mathrm{S}$ and $\mathrm{N}$ nutrition on grain yield and quality of durum wheat.

Studies conducted in the Mediterranean basin show different results leading to different conclusions. Garrido-Lestache et al. (2005) [11] in a three-year field experiment in southern Spain found that soil or leaf application of $S$ had no effect on quality indices, with the exception of ash content. Conversely, Lerner et al. (2006) [41] in Argentina described a positive effect of sulfur fertilization on wheat quality traits. A similar result was observed in Southern Italy [42] and by Ercoli et al. (2011) [15] in Central Italy, even if they did not find a significant effect of $S$ fertilization on grain protein content. Moreover, to the best of our knowledge, no studies have been conducted on durum wheat aiming to test simultaneously the interaction of $\mathrm{S}$ fertilization type with both mineral and organic $\mathrm{N}$ source.

Thus, the aims of the present study were: (1) to evaluate the effect of different N-S fertilization rates and types on grain yield and quality of three durum wheat cultivars representative of the Mediterranean region; and (2) to verify the hypothesis that soil $S$ fertilization has a synergetic effect with organic $\mathrm{N}$ fertilization, on improving grain yield and quality of durum wheat.

\section{Materials and Methods}

\subsection{Site and Experimental Design}

A field experiment was set up in Tarquinia, Central Italy $\left(42^{\circ} 12^{\prime} \mathrm{N}, 11^{\circ} 45^{\prime} \mathrm{E}\right.$; altitude: $22 \mathrm{~m}$ a.s.l.), during the 2010-2011 and 2011-2012 growing seasons. The area has a Mediterranean climate, with a mean air temperature of $15.5^{\circ} \mathrm{C}$ and a mean annual precipitation of $658 \mathrm{~mm}$. The weather data were retrieved from a meteorological station located in Tarquinia, at a short distance from the site. Meteorological data were characterized by a consistent difference between the growing seasons, particularly in terms of precipitation, so that in 2010-2011 rainfall was 38\% higher compared to the 20-year average rainfall, while in 2011-2012 it was lower by 58\%. Mean monthly temperature and total rainfall during 2010-2011 and 2011-2012 growing seasons are shown in Figure 1.

Temperatures were similar in the 2010-2011 and 2011-2012 growing seasons and, compared to the 20-year averages, were higher by $2{ }^{\circ} \mathrm{C}$ over the period from sowing to tillering stage and lower by $5.5^{\circ} \mathrm{C}$ on average from February until grain ripening. Rainfall were under the average for more than five months in 2012. 


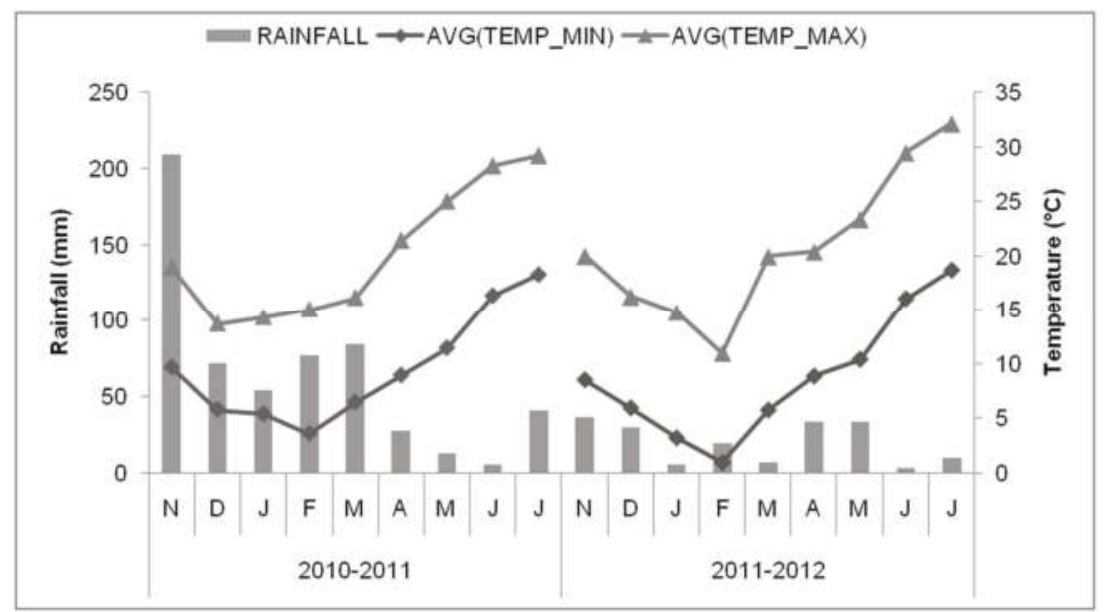

Figure 1. Minimum and maximum temperatures and rainfall recorded during the growing season (November-July) in 2010-2011 and 2011-2012.

Soil samples were collected from fields in both years before sowing. Samples, taken at 0-40 cm depth, were oven dried, grounded and then analyzed for texture and chemical analysis: $\mathrm{pH}, \mathrm{OM}$, sulfur content, total N, and total carbonate content. The soil was classified as clay according to the International Soil Science Society (ISSS) classification. The relevant soil characteristics are presented in Table 1.

Table 1. Soil characteristics of the experimental sites.

\begin{tabular}{cccc}
\hline Parameter & Unit & 2010-2011 & 2011-2012 \\
\hline Clay $(\varnothing<2 \mu \mathrm{m})$ & $\%$ & 45.2 & 55.9 \\
Silt $(2.0<\varnothing<20 \mu \mathrm{m})$ & $\%$ & 20.5 & 19.5 \\
Sand $(2.0>\varnothing>0.02 \mathrm{~mm})$ & $\%$ & 34.3 & 24.6 \\
$\mathrm{pH}$ & $\%$ & 7.4 & 7.2 \\
Organic matter & $\%$ & 1.8 & 1.6 \\
Total CaCO 3 & $\%$ & 0.1 & 0.4 \\
Total N & $\mathrm{mg} \mathrm{kg}^{-1}$ & 11.4 & 0.1 \\
Available P & $\mathrm{mg} \mathrm{kg}^{-1}$ & 488.0 & 40.1 \\
Exchangeable K & $\mathrm{mg} \mathrm{kg}^{-1}$ & 8.2 & 4.16 \\
Available S & & &
\end{tabular}

A split-split plot design with three replications was used: nitrogen fertilization levels was the main treatment, sulfur soil and foliar fertilization were the sub-treatments and varieties were the sub-sub-treatment. $\mathrm{N}$-fertilization was arranged in five main plots while soil sulfur rates in two subplots in each main plot, as well as foliar sulfur rates and the three varieties were arranged in three sub-subplots in each subplot.

At the end of summer, the experimental field was ploughed at $30 \mathrm{~cm}$ depth and then divided into plots and subplots with three replicates for a total of 180 sub-subplots. The area of each sub-subplot was $180 \mathrm{~m}^{2}$. Plots were sown on 20 January 2010 and 23 December 2011 at a seeding rate of 350 viable seeds $\mathrm{m}^{-2}$. Three durum wheat varieties (Dylan, Iride and Saragolla) were chosen as representative of the cultivation area. They are widely adapted to different Mediterranean environments and characterized by high and constant productivity and good grain quality. Iride and Saragolla are early maturing and medium size varieties, while Dylan is medium-late maturing having a medium-taller size. All of them 
are relatively new varieties, released and registered in the Italian register of varieties since 1996 (Iride), 2004 (Saragolla) and 2002 (Dylan). The preceding crop was tomato (Solanum lycopersicum L.) in the first season and melon (Cucumis melo L.) in the second season.

Different nitrogen fertilizers (organic and mineral) and rates were applied: for organic fertilization 160 and $200 \mathrm{~kg} \mathrm{ha}^{-1}$ of $\mathrm{N}$ (hereafter referred to as NO160 and NO200, respectively) and for the mineral fertilization 120, 160 and $200 \mathrm{~kg} \mathrm{ha}^{-1}$ of $\mathrm{N}$ (hereafter referred to as NM120, NM160 and NM200, respectively). All NM plots received $92 \mathrm{~kg} \mathrm{ha}^{-1}$ of $\mathrm{P}_{2} \mathrm{O}_{5}$ before sowing as diammonium phosphate. Nitrogen doses were determined by considering the minimum crop requirement of $3 \mathrm{~kg}$ of $\mathrm{N}$ per $100 \mathrm{~kg}$ of grain produced [43] and the more common yields recorded for the above mentioned cultivars in that environment $\left(4-6 \mathrm{tha}^{-1}\right)$. In addition, subplots were treated with four combinations of sulfur fertilization: nil (hereafter referred to as SS0 or FS0), granular soil-sulfur fertilization (70 $\mathrm{kg} \mathrm{ha}^{-1}$ of elemental S, hereafter referred to as SS70), foliar fertilization (5 kg ha ${ }^{-1}$ of S, hereafter referred to as FS5) and soil and foliar fertilization. Foliar S fertilization was applied at flag leaf emergence stage and soil $\mathrm{S}$ fertilization before sowing, as well as organic nitrogen fertilizer. This latter was a pelletized organic NP fertilizer $\left(6 \% \mathrm{~N} ; 3 \% \mathrm{P}_{2} \mathrm{O}_{5} ; 30 \% \mathrm{C}\right)$ derived from the fermentation of organic materials such as feather meal, bone meal, manure, etc. Nitrogen mineral fertilization was split as follows: (i) $36 \mathrm{~kg} \mathrm{ha}^{-1}$ as diammonium phosphate for all rates at sowing; and (ii) 42-42, 62-62 and $82-82 \mathrm{~kg} \mathrm{ha}^{-1}$ in the form of ammonium nitrate at early tillering stage and flag leaf emergence for NM120, NM160 and NM200, respectively. Weeds and diseases were chemically controlled.

\subsection{Sampling and Measurements}

Grain yield was determined at $13 \%$ moisture content, harvesting $15 \mathrm{~m}^{2}$ sampling areas. At the same time, one square meter of plants was cut and then processed to obtain the following grain yield components: number of spikes, number of kernels per spike, and mean kernel weight. From each main sample, a sub-sample of grains was taken for the following measurements: test weight, vitreousness, thousand kernels weight, protein content, sodium dodecyl sulfate (SDS) sedimentation test and yellow index. Grain test weight was measured by the Schopper chondrometer. To determine protein content and yellow index and perform the SDS sedimentation test, samples were ground and analyzed using a Foss NIR System 6500 monochromator (Foss NIR Systems Inc., Silver Spring, Laurel, MD, USA), equipped with a sample transport module and a small ring cup. Prior to taking the measurements, the instrument was validated according to the diagnostic procedure of Win ISI II (InfraSoft International, LLC., Port Mathilda, PA, USA) software. The calibration equation developed at the Società Produttori Sementi Spa (Bologna, Italy) in accordance with the NIR guidelines for prediction model development [44] was used in this study. The range of wavelength used for analyses was set from 400 to $2500 \mathrm{~nm}$ and recorded at 2-nm intervals as $\log (1 / \mathrm{R})$, where $\mathrm{R}$ represents decimal fraction transmittance [45]. Each sample was analyzed twice.

\subsection{Data Analysis}

All data were processed using R statistic software (R Development Core Team, 2006). Statistically significant differences among means were detected by the least significant difference test [46] after analysis of variance (ANOVA). The main effect of Year, $\mathrm{N}$ rate, $\mathrm{S}$ application and variety and their interactions were tested. Means were separated at 95\% probability level. Each set of data was checked for normality and appropriate transformations were used, when necessary, prior to the ANOVA to improve normality [47].

\section{Results}

\subsection{Yield and Yield Components}

The analysis of variance for yield, protein content, test weight, SDS test, yellow index, vitrousness, and yield components are presented in Table 2. Treatments differently affected the measured traits. 
Fourth and fifth order interaction was never significant. Third order interactions were significant only for $\mathrm{V} \times \mathrm{N} \times \mathrm{Y}$.

For the same nitrogen treatment, grain yield was significantly lower in 2012 as compared to 2011 in all tested cultivars (Table 3). This may be largely attributed to the dramatic reduction of rainfall amount in 2012 which had a negative effect on the number of kernels per spike and mean kernel weight. A decrease in the number of kernels per spike were detected for Dylan in NO160 $(-37 \%)$, Iride in both NO160 and NO200 ( $-36 \%$ and $-40 \%$, respectively) and Saragolla in NO200 treatment $(-47 \%)$. On the contrary, the mean kernel weight showed a lower variation in the NO treatments (5-10\%) than in the NM ones (18-20\% in NM200) for all cultivars. Considering these results and the number of spikes per unit area, more yield decreases were registered for Iride in NM120 and NO200 plots $(-52.6 \%$ and $-52.5 \%$, respectively) and for Saragolla in NM160 plots ( $-53.4 \%)$. In contrast, the lower differences in grain yield between 2011 and 2012 were found for Dylan in both NM160 and NO160 plots $(-29.8 \%)$. Iride showed a high yield stability throughout the NM rates in the most favorable year (2011) and, in the same year, was the top performing cultivar in NO treatments. However, when limiting weather conditions occurred (2012), Dylan had a grain yield significantly higher than that of Iride and Saragolla, both in NO160 ( $+21 \%$ and $+19 \%$, respectively) and NO200 ( $+23 \%$ and $+19 \%$, respectively). In general, at the same $\mathrm{N}$ rate, yield responses were dramatically higher for mineral than organic $\mathrm{N}$ because of a significantly higher number of both spikes per unit area and kernels per spike. Cultivars differently responded to the increase of $\mathrm{N}$ rate, both for mineral and organic form. Particularly, 2011 grain yield significantly increased in Dylan by 11\% from NM160 to NM200, while it did not change significantly between NO rates. By contrast, grain yield did not significantly vary in Iride through NM rates but it increased significantly from NO160 to NO200 (+11\%). Finally, Saragolla showed the best yield performance at $160 \mathrm{~kg} \mathrm{ha}^{-1}$ of $\mathrm{N}$, both mineral and organic form, since no significant increases were detected at the higher rate. NM160 was also the best solution in 2012 with the exception of Saragolla which yielded significantly higher with NM200 ( $+25 \%)$.

Regarding the effect of S fertilization, $\mathrm{SS} \times \mathrm{N}$ interaction significantly affected grain yield, highlighting a positive effect of $S$ soil application in both organic nitrogen fertilization rates, while no significant effect was detected for mineral nitrogen (Table 4). This was due to a significant increase in both the number of spike per unit area and the number of kernels per spike (this latter significant only for NO160).

$\mathrm{S}$ foliar treatment had no significant effect on yield (Table 5), as it increased the number of kernels per spike $(+3.4 \%)$ but decreased the mean kernel weight $(-2.4 \%)$.

\subsection{Quality Traits}

As expected from such an assorted collection of cultivars and fertilization treatments, quality characteristics of grain varied considerably.

As for yield, $\mathrm{V} \times \mathrm{N} \times \mathrm{Y}$ interaction was significant for all quality traits.

For the same nitrogen treatment, test weight significantly decreased in 2012 in all tested cultivars (Table 6). This was due to kernel shriveling caused by the severe drought and heat stress which occurred in the second year during grain filling. NM200 treatment resulted in the highest test weight decrease between the two years for all cultivars (from 14.3\% of Dylan to $18.2 \%$ of Saragolla). On the contrary, organic fertilization showed the lowest differences in the test weight values between the two years (from $4.3 \%$ of Dylan in NO200 to $8.7 \%$ of Iride in NO160). Moreover, Dylan was the only cultivar which accomplished market request for test weight in 2012, overcoming $80 \mathrm{~kg} \mathrm{hL}^{-1}$ in NO treatments. Soil sulfur fertilization had no significant effect on the test weight (data not shown), whereas foliar $\mathrm{S}$ application slightly increased this trait from 79.9 to $81 \mathrm{~kg} \mathrm{hL}^{-1}$ (Table 5). 


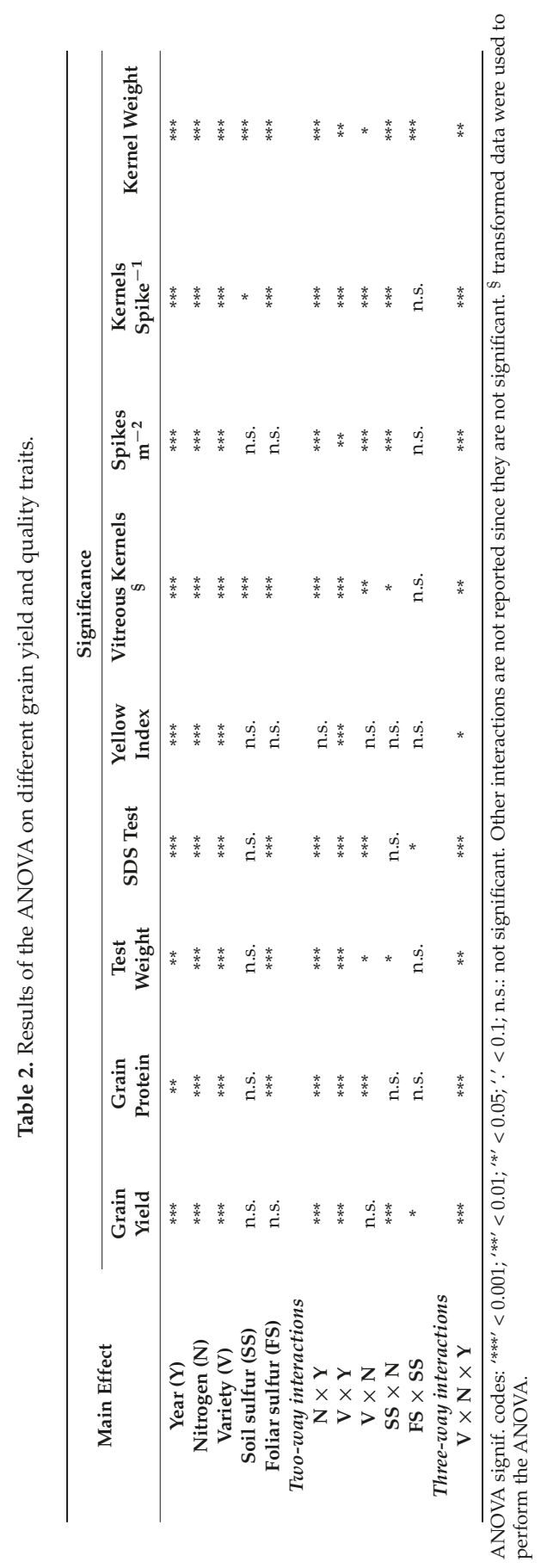




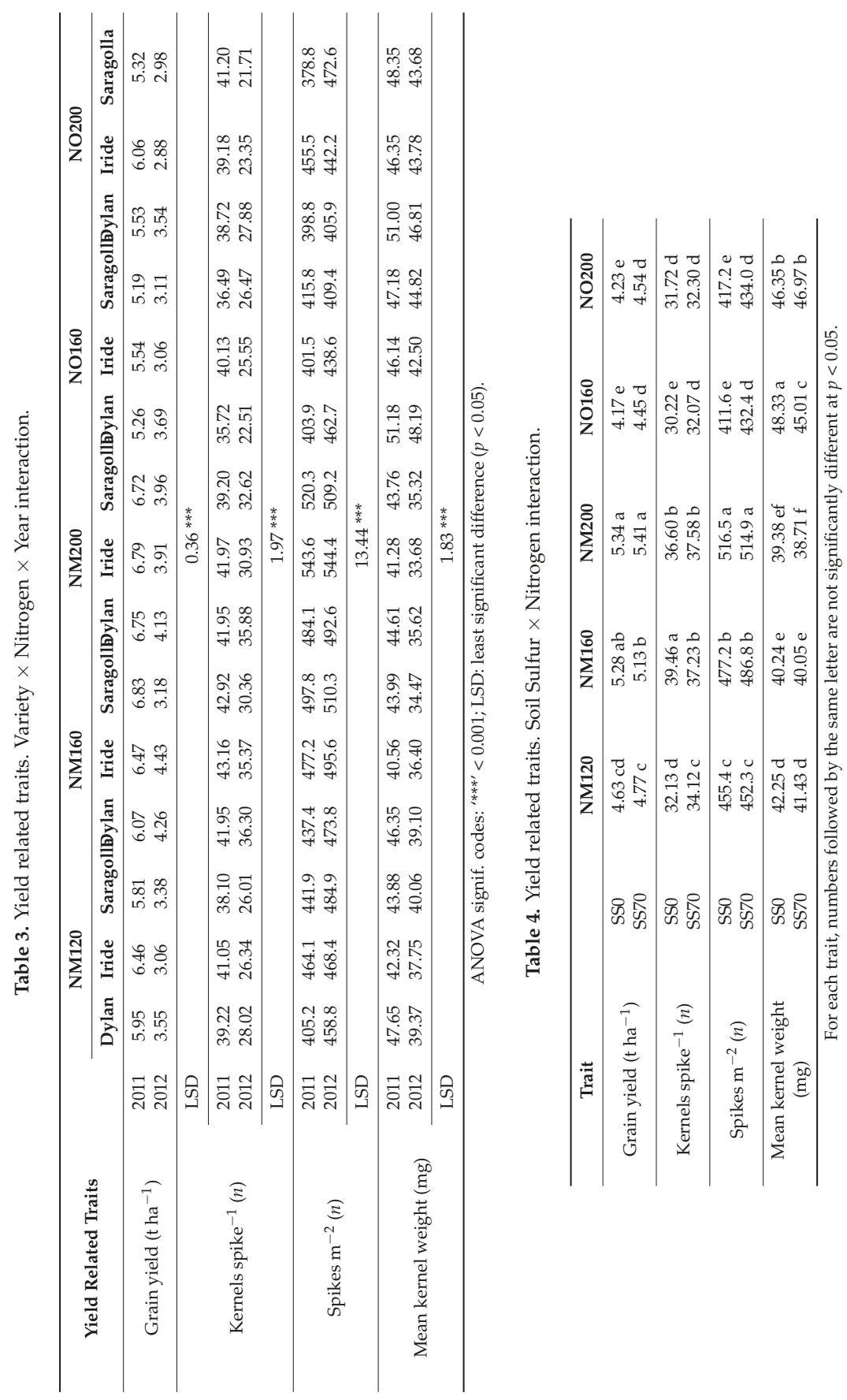




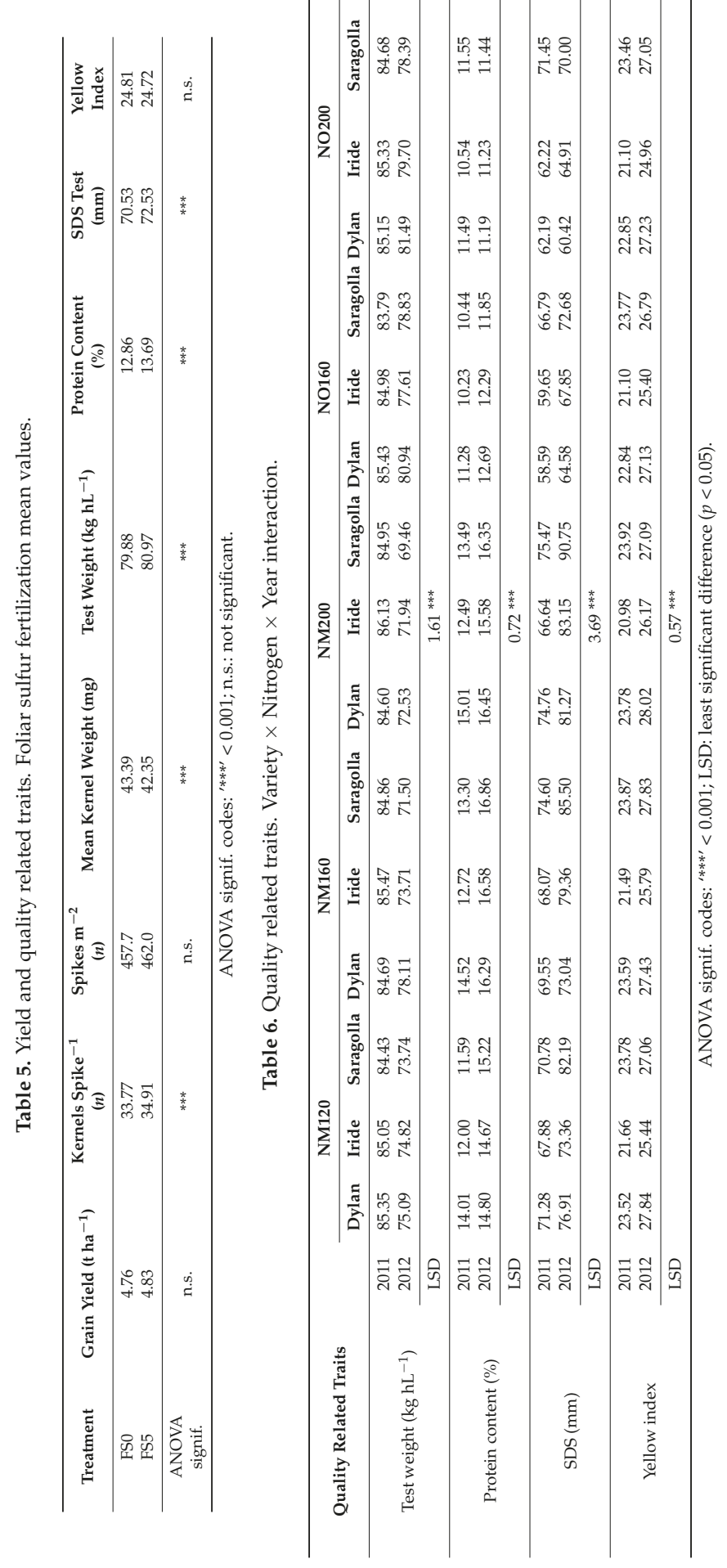


Grain protein content was significantly higher in 2012 than 2011 for all cultivars and N treatments with the exception of NO200, in which it remained substantially unchanged (Table 6). This increase between the two years was due to the fact that in 2012 grains were shriveled, with low starch accumulation, resulting in higher protein concentration [4]. Dylan showed a protein content significantly higher than Iride and Saragolla for each $\mathrm{N}$ fertilization treatment in 2011 with the exception of NO200. Even with lower rates, mineral nitrogen fertilization always showed a significantly higher protein content with respect to NO treatments, with the exception of NM120, where the protein content was similar to that of NO200 for Saragolla in 2011.

Even though grain protein content was not affected when sulfur was applied to the soil (data not shown), foliar S fertilization had a positive effect, increasing this trait significantly from $12.9 \%$ to $13.7 \%$ (Table 5).

As for grain protein content, the sedimentation values (SDS test) increased markedly in 2012 over 2011, with the exception of NO200 treatments (Table 6). Generally, mineral fertilization showed higher values than $\mathrm{NO}$ and the best performing cultivar for this trait was Saragolla in both years.

Similar to grain protein concentration, $S$ fertilization applied to the soil had no effect on the sedimentation values (data not shown), while foliar application significantly increased this trait, especially when coupled with soil application (Figure 2).

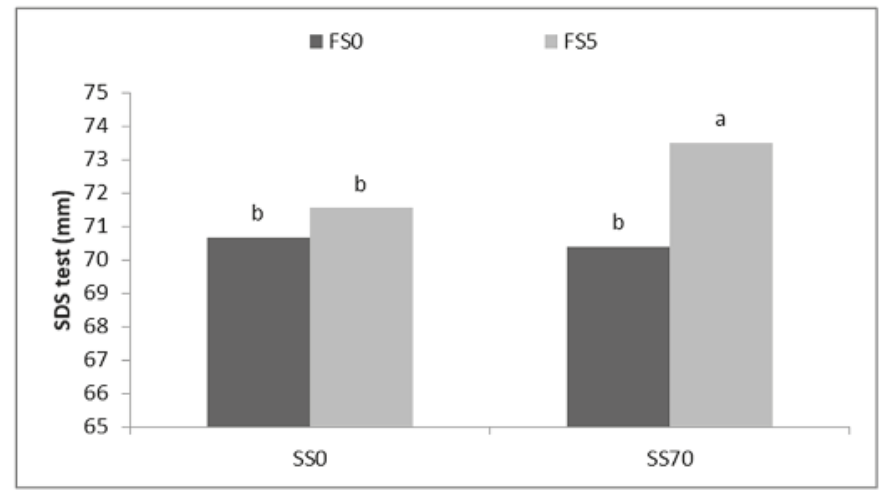

Figure 2. SDS sedimentation test. Foliar and soil sulfur interaction. Bars sharing the same letter are not significantly different $(p<0.05)$.

Values for the yellow index from 2012 were significantly higher than those from 2011 for all cultivars and $\mathrm{N}$ treatments (Table 6). In general, Dylan and Saragolla showed similar results for each $\mathrm{N}$ treatment while Iride always highlighted a significantly lower yellow index. Moreover, the increase of $\mathrm{N}$ rate had a significant effect on this trait just in two circumstances (from NM120 to NM200 for Iride and from NM120 to NM160 for Saragolla, both in 2012).

Sulfur fertilization had no effect on this trait.

Similar to the other quality traits, vitrousness was also affected by $\mathrm{N} \times \mathrm{V} \times \mathrm{Y}$ interaction, showing significantly higher values in 2012 than 2011 for all cultivars and N treatments (Figure 3). Compared to the other cultivars, Dylan showed a significantly higher percentage of vitrous kernels in 2011 NM treatments, while it performed similar to Iride and Saragolla in 2011 NO200 fertilization and in all $2012 \mathrm{~N}$ treatments. Mineral nitrogen fertilization always caused a significantly higher percentage of vitrous kernels than NO treatments, with the exception of NM120 compared with NO 200 for Saragolla in 2011.

Consistent with the result on grain protein concentration, vitrousness of kernels increased with foliar sulfur application from $80.8 \%$ to $83.5 \%$ (data not shown). 


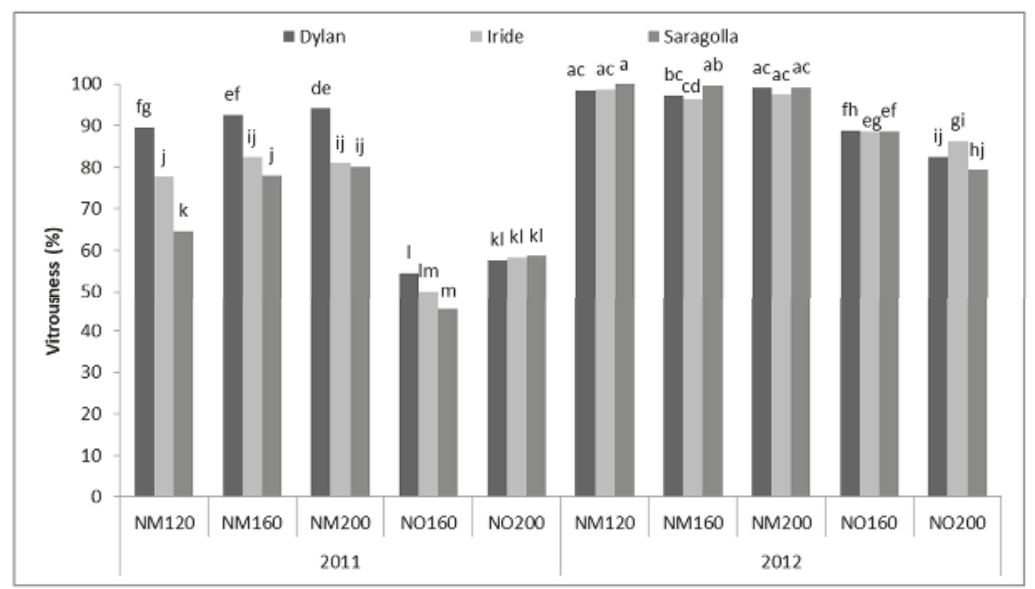

Figure 3. Grain vitrousness. Nitrogen $\times$ variety $\times$ year interaction. Bars sharing the same letter are not significantly different $(p<0.05)$.

\section{Discussion}

Results of this study demonstrate that fertilization type and rate have a strong influence on durum wheat yield, yield components and quality characteristics of grain. However, as also found by other authors [6,11,17], crop growth, yield and quality traits are mainly a function of environmental conditions. In fact, significant second and third order interactions were found which confirm the year on year variations for durum wheat production. This variability may be due to changes in the rainfall amount and distribution throughout the growing seasons [48].

Overall, organic fertilization was a determining factor in the observed reduction of grain yield and quality. As other studies confirm, mineral $\mathrm{N}$ fertilization gives better results as compared to organic fertilization, either in terms of yield and protein content $[49,50]$. These studies reported that winter wheat receiving organic fertilization had yields up to $19 \%$ lower than that fertilized with mineral $\mathrm{N}$, on average. In our study, considering only the $\mathrm{N}$ effects and the same $\mathrm{N}$ rate, mineral nitrogen fertilization gained significantly higher grain yield than NO, ranging from $+21 \%$ to $+23 \%$.

Similarly, protein content and SDS test values were higher for mineral fertilization as compared to the organic one, and they increased with the increase of nitrogen rate. These results are consistent with those by other authors and corroborate the issue of $\mathrm{N}$ availability in the case of organic fertilization, which is limited during the crop reproductive phases and always lower when compared to mineral nitrogen $[12,50]$. Systems that are based on organic fertilization usually have very different seasonal $\mathrm{N}$ cycle and availability than those that use mineral fertilizers. Thus, reliance on organic $\mathrm{N}$ sources requires an understanding of organic $\mathrm{N}$ mineralization-immobilization and turnover patterns in relation to crop $\mathrm{N}$ demands and $\mathrm{N}$ loss pathways. Besides the dependence of mineralization on pedoclimatic conditions [51], it usually takes many years to mineralize past organic fertilizer and support crops with appropriate $\mathrm{N}$ availability [52]. Moreover, even if a balance is reached, winter crops generally suffer significant yield reduction due to slow mineralization during their growth cycle. Even though commercial organic fertilizer, such as that used in this study, contains this reduction due to its low $\mathrm{C} / \mathrm{N}$ ratio and higher nutrient availability, the yield gap was found to be significant even after six years [53]. However, a long-term study would better clarify if a multi-year application of an organic fertilizer may reduce this yield gap, thanks to the positive effects that organic matter has on physical, chemical and biological properties of the soil.

In this study, yield gain for NM fertilization treatments was at $14.5 \%$ between 120 and $200 \mathrm{~kg} \mathrm{ha}^{-1}$ while it was just at $3 \%$ from 160 to $200 \mathrm{~kg} \mathrm{ha}^{-1}$. On the contrary, no significant increase was detected 
with the increase of NO rate (from 160 to $200 \mathrm{~kg} \mathrm{ha}^{-1}$ ). Ercoli et al. (2011) [15] found an increase of 20\% (from 120 to $180 \mathrm{~kg} \mathrm{ha}^{-1}$ of NM) in similar climatic conditions. Other authors in Spain reported no grain yield response to NM rates of up to $100 \mathrm{~kg} \mathrm{ha}^{-1}[11,54,55]$. Such a large difference is probably because wheat yield is influenced by $\mathrm{N}$ rate only when the amount of rainfall exceeds $450 \mathrm{~mm}$ during the growing season, as reported by Lopez-Bellido et al. (1996) [48] in a long-term experiment. In fact, in the wetter year (2011), we obtained significantly different yields at each N rates (both NM and NO), whereas in the drier year (2012), NM160 and NM200 yields were similar. In 2012, only the NM120 yield was significantly lower, supporting the finding that the crop fertilized with $120 \mathrm{~kg} \mathrm{ha}^{-1}$ of N, often has sub-optimal yield performance [15].

Concerning varieties, all the tested genotypes responded similarly to the year-on-year variations of climatic conditions, but were differently sensitive to $\mathrm{N}$ fertilization in each year. Particularly, all the three cultivars were markedly sensitive to water shortage which especially reduced the number of kernels per spike and the mean kernel weight. This behavior was also verified by Ercoli et al. (2011) [15] in medium and late-maturing varieties (Claudio and Creso, respectively), while in early or medium-early varieties they did not find any yield difference between wet and dry season. However, other authors also found short-cycle cultivars decreasing grain yield with the decrease of the rainfall amount in the Mediterranean environment $[11,56]$. The different behavior of cultivars in response to climatic fluctuations is of crucial importance for Mediterranean environments, because of the high year-to-year variability in rainfall and temperature pattern existing in the climate.

In our study, the yield performance of the cultivar Dylan in the drier year was unexpected. This medium-late variety was expected to yield poorly in the most limiting environmental conditions of the second year, while it performed similarly to early-maturing cultivars with NM treatments and even better with $\mathrm{NO}$ fertilization. This finding is consistent with the results from the Italian durum wheat network, which show that, in the last seven years (from 2011 to 2017) and in an environment comparable to that of this study, Dylan yielded similarly to Iride and/or Saragolla in five different seasons (2012, 2013, 2014, 2015, and 2017). Although Iride had the same yielding performance of Dylan, it did not have the same quality of grains, showing a significantly lower protein content, yellow index, test weight and grain vitrousness. Saragolla was the lowest yielding variety but that with the highest SDS value.

Concerning the effect of sulfur, it is known that elemental sulfur (ES) has to be oxidized to $\mathrm{SO}_{4}{ }^{2-}$ before it is available for plants and that the response to sulfur fertilization can be very variable in wheat. Sulfur uptake and metabolization depends on soil $\mathrm{N}$ and $\mathrm{S}$ balance, water supply, timing and rates of $\mathrm{N}$ and $\mathrm{S}$ application $[28,57,58]$. With regard to grain yield, we found that, for a given $\mathrm{N}$ rate, the $\mathrm{S}$ application to the soil had a synergistic effect with organic rather than mineral $\mathrm{N}$ fertilization. Yield gains obtained from S fertilization ranged between 280 and $310 \mathrm{~kg} \mathrm{ha}^{-1}(+7 \%)$ within a same NO rate and were caused by a higher number of both spikes per unit area and kernels per spike. Consistently with our findings, several studies reported a similar grain yield increase and suggested that $\mathrm{S}$ deficiency leads to a reduction of the number of spikelets or to an increase of floret mortality $[28,39,59,60]$. The synergistic effect of $\mathrm{S}$ with $\mathrm{NO}$ fertilization may be attributed to the higher rates of OM degradation achieved by the improved activity of the heterotrophic S-oxidizing microorganisms and the resulting release of other nutrients [61,62]. In fact, there is evidence which shows that organic amendments to the soil promote ES oxidation rates and that some specific rhizosphere (e.g., wheat and canola) may stimulate the proliferation of heterotrophic ES oxidizing microorganisms and arbuscular mycorrhyzal fungi [21,23,24,63-66]. Moreover, in a recent study, regression analysis showed that initial soil $\mathrm{pH}$ was the most important factor affecting ES oxidation, followed by OM content [67]. Specifically, in soils with $\mathrm{pH}$ above 6.65 and higher $\mathrm{S}$ and OM content, the ES oxidation rate was found to be significantly higher than that of the other soils. In our study, $\mathrm{pH}$ after fertilization treatments may have played an important role in the ES oxidation dynamic, considering that ammonium nitrate (used to fertilize the NM plots) has soil acidifying potential while organic fertilization often resulted in an increased soil $\mathrm{pH}$ [68]. 
Even though some authors found that $\mathrm{S}$ deficiency may have a significant effect on the synthesis and accumulation of proteins $[29,69]$, generally, the S nutrition of wheat has a marked effect on the composition of the seed storage protein, rather than the concentration of total proteins in seeds [28,70]. Although we did not find any effect of $\mathrm{S}$ application to the soil on grain protein concentration and SDS test $[15,71,72]$, it must be observed that foliar S application significantly increased both these traits. This effect could be due to a better assimilation of $\mathrm{N}$ and $\mathrm{S}$, as previously reported by Tea et al. (2007) [30]. In that same study, the authors demonstrated that $S$ applied by foliar spray was mainly assimilated in the grain and here it may favor $\mathrm{N}$ accumulation. Furthermore, many studies, as reviewed by Zhao et al. (1999) [28], demonstrated that the higher $S$ accumulation in grain determines an increase in disulfide groups (polymeric glutenins), which are related to a higher gluten strength that means a higher SDS sedimentation value. Our results are consistent with those by Ercoli et al. (2011) [15], who showed that SDS sedimentation values and alveograph W were the quality indices highlighting the highest correlation with $S$ concentration. The same authors argued that a high $\mathrm{S}$ concentration in grain is a key factor in obtaining a high quality pasta.

\section{Conclusions}

Our results evidenced the clear advantage of the mineral nitrogen fertilization when compared with the organic one in a relatively short time frame (two-year study). Nevertheless, for those cropping systems that base soil fertility on organic sources, soil $\mathrm{S}$ fertilization may be a winning strategy to improve grain yield in the Mediterranean environment. Even though future long-term studies should be conducted under strict organic conditions, also involving organic weed and disease control, results from our study may help to contain the large yield gap that farmers usually experience during the transition from a conventional system to an organic one or when they aim to improve the environmental sustainability of conventional farming systems. In general, we did not find any effect of soil $\mathrm{S}$ fertilization on the quality indices of durum wheat, whereas foliar $\mathrm{S}$ application proved to be a key factor in determining higher protein content and SDS value. Further studies are needed to verify if this finding results in improved rheological characteristics of grain. Concerning varieties, Iride and Dylan yielded similarly under both mineral and organic fertilization but Dylan had higher quality indices. However, all tested genotypes responded similarly to the year-on-year climatic fluctuations, which remain the most limiting factors for yield and quality performance of durum wheat in the Mediterranean region. Finally, from our results, a rate of $160 \mathrm{~kg} \mathrm{ha}^{-1}$ of $\mathrm{N}$ (both mineral and organic) determined the optimal response in terms of both grain yield and quality.

Author Contributions: Conceptualization and supervision, F.R.; Data Curation, M.E.P., R.R. and F.S.; Writing-Original Draft Preparation and Review \& Editing, R.R.

funding: This research was funded by the Regione Lazio [PSR 2007-2013; PIF RL 011; misura 124].

Acknowledgments: The authors gratefully acknowledge PANTANO cooperative (Tarquinia, Italy) for the collaboration during the project and Società Produttori Sementi Spa (Bologna, Italy) for NIR analysis.

Conflicts of Interest: The authors declare no conflict of interest. The funders had no role in the design of the study, in the collection, analyses, or interpretation of data, in the writing of the manuscript, and in the decision to publish the results.

\section{References}

1. Europoean Commission: Agriculture and Rural Development EU Crops Market Observatory-Cereals. Available online: https://ec.europa.eu/agriculture/market-observatory/crops/cereals/statistics_en (accessed on 20 Jul 2018).

2. Ceoloni, C.; Kuzmanović, L.; Ruggeri, R.; Rossini, F.; Forte, P.; Cuccurullo, A.; Bitti, A. Harnessing genetic diversity of wild gene pools to enhance wheat crop production and sustainability: Challenges and opportunities. Diversity 2017, 9, 55. [CrossRef] 
3. Camerlengo, F.; Sestili, F.; Silvestri, M.; Colaprico, G.; Margiotta, B.; Ruggeri, R.; Lupi, R.; Masci, S.; Lafiandra, D. Production and molecular characterization of bread wheat lines with reduced amount of $\alpha$-type gliadins. BMC Plant Biol. 2017, 17, 1-11. [CrossRef] [PubMed]

4. Troccoli, A.; Borrelli, G.M.; De Vita, P.; Fares, C.; Di Fonzo, N. Durum wheat quality: A multidisciplinary concept. J. Cereal Sci. 2000, 32, 99-113. [CrossRef]

5. Dexter, J.E.; Marchylo, B.A. Recent Trends in Durum Wheat Milling and Pasta Processing: Impact on Durum Wheat Quality Requirements. In Proceedings International Workshop on Durum Wheat, Semolina and Pasta Quality: Recent Achievements and New Trends; Abecassis, J., Autran, J., Feillet, P., Eds.; INRA: Montpellier, Franch, 2000; pp. 139-164.

6. Campbell, C.A.; Davidson, H.R.; Winkleman, G.E. Effect of Nitrogen, Temperature, Growth Stage and Duration of Moisture Stress on Yield Components and Protein Content of Manitou Spring Wheat. Can. J. Plant Sci. 1981, 61, 549-563. [CrossRef]

7. Rao, A.C.S.; Smith, J.L.; Jandhyala, V.K.; Papendick, R.I.; Parr, J.F. Cultivar and Climatic Effects on the Protein Content of Soft White Winter Wheat. Agron. J. 1993, 85, 1023-1028. [CrossRef]

8. Uhlen, A.K.; Hafskjold, R.; Kalhovd, A.-H.; Sahlström, S.; Longva, Å.; Magnus, E.M. Effects of Cultivar and Temperature During Grain Filling on Wheat Protein Content, Composition, and Dough Mixing Properties. Cereal Chem. J. 1998, 75, 460-465. [CrossRef]

9. Rharrabti, Y.; Villegas, D.; Del Moral, L.F.G.; Aparicio, N.; Elhani, S.; Royo, C. Environmental and genetic determination of protein content and grain yield in durum wheat under Mediterranean conditions. Plant Breed. 2001, 120, 381-388. [CrossRef]

10. Ficco, D.B.M.; Mastrangelo, A.M.; Trono, D.; Borrelli, G.M.; De Vita, P.; Fares, C.; Beleggia, R.; Platani, C.; Papa, R. The colours of durum wheat: A review. Crop Pasture Sci. 2014, 65, 1-15. [CrossRef]

11. Garrido-Lestache, E.; López-Bellido, R.J.; López-Bellido, L. Durum wheat quality under Mediterranean conditions as affected by $\mathrm{N}$ rate, timing and splitting, $\mathrm{N}$ form and $\mathrm{S}$ fertilization. Eur. J. Agron. 2005, 23, 265-278. [CrossRef]

12. Fagnano, M.; Fiorentino, N.; D’Egidio, M.G.; Quaranta, F.; Ritieni, A.; Ferracane, R.; Raimondi, G. Durum Wheat in Conventional and Organic Farming: Yield Amount and Pasta Quality in Southern Italy. Sci. World J. 2012, 2012, 1-9. [CrossRef] [PubMed]

13. Dexter, J.E.; Matsuo, R.R.; Kosmolak, F.G.; Leisle, D.; Marchylo, B.A. The Suitability of the sds-sedimentation test for assessing gluten strenght in durum wheat. Can. J. Plant Sci. 1980, 60, 25-29. [CrossRef]

14. Carter, B.P.; Morris, C.F.; Anderson, J.A. Optimizing the SDS sedimentation test for end-use quality selection in a soft white and club wheat breeding program. Cereal Chem. 1999, 76, 907-911. [CrossRef]

15. Ercoli, L.; Lulli, L.; Arduini, I.; Mariotti, M.; Masoni, A. Durum wheat grain yield and quality as affected by $\mathrm{S}$ rate under Mediterranean conditions. Eur. J. Agron. 2011, 35, 63-70. [CrossRef]

16. Alcoz, M.M.; Hons, F.M.; Haby, V.A. Nitrogen Fertilization Timing Effect on Wheat Production, Nitrogen Uptake Efficiency, and Residual Soil Nitrogen. Agron. J. 1993, 85, 1198-1203. [CrossRef]

17. Barraclough, P.B.; Howarth, J.R.; Jones, J.; Lopez-Bellido, R.; Parmar, S.; Shepherd, C.E.; Hawkesford, M.J. Nitrogen efficiency of wheat: Genotypic and environmental variation and prospects for improvement. Eur. J. Agron. 2010, 33, 1-11. [CrossRef]

18. Mäder, P.; Hahn, D.; Dubois, D.; Gunst, L.; Alföldi, T.; Bergmann, H.; Oehme, M.; Amadò, R.; Schneider, H.; Graf, U.; et al. Wheat quality in organic and conventional farming: Results of a 21 year field experiment. J. Sci. Food Agric. 2007, 87, 1826-1835. [CrossRef]

19. Bilsborrow, P.; Cooper, J.; Tétard-Jones, C.; Średnicka-Tober, D.; Barański, M.; Eyre, M.; Schmidt, C.; Shotton, P.; Volakakis, N.; Cakmak, I.; et al. The effect of organic and conventional management on the yield and quality of wheat grown in a long-term field trial. Eur. J. Agron. 2013, 51, 71-80. [CrossRef]

20. Mayer, J.; Gunst, L.; Mäder, P.; Samson, M.-F.; Carcea, M.; Narducci, V.; Thomsen, I.K.; Dubois, D. Productivity, quality and sustainability of winter wheat under long-term conventional and organic management in Switzerland. Eur. J. Agron. 2015, 65, 27-39. [CrossRef]

21. Dai, M.; Hamel, C.; Bainard, L.D.; Arnaud, M.St.; Grant, C.A.; Lupwayi, N.Z.; Malhi, S.S.; Lemke, R. Negative and positive contributions of arbuscular mycorrhizal fungal taxa to wheat production and nutrient uptake efficiency in organic and conventional systems in the Canadian prairie. Soil Biol. Biochem. 2014, 74, 156-166. [CrossRef] 
22. Kirchman, D.L. Degradation of organic material. In Processes in Microbial Ecology; Oxford University Press: New York, NY, USA, 2012.

23. Graystone, S.; Germida, J. Influence of crop rhizospheres on populations and activity of heterotrophic sulfur-oxidizing microorganisms. Soil Biol. Biochem. 1990, 22, 457-463. [CrossRef]

24. Germida, J.J.; Janzen, H.H. Factors affecting the oxidation of elemental sulfur in soils. Fertil. Res. 1993, 35, 101-114. [CrossRef]

25. Scherer, H.W. Sulphur in crop production-Invited paper. Eur. J. Agron. 2001, 14, 81-111. [CrossRef]

26. Legris-Delaporte, S.; Ferron, F.; Landry, J.; Costes, C. Metabolization of elemental sulfur in wheat leaves consecutive to its foliar application. Plant Physiol. 1987, 85, 1026-1030. [CrossRef] [PubMed]

27. Tea, I.; Genter, T.; Naulet, N.; Morvan, E.; Kleiber, D. Isotopic study of post-anthesis foliar incorporation of sulphur and nitrogen in wheat. Isot. Environ. Health Stud. 2003, 39, 289-300. [CrossRef] [PubMed]

28. Zhao, F.J.; Hawkesford, M.; McGrath, S. Sulphur assimilation and effects on yield and quality of wheat. J. Cereal Sci. 1999, 30,1-17. [CrossRef]

29. Tea, I.; Genter, T.; Naulet, N. Effect of foliar sulfur and nitrogen fertilization on wheat storage protein composition and dough mixing properties. Cereal 2004, 81, 759-766. [CrossRef]

30. Tea, I.; Genter, T.; Naulet, N.; Lummerzheim, M.; Kleiber, D. Interaction between nitrogen and sulfur by foliar application and its effects on flour bread-making quality. J. Sci. Food Agric. 2007, 87, 2853-2859. [CrossRef]

31. Blake-Kalff, M.M.A.; Hawkesford, M.J.; Zhao, F.J.; McGrath, S.P. Diagnosing sulfur deficiency in field-grown oilseed rape (Brassica napus L.) and wheat (Triticum aestivum L.). Plant Soil 2000, 225, 95-107. [CrossRef]

32. Zhao, F.J.; Wood, A.P.; McGrath, S.P. Effects of sulphur nutrition on growth and nitrogen fixation of pea (Pisum sativum L.). Plant Soil 1999, 212, 207-217. [CrossRef]

33. Zhao, F.; Evans, E.J.; Bilsborrow, P.E.; Syers, J.K. Influence of sulphur and nitrogen on seed yield and quality of low glucosinolate oilseed rape (Brassica napus L.). J. Sci. Food Agric. 1993, 63, 29-37. [CrossRef]

34. Chan, K.X.; Wirtz, M.; Phua, S.Y.; Estavillo, G.M.; Pogson, B.J. Balancing metabolites in drought: The sulfur assimilation conundrum. Trends Plant Sci. 2013, 18, 18-29. [CrossRef] [PubMed]

35. Nazar, R.; Iqbal, N.; Masood, A.; Syeed, S.; Khan, N.A. Understanding the significance of sulfur in improving salinity tolerance in plants. Environ. Exp. Bot. 2011, 70, 80-87. [CrossRef]

36. Rausch, T.; Wachter, A. Sulfur metabolism: A versatile platform for launching defence operations. Trends Plant Sci. 2005, 10, 503-509. [CrossRef] [PubMed]

37. Luo, C.; Branlard, G.; Griffin, W.B.; McNeil, D.L. The effect of nitrogen and sulphur fertilisation and their interaction with genotype on wheat glutenins and quality parameters. J. Cereal Sci. 2000, 31, 185-194. [CrossRef]

38. Moss, H.; Wrigley, C.; MacRichie, R.; Randall, P. Sulfur and nitrogen fertilizer effects on wheat. II. Influence on grain quality. Aust. J. Agric. Res. 1981, 32, 213. [CrossRef]

39. Ramig, R.; Rasmussen, P.; Allmaras, R.; Smith, C. Nitrogen-Sulfur Relations in Soft White Winter Wheat. I. Yield Response to Fertilizer and Residual Sulfur. Agron. J. 1975, 67, 219-224. [CrossRef]

40. Salvagiotti, F.; Miralles, D.J. Wheat development as affected by nitrogen and sulfur nutrition. Aust. J. Agric. Res. 2007, 58, 39-45. [CrossRef]

41. Lerner, S.E.; Seghezzo, M.L.; Molfese, E.R.; Ponzio, N.R.; Cogliatti, M.; Rogers, W.J. N- and S-fertiliser effects on grain composition, industrial quality and end-use in durum wheat. J. Cereal Sci. 2006, 44, 2-11. [CrossRef]

42. Pompa, M.; Giuliani, M.M.; Giuzio, L.; Gagliardi, A.; di Fonzo, N.; Flagella, Z. Effect of sulphur fertilization on grain quality and protein composition of durum wheat (Triticum durum Desf.). Ital. J. Agron. 2009, 4, 159-170. [CrossRef]

43. Borghi, B. Nitrogen as determinant of wheat growth and yield. In Wheat: Ecology and Physiology of Yield Determination; Satorre, E.H., Slafer, G.A., Eds.; Haworth Press Inc.: Binghmanton, NY, USA, 1999; pp. 67-84. ISBN 1-56022-874-1.

44. AACC (American Association of Cereal Chemists) AACC Method 39-00 1999. Available online: http: //methods.aaccnet.org/summaries/39-00-01.aspx (accessed on 20 June 2018).

45. Botticella, E.; Sestili, F.; Ferrazzano, G.; Mantovani, P.; Cammerata, A.; D’Egidio, M.G.; Lafiandra, D. The impact of the SSIIa null mutations on grain traits and composition in durum wheat. Breed. Sci. 2016, 66, 572-579. [CrossRef] [PubMed]

46. Steel, R.; Torrie, J.; Dickey, D. Principles and Procedures of Statistics: A Biometrical Approach; McGraw-Hill: New York, NY, USA, 1997. 
47. Smith, J.E.K. Data transformations in analysis of variance. J. Verbal Learn. Verbal Behav. 1976, 15, 339-346. [CrossRef]

48. López-Bellido, L.; Fuentes, M.; Castillo, J.; López-Garrido, F.; Fernández, E. Long-Term Tillage, Crop Rotation, and Nitrogen Fertilizer Effects on Wheat Yield under Rainfed Mediterranean Conditions. Agron. J. 1996, 88, 783-791. [CrossRef]

49. Černý, J.; Balík, J.; Kulhánek, M.; Časová, K.; Nedvěd, V. Mineral and organic fertilization efficiency in long-term stationary experiments. Plant Soil Environ. 2010, 56, 28-36. [CrossRef]

50. Tosti, G.; Farneselli, M.; Benincasa, P.; Guiducci, M. Nitrogen fertilization strategies for organic wheat production: Crop yield and nitrate leaching. Agron. J. 2016, 108, 770-781. [CrossRef]

51. Dawson, J.C.; Huggins, D.R.; Jones, S.S. Characterizing nitrogen use efficiency in natural and agricultural ecosystems to improve the performance of cereal crops in low-input and organic agricultural systems. Field Crops Res. 2008, 107, 89-101. [CrossRef]

52. Drinkwater, L.E.; Letourneau, D.K.; Workneh, F.; van Bruggen, A.H.C.; Shennan, C. Fundamental Differences Between Conventional and Organic Tomato Agroecosystems in California. Ecol. Appl. 1995, 5, 1098-1112. [CrossRef]

53. Sacco, D.; Moretti, B.; Monaco, S.; Grignani, C. Six-year transition from conventional to organic farming: Effects on crop production and soil quality. Eur. J. Agron. 2015, 69, 10-20. [CrossRef]

54. Garrido-Lestache, E.; López-Bellido, R.J.; López-Bellido, L. Effect of N rate, timing and splitting and N type on bread-making quality in hard red spring wheat under rainfed Mediterranean conditions. Field Crops Res. 2004, 85, 213-236. [CrossRef]

55. López-Bellido, L.; López-Bellido, R.; Castillo, J.; López-Bellido, F. Effects of Tillage, Crop Rotation, and Nitrogen Fertilization on Wheat under Rainfed Mediterranean Conditions. Agron. J. 2000, 92, 1054-1063. [CrossRef]

56. Flagella, Z.; Giuliani, M.M.; Giuzio, L.; Volpi, C.; Masci, S. Influence of water deficit on durum wheat storage protein composition and technological quality. Eur. J. Agron. 2010, 33, 197-207. [CrossRef]

57. Ercoli, L.; Arduini, I.; Mariotti, M.; Lulli, L.; Masoni, A. Management of sulphur fertiliser to improve durum wheat production and minimise S leaching. Eur. J. Agron. 2012, 38, 74-82. [CrossRef]

58. Rasmussen, P.; Ramig, R.; Allmaras, R.; Smith, C. Nitrogen-Sulfur Relations in Soft White Winter Wheat. II. Initial and Residual Effects of Sulfur Application on Nutrient Concentration, Uptake, and N/S Ratio. Agron. J. 1975, 67, 224-228. [CrossRef]

59. Withers, P.J.A.; Zhao, F.J.; McGrath, S.P.; Evans, E.J.; Sinclair, A.H. Sulphur inputs for optimum yields of cereals. In Aspects of Applied Biology 50, Optimising Cereal Inputs: Its Scientific Basis; Gooding, M., Shewry, P., Eds.; The Association of Applied Biologists: Wellesbourne, UK, 1997; pp. 191-198.

60. Archer, M. A sand culture experiment to compare the effects of sulphur on five wheat cultivars (T. aestivum L.). Aust. J. Agric. Res. 1974, 25, 369-380. [CrossRef]

61. Attia, K.; El-Dosuky, M. Effect of elemental sulfur and inoculation with Thiobacillus, organic manure and nitrogen fertilization on wheat. Assiut. J. Agric. Sci. 1996, 27, 191-206.

62. Badawy, F.; Ahmed, M.; El-Rewainy, H.; Ali, M. Response of wheat grown on sandy calcareous soils to organic manures and sulfur application. Egypt. J. Agric. Res. 2011, 89, 785-807.

63. Lawrence, J.; Germida, J. Relationship between microbial biomass and elemental sulfur oxidation in agricultural soils. Soil Sci. Soc. Am. J. 1988, 52, 672-677. [CrossRef]

64. Pepper, I.; Miller, R. Comparison of the oxidation of thiosulfate and elemental sulfur by two heterotrophic bacteria and Thiobacillus thiooxidans. Soil Sci. 1978, 126, 9-14. [CrossRef]

65. Skiba, U.; Wainwright, M. Oxidation of elemental-S in coastal-dune sands and soils. Plant Soil 1984, 77, 87-95. [CrossRef]

66. Janzen, H.; Bettany, J. Measurement of sulfur oxidation in soils. Soil Sci. 1987, 143, 444-452. [CrossRef]

67. Zhao, C.; Degryse, F.; Gupta, V.; McLaughlin, M.J. Elemental Sulfur Oxidation in Australian Cropping Soils. Soil Sci. Soc. Am. J. 2015, 79, 89-96. [CrossRef]

68. Clark, M.S.; Horwarth, W.R.; Shennan, C.; Scow, K.M. Changes in soil chemical properties resulting from organic and low-input farming practices. Agron. J. 1998, 90, 662-671. [CrossRef]

69. Castle, S.; Randall, P. Effects of Sulfur Deficiency on the Synthesis and Accumulation of Proteins in the Developing Wheat Seed. Funct. Plant Biol. 1987, 14, 503-516. [CrossRef] 
70. Klikocka, H.; Cybulska, M.; Barczak, B.; Narolski, B.; Szostak, B.; Kobiałka, A.; Nowak, A.; Wójcik, E. The effect of sulphur and nitrogen fertilization on grain yield and technological quality of spring wheat. Plant Soil Environ. 2016, 62, 230-236. [CrossRef]

71. Wieser, H.; Gutser, R.; Von Tucher, S. Influence of sulphur fertilisation on quantities and proportions of gluten protein types in wheat flour. J. Cereal Sci. 2004, 40, 239-244. [CrossRef]

72. Karamanos, R.; Harapiak, J.; Flore, N. Sulphur application does not improve wheat yield and protein concentration. Can. J. Soil Sci. 2013, 93, 223-228. [CrossRef]

(C) 2018 by the authors. Licensee MDPI, Basel, Switzerland. This article is an open access article distributed under the terms and conditions of the Creative Commons Attribution (CC BY) license (http:/ / creativecommons.org/licenses/by/4.0/). 
Article

\title{
Phosphorus and Potassium Fertilizer Application Strategies in Corn-Soybean Rotations
}

\author{
Timothy J. Boring ${ }^{1}$, Kurt D. Thelen ${ }^{2, *}$, James E. Board ${ }^{3}$, Jason L. De Bruin ${ }^{4}$, Chad D. Lee ${ }^{5}$, \\ Seth L. Naeve ${ }^{6}$, William J. Ross ${ }^{7}$, Wade A. Kent ${ }^{8}$ and Landon L. Ries ${ }^{9}$ \\ 1 Michigan Agri-Business Association, East Lansing, MI 48824, USA; boringti@msu.edu \\ 2 Plant, Soil, and Microbial Sciences, Michigan State University, East Lansing, MI 48824, USA \\ 3 Emiritus, Department of Plant, Environmental, and Soil Science, Louisiana State University, Baton Rouge, \\ LA 70803, USA; jboard@agcenter.lsu.edu \\ 4 DuPont Pioneer, Macomb, IL 61455, USA; jason.debruin@pioneer.com \\ 5 Department of Plant and Soil Sciences, University of Kentucky, Lexington, KY 40546, USA; cdlee2@uky.edu \\ 6 Department of Agronomy and Plant Genetics, University of Minnesota, St. Paul, MN 55108, USA; \\ naeve002@umn.edu \\ 7 Department of Crop, Soil, and Environmental Science, University of Arkansas, Little Rock, AR 72204, USA; \\ jross@uaex.edu \\ 8 Becks Hybrids, Urbandale, IA 55032, USA; wkent@beckshybrids.com \\ 9 DuPont Pioneer, Algona, IA 50511, USA; Landon.l.ries@gmail.com \\ * Correspondence: thelenk3@msu.edu; Tel.: +517-355-0271
}

Received: 3 August 2018; Accepted: 17 September 2018; Published: 19 September 2018

\begin{abstract}
To determine if current university fertilizer rate and timing recommendations pose a limitation to high-yield corn (Zea mays subsp. mays) and soybean (Glycine max) production, this study compared annual Phosphorous (P) and Potassium (K) fertilizer applications to biennial fertilizer applications, applied at $1 \times$ and $2 \times$ recommended rates in corn-soybean rotations located in Minnesota (MN), Iowa (IA), Michigan (MI), Arkansas (AR), and Louisiana (LA). At locations with either soil test $\mathrm{P}$ or $\mathrm{K}$ in the sub-optimal range, corn grain yield was significantly increased with fertilizer application at five of sixteen site years, while soybean seed yield was significantly increased with fertilizer application at one of sixteen site years. At locations with both soil test $\mathrm{P}$ and $\mathrm{K}$ at optimal or greater levels, corn grain yield was significantly increased at three of thirteen site years and soybean seed yield significantly increased at one of fourteen site years when fertilizer was applied. Site soil test values were generally inversely related to the likelihood of a yield response from fertilizer application, which is consistent with yield response frequencies outlined in state fertilizer recommendations. Soybean yields were similar regardless if fertilizer was applied in the year of crop production or before the preceding corn crop. Based on the results of this work across the US and various yield potentials, it was confirmed that the practice of applying $\mathrm{P}$ and $\mathrm{K}$ fertilizers at recommended rates biennially prior to first year corn production in a corn-soybean rotation does not appear to be a yield limiting factor in modern, high management production systems.
\end{abstract}

Keywords: phosphorous; potassium; corn-soybean rotation; management; production system

\section{Introduction}

Phosphorus (P) and potassium (K) are essential nutrients for corn and soybean, comprising a significant proportion of total fertilizer expenditures, and can be yield limiting in many major crop production areas in the United States. Determining optimum application rates and timings for these fertilizers has been an ongoing research focus for decades and efforts continue to refine recommendations. Perceptions by producers of stagnant crop yield increases, particularly in soybeans, 
have spurred interest in revisiting the role of production inputs in an attempt to determine yield-limiting factors. Previous studies have investigated optimizing factors including planting date, seed treatment, weed management, variety selection, and tillage in a high management scheme, although no studies have explored the role of fertilizer recommendation schemes on a multi-regional scale.

A central tenet of crop fertilizer recommendations is the identification of the soil test critical level, the point below which crop growth and yield will be limited by nutritional deficiency. Specific soil critical test values differ by geographic region, soil characteristics, crop, and environment and emphasize the need for regional specific recommendations. Fertilizer recommendations for soils with nutrient values below the critical level include fertilizer to meet intended crop needs and to elevate soil test levels above the critical point. Terminology differs by state for soils testing above the critical level, with soils classified as either optimum or medium. Soils in this range are expected to have a good probability of not responding in yield increases with the addition of fertilizer. As such, this range is considered the most economical category in which to maintain soil test values.

While the specific numerical delineations of soil test ranges vary by state, the premise of these ranges serving as a guide to quantify the likelihood of economic yield response to fertilizer application is a consistent theme. Fertility experiments conducted in the time following the development of these recommendations have generally validated existing fertility standards. As expected, corn and soybean grain yield increases to applications of $\mathrm{P}$ and $\mathrm{K}$ have generally not been found in soils testing at or above medium ranges [1-5].

In a corn-soybean crop rotation, a biennial fertilizer application of $\mathrm{P}$ and $\mathrm{K}$ preceding soybean has become a common management practice. While fertilizer recommendations have been specifically developed to meet a single year of crop production following a soil sample, multiple year fertilization for corn and soybeans produced on soils testing in an optimum or higher range is a reasonable practice when combining the recommended rates for each crop in one application [6,7]. The lack of documented yield response to fertilizer applications on high testing soils supports fertility management that consists of periodic fertilizer application to maintain optimal soil test levels. On high testing soils, extended intervals between maintenance fertilizer applications may be possible. Dodd and Mallarino (2005) [8] found eight to nine years of non-fertilizer corn and soybean production could be conducted on high $P$ testing soils before yield responses could be seen from fertilizer application. Buah et al. (2000) [2] documented conflicting soybean yield results comparing annual and biennial $\mathrm{P}$ and $\mathrm{K}$ applications at eight site years on Iowa farmer fields, but recorded increased soybean yield from annual $\mathrm{P}$ applications compared to biennial in two of three years on research station plots testing optimum for P. McCallister et al. (1987) [9] measured greater extractable P when applying P fertilizer annually rather than equivalent total applications made every two, three, or six years. Corn grain yields were not responsive to application frequency, but the authors suggested that smaller, more frequent fertilizer applications lead to increase plant available phosphorous.

The objective of this study was to determine if current fertilizer rate and timing recommendations constitute a yield limitation in modern, high yielding corn and soybean rotations across a range of production regions in the United States.

\section{Materials and Methods}

\subsection{Site Description}

Research trials were established at four sites in Minnesota, three sites each in Iowa, Arkansas and Louisiana, and two sites in Michigan in 2009 (Table 1). Experiments were established on sites with a history of corn-soybean rotations in a randomized complete block design, blocked by crop rotation, with four replications. Corn was established in 2009 for rotation to soybeans in 2010. A second rotation cycle was initiated in 2010 adjacent to existing plots; corn was planted in 2010 for rotation to soybean 
in 2011. Corn and soybean production was conducted following local cultural practices for tillage, row spacing, population and variety.

Table 1. Description of soil characteristics at research sites used in this study in the years 2009 to 2011.

\begin{tabular}{|c|c|c|c|c|c|}
\hline Site & Soil Type & Soil Series & $\mathrm{pH}$ & Initial $P^{\mathbf{a}}$ & Initial K \\
\hline & & & & \multicolumn{2}{|c|}{$\mathrm{Mg} \mathrm{kg}^{-1}$} \\
\hline \multicolumn{6}{|l|}{ Minnesota } \\
\hline Delavan & Fostoria loam & Aquic Hapludolls & 6.8 & $9 \mathrm{M}^{\mathrm{b}}$ & $141 \mathrm{H}$ \\
\hline Lamberton & Ves loam & Calcic Hapludolls & 5.5 & $24 \mathrm{VH}$ & $114 \mathrm{M}$ \\
\hline Morris & Tara silt loam & Aquic Hapludolls & 7.9 & $6 \mathrm{~L}$ & $150 \mathrm{H}$ \\
\hline St. Charles & Seaton silt loam & Typic Hapludolls & 6.2 & $14 \mathrm{M}$ & $77 \mathrm{~L}$ \\
\hline \multicolumn{6}{|l|}{ Iowa } \\
\hline Lewis & Marshall silty clay loam & Typic Hapludolls & 6.8 & $9 \mathrm{~L}$ & $160 \mathrm{H}$ \\
\hline Sutherland & Sac silty clay loam & Oxyaquic Hapludolls & 5.9 & $20 \mathrm{O}$ & $198 \mathrm{VH}$ \\
\hline Ames 2009-2010 & Clarion loam & Typic Hapludolls & 7.2 & $9 \mathrm{~L}$ & $128 \mathrm{~L}$ \\
\hline Ames 2010-2011 & Canisteo silty clay loam & Typic Endoaquolls & 7.2 & $11 \mathrm{O}$ & $82 \mathrm{VL}$ \\
\hline \multicolumn{6}{|l|}{ Michigan } \\
\hline Ingham & Capac loam & Aquic Glossudalfs & 6.3 & $37 \mathrm{AO}$ & $149 \mathrm{AO}$ \\
\hline Branch & Matherton loam & Typic Argiaquolls & 6.5 & $25 \mathrm{O}$ & $136 \mathrm{AO}$ \\
\hline \multicolumn{6}{|l|}{ Arkansas } \\
\hline Colt & Calhoun silt loam & Typic Glossaqualfs & 6.3 & $15 \mathrm{~L}$ & $100 \mathrm{M}$ \\
\hline Keiser & Sharkey silty clay & Chromic Epiaquerts & 6.8 & $45 \mathrm{O}$ & $201 \mathrm{AO}$ \\
\hline Rohwer & Henery silt loam & Typic Fragiaqualfs & 7.3 & $26 \mathrm{M}$ & $58 \mathrm{VL}$ \\
\hline \multicolumn{6}{|l|}{ Louisiana } \\
\hline Baton Rouge & Commerce silt loam & Fluvaquentic Endoaquepts & 6.6 & $29 \mathrm{M}$ & $136 \mathrm{~L}$ \\
\hline St. Joseph & Commerce silt loam & Fluvaquentic Endoaquepts & 6.6 & $51 \mathrm{H}$ & $239 \mathrm{H}$ \\
\hline Winnsboro & Gigger silt loam & Typic Fragiudalfs & 6.3 & $31 \mathrm{M}$ & $115 \mathrm{~L}$ \\
\hline
\end{tabular}

\subsection{Treatment Plans}

Fertility treatments consisted of annual applications of $\mathrm{P}$ and $\mathrm{K}$ prior to corn in 2009 and soybeans in 2010 or biennial applications of $\mathrm{P}$ and $\mathrm{K}$ for both corn and soybeans applied preceding the corn crop. Fertilizer rates were determined from state specific fertilizer recommendations according to soil test values and applied at $1 \times$ and $2 \times$ rates in both annual and biennial practices $[7,10-12]$. Specific fertilizer rates, which varied by site, can be found at Boring, 2013 [13]. Soils testing below optimal or medium were fertilized with specific state recommended rates; crop removal rate combined with additional fertilizer to bring test levels to optimal ranges. Sites testing above the optimal or medium level were fertilized at crop removal rates. These treatments were compared to a control receiving no $\mathrm{P}$ or $\mathrm{K}$ fertilizer. Fertilizer treatments were broadcast and incorporated in the spring with mono-ammonium phosphate (10-52-0) and potassium chloride (0-0-62). Tillage, row spacing, variety, plant population, planting date and harvest date can be referenced at Boring, 2013 [13] in the study done at Michigan State University, East Lansing, Michigan, USA. Nitrogen management was conducted in accordance with local practices.

Fertility rates were determined for each site from the composite of 10-15 cores sampled to a $15 \mathrm{~cm}$ depth. All samples were analyzed in the originating state's university soil testing lab following standard soil testing procedures. Phosphorus analysis was determined in Minnesota with the Olson method [14] at sites with pH levels of 6.8 and greater, the Bray-P1 method [14] at sites with pH below 6.8, in Iowa and Michigan with the Bray-P1 method, and Arkansas and Louisiana with the Mehlich 3 method [15]. Potassium analysis was determined by ammonium acetate extraction [16] in Minnesota, Iowa and Michigan and by Mehlich 3 in Arkansas and Louisiana. Soils were categorized as to relative $\mathrm{P}$ and $\mathrm{K}$ test levels according to state fertilizer recommendations. Categorization of soil test ranges varied by state, both the number and names of categories and the degree to which additional soil information is utilized. Soil test classification included texture, cation exchange capacity, subsoil nutrient concentrations and irrigation supplementation. A commonality among all state classifications 
is the delineation between sub-optimal, optimal, and above optimal test levels. Sub-optimal ranges include very low and low in Minnesota, Iowa and Louisiana; below optimal in Michigan; and very low, low, and medium in Arkansas. Optimal ranges include medium in Minnesota and Louisiana and optimal in Iowa, Michigan and Arkansas. Above optimal soil test ranges include high and very high in Minnesota and Iowa, above optimal in Michigan and Arkansas, and high in Louisiana. These three ranges, sub-optimal, optimal, and above optimal, are used for delineation of individual sites in this study (Table 2). Plot width varied between 3.9 and $7.8 \mathrm{~m}$ and ranged from 9.1 and $12.2 \mathrm{~m}$ in length. Soybean seed yields were obtained by machine from plot centers and adjusted to $130 \mathrm{~g} \mathrm{~kg}^{-1} \mathrm{H}_{2} \mathrm{O}$. Corn grain yields were obtained by either hand or machine harvest and adjusted to $150 \mathrm{~g} \mathrm{~kg}^{-1} \mathrm{H}_{2} \mathrm{O}$.

Table 2. Description of site soil test levels used in the study in the years 2009 to 2011.

\begin{tabular}{lcc}
\hline \multicolumn{1}{c}{ Site } & P Range & K Range \\
\hline Ames 2009-2010, Colt, Rohwer & Sub-optimal & Sub-optimal \\
Lewis, Morris & Sub-optimal & Above optimal \\
Ames 2010-2011, Baton Rouge, St. Charles, Winnsboro & Optimal & Sub-optimal \\
Branch, Delavan, Keiser, Sutherland & Optimal & Above optimal \\
Lamberton, St. Joseph & Above optimal & Optimal \\
Ingham & Above optimal & Above optimal \\
\hline
\end{tabular}

\subsection{Statistical Analysis}

Data were analyzed with SAS statistical software (SAS Institute, Inc. 2014. SAS v. 9.3. SAS Institute, Cary, NC, USA). Analysis of variance was performed using PROC MIXED. Coefficient of variance was determined using PROC GLM. Treatment means were considered statistically different at the $p<0.10$ level. The $90 \%$ confidence interval was chosen because it was considered conservative enough to meet the objective of evaluating fertilizer application practices across the broad study area $[17,18]$.

\section{Results}

\subsection{Sites Testing in the Sub-Optimal Range for Soil $P$ and $K$}

At 10 total site-years testing sub-optimal for both soil P and K, fertilizer applications significantly increased corn yields in two of five comparisons and soybean yields in one of five. In all cases where a yield response was documented, annual fertilizer applications at the $1 \times$ rate maximized yield of corn. At Ames, corn grain yield was significantly increased in 2009 by all fertilizer treatments (Table 3) and the annual and biennial $1 \times$ rates resulted in significantly greater yield than the $2 \times$ biennial treatment. Corn grain yield in 2010 was significantly increased at Colt by $1 \times$ annual and $2 \times$ biennial fertilizer treatments compared to the control and $1 \times$ biennial treatments. At Colt, the corn yield in 2009 was not influenced by fertilizer treatments. At Rowher, the $2 \times$ biennial fertilizer treatment significantly reduced 2010 corn grain yield compared to the control. Yield for all other fertilizer treatments were similar to the control. No differences in corn grain yield were observed at Rohwer in 2009. Soybean grain yield was significantly increased by annual $2 \times$ and biennial $1 \times$ fertilizer applications compared to the biennial $2 \times$ and control treatments at Ames in 2009. Soybean seed yield was not affected by fertilizer applications in 2010 or 2011 at Colt and Rohwer locations. At Colt following the 2010-2011 rotation, soil test $\mathrm{P}$ and $\mathrm{K}$ were significantly increased with biennial $2 \times$ application compared to all other treatments (Table 3). Following the 2010-2011 rotation at Rowher, all fertilizer treatments significantly increased soil test $\mathrm{K}$ compared to the control. Fertilizer rates at the $2 \times$ rate significantly increased soil test $\mathrm{K}$ compared to $1 \times$ rates. 
Table 3. Corn and soybean seed yield and soil test results affected by fertilizer treatments at sites with sub-optimal $\mathrm{P}$ and sub-optimal K.

\begin{tabular}{|c|c|c|c|c|c|c|c|c|}
\hline \multirow[t]{2}{*}{ Site } & \multirow[t]{2}{*}{ Crop Rotation } & \multirow[t]{2}{*}{ Control } & \multicolumn{2}{|c|}{ Annual } & \multicolumn{2}{|c|}{ Biennial } & \multirow[t]{2}{*}{$P>F$} & \multirow[t]{2}{*}{$\mathrm{CV}$} \\
\hline & & & $1 \times$ & $2 \times$ & $1 \times$ & $2 \times$ & & \\
\hline & & \multicolumn{7}{|c|}{ Grain yield $\left(\mathrm{Mg} \mathrm{ha}^{-1}\right)$} \\
\hline Ames, IA & 2009 Corn & $10.39 c^{*}$ & $12.89 \mathrm{a}$ & $12.29 \mathrm{a}, \mathrm{b}$ & $12.91 \mathrm{a}$ & $11.54 \mathrm{~b}$ & 0.0026 & 6.37 \\
\hline & 2010 Soybean & $3.62 \mathrm{~b}$ & $4.00 \mathrm{a}, \mathrm{b}$ & $4.03 \mathrm{a}$ & $4.02 \mathrm{a}$ & $3.80 \mathrm{~b}$ & 0.0132 & 4.11 \\
\hline Colt, AK & 2009 Corn & 7.32 & 7.98 & 7.51 & 7.53 & 6.90 & 0.9090 & 21.44 \\
\hline \multirow{7}{*}{ Rohwer, AK } & 2010 Soybean & 2.62 & 2.56 & 2.49 & 2.26 & 2.43 & 0.6031 & 13.16 \\
\hline & 2010 Corn & $5.32 \mathrm{~b}$ & $6.29 \mathrm{a}$ & $5.80 \mathrm{a}, \mathrm{b}$ & $5.28 \mathrm{~b}$ & $6.04 \mathrm{a}$ & 0.0856 & 10.51 \\
\hline & 2011 Soybean & 3.80 & 3.83 & 3.78 & 4.10 & 4.03 & 0.2233 & 5.77 \\
\hline & 2009 Corn & 12.73 & 11.79 & 11.87 & 12.27 & 11.81 & 0.7851 & 11.45 \\
\hline & 2010 Soybean & 2.95 & 3.05 & 3.31 & 3.11 & 3.02 & 0.4121 & 8.66 \\
\hline & 2010 Corn & $9.38 \mathrm{a}$ & $9.10 \mathrm{a}$ & $8.82 \mathrm{a}, \mathrm{b}$ & $9.36 \mathrm{a}$ & $8.50 \mathrm{~b}$ & 0.0293 & 4.55 \\
\hline & 2011 Soybean & 2.28 & 2.38 & 2.21 & 2.11 & 2.28 & 0.3412 & 8.10 \\
\hline & & \multicolumn{7}{|c|}{ Soil test results $\left(\mathrm{Mg} \mathrm{ha}^{-1}\right)$} \\
\hline \multirow[t]{2}{*}{ Colt, AK } & 2010-2011 P & $29 \mathrm{~b}$ & $32 \mathrm{~b}$ & $33 \mathrm{~b}$ & $31 \mathrm{~b}$ & 39 a & 0.0255 & 11.48 \\
\hline & 2010-2011 K & $94 \mathrm{~b}$ & $96 b$ & $100 \mathrm{~b}$ & $94 \mathrm{~b}$ & $106 \mathrm{a}$ & 0.0277 & 5.18 \\
\hline \multirow[t]{2}{*}{ Rohwer, AK } & $2010-2011 \mathrm{P}$ & 37 & 42 & 49 & 41 & 48 & 0.1546 & 14.90 \\
\hline & 2010-2011 K & $75 c$ & $103 \mathrm{~b}$ & $116 \mathrm{a}$ & $94 \mathrm{~b}$ & $117 \mathrm{a}$ & 0.0004 & 8.74 \\
\hline
\end{tabular}

* Letters following numbers within a row represent differences between treatments at the $p \leq 0.10$ level.

\subsection{Sites Testing in the Sub-Optimal Range for P and Above Optimal Range for $K$}

There were eight site-years with suboptimal $\mathrm{P}$ and optimal soil test $\mathrm{K}$. All fertilizer treatments significantly increased corn grain yield compared to the control at Lewis in 2009 (Table 4). No significant differences in corn grain yield were observed at Lewis in 2010 or at Morris in 2009 or 2010. Soybean seed yield was not affected by fertilizer treatment at either site. No significant differences in soil test P or K levels were noted at either site following 2009-2010 or 2010-2011 crop rotations (Table 4).

Table 4. Corn and soybean grain yield and soil test results affected by fertilizer treatments at sites with sub-optimal P and above optimal K.

\begin{tabular}{|c|c|c|c|c|c|c|c|c|}
\hline \multirow[t]{2}{*}{ Site } & \multirow[t]{2}{*}{ Crop Rotation } & \multirow[t]{2}{*}{ Control } & \multicolumn{2}{|c|}{ Annual } & \multicolumn{2}{|c|}{ Biennial } & \multirow[t]{2}{*}{$\mathrm{P}>\mathrm{F}$} & \multirow[t]{2}{*}{$\mathrm{CV}$} \\
\hline & & & $1 \times$ & $2 \times$ & $1 \times$ & $2 \times$ & & \\
\hline & & \multicolumn{7}{|c|}{ Grain yield $\left(\mathrm{Mg} \mathrm{ha}^{-1}\right)$} \\
\hline \multirow[t]{4}{*}{ Lewis, IA } & 2009 Corn & $11.88 \mathrm{~b}$ * & $13.78 \mathrm{a}$ & $13.98 \mathrm{a}$ & $14.06 \mathrm{a}$ & $14.52 \mathrm{a}$ & 0.0014 & 5.02 \\
\hline & 2010 Soybean & 4.07 & 4.19 & 4.03 & 4.27 & 4.18 & 0.4448 & 4.61 \\
\hline & 2010 Corn & 13.30 & 13.19 & 13.52 & 12.98 & 12.91 & 0.7904 & 5.76 \\
\hline & 2011 Soybean & 4.32 & 4.16 & 4.41 & 4.46 & 4.32 & 0.1176 & 3.10 \\
\hline \multirow[t]{5}{*}{ Morris, $\mathrm{MN}$} & 2009 Corn & 9.73 & 10.41 & 10.83 & 10.51 & 11.26 & 0.4766 & 11.38 \\
\hline & 2010 Soybean & 3.01 & 3.16 & 2.98 & 3.14 & 3.06 & 0.7899 & 7.74 \\
\hline & 2010 Corn & 14.77 & 14.91 & 14.97 & 14.81 & 15.14 & 0.7201 & 2.69 \\
\hline & 2011 Soybean & 2.34 & 3.21 & 2.68 & 2.92 & 2.82 & 0.3405 & 20.48 \\
\hline & & \multicolumn{7}{|c|}{ Soil test results $\left(\mathrm{Mg} \mathrm{ha}^{-1}\right)$} \\
\hline \multirow[t]{2}{*}{ Lewis, IA } & 2010-2011 P & 28 & 39 & 40 & 32 & 27 & 0.5467 & 45.58 \\
\hline & $2010-2011 \mathrm{~K}$ & 196 & 252 & 213 & 240 & 195 & 0.1098 & 14.47 \\
\hline \multirow[t]{4}{*}{ Morris, $\mathrm{MN}$} & 2009-2010 P & 7 & 9 & 6 & 5 & 4 & 0.4408 & 58.29 \\
\hline & $2009-2010 \mathrm{~K}$ & 156 & 157 & 152 & 152 & 144 & 0.9076 & 14.56 \\
\hline & 2010-2011 P & 9 & 11 & 10 & 9 & 9 & 0.8148 & 27.63 \\
\hline & 2010-2011 K & 165 & 170 & 164 & 169 & 166 & 0.8985 & 6.65 \\
\hline
\end{tabular}

* Letters following numbers within a row represent differences between treatments at the $p \leq 0.10$ level.

\subsection{Sites Testing in the Optimal Range for P and Sub-Optimal Range for K}

There were 14 comparisons with optimal soil test $\mathrm{P}$ and sub-optimal soil test $\mathrm{K}$. A fertilizer treatment significantly increased yields in only one site-year for each corn and soybean. At Baton Rouge in 2009, all fertilizer treatments resulted in significantly higher corn yield compared to the control (Table 5). Yields were significantly greater for biennial $1 \times$ and $2 \times$ treatments compared to the annual treatment. No significant differences in corn grain yield were observed at other sites testing in the optimal range for $\mathrm{P}$ and sub-optimal range for K. In 2010 at Baton Rouge, soybean seed yields were significantly lower with annual and biennial $2 \times$ treatments compared to the control. Soybean seed 
yield did not significantly differ between fertilizer treatments at other sites. At Baton Rouge, soil test $\mathrm{P}$ levels following the 2010-2011 crop rotation were highest with the biennial $2 \times$ treatment compared to all other treatments (Table 5). Additionally, soil test P levels were significantly greater with annual $1 \times$, annual $2 \times$, and biennial $1 \times$ treatments compared to the control. Soil test $\mathrm{P}$ and $\mathrm{K}$ following the 2009-2010 rotation and soil test $\mathrm{K}$ following the 2010-2011 rotation did not differ by fertilizer treatment at Baton Rouge. At Ames 2010-2011 and St. Charles, no differences in soil test P and K were observed.

Table 5. Corn and soybean grain yield and soil test results affected by fertilizer treatments at sites with optimal P and sub-optimal K.

\begin{tabular}{|c|c|c|c|c|c|c|c|c|}
\hline \multirow[t]{2}{*}{ Site } & \multirow[t]{2}{*}{ Crop Rotation } & \multirow[t]{2}{*}{ Control } & \multicolumn{2}{|c|}{ Annual } & \multicolumn{2}{|c|}{ Biennial } & \multirow[t]{2}{*}{$\mathrm{P}>\mathrm{F}$} & \multirow[t]{2}{*}{ CV } \\
\hline & & & $1 \times$ & $2 \times$ & $1 \times$ & $2 \times$ & & \\
\hline & & \multicolumn{7}{|c|}{ Grain yield $\left(\mathrm{Mg} \mathrm{ha}^{-1}\right)$} \\
\hline \multirow[t]{2}{*}{ Ames, IA } & 2010 Corn & 12.31 & 12.38 & 13.17 & 13.13 & 13.73 & 0.1405 & 6.94 \\
\hline & 2011 Soybean & 3.48 & 3.83 & 3.62 & 3.73 & 3.86 & 0.9278 & 20.26 \\
\hline \multirow[t]{4}{*}{ Baton Rouge, LA } & 2009 Corn & $3.56 c^{*}$ & $4.73 \mathrm{a}, \mathrm{b}$ & $4.45 \mathrm{~b}$ & $5.12 \mathrm{a}$ & $5.20 \mathrm{a}$ & 0.0068 & 11.67 \\
\hline & 2010 Soybean & $4.32 \mathrm{a}, \mathrm{b}$ & $3.94 \mathrm{~b}, \mathrm{c}$ & $3.76 \mathrm{c}$ & $4.36 \mathrm{a}$ & $3.71 \mathrm{c}$ & 0.0752 & 9.68 \\
\hline & 2010 Corn & 6.33 & 8.57 & 8.62 & 7.92 & 8.12 & 0.1693 & 12.46 \\
\hline & 2011 Soybean & 2.74 & 2.58 & 2.88 & 2.68 & 2.58 & 0.7907 & 14.47 \\
\hline \multirow[t]{4}{*}{ St. Charles, MN } & 2009 Corn & 12.10 & 13.29 & 12.52 & 13.02 & 13.11 & 0.1372 & 4.61 \\
\hline & 2010 Soybean & 3.36 & 3.48 & 3.61 & 3.16 & 3.51 & 0.4408 & 10.07 \\
\hline & 2010 Corn & 12.76 & 12.52 & 13.19 & 12.80 & 12.58 & 0.8802 & 7.70 \\
\hline & 2011 Soybean & 3.32 & 3.28 & 3.47 & 3.34 & 3.26 & 0.6177 & 5.78 \\
\hline \multirow[t]{5}{*}{ Winnsboro, LA } & 2009 Corn & 11.23 & 11.26 & 11.44 & 11.48 & 10.86 & 0.9181 & 9.29 \\
\hline & 2010 Soybean & 4.10 & 4.03 & 4.43 & 4.57 & 4.63 & 0.2777 & 10.36 \\
\hline & 2010 Corn & 10.76 & 10.41 & 10.95 & 11.13 & 10.68 & 0.4588 & 5.70 \\
\hline & 2011 Soybean & 2.06 & 1.23 & 2.15 & 1.87 & 1.66 & 0.1494 & 28.56 \\
\hline & & \multicolumn{7}{|c|}{ Soil test results $\left(\mathrm{Mg} \mathrm{ha}^{-1}\right)$} \\
\hline \multirow[t]{2}{*}{ Ames, IA } & 2010-2011 P & 16 & 20 & 27 & 21 & 34 & 0.2086 & 49.28 \\
\hline & 2010-2011 K & 143 & 58 & 176 & 167 & 199 & 0.1097 & 17.28 \\
\hline \multirow[t]{4}{*}{ Baton Rouge, LA } & $2009-2010 \mathrm{P}$ & 54 & 56 & 53 & 48 & 54 & 0.2606 & 9.62 \\
\hline & $2009-2010 \mathrm{~K}$ & 230 & 244 & 222 & 215 & 228 & 0.1250 & 6.59 \\
\hline & 2010-2011 P & $47 \mathrm{c}$ & $52 \mathrm{~b}$ & $54 \mathrm{~b}$ & $53 \mathrm{~b}$ & $59 a$ & 0.0033 & 6.39 \\
\hline & 2010-2011 K & 229 & 230 & 230 & 216 & 234 & 0.6141 & 7.73 \\
\hline \multirow[t]{4}{*}{ St. Charles, MN } & 2009-2010 P & 6 & 6 & 6 & 6 & 7 & 0.9577 & 41.25 \\
\hline & 2009-2010 K & 72 & 79 & 77 & 73 & 71 & 0.5816 & 10.71 \\
\hline & 2010-2011 P & 5 & 6 & 5 & 5 & 6 & 0.4382 & 29.68 \\
\hline & $2010-2011 \mathrm{~K}$ & 78 & 71 & 70 & 79 & 74 & 0.4112 & 10.17 \\
\hline
\end{tabular}

* Letters following numbers within a row represent differences between treatments at the $p \leq 0.10$ level.

\subsection{Sites Testing for the Optimal Range for $P$ and Above Optimal Range in $K$}

There were 15 comparisons with optimal soil test $\mathrm{P}$ and above optimal soil test $\mathrm{K}$. A fertilizer treatment significantly increased corn grain yields in three of seven comparisons and soybean seed yield in one of eight site-years. Corn grain yield was significantly increased by any fertilizer application at Branch 2009, Delavan in 2010 and Sutherland in 2010 (Table 6). All fertilizer applications at Branch in 2009 and Delavan in 2010 resulted in significantly higher corn grain yield compared to the untreated control. At Sutherland in 2010, fertilizer application of any kind significantly increased corn yield above that of the control, but yield was significantly lower for the biennial $1 \times$ treatment compared to other fertilizer treatments. Corn grain yield at Delavan in 2009, Keiser in 2009 and 2010, and Sutherland in 2009 were not influenced by fertilizer application. At Branch following the 2009-2010 rotation, all treatments except the biennial $1 \times$ treatment significantly increased soil test $\mathrm{K}$ compared to the control (Table 6). Soil test $\mathrm{K}$ was significantly increased at Branch for $2 \times$ rate treatments compared to $1 \times$ treatments. Soil test $\mathrm{K}$ following the 2010-2011 rotation and soil test $\mathrm{P}$ following the 2009-2010 and 2010-2011 crop rotations did not differ by fertilizer treatment. At Delavan, soil test P and K following 2009-2010 and 2010-2011 rotations were not affected by fertilizer treatment. No significant differences in soil test P or K were observed following the 2010-2011 crop rotation at Keiser. Following the 2010-2011 crop rotation at Sutherland, all fertilizer treatments increased soil test P compared to the control. All fertilizer treatments except the biennial $1 \times$ treatment increased soil test $\mathrm{K}$ compared to the control. Soil test $\mathrm{P}$ and $\mathrm{K}$ was significantly greater for $2 \times$ rate treatments compared to $1 \times$ rate treatments. 
Table 6. Corn and soybean grain yield and soil test results affected by fertilizer treatments at sites with optimal $\mathrm{P}$ and above optimal $\mathrm{K}$.

\begin{tabular}{|c|c|c|c|c|c|c|c|c|}
\hline \multirow[t]{2}{*}{ Site } & \multirow[t]{2}{*}{ Crop Rotation } & \multirow[t]{2}{*}{ Control } & \multicolumn{2}{|c|}{ Annual } & \multicolumn{2}{|c|}{ Biennial } & \multirow[t]{2}{*}{$P>F$} & \multirow[t]{2}{*}{$\mathrm{CV}$} \\
\hline & & & $1 \times$ & $2 \times$ & $1 \times$ & $2 \times$ & & \\
\hline & & \multicolumn{7}{|c|}{ Grain yield $\left(\mathrm{Mg} \mathrm{ha}^{-1}\right)$} \\
\hline \multirow[t]{3}{*}{ Branch, MI } & 2009 Corn & $5.36 \mathrm{~b}$ * & $6.86 \mathrm{a}$ & $6.99 \mathrm{a}$ & $7.01 \mathrm{a}$ & $7.21 \mathrm{a}$ & 0.0013 & 7.46 \\
\hline & 2010 Soybean & 2.70 & 2.78 & 2.86 & 2.83 & 2.89 & 0.9775 & 16.26 \\
\hline & 2011 Soybean & 0.94 & 0.86 & 1.06 & 1.04 & 0.95 & 0.6076 & 20.43 \\
\hline \multirow[t]{4}{*}{ Delavan, $\mathrm{MN}$} & 2009 Corn & 12.50 & 13.59 & 13.45 & 14.05 & 13.66 & 0.3965 & 8.11 \\
\hline & 2010 Soybean & 2.72 & 2.73 & 2.97 & 3.00 & 2.94 & 0.5463 & 10.68 \\
\hline & 2010 Corn & $9.79 \mathrm{~b}$ & $12.16 \mathrm{a}$ & $12.82 \mathrm{a}$ & $11.82 \mathrm{a}$ & $12.34 \mathrm{a}$ & 0.0019 & 6.91 \\
\hline & 2011 Soybean & $2.39 \mathrm{~b}$ & $3.04 \mathrm{a}$ & $3.11 \mathrm{a}$ & $3.05 \mathrm{a}$ & $3.12 \mathrm{a}$ & 0.0159 & 9.69 \\
\hline \multirow[t]{4}{*}{ Keiser, AK } & 2009 Corn & 10.04 & 10.72 & 9.98 & 10.13 & 10.16 & 0.6352 & 7.46 \\
\hline & 2010 Soybean & 3.80 & 3.76 & 3.71 & 3.79 & 3.76 & 0.9902 & 7.79 \\
\hline & 2010 Corn & 10.73 & 10.71 & 10.43 & 11.00 & 10.63 & 0.4529 & 3.91 \\
\hline & 2011 Soybean & 4.31 & 4.32 & 4.40 & 4.37 & 4.51 & 0.4181 & 3.53 \\
\hline \multirow[t]{5}{*}{ Sutherland, IA } & 2009 Corn & 13.60 & 14.27 & 14.3 & 14.46 & 14.41 & 0.3242 & 4.51 \\
\hline & 2010 Soybean & 4.65 & 4.60 & 4.66 & 4.82 & 4.63 & 0.5157 & 3.67 \\
\hline & 2010 Corn & $12.61 \mathrm{c}$ & $13.72 \mathrm{a}$ & $13.90 \mathrm{a}$ & $13.20 \mathrm{~b}$ & $13.46 \mathrm{a}$ & 0.0032 & 2.79 \\
\hline & 2011 Soybean & 3.74 & 3.94 & 3.93 & 4.04 & 3.96 & 0.1382 & 3.90 \\
\hline & & \multicolumn{7}{|c|}{ Soil test results $\left(\mathrm{Mg} \mathrm{ha}^{-1}\right)$} \\
\hline \multirow[t]{4}{*}{ Branch, MI } & 2009-2010 P & 69 & 68 & 70 & 69 & 69 & 0.1238 & 0.85 \\
\hline & $2009-2010 \mathrm{~K}$ & $16 c$ & $28 \mathrm{~b}$ & $42 \mathrm{a}$ & $21 \mathrm{c}$ & $40 \mathrm{a}$ & $<0.0001$ & 18.30 \\
\hline & 2010-2011 P & 42 & 33 & 54 & 36 & 24 & 0.2943 & 48.33 \\
\hline & $2010-2011 \mathrm{~K}$ & 117 & 89 & 126 & 115 & 77 & 0.3497 & 36.15 \\
\hline \multirow[t]{4}{*}{ Delavan, $\mathrm{MN}$} & 2009-2010 P & 7 & 9 & 10 & 9 & 11 & 0.9223 & 67.03 \\
\hline & 2009-2010 K & 141 & 149 & 148 & 138 & 131 & 0.4673 & 10.68 \\
\hline & $2010-2011 \mathrm{P}$ & 4 & 4 & 8 & 5 & 5 & 0.3789 & 63.46 \\
\hline & $2010-2011 \mathrm{~K}$ & 135 & 136 & 133 & 124 & 130 & 0.7199 & 10.28 \\
\hline \multirow[t]{2}{*}{ Keiser, AK } & 2010-2011 P & 48 & 56 & 54 & 56 & 57 & 0.4226 & 13.19 \\
\hline & $2010-2011 \mathrm{~K}$ & 337 & 341 & 338 & 341 & 341 & 0.9981 & 6.77 \\
\hline \multirow[t]{2}{*}{ Sutherland, IA } & $2010-2011 \mathrm{P}$ & $17 \mathrm{~d}$ & $28 \mathrm{~b}, \mathrm{c}$ & $43 a$ & $23 c$ & $34 \mathrm{a}, \mathrm{b}$ & $<0.0001$ & 16.27 \\
\hline & $2010-2011 \mathrm{~K}$ & $188 \mathrm{~d}$ & $218 b, c$ & $241 \mathrm{a}$ & $200 \mathrm{c}, \mathrm{d}$ & $222 b$ & 0.0019 & 7.15 \\
\hline
\end{tabular}

* Letters following numbers within a row represent differences between treatments at the $p \leq 0.10$ level.

\subsection{Sites Testing in the Optimal Range for Soil $P$ and $K$}

There were eight comparisons with optimal soil test $P$ and optimal soil test $K$, though fertilizer application had no effect on corn or soybean seed yield (Table 7). At Lamberton, no differences in soil test P or K levels following 2009-2010 and 2010-2011 crop rotations were observed. At St. Joseph following the 2010-2011 crop rotation, the annual $2 \times$ fertilizer application resulted in significantly greater soil test with both $\mathrm{P}$ and $\mathrm{K}$ compared to the control (Table 7).

Table 7. Corn and soybean grain yield and soil test results affected by fertilizer treatments at sites with above optimal $\mathrm{P}$ and optimal $\mathrm{K}$.

\begin{tabular}{|c|c|c|c|c|c|c|c|c|}
\hline \multirow[t]{2}{*}{ Site } & \multirow[t]{2}{*}{ Crop Rotation } & \multirow[t]{2}{*}{ Control } & \multicolumn{2}{|c|}{ Annual } & \multicolumn{2}{|c|}{ Biennial } & \multirow[t]{2}{*}{$\mathrm{P}>\mathrm{F}$} & \multirow[t]{2}{*}{$\mathrm{CV}$} \\
\hline & & & $1 \times$ & $2 \times$ & $1 \times$ & $2 \times$ & & \\
\hline & & \multicolumn{7}{|c|}{ Grain yield $\left(\mathrm{Mg} \mathrm{ha}^{-1}\right)$} \\
\hline \multirow[t]{4}{*}{ Lamberton, $\mathrm{MN}$} & 2009 Corn & 8.22 & 8.84 & 10.31 & 10.33 & 9.23 & 0.3951 & 20.14 \\
\hline & 2010 Soybean & 3.45 & 3.64 & 3.73 & 3.63 & 3.48 & 0.3221 & 5.74 \\
\hline & 2010 Corn & 11.82 & 13.00 & 12.81 & 12.33 & 12.99 & 0.2422 & 6.40 \\
\hline & 2011 Soybean & 2.89 & 3.30 & 3.20 & 3.15 & 3.18 & 0.1348 & 6.68 \\
\hline \multirow[t]{5}{*}{ St. Joseph, LA } & 2009 Corn & 11.49 & 11.35 & 11.06 & 11.16 & 11.41 & 0.6394 & 3.67 \\
\hline & 2010 Soybean & 3.58 & 3.89 & 3.84 & 3.80 & 3.79 & 0.6005 & 3.63 \\
\hline & 2010 Corn & 10.29 & 10.19 & 10.71 & 10.53 & 10.39 & 0.4447 & 3.90 \\
\hline & 2011 Soybean & 3.74 & 3.63 & 3.52 & 3.67 & 3.76 & 0.1003 & 3.38 \\
\hline & & \multicolumn{7}{|c|}{ Soil test results $\left(\mathrm{Mg} \mathrm{ha}^{-1}\right)$} \\
\hline \multirow[t]{4}{*}{ Lamberton, $\mathrm{MN}$} & 2009-2010 P & 12 & 12 & 11 & 10 & 12 & 0.9423 & 31.29 \\
\hline & 2009-2010 K & 111 & 107 & 111 & 115 & 121 & 0.7398 & 14.10 \\
\hline & $2010-2011 \mathrm{P}$ & 6 & 8 & 7 & 7 & 6 & 0.2872 & 15.99 \\
\hline & $2010-2011 \mathrm{~K}$ & 104 & 111 & 104 & 106 & 110 & 0.3129 & 5.40 \\
\hline \multirow[t]{2}{*}{ St. Joseph, LA } & 2010-2011 P & $43 b$ & $49 \mathrm{~b}$ & $61 \mathrm{a}$ & $47 \mathrm{~b}$ & $49 b$ & 0.0067 & 10.57 \\
\hline & 2010-2011 K & $172 b$ & $189 \mathrm{~b}$ & $211 \mathrm{a}$ & $174 \mathrm{~b}$ & $180 \mathrm{~b}$ & 0.0446 & 9.18 \\
\hline
\end{tabular}

Letters following numbers within a row represent differences between treatments at the $p \leq 0.10$ level. 


\subsection{Sites Testing in the Above Optimal Range for Both $P$ and $K$}

One site had above optimal soil test levels for both $\mathrm{P}$ and $\mathrm{K}$, for a total of four site year comparisons. No differences were measured in corn or soybean seed yield (Table 8). Annual fertilizer application at the $2 \times$ rate significantly increased soil test $P$ following the 2010-2011 rotation compared to all other treatments. No differences were observed in soil test $\mathrm{P}$ following the 2009-2010 crop rotation or soil test $\mathrm{K}$ following the 2009-2010 and 2010-2011 crop rotations.

Table 8. Corn and soybean grain yield and soil test results affected by fertilizer treatments at sites with above optimal $\mathrm{P}$ and above optimal $\mathrm{K}$.

\begin{tabular}{|c|c|c|c|c|c|c|c|c|}
\hline \multirow[t]{2}{*}{ Site } & \multirow[t]{2}{*}{ Crop rotation } & \multirow[t]{2}{*}{ Control } & \multicolumn{2}{|c|}{ Annual } & \multicolumn{2}{|c|}{ Biennial } & \multirow[t]{2}{*}{$P>F$} & \multirow[t]{2}{*}{ CV } \\
\hline & & & $1 \times$ & $2 \times$ & $1 \times$ & $2 \times$ & & \\
\hline & & \multicolumn{7}{|c|}{ Grain yield $\left(\mathrm{Mg} \mathrm{ha}^{-1}\right)$} \\
\hline \multirow[t]{5}{*}{ Ingham, MI } & 2009 Corn & 9.58 & 9.6 & 9.68 & 9.61 & 10.23 & 0.9249 & 12.86 \\
\hline & 2010 Soybean & 2.92 & 2.9 & 3.1 & 3.01 & 3.04 & 0.6311 & 7.05 \\
\hline & 2010 Corn & 9.78 & 9.65 & 9.07 & 9.63 & 9.88 & 0.2297 & 5.01 \\
\hline & 2011 Soybean & 2.81 & 2.66 & 2.66 & 2.7 & 2.73 & 0.1842 & 3.47 \\
\hline & & \multicolumn{7}{|c|}{ Soil test results $\left(\mathrm{Mg} \mathrm{ha}^{-1}\right)$} \\
\hline \multirow[t]{4}{*}{ Ingham, MI } & 2009-2010 P & 67 & 67 & 67 & 66 & 67 & 0.7257 & 1.71 \\
\hline & 2009-2010 K & 64 & 69 & 90 & 78 & 89 & 0.1411 & 21.42 \\
\hline & 2010-2011 P & $63 \mathrm{~b}$ & $69 \mathrm{~b}$ & $80 \mathrm{a}$ & $59 \mathrm{~b}$ & $66 \mathrm{~b}$ & 0.0415 & 12.54 \\
\hline & 2010-2011 K & 209 & 222 & 238 & 207 & 236 & 0.2243 & 10.17 \\
\hline
\end{tabular}

Letters following numbers within a row represent differences between treatments at the $p \leq 0.10$ level.

\section{Discussion}

\subsection{Fertilizer Recommendations}

Fertilizer recommendations are built upon the principle that soil test values exceeding the critical soil test level are expected to supply adequate nutrients to support optimal economic growth [10]. However, variability in soil test values and crop responses mean yield responses can be observed from fertilizer applications at all soil test levels, although with decreasing frequency as soil test levels increase. Iowa fertilizer recommendations cite the probability of yield responses as $80 \%$ on very low testing sites, $65 \%$ on low testing, $25 \%$ on optimal soils, $5 \%$ for soils in the high range and less than $1 \%$ in the very high range [7]. Bruulsema (2004) [19] noted that, in Ontario, Canada, corn and soybean have been documented to have a $59 \%$ and $49 \%$, respectively, probability of response to fertilizer applications on soils testing in the medium soil test level. Results from this multi-state study generally agree with these response frequencies, both in terms of the greater probability of a corn yield response compared to soybean and the overall likelihood of yield response. Of the 14 site years with soil test $\mathrm{P}$ and $\mathrm{K}$ values in the optimal or higher range, corn yield was significantly increased at three, or $21 \%$ of sites, while soybean yield was significantly increased at one, or 7\% of sites. Mallarino et al. (2011) [20] observed corn grain responses to broadcast $\mathrm{P}$ and $\mathrm{K}$ fertilizer treatments at five sites with soil test $\mathrm{P}$ and $\mathrm{K}$ testing at optimal levels or below. The only site they found to be unresponsive to preplant broadcast fertilizer application tested in the very high range for soil $\mathrm{P}$ and medium for soil $\mathrm{K}$. In our study, sites with soil test levels in the sub-optimal range for at least one nutrient demonstrated a significant response on corn grain yield at five of sixteen site years. Bordoli and Mallarino (1998) [21] observed frequent corn grain yield responses to $\mathrm{P}$ fertilizer on low testing sites in Iowa, but not every low testing site responded to fertilizer application. In our study, soybean seed yield was significantly increased with fertilizer application at two of sixteen site years. These responses are less than those predicted in the Iowa Fertilizer recommendations, but follow the trend illustrated by Bruulsema (2004) [19] of an increased frequency of fertilizer response in corn compared to soybean. 


\subsection{Corn Yield after Treatment}

Corn yield increases in response to fertilizer applications, when observed, did not follow trends with rate or timing. At Branch in 2009, Delavan in 2010, and Lewis in 2009, all fertilizer treatments resulted in a similar increase in yield compared to the control. At Baton Rouge in 2009, yield generally increased with increasing fertilizer rate. This was contrasted by high fertilizer rates detrimentally impacting yield at Ames in 2009 and Rowher in 2010. At these locations, the biennial $2 \times$ treatment had significantly lower yields than other fertilizer treatments. At Rowher, yield from the untreated control exceeded the biennial $2 \times$ treatment, indicating a yield reducing effect of fertilizer application rather than a simple lack of response. Fertilizer applications have been previously associated with reductions in crop growth and yield, although generally these responses have been attributed to proximity of fertilizer and seed. Anghinoni and Barber (1980) [22] measured decreasing corn root length with increasing P rate in pots. Heckman and Kamprath (1992) [23] observed decreased early season corn growth and $\mathrm{K}$ accumulation with increased broadcast $\mathrm{K}$ rates, a phenomenon they attributed to high salt concentrations. Numerous site years of phosphorus and potassium rate studies in Arkansas have generally observed a lack of response on high testing soils, response to rate on low testing sites, and agreement with established fertilizer recommendations. Muir and Hedge (2001) [24] measured corn yield reductions when increasing the fertilizer rate from $101 \mathrm{~kg} \mathrm{~K}_{2} \mathrm{O}$ ha ${ }^{-1}$, the recommended rate, to $202 \mathrm{~kg} \mathrm{~K}_{2} \mathrm{O} \mathrm{ha}^{-1}$, on both a low and a high $\mathrm{K}$ testing site.

\subsection{Soil Test Levels}

Yield responses at several sites failed to follow patterns that could be directly correlated to fertilizer rate. At Colt in 2010 and Sutherland in 2010, yield among the fertilizer treatments was lowest for the $1 \times$ biennial treatment compared to other fertilizer treatments. Fertilizer rates for this treatment were neither the lowest nor highest, precluding high fertilizer rate injury as an explanation. The occurrence of this trend at three sites in different production regions suggests more than a statistical anomaly or protocol errors. Soil test values following soybean did not differ between fertilizer treatments at Branch. At Colt, soil test $\mathrm{P}$ and $\mathrm{K}$ were increased by biennial $2 \times$ applications compared to all other treatments. While fertilizer applications at $2 \times$ rates would be expected to increase soil test values compared to $1 \times$ rates, this effect would be expected to be more pronounced when fertilizer applications were made closer in time to soil sampling. The lack of expected increases in soil test $\mathrm{P}$ and $\mathrm{K}$ levels, particularly the lack of differences in the annual $1 \times$ from the annual $2 \times$, may provide an explanation for differences in yield between these two treatments. At Sutherland in 2010, corn grain yield was maximized with annual $1 \times$, annual $2 \times$, and biennial $2 \times$ fertilizer treatments. Grain yield for the biennial $1 \times$ treatment was greater than the control, but lagged behind these other treatments. Increases in both soil test $\mathrm{P}$ and K following the 2010-2011 crop rotation generally followed the same pattern of increase as corn grain yield. Initial soil test $\mathrm{K}$ levels were in the high range and tested in this same range in 2011. Soil test $\mathrm{P}$ values were initially in the low range, but fertilizer treatments with the highest corn yields in 2010 had soil test $\mathrm{P}$ levels in the high range when tested following the two-year rotation, medium test values for the $1 \times$ biennial treatment that was associated with lower corn yield in 2010 , and low soil test $P$ values for the control. These trends in soil test results seem to explain 2010 corn grain results, but the low yielding biennial $1 \times$ treatment received medium amounts of $\mathrm{P}$ and $\mathrm{K}$ fertilizer in comparison to other treatments. Examples of decreased yield at medium fertilizer rates have been observed by other researchers as well. Muir and Hedge (2002) [25] noted reduced corn grain yield with a $78 \mathrm{~kg} \mathrm{P}_{2} \mathrm{O}_{5} \mathrm{ha}^{-1}$ application compared to $39 \mathrm{~kg} \mathrm{P}_{2} \mathrm{O}_{5} \mathrm{ha}^{-1}, 157 \mathrm{~kg} \mathrm{P}_{2} \mathrm{O}_{5} \mathrm{ha}^{-1}$ and an untreated control at one site. Mozaffari et al. (2012) [1] observed significant corn yield increases with $224 \mathrm{~kg} \mathrm{~K}_{2} \mathrm{O} \mathrm{ha}^{-1}$ compared to the control at a low $\mathrm{K}$ testing site, though a $179 \mathrm{~kg} \mathrm{~K}_{2} \mathrm{O}$ ha ${ }^{-1}$ rate decreased yield compared to the control. At two medium $\mathrm{K}$ testing sites, yield responses were not statistically significant, but a similar trend of decreased yield with a $179 \mathrm{~kg} \mathrm{~K}_{2} \mathrm{O} \mathrm{ha}^{-1}$ application was apparent. 


\subsection{Soybean Yield}

Soybean yield responses to fertilizer applications were observed at three sites: Ames in 2010 with sub-optimal P and K, Baton Rouge in 2010 with optimal P and sub-optimal K, and Delavan in 2011 with optimal P and above optimal K. All fertilizer applications resulted in similar yields at Delavan, but fertilizer applications at Ames 2009-2010 and Baton Rouge did not always result in yield increases. At Ames 2009-2010, yield was significantly increased by annual $2 \times$ and biennial $1 \times$ treatments compared to the control, but yield from annual $1 \times$ and biennial $2 \times$ treatments were similar to the control. At Baton Rouge, annual $2 \times$ and biennial $2 \times$ fertilizer treatments resulted in significant yield reductions compared to the control. Instances of yield reduction from high rates of broadcast fertilizer are not commonly observed, but have been noted to occur from both $\mathrm{P}$ and $\mathrm{K}$ applications. Ebelhar and Varsa (2000) [26] documented greater soybean yield at $56 \mathrm{~kg} \mathrm{~K}^{-1}$ than at higher K fertilizer rates, suggesting yield sensitivity to salt concentrations. Farmaha et al. (2011) [27] saw decreasing soybean yields with increasing $\mathrm{K}$ application in no-till systems but were unable to identify a definitive cause. They pointed to Ebelhar and Varsa's postulation of salt injury as a likely explanation. In Arkansas, Slaton et al. (2008) [28] observed a slight decrease in soybean yield with $179 \mathrm{~kg} \mathrm{~K}_{2} \mathrm{O} \mathrm{ha}^{-1}$ compared to $90 \mathrm{~kg} \mathrm{~K}_{2} \mathrm{O} \mathrm{ha}^{-1}$. Slaton et al. (2001) [29] observed decreased soybean yield with $134 \mathrm{~kg} \mathrm{P}_{2} \mathrm{O}_{5} \mathrm{ha}^{-1}$ compared to $90 \mathrm{~kg} \mathrm{P}_{2} \mathrm{O}_{5} \mathrm{ha}^{-1}$ applied annually in a soybean-rice rotation. While maximum $\mathrm{P}$ and $\mathrm{K}$ rates at Baton Rouge were less than those applied at other sites, salt injury from high rates of broadcast applied fertilizer appear to have negatively impacted yield.

Soybean yield was influenced by the timing of fertilizer application in the rotation at two of thirty-two site years of soybean. At Baton Rouge in 2010, the biennial $1 \times$ treatment resulted in significantly greater yield than the $1 \times$ annual treatment. Both annual and biennial $2 \times$ fertilizer treatments resulted in significantly lower yield compared to the control. It is possible that the difference in yield between the $1 \times$ annual and $1 \times$ biennial occurred due to a greater time interval between fertilizer application and soybean production in the biennial fertilizer treatment. At Ames in 2010, no differences were observed when comparing annual $1 \times$ and biennial $1 \times$ application, but annual $2 \times$ applications resulted in higher yield compared to biennial $2 \times$.

\subsection{Comparisons of Soil Test Levels}

Soil test levels following each crop rotation did not consistently differ between treatments. When responses in soil test $\mathrm{P}$ or $\mathrm{K}$ were observed, treatments did not tend to have consistent effects. At Branch following the 2009-2010 rotation, Sutherland following the 2010-2011 rotation, and Rowher following the 2010-2011 rotation, soil test $\mathrm{K}$ levels were increased with $2 \times$ application rates compared to $1 \times$ rates. At all three sites, corn yield increases were documented in the first year of the rotation. Soil test $\mathrm{K}$ levels in control treatments at both Branch and Rowher were in the sub-optimal range, suggesting $\mathrm{K}$ levels could pose a yield limiting condition. While $2 \times$ application rates resulted in higher soil test $\mathrm{K}$ levels than $1 \times$ rates, these increased levels were still below the critical level at both sites. Soil test K levels at Sutherland were initially characterized as very high and continued to test in this range following the 2010-2011 crop rotation.

The effects of fertilizer application timing were not consistent when increases in soil test $\mathrm{P}$ or $\mathrm{K}$ were observed. Soil test P levels at Ingham following the 2010-2011 rotation, soil test K levels at Sutherland following the 2010-2011 rotation, and soil test P and K levels at St Joseph following the 2010-2011 rotation were increased by the annual $2 \times$ treatment compared to all other treatments. In contrast, biennial $2 \times$ fertilizer applications resulted in the highest soil test $\mathrm{P}$ and $\mathrm{K}$ at Colt following the 2010-2011 rotation and soil test P following the 2010-2011 rotation at Baton Rouge. Treatment effects on corn grain yield were only observed at the Sutherland and Colt sites. At both sites, the biennial $1 \times$ application resulted in the lowest yield of all fertilizer treatments. Soil test value responses to fertilizer applications were not consistently increased, but, when observed, increases from annual applications tended to be more associated with greater corn grain yield than when soil test values were increased with biennial applications. 


\section{Conclusions}

Results of this study conducted at several locations showed that present fertilizer recommendations meet nutrient needs of corn and soybean. Corn and soybean yield increases in response to fertilizer applications were observed at sites with adequate fertility levels, but these responses were infrequent and in line with expected response frequencies. Corn yields were more responsive to fertilizer timing and rate than soybean. High fertilizer rates in excess of university fertilizer recommendations were observed to, at best, result in no significant increase in corn or soybean seed yield, and, at worst, result in significant yield reductions. These responses serve to reinforce the current widespread practice of biennial fertilizer applications preceding corn, applied at recommended rates, to supply both corn and soybean fertility needs in a high yield environment.

Author Contributions: Conceptualization, methodology and validation were undertaken by J.E.B., C.D.L., S.L.N., W.J.R. and K.D.T. Formal analysis and investigation were undertaken by T.J.B., L.L.R., W.A.K. and J.L.D.B. The original draft was written by T.J.B. and K.D.T. Review and editing were done by C.D.L., S.L.N., W.J.R. Visualization, supervision, project administration and funding acquisition were undertaken by C.D.L., S.L.N., W.J.R. and K.D.T.

Acknowledgments: The authors wish to thank the field personnel at Michigan State University, University of Arkansas, University of Kentucky, University of Minnesota, Iowa State University, and Louisiana State University, for their technical assistance and support in conducting this research. The authors would also like to thank the United Soybean Board for funding this research.

Conflicts of Interest: The authors declare no conflict of interest.

\section{References}

1. Mozaffari, M.; Slaton, N.A.; Hayes, S.; Griffin, B. Corn response to soil applied phosphorus and potassium fertilization in Arkansas. In Sabbe Arkansas Soil Fertility Studies 2011; Wayne, E., Slaton, N.A., Eds.; Research Series; Arkansas Agricultural Experiment Station, University of Arkansas: Fayetteville, AK, USA, 2012; p. 599.

2. Buah, S.S.J.; Polito, T.A.; Killorn, R. No-tillage soybean response to banded and broadcast and direct and residual fertilizer phosphorus and potassium applications. Agron. J. 2000, 92, 657-662. [CrossRef]

3. Webb, J.R.; Mallarino, A.P.; Blackmer, A.M. Effects of residual and annual applied phosphorus on soil test vales and yields of corn and soybean. J. Prod. Agric. 1992, 5, 148-152. [CrossRef]

4. Mallarino, A.P.; Webb, J.R.; Blackmer, A.M. Corn and soybean yields during 11 years of phosphorus and potassium fertilization on a high-testing soil. J. Prod. Agric. 1991, 4, 312-331. [CrossRef]

5. DeMoody, C.J.; Young, J.L.; Kaap, J.D. Comparative response of soybeans and corn to phosphorus and potassium. Agron. J. 1973, 65, 851-855. [CrossRef]

6. Murdock, L.; Schwab, G. 2010-2011 Lime and Nutrient Recommendations; University of Kentucky College of Agriculture: Lexington, KY, USA, 2010.

7. Sawyer, J.E.; Mallarino, A.P.; Killorn, R.; Barnhart, S.K. A General Guide for Crop Nutrient and Limestone Recommendations in Iowa; Publ. PM 1688 (Rev.); Iowa State Univercity Extension and Outreach: Ames, IA, USA, 2011.

8. Dodd, J.R.; Mallarino, A.P. Soil-test phosphorus and crop grain yield response to long-term phosphorus fertilization for corn-soybean rotations. Soil Sci. Soc. Am. J. 2005, 69, 1118-1128. [CrossRef]

9. McCallister, D.L.; Shapiro, C.A.; Raun, W.R.; Anderson, F.N.; Rehm, G.W.; Engelstad, O.P.; Russelle, M.P.; Olson, R.A. Rate of phosphorus and potassium buildup/decline with fertilization for corn and wheat on Nebraska Mollisols. Soil Sci. Soc. Am. J. 1987, 51, 1646-1652. [CrossRef]

10. Vitosh, M.L.; Johnson, J.W.; Mengel, D.B. Tri-State Fertilizer Recommendations for Corn, Soybean, Wheat and Alfalfa; Extension Bulletin E-2267; Michigan State University: East Lansing, MI, USA; Ohio State University: Columbus, OH, USA; Purdue University: West Lafayette, IN, USA, 1995.

11. Espinoza, L.; Slaton, N.; Mozaffari, M. Understanding the Numbers on Your Soil Test Report; Cooperative Extension Service FAS2118; University of Arkansas: Fayetteville, AR, USA, 2012.

12. Kaiser, D.E.; Lamb, J.A.; Eiason, R. Fertilizer Guidelines for Agronomic Crops in Minnesota; University of Minnesota: Minneapolis, MN, USA, 2011. 
13. Boring, T.J. Field Investigations of Foliar Fertilizer Strategies of Soybean Mn deficiency in Michigan and Phosphorus and Potassium Fertilizer Application Strategies in Corn-Soybean Rotations in the United States. Ph.D. Thesis, Michigan State University, East Lansing, MI, USA, 2013.

14. Frank, K.; Beegle, D.; Denning, J. Phosphorus: Recommended Chemical Soil Test Procedures for the North Central Region; North Central Regional Publ. 221 (Rev.); University of Missouri: Columbia, MO, USA, 1998; pp. 21-29.

15. Mehlich, A. Mehlich 3 soil extractant: A modification of Mehlich 2 extractant. Commun. Soil Sci. Plant Anal. 1984, 15, 1409-1416. [CrossRef]

16. Warncke, D.; Brown, J.R. Potassium and Other Basic Cations: Recommended Chemical Soil Test Procedures for the North Central Region; North Central Regional Publ. 221 (Rev.); University of Missouri: Columbia, MO, USA, 1998; pp. 31-33.

17. Young, F.J.; Hammer, R.D.; Maatta, J.M. Confidence intervals for soil properties based on differing statistical assumptions. Conf. Appl. Stat. Agric. 1992. [CrossRef]

18. Loescher, H.; Ayres, E.; Duffy, P.; Luo, H.; Brunke, M. Spatial variation in soil properties among North American Ecosystems and guidelines for sampling designs. PLoS ONE 2014, 9, e83216. [CrossRef] [PubMed]

19. Bruulsema, T.W. Understanding the science behind fertilizer recommendations. Better Crops Plant Food 2004, $88,16-19$.

20. Mallarino, A.P.; Bergmann, N.; Kaiser, D.E. Corn responses to in-furrow phosphorus and potassium starter fertilizer applications. Agron. J. 2011, 103, 685-694. [CrossRef]

21. Bordoli, J.M.; Mallarino, A.P. Deep and shallow banding of phosphorus and potassium as alternatives to broadcast fertilization for no-till corn. Agron. J. 1998, 90, 27-33. [CrossRef]

22. Anghinoni, I.; Barber, S.A. Phosphorus application rate and distribution in the soil and phosphorus uptake by corn. Soil Sci. Soc. Am. J. 1980, 44, 1041-1044. [CrossRef]

23. Heckman, J.R.; Kamprath, E.J. Potassium accumulation and corn yield related to potassium fertilization rate and placement. Soil Sci. Soc. Am. J. 1992, 56, 141-148. [CrossRef]

24. Muir, J.H.; Hedge, J.A. Corn response to phosphorus and potassium fertilization at different soil test levels. In Arkansas Soil Fertility Studies 2000; Norman, R.J., Chapman, S.L., Eds.; Research Series 480; Arkansas Agricultural Experiment Station, University of Arkansas: Fayetteville, AK, USA, 2001.

25. Muir, J.H.; Hedge, J.A. Corn response to phosphorus and potassium fertilization at different soil test levels. In Sabbe Arkansas Soil Fertility Studies 2001; Wayne, E., Slaton, N.A., Eds.; Research Series 490; Arkansas Agricultural Experiment Station, University of Arkansas: Fayetteville, AK, USA, 2002.

26. Ebelhar, S.A.; Varsa, E.C. Tillage and potassium placement effects on potassium utilization by corn and soybean. Commun. Soil Sci. Plant Anal. 2000, 31, 2367-2377. [CrossRef]

27. Farmaha, B.S.; Ferández, F.G.; Nafziger, E.D. No-till and strip-till soybean production with surface and subsurface phosphorus and potassium fertilization. Agron. J. 2011, 103, 1862-1869. [CrossRef]

28. Slaton, N.A.; DeLong, R.E.; Mozaffari, M.; Shafer, J.; Branson, J. Soybean response to phosphorus and potassium fertilization rate. In Sabbe Arkansas Soil Fertility Studies 2007; Wayne, E., Slaton, N.A., Eds.; Research Series; Arkansas Agricultural Experiment Station, University of Arkansas: Fayetteville, AK, USA, 2008; p. 558.

29. Slaton, N.A.; DeLong, R.E.; Ntamatungiro, S.; Clark, S.D.; Boothe, D.L. Phosphorus fertilizer rate and application time effect on soybean yield. In Arkansas Soil Fertility Studies 2000; Norman, R.J., Chapman, S.L., Eds.; Research Series; Arkansas Agricultural Experiment Station, University of Arkansas: Fayetteville, AK, USA, 2001; p. 480.

(C) 2018 by the authors. Licensee MDPI, Basel, Switzerland. This article is an open access article distributed under the terms and conditions of the Creative Commons Attribution (CC BY) license (http:/ / creativecommons.org/licenses/by/4.0/). 
Article

\title{
Bacillus Pumilus Strain TUAT-1 and Nitrogen Application in Nursery Phase Promote Growth of Rice Plants under Field Conditions
}

\author{
Khin Thuzar Win ${ }^{1, \dagger}$, Aung Zaw Oo ${ }^{1, \ddagger}$, Naoko Ohkama-Ohtsu ${ }^{2}$ and Tadashi Yokoyama ${ }^{2, *}$ \\ 1 Faculty of Agriculture, Tokyo University of Agriculture and Technology, Saiwaicho 3-5-8, Fuchu, \\ Tokyo 183-8509, Japan; khinthuzarwin@gmail.com (K.T.W.); aungzawo@gmail.com (A.Z.O.) \\ 2 Institute of Agriculture, Tokyo University of Agriculture and Technology, Saiwaicho 3-5-8, Fuchu, \\ Tokyo 183-8509, Japan; nohtsu@cc.tuat.ac.jp \\ * Correspondence: tadashiy@cc.tuat.ac.jp \\ $+\quad$ Current Address (K.T.W.): Central Region Agricultural Research Center, National Agriculture and Food \\ Research Organization (NARO), Tsukuba, Kanondai 2-1-18, Ibaraki 305-8666, Japan. \\ $\ddagger$ Current Address (A.Z.O.): Natural Science Research Unit, Tokyo Gakugei University, Koganei, \\ Tokyo 184-8501, Japan.
}

Received: 24 August 2018; Accepted: 1 October 2018; Published: 4 October 2018

\begin{abstract}
The aims of this study were to boost growth attributes, yield, and nutrient uptake of rice in paddy fields using a combination of Bacillus pumilus strain TUAT-1 biofertilizer and different nitrogen $(\mathrm{N})$ application rates in nursery boxes. Bacillus pumilus strain TUAT-1 was applied as an inoculant biofertilizer in conjunction with different rates of $\mathrm{N}$ fertilizer to rice seedlings in a nursery. Plant growth and yield parameters were evaluated at two stages: in 21-day-old nursery seedlings and in mature rice plants growing in a paddy field. Inoculation with TUAT-1 significantly increased the seedling growth and root morphology of 21-day-old nursery seedlings. There was a marked increase in chlorophyll content, plant height, number of tillers, and tiller biomass of rice plants with the use of TUAT- 1 and $\mathrm{N}$ fertilizers alone, and their combinations, at the maximum tillering stage in the field. The combination of TUAT- 1 and $100 \% \mathrm{~N}$ (farmer recommended rate of N) resulted in the greatest tiller number and biomass at the maximum tillering stage, and positively affected other growth attributes and yield. The growth and yield were similar in the TUAT- $1+50 \% \mathrm{~N}$ and $100 \% \mathrm{~N}$ (uninoculated) treatments, because TUAT-1 promoted root development, which increased nutrient uptake from the soil. These results suggest that the B. pumilus strain TUAT-1 has a potential to enhance the nutritional uptake of rice by promoting the growth and development of roots.
\end{abstract}

Keywords: biofertilizer; Bacillus pumilus; growth promotion; $\mathrm{N}$ fertilizer; rice; yield

\section{Introduction}

Rice (Oryza sativa L.) is considered as one of the world's most important staple foods and is the key to food security, especially under the threats of climate change in the coming decades [1]. The global rice cultivation area in 2015/2016 approached 158.8 million hectares, and total global rice production amounted to 711.24 million metric tons [2]. Nitrogen $(\mathrm{N})$ fertilizers are used extensively in rice cultivation to meet the growth demands of the crop. However, excessive use of chemical fertilizers, in recent decades, has led to soil toxicity by contamination with toxic heavy metals, which adversely affect the health of rice plants [3]. Inoculating rice plants with plant growth promoting rhizobacteria (PGPR) can significantly enhance rice production, thus reducing the need for $\mathrm{N}$ fertilizers and contributing to sustainable rice production and reduced environmental problems [4]. Therefore, the use of biological fertilizers for reducing chemical fertilizers is one of the most effective steps towards sustainable agriculture [5]. 
Several root-colonizing Bacillus species have been shown to enhance plant growth [6]. It is likely that the growth-promoting effects of various PGPR are due to bacterial production of plant growth regulators, such as auxins, gibberellins, and cytokinins $[7,8]$. Bacillus pumilus strain TUAT-1 (hereafter referred to as TUAT-1) has been shown to increase shoot and root growth in rice, mustard, radish, and komatsuna $[9,10]$, mainly due to its effects to promote nutrient uptake by plant roots. Inoculation of plants with TUAT-1 biofertilizer at sowing and transplanting resulted in significant changes in plant biomass, nutrient uptake, tissue $\mathrm{N}$ content, tiller number, root length, and number of roots in the forage rice "leaf star" [10]. Despite the large body of experimental evidence on the growth-promoting effects of TUAT-1, our knowledge of the conditions required for a consistent positive interaction between the bacteria and the plant (i.e., increased grain yield), in field conditions, is limited. Generally, bacterial inoculation improves plant growth and rice yield, but not uniformly. The yield response to inoculation is more pronounced in the presence of moderate levels of $\mathrm{N}$ fertilizer [11]. Fertilization management can also affect the community structures of plant-associated bacteria [12]. There is an ongoing debate regarding the impacts of fertilization strategies on the effects of PGPR [13].

Several studies have focused on interactions between PGPR and N fertilizers. However, the optimization of inoculant biofertilizer in conjunction with chemical $\mathrm{N}$ fertilizer for rice from the nursery tray to field stage has not been reported. We hypothesized that the combination of TUAT-1 biofertilizer and nitrogen fertilizer $(\mathrm{N})$ applied to rice seedlings in nursery trays will promote plant growth and ensure a consistent positive interaction between the bacterium and the plant in terms of grain yield under field conditions. The specific objectives of this study were as follows: (1) to determine the effect of nursery application of TUAT-1 biofertilizer and different $\mathrm{N}$ fertilizer rates on growth and root morphology of rice seedlings; and (2) to evaluate the effect these treatments on the growth, yield, and $\mathrm{N}$ content of the mature rice plants after transplanting into field conditions.

\section{Materials and Methods}

The TUAT-1 and N fertilizer treatments were applied to rice seedlings growing in nursery trays in a greenhouse. The treated rice plants were transplanted into a paddy field and grown to maturity.

\subsection{Soil Preparation and Chemical Analysis}

The experimental field site was the Fuchu Honmachi paddy field $\left(35^{\circ} 41^{\prime} \mathrm{N}, 139^{\circ} 29^{\prime} \mathrm{E}, 59 \mathrm{MSL}\right)$ of Tokyo University of Agriculture and Technology, Tokyo, Japan. Soil samples were collected from four points in each plot at a depth of $0-15 \mathrm{~cm}$, before the seedlings were transplanted. The samples were air dried, ground, and passed through a $2-\mathrm{mm}$ sieve. The soil physicochemical properties were measured using conventional methods [14,15], and are summarized in Table 1.

Table 1. Physiochemical properties of paddy soil $(0-15 \mathrm{~cm})$ in experimental plots.

\begin{tabular}{cc}
\hline Soil Physiochemical Property & Value \\
\hline $\mathrm{pH}\left(\mathrm{H}_{2} \mathrm{O}\right)$ & 6.25 \\
Total carbon content $(\%)$ & 5.25 \\
Total nitrogen content $(\%)$ & 0.33 \\
Cation-exchange capacity (cmolc/kg) & 20.55 \\
Sand (\%) & 40.12 \\
Silt (\%) & 32.27 \\
Clay (\%) & 27.61 \\
\hline
\end{tabular}

\subsection{Nursery Preparation}

One of the main cultivars of paddy rice (Oryza sativa L.) in Japan, Koshihikari, was used in this study. Seeds (100 g nursery tray ${ }^{-1}$ ) were surface-sterilized by immersion in $1 \%$ sodium hypochlorite solution for 2-3 $\mathrm{min}$, and in 80\% ethanol for 3-4 $\mathrm{min}$, before being washed thoroughly with distilled water. The seeds were then allowed to imbibe in tap water for $72 \mathrm{~h}$, and incubated for $12 \mathrm{~h}$ to hasten 
germination. Pre-germinated seeds were uniformly broadcast in each nursery tray $(30 \mathrm{~cm} \times 60 \mathrm{~cm})$ on 22 April 2015. Each nursery tray contained $3.2 \mathrm{~kg}$ commercial rice nursery soil (Shinano Soil, Shinano Baiyoudo Co., Ltd., Nagano, Japan). Before sowing the pre-germinated seeds, biofertilizer with or without TUAT-1 was mixed thoroughly into the soil at a rate of $5 \mathrm{~g}$ granular biofertilizer per $100 \mathrm{~g}$ soil (160 $\mathrm{g}$ in $3.2 \mathrm{~kg}$ soil). The density of TUAT-1 Bacillus cells in biofertilizer was approximately $1.2 \times 10^{7}$ colony forming units $(\mathrm{cfu}) \mathrm{g}^{-1}$. The experiment included eight different treatments combining $\mathrm{N}$ fertilizer at various application rates with or without TUAT1; (1) $0 \% \mathrm{~N}$, (2) TUAT-1 + $0 \% \mathrm{~N}$, (3) $50 \% \mathrm{~N}$, (4) TUAT-1 + 50\% N, (5) $100 \% \mathrm{~N}$, (6) TUAT-1 + 100\% N, (7) $150 \% \mathrm{~N}$, and (8) TUAT-1 + 150\% N. The N fertilizer was solid form of ammonium sulfate, $\left(\mathrm{NH}_{4}\right)_{2} \mathrm{SO}_{4}$. The $100 \% \mathrm{~N}$ rate consisted of $2.64 \mathrm{~g}$ $\left(\mathrm{NH}_{4}\right)_{2} \mathrm{SO}_{4}$ per nursery tray, which is the application rate recommended for rice farmers in Japan.

The TUAT-1 isolate was grown as a liquid culture in trypticase soy broth (TSB) (Becton Dickinson, Sparks, MD, USA). When the culture density reached $10^{7} \mathrm{cfu} \mathrm{mL}^{-1}$, overnight cultures were then centrifuged at $10,000 \mathrm{rpm}$ for $10 \mathrm{~min}$ at $6^{\circ} \mathrm{C}$, and were then washed twice in sterile Milli-Q water and diluted to an optical density of 0.4 at $600 \mathrm{~nm}$, corresponding to approximately $10^{7}$ cells $\mathrm{mL}^{-1}$. Five hundred milliliters were applied to each nursery seedling, once per week for 3 successive weeks. The treatments were arranged in a completely randomized design (CRD) and were replicated three times. At 21 days after sowing (DAS), 30 seedlings were randomly selected from three positions in each nursery tray, and the following data were recorded: chlorophyll content (SPAD value), shoot length, shoot biomass, total root length, root number, root surface area, root biomass, and total biomass.

Upon harvest, root systems were removed gently from the nursery tray and stored in $70 \%$ ethanol until root parameters were measured. At the time of measurement, the roots were washed gently with deionized water and the root surface area and total root length were measured with an image analyzer (Win-Rhizo REG V 2004 b; Regent Inc., Quebec, Canada).

\subsection{Transplanting of Rice Plants into the Paddy Field}

The field experiment was conducted at the experimental paddy field of the Tokyo University of Agriculture and Technology in Fuchu Honmachi, Tokyo, Japan. The experiment was conducted in a split-plot design with four replications. The $\mathrm{N}$, phosphorus, and potassium fertilizers were applied as basal dressings at the rate of $80\left(\left(\mathrm{NH}_{4}\right)_{2} \mathrm{SO}_{4}\right), 100\left(\mathrm{P}_{2} \mathrm{O}_{5}\right)$, and $30\left(\mathrm{~K}_{2} \mathrm{O}\right) \mathrm{kg} \mathrm{ha}^{-1}$, respectively. The roots of 21-day-old seedlings were reinoculated in a bacterial suspension $\left(10^{7} \mathrm{cfu} \mathrm{mL}^{-1}\right)$ or tap water (control) for 1 night before transplanting. The main plot treatment factor was presence/absence of TUAT-1, and the subplot treatment factor was $\mathrm{N}$ fertilization rate $(0 \%, 50 \%, 100 \%$, and $150 \% \mathrm{~N})$. Each plot was about $52 \mathrm{~m}^{2}(7.2 \mathrm{~m} \times 7.2 \mathrm{~m})$.

The 21-day-old seedlings were manually transplanted on 13 May 2015 into the paddy field at a planting density of 22.2 hills $\mathrm{m}^{2}$. Each hill contained three seedlings with $30 \mathrm{~cm}$ row spacing and $15 \mathrm{~cm}$ intra-row spacing. The experiment was conducted in irrigated paddy conditions. At 45 days after transplanting (DAT) in the field, chlorophyll content (SPAD value), plant height, tiller number, and tiller biomass were measured at the maximum tillering stage.

Upon harvest, 120 DAT, the following data were recorded: number of panicles, panicle length, panicle weight, straw yield, aboveground biomass, and grain yield. Straw yield and grain yield were recorded from 44 hills $\left(2 \mathrm{~m}^{2}\right)$ of each plot, which is reasonable for sampling in some area of Japan $[16,17]$. Grain yield was adjusted to $14 \%$ moisture content while straw yield was recorded on an oven-dry basis $\left(80^{\circ} \mathrm{C}\right)$. Nitrogen contents in the grain and straw samples were estimated colorimetrically after $\mathrm{H}_{2} \mathrm{SO}_{4}-\mathrm{H}_{2} \mathrm{O}_{2}$ wet digestion, as described by Mizuno and Minami [18].

\subsection{Data Analysis}

Analysis of variance was performed for all measurements with the CROP-STAT version 7.2 software (International Rice Research Institute, IRRI, Philippines). The statistical model included replication, TUAT-1, N rate, and the interaction between TUAT- 1 treatment and $\mathrm{N}$ rate. The results were subjected to a two-way analysis of variance, and mean values were then compared by $5 \%$ level 
by Fisher (LSD) test $(p<0.05)$ when the $F$ probability value was significant, using XLSTAT Version 2017 (Addinsoft, Paris, France). Data were reported as means \pm the standard deviation (SD).

\section{Results}

\subsection{Seedling Growth at Nursery Stage}

Root morphology was significantly changed with TUAT-1 inoculation in each $\mathrm{N}$ treatment when compared with its uninoculated treatment (Table 2). Rice seedlings receiving TUAT- $1+150 \% \mathrm{~N}$ showed the greatest root surface area and total length than that of these root parameters of uninoculated plants and other inoculated plants receiving $100 \% \mathrm{~N}, 50 \% \mathrm{~N}$, and $0 \% \mathrm{~N}$ (Table 2). Treatments of TUAT- $1+$ $150 \% \mathrm{~N}$ and TUAT- $1+100 \% \mathrm{~N}$ were on par with each other with respect to root surface area and it did not reach significant level between these two treatments. Root parameters increased by either of inoculation or $\mathrm{N}$ fertilizer application alone. The TUAT-1 inoculation and $\mathrm{N}$ fertilizer interactions were significant with respect to total root length.

Table 2. Effects of nitrogen (N) levels and TUAT-1 on chlorophyll content (SPAD value), shoot length plant-1 (SL), shoot biomass plant-1 (SB), root biomass plant-1 (RB), Total root length plant-1 (TRL) and root surface area plant-1 (RSA) (g) of 21 days old seedlings. Means in columns followed by the different letters are significantly different according to Least Significant difference (LSD) test $(p<0.05)$. $p$ values indicate that the differences are statistically significant (2-way ANOVA, $p<0.05$ ), ns = non-significant.

\begin{tabular}{|c|c|c|c|c|c|c|}
\hline Treatments & $S P A D$ & SL (cm) & SB (g) & RB (g) & TRL (cm) & $\operatorname{RSA}\left(\mathrm{cm}^{2}\right)$ \\
\hline $0 \% \mathrm{~N}$ & $18.6^{\mathrm{c}}$ & $12.1^{\mathrm{cd}}$ & $16.0^{\mathrm{b}}$ & $15.3^{\mathrm{d}}$ & $12.7^{\mathrm{f}}$ & $240.3^{d}$ \\
\hline $0 \% \mathrm{~N}+$ TUAT-1 & $19.6^{c}$ & $13.6^{c}$ & $21.6^{b}$ & $20.6^{c}$ & $19.7^{\text {de }}$ & $335.7^{c}$ \\
\hline $50 \% \mathrm{~N}$ & $18.1^{b c}$ & $15.2^{\mathrm{ab}}$ & $27.0^{\mathrm{a}}$ & $18.3^{c}$ & $17.1^{\text {ef }}$ & $268.7^{\mathrm{cd}}$ \\
\hline $50 \% \mathrm{~N}+$ TUAT-1 & $24.8^{\mathrm{cd}}$ & $15.0 \mathrm{bc}$ & $29.1^{a}$ & $25.0^{b}$ & $29.2 \mathrm{bc}$ & $466.9^{b}$ \\
\hline $100 \% \mathrm{~N}$ & $21.4^{b c}$ & $15.0^{\mathrm{ab}}$ & $25.3^{a}$ & $19.6^{c}$ & $18.7^{\text {de }}$ & $315.7^{c}$ \\
\hline $100 \% \mathrm{~N}+\mathrm{TUAT}-1$ & $26.8^{b c}$ & $15.2^{\mathrm{ab}}$ & $25.9^{a}$ & $25.9^{b}$ & $31.9^{b}$ & $520.9^{a b}$ \\
\hline $150 \% \mathrm{~N}$ & $25.4^{\mathrm{ab}}$ & $16.3^{a}$ & $26.9^{a}$ & $23.8^{\mathrm{b}}$ & $26.6^{\mathrm{cd}}$ & $405.3^{b}$ \\
\hline $150 \% \mathrm{~N}+\mathrm{TUAT}-1$ & $32.1^{\mathrm{a}}$ & $16.2^{\mathrm{a}}$ & $28.1^{\mathrm{a}}$ & $29.2^{a}$ & $39.2^{\mathrm{a}}$ & $682.0^{\mathrm{a}}$ \\
\hline Analysis of variance & \multicolumn{6}{|c|}{$p$ value } \\
\hline Nitrogen $(\mathrm{N})$ & 0.001 & 0.0001 & 0.0001 & 0.0001 & 0.0001 & 0.0001 \\
\hline TUAT-1 (T) & 0.006 & 0.957 & 0.127 & 0.0001 & 0.0001 & 0.0001 \\
\hline $\mathrm{N} \times \mathrm{T}$ & 0.439 & 0.512 & 0.387 & 0.76 & 0.074 & 0.127 \\
\hline
\end{tabular}

TUAT-1 inoculation significantly enhanced seedling growth. Rice nursery seedlings receiving TUAT- $1+150 \% \mathrm{~N}$ showed the highest chlorophyll content, shoot length, and shoot biomass (Table 2). The lowest growth parameters were recorded in uninoculated plants receiving $0 \% \mathrm{~N}$. Chlorophyll content was not significantly different among the treatments with and without TUAT- 1 inoculation (Figure 1A). At each N treatment, TUAT-1 inoculation showed a significant greater root biomass, as compared to those of their respective uninoculated plants. TUAT-1 inoculation did not enhance the shoot length and shoot biomass significantly over its respective uninoculated plants.

\subsection{Growth at Maximum Tillering Stage}

The effect of TUAT- 1 on growth at maximum tillering stage was significant at an $F$ probability level $p<0.002$. Increase of growth parameters measured at maximum tillering stage were also significant, due to $\mathrm{N}$ fertilization, with an $F$ probability level of $p<0.004$. The interaction effect between TUAT-1 and $\mathrm{N}$ fertilizer was also significant for chlorophyll content, plant height, and tiller biomass (Table 3 ). 
Table 3. Effects of $\mathrm{N}$ levels and TUAT-1 on chlorophyll content (SPAD value), plant height, tiller number (TN), and tiller biomass plant ${ }^{-1}(\mathrm{~TB})$ at 45 days after transplanting (DAT). The significance $\left(^{*}\right)$ derived from two ways analysis of $p$ value ${ }^{*},{ }^{* *}$, and ${ }^{* * *}$, significant at $p \leq 0.05, p \leq 0.01$, and $p \leq 0.001$, respectively. Means in columns, followed by the different letters, are significantly different according to LSD test $(p<0.05)$. $p$ values indicate that the differences are statistically significant (2-way ANOVA, $p<0.05)$, ns $=$ non-significant.

\begin{tabular}{|c|c|c|c|c|}
\hline Treatments & $S P A D$ & Plant Height $(\mathrm{cm})$ & TN & TB (g) \\
\hline $0 \% \mathrm{~N}$ & $39.6^{d}$ & $82.2^{c}$ & $8.7^{\mathrm{c}}$ & $9.5^{\mathrm{d}}$ \\
\hline $0 \% \mathrm{~N}+$ TUAT-1 & $40.2^{d}$ & $86.7^{a b}$ & $13.6^{\mathrm{ab}}$ & $17.0^{\mathrm{c}}$ \\
\hline $50 \% \mathrm{~N}$ & $40.0^{\mathrm{d}}$ & $82.8^{c}$ & $11.2^{b c}$ & $10.7^{\mathrm{d}}$ \\
\hline $50 \% \mathrm{~N}+$ TUAT-1 & $41.4^{\mathrm{c}}$ & $86.8^{a b}$ & $13.4^{\mathrm{ab}}$ & $18.4^{b c}$ \\
\hline $100 \% \mathrm{~N}$ & $40.5^{c}$ & $84.4^{\text {bc }}$ & $12.5^{\mathrm{ab}}$ & $16.2^{b c}$ \\
\hline $100 \% \mathrm{~N}+\mathrm{TUAT}-1$ & $41.7^{\mathrm{b}}$ & $88.4^{\mathrm{a}}$ & $15.7^{\mathrm{a}}$ & $20.9^{a}$ \\
\hline $150 \% \mathrm{~N}$ & $42.1^{\mathrm{a}}$ & $87.6^{\mathrm{a}}$ & $13.7^{\mathrm{ab}}$ & $18.6^{\mathrm{ab}}$ \\
\hline $150 \%$ N + TUAT-1 & $42.3^{\mathrm{ab}}$ & $89.1^{\mathrm{a}}$ & $16.4^{\mathrm{a}}$ & $21.8^{\mathrm{a}}$ \\
\hline Analysis of variance & & $p$ value & & \\
\hline Nitrogen $(\mathrm{N})$ & 0.002 & 0.0001 & 0.004 & 0.0001 \\
\hline TUAT-1 (T) & 0.001 & 0.001 & 0.002 & 0.0001 \\
\hline $\mathrm{N} \times \mathrm{T}$ & 0.232 & 0.023 & 0.536 & 0.029 \\
\hline
\end{tabular}

Under the field condition, chlorophyll content at maximum tillering stage was significant difference between the treatments with and without TUAT-1 inoculation at $50 \% \mathrm{~N}$ and $100 \% \mathrm{~N}$. TUAT-1 inoculation also promoted plant height at $0 \%, 50 \%$, and $100 \% \mathrm{~N}$ (Table 3). Besides plant height, tiller number and tiller biomass are also important parameters in terms of the vegetative growth of the plants, and these were also found to be increased in response to nursery application of TUAT-1 inoculation. The best combination of nursery seedling treatment with TUAT- 1 and different $\mathrm{N}$ rates on rice tiller number was observed in TUAT- $1+100 \% \mathrm{~N}$. The combined application of TUAT- $1+100 \% \mathrm{~N}$ also gave the best effect on dry matter accumulation (tiller biomass) by plants at maximum tillering stage followed by TUAT- $1+50 \% \mathrm{~N}$. The nursery application of TUAT- $1+150 \% \mathrm{~N}$ did not further enhance the above plant growth parameters significantly over application of TUAT- $1+100 \% \mathrm{~N}$.

\subsection{Yield and Yield Component Parameters}

The yield and yield components showed similar trends to those of other growth parameters at the maximum tillering stage. Application of $\mathrm{N}$ to nursery seedlings, alone or in combination with TUAT-1, led to significant increases in the number of panicles, panicle length, panicle weight, straw yield, aboveground biomass, and grain yield, compared with uninoculated plants with $0 \% \mathrm{~N}$ (Figure 1). The values of yield and yield components were significantly higher in TUAT-1-inoculated plants than in uninoculated plants, with $F$ probability levels range of $p-0.002$ to $p-0.048$. N fertilization also increased yield and yield components with $F$ probability values of $p<0.001$. Interaction between TUAT- 1 and $\mathrm{N}$ levels was not observed for yield and yield component characters.

Nursery treatments of TUAT- $1+100 \% \mathrm{~N}$ gave the best values on panicle length, number, and weight (Figure $1 \mathrm{~A}-\mathrm{C}$ ). No further significant increase in the above parameters was found in the treatment of TUAT- $1+150 \% \mathrm{~N}$. In the $0 \% \mathrm{~N}$ treatments, panicle length and number were significantly greater in TUAT-1-inoculated plants than in uninoculated plants (Figure 1A,B). In addition, TUAT-1 led to significant increases in the panicle weight compared with uninoculated plants with $50 \% \mathrm{~N}$ treatment (Figure 1C).

The maximum estimated straw yield was in the TUAT- $1+150 \% \mathrm{~N}$ treatment $\left(11.16\right.$ ton ha $\left.^{-1}\right)$, followed by the $150 \% \mathrm{~N}$ treatment $\left(9.72\right.$ ton ha $\left.{ }^{-1}\right)$, the TUAT- $1+100 \% \mathrm{~N}$ treatment $\left(9.69\right.$ ton ha $\left.{ }^{-1}\right)$, and then the TUAT- $1+50 \% \mathrm{~N}$ treatment $\left(9.18\right.$ ton ha $^{-1}$ ) (Figure 1D). In the $50 \%$ and $150 \% \mathrm{~N}$ treatments, the estimated straw yield was significantly higher in TUAT-1-inoculated plants than in the uninoculated 
plants. The aboveground biomass was also significantly higher in TUAT-1-inoculated plants with the $50 \% \mathrm{~N}$ treatment (Figure 1E).

The highest estimated grain yield was in the TUAT- $1+100 \% \mathrm{~N}$ treatment $\left(4.89\right.$ ton ha $\left.^{-1}\right)$ and the TUAT- $1+150 \% \mathrm{~N}$ treatment $\left(5.05\right.$ ton $^{-1}{ }^{-1}$ ) (Figure $\left.1 \mathrm{~F}\right)$. The grain yield of plants in the TUAT- $1+$ $50 \% \mathrm{~N}$ treatment $\left(4.4\right.$ ton $^{-1}$ ) was statistically insignificant to that of plants in the $100 \% \mathrm{~N}$ treatment $\left(4.6\right.$ ton $\mathrm{ha}^{-1}$ ) or TUAT- $1+100 \% \mathrm{~N}$.
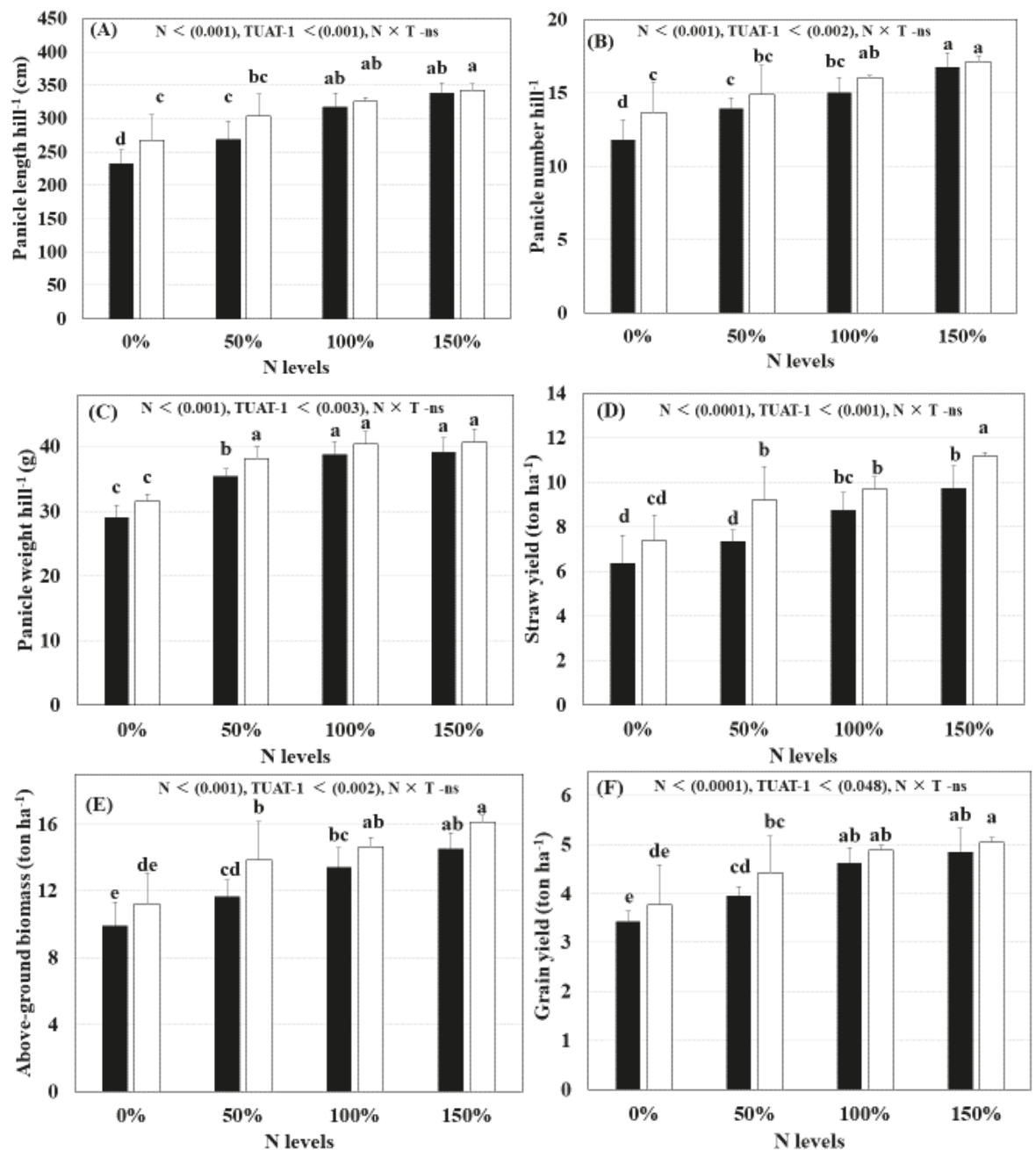

Figure 1. Effect of TUAT-1 biofertilizer and nitrogen fertilizer treatments at the seedling stage on yield and yield components of mature rice plants. (A) Panicle length hill ${ }^{-1}$, (B) panicle number hill ${ }^{-1}$, (C) panicle weight hill ${ }^{-1}$, (D) straw yield, (E) aboveground biomass, and (F) grain yield. Black and white bars represent uninoculated and inoculated with TUAT-1. Error bars indicate standard deviation. Different letters indicate significant difference at $5 \%$ level by Fisher (LSD) test $(p<0.05)$. $p$ values are shown in brackets. $p$ values indicate that the differences are statistically significant (2-way ANOVA, $p<0.05)$, ns = non-significant. 


\subsection{Nitrogen Content (\%) in Grain and Straw}

The patterns of $\mathrm{N}$ content in rice grain and straw were affected by TUAT-1 inoculation and $\mathrm{N}$ application levels in the nursery (Figure 2A,B). In the 50\% N treatment, grain $\mathrm{N}$ content was significantly higher in TUAT-1-inoculated plants than in uninoculated plants. However, TUAT-1 inoculation did not significantly increase grain $\mathrm{N}$ content in the other treatments. Nitrogen fertilization alone did not significantly promote $\mathrm{N}$ content in rice grain. TUAT-1 significantly increased the $\mathrm{N}$ content in straw in the $0 \% \mathrm{~N}$ treatments (Figure $2 \mathrm{~B}$ ).
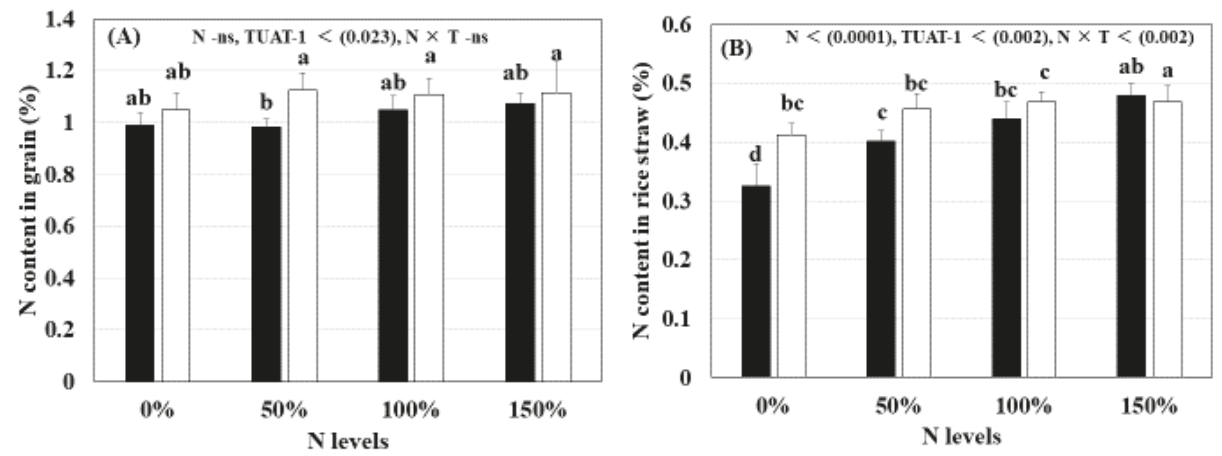

Figure 2. Effect of TUAT-1 biofertilizer and nitrogen fertilizer treatments at the seedling stage on $\mathrm{N}$ content (\%) (A) in grain and (B) in straw of mature rice plants. Black and white bars represent uninoculated and inoculated with TUAT-1, respectively. Error bars indicate standard deviation. Different letters indicate significant difference at $5 \%$ level by Fisher (LSD) test $(p<0.05)$. $p$ values are shown in brackets. $p$ values indicate that the differences are statistically significant (2-way ANOVA, $p<0.05)$, ns = non-significant.

\section{Discussion}

Seedling growth is the most important growth stage of any crop, as it determines the amount of biomass generated. In rice, it is also important for tiller development [19]. In our study, nursery seedling growth was increased by TUAT-1 inoculation (Table 2). The values of root parameters (total root length and root surface area) were significantly higher for TUAT-1-inoculated plants than for uninoculated plants. A larger and stronger root system can increase seedling vigor, plant growth, and micronutrient status [20]. An increase in rice root biomass in response to PGPR inoculation was also reported by Souza et al. [4]. The root system plays an important role in plant productivity because roots take up essential nutrients from the soil [21]. Various PGPR have been shown to enhance root hair proliferation and deformation, increase root branching, promote seedling emergence, and increase leaf surface area, vigor, biomass, endogenous plant hormone levels, and uptake of minerals and water [22,23].

After 21 days in the nursery, in each $\mathrm{N}$ treatment, rice seedlings inoculated with TUAT-1 produced approximately $17 \%$ greater total biomass than did uninoculated seedlings (Supplementary Figure S1). Like other PGPR, TUAT-1 produces growth-promoting and growth-regulating substances to support root growth, allowing inoculated rice plants to absorb more nutrients to enhance their growth. A wide range of nutrients and signaling molecules are exuded from roots, directing plant-microbe interactions [24]. The associated microbes may affect root morphogenesis [25], and many studies suggest that the acceleration of plant growth by PGPR involves phytohormone modulation. Numerous studies have reported on Plant growth-promoting bacteria (PGBs), particularly on Bacillus spp. exerting a number of characteristics enabling mobilization of soil nutrients and synthesis of 
phytohormones, leading to plant growth promotion [26-28]. Further research is required to determine the exact mechanism by which TUAT-1 promotes rice growth.

The combination of TUAT- 1 and different rates of $\mathrm{N}$ application in the nursery also have a significant effect on chlorophyll content, plant height, and tiller biomass at 45 DAT (Figure 2A). Promoting crop growth in the early stage is important for early and rapid tiller production. Herein, we suggested that TUAT-1 inoculation had the higher tiller biomass production as a result of vigorous early growth and early leaf expansion at tillering stage. Similar responses to fertilizer addition at the nursery stage were reported by Ros et al. [29] and Panda et al. [30]. Increased tiller number and tiller biomass have been reported for rice plants treated with PGPR [31].

Furthermore, in the other section of this study, the results of the present study also showed that the seedling growth parameters of root, such as total root surface area, total root length, and root biomass, increased significantly due to TUAT-1 inoculation, which can improve uptake of water and nutrition from soil. Wang et al. [32] also recently reported vigorous root growth and long and dense root hairs ensured efficient acquisition of macro- and micronutrients during early growth, and a high root length to shoot dry matter ratio favored high macronutrient concentrations in the shoots, which is assumed to be important for later plant development.

Herein, inoculating rice with TUAT-1 was also reported to improve the water and nutrition absorption capacity of the root system, and promote the absorption of $\mathrm{N}$ from soil during the early growth period [10]. Matsumura et al. [33] suggested that increased $\mathrm{N}$ absorption may promote tillering, increase the number of ears, and maintain photosynthetic activity during the growth period of the plant, so that crop yield is boosted. The increase in tiller number and tiller biomass by TUAT-1 may be due to the effects of Bacillus species to improve tolerance of plants to the drought and salinity stresses $[34,35]$ and their water and nutrient uptake ability [10]. Furthermore, compared with untreated seedlings, the seedlings treated with TUAT- 1 and $\mathrm{N}$ fertilizer with vigorous dense root systems and strong stems may have coped better with transplanting shock by rapidly developing new roots. It is likely that the vigorous dense root systems and strong stems contributed to the higher tiller production (biomass) in TUAT-1-inoculated plants than in uninoculated plants.

Nursery application of TUAT-1 with $\mathrm{N}$ fertilizer led to higher tiller number at the maximum tillering stage, which resulted in increased panicle number, panicle length, panicle weight, and yield (Figure 1). The higher panicle number resulted from increased number of effective tillers. Hence, increased panicle number resulted in increased panicle weight, leading to increased grain number per panicle and ultimately increased yield. The beneficial effects of PGPR on rice yield have been observed in both greenhouse and field conditions [36,37]. In our study, the combination of TUAT-1 and $\mathrm{N}$ fertilizer applied to rice plants at the nursery stage clearly increased the values of most growth parameters.

The greatest yield was shown in the TUAT- $1+150 \% \mathrm{~N}$ and the TUAT- $1+100 \% \mathrm{~N}$ treatments. The grain yield of plants in the TUAT- $1+50 \% \mathrm{~N}$ treatment $\left(4.4\right.$ ton ha $\left.{ }^{-1}\right)$ was statistically insignificant to that of uninoculated plants in the $100 \% \mathrm{~N}$ treatment $\left(4.6\right.$ ton ha $\left.^{-1}\right)$; that is, inoculation with TUAT-1 has a potential of reducing fertilizer use at the seedling stage by $50 \%$ without negatively affecting yield. This result is consistent with earlier studies by Okon and Labandera-Gonzalez [38] and Dobbelaere et al. [39], and beneficial effects of PGPB on crop yield were mainly observed under intermediate levels of fertilizer, rather than maximum or minimum fertilization. The similar rice grain yield in TUAT- $1+$ $50 \% \mathrm{~N}$ and $100 \% \mathrm{~N}$ may be ascribed to the significantly increased root to shoot growth at the seedling stage (Table 2), which can improve dry matter accumulation (tiller biomass) at maximum tillering stage (Table 3) by supplying a sufficient amount of nutrients, water, and phytohormones to shoots and, subsequently, ensure an increase in rice productivity [10]. We suggested that the nursery applications of $\mathrm{N}$ fertilizer at appropriate levels with TUAT- 1 biofertilizer in this field study may have masked our ability to observe significant growth impacts on rice grain yields. Previous investigations suggested that strategies combining both reduced rates of agriculture fertilizers and biofertilizers can benefit plant development and nutrient uptake $[40,41]$. 
Hence, on the basis of our results, we suggested that the inoculation of TUAT- 1 resulted in improving the growth of the rice plants and grain yield, and its inoculation may be applied to spare the use of chemical $\mathrm{N}$ fertilization. However, biofertilizer performance may be specific to each situation, as its effectiveness depends on factors like plant species, soil type, and environmental conditions [42]. Since the results reported here for enhancing of growth and yield of rice in the field experiment, as influenced by the application of a combination of TUAT- 1 and N fertilizer at the nursery stage, was conducted only for a one year experiment, we suggest that further studies should evaluate the performance of TUAT-1 in different field conditions/locations with different rice cultivars and environmental field conditions of specific issues for a given year. Such studies will determine whether TUAT- 1 can substantially decrease the use of chemical $\mathrm{N}$ fertilizers in rice cultivation, which is an important economic and environmental goal.

The increases in $\mathrm{N}$ contents in grain and straw as a result of $\mathrm{N}$ fertilization were consistent with the results of a previous study [43]. Growth promotion by inoculation with the TUAT-1 was accompanied by increased $\mathrm{N}$ levels in all plant tissues tested in forage rice [10]. TUAT- 1 inoculation significantly promoted straw $\mathrm{N}$ content $(\%)$ at $0 \% \mathrm{~N}$ and grain $\mathrm{N}$ content (\%) at $50 \% \mathrm{~N}$ than those of their respective uninoculated plants (Figure 2). It has been suggested that PGPR improves mineral nutrition, especially under low-N input conditions [19]. Hence, it is also postulated that growth promotion effects of TUAT-1 with a moderate amount of $\mathrm{N}$ application yielded the result, at least partly, of an enhanced $\mathrm{N}$ uptake efficiency. In the other studies, the enhancement of $\mathrm{N}$ uptake by plants inoculated with the PGPR strains might be through associative $\mathrm{N}$ fixation and phosphorus solubilization [44]. However, such evidence is lacking for TUAT-1. These observations could indicate that growth promotion mechanisms other than nitrogen fixation, such as phytohormone production, improved nutrient uptake balance. In addition, the higher nutrient uptake might be attributed to morphological changes in rice roots, such as increased root number, length, and thickness [45].

\section{Conclusions}

The increase in grain yield resulting from application of TUAT- 1 combined with $\mathrm{N}$ fertilizer to rice seedlings at the nursery stage could be related to the increased size of the root system at the early growth stage, which increased nutrient uptake to promote tiller growth (biomass), and yield. As observed the straw and yield were similar in the TUAT- $1+50 \% \mathrm{~N}$ and $100 \% \mathrm{~N}$ (un-inoculated) treatments, we conclude that TUAT- 1 biofertilizer should be used with $\mathrm{N}$ fertilizer at appropriate levels to maximize benefits in terms of saving fertilizer and improving yield.

Supplementary Materials: The following are available online at http:/ /www.mdpi.com/2073-4395/8/10/216/s1, Figure S1: Effect of TUAT-1 biofertilizer and nitrogen fertilizer on total biomass plant ${ }^{-1}$ at nursery stage.

Author Contributions: The individual contribution and responsibilities of the authors were as follows: K.T.W.: experiment, sample analysis, data analysis and article writing. T.Y.: research idea and design, and supervision of data collection and analysis. N.O.-O.: research idea and design and A.Z.O.: conceptualization, research idea and data analysis.

funding: (1) MAFF Japan: Research and development projects for application in promoting new policy of Agriculture Forestry and Fisheries [No.26073C], Research and development of new rice cultivation technology using multi-functional biofertilizer in order to increase of grain yield under low fertilizer input condition (2014 2016); (2) Special research fund of MEXT Japan: "Research and development of security and safe crop production to reconstruct agricultural lands in Fukushima prefecture based on novel techniques to remove radioactive compounds using advanced bio-fertilizer and plant protection strategies." (2012 2016).

Acknowledgments: This study was supported by MAFF Science and Technology Research Promotion Project for Agriculture, forestry and fisheries and food industries (26073C).

Conflicts of Interest: The authors declare no conflict of interest. 


\section{References}

1. Ali, J.; Aslam, U.M.; Tariq, R.; Murugaiyan, V.; Schnable, P.S.; Li, D.; Marfori-Nazarea, M.C.; Hernandez, J.E.; Arif, M.; Xu, J.; et al. Exploiting the Genomic Diversity of Rice (Oryza sativa L.): SNP-Typing in 11 Early-Backcross Introgression-Breeding Populations. Front. Plant Sci. 2018, 9, 849. [CrossRef] [PubMed]

2. World Rice Acreage from 2008/2009 to 2015/2016 (In Million Hectares): Statista; 2017. Available online: https:/ / www.statista.com/statistics/271969/world-rice-acreage-since-2008/ (accessed on 21 August 2017).

3. Habibah, J.; Le, P.T.; Khairiah, J.; Ahmad, M.R.; Fouzi, B.A.; Ismail, B.S. Speciation of heavy metals in paddy soils from selected areas in Kedah and Penang, Malaysia. Afri. J. Biotechnol. 2011, 4, 13505-13513. [CrossRef]

4. Souza, R.; Beneduzi, A.; Ambrosini, A.; Costa, P.B.; Meyer, J.; Vargas, L.K.; Schoenfeld, R.; Passaglia, L.M.P. The effect of plant growth-promoting rhizobacteria on the growth of rice (Oryza sativa L.) cropped in southern Brazilian fields. Plant Soil. 2013, 366, 585-603. [CrossRef]

5. Shariatmadari, Z.; Riahi, H.; Seyed-Hashtroudi, M.; Ghassempour, A.; Aghashariatmadary, Z. Plant growth promoting cyanobacteria and their distribution in terrestrial habitats of Iran. Soil Sci. Plant Nutri. 2013, 59, 535-547. [CrossRef]

6. Idris, E.E.S.; Iglesias, D.J.; Talon, M.; Borriss, R. Tryptophan-dependent production of Indole 3-Acetic Acid (IAA) affects level of plant growth promotion by Bacillus amyloliquefaciens FZB42. Mol. Plant Microbe Interact. 2007, 20, 619-626. [CrossRef] [PubMed]

7. Bottini, R.; Cassan, F.; Picolli, P. Gibberellin production by bacteria and its involvement in plant growth promotion and yield increase. Appl. Microbiol. Biotechnol. 2004, 65, 497-503. [CrossRef] [PubMed]

8. Bloemberg, G.V.; Lugtenberg, B.F.J. Molecular Basis of plant growth promotion and biocontrol by rhizobacteria. Curr. Opin. Plant Biol. 2001, 4, 343-350. [CrossRef]

9. $\quad$ Aung, H.P.; Salem, D.; Oo, A.Z.; Aye, Y.S.; Yokoyama, T.; Suzuki, S.; Sekimoto, H.; Bellingrath-Kimura, S.D. Growth and ${ }^{137} \mathrm{C}$ s uptake of four Brassica species influenced by inoculation with a plant growth-promoting rhizobacterium Bacillus pumilus in three contaminated farmlands in Fukushima prefecture, Japan. Sci. Total Environ. 2015, 521, 261-269. [CrossRef] [PubMed]

10. Torii, A. Analysis of field factors resulting frutuations of yield and nutritional uptakes of forage rice Leaf Star with inoculation of an endophytic nitrogen fixing bacteria TUAT-1. Master Thesis, Tokyo University of Agriculture and Technology, Tokyo, Japan, March 2012.

11. Rao, V.R.; Jena, P.K.; Adhya, T.K. Inoculation of rice with nitrogen-fixing bacteria problems and perspectives. Biol. Fertil. Soils. 1987, 4, 21-26.

12. Ikeda, S.; Okubo, T.; Kaneko, T.; Inaba, S.; Maekawa, T.; Eda, S.; Sato, S.; Tabata, S.; Mitsui, H.; Minamisawa, K. Community shifts of soybean stem-associated bacteria responding to different nodulation phenotypes and N levels. ISME J. 2010, 4, 315-326. [CrossRef] [PubMed]

13. Sasaki, K.; Ikeda, S.; Eda, S.; Mitsui, H.; Hanzawa, E.; Kisara, C.; Kazama, Y.; Kushida, A.; Shinano, T.; Minamisawa, K.; et al. Impact of plant genotype and nitrogen level on rice growth response to inoculation with Azospirillum sp. Strain B510 under paddy field conditions. Soil Sci. Plant Nutri. 2010, 56, 636-644. [CrossRef]

14. Blakemore, L.C.; Searle, P.L.; Daly, B.K. Science Report: Methods for Chemical Analysis of Soils; New Zealand Soil Bureau: Australia, 1977.

15. Klute, A. Methods of soil analysis, Part 1. In Physical and Mineralogical Methods, 2nd ed.; Soil Science Society of America, Inc.: Madison, WI, USA, 1990.

16. Yoshinaga, S.; Heinai, H.; Ohsumi, A.; Furuhata, M.; Ishimaru, T. Characteristics of growth and quality, and factors contributing to high yield in newly developed rice variety 'Akidawara'. Plant Prod. Sci. 2018, 21, 186-192. [CrossRef]

17. Saito, K.; Fukuta, Y.; Yanagihara, S.; Ahouanton, K.; Sokei, Y. Beyond NERICA: Identifying high-yielding rice varieties adapted to rainfed upland conditions in Benin and their plant Characteristics. Jpn. J. Trop. Agric. 2014, 58, 51-57.

18. Mizuno, N.; Minami, M. Rapid decomposition method for determination of N, K, Mg, Ca, Fe and Mn in agricultural plants with sulfuric acid and hydrogen peroxide. Jpn. Soil Sci. Plant Nutr. 1980, 51, 418-420. (In Japanese)

19. Sharma, A.; Shankhdhar, D.; Sharma, A.; Shankhdhar, S.C. Growth promotion of the rice genotypes by PGPRs isolated from rice rhizosphere. J. Soil Sci. Plant Nutri. 2014, 14, 505-517. [CrossRef] 
20. Lynch, J.P.; Lynch, A.F.; Jonathan, P. Roots of the second green revolution. Aust. J. Bot. 2007, 55, 493-512. [CrossRef]

21. Shaharoona, B.; Naveed, M.; Arshad, M.; Zahir, Z.A. Fertilizer-dependent efficiency of Pseudomonads for improving growth, yield, and nutrient use efficiency of wheat (Triticum aestivum L.). Appl. Microbiol. Biotechnol. 2008, 79, 147-155. [CrossRef] [PubMed]

22. Spaepen, S.; Vanderleyden, J.; Remans, R. Indole-3-acetic acid in microbial and microorganism-plant signaling. FEMS Microbiol Rev. 2007, 31, 425-448. [CrossRef] [PubMed]

23. Podile, A.R.; Kishore, G.K. Plant growth promoting rhizobacteria. In Plant Associated Bacteria; Gnanamanickam, S.S., Ed.; Springer: Amsterdam, The Netherlands, 2006; pp. 195-230. [CrossRef]

24. Badri, D.V.; Vivanco, J.M. Regulation and function of root exudates. Plant Cell Environ. 2009, 32, 666-681. [CrossRef] [PubMed]

25. Persello-Cartieaux, F.; Naussaume, L.; Robaglia, C. Tales from the underground: Molecular plantrhizobacteria interactions. Plant Cell Environ. 2003, 26, 189-199. [CrossRef]

26. Niu, D.D.; Liu, H.X.; Jiang, C.H.; Wang, Y.P.; Wang, Q.Y.; Jin, H.L.; Guo, J.H. The plant growth-promoting rhizobacterium Bacillus cereus AR156 induces systemic resistance in Arabidopsis thaliana by simultaneously activating salicylate-and jasmonate/ethylene-dependent signaling pathways. Mol. Plant Microbe. 2011, 24, 533-542. [CrossRef] [PubMed]

27. Wahyudi, A.T.; Astuti, R.P.; Widyawati, A.; Meryandini, A.; Nawangsih, A.A. Characterization of Bacillus spp. strains isolated from rhizosphere of soybean plants for their use as potential plant growth for promoting Rhizobacteria. J. Microbiol. Antimicrob. 2011, 2, 406-417.

28. Ortíz-Castro, R.; Valencia-Cantero, E.; López-Bucio, J. Plant growth promotion by Bacillus megaterium involves cytokinin signaling. Plant Signal Behav. 2008, 3, 263-265. [CrossRef] [PubMed]

29. Ros, C.; White, P.F.; Bell, R.W. Nursery Fertilizer Application Increases Rice Growth and Yield in Rainfed Lowlands with or without Post-Transplanting Crop Stress. Am. J. Plant Sci. 2015, 6, 2878-2892. [CrossRef]

30. Panda, M.M.; Reddy, M.D.; Sharma, A.R. Yield performance of rainfed lowland rice as affected by nursery fertilizer under conditions of intermediate deepwater $(15-50 \mathrm{~cm})$ and flash floods. Plant Soil. 1991, 132, 65-71. [CrossRef]

31. Kumar, K.V.K.; Yellareddygari, S.K.; Reddy, M.S.; Kloepper, J.W.; Lawrence, K.S.; Zhou, X.G.; Groth, D.E.; Krishnam Raju, S.K.; Miller, M.E. Efficacy of Bacillus subtilis MBI 600 against sheath blight caused by Rhizoctonia solani and on growth and yield of rice. Rice Sci. 2012, 9, 55-63. [CrossRef]

32. Wang, Y.; Thorup-Kristensen, K.; Jensen, L.S.; Magid, J. Vigorous Root Growth Is a Better Indicator of Early Nutrient Uptake than Root Hair Traits in Spring Wheat Grown under Low Fertility. Front. Plant Sci. 2016, 7, 865. [CrossRef] [PubMed]

33. Matsumura, S.; Ban, T.; Kanda, S.; Win, A.T.; Toyota, K. Biomass production and nutrient cycling. In Research Approaches to Sustainable Biomass Systems; Tojo, S., Hirasawa, T., Eds.; Elsevier: Oxford, UK, 2013; pp. $290-294$.

34. Khan, A.; Sirajuddin, M.; Zhao, X.Q.; Javed, T.; Khan, K.S.; Bano, A.; Shen, R.F.; Masood, S. Bacillus pumilus enhances tolerance in rice (Oryza sativa L.) to combined stresses of $\mathrm{NaCl}$ and high boron due to limited uptake of $\mathrm{Na}^{+}$. Environ. Experi. Bot. 2016, 124, 120-129. [CrossRef]

35. Armada, E.; Azcón, R.; López-Castillo, O.M.; Calvo-Polanco, M.; Ruiz-Lozano, J.M. Autochthonous arbuscular mycorrhizal fungi and Bacillus thuringiensis from a degraded Mediterranean area can be used to improve physiological traits and performance of a plant of agronomic interest under drought conditions. Plant Physiol. Biochem. 2015, 90, 64-74. [CrossRef] [PubMed]

36. Yadav, J.; Verma, J.P.; Jaiswal, D.K.; Kumar, A. Evaluation of PGPR and different concentration of phosphorus level on plant growth, yield and nutrient content of rice (Oryza sativa). Ecol. Eng. 2014, 62, 123-128.

37. Mishra, R.P.N.; Singh, R.K.; Jaiswal, H.K.; Kumar, V.; Maurya, S. Rhizobium-mediated induction of phenolics and plant growth promotion in rice (Oryza sativa L.). Curr. Microbiol. 2006, 52, 383-389. [CrossRef] [PubMed]

38. Okon, Y.; Labandera-Gonzalez, C.A. Agronomic applications of Azospirillum-An evaluation of 20 years worldwide field inoculation. Soil Biol. Biochem. 1994, 26, 1591-1601. [CrossRef]

39. Dobbelaere, S.; Croonenborghs, A.; Thys, A.; Ptacek, D.; Vanderleyden, J.; Dutto, P.; Labandera-Gonzalez, C.; Caballero-Mellado, J.; Aguirre, J.F.; Kapulnik, Y.; et al. Responses of agronomically important crops to inoculation with Azospirillum. Aust. J. Plant Physiol. 2001, 28, 871-879. [CrossRef]

40. Adesemoye, A.O.; Torbert, H.A.; Kloepper, J.W. Increased plant uptake of nitrogen from ${ }^{15} \mathrm{~N}$-depleted fertilizer using plant growth promoting rhizobacteria. Appl. Soil Ecol. 2010, 46, 54-58. [CrossRef] 
41. Duarah, I.; Deka, M.; Saikia, N.; Deka, B.H.P. Phosphate solubilizers enhance NPK fertilizer use efficiency in rice and legume cultivation. 3 Biotech 2011, 1, 227-238. [CrossRef] [PubMed]

42. Adesemoye, A.O.; Egamberdieva, D. Beneficial effects of plant growth-promoting rhizobacteria on improved crop production: Prospects for developing economies. In Bacteria in Agrobiology: Crop Productivity; Maheshwari, D.K., Saraf, M., Aeron, A., Eds.; Springer: Berlin, Germany, 2013; pp. 45-63. [CrossRef]

43. Liu, X.; Wang, H.; Zhou, J.; Hu, F.; Zhu, D.; Chen, Z.; Liu, Y. Effect of N fertilization pattern on rice yield, N use efficiency and fertilizer-N fate in the Yangtze river Basin, China. PLoS ONE 2016, 11, e0166002. [CrossRef] [PubMed]

44. Çakmakçi, R.; Dönmez, F.; Aydın, A.; Şahin, F. Growth promotion of plants by plant growth-promoting rhizobacteria under greenhouse and two different field soil conditions. Soil Biol. Biochem. 2006, 38, 1482-1487. [CrossRef]

45. Biswas, J.C.; Ladha, J.K.; Dazzo, F.B.; Yanni, Y.G.; Rolfe, B.G. Rhizobial inoculation influences seedling vigor and yield of rice. Agron. J. 2000, 92, 880-886. [CrossRef]

(C) 2018 by the authors. Licensee MDPI, Basel, Switzerland. This article is an open access article distributed under the terms and conditions of the Creative Commons Attribution (CC BY) license (http:/ / creativecommons.org/licenses/by/4.0/). 
Article

\title{
Green Manuring Effect on Changes of Soil Nitrogen Fractions, Maize Growth, and Nutrient Uptake
}

\author{
Lu Yang ${ }^{1,2}$, Jinshun Bai ${ }^{2}$, Jia Liu ${ }^{3}$, Naohua Zeng ${ }^{2}$ and Weidong Cao ${ }^{2, *}$ \\ 1 Graduate School, Chinese Academy of Agricultural Sciences, Beijing 100081, China; luckyyl_520@163.com \\ 2 Key Laboratory of Plant Nutrition and Fertilizer, Ministry of Agriculture and Rural Affairs/Institute of \\ Agricultural Resources and Regional Planning, Chinese Academy of Agricultural Sciences, \\ Beijing 100081, China; baijinshun@caas.cn (J.B.); zengnaohua@caas.cn (N.Z.) \\ 3 Institute of Soil \& Fertilizer and Resources \& Environment, Jiangxi Academy of Agricultural Sciences, \\ Nanchang 330200, China; liujia422@126.com \\ * Correspondence: caoweidong@caas.cn; Tel.: +86-10-8210-6733
}

Received: 10 September 2018; Accepted: 9 November 2018; Published: 12 November 2018

\begin{abstract}
Green manure is a promising, at least partial, substitution for chemical fertilizer in agriculture, especially for nitrogen $(\mathrm{N})$, which in soil can be radically changed by exogenous input. However, it is not well understood how, after green manure incorporation, soil $\mathrm{N}$ changes coordinate with crop $\mathrm{N}$ uptake and consequently contribute to fertilizer reduction in a maize-green manure rotation. A four-year field study was performed consisting of (1) control, no fertilization; (2) $F_{100}$, recommended inorganic fertilization alone; (3) $G$, green manure incorporation alone; (4) $F_{70}+G$ ( $70 \%$ of $F_{100}$ plus G); (5) $F_{85}+G$; and (6) $F_{100}+G$. The results show that treatments with $15-30 \%$ reduction of inorganic fertilizer (i.e., $\mathrm{F}_{70}+\mathrm{G}$ and $\mathrm{F}_{85}+\mathrm{G}$ ) had similar grain yield, dry matter $(\mathrm{DM})$ accumulation, and $N$ uptake as $F_{100}$ treatment. $F_{100}+G$ maize had $17 \%$ greater DM and $15 \%$ more $N$ uptake at maturity relative to $\mathrm{F}_{100}$. Of the five soil $\mathrm{N}$ fractions examined, dissolved organic $\mathrm{N}(\mathrm{DON})$ and mineral $\mathrm{N}\left(\mathrm{N}_{\min }\right)$ explained over $70 \%$ of the variation of maize $\mathrm{DM}$ and $\mathrm{N}$ accumulation. Partial least squares path modeling further revealed that soil $\mathrm{N}$ fractions had positive indirect effects on DM production through $\mathrm{N}$ uptake, which might be coordinated with improved DON and $\mathrm{N}_{\min }$ status at both early and mid-late stages of maize growth. Overall, the results highlight enhanced maize production with reduced fertilizer inputs based on green manure incorporation in temperate regions.
\end{abstract}

Keywords: green manure; nitrogen uptake; Orychophragmus violaceus L.; soil nitrogen pools; grain yield; Zea mays L.

\section{Introduction}

Improving crop yield and nutrient use efficiency simultaneously is challenging due to the increasing demand for food and intensifying environmental issues [1,2]. To pursue higher crop yields, farmers in some intensive agriculture areas of China apply excessively high rates of nitrogen $(\mathrm{N})$ and phosphorous (P) fertilizer. The annual $\mathrm{N}$ fertilizer input in a maize-wheat cropping system in North China is up to $588 \mathrm{~kg} \mathrm{ha}^{-1}$ year $^{-1}$, which far exceeds levels in the United States and Northern European countries [3]. However, the substantial inputs do not reliably maintain the expected yields [3,4]. The ratio of an average farmer's yield-to-yield potential is 0.41 [5], which illuminates a large yield gap for maize in this region. Much of the applied N fertilizer is lost to the environment [6], through nitrates leaching to groundwater [7] and greenhouse gas emissions [8]. Thus, it is of great importance to produce more grain yield with less environmental impact, e.g., lower nutrient losses [3,4].

Substitution of inorganic fertilizer by green manure has been adopted to reduce chemical inputs in agriculture [9,10]. Winter green manure Orychophragmus violaceus (OV)-maize rotation is an innovative eco-agricultural practice in the North China Plain, where OV is cultivated during the winter-spring 
fallow season (September to April) and well matched with the sowing of maize [11,12]. It is an alternative to maize-fallow or maize-wheat rotation that consumes plenty of groundwater and causes severe nutrient losses during the winter wheat season [13]. Integrated incorporation of OV residues with chemical fertilizers has been practiced to reduce nitrogen losses and improve grain yield and $\mathrm{N}$ economy in maize [11,12]. OV belongs to the Brassicaceae family, without the ability to fix atmospheric $\mathrm{N}_{2}$, but it can trap residual nitrate and reduce $\mathrm{N}$ leaching losses. Other members of the Brassicaceae family have been found to have extensive rooting depth, which has been shown to correlate with soil $\mathrm{N}$ depletion [10,14]. Therefore, in green manure-based systems, both inputs and losses of inorganic $\mathrm{N}$ fertilizer could be decreased [15-17]. In addition, previous studies have shown that, although $\mathrm{OV}$ crop is less capable than legume green manure Vicia villosa of enhancing soil $\mathrm{N}$ availability, the total ecological service value is slightly greater for OV crops (by $3.5 \%$ ) in terms of succeeding crop production, greenhouse gas and air pollutant reduction, water and soil conservation, and soil nutrient improvement [18]. The green manure-maize rotation may give farmers less gross return relative to wheat-maize rotation, while it is ecologically beneficial for sustainable development, at least outperforming maize-fallow rotation [18].

The effects of green manuring on crop growth and nutrient utilization are associated with an improvement in soil physiochemical properties, such as bulk density, water conductivity, and carbon and $\mathrm{N}$ levels $[10,19]$. Increasing $\mathrm{N}$ use efficiency in crop production highly depends on the synchrony between crop $\mathrm{N}$ demand and supply from various sources through the growing season $[4,20]$. A model-driven integrated soil-crop management system has been well established for maize production in the North China Plain based on the timing of in-season soil $\mathrm{N}$ monitoring and application [4], while many farmers are still applying $\mathrm{N}$ as basal fertilizer for maize in practice, leading to $\mathrm{N}$ losses and a mismatch between $\mathrm{N}$ supply and crop demand [6]. A previous study using ${ }^{15} \mathrm{~N}$ isotope technique showed that with the combination of green manure and fertilizer, $\mathrm{N}$ supply is greatly consistent with maize $\mathrm{N}$ requirements at different stages [11]. This is associated with the concept that green manure $\mathrm{N}$ could potentially be retained longer in soil when combined with inorganic $\mathrm{N}[11,21]$, implying coordinated effects of green manure incorporation on $\mathrm{N}$ uptake in maize. However, it is still not well understood how the coordination is processed between maize $\mathrm{N}$ uptake and soil $\mathrm{N}$ changes after $\mathrm{OV}$ incorporation.

The changes of soil $\mathrm{N}$ pools after green manure incorporation involve transformations between soil $\mathrm{N}$ fractions, such as microbial biomass $\mathrm{N}$, dissolved organic $\mathrm{N}$, and mineral $\mathrm{N}$. The positive effect of green manure incorporation on succeeding crop growth is proposed to relate to the stimulated microbial processes. Along with nitrate and ammonium, dissolved organic $\mathrm{N}$ is another soluble $\mathrm{N}$ source for microbes or plant uptake [22]. These three components are recognized as active fractions in soil $\mathrm{N}$ cycling and closely associated with plant $\mathrm{N}$ uptake [23]. Given the crucial role of soil N fractions in influencing crop $\mathrm{N}$ utilization, the objective of this study was to investigate the temporal changes of soil $\mathrm{N}$ fractions after $\mathrm{OV}$ incorporation and their effects on subsequent maize growth and $\mathrm{N}$ uptake in an $\mathrm{OV}$-maize rotation system.

\section{Materials and Methods}

\subsection{Field Experiments}

The field experiments were carried out from 14 September 2008, to 13 August 2012, at the Wanzhuang Experimental Station ( $\left.116^{\circ} 35^{\prime} \mathrm{E}, 39^{\circ} 34^{\prime} \mathrm{N}\right)$, Chinese Academy of Agricultural Sciences, China, on calcareous sandy soil. Before the start of the field experiment, maize was cultivated followed by a fallow season each year. Soil background properties at $0-20 \mathrm{~cm}$ depth were: organic matter $4.16 \mathrm{~g}$

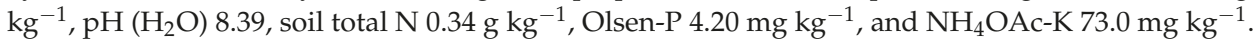
Green manure Orychophragmus violaceus L. (OV) was planted in September and incorporated into the soil the following April at its full blooming stage, followed by maize (hybrid Zhengdan 958) cultivation from May to August each year. The total yearly precipitation was $514 \mathrm{~mm}$, with $70 \%$ distributed in June, 
July, and August based on a 30-year average from 1981 to 2010 (http:/ / data.cma.cn/). Starting from October 2010 (the third cycle of OV-maize rotation), in-season meteorological data were recorded until the end of the experiment (Figure 1).

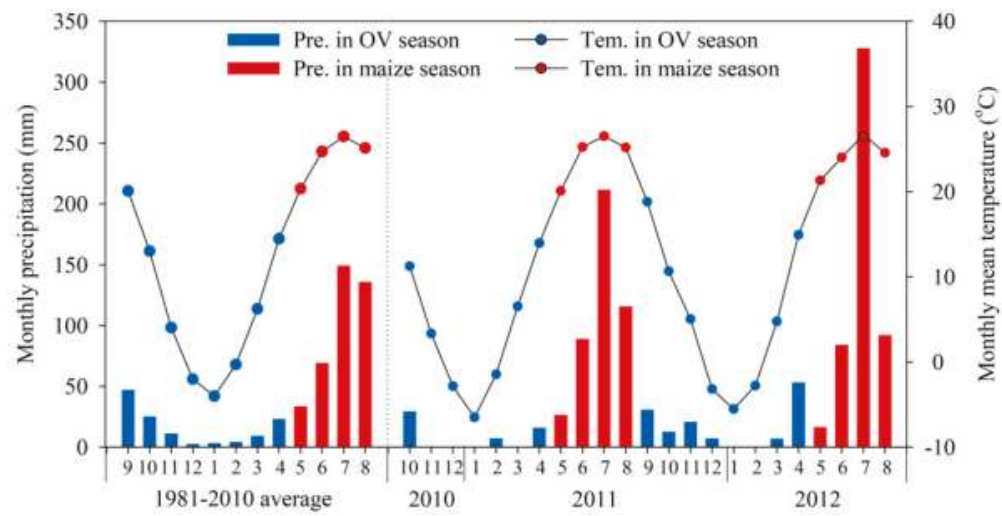

Figure 1. Monthly total precipitation (pre.) and average temperature (tem.) during the green manure (Orychophragmus violaceus (OV)) season (blue) and maize growing season (red) based on the 30-year average from 1981-2010 and in-season recording from October 2010 to August 2012.

The following regimes of inorganic fertilization or green manure incorporation were followed, as given in Table 1: (1) control, no fertilizer application and no OV incorporation; (2) $F_{100}$, the recommended fertilizer rate, alone; (3) G, incorporation of green manure OV alone; (4) $F_{70}+G\left(70 \%\right.$ of $F_{100}$ plus G); (5) $F_{85}+G$ (85\% of $\mathrm{F}_{100}$ plus $\mathrm{G}$ ); and (6) $\mathrm{F}_{100}+\mathrm{G}$. The 6 treatments were imposed on a randomized complete block design with 4 replications. Each treatment was in the same plot in all study years. Each plot was $4.8 \mathrm{~m}$ long and $2.4 \mathrm{~m}$ wide. The fertilizer rate of $\mathrm{F}_{100}$ was recommended by the National Soil Testing and Fertilization Recommendation Project on a yield basis for farmers in this region of China, which was also consistent with other reports [4,24]. Amounts of $225 \mathrm{~kg} \mathrm{~N} \mathrm{ha}^{-1}, 49 \mathrm{~kg} \mathrm{P} \mathrm{ha}^{-1}$, and $94 \mathrm{~kg} \mathrm{~K} \mathrm{ha}^{-1}$ were applied as urea, super phosphate, and potassium sulfate, respectively. A half rate of $\mathrm{N}$ and full rates of $\mathrm{P}$ and $\mathrm{K}$ were applied as base fertilizer before sowing, and the remaining half rate of $\mathrm{N}$ was top-dressed at maize tasseling. Maize seedlings were hand-thinned to a stand of 75,000 plants ha ${ }^{-1}$.

No fertilizer was applied during the OV growth. Green manure OV was grown in situ and incorporated from 2008 to 2011, while part of the OV residues was imported to the field with an OV incorporation amount of 22,500 kg/ha in 2012 (Table 2). That year, the biomass of green manure in some of the plots, such as in treatment $\mathrm{G}$, was extremely low. To investigate the effects of green manure incorporation, certain amounts of OV residues were introduced from an adjacent field. The water content of fresh OV residues for incorporation ranged from $83.4 \%$ to $87.5 \%$, and the carbon (C), $\mathrm{N}$, $\mathrm{P}$, and $\mathrm{K}$ concentrations were, respectively, $38.2 \%, 2.38-3.36 \%, 0.33-0.51 \%$, and $3.32-3.53 \%$ on a dry weight basis in different years. Fresh OV residues were incorporated into $0-20 \mathrm{~cm}$ soil 8 days before maize sowing each year. The total amounts of $\mathrm{OV}$ incorporation and nutrients introduced each year are listed in Table 2. The $\mathrm{C} / \mathrm{N}$ ratio of decomposing OV residues in maize season (from OV incorporation to maize maturity) ranged from 9.7 to 15.3 , with an average of 13 [25]. 
Table 1. Cropping system and chemical fertilizer input for each treatment.

\begin{tabular}{clccc}
\hline \multirow{2}{*}{ Treatment } & Cropping System & \multicolumn{3}{c}{ Input of Chemical Fertilizer Each Year (kg/ha) ${ }^{\mathbf{1}}$} \\
\cline { 3 - 5 } & & $\mathbf{N}$ & $\mathbf{P}$ & $\mathbf{K}$ \\
\hline Control & Maize-winter fallow & 0 & 0 & 0 \\
$\mathrm{~F}_{100}$ & Maize-winter fallow & 225 & 49 & 94 \\
$\mathrm{G}$ & Maize-green manure & 0 & 0 & 0 \\
$\mathrm{~F}_{70}+\mathrm{G}$ & Maize-green manure & 158 & 34 & 66 \\
$\mathrm{~F}_{85}+\mathrm{G}$ & Maize-green manure & 191 & 42 & 80 \\
$\mathrm{~F}_{100}+\mathrm{G}$ & Maize-green manure & 225 & 49 & 94
\end{tabular}

${ }^{1}$ Chemical fertilizer was applied only for maize growth, and not for green manure. $F_{100}$, the recommended fertilizer rate, alone; $G$, incorporation of green manure OV alone; $F_{70}+G, 70 \%$ of $F_{100}$ plus $G ; F_{85}+G, 85 \%$ of $F_{100}$ plus $G$.

Table 2. Amounts of incorporated green manure and introduced nutrients for each treatment.

\begin{tabular}{|c|c|c|c|c|c|c|c|c|}
\hline \multirow{2}{*}{ Treatment } & \multicolumn{4}{|c|}{ Incorporated Amount of Green Manure (Fresh Weight, $\left.\mathrm{tha}^{-1}\right)^{1}$} & \multicolumn{4}{|c|}{ Amount of Introduced Nutrient by Green Manure (N-P-K) $\left(\mathrm{kg} \mathrm{ha}^{-1}\right)$} \\
\hline & 2009 & 2010 & 2011 & 2012 & 2009 & 2010 & 2011 & 2012 \\
\hline Control & 0 & 0 & 0 & 0 & 0 & 0 & 0 & 0 \\
\hline$F_{100}$ & 0 & 0 & 0 & 0 & 0 & 0 & 0 & 0 \\
\hline G & 15.6 & n.d. ${ }^{2}$ & 4.6 & $22.5(18.7)^{3}$ & $52.6-9.6-77.4$ & n.d. & $21.5-2.2-21.2$ & $94.0-9.8-99.2(78.5-8.2-82.7)^{3}$ \\
\hline $\mathrm{F}_{70}+\mathrm{G}$ & 15.6 & n.d. & 10.2 & $22.5(10.9)$ & $52.6-9.6-77.4$ & n.d. & $48.0-4.8-47.0$ & $94.0-9.8-99.2(45.8-4.8-48.2)$ \\
\hline $\mathrm{F}_{85}+\mathrm{G}$ & 15.6 & n.d. & 19.0 & $22.5(6.3)$ & $52.6-9.6-77.4$ & n.d. & $89.8-9.0-87.9$ & $94.0-9.8-99.2(26.5-2.8-27.9)$ \\
\hline $\mathrm{F}_{100}+\mathrm{G}$ & 15.6 & n.d. & 15.2 & $22.5(7.0)$ & $52.6-9.6-77.4$ & n.d. & $71.5-7.2-70.0$ & $94.0-9.8-99.2(29.4-3.1-31.0)$ \\
\hline
\end{tabular}

\subsection{Sampling and Measurements}

Maize grain yield was measured based on the entire plot every year, while the dynamics of soil $\mathrm{N}$ fractions and their effects on maize $\mathrm{N}$ uptake were investigated in the final year, 2012. Plants and 0-20 cm soils were sampled at the V3 (third leaf fully expanded), V8 (eighth leaf fully expanded), VT (tasseling), R3 (milk), and R6 (physiological maturity) stages of maize growth. Soil samples at the maize tasseling stage were taken before the second $\mathrm{N}$ application. At each harvest, 3 uniform and randomly selected maize plants from each plot were cut at the stem base. The shoot parts were dried at $70{ }^{\circ} \mathrm{C}$ to a constant weight, weighed, and ground to a fine powder. Around $0.2 \mathrm{~g}$ of plant material was used to determine total $\mathrm{N}$ concentration using a modified Kjeldahl digestion method [26]. The remaining digests were used for analysis of total $\mathrm{P}$ concentration (molybdivanadate method) by automated colorimetry [27] and total K concentration by a flame photometer [28].

Soil $\mathrm{N}$ fractions were analyzed as follows: (1) Soil total $\mathrm{N}$ content was measured with a Kjeldahl method [29]. (2) Soil mineral $\mathrm{N}\left(\mathrm{N}_{\min }=\mathrm{NO}_{3}{ }^{-}-\mathrm{N}+\mathrm{NH}_{4}{ }^{+}-\mathrm{N}\right)$ was extracted with $2 \mathrm{~mol} \mathrm{~L}{ }^{-1} \mathrm{KCl}$ and measured with continuous flow analysis (Seal AA3, Norderstedt, Germany). (3) Soil organic N: soil samples were extracted by $2 \mathrm{~mol} \mathrm{~L}^{-1} \mathrm{KCl}$ (soil-to-solution ratio 1:5, w:v) for $60 \mathrm{~min}$. The supernatant was carefully discarded, and the soil was re-extracted by $2 \mathrm{~mol} \mathrm{~L}^{-1} \mathrm{KCl}$ (soil-to-solution ratio 1:2.5, $w: v)$ for $20 \mathrm{~min}$ and centrifuged, and the supernatant was removed. The pellet soil was washed with distilled water by shaking for $20 \mathrm{~min}$, dried at $60^{\circ} \mathrm{C}$, and analyzed for $\mathrm{N}$ content with the Kjeldahl method [29]. (4) The fumigation extraction method was used to determine soil microbial biomass $\mathrm{N}$ (SMBN) [30]. Briefly, each fresh soil sample was divided into 6 subsamples (equivalent to $25 \mathrm{~g}$ oven-dried weight). Three unfumigated subsamples were immediately extracted with $100 \mathrm{~mL} 0.5 \mathrm{M}$ $\mathrm{K}_{2} \mathrm{SO}_{4}$ on a rotary shaker at $220 \mathrm{rpm}$ for $30 \mathrm{~min}$ and then filtered through Whatman qualitative filter paper. The remaining 3 subsamples were fumigated with alcohol-free chloroform for $24 \mathrm{~h}$ at $25^{\circ} \mathrm{C}$, and then extracted and filtered as described above. Soil filtrates were stored at $-20^{\circ} \mathrm{C}$ prior to $\mathrm{N}$ assay. The SMBN content was calculated by the $\mathrm{N}$ differences between fumigated and unfumigated samples with a conversion factor of 0.54 [30]. (5) The soil dissolved organic N (DON) content was expressed as the difference between total dissolved $\mathrm{N}$ content and $\mathrm{N}_{\min }$ content, extracted with $0.5 \mathrm{M} \mathrm{K}_{2} \mathrm{SO}_{4}$ and $2 \mathrm{M} \mathrm{KCl}$, respectively, using the method by Jones and Willett [31]. 


\subsection{Statistical Analysis}

Data were subjected to analysis of variance using PROC ANOVA with SAS package 9.1 (SAS Institute, Cary, NC, USA). The management of OV incorporation and/or fertilizer application was treated as a fixed effect and replications as random factors. The least significant difference (LSD) was used to determine treatment differences at a $p<0.05$ level of probability.

The relative weight analysis and partial least squares path modeling (PLS-PM) were performed in R with "relweights" [32] and "plspm" [33] packages, respectively. Pooled data from 120 samples across treatments and stages were used for the analysis. The PLS-PM model path used 1000 bootstraps to validate the estimates of path coefficients and the coefficients of determination $\left(r^{2}\right)$. The direct effects were represented by path coefficients, indicating the direction and strength of the linear relationships between variables. Indirect effects were the sum of multiplied path coefficients between a predictor and a response variable except the direct effect. Path model was evaluated using the goodness of fit statistic to measure its overall predictive power.

\section{Results}

\subsection{Effects of OV Incorporation on Maize Growth, Yield, and Nutrient Uptake}

High variability was observed between years $(p=0.0013)$, as well as between treatments $(p<0.0001)$ and years by treatment $(p<0.0001)$ (Figure 2$)$. Maize grain yield in the control without fertilization declined from 6.1 to $3.2 \mathrm{tha}^{-1}$ over the years, implying an unsustainable development of maize production (Figure 2). Compared to the control, the average grain yield was $22 \%$ greater in the $\mathrm{G}$ treatment, and was further increased by the F plus $\mathrm{G}$ combinations $(p<0.05$; Figure 2). On average, similar grain yield around $9 \mathrm{t} \mathrm{ha}^{-1}$ was observed in the $\mathrm{F}_{100}, \mathrm{~F}_{70}+\mathrm{G}$, and $\mathrm{F}_{85}+\mathrm{G}$ treatments.

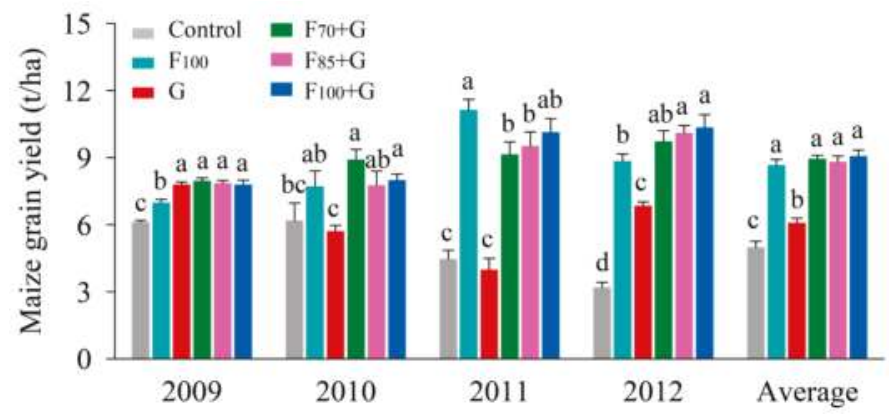

Figure 2. Maize grain yield and average yield from 2009 to 2012. Data are mean \pm standard error (vertical bars, $n=4$ ). Different letters above columns indicate statistical differences between treatments by least significant difference (LSD) test $(p<0.05)$. Control, no fertilization; $\mathrm{F}_{100}$, recommended inorganic fertilization alone; $G$, green manure incorporation alone; $F_{70}+G, F_{85}+G$, and $F_{100}+G$ are $70 \%, 85 \%$, and $100 \%$ of $F_{100}$ plus $G$, respectively. 
Dry matter (DM) accumulation and N uptake in the G treatment were $28-114 \%$ and $83 \%$ to $146 \%$ greater, respectively, than the control across maize developmental stages, but were still far lower than other $F$ plus $G$ treatments (Figure $3 a, b$ ). No significant differences were detected between $F_{100}$, $\mathrm{F}_{70}+\mathrm{G}$, and $\mathrm{F}_{85}+\mathrm{G}$ treatments. Compared to $\mathrm{F}_{100}$, maize plants in the $\mathrm{F}_{100}+\mathrm{G}$ treatment had $17 \%$ greater DM accumulation and 15\% more N uptake at maturity, respectively $(p<0.05$; Figure 3a,b). In addition, the $\mathrm{P}$ and $\mathrm{K}$ uptake in G-treated maize was 0.7 - and 1.2-fold greater, respectively, than in the control plants. $F_{70}+G, F_{85}+G$, and $F_{100}+G$ treatments had similar P uptake compared to $F_{100}$ treatment, while $\mathrm{K}$ uptake was significantly increased by $55 \%, 48 \%$, and $50 \%$, respectively, at maturity (Figure 3c,d).
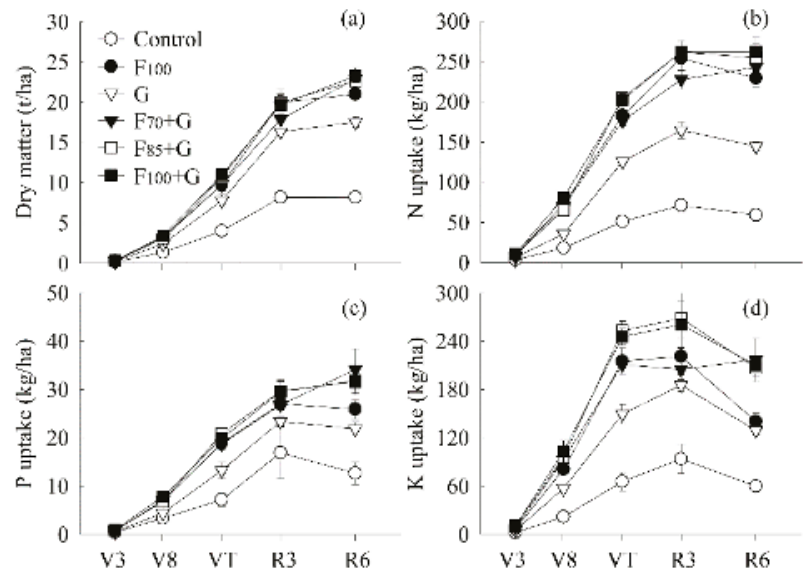

Figure 3. (a) Dry matter accumulation, (b) nitrogen (N) uptake, (c) phosphorus (P) uptake, and (d) potassium (K) uptake along maize development stages in 2012. Vertical bars indicate standard error of means $(n=4)$. V3 and V8 (the third and eighth leaf fully expanded, respectively), VT (tasseling), R3 (milk), and R6 (physiological maturity). Control, no fertilization; $\mathrm{F}_{100}$, recommended inorganic fertilization alone; $G$, green manure incorporation alone; $F_{70}+G, F_{85}+G$, and $F_{100}+G$ are $70 \%$, 85\%, and $100 \%$ of $F_{100}$ plus $G$, respectively.

3.2. Temporal Changes of Soil N Fractions during Maize Growth as Influenced by Fertilizer Application and OV Incorporation

Total $\mathrm{N}$ and organic $\mathrm{N}$ contents of soil were relatively constant during maize growth, with a slight decrease after harvest (Figure 4). Compared to the initial total soil $\mathrm{N}$ content $(0.34 \mathrm{~g} / \mathrm{kg})$ in 2008 , the value in the control treatment remained fairly constant, while total soil $\mathrm{N}$ increased in most treatments with fertilizer and OV incorporation. $F_{70}+G, F_{85}+G$, and $F_{100}+G$ treated soil had similar or greater contents of total $\mathrm{N}$ and organic $\mathrm{N}$ than $\mathrm{F}_{100}$ treatment through the maize growing seasons. The $\mathrm{OV}$ incorporation alone led to lower levels of soil total $\mathrm{N}$ and organic $\mathrm{N}$ than $\mathrm{F}$ plus $\mathrm{G}$ treatments (Figure 4). 


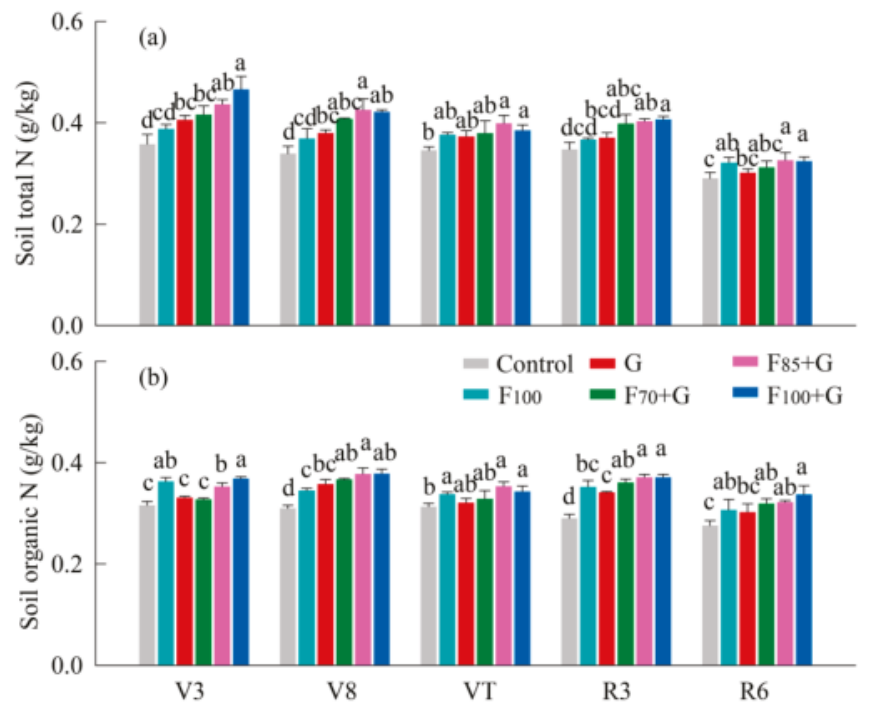

Figure 4. Changes of soil (a) total $\mathrm{N}$ and (b) organic $\mathrm{N}$ in the $0-20 \mathrm{~cm}$ soil layer during maize growth. Data are mean \pm standard error (vertical bars, $n=4$ ). Different letters above columns at each harvest indicate statistical differences between treatments by LSD test $(p<0.05)$. V3 and V8 (the third and eighth leaf fully expanded, respectively), VT (tasseling), R3 (milk), and R6 (physiological maturity). Control, no fertilization; $\mathrm{F}_{100}$, recommended inorganic fertilization alone; $\mathrm{G}$, green manure incorporation alone; $F_{70}+G, F_{85}+G$, and $F_{100}+G$ are $70 \%, 85 \%$, and $100 \%$ of $F_{100}$ plus $G$, respectively.

In contrast to soil total $\mathrm{N}$ and organic $\mathrm{N}$, the contents of soil microbial biomass $\mathrm{N}$ (SMBN), mineral $\mathrm{N}\left(\mathrm{N}_{\min }\right)$, and dissolved organic $\mathrm{N}(\mathrm{DON})$ fluctuated over maize development stages, with greater values occurring at V3 and V8 (Figure 5). At these two stages, the SMBN content was 25-44\% greater in the $F_{70}+G, F_{85}+G$, and $F_{100}+G$ treatments than both control and $F_{100}$ treatment (Figure 5a). The DON content was also significantly increased in F plus $G$ treatments over control or $F_{100}$ during maize growth, especially at the stem elongation V8 (Figure $5 \mathrm{~b}$ ). The $\mathrm{N}_{\text {min }}$ content was quite sensitive to inorganic fertilizer $\mathrm{N}$ input and environmental conditions, where the higher fertilizer $\mathrm{N}$ application generally produced more $\mathrm{N}_{\text {min }}$ than the control or $\mathrm{G}$ treatment (Figure $5 \mathrm{c}$ ). However, with 15-30\% reduction of fertilizer $N$ application, similar $N_{\min }$ content was obtained with $F_{70}+G$ and $F_{85}+G$ and $F_{100}$ treatments, while it was further increased by $F_{100}+G$ treatment. Soil $N_{\text {min }}$ content decreased to a low level after the V8 stage, but was still greater in F and G treatments than control.

\subsection{Interactions between Soil N Fractions and Maize Growth and Nutrient Uptake}

A relative weights analysis was performed to quantify the relative contribution of soil $\mathrm{N}$ fractions to maize growth and $\mathrm{N}$ uptake (Figure 6). Of the five $\mathrm{N}$ fractions examined in the present study, DON and $\mathrm{N}_{\min }$ together explained over $70 \%$ of the variation in DM production and $\mathrm{N}$ uptake, i.e., there was a greater contribution of these two $\mathrm{N}$ components than other variables (soil total N, organic N, and SMBN).

Further, large indirect effects (0.53, calculated as the sum of multiplied path coefficients from soil $\mathrm{N}$ to yield except the direct effect) of soil $\mathrm{N}$ status on maize grain yield were observed through plant nutrient uptake and DM production in the PLS-PM model (Figure 7). The direct effects of soil N on nutrient uptake, plant NPK uptake on dry matter production, and dry matter production on final grain yield were $0.66(p<0.001), 0.99(p<0.001)$, and $0.83(p<0.01)$, respectively, which together constituted a predominant indirect path from soil $\mathrm{N}$ pools to grain yield (Figure 7). 

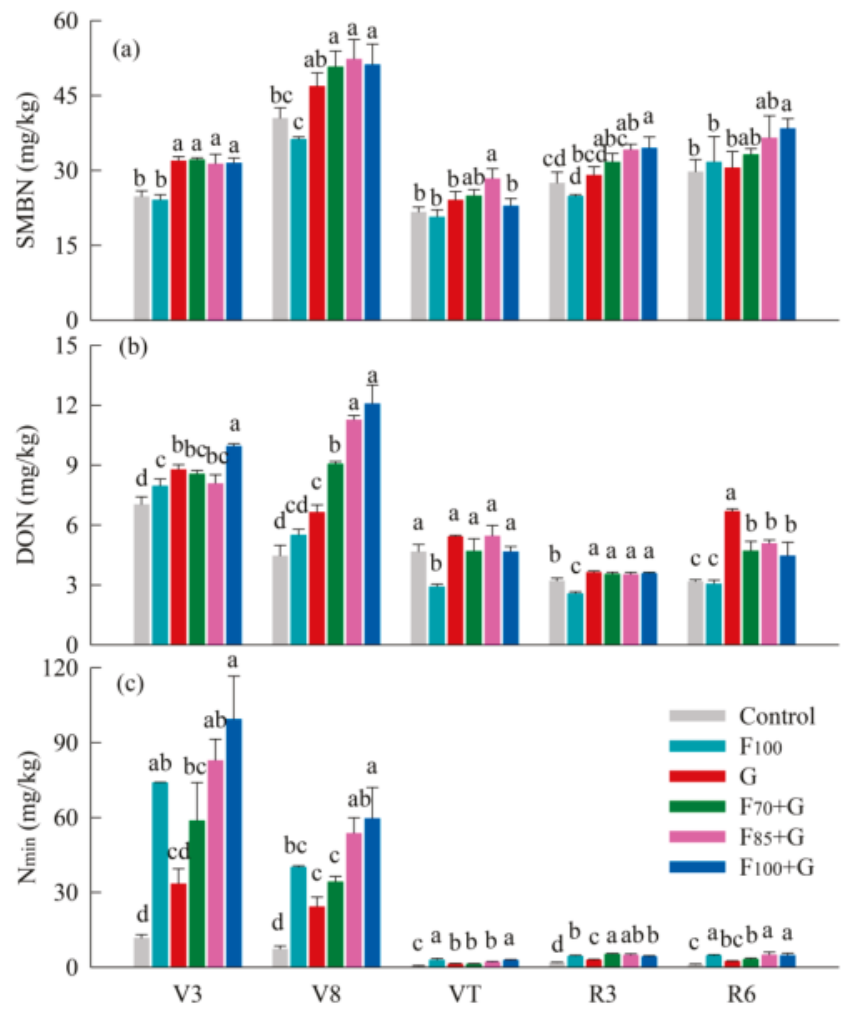

Figure 5. Changes in (a) soil microbial biomass $\mathrm{N}(\mathrm{SMBN}),(\mathbf{b})$ dissolved organic $\mathrm{N}(\mathrm{DON})$, and (c) mineral $\mathrm{N}\left(\mathrm{N}_{\min }\right)$ in the $0-20 \mathrm{~cm}$ soil layer during maize growth. Data are mean \pm standard error (vertical bars, $n=4$ ). Different letters above columns at each harvest indicate statistical differences between treatments by LSD test $(p<0.05)$. V3 and V8 (the third and eighth leaf fully expanded, respectively), VT (tasseling), R3 (milk), and R6 (physiological maturity). Control, no fertilization; $\mathrm{F}_{100}$, recommended inorganic fertilization alone; $G$, green manure incorporation alone; $F_{70}+G, F_{85}+G$, and $F_{100}+\mathrm{G}$ are $70 \%, 85 \%$, and $100 \%$ of $F_{100}$ plus $G$, respectively.

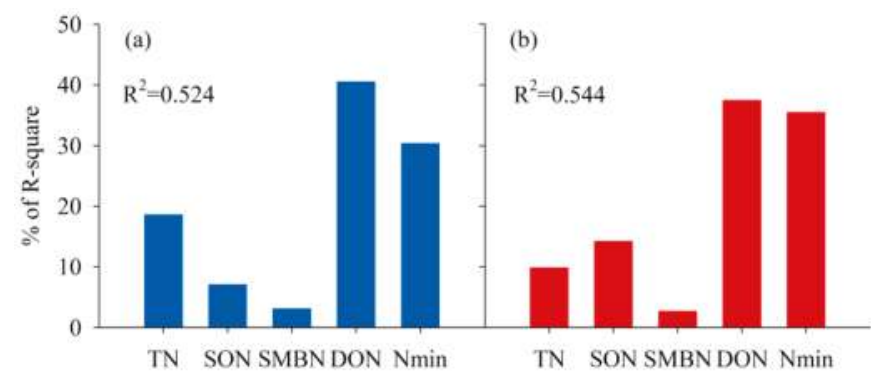

Figure 6. Relative influences of soil nitrogen (N) fractions on (a) dry matter production and (b) $\mathrm{N}$ uptake of maize. TN, total N; SON, soil organic N; SMBN, soil microbial biomass N; DON, dissolved organic $\mathrm{N} ; \mathrm{N}_{\min }$, mineral $\mathrm{N}$. 


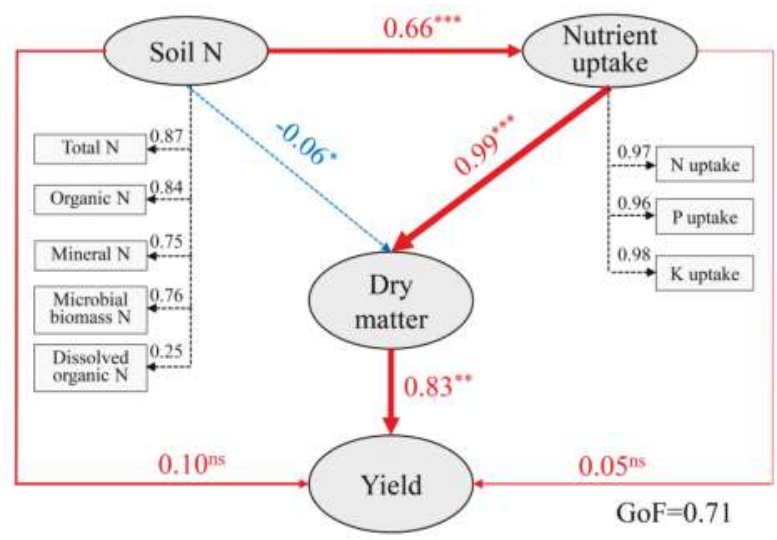

Figure 7. Partial least squares path model based on the effects of soil $\mathrm{N}$ fractions, nutrient uptake, and dry matter production on maize grain yield. The loading for soil $\mathrm{N}$ pools and plant nutrient uptake that create the latent variables are shown in rectangles. Numbers adjacent to arrows are standardized path coefficients. Continuous red and dashed blue arrows indicate positive and negative effects, respectively. Width of arrows is proportional to the strength of path coefficients. Coefficients differing significantly from zero are indicated by ${ }^{* *} p<0.01$, and ${ }^{* * *} p<0.001$; ns, not significant. The model is assessed using the goodness of fit $(\mathrm{GoF})$ statistic, a measure of overall prediction performance.

\section{Discussion}

\subsection{At Least 15-30\% of Inorganic Fertilizer Input Could Be Reduced in the OV Incorporation-Based Maize Rotation}

From 1980 to 2010, the inorganic N input on cropland in China increased from 9.4 to $28.9 \mathrm{Tg} /$ year [34], while the rates of cereal grain yield increased slowly [4,20]. Often twice as much fertilizer $\mathrm{N}$ and $\mathrm{P}$ is applied than is recovered in crops, and this nutrient imbalance in turn aggravates environmental issues $[4,20]$. Thus, it is very important to reduce the chemical fertilizer input to the agricultural system, while also maintaining or increasing crop yield [1]. One of the realistic ways is to substitute chemical $\mathrm{N}$ or $\mathrm{P}$ by green manure. Many studies have shown that either green manure alone or combined with fertilizer can stimulate the following crop growth, yield, and nutrient uptake $[11,12,15]$. Under the present conditions, the yield, biomass, and $\mathrm{N}$ uptake of $\mathrm{F}_{70}+\mathrm{G}$ and $\mathrm{F}_{85}+$ $\mathrm{G}$ treatments were similar to or even greater than the recommended fertilization $\left(\mathrm{F}_{100}\right)$, indicating that with OV incorporation, $15-30 \%$ reduction of fertilizer input could still maintain soil $\mathrm{N}$ availability to sustain maize growth and yield. In addition, green manure incorporation further increased maize yield and $\mathrm{N}$ uptake based on the full rates of fertilizer recommendations, showing stimulated crop growth and $\mathrm{N}$ uptake, which was in agreement with other studies using either legume or non-legume green manures $[11,12,15]$. Overall, the results highlight the crucial role of OV incorporation in enhancing maize growth and nutrient uptake under reduced inorganic fertilizer input.

\subsection{Integrated Management of OV Incorporation and Fertilizer Application Compensated for Soil N Pools}

Leguminous green manure is mainly cultivated for its ability to fix, accumulate, and supply large amounts of $\mathrm{N}$, while non-legumes are mainly used to prevent soil erosion, trap $\mathrm{N}$, and reduce leaching to the water table $[10,35]$. Among the desired effects of green manure are improving soil fertility and increasing the stability of $\mathrm{N}$ supply [10]. OV incorporation with reduced chemical fertilizer application increased the soil total $\mathrm{N}$ content in most cases compared to control, which is in agreement with other reports that application of either inorganic fertilizer or organic substrates can increase soil 
total $\mathrm{N}$ storage $[10,36]$. Green manure application combined with reduced fertilization had similar or greater soil total $\mathrm{N}$ and organic $\mathrm{N}$ content than the recommended fertilization through the maize growing season, indicating that $\mathrm{OV}$ incorporation well compensated for soil $\mathrm{N}$ reserves when $15-30 \%$ of fertilizer $\mathrm{N}$ input was removed. This was associated with the $\mathrm{N}$ supplement by $\mathrm{OV}$ incorporation per se, since there was a certain amount of green manure N imported to F plus G treatments, partially contributing to total $\mathrm{N}$ increase. For instance, in 2012, exogenous $\mathrm{N}$ inputs through imported OV plants were 78.5, 45.8, 26.5, and $29.4 \mathrm{~kg} / \mathrm{ha}$ in the $\mathrm{G}, \mathrm{F}_{70}+\mathrm{G}, \mathrm{F}_{85}+\mathrm{G}$, and $\mathrm{F}_{100}+\mathrm{G}$ treatments, respectively (Table 2). A previous study showed that $67.5 \%$ of OV residues can be decomposed during the maize growing season, and $85.3 \%$ of OV's $\mathrm{N}$ can be released to the soil [25]. Such substantial N release likely furnished the soil $\mathrm{N}$ pools, while it is hard to quantify the contribution of exogenous $\mathrm{N}$ input to soil total $\mathrm{N}$ increase in the present study.

Alternatively, the amount of OV's $\mathrm{N}$ input was not the only factor affecting soil total $\mathrm{N}$ levels, since $\mathrm{N}$ input in the $\mathrm{G}$ treatment (from OV alone) was about one-third of that in the $\mathrm{F}_{100}$ treatments (from fertilizer $\mathrm{N}$ ), but it produced slightly more soil total $\mathrm{N}$ content during maize season, an average of 0.37 vs. $0.36 \mathrm{~g} \mathrm{~kg}^{-1}$ (Figure 4a). In this case, it might be attributed to enhanced mineralization of soil residual organic matter by $\mathrm{OV}$ incorporation, as indicated by similar or greater SMBN content in $\mathrm{G}$ relative to $\mathrm{F}_{100}$ treatment (Figure 5a). Although we claim that $\mathrm{N}, \mathrm{P}$, and $\mathrm{K}$ in green manure were taken up and returned in situ within the system from 2008 to 2011, and not considered as exogenous inputs (such as fertilizer application), the OV incorporation may affect the in-season mineralization processes of organic residues and soil nutrient availability. In addition, the pattern of maize grain yield in the first year was different from other years; for example, yield in $G$ treatment was significantly greater than in $\mathrm{F}_{100}$ treatment. This further supports the point of stimulated $\mathrm{N}$ mineralization by OV incorporation.

4.3. Temporal Changes of Soil N Pools Highlights Dominant Contribution of Dissolved Organic N and Mineral $N$ to Maize $N$ Uptake and Growth

DON and $\mathrm{N}_{\min }$ represent the soluble organic and inorganic $\mathrm{N}$ fractions related to quick turnover of soil N pools, which fluctuated over maize growth with higher content at the V3 or V8 stage. These results imply that even at early and fast-growing stages, OV's $\mathrm{N}$ could be quickly and easily released to increase soil $\mathrm{N}$ availability (Figure 3) due to the low-residue $\mathrm{C} / \mathrm{N}$ ratio ( 13) [25]. Other studies found that a lower substrate $\mathrm{C} / \mathrm{N}$ ratio favors $\mathrm{N}$ mineralization $[15,23,37]$. Mineral $\mathrm{N}$ and DON are two major $\mathrm{N}$ sources for microbes and plant uptake, and play a pivotal role in crop N utilization [22,38]. Dissolved organic N mainly consists of amino acids, amino sugars, and low-molecular-mass proteins. These $\mathrm{N}$-containing compounds can be taken up by plants directly through roots or mycorrhiza, especially for the amino acid groups [38,39]. There was a tight relationship between SMBN and DON after long-term fertilization, suggesting a close interaction of these soil $\mathrm{N}$ forms in the mineralization processes from incorporated organic residues [23,36].

Under the present conditions, $F_{70}+G, F_{85}+G$, and $F_{100}+G$ treated soil had significantly greater DON content than control or $\mathrm{F}_{100}$ treatment at early (particularly V3 and V8) and mid-late stages. Similar $\mathrm{N}_{\min }$ content was obtained with $\mathrm{F}_{100}$ and $\mathrm{F}_{70}+\mathrm{G}, \mathrm{F}_{85}+\mathrm{G}$ and even increased in the $\mathrm{F}_{100}+\mathrm{G}$ treatment (Figure 5), which was consistent with the similar or greater $\mathrm{N}$ uptake and yield in the $\mathrm{F}$ plus $\mathrm{G}$ treatments. The relative weight analysis showed that the variation of $\mathrm{N}$ uptake and dry matter production of maize was mainly contributed by $\mathrm{DON}$ and $\mathrm{N}_{\min }$, rather than other variables of soil total $\mathrm{N}$, organic $\mathrm{N}$, and SMBN (Figure 6). This might be because $\mathrm{N}_{\min }$ and DON, but not SMBN, are two major inorganic and organic sources of plant-available $\mathrm{N}$ in soil. The changes of $\mathrm{N}_{\min }$ and DON could directly influence plant $\mathrm{N}$ uptake, while the effects of SMBN have to be achieved through $\mathrm{N}$ mineralization (involving the turnover of organic and inorganic $\mathrm{N}$ fractions). Taken together with the partial least squares path modeling, soil $\mathrm{N}$ pools had a positive indirect effect on dry matter production through $\mathrm{N}$ uptake (Figure 7), and the enhanced $\mathrm{N}$ uptake of maize plants with integrated application of green manure and fertilizer might be coordinated with improved soil DON and $\mathrm{N}_{\min }$ content, even at the mid-late stages. 
In addition, the overall dramatic decrease of DON and $\mathrm{N}_{\min }$ after the maize $\mathrm{V} 8$ stage corresponded to a period with continuous and heavy rainfall (Figure 1), implying $\mathrm{N}$ leaching losses by the precipitation. As with nitrate, DON leaching is also a significant pathway of $\mathrm{N}$ losses because of its easy movement along the soil profile [7,40]. The nitrate and DON contents in deeper soil layers were not investigated in the present study; however, since other studies have shown that $\mathrm{N}$ leaching losses were reduced under OV incorporation [12], it was speculated that the uptake of leached nitrate or DON below the $20 \mathrm{~cm}$ layer might be enhanced in the F plus $\mathrm{G}$ treatments, which partly contributed to the greater $\mathrm{N}$ uptake in maize.

\section{Conclusions}

In conclusion, the present study demonstrated a promising way of protecting $\mathrm{N}$ in fallow seasons by green manure cultivation and reducing the fertilizer inputs in maize production. Due to the enhanced dissolved organic and inorganic $\mathrm{N}$ levels by $\mathrm{OV}$ incorporation and increased nutrient uptake in soil, $15-30 \%$ of recommended fertilizer input could be reduced for maize. The results suggest that green manure-maize rotation could hold great promise in substituting a certain amount of inorganic fertilizer input by OV incorporation without sacrificing crop yield in the North China Plain and other temperate regions.

Author Contributions: Conceptualization, L.Y., J.B., J.L., N.Z., and W.C.; Funding acquisition, W.C.; Project administration, J.B. and N.Z., Supervision, W.C.; Methodology, L.Y., J.B., and J.L.; Software, L.Y.; Investigation, L.Y., J.B., and J.L.; Formal analysis, L.Y. and J.L.; Writing—original draft preparation, L.Y.; Writing-review and editing, L.Y. and W.C.

funding: This work was supported by China Agriculture Research System-Green Manure, Science and Technology Innovation Project of Chinese Academy of Agricultural Sciences, and Chinese Outstanding Talents Program in Agricultural Science.

Acknowledgments: The authors would like to thank Songjuan Gao, Jing Xiong, and Danna Chang for their assistance with the field work, and Michael J.W. Maw at Abraham Baldwin Agricultural College, USA, and Charles B. Krueger at the University of Missouri, USA, for their comments and language editing.

Conflicts of Interest: The authors declare no conflict of interest.

\section{References}

1. Chen, X.; Cui, Z.; Fan, M.; Vitousek, P.; Zhao, M.; Ma, W.; Wang, Z.; Zhang, W.; Yan, X.; Yang, J.; et al. Producing more grain with lower environmental costs. Nature 2014, 514, 486. [CrossRef] [PubMed]

2. Yu, W.; Elleby, C.; Zobbe, H. Food security policies in India and China: Implications for national and global food security. Food Secur. 2015, 7, 405-414. [CrossRef]

3. Vitousek, P.M.; Naylor, R.; Crews, T.; David, M.B.; Drinkwater, L.E.; Holland, E.; Johnes, P.J.; Katzenberger, J.; Martinelli, L.A.; Matson, P.A.; et al. Nutrient imbalances in agricultural development. Science 2009, 324, 1519-1520. [CrossRef] [PubMed]

4. Chen, X.P.; Cui, Z.L.; Vitousek, P.M.; Cassman, K.G.; Matson, P.A.; Bai, J.S.; Meng, Q.F.; Hou, P.; Yue, S.C.; Römheld, V.; et al. Integrated soil-crop system management for food security. Proc. Natl. Acad. Sci. USA 2011, 108, 6399-6404. [CrossRef] [PubMed]

5. Meng, Q.; Hou, P.; Wu, L.; Chen, X.; Cui, Z.; Zhang, F. Understanding production potentials and yield gaps in intensive maize production in China. Field Crop Res. 2013, 143, 91-97. [CrossRef]

6. Ju, X.T.; Xing, G.X.; Chen, X.P.; Zhang, S.L.; Zhang, L.J.; Liu, X.J.; Cui, Z.L.; Yin, B.; Christie, P.; Zhu, Z.L.; et al. Reducing environmental risk by improving $\mathrm{N}$ management in intensive Chinese agricultural systems. Proc. Natl. Acad. Sci. USA 2009, 106, 3041-3046. [CrossRef] [PubMed]

7. Zhou, J.; Gu, B.; Schlesinger, W.H.; Ju, X. Significant accumulation of nitrate in Chinese semi-humid croplands. Sci. Rep. 2016, 6, 25088. [CrossRef] [PubMed]

8. Zheng, X.; Han, S.; Huang, Y.; Wang, Y.; Wang, M. Re-quantifying the emission factors based on field measurements and estimating the direct $\mathrm{N}_{2} \mathrm{O}$ emission from Chinese croplands. Glob. Biogeochem. Cycles 2004, 18, GB2018. [CrossRef] 
9. Xie, Z.; Tu, S.; Shah, F.; Xu, C.; Chen, J.; Han, D.; Liu, G.; Li, H.; Muhammad, I.; Cao, W. Substitution of fertilizer-N by green manure improves the sustainability of yield in double-rice cropping system in south China. Field Crop Res. 2016, 188, 142-149. [CrossRef]

10. Thorup-Kristensen, K.; Magid, J.; Jensen, L.S. Catch crops and green manures as biological tools in nitrogen management in temperate zones. Adv. Agron. 2003, 79, 227-302.

11. Yang, L.; Cao, W.; Thorupkristensen, K.; Bai, J.; Gao, S.; Chang, D. Effect of Orychophragmus violaceus incorporation on nitrogen uptake in succeeding maize. Plant Soil Environ. 2015, 61, 260-265. [CrossRef]

12. Bai, J.; Cao, W.; Xiong, J.; Zeng, N.; Gao, S.; Katsuyoshi, S. Integrated application of February Orchid (Orychophragmus violaceus) as green manure with chemical fertilizer for improving grain yield and reducing nitrogen losses in spring maize system in northern China. J. Integr. Agric. 2015, 14, 2490-2499. [CrossRef]

13. Li, H.; Zheng, L.; Lei, Y.; Li, C.; Liu, Z.; Zhang, S. Estimation of water consumption and crop water productivity of winter wheat in North China Plain using remote sensing technology. Agric. Water Manag. 2008, 95, 1271-1278. [CrossRef]

14. Thorup-Kristensen, K. Are differences in root growth of nitrogen catch crops important for their ability to reduce soil nitrate-N content, and how can this be measured? Plant Soil 2001, 230, 185-195. [CrossRef]

15. Zhang, D.; Yao, P.; Na, Z.; Yu, C.; Cao, W.; Gao, Y. Contribution of green manure legumes to nitrogen dynamics in traditional winter wheat cropping system in the Loess Plateau of China. Eur. J. Agron. 2016, 72, 47-55.

16. Yu, Y.; Xue, L.; Yang, L. Winter legumes in rice crop rotations reduces nitrogen loss, and improves rice yield and soil nitrogen supply. Agron. Sustain. Dev. 2014, 34, 633-640. [CrossRef]

17. Hooker, K.V.; Coxon, C.E.; Hackett, R.; Kirwan, L.E.; O'Keeffe, E.; Richards, K.G. Evaluation of cover crop and reduced cultivation for reducing nitrate leaching in Ireland. J. Environ. Qual. 2008, 37, 138-145. [CrossRef] [PubMed]

18. Zhou, Z.; Zhang, L.; Cao, W.; Huang, Y. Appraisal of agro-ecosystem services in winter green manure-spring maize. Ecol. Environ. Sci. 2016, 25, 597-604. (In Chinese with English Abstract)

19. Mandal, U.K.; Singh, G.; Victor, U.S.; Sharma, K.L. Green manuring: Its effect on soil properties and crop growth under rice-wheat cropping system. Eur. J. Agron. 2003, 19, 225-237. [CrossRef]

20. Zhang, F.; Cui, Z.; Chen, X.; Ju, X.; Shen, J.; Chen, Q.; Liu, X.; Zhang, W.; Mi, G.; Fan, M. Chapter one-Integrated nutrient management for food security and environmental quality in China. Adv. Agron. 2012, 116, 1-40.

21. Glasener, K.M.; Wagger, M.G.; Mackown, C.T.; Volk, R.J. Contributions of shoot and root nitrogen-15 labeled legume nitrogen sources to a sequence of three cereal crops. Soil Sci. Soc. Am. J. 2002, 66, 523-530. [CrossRef]

22. Kielland, K. Amino acid absorption by arctic plants: Implications for plant nutrition and nitrogen cycling. Ecology 1994, 75, 2373-2383. [CrossRef]

23. Stark, C.; Condron, L.M.; Stewart, A. Influence of organic and mineral amendments on microbial soil properties and processes. Appl. Soil Ecol. 2007, 35, 79-93. [CrossRef]

24. Wu, L.Q.; Wu, L.; Cui, Z.L.; Chen, X.P.; Zhang, F.S. Basic NPK fertilizer recommendation and fertilizer formula for maize production regions in China. Acta Pedol. Sin. 2015, 52, 802-817. (In Chinese with English Abstract)

25. Liu, J.; Chen, X.; Zhang, J.; Xu, C.; Cao, W. Study on characteristics of decomposition and nutrients release of winter green manure crop Orychophragmus violaceus in North China. Chin. J. Grassl. 2013, 35, 58-63. (In Chinese with English Abstract)

26. Nelson, D.W.; Sommers, L.E. Determination of total nitrogen in plant material. Agron. J. 1973, 65, $109-112$. [CrossRef]

27. Soon, Y.K.; Kalra, Y.P. A comparison of plant tissue digestion methods for nitrogen and phosphorus analyses. Can. J. Soil Sci. 1995, 75, 243-245. [CrossRef]

28. Walker, J.M.; Barber, S.A. Absorption of potassium and rubidium from the soil by corn roots. Plant Soil 1962, 17, 243-259. [CrossRef]

29. Bremner, J.M. Determination of nitrogen in soil by the Kjeldahl method. J. Agric. Sci. 1960, 55, 11-33. [CrossRef]

30. Brookes, P.C.; Landman, A.; Pruden, G.; Jenkinson, D.S. Chloroform fumigation and the release of soil nitrogen: A rapid direct extraction method to measure microbial biomass nitrogen in soil. Soil Biol. Biochem. 1985, 17, 837-842. [CrossRef] 
31. Jones, D.L.; Willett, V.B. Experimental evaluation of methods to quantify dissolved organic nitrogen (DON) and dissolved organic carbon (DOC) in soil. Soil Biol. Biochem. 2006, 38, 991-999. [CrossRef]

32. Kabacoff, R. R in Action: Data Analysis and Graphics with R.; Manning Publications Co.: Shelter Island, NY, USA, 2015.

33. Sanchez, G. Plsdepot: Partial Least Squares (PLS) Data Analysis Methods v. 0.1.17. 2012. Available online: http:/ / cran.r-project.org/web/packages/plsdepot/index.html (accessed on 9 September 2018).

34. Gu, B.; Ju, X.; Chang, J.; Ge, Y.; Vitousek, P.M. Integrated reactive nitrogen budgets and future trends in china. Proc. Natl. Acad. Sci. USA 2015, 112, 8792. [CrossRef] [PubMed]

35. Tosti, G.; Benincasa, P.; Farneselli, M.; Pace, R.; Tei, F.; Guiducci, M.; Thorup-Kristensen, K. Green manuring effect of pure and mixed barley-hairy vetch winter cover crops on maize and processing tomato $\mathrm{N}$ nutrition. Eur. J. Agron. 2012, 43, 136-146. [CrossRef]

36. Liang, B.; Yang, X.; He, X.; Zhou, J. Effects of 17-year fertilization on soil microbial biomass C and $\mathrm{N}$ and soluble organic $C$ and $N$ in Loessial soil during maize growth. Biol. Fertil. Soils 2011, 47, 121-128. [CrossRef]

37. Kumar, K.; Goh, K.M. Crop Residues and Management Practices: Effects on Soil Quality, Soil Nitrogen Dynamics, Crop Yield, and Nitrogen Recovery. Adv. Agron. 2000, 68, 197-319.

38. Streeter, T.C.; Bol, R.; Bardgett, R.D. Amino acids as a nitrogen source in temperate upland grasslands: The use of dual labelled $\left({ }^{13} \mathrm{C},{ }^{15} \mathrm{~N}\right)$ glycine to test for direct uptake by dominant grasses. Rapid Commun. Mass Spectrom. 2015, 14, 1351-1355. [CrossRef]

39. Jones, D.L.; Darrah, P.R. Amino-acid influx at the soil-root interface of Zea mays L. and its implications in the rhizosphere. Plant Soil 1994, 163, 1-12. [CrossRef]

40. Yu, Z.S.; Northup, R.R.; Dahlgren, R.A. Determination of dissolved organic nitrogen using persulfate oxidation and conductimetric quantification of nitrate-nitrogen. Commun. Soil Sci. Plant Anal. 1994, 25, 3161-3169. [CrossRef]

(C) 2018 by the authors. Licensee MDPI, Basel, Switzerland. This article is an open access article distributed under the terms and conditions of the Creative Commons Attribution (CC BY) license (http:/ / creativecommons.org/licenses/by/4.0/). 
Article

\title{
Optimizing Potassium Application for Hybrid Rice (Oryza sativa L.) in Coastal Saline Soils of West Bengal, India
}

\author{
Hirak Banerjee ${ }^{1}$, Krishnendu Ray ${ }^{2}$, Sudarshan Kumar Dutta ${ }^{3, *}$, Kaushik Majumdar ${ }^{4}$, \\ Talatam Satyanarayana ${ }^{5}$ and Jagadish Timsina ${ }^{6}$ \\ 1 Bidhan Chandra Krishi Viswavidyalaya, Regional Research Station (CSZ), Kakdwip 743347, \\ South 24 Parganas, West Bengal, India; hirak.bckv@gmail.com \\ 2 Ramakrishna Mission Vivekananda Educational and Research Institute, Sasya Shyamala Krishi Vigyan \\ Kendra, Narendrapur, Kolkata 700103, West Bengal, India; krishnenduray.bckv@gmail.com \\ 3 International Plant Nutrition Institute, South Asia (East India and Bangladesh) Program, \\ 36 Gorakshabasi Road, Kolkata 700028, West Bengal, India \\ 4 International Plant Nutrition Institute, Asia and Africa Programs, Palm Drive, B-1602, Golf Course \\ Extension Road, Sector-66, Gurgaon 122001, Haryana, India; kmajumdar@ipni.net \\ 5 International Plant Nutrition Institute, South Asia Program, 354, Sector 21, Gurgaon 122016, Haryana, India; \\ tsatya@ipni.net \\ 6 Soils and Environment Research Group, Faculty of Veterinary and Agricultural Sciences, \\ University of Melbourne, Melbourne, VIC 3010, Australia; timsinaj@hotmail.com \\ * Correspondence: sdutta@ipni.net; Tel.: +91-9836293999
}

Received: 23 October 2018; Accepted: 27 November 2018; Published: 4 December 2018

\begin{abstract}
The present study assesses the response of hybrid rice (variety Arize 6444) to potassium (K) application during rainy (wet) seasons of 2016 and 2017 in coastal saline soils of West Bengal, India. The study was conducted at the Regional Research Farm, Bidhan Chandra Krishi Viswavidyalaya, Kakdwip, West Bengal. The soil is clayeywith acidic $\mathrm{pH}$ (5.91), saline (Electrical conductivity/EC $1.53 \mathrm{dS} \mathrm{m}^{-1)}$ and of high $\mathrm{K}$ fertility $\left(366 \mathrm{~kg} \mathrm{ha}^{-1}\right)$. The experimental plots were laid out in a randomized complete block design with five (5) $\mathrm{K}$ treatments (0, 30, 60, 90, and $120 \mathrm{~kg} \mathrm{~K}_{2} \mathrm{O}^{-1}$ ) with four replications. Plant height, dry matter (DM) in different plant parts, number of tillers, and grain yield were measured in each treatment for the determination of optimum $\mathrm{K}$ dose. The study revealed that the stem, leaf, and grain dry matter production at 60 days after transplanting (DAT) and harvest were significantly $(p \leq 0.05)$ higher at $90 \mathrm{~kg} \mathrm{~K}_{2} \mathrm{O} \mathrm{ha}^{-1}$ application. The number of tillers hill $^{-1}$ was also higher $(p \leq 0.05)$ in plants fertilized with $90 \mathrm{~kg} \mathrm{~K}_{2} \mathrm{O} \mathrm{ha}^{-1}$ over $\mathrm{K}$ omission. At harvest, grain $\mathrm{K}$ concentration improved $(p \leq 0.05)$ with $\mathrm{K}$ fertilization at $90 \mathrm{~kg} \mathrm{~K}_{2} \mathrm{O} \mathrm{ha}^{-1}, 116 \%$ more than the zero-K. Omission of $\mathrm{K}$ application from the best treatment $\left(90 \mathrm{~kg} \mathrm{~K}_{2} \mathrm{O} \mathrm{ha}{ }^{-1}\right)$ reduced grain yield by $3.5 \mathrm{tha}^{-1}$ even though the available $\mathrm{K}$ content was high. Potassium uptake restriction due to higher $\mathrm{Mg}$ content in the soil may have caused reduced uptake of $\mathrm{K}$ leading to yield losses. The present study also showed higher profits with $90 \mathrm{~kg} \mathrm{~K}_{2} \mathrm{O} \mathrm{ha}^{-1}$ with higher net returns (US\$ $452 \mathrm{ha}^{-1}$ ) and benefit:cost ratio (1.75) over other treatments from hybrid rice (var. Arize 6444). From the regression equation, the economic optimum level of $\mathrm{K}\left(\mathrm{K}_{\mathrm{opt}}\right)$ was derived as $101.5 \mathrm{~kg} \mathrm{~K}_{2} \mathrm{O}$ ha ${ }^{-1}$ that could improve productivity of hybrid rice during the wet season in coastal saline soils of West Bengal.
\end{abstract}

Keywords: hybrid rice; K use efficiency; potassium; saline tract

\section{Introduction}

With growing population and urbanization, the total area under rice cultivation in India as well as in the state of West Bengal is decreasing at a rapid rate. However, the demand for rice in the 
future is bound to increase with the growing population [1]. Predominantly medium and low lands in the eastern part of India leave no other option for farmers but to go for rice cultivation in the rainy (khairf / wet) season. Rice is grown in about 1 million hectares under the coastal ecosystem of West Bengal, accounting for nearly $17 \%$ of the net ricearea in the state. The farmers usually grow low yielding, long duration (145-150 days) traditional rice cultivars during the kharif (rainy) season, while the landsremainfallow during the rabi (winter) season [2].

Salinity is a major yield-reducing factor in thecoastal ecosystems for rice [3]. Rice experiences osmotic stress in saline soils that result in reduced osmotic potential and water stress [4]. Salinity reduces dry matter, grain yield, and the harvest index, and thus affects bothvegetative and reproductive stages of the crop [5]. The productivity of rice is not satisfactory in the coastal areas due to aberrant climatic conditionsand non-availability of hybrid varieties [6]. Water stagnation (medium-deep, 25-50 cm) for most of the crop growing season, flash floods (complete submergence for 1-2 weeks), and water and soil salinity [7] are typical deterrents to high productivity. The South 24-Parganas district ranks 12th amongst all rice growing districts of West Bengal in rice productivity [8]. Considering the demand-supply gap of rice, adoption of superior rice varieties could be effective for narrowing yield gap, and for breaking the yield ceiling in the coastal ecosystem.

Large scale adoption of hybrid rice during wet season in the coastal area could boost rice yield by about $15-20 \%$ with the same level of input [6,9]. The hybrid seeds are also tolerant to biotic and abiotic stresses [10]. Along with the improved seeds, a good nutrient management plan is also needed to make the higher production sustainable.

Hybrid rice varieties were already introduced to the region to augment the rice production. However, lack of awareness about the recommended package of practices was the main barrier to its adoption [11]. Consequently, an inadequate nutrient management strategy failed to produce the desired result. The use of nutrient rates suitable for high yielding varieties (HYVs) did not produce the higher yields expected from hybrid rice varieties [12]. Hybrid varieties with higher yield potential require larger quantities of nutrients compared to HYVs. Studies in West Bengal have shown that integrated and adequate use of chemical fertilizers and organic sources of fertilizers can result in improved soil fertility, higher nutrient-use efficiency, and better crop growth, translating into higher yield and profit $[13,14]$.

Potassium is a key nutrient required for optimum yield of hybrid rice. Hybrid rice with high yield potential per unit area and time requires higher amount of $\mathrm{K}$ than HYVs. On an average, the crop accumulates $27-36 \mathrm{~kg} \mathrm{~K}^{-1}$ to produce a ton of grain, with an equal amount of straw during wet season [15]. A K management strategy based only on attainable yield potential of HYVs are not sufficient to supply the requirement of hybrid rice [9]. Hybrid rice was reported to absorb $79 \%$ of total $\mathrm{K}$ requirement from soil and remainder from the fertilizer, and utilized $28.1 \%$ of the applied $\mathrm{K}$ [16]. For improved K use efficiency (KUE) of hybrid rice, appropriate K fertilization strategies should be adopted to fine tune the supply-demand balance of crop and soil. A regular application of $\mathrm{K}$ to the crop increased total tillers, dry matter accumulation, effective tillers, number and weight of filled grains and KUE, and enhanced the grain yield besides improving soil properties $[17,18]$. It was also reported that greater $\mathrm{K}$ uptake improved carbohydrate metabolism in plants [18], and adequate $\mathrm{K}$ increases the translocation of $\mathrm{N}$ to the grain during grain filling period, increasing efficiency of $\mathrm{N}$. Potassium helps to overcome stresses common in this region, and high $\mathrm{K}$ uptake in the panicle, especially at the early developmental stage, mitigates the negative effect of sodium uptake by the panicles [3].

For exploiting the full heterotic potential of hybrids, it is necessary to assess the performance of promising rice hybrids at graded levels of $\mathrm{K}$ when other management practices are optimum. A quantitative understanding of the crop response to $\mathrm{K}$ fertilizer is crucial to optimize $\mathrm{K}$ input for higher productivity. Reports on yield performance of superior hybrid rice cultivars under proper $\mathrm{K}$ management in the coastal saline soils are limited. The present study evaluates the effects of $\mathrm{K}$ fertilization on growth, yield and K-acquisition pattern to estimate appropriate $\mathrm{K}$ rates for achieving optimum yield and KUE in hybrid rice cultivation. 


\section{Materials and Methods}

\subsection{Field Site}

The field study was undertaken during two consecutives rainy (wet) seasons of 2016 and 2017 at the Research Farm of Bidhan Chandra Krishi Viswavidyalaya (BCKV), Kakdwip, South 24-Parganas, West Bengal $\left(22^{\circ} 40^{\prime} \mathrm{N}\right.$ latitude, $88^{\circ} 18^{\prime} \mathrm{E}$ longitude and $7 \mathrm{~m}$ above mean sea level). The maximum and minimum air temperatures fluctuated from 24.9 to $32.1^{\circ} \mathrm{C}$ and from 12.3 to $20.4^{\circ} \mathrm{C}$ during rainy season of 2016 , and from 23.2 to $32.9^{\circ} \mathrm{C}$ and from 12.1 to $19.3^{\circ} \mathrm{C}$ during the same period of 2017 , respectively. The maximum and minimum air relative humidity was between $85 \%$ and $86 \%$ (max) and $49 \%$ and $63 \%$ (min) during rainy season of 2016 and between $87 \%$ and $89 \%$ (max) and $34 \%$ and $58 \%(\min )$ during rainy season of 2017. The rainfall during the experimental period (July to November) was $474 \mathrm{~mm}$ and $654 \mathrm{~mm}$ during 2016 and 2017, respectively. The long-term average values of weather parameters showed that average maximum and minimum temperatures fluctuated from $25.3^{\circ} \mathrm{C}$ to $35.7{ }^{\circ} \mathrm{C}$ and from $10.5{ }^{\circ} \mathrm{C}$ to $24.3^{\circ} \mathrm{C}$ during rainy season, respectively. The average maximum and minimum relative humidity prevailed between $84 \%$ and $85 \%$ (max) and $50 \%$ and $65 \%(\min )$ during rainy season, respectively. The long-term average of total rainfall during July to November was $524 \mathrm{~mm}$. Hence, overall weather conditions during the experimental periods were congenial for growth and development of hybrid rice.

Surface soil samples from the field site were collected and analyzed using established procedures mentioned in Table 1.

Table 1. Initial physico-chemical properties of the experimental soil (0-30 cm depth).

\begin{tabular}{cccc}
\hline Parameter & Values & Methodology & Citation \\
\hline $\mathrm{pH}$ & 5.91 & Soil-water suspension $(1: 2.5)$ & {$[19]$} \\
Electrical conductivity $/ \mathrm{EC}\left(\mathrm{dS} \mathrm{m}^{-1}\right)$ & 1.53 & Soil-water suspension $(1: 2.5)$ & {$[19]$} \\
Sand $(\%)$ & 16.8 & & \\
Silt $(\%)$ & 28.0 & Hydrometer method & {$[20]$} \\
Clay $(\%)$ & 55.2 & & \\
Available N $\left(\mathrm{kg} \mathrm{ha}^{-1}\right)$ & 155 & Hot alkaline permanganate & {$[21]$} \\
Available P $\left(\mathrm{kg} \mathrm{ha}^{-1}\right)$ & 106 & $0.5 \mathrm{M} \mathrm{NaHCO}_{3}$ & {$[22]$} \\
Available K $\left(\mathrm{kg} \mathrm{ha}^{-1}\right)$ & 366 & Neutral N NH $\mathrm{OAc}_{4}$ & {$[23]$} \\
\hline
\end{tabular}

\subsection{Treatment Arrangements and Cultural Practices}

The experimental plots were laid out in a randomized complete block design with five rates of $\mathrm{K}\left(0,30,60,90\right.$, and $\left.120 \mathrm{~kg} \mathrm{~K}_{2} \mathrm{O} \mathrm{ha}^{-1}\right)$ that were replicated four times. The individual plot size was $5 \times 5 \mathrm{~m}$. Pre-germinated seeds of hybrid rice var. Arize 6444 with 125 days duration (produced and marketed by Bayer Crop Science Company and notified by Govt. of India) were sown at $20 \mathrm{~g} \mathrm{~m}^{-2} \mathrm{of}$ nursery area on the second week of July. In the main field, total 3-4 ploughings were done followed by one laddering. For the next 5-7 days, standing water $(5-7 \mathrm{~cm})$ was maintained to control all weeds and full decomposition of stubbles. Then another 2-3 ploughings were given followed by laddering in order to make leveled land. Seedlings of 25 days old were manually transplanted in the first week of August on puddled and leveled land at 1 seedling hill ${ }^{-1}$ with a spacing of $20 \times 20 \mathrm{~cm}$. Urea, single super phosphate (SSP) and muriate of potash (MOP) were manually applied as sources of N, P and K, respectively. Based on the soil test recommendations provided by Chinsurah Rice Research Station, Government of West Bengal, $80 \mathrm{~kg} \mathrm{~N} \mathrm{ha}^{-1}$ and $40 \mathrm{~kg} \mathrm{P} \mathrm{ha}^{-1}$ were applied in all plots. About $25 \%$ of total $\mathrm{N}$, entire amount of $\mathrm{P}$, and $75 \%$ of the $\mathrm{K}$ as per treatments were applied as basal after draining out the standing water but before final puddling. Rest of the $\mathrm{N}$ was top-dressed in threeequal splits, each at an interval of threeweeks, i.e., after transplanting, panicle initiation (PI), and panicle emergence stages. The remaining $25 \%$ of the $\mathrm{K}$ fertilizer was also applied at the PI stage. Post-emergence application of Bispyribac sodium 10\% soluble concentrates/SC (Nominee Gold) at $200 \mathrm{~mL} \mathrm{ha}^{-1}$ at 15 days after 
transplanting (DAT) followed by one hand weeding (HW) at 42 DAT were done to promote early crop growth by controlling weeds. Other agronomic management practices were followed based on recommended standards for the coastal region of West Bengal [24] and were applied uniformly across all treatments. The crop was harvested in the first week of November when $80 \%$ of the grains in the panicles were ripe, and later dried, winnowed, and weighed for yield estimation.

\subsection{Field Measurements}

At harvest maturity, plants from 25 hills $\left(1 \mathrm{~m}^{2}\right.$ area) were harvested and grains were separated to estimate grain yield, while the moisture content of grain was adjusted to $0.15 \mathrm{~g} \mathrm{H}_{2} \mathrm{O} \mathrm{g}^{-1}$. Growth attributes and yield components were measured from randomly harvested 10 plants. The plants were then partitioned into leaf, stem and panicles. Production of stem, leaf and grain dry matter (DM) was recorded at $60 \mathrm{DAT}$ and harvest. Panicles were hand-threshed, and the filled and unfilled seeds were separated by submerging them into water. Light weight unfilled seeds floating on the water surface were removed, while filled seeds settled down. Filled seeds were further sun-dried to $14 \%$ moisture. Dry weight of different plant parts, after oven-drying at $70{ }^{\circ} \mathrm{C}$ until constant weight, was determined to estimate above-ground biomass. The grain weight was determined from filled grains per panicle.

\subsection{Potassium Determination and Performance Indicators}

For $\mathrm{K}$ analysis, plant samples (stem, leaf, and grain) were digested with tri-acid mixture $\left(\mathrm{HNO}_{3}: \mathrm{H}_{2} \mathrm{SO}_{4}: \mathrm{HClO}_{4}, 9: 1: 4\right)$, and the $\mathrm{K}$ concentration $(\mathrm{K} \%)$ in plant was determined using a flame photometer [25].

Total K uptake was first calculated by the following formula [26].

$$
\mathrm{K} \text { Uptake }\left(\mathrm{kg} \mathrm{ha}^{-1}\right)=\frac{\mathrm{K} \% \times \text { Dry matter }\left(\mathrm{kg} \mathrm{ha}^{-1}\right)}{100}
$$

To measure the re-translocation efficiency of absorbed $\mathrm{K}$ from vegetative plant parts to grain and also to measure $\mathrm{K}$ partitioning in plant, $\mathrm{K}$ harvest index (KHI) was estimated as per the following formula [27].

$$
\mathrm{KHI}(\%)=\frac{\text { Uptake of } \mathrm{K} \text { in grain }\left(\mathrm{kg} \mathrm{ha}^{-1}\right)}{\text { Uptake of } \mathrm{K} \text { in total above ground biomass }\left(\mathrm{kg} \mathrm{ha}^{-1}\right)} \times 100
$$

$\mathrm{K}$ mobilization efficiency index (KMEI) of applied $\mathrm{K}$ was calculated using the following expressions [28].

$$
\operatorname{KMEI}(\%)=\frac{\mathrm{K} \text { concentration in grain }\left(\mathrm{mg} \mathrm{kg}^{-1}\right)}{\mathrm{K} \text { concentration in stem }+ \text { leaf }\left(\mathrm{mg} \mathrm{kg}^{-1}\right)} \times 100
$$

KUE was calculated using following formulae [29].

$$
\begin{gathered}
\text { Partial factor productivity of } \mathrm{K}\left(\mathrm{PFP}_{\mathrm{K}}\right)=\frac{\text { Grain yield }\left(\mathrm{kg} \mathrm{ha}^{-1}\right)}{\text { Applied fertilizer } \mathrm{K}\left(\mathrm{kg} \mathrm{ha}^{-1}\right)} \\
\text { Agronomic efficiency of } \mathrm{K}\left(\mathrm{AE}_{\mathrm{K}}\right)=\frac{\mathrm{Y}_{\mathrm{K}}-\mathrm{Y}_{\mathrm{C}}}{\mathrm{K}_{\mathrm{a}}} \\
\text { Physiological efficiency of } \mathrm{K}\left(\mathrm{PE}_{\mathrm{K}}\right)=\frac{\mathrm{Y}_{\mathrm{K}}-\mathrm{Y}_{\mathrm{C}}}{\mathrm{U}_{\mathrm{K}}-\mathrm{U}_{\mathrm{C}}}
\end{gathered}
$$


where, $\mathrm{Y}$ and $\mathrm{U}$ refer to grain yield and $\mathrm{K}$ uptake by hybrid rice and subscripts $\mathrm{K}$ and $\mathrm{C}$ refer to $\mathrm{K}$ fertilized and control plots, respectively. $K_{a}$ refers to applied fertilizer $K$. All values are in $\mathrm{kg} \mathrm{ha}^{-1}$.

\subsubsection{Dose-Response Curve}

Dose-response curves were drawn to evaluate the changes in grain yieldwith increasing dose of $\mathrm{K}$ fertilization. The curve was drawn by fitting the following quadratic response model to grain yield data

$$
\mathrm{y}=\mathrm{a}+\mathrm{bK}+\mathrm{cK}^{2}
$$

where $\mathrm{a}, \mathrm{b}$, and $\mathrm{c}$ are the regression co-efficient of the quadratic equation; $\mathrm{y}$ is the grain yield $\left(\mathrm{kg} \mathrm{ha}^{-1}\right)$; $\mathrm{K}$ is the applied fertilizer $\mathrm{K}\left(\mathrm{kg} \mathrm{ha}^{-1}\right)$.

The economic optimum for $\mathrm{K}\left(\mathrm{K}_{\mathrm{opt}}\right)$ was estimated from the above quadratic regression by using the formula [29]

$$
\mathrm{K}_{\mathrm{opt}}\left(\mathrm{kg} \mathrm{ha}^{-1}\right)=\frac{[\mathrm{q}-(\mathrm{p} \times \mathrm{b})]}{2 \times \mathrm{p} \times \mathrm{c}}
$$

where, $\mathrm{q}$ is price per $\mathrm{kg}$ of $\mathrm{K}$, and $\mathrm{p}$ is price per $\mathrm{kg}$ of grain.

\subsubsection{Sustainable Yield Index (SYI)}

In this study, the SYI for each treatment was calculated from the ratio of minimum assured grain yield to maximum observed yield [28].

$$
\text { Sustainable yield index }(\mathrm{SYI})=\frac{\left(\mathrm{Y}_{\mathrm{a}}-\sigma\right)}{\mathrm{Y}_{\mathrm{m}}}
$$

where, $Y_{a}=$ mean yield achieved with the treatment, $\sigma=$ standard deviation of yield, $Y_{m}=$ maximum yield achieved with the treatment. The SYI is a quantitative measure to judge sustainability of an agricultural practice [30]. Under SYI concept, low value of $\sigma$ suggests sustainability of anagricultural system. Conversely, if the $\sigma$ value is large then SYI will be low indicating unsustainable agricultural practice. The value of SYI varies between zero and unity. The best technology is one where $\sigma$ is zero and mean = maximum observed yield $\left(Y_{m}\right)$, indicating $S Y I=1$, hence, the practice gives consistently maximum yield over the years.

\subsection{Potassium Balance}

The post-harvest $\mathrm{pH}, \mathrm{EC}$, and available $\mathrm{K}$ contents were assessed for each of the treatments and the extent of change of these values as compared to the initial soil values were estimated. The $\mathrm{K}$ balance sheet was prepared according to nutrient balance sheet model [31]. Expected balance was derived from the equation

$$
\text { Expected } \mathrm{K} \text { balance }=\text { Total } \mathrm{K} \text { available }- \text { Total } \mathrm{K} \text { uptake }
$$

where total $\mathrm{K}$ available is the sum of initial $\mathrm{K}$ content and $\mathrm{K}$ applied through fertilizer. Total $\mathrm{K}$ uptake is the sum of $\mathrm{K}$ uptake in stem, leaf, and grain at harvest. Actual $\mathrm{K}$ balance represents the values derived from post-harvest soil analysis. Finally, net K gain (+) or loss (-) in post-harvest soil was estimated by subtracting actual balance from expected balance.

\subsection{Economic Analysis}

Common cost of hybrid rice cultivation was derived from summing all expenditure, excluding fertilizer cost. The cost of fertilizer (treatment cost) was estimated on the basis of average retail price in West Bengal. The gross returns from the crop were calculated based on minimum procurement price of the Government of West Bengal. The following equations were used for calculating gross returns, net returns and benefit:cost ratio [28]. 


$$
\begin{gathered}
\mathrm{GR}=\mathrm{Y}_{\mathrm{t}} \times \mathrm{P}_{\mathrm{t}} \\
\mathrm{NR}=\mathrm{GR}-\mathrm{C}_{\mathrm{p}} \\
\mathrm{BCR}=\frac{\mathrm{GR}}{\mathrm{C}_{\mathrm{p}}}
\end{gathered}
$$

where GR is gross returns (US\$ ha ${ }^{-1}$ ); NR is net returns (US\$ ha ${ }^{-1}$ ); BCR is benefit: cost ratio; $Y_{t}$ is grain yield $\left(\mathrm{t} \mathrm{ha}^{-1}\right)$; $\mathrm{P}_{\mathrm{t}}$ is the minimum support price of grain (US\$ t $\mathrm{t}^{-1}$ ) and $\mathrm{C}_{\mathrm{p}}$ is total cost of production. All economic data were converted into US\$ using an exchange rate of 1 US\$ = INR 64.56.

\subsection{Statistical Analysis}

Experimental data were subjected to analysis of variance (ANOVA) as randomized complete block design and the mean values were adjudged by Tukey's HSD (honest significant difference) test method using SPSS (Version 23.0, IBM SPSS Statistics for Windows, IBM Corporation, Armonk, NY, USA) software. Bartlett's chi-square test was performed to test the homogeneity of variance over both the years and pooled values of observations are given to explain the results logically. The Excel software (version 2007, Microsoft Inc., Redmond, WA, USA) was used to draw graphs and figures.

\section{Results}

\subsection{Grain and Straw Yield and Yield Components of Hybrid Rice}

Both grain and straw yield of hybrid rice (var. Arize 6444) were significantly ( $p \leq 0.05)$ influenced by $\mathrm{K}$ application levels (Table 2); grain yield increased with the increase in $\mathrm{K}$ level from 0 to $90 \mathrm{~kg} \mathrm{~K}_{2} \mathrm{O} \mathrm{ha}{ }^{-1}$. The grain and straw yielddid not vary significantly between $90 \mathrm{~kg}$ and $120 \mathrm{~kg}$ $\mathrm{K}_{2} \mathrm{O}$ ha $^{-1}$. The grain yield obtained with $90 \mathrm{~kg} \mathrm{~K}_{2} \mathrm{O} \mathrm{ha}^{-1}$ was $85 \%$ more than the yield obtained with control (zero-K). Figure 1 depicts the regression between applied fertilizer $\mathrm{K}$ and grain yield of hybrid rice. Straw yield also increased with increase in $\mathrm{K}$ from 0 to $90 \mathrm{~kg} \mathrm{~K}_{2} \mathrm{O}$ ha ${ }^{-1}$. Significantly $(p \leq 0.05)$ higher straw yield was obtained with $90 \mathrm{~kg} \mathrm{~K}_{2} \mathrm{O}_{\text {ha }}{ }^{-1}, 80.9 \%$ more than with $\mathrm{K}$ omission. Zero $\mathrm{K}$ resulted in the largest reduction in grain and straw yield.

\begin{tabular}{|c|c|c|c|c|c|c|c|c|}
\hline $\begin{array}{c}\text { Levels of K } \\
\left(\mathrm{kg} \mathrm{ha}^{-1}\right)\end{array}$ & $\begin{array}{c}\text { No. of } \\
\text { Panicles } \\
\text { Hill }^{-1}\end{array}$ & $\begin{array}{c}\text { No. of Filled } \\
\text { Seeds } \\
\text { Panicle }^{-1}\end{array}$ & $\begin{array}{c}\text { No. of } \\
\text { Unfilled Seeds } \\
\text { Panicle }^{-1}\end{array}$ & $\begin{array}{l}\text { Panicle } \\
\text { Length } \\
(\mathrm{cm})\end{array}$ & $\begin{array}{c}\text { Panicle } \\
\text { Weight (g) }\end{array}$ & $\begin{array}{r}\text { 1000-Seed } \\
\text { Weight (g) }\end{array}$ & $\begin{array}{l}\text { Grain Yield } \\
\left(\mathrm{t} \mathrm{ha} \mathbf{h}^{-1}\right)\end{array}$ & $\begin{array}{c}\text { Straw Yield } \\
\left(\mathrm{t} \mathrm{ha}^{-1}\right)\end{array}$ \\
\hline $\mathrm{K}_{0}$ & $7^{a}$ & $115.5^{b}$ & $47.0^{\mathrm{c}}$ & $25.95^{a}$ & $2.88^{\mathrm{c}}$ & $22.8^{a}$ & $4.08^{c}$ & $4.29^{\mathrm{d}}$ \\
\hline $\mathrm{K}_{30}$ & $8^{a}$ & $102.5^{\mathrm{b}}$ & $50.5^{c}$ & $26.60^{a}$ & $2.97^{b c}$ & $23.5^{\mathrm{a}}$ & $5.74^{\mathrm{b}}$ & $5.52^{c}$ \\
\hline $\mathrm{K}_{60}$ & $9^{a}$ & $143.0^{\mathrm{a}}$ & $58.0^{b}$ & $27.65^{a}$ & $3.63^{\mathrm{a}}$ & $23.6^{\mathrm{a}}$ & $7.04^{\mathrm{ab}}$ & $7.02^{b}$ \\
\hline$K_{90}$ & $10^{a}$ & $146.0^{\mathrm{a}}$ & $76.0^{\mathrm{a}}$ & $27.90^{a}$ & $3.64^{\mathrm{a}}$ & $25.7^{\mathrm{a}}$ & $7.56^{\mathrm{a}}$ & $7.76^{a}$ \\
\hline $\mathrm{K}_{120}$ & $10^{\mathrm{a}}$ & $117.0^{\mathrm{b}}$ & $70.0^{\mathrm{a}}$ & $27.40^{a}$ & $3.35^{\mathrm{ab}}$ & $24.5^{\mathrm{a}}$ & $7.49^{a}$ & $6.97^{b}$ \\
\hline $\begin{array}{c}\mathrm{LSD}(p \leq \\
0.05)\end{array}$ & NS & 14.38 & 6.35 & NS & 0.38 & NS & 1.62 & 0.61 \\
\hline
\end{tabular}

Table 2. Yield components and yield of hybrid rice (var. Arize 6444) as influenced by potassium fertilization (means for 2016 and 2017).

NS, non-significant; Means followed by a different letter are significantly different at $p \leq 0.05$ by Tukey's HSD (honest significant difference) test; LSD, Least Significant Difference.

\subsection{Growth Attributes of Hybrid Rice}

The growth attributes (except plant height) of hybrid rice were influenced $(p \leq 0.05)$ by different $\mathrm{K}$ levels (Table 3). Dry weights of stem and leaf were higher $(p \leq 0.05)$ at $90 \mathrm{~kg} \mathrm{~K}_{2} \mathrm{O} \mathrm{ha}^{-1}$ compared to the treatments receiving less $\mathrm{K}$, and were statistically at par with $120 \mathrm{~kg} \mathrm{~K}_{2} \mathrm{O} \mathrm{ha}^{-1}$. Similar trend was observed for leaf dry matter at harvest although no significant difference was observed for the stem dry matter. The grain dry weight was also higher $(p \leq 0.05)$ with $120 \mathrm{~kg} \mathrm{~K}_{2} \mathrm{O}$ ha $^{-1}$ compared 
to the lower application rates. The number of tillers hill ${ }^{-1}$ increased significantly $(p \leq 0.05)$ with $120 \mathrm{~kg} \mathrm{~K}_{2} \mathrm{O} \mathrm{ha}^{-1}$, accounting for $64.3 \%$ more tillers than that with $\mathrm{K}$ omission.

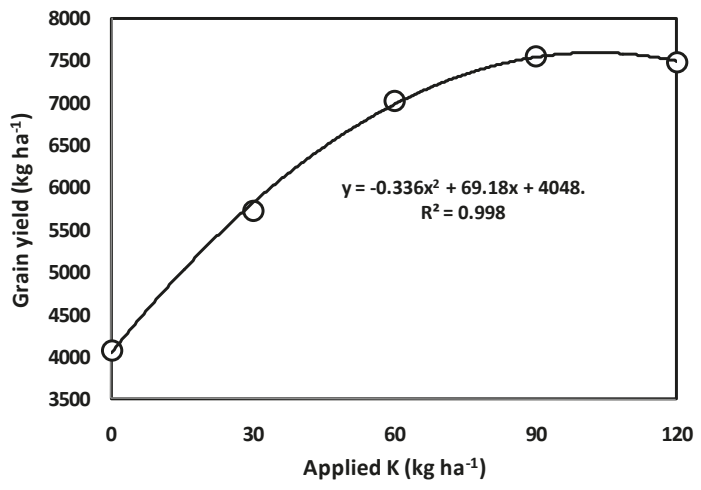

Figure 1. Dose-response curve showing the regression between applied $\mathrm{K}\left(\mathrm{kg} \mathrm{ha}^{-1}\right)$ and grain yield $\left(\mathrm{kg} \mathrm{ha}^{-1}\right)\left(\right.$ Optimum dose of potassium $\left./ \mathrm{K}_{\mathrm{opt}}=101.5 \mathrm{~kg} \mathrm{ha}^{-1}\right)$.

Table 3. Growth attributes of hybrid rice (var. Arize 6444) as influenced by potassium fertilization (means for 2016 and 2017).

\begin{tabular}{|c|c|c|c|c|c|c|c|}
\hline \multirow{3}{*}{$\begin{array}{c}\text { Levels of } \mathrm{K} \\
\left(\mathrm{kg} \mathrm{ha}^{-1}\right)\end{array}$} & \multirow{3}{*}{$\begin{array}{l}\text { Plant Height } \\
(\mathrm{cm})\end{array}$} & \multicolumn{5}{|c|}{ Dry Weight (g plant ${ }^{-1}$ ) } & \multirow{3}{*}{$\begin{array}{l}\text { No. of Tillers } \\
\text { Hill }^{-1}\end{array}$} \\
\hline & & \multicolumn{2}{|c|}{ At 60 DAT } & \multicolumn{3}{|c|}{ At Harvest } & \\
\hline & & Stem & Leaf & Stem & Leaf & Grain & \\
\hline $\mathrm{K}_{0}$ & $84^{a}$ & $24.15^{b c}$ & $1.38^{c}$ & $10.14^{a}$ & $23.57^{c}$ & $24.80^{\mathrm{d}}$ & $14^{\mathrm{c}}$ \\
\hline $\mathrm{K}_{30}$ & $87^{a}$ & $17.69^{\mathrm{c}}$ & $1.25^{c}$ & $10.65^{\mathrm{a}}$ & $26.32^{b c}$ & $27.79 \mathrm{~cd}$ & $16^{\mathrm{bc}}$ \\
\hline $\mathrm{K}_{60}$ & $87^{a}$ & $27.06^{b}$ & $1.88^{\mathrm{b}}$ & $11.47^{\mathrm{a}}$ & $27.33^{b c}$ & $30.78 \mathrm{bc}$ & $20^{a b}$ \\
\hline $\mathrm{K}_{90}$ & $89^{a}$ & $32.78^{a}$ & $2.71^{a}$ & $11.75^{\mathrm{a}}$ & $30.82^{a b}$ & $32.91^{\mathrm{ab}}$ & $21^{\mathrm{a}}$ \\
\hline $\mathrm{K}_{120}$ & $89^{a}$ & $33.86^{a}$ & $2.54^{\mathrm{a}}$ & $12.88^{a}$ & $32.96^{\mathrm{a}}$ & $33.29 \mathrm{ab}$ & $23^{a}$ \\
\hline $\operatorname{LSD}(p \leq 0.05)$ & NS & 7.48 & 0.19 & NS & 4.43 & 3.90 & 4.00 \\
\hline
\end{tabular}

NS, non-significant; DAT, days after transplanting; Means followed by a different letter within a column are significantly different at $p \leq 0.05$ by Tukey's HSD (honest significant difference) test; LSD, Least Significant Difference.

K fertilization significantlyaffected $(p \leq 0.05)$ yield components of hybrid rice, such as, number of filled seeds panicle $e^{-1}$, number of unfilled seeds panicle ${ }^{-1}$ and panicle weight, while the effect was non-significant $(p \geq 0.05)$ for number of panicles hill ${ }^{-1}$, panicle length and 1000-seed weight (Table 3). $\mathrm{K}$ application at $90 \mathrm{~kg} \mathrm{~K}_{2} \mathrm{O} \mathrm{ha}^{-1}$ produced higher number of filled seeds panicle ${ }^{-1}$ accounting for $26.4 \%$ more than that with $\mathrm{K}$ omission. Panicle weight increased with increase in $\mathrm{K}$ dose up to $60 \mathrm{~kg} \mathrm{ha}^{-1}$, remained at par at $\mathrm{K}$ dose of $90 \mathrm{~kg} \mathrm{ha}^{-1}$, and decreased with further increase in $\mathrm{K}$ rate. Plants in the control plot produced the lowest panicle weight.

\subsection{K Accumulation in Different Plant Parts}

The $\mathrm{K}$ concentration (\%) in stem at peak growth stage, i.e., 60 DAT, increased steadily upto $90 \mathrm{~kg} \mathrm{~K}_{2} \mathrm{O} \mathrm{ha}^{-1}$ although the difference is statistically non-significant ( $p \geq 0.05$ ) (Table 4). The leaf $\mathrm{K}$ concentration also increased up to $60 \mathrm{~kg} \mathrm{~K}_{2} \mathrm{O} \mathrm{ha}^{-1}$, although insignificantly. A similar trend of $\mathrm{K}$ concentration was observed for stem, leaf, and grain at harvest (Table 4). As expected, the $\mathrm{K}$ accumulation in grain was lower than in stem or leaf. The relationships between grain yield and stem $\left(R^{2}=0.77\right)$ as well as grain $\mathrm{K}$ concentration $\left(R^{2}=0.89\right)$ were significant $(p \leq 0.05)$, while between grain yield and leaf $\mathrm{K}$ concentration was non-significant $\left(R^{2}=0.32\right)$ (Figure 2$)$. 
Table 4. Potassium concentration (\%) in different plant parts, mobilization, and utilization by hybrid rice (var. Arize 6444) as influenced by potassium fertilization (means for 2016 and 2017).

\begin{tabular}{|c|c|c|c|c|c|c|c|}
\hline \multirow{3}{*}{$\begin{array}{l}\text { Levels of K } \\
\left(\mathrm{kg} \mathrm{ha}^{-1}\right)\end{array}$} & \multicolumn{5}{|c|}{ Potassium Concentration ( $\%$ ) } & \multirow{3}{*}{ KHI (\%) } & \multirow{3}{*}{ KMEI (\%) } \\
\hline & \multicolumn{2}{|c|}{ At 60 DAT } & \multicolumn{3}{|c|}{ At Harvest } & & \\
\hline & Stem & Leaf & Stem & Leaf & Grain & & \\
\hline $\mathrm{K}_{0}$ & $3.68^{\mathrm{a}}$ & $2.52^{\mathrm{a}}$ & $4.48^{\mathrm{a}}$ & $1.57^{\mathrm{ab}}$ & $0.043^{\mathrm{d}}$ & $1.29^{c}$ & $0.71^{\mathrm{c}}$ \\
\hline $\mathrm{K}_{30}$ & $3.73^{a}$ & $2.72^{a}$ & $4.49^{\mathrm{a}}$ & $1.27^{\mathrm{c}}$ & $0.055^{\mathrm{cd}}$ & $1.87^{b}$ & $0.96^{\mathrm{bc}}$ \\
\hline $\mathrm{K}_{60}$ & $3.83^{\mathrm{a}}$ & $2.82^{\mathrm{a}}$ & $4.52^{\mathrm{a}}$ & $1.58^{\mathrm{ab}}$ & $0.068^{b c}$ & $2.21^{b}$ & $1.12^{\mathrm{b}}$ \\
\hline $\mathrm{K}_{90}$ & $4.02^{\mathrm{a}}$ & $2.82^{\mathrm{a}}$ & $4.56^{\mathrm{a}}$ & $1.70^{\mathrm{a}}$ & $0.073^{\mathrm{b}}$ & $2.31^{b}$ & $1.18^{\mathrm{b}}$ \\
\hline $\mathrm{K}_{120}$ & $4.02^{\mathrm{a}}$ & $2.87^{\mathrm{a}}$ & $4.62^{\mathrm{a}}$ & $1.42^{b c}$ & $0.093^{\mathrm{a}}$ & $2.96^{\mathrm{a}}$ & $1.54^{\mathrm{a}}$ \\
\hline $\operatorname{LSD}(p \leq 0.05)$ & NS & NS & NS & 0.23 & 0.01 & 0.59 & 0.29 \\
\hline
\end{tabular}

NS, non-significant; DAT, days after transplanting; KHI, potassium harvest index; KMEI, potassium mobilization efficiency index; Means followed by a different letter within a column are significantly different at $p \leq 0.05$ by Tukey's HSD (honest significant difference) test; LSD, Least Significant Difference.
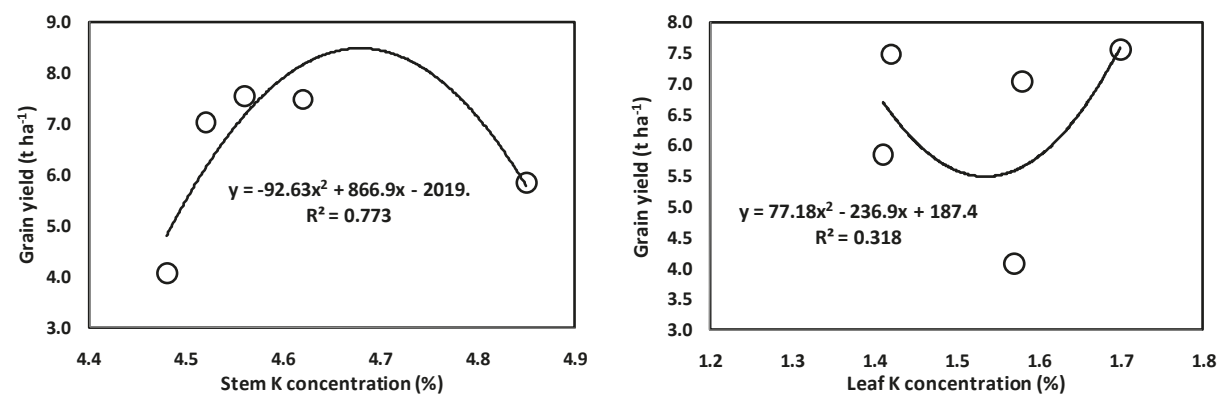

(a)

(b)

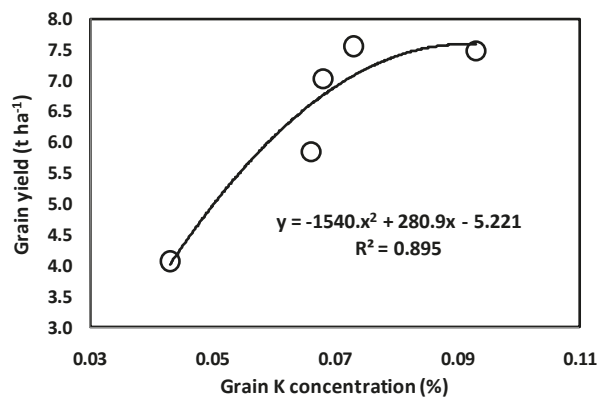

(c)

Figure 2. Relationship between grain yield $\left(\mathrm{tha}^{-1}\right)$ and stem $(\mathbf{a})$, leaf (b), and grain $(\mathbf{c}) \mathrm{K}$ concentration (\%).

\subsection{K-Use Efficiency, Sustainable Yield Index, and Partial Factor Productivity}

Potassium harvest index (KHI) in hybrid rice ranged from 1.29 to $2.96 \%$ at different $\mathrm{K}$ rates (Table 4). Potassium fertilization had a significant $(p \leq 0.05)$ influence on KHI of the tested hybrid, and it was maximum with $120 \mathrm{~kg} \mathrm{~K}_{2} \mathrm{O} \mathrm{ha}^{-1}$, accounting for $130 \%$ higher $\mathrm{KHI}$ over the control. Theapplication rates of 30, 60, and $90 \mathrm{~kg} \mathrm{~K}_{2} \mathrm{O} \mathrm{ha}^{-1}$ resulted in statistically at par $\mathrm{KHI}$ values. Potassium mobilization efficiency index (KMEI) in the tested hybrid rice cultivar ranged from 0.71 to $1.54 \%$ (Table 4), with significant $(p \leq 0.05)$ variation over control. Agronomic efficiency and physiological efficiency decreased with every incremental dose of $\mathrm{K}$ (Table 5). The KUE indices were highest at $30 \mathrm{~kg} \mathrm{~K} \mathrm{ha}^{-1}$ and lowestat the highest $\mathrm{K}$ dose $\left(120 \mathrm{~kg} \mathrm{~K}_{2} \mathrm{O} \mathrm{ha}^{-1}\right)$. 
Table 5. Potassium use efficiency, sustainable yield index, and partial factor productivity of hybrid rice as influenced by potassium fertilization (means for 2016 and 2017).

\begin{tabular}{|c|c|c|c|c|}
\hline $\begin{array}{l}\text { Levels of K } \\
\left(\mathrm{kg} \mathrm{ha}^{-1}\right)\end{array}$ & $\begin{array}{c}\text { Agronomic } \\
\text { Efficiency } \\
\left(\mathrm{kg} \mathrm{Grain} \mathrm{kg}^{-1} \mathrm{~K}\right)\end{array}$ & $\begin{array}{c}\text { Physiological } \\
\text { Efficiency } \\
\left(\mathrm{kg} \mathrm{Grain} \mathrm{kg}^{-1} \mathrm{~K}\right)\end{array}$ & $\begin{array}{l}\text { Sustainable } \\
\text { Yield Index }\end{array}$ & $\begin{array}{c}\text { Partial Factor } \\
\text { Productivity } \\
\left(\mathrm{kg} \mathrm{Grain} \mathrm{kg}^{-1} \mathrm{~K}\right)\end{array}$ \\
\hline $\mathrm{K}_{30}$ & 55.33 & 48.64 & 0.83 & 191.33 \\
\hline $\mathrm{K}_{60}$ & 49.33 & 48.14 & 0.71 & 117.33 \\
\hline $\mathrm{K}_{90}$ & 38.66 & 53.35 & 0.65 & 84.00 \\
\hline $\mathrm{K}_{120}$ & 28.42 & 53.35 & 0.64 & 62.42 \\
\hline
\end{tabular}

Overall trend shows that the SYI varied from 0.64 to 0.83 due to changes in $\mathrm{K}$ rates from 30 to $120 \mathrm{~kg} \mathrm{~K}_{2} \mathrm{O} \mathrm{ha}^{-1}$ (Table 5). The highest value of SYI (0.83) was obtained with $30 \mathrm{~kg} \mathrm{~K}_{2} \mathrm{O} \mathrm{ha}^{-1}$. Partial factor productivity $\left(\mathrm{PFP}_{\mathrm{K}}\right)$ decreased as the $\mathrm{K}$ ratesincreased from 30 to $120 \mathrm{~kg} \mathrm{~K}_{2} \mathrm{O}$ ha $^{-1}$. As expected, the highest $\mathrm{PFP}_{\mathrm{K}}$ (191.33 $\mathrm{kg}_{\text {grain kg }}{ }^{-1}$ of $\mathrm{K}$ fertilizer) was recorded in plots with $30 \mathrm{~kg} \mathrm{~K}_{2} \mathrm{O} \mathrm{ha}^{-1}$ and the lowest (62.42 $\mathrm{kg}_{\text {grain }} \mathrm{kg}^{-1}$ of K-fertilizer) was found at $120 \mathrm{~kg} \mathrm{~K}_{2} \mathrm{O} \mathrm{ha}^{-1}$.

\subsection{Post-Harvest Soil Status and K Balance Sheet}

Significant changes in $\mathrm{pH}, \mathrm{EC}$, and available $\mathrm{K}$ in post-harvest soil was observed compared to their initial values (Figure 3). K application significantly reduced the soil $\mathrm{pH}$ (7.8 to $12.9 \%$ lower than the initial value) (Figure 3a). The EC of the post-harvest soil increased with $\mathrm{K}$ application beyond $30 \mathrm{~kg}$ $\mathrm{K}_{2} \mathrm{O} \mathrm{ha}^{-1}$ (6.5 to $34.6 \%$ higher than initial value) (Figure $3 \mathrm{~b}$ ). The available $\mathrm{K}$ content in post-harvest soil samples improved significantly $(p \leq 0.05)$ over the initial value by 24 to $91 \%$ when the crop received $\mathrm{K}$ fertilization (Figure 3c). For better understanding of $\mathrm{K}$ gain or loss, we followed a balance sheet approach (Table 6). A positive balance of $K$ in all plots was observed, irrespective of $K$ rates. The actual net gain (+) of $\mathrm{K}$ in post-harvest soil was higher compared to the expected net gain.

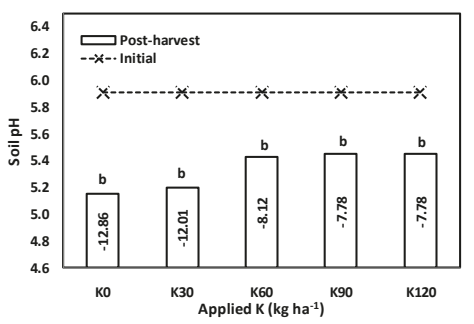

(a)

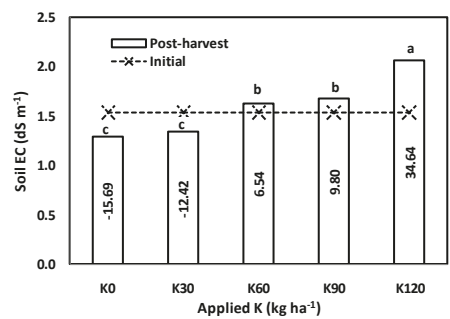

(b)

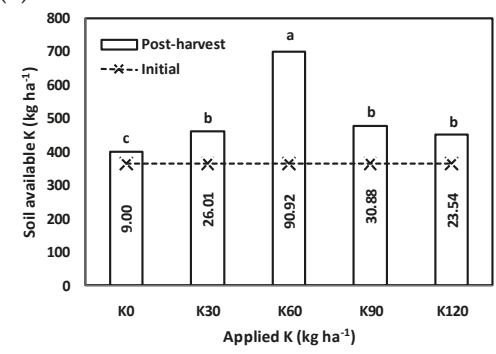

(c)

Figure 3. Soil pH (a), EC ( $\left.\mathrm{dS} \mathrm{m}^{-1}\right)(\mathbf{b})$, and available $\mathrm{K}\left(\mathrm{kg} \mathrm{ha}^{-1}\right)(\mathbf{c})$ at different levels of $\mathrm{K}\left(\mathrm{kg} \mathrm{ha}^{-1}\right)$ (means followed by same letter are statistically at par, otherwise significantly different at $p \leq 0.05$ by Tukey's HSD (honest significant difference) test; data within bars are percent increase or decrease (-) in any parameter from its initial value). 
Table 6. Potassium balance in soil after harvesting of hybrid rice (var. Arize 6444) as influenced by potassium fertilization (means for 2016 and 2017).

\begin{tabular}{|c|c|c|c|c|c|c|c|}
\hline $\begin{array}{l}\text { Levels of K } \\
\left(\mathrm{kg} \mathrm{ha}^{-1}\right)\end{array}$ & $\begin{array}{l}\text { Initial Soil } \\
\text { K Status } \\
\left(\mathrm{kg} \mathrm{ha}^{-1}\right) \text { (a) }\end{array}$ & $\begin{array}{c}\text { K Added } \\
\text { through } \\
\text { Fertilizer } \\
\left(\mathrm{kg} \mathrm{ha}^{-1}\right)(\mathrm{b})\end{array}$ & $\begin{array}{c}\text { Total K } \\
\left(\mathrm{kg} \mathrm{ha}^{-1}\right) \\
(\mathrm{c}=\mathrm{a}+\mathrm{b})\end{array}$ & $\begin{array}{c}\text { Crop K } \\
\text { Uptake } \\
\left(\mathrm{kg} \mathrm{ha}^{-1}\right) \\
\text { (d) }\end{array}$ & $\begin{array}{c}\text { Expected } \\
\text { Balance } \\
\left(\mathrm{kg} \mathrm{ha}^{-1}\right) \\
(\mathrm{e}=\mathrm{c}-\mathrm{d})\end{array}$ & $\begin{array}{c}\text { Actual K } \\
\text { Balance }^{*} \\
\left(\mathrm{~kg} \mathrm{ha}^{-1}\right)(\mathrm{f})\end{array}$ & $\begin{array}{l}\text { Net K Gain (+) or } \\
\text { Loss }(-) \\
\left(\mathrm{kg} \mathrm{ha}^{-1}\right)(\mathrm{f}-\mathrm{e})\end{array}$ \\
\hline $\mathrm{K}_{0}$ & 343.6 & 0 & 343.6 & 208.7 & 134.9 & 398.8 & 263.9 \\
\hline $\mathrm{K}_{30}$ & 343.6 & 30 & 373.6 & 243.2 & 130.4 & 451.0 & 320.6 \\
\hline $\mathrm{K}_{60}$ & 343.6 & 60 & 403.6 & 270.2 & 133.4 & 461.0 & 327.6 \\
\hline $\mathrm{K}_{90}$ & 343.6 & 90 & 433.6 & 273.9 & 159.6 & 498.8 & 339.2 \\
\hline $\mathrm{K}_{120}$ & 343.6 & 120 & 463.6 & 272.7 & 190.9 & 698.5 & 507.6 \\
\hline
\end{tabular}

Crop K uptake was calculated by multiplying total plant K concentration (\%) with dry matter $\left(\mathrm{kg} \mathrm{ha}^{-1}\right)$; ${ }^{*}$ Represents data on available $\mathrm{K}$ content in post-harvest soil.

\subsection{Economic Returns}

Higher profitability from hybrid rice was achieved with $90 \mathrm{~kg} \mathrm{~K}_{2} \mathrm{O}$ ha ${ }^{-1}$ due to higher net returns (US\$ $452 \mathrm{ha}^{-1}$ ) and BCRs (1.75) over other treatments (Table 7). Both higher $\left(120 \mathrm{~kg} \mathrm{ha}^{-1}\right)$ and lower K rates $\left(30 \mathrm{~kg} \mathrm{~K}_{2} \mathrm{O} \mathrm{ha}^{-1}\right)$ resulted in decline in net return and BCR. Both net return and BCR showed a sharp decline in the $\mathrm{K}$ omission treatment.

Table 7. Economic analysis of hybrid rice (var. Arize 6444) cultivation as influenced by potassium fertilization (means for 2016 and 2017).

\begin{tabular}{|c|c|c|c|c|c|c|}
\hline $\begin{array}{l}\text { Levels of } K \\
\left(\mathrm{~kg} \mathrm{ha}^{-1}\right)\end{array}$ & $\begin{array}{l}\text { Common Cost } \\
\left(\mathrm{US} \$ \mathrm{ha}^{-1}\right)\end{array}$ & $\begin{array}{l}\text { Treatment Cost } \\
*\left(\mathrm{US} \$ \mathrm{ha}^{-1}\right)\end{array}$ & $\begin{array}{l}\text { Total Cost } \\
\left(\mathrm{US} \$ \mathrm{ha}^{-1}\right)\end{array}$ & $\begin{array}{c}\text { Gross Return } \\
\left(\mathrm{US} \$ \mathrm{ha}^{-1}\right)\end{array}$ & $\begin{array}{l}\text { Net Return } \\
\left(\mathrm{US} \$ \mathrm{ha}^{-1}\right)\end{array}$ & BCR \\
\hline $\mathrm{K}_{0}$ & 517 & 47 & 564 & 569 & 12 & 1.01 \\
\hline $\mathrm{K}_{30}$ & 517 & 60 & 577 & 800 & 416 & 1.39 \\
\hline$K_{60}$ & 517 & 73 & 590 & 981 & 476 & 1.66 \\
\hline$K_{90}$ & 517 & 86 & 603 & 1054 & 452 & 1.75 \\
\hline $\mathrm{K}_{120}$ & 517 & 99 & 616 & 1044 & 208 & 1.69 \\
\hline
\end{tabular}

$\mathrm{BCR}$, benefit:cost ratio; ${ }^{*}$ Treatment cost varies only due to difference in fertilizer levels; 1 US $\$=65.00$.

\section{Discussion}

The cultivation of hybrid rice using K rates applicable to high yielding varieties (HYVs) has failed to realize higher yields under any given conditions [12]. Thus, improved K management (particularly timing and splitting) for superior cultivarsis required to increase yield and KUE of hybrid rice. An uninterrupted supply of $\mathrm{K}$ during the entire crop growth period was found to be more effective as it increased growth parameters, yield attributes, yield, and KUE of rice hybrids [17]. The present study quantified the impact of $\mathrm{K}$ fertilization on growth, development, and yield of var. Arize 6444. In this study, leaf and grain dry matter (DM) at harvest and number of tillers hill ${ }^{-1}$ were highest at $120 \mathrm{~kg} \mathrm{~K}_{2} \mathrm{O} \mathrm{ha}^{-1}$, followed by $90 \mathrm{~kg} \mathrm{~K}_{2} \mathrm{O} \mathrm{ha}^{-1}$. This finding is supported by a previous study indicating improved growth parameters due to increase in $\mathrm{K}$ level [32]. Higher uptake of $\mathrm{K}$ in above-ground biomass with high dose of $\mathrm{K}$ might have resulted in larger canopy of the hybrid cultivar [33]. Another study has shown that macro and micronutrient uptake increased considerably under higher $\mathrm{K}$ application rates. Hence, increased apparent recovery of N, P, S, and Ca with higher K application rates could improve growth of rice hybrids [12]. Other investigators opined that significant $(p \geq 0.05)$ increase in total photosynthetic rate and net assimilation rate at heading and maturing stages with high $\mathrm{K}$ application might have led to greater DM production [34]. On the other hand, plants in control plots had lower DM accumulation. This result is in conformity with the findings of other investigators who observed increased total tillers, dry matter accumulation, and effective tillers with $75 \mathrm{~kg} \mathrm{~K}_{2} \mathrm{O} \mathrm{ha}^{-1}$ [17].

We observed significant $(p \leq 0.05)$ beneficial effect of $\mathrm{K}$ fertilization on yield components of hybrid rice, mainly on number of filled and unfilled grains panicle ${ }^{-1}$ and panicle weight, and $\mathrm{K}$ application at $90 \mathrm{~kg} \mathrm{ha}^{-1}$ had the best result. In line with our results, other investigators found that high levels of $\mathrm{K}$ 
significantly increased $(p \geq 0.05)$ panicle weight due to higher number of filled grains panicle ${ }^{-1}[35,36]$. Potassium appeared to help enhance grain weight by delaying abscisic acid (ABA) peak by fourto fivedays, thereby delaying maturation and increasing carbohydrate translocation to the seeds [37]. The same study also reported that $\mathrm{K}$ application markedly reduced the number of unfilled spikelets due to its promoting effect on cytokinin synthesis, which resulted in less zygote degeneration.

The present study highlights that the number of filled grains panicle ${ }^{-1}$ and panicle weight were strongly associated with grain yield. This finding again confirms that productivity of crop is collectively determined by vegetative growth and its yield components. Better vegetative growth coupled with higher yield components might have resulted in higher grain and straw yield of hybrid rice $[9,13,14,38]$. In addition, limited supply of assimilates to the grains might be responsible for the reduced panicle weight at lower doses of $K$. The panicle length and test weight had non-significant contribution to grain yield. Several investigators identified the number of grains panicle ${ }^{-1}$ as the key yield components for higher grain yield in hybrids, rather than panicle number and panicle length [39]. Similar to the present study, other researchers also did not find any relation between test weight and grain yield of hybrid rice grown in the wet season [1].

The regression between $\mathrm{K}$ and grain yield indicated that the relationship was highly significant in the observed quadratic relationship (Figure 1). From the regression equation, the economic optimum level of $\mathrm{K}\left(\mathrm{K}_{\mathrm{opt}}\right)$ was derived as $101.5 \mathrm{~kg} \mathrm{~K}_{2} \mathrm{O} \mathrm{ha}{ }^{-1}$. Other investigators also used a similar approach for determining $\mathrm{K}_{\text {opt }}$ and found $80 \mathrm{~kg} \mathrm{~K}_{2} \mathrm{O} \mathrm{ha}^{-1}$ as the best dose for hybrid rice in summer season at red and lateritic soils of Orissa [40]. Results are in accordance with earlier reports [17], wherein higher yield response of hybrid rice to $\mathrm{K}$ nutrition was found at $75 \mathrm{~kg} \mathrm{ha}^{-1}$. However, in the salt affected soil the $\mathrm{K}$ requirement is higher as the soil salinity caused a reduction in growth and yield of rice and higher $\mathrm{K}$ is required for alleviation [41]. A study in a coastal saline soil of Bangladesh reported that the required $\mathrm{K}$ dose is more than $100 \mathrm{~kg} \mathrm{ha}^{-1}$ to achieve hybrid rice yield of $4 \mathrm{tha}^{-1}$ [41], which is similar to the present study.

The $\mathrm{K}$ content of rice plant is an important index for obtaining higher grain yield of hybrid rice [42]. The regression study with grain yield as a dependent variable showed that the stem $\left(R^{2}=0.77\right)$ and grain $\mathrm{K}$ concentrations $\left(R^{2}=0.89\right)$ had positive significant relationship with yield. Strategies to increase stem and grain $\mathrm{K}$ concentration can thereby enhance grain yield. However, leaf $\mathrm{K}$ concentration was not a good indicator of the response of hybrid rice to $\mathrm{K}$ fertilization. Information regarding increase of both grain yield and KUE, as well as their relationship with $\mathrm{K}$ accumulation and utilization characteristics is limited. Only few earlier studies revealed higher $\mathrm{K}$ accumulation during the period from primary branch initiation to spikelet initiation [43]. About $45-67 \%$ of total $\mathrm{K}$ accumulation was observed from panicle initiation (PI) to heading stage. In addition, $50 \%$ of the $\mathrm{K}$ in leaf sheath might had been translocated to spikelets after heading which accounted for two-thirds of grain $\mathrm{K}$ concentration [43]. In the present study, Arize 6444 had high $\mathrm{K}$ accumulation both in vegetative (particularly leaf) and reproductive part (grain) at harvest with 90 and $120 \mathrm{~kg} \mathrm{~K}_{2} \mathrm{O} \mathrm{ha}^{-1}$ that might have contributed significantly to high yield. Additionally, the higher $\mathrm{K}$ accumulation in its stems both at $60 \mathrm{DAT}$ and harvest helped increase lodging resistance [44]. The present work has also shown that $\mathrm{K}$ omission treatment decreased $\mathrm{K}$ uptake, transfer and efficiency.

The KUE indices (agronomic efficiency and physiological efficiency) for the tested hybrid cultivar decreased with the increase in $\mathrm{K}$ from 30 to $120 \mathrm{~kg} \mathrm{ha}^{-1}$, being maximum and minimum at 30 and $120 \mathrm{~kg} \mathrm{~K}_{2} \mathrm{O} \mathrm{ha}^{-1}$, respectively. There was not much difference in SYI of hybrid rice due to variation in $\mathrm{K}$ fertilization. The fertilizer productivity, estimated as PFP, decreased with the increasing level of $\mathrm{K}$ fertilization. This indicates poor rate of $\mathrm{K}$ utilization at higher application rates. This might be due to the curvilinear return to the conversion of $K$ to seed as yield approaches the ceiling at higher $\mathrm{K}$-levels [24,45]. The fertilizer productivity decreased to a greater degree passing from 30 to $60 \mathrm{~kg}$ $\mathrm{K}_{2} \mathrm{O} \mathrm{ha}^{-1}$ (PFP $117.33 \mathrm{~kg}_{\text {grain kg }}{ }^{-1}$ of K-fertilizer) than passing from 60 to 90 (PFP $84.00 \mathrm{~kg}$ grain $\mathrm{kg}^{-1} \mathrm{~K}$ ) or 90 to 120 (PFP $62.42 \mathrm{~kg}$ grain $\mathrm{kg}^{-1} \mathrm{~K}$ ). The results point to the advantage of using an optimum $\mathrm{K}$ rate that creates the right balance between efficiency and effectivity of applied $\mathrm{K}$ fertilizer. 
The $\mathrm{K}$ balance in the post-harvest soil was positive for all the treatments. Interestingly, the net $\mathrm{K}$ balance was positive even for the $\mathrm{K}$ omission plots. Thepositive balance was driven by the high initial $\mathrm{K}$ level of the experimental soil $\left(366 \mathrm{~kg} \mathrm{~K}_{2} \mathrm{O} \mathrm{ha}{ }^{-1}\right)$. A recent study [46] from the same area revealed that the soils of the area are rich in illitic clays and are expected to release non-exchangeable $\mathrm{K}$ (NEK)effectively when under stress. The same study, through sequential extraction with boiling $1 \mathrm{M}$ $\mathrm{HNO}_{3}$, showed that the NEK release could be triggered at a relatively high activity coefficient $\left(\mathrm{AR}^{\mathrm{K}}\right)$ of K [46]. Such NEK release could augment the already high native K level in the soil and may explain the positive net $\mathrm{K}$ balance observed in our study. Crop response to $\mathrm{K}$ fertilizer application in soils with such high initial $\mathrm{K}$ level is not expected. However, every incremental dose of $\mathrm{K}$ over the zero-K treatment produced significant yield increases in this study, and the best yield was achieved at $90 \mathrm{~kg} \mathrm{~K}_{2} \mathrm{O} \mathrm{ha}^{-1}$. This suggest that hybrid rice was unable to use the native $\mathrm{K}$ till $\mathrm{K}$ fertilizer application increased the activity of $\mathrm{K}$ to a sufficiently high level. Such $\mathrm{K}$ uptake restriction may happen when soils have high magnesium concentration relative to $\mathrm{K}$ concentration. The $\mathrm{Mg}$-induced $\mathrm{K}$ deficiency in crops is well documented and can occur in soils with an available $\mathrm{K} / \mathrm{Mg}$ concentration below 0.32 [47]. A recent assessment of $\mathrm{K}^{+} /\left(\mathrm{Ca}^{2+}+\mathrm{Mg}^{2+}\right)$ ratios in soils from two similar locations nearby our experimental sites indicated values less than 0.17 [46]. Such low values of the said ratio in our study area may create restriction to $\mathrm{K}$ uptake leading to hybrid rice yield losses when $\mathrm{K}$ fertilizer was not applied.

Application of $90 \mathrm{~kg} \mathrm{~K}_{2} \mathrm{O}$ ha ${ }^{-1}$ has been found to be economically effective, mainly because of increased grain yield realized at this $\mathrm{K}$ application rate. However, the economic optimum level of $\mathrm{K}_{\mathrm{opt}}$ was derived from regression study as $101.5 \mathrm{~kg} \mathrm{~K}_{2} \mathrm{O} \mathrm{ha}^{-1}$. On the contrary, the lowest net returns and BCR were found in K-omitted plots because of lower grain yield, resulting from a smaller number of filled grains panicle ${ }^{-1}$, short length of panicle and reduced panicle weight. This result corroborates the earlier studies that hybrid rice cultivars responded to K application appreciably, although economic efficiency of $\mathrm{K}$ declined at higher levels of application [9,32,33].

\section{Conclusions}

In the main rice growing areas of the coastal saline belt of West Bengal (India), productivity, and profitability of hybrid rice (var. Arize 6444) could be increased through site-specific K management practice. Our research confirms that adequate $\mathrm{K}$ application is necessary to obtain high grain yield in hybrid rice even though the soils of the coastal areas are high in illitic clay and high available $\mathrm{K}$ content. This explains why a K management strategy appropriate for HYVs may not work for hybrid rice. Our results also confirm that the present recommended level $\left(40 \mathrm{~kg} \mathrm{~K}_{2} \mathrm{O} \mathrm{ha}^{-1}\right)$ is inadequate to support attainable yield potentials of hybrid rice. A rate of $101.5 \mathrm{~kg} \mathrm{~K}_{2} \mathrm{O} \mathrm{ha}{ }^{-1}$ (through muriate of potash/MOP) may be recommended to achieve higher productivity of hybrid rice during wet season in coastal region of West Bengal (India).

Author Contributions: H.B. and S.K.D. conceived and designed the experiment; H.B. and S.K.D. conducted the experiments; H.B. recorded the data; H.B. and K.R. analyzed the data; H.B. and K.R. wrote the paper; S.K.D., K.M., T.S., and J.T. reviewed, edited, and approved the final manuscript.

funding: This work was funded by International Plant Nutrition Institute (IPNI), South-Asia Program.

Acknowledgments: Authors pay special thanks to Bidhan Chandra KrishiViswavidyalaya (BCKV), India, for giving the opportunity to conduct field experiment in their Research Farm. We are grateful to Pravat Kumar Maity, Ajay Kar, and GurupadaKhanra for managing the field experiments at Kakdwip, West Bengal. We also thank BiswanathHalder who carried out the chemical analysis for plant and soil samples at BCKV.

Conflicts of Interest: The authors declare no conflict of interest.

\section{References}

1. Banerjee, H.; Pal, S. Effect of planting geometry and different levels of nitrogen on hybrid rice. Oryza 2011, 48, 274-275.

2. Banerjee, H.; Chatterjee, S.; Sarkar, S.; Gantait, S.; Samanta, S. Evaluation of rapeseed-mustard cultivars under late sown condition in coastal ecosystem of West Bengal. J. Appl. Natl. Sci. 2017, 9, 940-949. [CrossRef] 
3. Asch, F.; Dingkuhn, M.; Wittstock, C.; Doerffling, K. Sodium and potassium uptake of rice panicles as affected by salinity andseason in relation to yield and yield components. Plant Soil 1999, 207, 133-145. [CrossRef]

4. Castillo, E.G.; Tuong, T.P.; Ismail, A.M.; Inubushi, K. Response to Salinity in Rice: Comparative Effects of Osmotic and Ionic Stresses. Plant Prod. Sci. 2007, 10, 159-170. [CrossRef]

5. Aslam, M.; Qureshi, R.H.; Ahmad, N. A rapid screening technique for salt tolerance in rice (Oryza sativa L.). Plant Soil 1993, 150, 99-107. [CrossRef]

6. Mondal, P.; Pal, S.; Alipatra, A.; Mandal, J.; Banerjee, H. Comparative study on growth and yield of promising rice cultivars during wet and dry season. Plant Arch. 2012, 12, 659-662.

7. Islam, M.R.; Sarker, M.R.A.; Sharma, N.; Rahman, M.A.; Collard, B.C.Y.; Gregorio, G.B.; Ismail, A.M. Assessment of adaptability of recently released salt tolerant rice varieties in coastal regions of South Bangladesh. Field Crop. Res. 2016, 190, 34-43. [CrossRef]

8. Adhikari, B.; Bag, M.K.; Bhowmick, M.K.; Kundu, C. Status Paper on Rice in West Bengal. In Rice Knowledge Management Portal (RKMP); Directorate of Rice Research: Hyderabad, India, 2011.

9. Banerjee, H.; Pal, S. Response of hybrid rice to nutrient management during wet season. Oryza 2012, 49, 108-111.

10. Khandkar, V.; Gandhi, V.P. Post-adoption experience of hybrid rice in India: Farmers' satisfaction and willingness to grow. Agric. Econ. Res. Rev. 2018, 31, 95-104. [CrossRef]

11. Singh, A.; Kumar, B.; Baghel, R.; Singh, R. Sustainability of hybrid rice technology vis a vis inbred rice in Uttar Pradesh. Ind. Res. J. Ext. Educ. 2009, 9, 22-25.

12. Pattanayak, S.K.; Mukhi, S.K.; Majumdar, K. Potassium unlocks the potential for hybrid rice. Better Crop. 2008, 92, 8-9.

13. Mondal, S.; Mallikarjun, M.; Ghosh, M.; Ghosh, D.C.; Timsina, J. Effect of Integrated Nutrient Management on Growth and Productivity of Hybrid Rice. J. Agric. Sci. Technol. 2015, 297-308.

14. Mondal, S.; Mallikarjun, M.; Ghosh, M.; Ghosh, D.C.; Timsina, J. Influence of integrated nutrient management (INM) on nutrient use efficiency, soil fertility and productivity of hybrid rice. Arch. Agron. Soil Sci. 2016. [CrossRef]

15. Fageria, N.K.; Sant'ana, E.P.; Morais, O.P.; de Morais, O.P. Response of promising upland rice genotypes to soil fertility. Pesqui. Agropecu. Bras. 1995, 30, 1155-1161.

16. Shi, H.; Zhang, X.H.; Pan, X.H.; Guo, J.Y.; Zhang, P. Studies on the characteristics of potassium absorption and yield formation on early hybrid rice. Acta Agric. Univ. JiangXiensis 1990, 12, 54-59.

17. Meena, S.L.; Singh, S.; Shivay, Y.S. Response of hybrid rice (Oryza sativa) to nitrogen and potassium application. Ind. J. Agron. 2002, 47, 207-211.

18. Prasad, K.; Chauhan, R.P.S. Efficiency of potassium under rainfed lowland rice. Ann. Plant Soil Res. 1999, 1, 52-57.

19. Jackson, M.L. Soil Chemical Analysis; Prentice Hall of India Pvt. Ltd.: New Delhi, India, 1967.

20. Dewis, J.; Freitas, F. Physical and Chemical Methods of Soil and Water Analysis. In Soil Bulletin; FAO: Rome, Italy, 1984.

21. Subbiah, B.; Asija, G.L. A rapid procedure for the estimation of available N in soils. Curr. Sci. 1956, 25, 259-260.

22. Olsen, S.R.; Cole, C.V.; Watanale, F.S.; Dean, L.A. Estimation of Available Phosphorus in Phosphorus in Soils by Extraction with Sodium Bicarbonate; United States Department of Agriculture: Washington, DC, USA, 1954.

23. Hanway, J.J.; Heidel, H. Soil analysis methods as used in Iowa State College Soil Testing Laboratory. Iowa Agric. 1952, 57, 1-13.

24. Sarangi, S.K.; Maji, B.; Singh, S.; Sharma, D.K.; Burman, D.; Mandal, S.; Haefele, S.M. Using improved variety and management enhances rice productivity in stagnant flood-affected tropical coastal zones. Field Crop. Res. 2016, 190, 70-81. [CrossRef]

25. Jackson, M.L. Soil Chemical Analysis; Prentice Hall of India Pvt. Ltd.: New Delhi, India, 1973; pp. $38-56$.

26. Sharma, N.K.; Singh, R.J.; Kumar, K. Dry matter accumulation and nutrient uptake by wheat (Triticumaestivum L.) under poplar (Populusdeltoides) based agroforestry system. ISRN Agron. 2012, 2012, 359673.

27. Fageria, N.K. Nitrogen harvest index and its association with crop yields. J. Plant Nutr. 2014, 37, 795-810. [CrossRef] 
28. Sarkar, S.; Banerjee, H.; Ray, K.; Ghosh, D. Boron fertilization effects in processing grade potato on an inceptisol of West Bengal, India. J. Plant Nutr. 2018, 41, 1456-1470. [CrossRef]

29. Mozumder, M.; Banerjee, H.; Ray, K.; Paul, T. Evaluation of potato (Solanumtuberosum) cultivars for productivity, $\mathrm{N}$ requirement and eco-friendly indices under different nitrogen levels. Ind. J. Agron. 2014, 59, 327-335.

30. Vittal, K.P.R.; MaruthiSankar, G.R.; Singh, H.P.; Samra, J.S. Sustainability of Practices of Dryland Agriculture: Methodology and Assessment. Available online: http://www.crida.in/AICRPDA/Sustainability.pdf (accessed on 4 October 2018).

31. Rana, R.; Banerjee, H.; Dutta, S.K.; Ray, K.; Majumdar, K.; Sarkar, S. Management practices of macronutrients for potato for smallholder farming system at alluvial soil (Entisols) of India. Arch. Agron. Soil Sci. 2017, 63, 1963-1976. [CrossRef]

32. Maiti, S.; Saha, M.; Banerjee, H.; Pal, S. Integrated nutrient management under hybrid rice-Hybrid rice (Oryza sativa) cropping sequence. Ind. J. Agron. 2006, 51, 157-159.

33. Banerjee, H.; Pal, S. Integrated nutrient management for rice-rice cropping system. Oryza 2009, 46, 32-36.

34. Fan, M.; Ge, D.Z. Potassium nutrition in hybrid rice. Int. Rice Res. Newsl. 1987, 12, 21.

35. Thakur, R.B.; Pandey, S.K.; Singh, H. Contribution of production factors on yield of midland rice. Oryza 1994, 31, 271-293.

36. Bhowmick, N.; Nayak, R.L. Response of hybrid rice (Oryza sativa L.) varieties to nitrogen, phosphorus and potassium fertilizers during dry (boro) season in West Bengal. Ind. J. Agron. 2000, 45, 323-326.

37. Yuan, L.; Huang, J.G. Effects of potassium on the variation of plant hormones in developing seeds of hybrid rice. J. South West Agric. Univ. 1993, 15, 38-41.

38. Dwivedi, A.P.; Dixit, R.S.; Singh, G.R. Effect of nitrogen, phosphorus and potassium levels on growth, yield and quality of hybrid rice (Oryza sativa L.). Oryza 2006, 43, 64-66.

39. Om, H.; Katyal, S.K.; Dhiman, S.D. Effect of time of transplanting and rice (Oryza sativa) hybrids on growth and yield. Ind. J. Agron. 1997, 42, 261-264.

40. Das, L.K.; Panda, S.C. Economics of hybrid rice cultivation as influenced by nitrogen and potassium levels. J. Res. Orissa Univ. Agric. Technol. 2002, 20, 50-52.

41. Kibria, M.G.; Farhad; Hoque, M.A. Alleviation of soil salinity in rice by potassium and zinc fertilization. Int. J. Exp. Agric. 2015, 5, 15-21.

42. Li, M.; Zhang, H.; Yang, X.; Ge, M.; Ma, Q.; Wei, H.; Dai, Q.; Huo, Z.; Xu, K.; Luo, D. Accumulation, and utilization of nitrogen, phosphorus and potassium of irrigated rice cultivars with high productivities and high $\mathrm{N}$ use efficiencies. Field Crop. Res. 2014, 161, 55-63. [CrossRef]

43. Huang, Y.M.; Li, Y.Z.; Zheng, J.S.; Zhung, Z.L. Studies on the NPK accumulation and transfer of high yielding colony of hybrid rice. J. Fujian Acad. Agric. Sci. 1997, 12, 1-6.

44. Yang, C.; Yang, L.; Yan, T.; Ou-Yang, Z. Effects of nutrient and water regimes on lodging resistance of rice. Chin. J. Appl. Ecol. 2004, 15, 646-650. (In Chinese with English abstract)

45. Premi, O.P.; Rathore, S.S.; Shekhawat, K.; Kandpal, B.K.; Chauhan, J.S. Sustainability of fallow-Indian mustard (Brassica juncea) system as influenced by green manure, mustard straw cycling and fertilizer application. Ind. J. Agron. 2012, 57, 229-234.

46. Sarkar, G.K.; Chattopadhyay, A.P.; Sanyal, S.K. Release pattern of non-exchangeable potassium reserves in Alfisols, Inceptisols and Entisols of West Bengal, India. Geoderma 2013, 207-208, 8-14. [CrossRef]

47. Hannan, J.M. Potassium-Magnesium Antagonism in High Magnesium Vineyard Soils. Available online: https: / / lib.dr.iastate.edu/etd/12096 (accessed on 24 May 2018). 


\title{
Soil Properties for Predicting Soil Mineral Nitrogen Dynamics Throughout a Wheat Growing Cycle in Calcareous Soils
}

\author{
Marta Aranguren ${ }^{1, *}$, Ana Aizpurua ${ }^{1}$, Ander Castellón ${ }^{1}$, Gerardo Besga ${ }^{1}$ and Nerea Villar ${ }^{2}$ \\ 1 NEIKER-Basque Institute for Agricultural Research and Development, Berreaga, 1, 48160 Derio, Biscay, \\ Spain; aizpurua@neiker.eus (A.A.); acastellon@neiker.eus (A.C.); gbesga@neiker.eus (G.B.) \\ 2 Department of Plant Biology and Ecology, The University of the Basque Country, Barrio Sarriena s/n, \\ 48940 Leioa, Biscay, Spain; nereavillar01@gmail.com \\ * Correspondence: maranguren@neiker.eus
}

Received: 26 October 2018; Accepted: 12 December 2018; Published: 15 December 2018

\begin{abstract}
A better understanding of the capacity of soils to supply nitrogen $(\mathrm{N})$ to wheat can enhance fertilizer recommendations. The aim of this study was to assess the soil mineral $\mathrm{N}\left(\mathrm{N}_{\min }\right)$ dynamics throughout the wheat growing season in crucial stages for the plant yield and grain protein content (GPC). To this aim, we evaluated the utility of different soil properties analyzed before sowing: (i) commonly used soil physicochemical properties, (ii) potentially mineralizable $\mathrm{N}$ or $\mathrm{N}_{\mathrm{o}}$ (aerobic incubation), and (iii) different extraction methods for estimating $N_{0}$. A greenhouse experiment was established using samples from 16 field soils from northern Spain. Wheat $\mathrm{N}$ uptake and soil $\mathrm{N}_{\text {min }}$ concentrations were determined at following growing stages (GS): sowing, GS30, GS37, GS60, harvest, post-harvest, and pre-sowing. Pearson's correlation analysis of the soil properties, aerobic incubations and chemical extractions with the soil $\mathrm{N}_{\min }$ dynamics and $\mathrm{N}$ uptake, yield and GPC was performed. In addition, correlations were performed between $\mathrm{N}_{\min }$ and the $\mathrm{N}$ uptake, yield, and GPC. The dynamics of soil $\mathrm{N}_{\min }$ throughout the cropping season were variable, and thus, the crop $\mathrm{N}$ necessities were variable. The soil $\mathrm{N}_{\min }$ values in the early wheat growth stages were well correlated with the yield, and in the late stages, they were well correlated with GPC. $\mathrm{N}_{0}$ was correlated with the late $\mathrm{N}$ uptake and GPC. However, the chemical methods that avoid the long periods required for $\mathrm{N}_{0}$ determinations were not correlated with the $\mathrm{N}$ uptake in the late wheat growth stages or GPC. Conversely, clay was positively correlated with the late $\mathrm{N}_{\min }$ values and GPC. Chemical methods were unable to estimate the available soil $\mathrm{N}$ in the later stages of the growing cycle. Consequently, as incubation methods are too laborious for their widespread use, further research must be conducted.
\end{abstract}

Keywords: soil $\mathrm{N}$ supply; soil $\mathrm{N}$ mineralization; $\mathrm{N}$ fertilization; potentially mineralizable $\mathrm{N}$; humid Mediterranean climate

\section{Introduction}

Few agroecosystems supply enough nitrogen $(\mathrm{N})$ to sustain satisfactory crop production without fertilizers. Throughout agricultural history, agriculturists have attempted to maintain fertility levels in the soil, depending on biologically fixed $\mathrm{N}$, through the application of organic amendments and the decomposition of soil organic matter (SOM) to provide $\mathrm{N}$ to crops. In cereal cropping systems, $\mathrm{N}$ is one of the most important elements controlling crop development [1]. Thus, to assure that the potential yield is achieved each year, $\mathrm{N}$ is frequently applied in excessive amounts without determining the appropriate $\mathrm{N}$ fertilization rate, which usually leads to $\mathrm{N}$ losses. To comply with economic and ecological regulations in recent years, concerns about the need for improving nitrogen use efficiency 
(NUE) in cereal production have increased. The $\mathrm{N}$ fertilizer demand is dependent on the plant available $\mathrm{N}$ supplied by soils and the potential yield, which varies from year to year. Available soil resources should be taken into account for the determination of appropriate $\mathrm{N}$ fertilization rates to enhance the efficiency of agricultural systems and ecosystem health.

It is necessary to provide better insight into the capacity of soils to provide $\mathrm{N}$ to crops (soil $\mathrm{N}$ supply) to understand the factors that control $\mathrm{N}$ mineralization in soils and therefore improve $\mathrm{N}$ fertilization recommendations for cereal [2]. In the field, different climatic and agronomic parameters affect wheat yield production, and among them, the contribution of soil $\mathrm{N}$ dynamics is very relevant. Nitrogen cycling in the soil-plant system is very complex and involves interactions between soil and plant factors. Only a small portion of $\mathrm{N}$ is biologically active, serving as a substrate for $\mathrm{N}$ mineralization [3]. To determine the rates of $\mathrm{N}$ fertilizer application, it is necessary to take into account the inorganic $\mathrm{N}$ of the soil and the organic $\mathrm{N}$ mineralized during crop growth $[4,5]$.

The method used most in Western Europe for $\mathrm{N}$ fertilization application in cereals is the $\mathrm{N}_{\text {min }}$ method, which is based on the measured amount of soil mineral $\mathrm{N}$ in the main rooting depth before $\mathrm{N}$ fertilizer application at the beginning of the rapid period of crop growth. The calculation of the $\mathrm{N}$ fertilizer recommended rate is made using the predicted $\mathrm{N}$ demand for the target yield minus the measured soil $\mathrm{N}_{\min }$ value. However, with this method, the $\mathrm{N}$ that has been mineralized during the remainder of the growing cycle is not taken into account. In addition, taking soil samples in a narrow period of time and analysing the mineral $\mathrm{N}$ in each individual field and each season is not practical. Therefore, with the aim of measuring the $\mathrm{N}$ supply capacity of the soil during the entire growing season, the potentially mineralizable $\mathrm{N}\left(\mathrm{N}_{\mathrm{o}}\right)$ or bioavailable $\mathrm{N}$ is measured [6]. The standard method for measuring $\mathrm{N}_{\mathrm{O}}$ was defined by Stanford and Smith [7], who developed a method based on long-term aerobic incubations, in which soil was maintained under optimum conditions $\left(35^{\circ} \mathrm{C}\right.$ and field capacity). However, this method is impractical for routine laboratory analysis due to the long incubation periods required (32 weeks). With the purpose of avoiding the long period required, several chemical methods have been developed to estimate $\mathrm{N}_{\mathrm{o}}$, such as extractions with different saline solutions. Different methodologies have been used to build a global strategy with the aim of estimating crop $\mathrm{N}$ availability [4,8-11]. However, no one method has yet obtained general approval [12]. In a previous article, in the area where this study was carried out (Araba, Basque Country, northern Spain), with calcareous soils and under humid Mediterranean conditions, Villar et al. [13] determined that the most appropriate laboratory technique to estimate the amount of available $\mathrm{N}$ that soils are able to provide to wheat was hot $\mathrm{KCl}$ extraction.

In Araba (Basque Country, northern Spain), traditionally, two applications of $\mathrm{N}$ fertilizer are supplied at following growing stages (GS): GS21 (beginning of tillering) and GS30 (stem elongation) for wheat, according to the Zadoks scale [14]. As soils differ in their composition and mineralization patterns, the $\mathrm{N}$ rate applied in these two main periods should be specific with respect to the available $\mathrm{N}$ [15]. Furthermore, as in many other wheat-producing countries, the demand for high grain protein content (GPC) has also increased. Therefore, it is essential to estimate the amount of $\mathrm{N}$ mineralized from SOM to adjust the rate of $\mathrm{N}$ fertilizer required to optimize crop yield and quality, reducing the negative impacts of excessive $\mathrm{N}$ on the environment.

The main objective of this study was to assess the soil $\mathrm{N}_{\min }$ dynamics throughout the wheat growing season at crucial stages for plant yield and GPC. To this aim, we analyzed the utility of different characteristics of the soil before sowing: (i) the commonly used routine soil physicochemical analyses ( $\mathrm{SOM}, \mathrm{Ntot}, \mathrm{pH}, \mathrm{CaCO}_{3}$ and texture), (ii) potentially mineralizable $\mathrm{N}\left(\mathrm{N}_{\mathrm{o}}\right.$ ), analyzed using aerobic incubation, and (iii) different extraction methods to estimate $\mathrm{N}_{\mathrm{o}}$. 


\section{Materials and Methods}

\subsection{Experimental Setup}

A greenhouse experiment was established in Derio (Bizkaia, Basque Country, Spain) at NEIKER-tecnalia experimental facilities using 16 field soils collected from Villanañe, Soportilla, Lantaron, Arangiz, Betolaza, Gauna, and Tuesta (Araba, Basque Country, Spain) from the 0-30 cm layers (Table 1). No organic amendments had been applied to the studied soils for several years before sample collection or $\mathrm{N}$ fertilization in the previous months. Moreover, no leguminous crops were grown in the fields preceding soil collection. Soils were air-dried and sieved though a $2 \mathrm{~mm}$ mesh and poured into pots (height of $30 \mathrm{~cm}$, and diameter of $22 \mathrm{~cm}$ ). Before sowing, $300 \mathrm{~mL}$ of a nutrient solution without $\mathrm{N}$ [10] was added to the soil to ensure that there were no nutrient limitations to the plants. Twenty seeds of soft red winter wheat (Triticum aestivum L., var Soissons) per pot were sown (30 May 2011), and after germination, the number of plants was reduced to 14 seedlings to simulate the common sowing dose of $240 \mathrm{~kg} \mathrm{ha}^{-1}$. There were three replicates per soil that were distributed in a completely randomized experimental design. Pots were kept at field capacity during the whole experiment. The experiment was extensively described in a previous article [13].

Table 1. Location, and physical and chemical characteristics, of the soils from Araba (Basque Country, northern Spain) used in the greenhouse experiment.

\begin{tabular}{|c|c|c|c|c|c|c|c|c|c|}
\hline Soil & Location & Soil Texture & Sand a $\%$ & Silt a \% & Clay ${ }^{a} \%$ & $\operatorname{SOM}^{b} \%$ & Ntot $\mathrm{c} \%$ & $\mathrm{pH}^{\mathrm{d} \%}$ & $\mathrm{CaCO}_{3}$ e $\%$ \\
\hline 1 & Villanañe & Clay-loam & 30.5 & 37.1 & 32.4 & 1.8 & 0.12 & 8.3 & 29.0 \\
\hline 2 & Soportilla & Loam & 35.9 & 39.3 & 24.8 & 1.0 & 0.07 & 8.5 & 29.4 \\
\hline 3 & Lantaron & Loam & 31.7 & 43.0 & 25.4 & 1.3 & 0.09 & 8.4 & 56.5 \\
\hline 4 & Arangiz & Silty-loam & 19.4 & 55.9 & 24.6 & 1.6 & 0.12 & 8.3 & 56.3 \\
\hline 5 & Arangiz & Clay-loam & 26.1 & 45.6 & 28.3 & 2.0 & 0.16 & 8.3 & 21.7 \\
\hline 6 & Arangiz & Silty-clay-loam & 16.2 & 56.9 & 27.0 & 2.0 & 0.13 & 8.3 & 53.0 \\
\hline 7 & Betolaza & Silty-clay-loam & 12.1 & 58.6 & 29.3 & 3.1 & 0.24 & 8.3 & 29.3 \\
\hline 8 & Gauna & Sandy-clay-loam & 47.4 & 24.9 & 27.6 & 2.0 & 0.15 & 8.1 & 8.0 \\
\hline 9 & Tuesta & Silty-loam & 18.8 & 54.8 & 26.4 & 1.4 & 0.11 & 8.3 & 55.8 \\
\hline 10 & Arangiz & Silty-clay-loam & 17.5 & 55.3 & 27.2 & 2.0 & 0.12 & 8.3 & 56.8 \\
\hline 11 & Arangiz & Silty-clay-loam & 18.0 & 52.8 & 28.5 & 1.8 & 0.11 & 8.4 & 40.9 \\
\hline 12 & Gauna & Clay-loam & 38.5 & 32.6 & 29.0 & 2.0 & 0.12 & 8.1 & 9.2 \\
\hline 13 & Arangiz & Silty-loam & 19.8 & 54.8 & 25.4 & 1.5 & 0.10 & 8.4 & 53.8 \\
\hline 14 & Tuesta & Clay-loam & 36.8 & 28.4 & 34.8 & 1.9 & 0.15 & 8.2 & 16.4 \\
\hline 15 & Gauna & Sandy-clay-loam & 47.6 & 24.5 & 27.9 & 2.2 & 0.17 & 8.0 & 12.1 \\
\hline 16 & Gauna & Clay loam & 44 & 25.9 & 30.1 & 2.1 & 0.16 & 8.0 & 7.2 \\
\hline
\end{tabular}

a Texture using a pipette method [16]; ${ }^{b}$ Soil organic matter [17]; ${ }^{c}$ Soil total $\mathrm{N}$ (dry combustion using a LECO TruSpec $\mathrm{CHN}) ;{ }^{\mathrm{d}} \mathrm{pH}$ (1:2.5 soil:water); ${ }^{\mathrm{e}} \mathrm{CaCO}_{3}\left(\mathrm{NH}_{4} \mathrm{AcO} ;[18]\right)$.

\subsection{Plant Sampling}

Wheat aboveground biomass was sampled at GS30 (stem elongation), GS37 (leaf flag emergence), and harvest (19 December 2011). Fresh biomass samples were weighed and oven dried, and the dried biomass samples were again weighed for dry matter content determination. Biomass was estimated, and the $\mathrm{N}$ concentration was determined using dry combustion with LECO equipment (TrueSpec ${ }^{\circledR}$ CHN-S, LECO Corporation, Michigan, USA). At harvest, grain and straw were separated and dried at $70{ }^{\circ} \mathrm{C}$ for two days to obtain the dry matter content. Grain yield was measured, and grain and straw $\mathrm{N}$ concentration were determined using dry combustion with LECO equipment (TrueSpec ${ }^{\circledR}$ CHN-S). Nitrogen uptake was calculated, and GPC was determined by multiplying the total grain N concentration by 5.7 [19].

\subsection{Soil Samples}

Soil was sampled with a soil sampling rod (full depth from each pot) at sowing, GS30 (stem elongation), GS37 (leaf flag emergence), GS60 (beginning of flowering), harvest, post-harvest, and pre-sowing 
to determine the ammonium and nitrate levels. $\mathrm{NH}_{4}-\mathrm{N}$ and $\mathrm{NO}_{3}-\mathrm{N}$ were spectrophotometrically determined $[20,21]$. $\mathrm{N}_{\text {min }}$ was calculated as the sum of $\mathrm{NH}_{4}-\mathrm{N}$ plus $\mathrm{NO}_{3}-\mathrm{N}$.

\subsection{Aerobic Incubation}

Aerobic incubation was performed following the method described by Stanford and Smith [7] and modified by Campbell et al. [22]. Fifteen grams of each soil sample was air-dried and sieved ( $2 \mathrm{~mm}$ mesh) and then mixed with an equal amount of quartz sand. Soils were incubated aerobically at field capacity for 32 weeks in a culture chamber at $35^{\circ} \mathrm{C}$. Samples were leached every 2 weeks during the first 8 weeks and every 4 weeks thereafter with a $0.01 \mathrm{M} \mathrm{CaCl}_{2}$ solution. Mineral $\mathrm{N}$ was determined in each sample spectrophotometrically, and $\mathrm{N}_{\mathrm{o}}$ was estimated by fitting the accumulated $\mathrm{N}_{\text {min }}$ against time to a first-order kinetic exponential model. $\mathrm{N}$ mineralized in the first two weeks (N2wk) and accumulated after 30 weeks of incubation (N30wk), and potentially mineralizable $\mathrm{N}\left(\mathrm{N}_{\mathrm{o}}\right)$ were calculated. The procedure of the experiment was extensively described in a previous article [13].

\subsection{Chemical Extractions}

\subsubsection{The $0.01 \mathrm{M} \mathrm{CaCl}_{2}$ Extraction}

Calcium chloride extraction was performed using the method described by Houba et al. [23] and modified by Velthof and Oenema [10]. Soil samples were divided into three parts: the first part was air-dried $\left(30{ }^{\circ} \mathrm{C}\right)$, the second part was dried at $40{ }^{\circ} \mathrm{C}$, and the last part was dried at $105^{\circ} \mathrm{C}$. After drying, $6 \mathrm{~g}$ of soil was extracted with $60 \mathrm{~mL}$ of $0.01 \mathrm{M} \mathrm{CaCl}_{2}$ via shaking for $2 \mathrm{~h}$. After extraction, the samples were centrifuged for $5 \mathrm{~min}$ at $2328 \times \mathrm{g}$. Nitrate and ammonium were

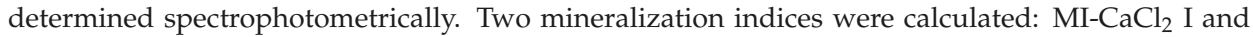
$\mathrm{MI}-\mathrm{CaCl}_{2} \mathrm{II}$. MI-CaCl 2 I was calculated as the difference between the ammonium extracted at $105{ }^{\circ} \mathrm{C}$ and the ammonium extracted from the air-dried samples. $\mathrm{MI}-\mathrm{CaCl}_{2}$ II was calculated as the difference between the ammonium extracted at $105^{\circ} \mathrm{C}$ and the ammonium extracted at $40{ }^{\circ} \mathrm{C}$.

\subsubsection{The $\mathrm{KCl}$ and HotKCl Extraction}

Ten grams of soil were extracted with $20 \mathrm{~mL}$ of $2 \mathrm{M} \mathrm{KCl}$ at room temperature [24]. After extraction, the samples were centrifuged at $2328 \times g$ for $5 \mathrm{~min}$ and analyzed spectrophotometrically to determine the concentrations of $\mathrm{NO}_{3}{ }^{-}-\mathrm{N}$ and $\mathrm{NH}_{4}{ }^{+}-\mathrm{N}$.

The value of $\mathrm{N}_{\min }$ obtained using hotKCl was determined by heating $1.5 \mathrm{~g}$ of soil with $10 \mathrm{~mL}$ of $2 \mathrm{M} \mathrm{KCl}$ solution on a digestion block set at $100{ }^{\circ} \mathrm{C}$ for $4 \mathrm{~h}$. After extraction, the $\mathrm{NO}_{3}{ }^{-}-\mathrm{N}_{\text {and }} \mathrm{NH}_{4}{ }^{+}-\mathrm{N}$ concentrations were determined as described for the room temperature procedure.

The $\mathrm{N}$ mineralization index (MI-hotKCl) was calculated as the difference between the amount of $\mathrm{NH}_{4}{ }^{+}-\mathrm{N}$ extracted using hotKCl and that extracted at room temperature.

\subsubsection{The $0.01 \mathrm{M} \mathrm{NaHCO}_{3}$ Extraction}

$\mathrm{NaHCO}_{3}$ extraction was carried out using the method described by MacLean [25] and modified by Serna and Pomares [8]. Two grams of soil was mixed with $40 \mathrm{~mL}$ of $0.01 \mathrm{M} \mathrm{NaHCO}_{3}$; the samples were then centrifuged at $2328 \times g$ for 5 min and filtered through Whatman No. 42 filters (Whatman International Ltd., Maidstone, England) and the absorbance of the filtrate was then measured at 205 and $260 \mathrm{~nm}$ (205ABS and 260ABS, respectively). The procedure of the experiment was extensively described in a previous article [13].

\subsection{Statistical Analysis}

For analyzing $\mathrm{N}_{\min }$ differences among soils, a one-way ANOVA was performed for each growing stage: sowing, GS30, GS37, GS60, harvest, post-harvest, and pre-sowing [26]. For analyzing differences among the soils' final N uptake, yield, and GPC, one-way ANOVA was performed [26]. To separate the means, Duncan's test was used $(p \leq 0.05)$ using the R package agricolae V. 1.2-4 [27]. 
Pearson's correlation analysis of the soil properties, aerobic incubation and chemical extractions with 1) $\mathrm{N}_{\min }$ values at sowing, GS30, GS37, GS60, harvest, post-harvest, and pre-sowing and with the 2) nitrogen uptake by the plant between sowing and GS30, GS30-GS37, GS37-harvest, and yield and GPC was performed. In addition, Pearson's correlation analysis was performed between $\mathrm{N}_{\min }$ and $\mathrm{N}$ uptake by the plant, sowing and GS30, GS30-GS37, GS37-harvest, and yield and GPC.

\section{Results}

\subsection{Range of Soil Physical and Chemical Characteristics}

The soils varied widely in their physical and chemical characteristics. Sixteen soils were classified into five texture classes: clay-loam (S-1, S-5, S-12, S-14, and S-16), loam (S-2 and S-3), silty-loam (S-4, S-9, and S-13), silty-clay-loam (S-6, S-7, S-10, and S-11), and sandy-clay-loam (S-8 and S-15). The pH values were high (8.0-8.5). Twelve soils were calcareous ( $\left.>15 \% \mathrm{CaCO}_{3}\right)$, and the remaining four soil values varied between 7.0 and $12.1 \%$. Soil organic matter values were low (SOM $\leq 1.9 \%$; S-1, S-2, S-3, S-4, S-9, S-11, S-13, and S-14), moderate (SOM 1.9-2.2\%; S-5, S-6, S-8, S-10, S-12, S-15, S-16, and S-17), or high (SOM 3.1\%; S-7).

\subsection{Availability of Mineral $N$ in Soil}

Soil mineral $\mathrm{N}$ availability values were different among soils and phenological stages (Table 2). Remarkably, $\mathrm{N}_{\text {min }}$ did not follow the same dynamic pattern throughout the crop cycle in different soils. Soil $\mathrm{N}_{\min }$ values decreased from sowing to GS37 in the vast majority of the soils, except for S-9, S-3, and S-5, which increased their $\mathrm{N}_{\min }$ values from sowing to GS30. $\mathrm{N}_{\min }$ values increased from GS37 to GS60 in each soil and then remained similar. Differences were especially evident at GS30, where S-9 had the highest value and S-2, S-8, S-10, S-12, S-14, and S-16 had the lowest values. Soils with the highest $\mathrm{N}$ availability in GS37 were S-1, S-6, S-7, S-8, S-12, and S-14, whereas at GS60, S-7, S-8, and S-14 had the highest $\mathrm{N}$ availability.

Table 2. Soil mineral nitrogen $\left(\mathrm{N}_{\mathrm{min}} ; \mathrm{mg} \mathrm{kg}^{-1}\right)$ evolution in 16 soils from Araba throughout the wheat growing season in a greenhouse experiment. Different letters represent significant differences $(p \leq 0.05)$ among soils for each growing stage: sowing, stem elongation (GS30), leaf flag emergence (GS37), flowering (GS60), harvest, post-harvest, and pre-sowing.

\begin{tabular}{|c|c|c|c|c|c|c|c|c|c|c|c|c|c|c|}
\hline \multirow{2}{*}{ Soil } & \multicolumn{2}{|c|}{ Sowing } & \multicolumn{2}{|l|}{ GS30 } & \multicolumn{2}{|c|}{ GS37 } & \multicolumn{2}{|c|}{ GS60 } & \multicolumn{2}{|c|}{ Harvest } & \multicolumn{2}{|c|}{ Post-Harvest } & \multicolumn{2}{|c|}{ Pre-Sowing } \\
\hline & Mean & sd & Mean & sd & Mean & sd & Mean & sd & Mean & sd & Mean & sd & Mean & sd \\
\hline 1 & $16.6 \mathrm{AB}$ & 4.0 & $10.2 \mathrm{ABC}$ & 3.2 & $2.6 \mathrm{~A}$ & 0.5 & $7.5 \mathrm{ABC}$ & 0.7 & $4.7 \mathrm{BC}$ & 0.9 & $7.2 \mathrm{AB}$ & 1.2 & $3.3 \mathrm{ABC}$ & 1.0 \\
\hline 2 & $8.5 \mathrm{EFG}$ & 2.1 & $3.7 \mathrm{C}$ & 0.9 & $0.4 \mathrm{~B}$ & 0.1 & $5.2 \mathrm{C}$ & 1.0 & $3.8 \mathrm{CD}$ & 0.6 & $3.0 \mathrm{C}$ & 0.7 & $2.5 \mathrm{C}$ & 0.9 \\
\hline 3 & $10.3 \mathrm{ABC}$ & 1.8 & $12.3 \mathrm{AB}$ & 1.7 & $1.7 \mathrm{AB}$ & 0.5 & $6.2 \mathrm{BC}$ & 2.2 & $3.7 \mathrm{CD}$ & 0.8 & $5.6 \mathrm{BC}$ & 0.3 & $3.2 \mathrm{ABC}$ & 0.6 \\
\hline 4 & $12.6 \mathrm{ABC}$ & 6.1 & 6.1 BC & 1.9 & $2.2 \mathrm{AB}$ & 0.7 & 7.1 ABC & 2.0 & $4.9 \mathrm{~B}$ & 0.9 & $8.0 \mathrm{AB}$ & 1.2 & $3.2 \mathrm{ABC}$ & 0.6 \\
\hline 5 & $11.3 \mathrm{ABC}$ & 2.3 & $9.0 \mathrm{ABC}$ & 1.9 & $1.7 \mathrm{AB}$ & 0.9 & $8.2 \mathrm{ABC}$ & 2.2 & $4.6 \mathrm{BC}$ & 0.8 & $6.5 \mathrm{BC}$ & 0.9 & $3.3 \mathrm{ABC}$ & 0.6 \\
\hline 6 & $11.4 \mathrm{ABC}$ & 5.9 & $5.3 \mathrm{BC}$ & 1.7 & $2.9 \mathrm{~A}$ & 0.3 & $8.0 \mathrm{ABC}$ & 0.8 & $5.1 \mathrm{~B}$ & 0.5 & $6.8 \mathrm{BC}$ & 0.8 & 3.6 ABC & 0.5 \\
\hline 7 & $6.5 \mathrm{FG}$ & 0.4 & $6.6 \mathrm{BC}$ & 0.9 & $3.0 \mathrm{~A}$ & 0.7 & $8.1 \mathrm{~A}$ & 0.9 & $6.6 \mathrm{~A}$ & 0.9 & $8.9 \mathrm{~A}$ & 0.6 & $3.8 \mathrm{ABC}$ & 1.0 \\
\hline 8 & $7.3 \mathrm{EFG}$ & 2.6 & $3.3 \mathrm{C}$ & 0.9 & $2.9 \mathrm{~A}$ & 0.6 & $7.5 \mathrm{~A}$ & 1.8 & $3.1 \mathrm{D}$ & 0.7 & $4.3 \mathrm{BC}$ & 1.0 & $2.7 \mathrm{C}$ & 0.2 \\
\hline 9 & $9.7 \mathrm{CDE}$ & 3.5 & $16.4 \mathrm{~A}$ & 1.2 & $0.9 \mathrm{AB}$ & 0.1 & $5.9 \mathrm{AB}$ & 1.0 & $4.4 \mathrm{BC}$ & 0.6 & $4.4 \mathrm{BC}$ & 0.8 & $3.2 \mathrm{ABC}$ & 0.2 \\
\hline 10 & $12.7 \mathrm{ABC}$ & 2.9 & $4.2 \mathrm{C}$ & 0.7 & $2.2 \mathrm{AB}$ & 0.4 & $8.3 \mathrm{ABC}$ & 0.7 & $4.9 \mathrm{BC}$ & 0.9 & $5.5 \mathrm{ABC}$ & 1.0 & $3.9 \mathrm{~A}$ & 0.5 \\
\hline 11 & $11.6 \mathrm{ABC}$ & 3.2 & $4.9 \mathrm{BC}$ & 1.1 & $1.6 \mathrm{AB}$ & 0.7 & $7.4 \mathrm{ABC}$ & 1.4 & $5.3 \mathrm{BC}$ & 1.7 & $7.0 \mathrm{AB}$ & 1.3 & $3.6 \mathrm{ABC}$ & 0.7 \\
\hline 12 & $5.7 \mathrm{G}$ & 2.0 & $4.4 \mathrm{C}$ & 0.7 & $2.7 \mathrm{~A}$ & 0.7 & $8.2 \mathrm{ABC}$ & 1.9 & $5.1 \mathrm{BC}$ & 1.2 & $5.2 \mathrm{ABC}$ & 0.7 & $3.3 \mathrm{ABC}$ & 0.8 \\
\hline 13 & $9.4 \mathrm{CDE}$ & 1.8 & $5.0 \mathrm{BC}$ & 0.9 & $1.3 \mathrm{BC}$ & 0.6 & $9.6 \mathrm{AB}$ & 1.4 & $4.7 \mathrm{BC}$ & 1.2 & $5.7 \mathrm{ABC}$ & 0.8 & $3.5 \mathrm{ABC}$ & 1.7 \\
\hline 14 & 10.3 CDE & 6.0 & $3.7 \mathrm{C}$ & 0.8 & $2.8 \mathrm{~A}$ & 0.3 & $10.2 \mathrm{~A}$ & 1.2 & $5.2 \mathrm{BC}$ & 1.3 & $7.1 \mathrm{AB}$ & 0.7 & $4.0 \mathrm{AB}$ & 0.9 \\
\hline 15 & $13.7 \mathrm{~A}$ & 3.5 & $5.0 \mathrm{BC}$ & 1.3 & $1.5 \mathrm{AB}$ & 0.4 & 8.1 ABC & 2.0 & $4.3 \mathrm{BC}$ & 1.0 & $5.8 \mathrm{ABC}$ & 1.7 & $3.5 \mathrm{ABC}$ & 0.2 \\
\hline 16 & $7.9 \mathrm{EFG}$ & 1.3 & $2.8 \mathrm{C}$ & 0.8 & $1.2 \mathrm{AB}$ & 0.5 & $4.9 \mathrm{C}$ & 2.3 & $4.5 \mathrm{BC}$ & 1.4 & $5.4 \mathrm{ABC}$ & 0.7 & $3.0 \mathrm{ABC}$ & 0.8 \\
\hline
\end{tabular}

\subsection{Wheat N Uptake, Yield, and GPC}

There were significant differences in wheat $\mathrm{N}$ uptake at harvest, yield, and GPC depending on the soil (Figure 1). The soil with the highest $\mathrm{N}$ uptake $\left(\mathrm{mg} \mathrm{pot}^{-1}\right)$ was S-1. The lowest $\mathrm{N}$ uptake was in S-2 and S-8. In the case of wheat yield $\left(\mathrm{g} \mathrm{pot}^{-1}\right)$, the highest values were achieved in S-3, S-9, and S-15 and 
the lowest in S-2, S-8, and S-16. Regarding GPC (\%), the highest values were achieved in S-14, and the lowest were in S-2.

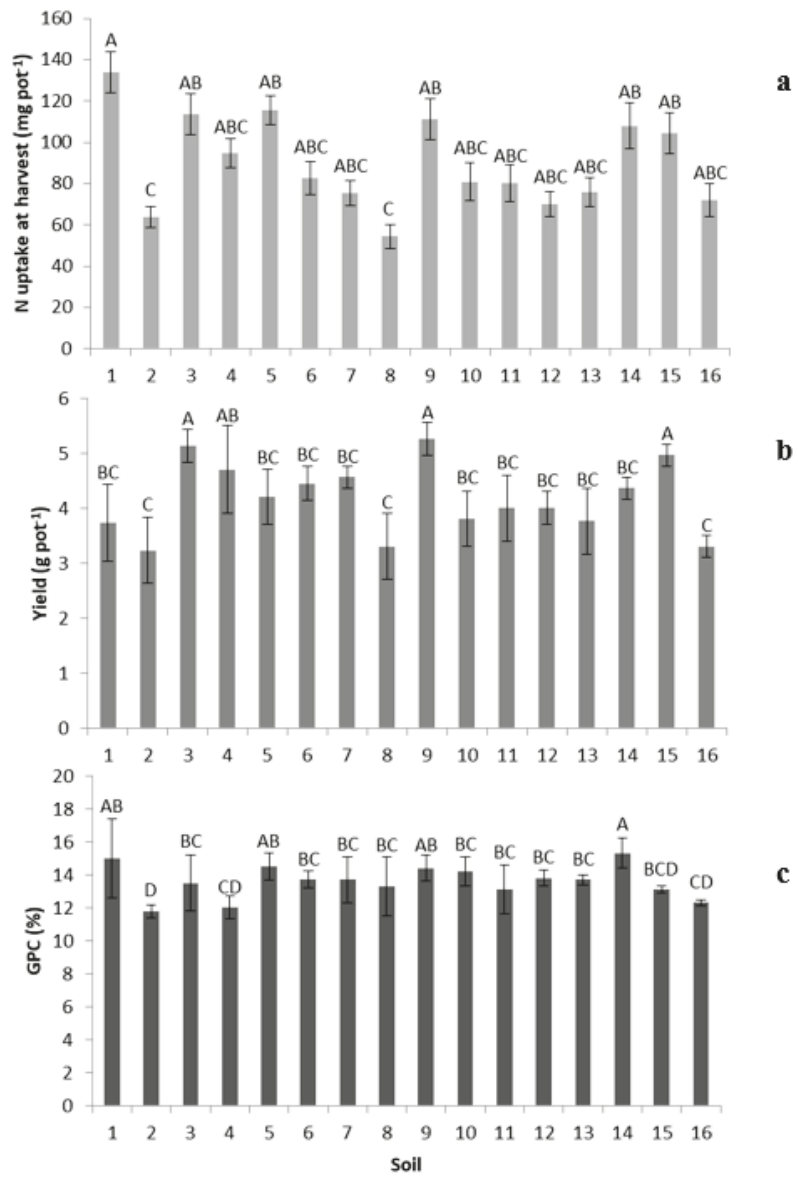

Figure 1. (a) Wheat $\mathrm{N}$ uptake at harvest $\left(\mathrm{mg} \mathrm{pot}^{-1}\right)$, (b) yield (g pot $\left.{ }^{-1}\right)$, and (c) GPC (\%) in 16 soils from Araba. Different letters represent significant differences $(p \leq 0.05)$ among soils. Values are the mean of three replicates \pm SD.

\subsection{Relationships between Initial Soil Characteristics with $N_{\text {min }}$ throughout the Growing Cycle}

Regarding the soil physicochemical properties (Table 3), sand had a negative correlation with $\mathrm{N}_{\text {min }}$ values at harvest, silt had a positive correlation with $\mathrm{N}_{\min }$ values at harvest, and clay had a positive correlation with $\mathrm{N}_{\min }$ values at GS37 and GS60. Ntot was positively correlated with $\mathrm{N}_{\text {min }}$ at GS37, harvest, and post-harvest. SOM had a positive correlation with $\mathrm{N}_{\min }$ values at GS37, GS60, harvest, and post-harvest. In the case of aerobic incubations, N2wk had a positive correlation with the sowing values, and N30wk had a positive and significant correlation with the GS60, harvest, post-harvest, and pre-sowing $\mathrm{N}_{\min }$. $\mathrm{N}_{\mathrm{o}}$ was positively correlated with the GS60 and pre-sowing $\mathrm{N}_{\min }$ values. Regarding the chemical extractants used to estimate $\mathrm{N}_{\mathrm{o}}$, $\mathrm{MI} \mathrm{CaCl} 2 \mathrm{I}$ was correlated with the $\mathrm{N}_{\min }$ values at GS60. MI-hotKCl was positively correlated with $\mathrm{N}_{\min }$ values from GS37 to pre-sowing. For $\mathrm{NaHCO}_{3}$, only $205 \mathrm{ABS}$ was correlated with the sowing and pre-sowing $\mathrm{N}_{\min }$ values. Remarkably, $\mathrm{SOM}, \mathrm{N} 30 \mathrm{wk}$, and hotKCl were correlated with the $\mathrm{N}_{\min }$ values after harvest. 
Table 3. Pearson correlation coefficients ( $\mathrm{r}$ ) between soil properties, $\mathrm{N}$ mineralization indices calculated from the aerobic incubations and chemical extractions with Nmin values at sowing, stem elongation (GS30), leaf flag emergence (GS37), flowering (GS60), harvest, post-harvest, and pre-sowing.

\begin{tabular}{|c|c|c|c|c|c|c|c|c|c|c|c|c|c|c|c|}
\hline \multicolumn{2}{|c|}{ Soil Characteristics } & \multicolumn{2}{|c|}{ Sowing } & \multicolumn{2}{|c|}{ GS30 } & \multicolumn{2}{|c|}{ GS37 } & \multicolumn{2}{|c|}{ GS60 } & \multicolumn{2}{|c|}{ Harvest } & \multicolumn{4}{|c|}{ Post-Harvest Pre-Sowing } \\
\hline & & $\mathbf{r}$ & $p$ & $\mathbf{r}$ & $p$ & $\mathbf{r}$ & $p$ & $\mathbf{r}$ & $p$ & $\mathbf{r}$ & $p$ & $\mathbf{r}$ & $p$ & $\mathbf{r}$ & $p$ \\
\hline \multirow{7}{*}{$\begin{array}{c}\text { Soil } \\
\text { properties }\end{array}$} & Sand & -0.11 & $n s$ & -0.25 & ns & 0.00 & ns & -0.01 & $n s$ & -0.63 & ** & -0.48 & $n s$ & -0.47 & $n s$ \\
\hline & Silt & 0.09 & ns & 0.27 & $n s$ & -0.12 & ns & -0.11 & ns & 0.50 & * & 0.36 & ns & 0.33 & $n s$ \\
\hline & Clay & 0.05 & ns & -0.11 & $n s$ & 0.55 & * & 0.56 & * & 0.38 & ns & 0.40 & $n s$ & 0.47 & $n s$ \\
\hline & SOM & -0.16 & ns & -0.24 & ns & 0.70 & $* *$ & 0.50 & $*$ & 0.60 & ** & 0.58 & * & 0.49 & $n s$ \\
\hline & Ntot & -0.16 & ns & -0.12 & ns & 0.57 & * & 0.43 & ns & 0.54 & * & 0.59 & $* *$ & 0.44 & ns \\
\hline & $\mathrm{pH}$ & 0.04 & ns & 0.22 & ns & -0.47 & $n s$ & -0.38 & $n s$ & 0.06 & $n s$ & -0.03 & $n s$ & -0.07 & $n s$ \\
\hline & $\mathrm{CaCO} 3$ & 0.33 & $n s$ & 0.40 & ns & -0.29 & ns & -0.25 & ns & 0.09 & ns & 0.10 & ns & 0.22 & ns \\
\hline \multirow{3}{*}{$\begin{array}{c}\text { Aerobic } \\
\text { incubations }\end{array}$} & N2wk & 0.54 & * & 0.02 & ns & 0.25 & ns & 0.30 & ns & 0.05 & ns & 0.14 & ns & 0.46 & $n s$ \\
\hline & N30wk & 0.37 & ns & 0.15 & ns & 0.43 & ns & 0.57 & $* *$ & 0.51 & * & 0.61 & $* *$ & 0.83 & $* * *$ \\
\hline & No & 0.29 & ns & 0.16 & ns & 0.43 & ns & 0.65 & ** & 0.38 & ns & 0.49 & ns & 0.73 & $* *$ \\
\hline \multirow{5}{*}{$\begin{array}{l}\text { Chemical } \\
\text { extractions }\end{array}$} & $\mathrm{MI} \mathrm{CaCl} \mathrm{I}_{2}$ & 0.19 & $n s$ & -0.44 & ns & 0.35 & ns & 0.55 & * & 0.16 & ns & 0.37 & ns & 0.43 & $n s$ \\
\hline & $\mathrm{MI} \mathrm{CaCl}{ }_{2} \mathrm{II}$ & 0.34 & ns & -0.41 & ns & 0.31 & ns & 0.52 & * & -0.03 & ns & 0.29 & ns & 0.38 & $n s$ \\
\hline & MI-HotKCl & 0.36 & ns & -0.29 & ns & 0.62 & $* *$ & 0.70 & $*$ & 0.50 & * & 0.69 & $* *$ & 0.64 & $* *$ \\
\hline & 205ABS & 0.59 & $* *$ & 0.07 & ns & -0.16 & ns & 0.23 & $n s$ & 0.18 & ns & 0.30 & $n s$ & 0.59 & $* *$ \\
\hline & 260ABS & 0.31 & $n s$ & 0.08 & ns & -0.15 & ns & 0.15 & ns & 0.26 & ns & 0.32 & ns & 0.33 & $n s$ \\
\hline
\end{tabular}

ns, not significant $(p>0.05) . * * *, * * *$ Significant at the $0.05,0.01$, and 0.001 probability levels, respectively.

\subsection{Relationships between Soil Characteristics and Plant N Uptake, Yield, and GPC}

Regarding the soil initial properties (Table 4), clay had a positive correlation with GPC. Ntot had a positive correlation with the N uptake between sowing and GS30 and with the N uptake between GS30 and GS37. In the aerobic incubations, N30wk and $\mathrm{N}_{0}$ showed a positive and significant correlation with the N uptake between GS37 and harvest and GPC. Concerning the chemical extractants, only 205ABS had a positive correlation with yield.

Table 4. Pearson correlation coefficients ( $\mathrm{r}$ ) among soil properties, $\mathrm{N}$ mineralization indices calculated from the aerobic incubations and chemical extractions with $\mathrm{N}$ uptake values between sowing and stem elongation (GS30), GS30 and leaf flag emergence (GS37), GS37 and flowering (GS60), and yield and GPC (grain protein content).

\begin{tabular}{|c|c|c|c|c|c|c|c|c|c|c|c|}
\hline \multirow{2}{*}{\multicolumn{2}{|c|}{ Soil Characteristics }} & \multicolumn{6}{|c|}{ N Uptake } & \multirow{2}{*}{\multicolumn{2}{|c|}{ Yield }} & \multirow{2}{*}{\multicolumn{2}{|c|}{ GPC }} \\
\hline & & \multicolumn{2}{|c|}{ Sowing-GS30 } & \multicolumn{2}{|c|}{ GS30-GS37 } & \multicolumn{2}{|c|}{ GS37-Harvest } & & & & \\
\hline & & $\mathbf{r}$ & $p$ & $\mathbf{r}$ & $p$ & $\mathbf{r}$ & $p$ & $\mathbf{r}$ & $p$ & $\mathbf{r}$ & $p$ \\
\hline \multirow{7}{*}{ Soil properties } & Sand & -0.06 & ns & -0.04 & $n s$ & 0.01 & ns & -0.22 & ns & -0.06 & ns \\
\hline & Silt & -0.02 & $n s$ & 0.09 & $n s$ & -0.10 & $n s$ & 0.22 & $n s$ & -0.10 & ns \\
\hline & Clay & 0.39 & ns & -0.26 & $n s$ & 0.45 & $n s$ & -0.07 & ns & 0.73 & $* * *$ \\
\hline & SOM & 0.46 & $n s$ & -0.47 & $n s$ & -0.10 & $n s$ & 0.09 & $n s$ & 0.31 & ns \\
\hline & Ntot & 0.52 & $*$ & 0.49 & $*$ & 0.06 & $n s$ & 0.24 & $n s$ & 0.26 & ns \\
\hline & $\mathrm{pH}$ & -0.43 & $n s$ & 0.33 & $n s$ & -0.06 & $n s$ & -0.16 & $n s$ & -0.22 & ns \\
\hline & $\mathrm{CaCO}_{3}$ & -0.24 & $n s$ & 0.33 & $n s$ & 0.08 & $n s$ & 0.32 & $n s$ & -0.13 & ns \\
\hline \multirow{3}{*}{$\begin{array}{c}\text { Aerobic } \\
\text { incubations }\end{array}$} & N2wk & 0.30 & $n s$ & -0.24 & $n s$ & 0.39 & $n s$ & 0.26 & $n s$ & 0.40 & ns \\
\hline & N30wk & 0.39 & ns & -0.25 & $n s$ & 0.64 & $* *$ & 0.34 & ns & 0.75 & $* *$ \\
\hline & No & 0.47 & $n s$ & -0.38 & $n s$ & 0.64 & $* *$ & 0.43 & $n s$ & 0.74 & ** \\
\hline \multirow{5}{*}{$\begin{array}{l}\text { Chemical } \\
\text { Extractions }\end{array}$} & $\mathrm{MI} \mathrm{CaCl} 2 \mathrm{I}$ & -0.01 & $n s$ & -0.21 & $n s$ & -0.11 & $n s$ & -0.07 & $n s$ & 0.04 & ns \\
\hline & $\mathrm{MI} \mathrm{CaCl}{ }_{2}$ II & -0.06 & $n s$ & -0.14 & $n s$ & -0.05 & $n s$ & -0.07 & $n s$ & 0.03 & ns \\
\hline & MI-HotKCl & 0.43 & $n s$ & -0.35 & $n s$ & 0.21 & $n s$ & -0.07 & ns & 0.05 & ns \\
\hline & 205ABS & 0.29 & $n s$ & -0.24 & ns & 0.24 & $n s$ & 0.57 & * & 0.00 & ns \\
\hline & 260ABS & -0.11 & $n s$ & 0.10 & ns & -0.04 & $n s$ & 0.10 & ns & -0.08 & ns \\
\hline
\end{tabular}

ns, not significant $(p>0.05){ }^{*}{ }^{* *}, * *$ Significant at the $0.05,0.01$ and 0.001 probability levels, respectively.

The soil $\mathrm{N}_{\min }$ values (Table 5) at sowing and GS30 were correlated positively with $\mathrm{N}$ uptake between GS37 and harvest. The $\mathrm{N}_{\text {min }}$ values at GS30 and GS60 had positive correlations with yield and GPC, respectively. 
Table 5. Pearson correlation coefficients ( $\mathrm{r}$ ) among the soil $\mathrm{N}_{\min }$ values, $\mathrm{N}$ uptake values between sowing and stem elongation (GS30), GS30 and leaf flag emergence (GS37), GS37 and flowering (GS60), and yield and GPC (grain protein content).

\begin{tabular}{|c|c|c|c|c|c|c|c|c|c|c|}
\hline \multirow{3}{*}{ Soil $\mathrm{N}_{\min }$} & \multicolumn{6}{|c|}{ N Uptake } & \multirow{2}{*}{\multicolumn{2}{|c|}{ Yield }} & \multirow{2}{*}{\multicolumn{2}{|c|}{ GPC }} \\
\hline & \multicolumn{2}{|c|}{ Sowing-GS30 } & \multicolumn{2}{|c|}{ GS30-GS37 } & \multicolumn{2}{|c|}{ GS37-Harvest } & & & & \\
\hline & $\mathbf{r}$ & $p$ & $\mathbf{r}$ & $p$ & $\mathbf{r}$ & $p$ & $\mathbf{r}$ & $p$ & $\mathbf{r}$ & $p$ \\
\hline Sowing & 0.01 & $n s$ & 0.18 & ns & 0.53 & $*$ & 0.22 & $n s$ & 0.09 & ns \\
\hline GS30 & -0.02 & $n s$ & 0.31 & ns & 0.65 & $* *$ & 0.59 & $* *$ & 0.31 & ns \\
\hline GS37 & 0.27 & ns & -0.25 & $n s$ & 0.00 & $n s$ & -0.04 & ns & 0.38 & ns \\
\hline GS60 & 0.22 & $n s$ & -0.31 & $n s$ & 0.09 & $n s$ & -0.07 & ns & 0.53 & ** \\
\hline Harvest & 0.38 & $n s$ & -0.25 & ns & 0.00 & $n s$ & 0.22 & ns & 0.24 & $n s$ \\
\hline
\end{tabular}

ns, not significant $(p>0.05) .{ }^{*}, * *$ Significant at the 0.05 and 0.01 probability levels, respectively.

\section{Discussion}

The tested soils differed in their initial $\mathrm{N}_{\text {min }}$ values and their physical and chemical properties [13], which significantly influenced the $\mathrm{N}$ mineralization patterns. Depending on their characteristics, soils mineralize in different ways, making available different $\mathrm{N}_{\min }$ values (Table 2). The first step in mineralization is ammonification, which is the conversion of organic $\mathrm{N}$ into ammonium by soil microbes. This process is carried out exclusively by heterotrophic microorganisms that utilize $\mathrm{C}$ as an energy source. Nitrate production is mediated via two groups of autotrophic bacteria (Nitrosomonas and Nitrobacter) that convert ammonium into nitrate by the process called nitrification. Nitrogen availability relies on both the initial availability of $\mathrm{N}_{\min }$ and the rate of mineralization or immobilization [28], as well as the previous $\mathrm{N}$ uptake by the crop, influencing the yield and GPC.

There were no correlations between the soil properties and $\mathrm{N}_{\min }$ values at sowing or GS30. It should be mentioned that the soil preparation (drying, sieving, and rewetting) prior to the experiment could have affected soil structure and functioning. This could explain the lack of correlation in the early stages. It should be mentioned that soil rewetting often causes abundant mineralization because microorganisms recover their activity [29]. However, Mikha et al. [30] suggested that $\mathrm{N}$ immobilization occurred in response to the easily accessible $\mathrm{C}$ due to the rapid increase in microbial activity. Later, in the growing cycle, from GS37 onwards, SOM, Ntot, sand, silt, and clay were relatively effective predictors of soil $\mathrm{N}_{\min }$ dynamics.

Soil organic matter (SOM) is a heterogeneous mixture of organic compounds that vary in their nutrient composition, molecular characteristics, age, and biological stability. Increasing SOM by adding carbon is a beneficial agronomic practice that stimulates microbial communities and enhances soil $\mathrm{N}$ and C pools [31]. The youngest compounds are the most biologically active compounds, and the materials with intermediate ages contribute to soil physical characteristics [28]. We found positive correlations from GS37 to post-harvest with the $\mathrm{N}_{\min }$ values (Table 3). Ros et al. [6] found that SOM explained $78 \%$ of the variation in mineralizable $\mathrm{N}$, whereas other soil properties only explained $8 \%$. In some studies, SOM fractions have been preferred to total SOM for predicting $\mathrm{N}_{\mathrm{o}}$ due to the easy release of labile compounds during the extractions [32]. However, other studies suggested that none of those $\mathrm{SOM}$ fractions is an a priori preferable indicator of $\mathrm{N}_{\mathrm{o}}[6,33]$.

Debosz and Kristensen [34] found that Ntot content had a positive relationship with $\mathrm{N}$ mineralization. Similarly, Dessureault-Rompré et al. [9] showed that Ntot was one of the best predictors of soil mineralizable $\mathrm{N}$ pools. However, in our case, Ntot only had positive correlations with the $\mathrm{N}_{\text {min }}$ values at harvest and post-harvest (Table 3). It is remarkable that only approximately $1-4 \%$ of the Ntot is mineralized as plant-available $\mathrm{N}\left(\mathrm{NH}_{4}-\mathrm{N}\right.$ and $\left.\mathrm{NO}_{3}-\mathrm{N}\right)$ each year [34]. Many authors have found that soil Ntot and SOM were the best predictors of $\mathrm{N}_{\mathrm{o}}[9,11]$.

The mineralization of $\mathrm{N}$ is often affected by the clay content, likely due to SOM binding to mineral particles. Clay was correlated with $\mathrm{N}_{\min }$ at the end of the growth cycle and with the GPC. In this experiment, soils with the highest GPC were S-1, S-5, S-9, and S-14 (15-16\%), where the clay 
values were $32.4,28.3,26.4$, and $34.8 \%$, respectively. Clay has indirect affects through the formation of aggregates that protect $\mathrm{SOM}$, and therefore microbial biomass, and direct effects with the stabilization of organic N [35]. Hassink [36] found that the mineralization of organic $\mathrm{N}$ was negatively affected by a high clay content due to SOM binding to mineral particles. Similarly, Ros et al. [6] found that clay had a negative influence on mineralizable $\mathrm{N}$ because mineralization in clayey soils was lower than that in sandy soils. In contrast, in this experiment, clay was positively correlated with $\mathrm{N}_{\text {min }}$ at GS37 and GS60, and sand was negatively correlated with $\mathrm{N}_{\min }$ at GS60 (Table 3). Some clayey soils are able to fix and release ammonium, but the regulation of $\mathrm{N}$ availability is not fully understood [37]. Chantigny et al. [38] showed that in clay soils, the fixation of the recently added ammonium was higher than that in sandy soil ( $34 \%$ and $11 \%$, respectively). The recently fixed ammonium that can be derived from added fertilizer or from soil organic matter [39] is quickly fixed by clay minerals and later released slowly during the crop growth season due to the increased crop demand. In a greenhouse experiment, Dou and Steffens [40] found that $90-95 \%$ of the recently fixed ammonium was released during a 14-week period. Under field conditions, $66 \%$ of the recently fixed ammonium was released 86 days after fixation [41]. Provision of root exudates by plants improved the activity of heterotrophic microorganisms, which foster the release of fixed ammonium [37], retarding nitrification. The silt fraction has also been reported to bind $\mathrm{NH}_{4}{ }^{+}$in a non-exchangeable form [37]; in our study, it was correlated with $\mathrm{N}_{\min }$ at harvest. In S-9, where high values of GPC were achieved (15\%), the silt content was 54.8.

The $\mathrm{pH}$ and $\mathrm{CaCO}_{3}$ did not present any effect on $\mathrm{N}$ mineralization. Dessureault-Rompré et al. [11] found that the effect of $\mathrm{pH}$ on soil mineralization was very low. In other studies, soil $\mathrm{pH}$, moisture and temperature were often non-linearly related to the dynamics of $\mathrm{N}[42,43]$. The $\mathrm{pH}$ range among our soils was very low.

With respect to wheat $\mathrm{N}$ uptake (Table 4), among the soil properties, only soil Ntot was positively correlated with the wheat N uptake at two times: from sowing to GS30 and from GS30 to GS37. In the case of aerobic incubation, N30wk and $\mathrm{N}_{0}$ were correlated with the $\mathrm{N}$ uptake from GS37 to harvest and with GPC. However, only soil $\mathrm{N}_{\min }$ at sowing and GS30 was correlated with the $\mathrm{N}$ uptake from GS37 to harvest (Table 5). Historically, soil $\mathrm{N}$ availability has been seen as an inaccurate indicator of plant $\mathrm{N}$ availability because plant roots are considered poor competitors for inorganic $\mathrm{N}$ against soil microorganisms [44]. This idea could explain the lack of correlation between the soil $\mathrm{N}$ availability and the $\mathrm{N}$ uptake from the crop. Conversely, it has been determined that a cereal crop was able to accumulate a greater amount of added inorganic $\mathrm{N}$ than microorganisms [45]. The results showed that different soils followed different mineralization patterns affecting yield and GPC. The soil $\mathrm{N}_{\min }$ at GS30 and at GS60 was positively correlated with the yield and GPC, respectively (Table 5). This suggests that the N status at those times is essential for determining the yield [15] or GPC [46,47]. Soils with the lowest N availability at GS30 and GS60 as S-2 and S-16 presented the lowest yields and GPC, respectively. However, when the $\mathrm{N}$ availability was high in these growth stages, the yields and GPC values were high. Remarkably, none of the soil properties was correlated with yield, but clay was positively correlated with GPC (Table 4). However, one of the methods of chemical extraction (205 ABS) was correlated with the yield.

The key to optimizing high yields, wheat quality (GPC), and environmental protection is to achieve synchronicity between the $\mathrm{N}$ supply and crop demand, while accounting for spatial and temporal variability in soil $\mathrm{N}$. As previously observed, many factors affect soil $\mathrm{N}$ mineralization, and therefore wheat $\mathrm{N}$ uptake. In Western Europe, the soil $\mathrm{N}_{\min }$ at the end of winter is used to correct the values of $\mathrm{N}$ fertilizer rates calculated from the potential yield. Nevertheless, it implies laborious and expensive sampling and analysis. In Araba (Basque Country, northern Spain), the usual last and greater $\mathrm{N}$ dressing application occurred at GS30, but there were no correlations between soil initial properties and $\mathrm{N}_{\min }$ values at GS30 (Table 3). This is remarkable because a high $\mathrm{N}$ availability at GS30 is key for achieving high yields [15]. As the last $\mathrm{N}$ dressing is at GS30, it is common to have low $\mathrm{N}$ in wheat plants at the end of the growing cycle (GS60-harvest) in Araba [46]. Moreover, the climatic 
conditions in this area, humid Mediterranean, can lead to very high yields and therefore low protein concentrations in grain. Fuertes-Mendizabal et al. [47] showed that late N availability (GS37 onwards) in wheat under humid Mediterranean conditions increased GPC, especially when no N was applied in the late stages, as in the area of study. As stated above, clay apparently allowed higher N availability at GS37 and GS60. This could be explained by the positive correlation between $\mathrm{N}_{\min }$ at GS60 and GPC or the correlation between clay and GPC. However, soils presented a narrow clay range (24.6-34.8\%) to confirm that finding. Inside the aerobic incubation, $\mathrm{N} 30 \mathrm{wk}$ and $\mathrm{N}_{\mathrm{o}}$ were able to estimate the $\mathrm{N}$ available for the wheat crop at the end of the growing cycle and thus the GPC. Identifying soils in Araba where it would be possible to have late N availability with the aim of improving GPC would be interesting. In the humid Mediterranean climatic conditions of Araba, a third application at GS37 is possible since rain water usually allows the utilization by wheat of this $\mathrm{N}$ applied late [46,47]. However, the chemical methods that avoid the long periods required for aerobic incubation did not correlate properly with the $\mathrm{N}$ uptake values in the late growth stages.

In order to make $\mathrm{N}$ recommendations that guarantee adequate levels of GPC, methods for the diagnosis of soil available $\mathrm{N}$ must be improved, especially in the later stages of the growing cycle. In this sense, it is necessary to explore quick and simple methods because the most effective ones require periods of incubations that are too long. This is even more important in certain circumstances, such as organic farming, where it is difficult to make late applications of $\mathrm{N}$ with authorized fertilizers (organic fertilizers).

\section{Conclusions}

Even in a relatively small cropping area where the variability of soil properties is narrow, the dynamics of soil nitrate and ammonium throughout the cropping season were variable, and therefore, so was the crop $\mathrm{N}$ uptake. The soil $\mathrm{N}_{\min }$ values at early wheat growth stages were well-correlated with yield, and at late stages, they were well-correlated with GPC.

$\mathrm{N}_{0}$ was correlated with late $\mathrm{N}$ uptake and GPC. However, the chemical methods that avoid the long periods required for $\mathrm{N}_{0}$ determinations were not correlated properly with the $\mathrm{N}$ uptake in the late wheat growth stages or GPC. Conversely, clay was positively correlated with the late $\mathrm{N}_{\min }$ values and GPC, although the clay range was not very wide. Chemical methods were unable to estimate the available soil $\mathrm{N}$ in the later stages of the growing cycle. Consequently, as incubation methods are too laborious for their widespread use, further research must be conducted.

funding: This study was funded by the National Institute of Agricultural and Food Research and Technology (RTA2009-00028 and RTA2013-00057-01) and by the Department for Economic Development and Infrastructures of the Basque Government. N.V. was the recipient of a predoctoral fellowship from the Department of Education, Language Policy and Culture of the Basque Government. M. Aranguren is the recipient of a predoctoral fellowship from the Department for Economic Development and Infrastructures of the Basque Government.

Conflicts of Interest: The authors declare no conflicts of interest.

\section{References}

1. Samborski, S.M.; Tremblay, N.; Fallon, E. Strategies to make use of plant sensors-based diagnostic information for nitrogen recommendations. Agron. J. 2009, 101, 800-816. [CrossRef]

2. Zebarth, B.J.; Drury, C.F.; Tremblay, N.; Cambouris, A.N. Opportunities for improved fertilizer nitrogen management in production of arable crops in eastern Canada: A review. Can. J. Soil Sci. 2009, 89, 113-132. [CrossRef]

3. Parton, W.J.; Schimel, D.S.; Cole, C.V.; Ojima, D.S. Analysis of factors controlling soil organic matter levels in Great Plains grassland. Soil Sci. Soc. Am. J. 1987, 51, 1173-1179. [CrossRef]

4. Martínez, J.M.; Galantini, J.A.; Duval, M.E. Contribution of nitrogen mineralization indices, labile organic matter and soil properties in predicting nitrogen mineralization. J. Soil Sci. Plant Nutr. 2018, 18, 73-89. [CrossRef] 
5. Van Groenigen, J.W.; Huygens, D.; Boeckx, P.; Kuyper, T.W.; Lubbers, I.M.; Rütting, T.; Groffman, P.M. The soil n cycle: New insights and key challenges. Soil 2015, 1, 235-256. [CrossRef]

6. Ros, G.H.; Hanegraaf, M.C.; Hoffland, E.; van Riemsdijk, W.H. Predicting soil N mineralization: Relevance of organic matter fractions and soil properties. Soil Biol. Biochem. 2011, 43, 1714-1722. [CrossRef]

7. Standford, G.; Smith, S.J. Nitrogen mineralization potentials of soils. Soil Sci. Soc. Am. J. 1972, 36, 465-472. [CrossRef]

8. Serna, M.D.; Pomares, F. Nitrogen mineralization of sludge-amended soil. Bioresour. Technol. 1992, 39, 285-290. [CrossRef]

9. Dessureault-Rompré, J.; Zebarth, B.J.; Burton, D.L.; Sharifi, M.; Cooper, J.; Grant, C.A.; Drury, C.F. Relationships among Mineralizable Soil Nitrogen, Soil Properties, and Climatic Indices. Soil Sci. Soc. Am. J. 2010, 74, 1218-1227. [CrossRef]

10. Velthof, G.; Oenema, O. Estimation of plant-available nitrogen in soils using rapid chemical and biological methods. Commun. Soil Sci. Plant Anal. 2010, 41, 52-71. [CrossRef]

11. Dessureault-Rompré, J.; Zebarth, B.J.; Burton, D.L.; Georgallas, A. Predicting soil nitrogen supply from soil properties. Can. J. Soil Sci. 2015, 95, 63-75. [CrossRef]

12. Luce, M.; Whalen, J.K.; Ziadi, N.; Zebarth, B.J. Nitrogen dynamics and indices to predict soil nitrogen supply in humid temperate soils. Adv. Agron. 2011, 112, 55-102.

13. Villar, N.; Aizpurua, A.; Castellón, A.; Ortuzar, M.A.; González-Moro, M.B.; Besga, G. Laboratory Methods for the Estimation of Soil Apparent N Mineralization and Wheat N Uptake in Calcareous Soils. Soil Sci. 2014, 179, 84-94. [CrossRef]

14. Zadoks, J.C.; Chang, T.T.; Konzak, C.F. A decimal code for growth stages of cereals. Weed Res. 1974, 4, 415-421. [CrossRef]

15. Aranguren, M.; Castellón, A.; Aizpurua, A. Topdressing nitrogen recommendation in wheat after applying organic manures: The use of field diagnostic tools. Nutr. Cycl. Agroecosyst. 2018, 110, 89-103. [CrossRef]

16. Gee, G.W.; Bauder, J.W. Particle size analysis. In Methods of Soil Analysis: Part I. Physical and Mineralogical Methods, 2nd ed.; Klute, A., Ed.; Soil Science Society of America: Madison, WI, USA, 1886; pp. 383-411.

17. Walkey, A.; Black, I.A. An examination of the Degtjareff method for determining soil organic matter and a proposed modification of the chromic acid titration method. Soil Sci. 1934, 37, 29-38. [CrossRef]

18. MAPA. Métodos Oficiales de Análisis. Tomo III; Ministerio de Agricultura, Pesca y Alimentación: Madrid, Spain, 1994.

19. Teller, G.L. Non-protein nitrogen compounds in cereals and their relation to the nitrogen factor for protein in cereals and bread. Cereal Chem. 1932, 9, 261-267.

20. Cawse, P.A. The determination of nitrate in soil solutions by ultraviolet spectrophotometry. Analyst 1967, 92, 311-315. [CrossRef]

21. Nelson, D.W. Determination of ammonium in $\mathrm{KCl}$ extracts of soils by the salicylate method. Commun. Soil Sci. Plant Anal. 1983, 14, 1051-1062. [CrossRef]

22. Campbell, C.A.; Ellert, B.H.; Jame, Y.W. Nitrogen mineralization potential in soils. In Soil Sampling and Methods of Analysis; Carter, M.R., Ed.; Canadian Society of Soil Science/Lewis Publishers: Boca Raton, FL, USA, 1993; pp. 341-349.

23. Houba, V.J.G.; Novozamsky, I.; Huybregts, A.W.M.; van der Lee, J.J. Comparison of soil extractions by 0.01 $\mathrm{M} \mathrm{CaCl}_{2}$ by EUF and by some conventional extraction procedures. Plant Soil 1986, 96, 433-437. [CrossRef]

24. Gianello, C.; Bremmer, J.M. Comparisons of chemical methods of assessing potentially available organic nitrogen in soil. Commum. Soil Sci. Plant Anal. 1986, 31, 1299-1396. [CrossRef]

25. MacLean, A.A. Measurement of nitrogen supplying power of soils by extraction with sodium bicarbonate. Nature 1964, 203, 1307-1308. [CrossRef]

26. R Core Team. R: A Language and Environment for Statistical Computing; R Foundation for Statistical Computing: Vienna, Austria, 2013.

27. De Mendiburu, F. Una Herramienta de Análisis Estadístico para la Investigación Agrícola. Ph.D. Thesis, Facultad de Economía y Planificación Departamento Académico de Estadística e Informática, Universidad Nacional de Ingeniería (UNI-PERU), Universidad Nacional Agraria La Molina, Lima, Peru, 2009.

28. Mohanty, M.; Sinha, N.K.; Reddy, K.S.; Chaudhary, R.S.; Rao, A.S.; Dalal, R.C.; Menzies, N.W. How important is the quality of organic amendments in relation to mineral N availability in soils? Agric. Res. 2013, 2, 99-110. [CrossRef] 
29. Griffin, T.S. Nitrogen availability. In Nitrogen in Agricultural Systems. Agronomy Monograph 49; Schepers, J.S., Raun, W.R., Eds.; ASA, CSSA, and SSSA: Madison, WI, USA, 2008; pp. 613-646.

30. Mikha, M.M.; Rice, C.; Milliken, G. Carbon and nitrogen mineralization as affected by drying and wetting cycles. Soil Biol. Biochem. 2005, 37, 339-347. [CrossRef]

31. Urra, J.; Mijangos, I.; Lanzén, A.; Lloveras, J.; Garbisu, C. Effects of corn stover management on soil quality. Eur. J. Soil Biol. 2018, 88, 57-64. [CrossRef]

32. Wander, M. Soil organic matter fractions and their relevance to soil function. In Soil Organic Matter in Sustainable Agriculture; Magdoff, F., Weil, R.R., Eds.; CRC Press: Boca Raton, FL, USA, 2004; pp. 67-102.

33. Haynes, R.J. Labile organic matter fractions as central components of the quality of agricultural soils: An overview. Adv. Agron. 2005, 85, 221-268.

34. Debosz, K.; Kristensen, K. Spatial covariability of N mineralisation and textural fractions in two agricultural fields. Semin. Site Specif. Farming 1995, 26, 174-180.

35. Tisdale, S.L.; Nelson, W.L.; Beaton, J.D. Soil Fertility and Fertilizers, 4th ed.; Macmillon Publishing Company: New York, NY, USA, 1985.

36. Hassink, J. The capacity of soils to preserve organic $\mathrm{C}$ and $\mathrm{N}$ by their association with clay and silt particles. Plant Soil 1997, 191, 77-87. [CrossRef]

37. Nieder, R.; Benbi, D.K.; Scherer, W. Fixation and defixation of ammonium in soils: A review. Biol. Fertil. Soils 2011, 47, 1-14. [CrossRef]

38. Chantigny, M.H.; Angers, D.A.; Morvan, T.; Pomar, C. Dynamics of pig slurry nitrogen in soil and plant as determined with 15 N. Soil Sci. Soc. Am. J. 2004, 68, 637-643. [CrossRef]

39. Nieder, R.; Benbi, D.K. Carbon and nitrogen transformations in soils. In Carbon and Nitrogen in the Terrestrial Environment; Nieder, R., Benbi, D.K., Eds.; Springer: Heidelberg, Germany, 2008; pp. 137-159.

40. Dou, H.; Steffens, D. Recovery of $15 \mathrm{~N}$ labelled urea as affected by fixation of ammonium by clay minerals. Pflanzenernahr. Bodenkd. 1995, 158, 351-354. [CrossRef]

41. Kowalenko, C.G. Nitrogen transformations and transport over 17 months in field fallow microplots using 15 N. Can. J. Soil Sci. 1978, 58, 69-76. [CrossRef]

42. Rodrigo, A.; Recous, S.; Neel, C.; Mary, B. Modelling temperature and moisture effects on C-N transformations in soils: Comparison of nine models. Ecol. Model. 1997, 102, 325-339. [CrossRef]

43. Paul, E.A. The nature and dynamics of soil organic matter: Plant inputs, microbial transformations, and organic matter stabilization. Soil Biol. Biochem. 2016, 98, 109-126. [CrossRef]

44. Schimel, J.P.; Bennett, J. Nitrogen Mineralization: Challenges of a Changing Paradigm. Ecology 2004, 85, 591-602. [CrossRef]

45. Inselsbacher, E.; Umana, N.H.N.; Stange, F.C.; Gorfer, M.; Schüller, E.; Ripka, K.; Zechmeister-Boltenstern, S.; Hood-Novotny, R.; Strauss, J.; Wanek, W. Short-term competition between crop plants and soil microbes for inorganic N fertilizer. Soil Biol. Biochem. 2010, 42, 360-372. [CrossRef]

46. Ortuzar-Iragorri, M.A.; Aizpurua, A.; Castellón, A.; Alonso, A.; José, M.; Estavillo, J.M.; Besga, G. Use of an $\mathrm{N}$-tester chlorophyll meter to tune a late third nitrogen application to wheat under humid Mediterranean conditions. J. Plant Nutr. 2017, 41, 627-635. [CrossRef]

47. Fuertes-Mendizabal, T.; Aizpurua, A.; González-Moro, M.B.; Estavillo, J.M. Improving wheat breadmaking quality by splitting the N fertilizer rate. Eur. J. Agron. 2010, 33, 52-61. [CrossRef]

(C) 2018 by the authors. Licensee MDPI, Basel, Switzerland. This article is an open access article distributed under the terms and conditions of the Creative Commons Attribution (CC BY) license (http:/ / creativecommons.org/licenses/by/4.0/). 
Article

\title{
Assessment of Fertilizer Management Strategies Aiming to Increase Nitrogen Use Efficiency of Wheat Grown Under Conservation Agriculture
}

\author{
Jesús Santillano-Cázares ${ }^{1}$, Fidel Núñez-Ramírez ${ }^{1}$, Cristina Ruíz-Alvarado ${ }^{1}$, \\ María Elena Cárdenas-Castañeda ${ }^{2}$ and Iván Ortiz-Monasterio ${ }^{2, *}$ \\ 1 Instituto de Ciencias Agrícolas, Universidad Autónoma de Baja California, Carretera a Delta s/n, \\ Ejido Nuevo Leon, Mexicali, Baja California C. P. 21705, Mexico; jsantillano@uabc.edu.mx (J.S.-C.); \\ fidel.nunez@uabc.edu.mx (F.N.-R.); mariacristina@uabc.edu.mx (C.R.-A.) \\ 2 Centro Internacional de Mejoramiento de Maíz y Trigo (CIMMYT), Km. 45, Carretera Mexico-Veracruz, \\ El Batan, Texcoco Edo. de Mexico C. P. 56237, Mexico; m.cardenas@cgiar.org \\ * Correspondence: i.ortiz-monasterio@cgiar.org; Tel.: +52-55-5804-2004.
}

Received: 14 November 2018; Accepted: 11 December 2018; Published: 16 December 2018

\begin{abstract}
Sustainable crop production systems can be attained by using inputs efficiently and nitrogen use efficiency (NUE) parameters are indirect measurements of sustainability of production systems. The objective of this study was to investigate the effect of selected nitrogen $(\mathrm{N})$ management treatments on wheat yields, grain and straw $\mathrm{N}$ concentration, and NUE parameters, under conservation agriculture (CA). The present study was conducted at the International Maize and Wheat Improvement Center (CIMMYT), in northwest, Mexico. Seventeen treatments were tested which included urea sources, timing, and methods of fertilizer application. Orthogonal contrasts were used to compare groups of treatments and correlation and regression analyses were used to look at the relationships between wheat yields and NUE parameters. Contrasts run to compare wheat yields or agronomic efficiency of $\mathrm{N}\left(\mathrm{AE}_{\mathrm{N}}\right)$ performed similarly. Sources of urea or timing of fertilizer application had a significant effect on yields or $\mathrm{AE}_{\mathrm{N}}(p>0.050)$. However, methods of application resulted in a highly significant $(p<0.0001)$ difference on wheat yields and agronomic efficiency of $\mathrm{N}$. NUE parameters recorded in this study were average but the productivity associated to NUE levels was high. Results in this study indicate that wheat grew under non-critically limiting $\mathrm{N}$ supply levels, suggesting that $\mathrm{N}$ mineralization and reduced $\mathrm{N}$ losses from the soil under CA contributed to this favorable nutritional condition, thus minimizing the importance of $\mathrm{N}$ management practices under stable, mature CA systems.
\end{abstract}

Keywords: conservation agriculture; NUE; nitrogen recovery efficiency; nitrogen physiological recovery; wheat yields; Agrotain $₫$ urea

\section{Introduction}

One of the most limiting inputs in crop production and quality is nitrogen (N) [1]. Ironically, $\mathrm{N}$ fertilizer that is not used to support crop production has the potential to cause a series of environmental issues such as eutrophication on water bodies, acid rain, $\mathrm{N}$ saturation in natural environments, and global warming [2,3]. Losses of $\mathrm{N}$ from agricultural systems negatively impact the environment as a result of poor $\mathrm{N}$ fertilizer management practices. This, in turn, results in low profitability to farmers $[4,5]$. Sustainable crop production systems, i.e., systems that take into account people's wellbeing, farmer's economy, and that are environmentally safe, can be attained by using inputs efficiently. Nitrogen use efficiency (NUE) and NUE components are indirect measurements of the sustainability of production systems [6-8], therefore, a strong emphasis is being placed on NUE in 
wheat production systems [9-11]. In this paper NUE is defined as grain yield per unit of available $\mathrm{N}$ in the soil [12-14]. NUE components, $\mathrm{N}$ uptake efficiency (NUpE), and $\mathrm{N}$ utilization efficiency (NUtE) have been typically used for characterizing newly developed cereal genotypes [14-16]. However, for testing the $\mathrm{N}$ efficiency of agronomic practices other NUE and associated components have been proposed. Dobermann (2005) [17] and Ladha et al. (2005) [18] recommend measuring the agronomic efficiency of applied $\mathrm{N}\left(\mathrm{AE}_{\mathrm{N}}\right)$, crop recovery efficiency of applied $\mathrm{N}\left(\mathrm{RE}_{\mathrm{N}}\right)$, and physiological efficiency of applied $\mathrm{N}\left(\mathrm{PE}_{\mathrm{N}}\right)$. $A E_{\mathrm{N}}$ is the product of the recovered $\mathrm{N}$ by the plant, multiplied by the efficiency with which this $\mathrm{N}$ is converted into the crop's part of economic interest (grain, for cereals). According with Dobermann (2005) [17] and Hawkesford (2017) [13], the $\mathrm{AE}_{\mathrm{N}}$ can be improved by crop management practices such as amount, timing, placement, and $\mathrm{N}$ source that can influence $\mathrm{RE}_{\mathrm{N}}$, $P E_{N}$, or both. $R_{N}$ relays on the efficacy with which applied $N$ is released for crop uptake, and can vary depending on amount, timing, placement and $\mathrm{N}$ sources. On the other hand, $\mathrm{PE}_{\mathrm{N}}$ measures the ability of a plant to convert the absorbed $N$ into the product of interest; $P E_{N}$, as well as $R E_{N}$, is also dependent on crop management factors but particularly on reproductive stages. According to Malhi et al. (2001) [19], an effective $\mathrm{N}$ management program must take into account four variables: Rate, source, timing, and placement of fertilizers. Yadav et al. (2017) [8] proposed site specific N management; integrated $\mathrm{N}$ management, i.e., taking into account indigenous $\mathrm{N}$ sources like crop residues, manure, biological $\mathrm{N}$ fixation, in addition to synthetic fertilizers; enhanced use of efficient sources; improved methods of application; adoption of conservation agriculture (CA); the use of $\mathrm{N}$-efficient genetically improved varieties; and precision farming. Because of the need to increase the sustainability of modern crop production systems, it's important to better understand the relationship between NUE and fertilizer management practices for wheat produced under CA systems. Published literature about NUE for irrigated wheat under CA is very scarce. The objective of the present study was to investigate the effect of selected treatments that included $\mathrm{N}$ (urea) sources, timing, and methods of application, on wheat yield, grain and straw $\mathrm{N}$ concentration, and NUE, under a CA system.

\section{Materials and Methods}

\subsection{Site Description}

The present study was conducted at the International Maize and Wheat Improvement Center (CIMMYT) agricultural experimental station, in the Yaqui valley, near Ciudad Obregon, Sonora, Mexico. The study consisted of five wheat growing cycles, from 2009-2010 to 2013-2014. The field within the station is located at $27^{\circ} 23^{\prime} 11.9^{\prime \prime} \mathrm{N}, 109^{\circ} 55^{\prime} 33^{\prime \prime} \mathrm{W}$. Historical temperatures during the wheat growing season are $9.8^{\circ} \mathrm{C}$ and $27.1^{\circ} \mathrm{C}$ for night and daytime, respectively. Soils in the area are predominantly vertisols; which are characterized by being clayey, have deep, wide cracks when they dry, and have slickensides within $100 \mathrm{~cm}$ of the mineral soil surface. The weather occurring during the crop growing cycles was recorded at a weather station located within the experimental station (Figure 1). 

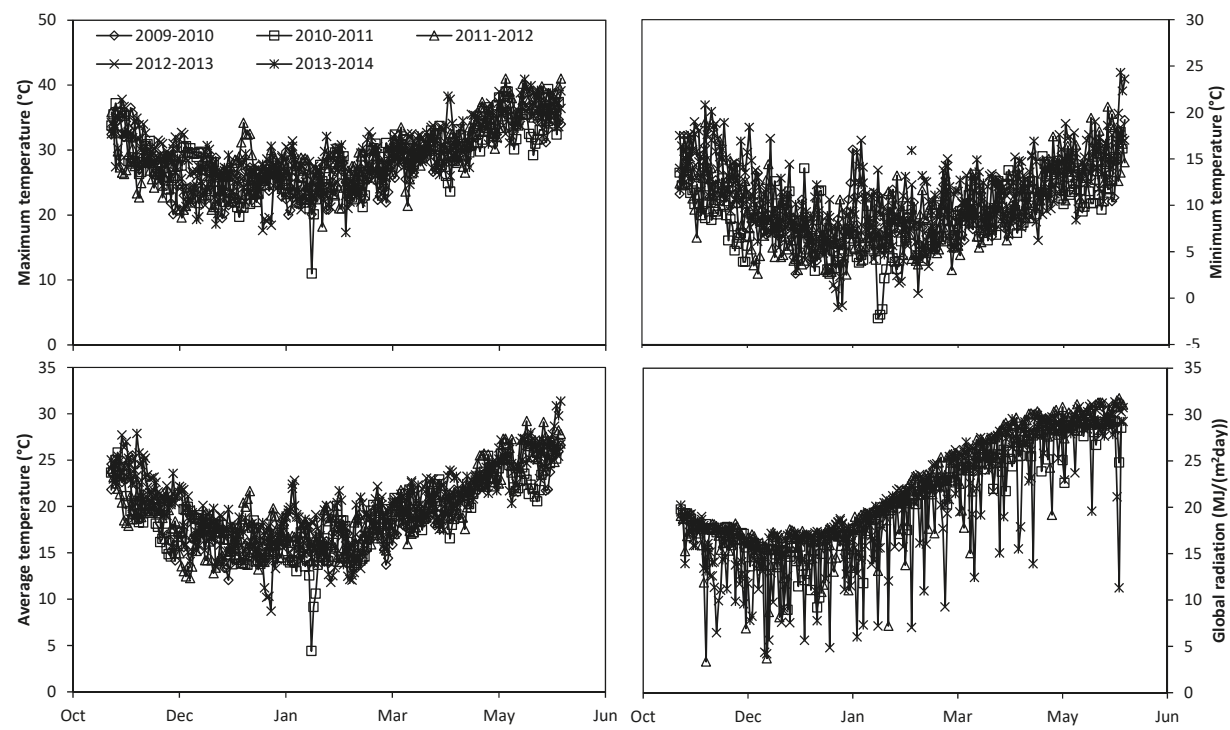

Figure 1. Maximum, minimum, average temperatures, and radiation occurring during five wheat growing cycles (2009-2010 to 2013-2014) at the International Maize and Wheat Improvement Center (CIMMYT), in the Yaqui valley, near Ciudad Obregon, Sonora, Mexico.

\subsection{Crop Management}

Planting dates over the five growing cycles ranged from the 23 of November to 11 of December. The wheat (Triticum Aestivum L.) varieties that were planted were Tacupeto F-2001 in cycle 2009-2010 and CIRNO C-2008 in the following four cycles. Seeding rates ranged between $100 \mathrm{~kg} \mathrm{ha}^{-1}$, in the first two cycles, to $120 \mathrm{~kg} \mathrm{ha}^{-1}$, in the last three cycles. In all five cycles furrow irrigation was applied when $50 \%$ available water had been depleted on the $60 \mathrm{~cm}$ in the soil profile. Seeding occurred after soil moisture allowed agricultural machinery traffic after applying a pre-plant irrigation. Four additional irrigations were applied during the growing cycle. Pre-plant phosphorus fertilizer was applied at a rate of $52 \mathrm{~kg} \mathrm{ha}^{-1}$ of $\mathrm{P}_{2} \mathrm{O}_{5}$ as mono-ammonium phosphate (11-52-00), during the first two cycles, and $46 \mathrm{~kg} \mathrm{ha}^{-1}$ of $\mathrm{P}_{2} \mathrm{O}_{5}$ as triple super phosphate (00-46-00), during the last three cycles. The experiments were established under conservation agriculture during all five cycles, leaving all residues on the soil surface, only reforming beds, planting and fertilizing with disks on top of beds. The experimental area had been under conservation agriculture at least for four years before the establishment of these experiments. Chemical and mechanical control of weeds was applied, as well as standard practices for pest and insect control was employed. Herbicides and pesticides utilized throughout the duration of the study, rates and dates of application are shown in Table 1. 


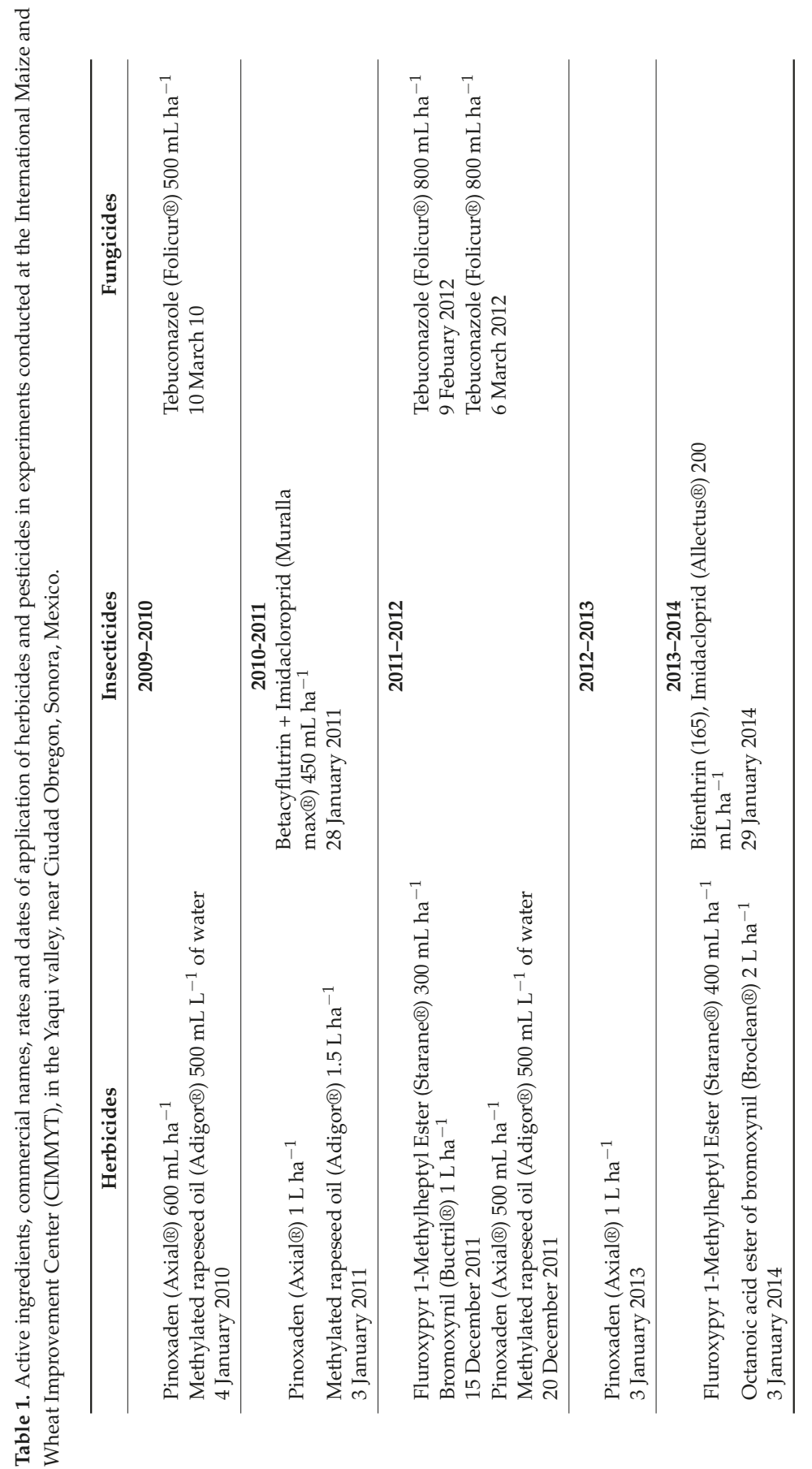




\subsection{Treatments Description}

Seventeen treatments were tested (Table 2). Except for the control that received only the pre-plant phosphorus fertilizer application, all treatments received a total of $150 \mathrm{~kg} \mathrm{~N} \mathrm{ha}^{-1}$. Treatments included combinations of N sources (urea or NBPT-urea $\left(\right.$ Agrotain $\left.^{\mathrm{TM}}\right)$ ); timings of fertilizer application [(once at planting, splitting $50 \mathrm{~kg} \mathrm{~N}$ ha $^{-1}$ at planting $+100 \mathrm{~kg} \mathrm{~N}^{-1}$ before first post-plant irrigation (by the onset of stem elongation), or $100 \mathrm{~kg} \mathrm{~N} \mathrm{ha}^{-1}$ at planting $+50 \mathrm{~kg} \mathrm{~N} \mathrm{ha}^{-1}$ before first post-plant irrigation (by the onset of stem elongation)]; and methods of fertilizer application [top-dress (or broadcast), incorporated at furrows, or incorporated at beds]. The plots received the same treatment every cycle and consisted on four $10 \mathrm{~m}$ long beds, with a separation of $80 \mathrm{~cm}$, with two rows of wheat on top. Incorporated $\mathrm{N}$ fertilizer applications were made with minimum tillage equipment and placed about 5 $\mathrm{cm}$ into the soil, below the residues.

Table 2. N management practices that included treatments composed of urea sources, timing, and methods of fertilizer application at the International Maize and Wheat Improvement Center (CIMMYT), in the Yaqui valley, near Ciudad Obregon, Sonora, Mexico.

\begin{tabular}{|c|c|c|c|c|}
\hline \multirow[b]{2}{*}{ Treatment } & \multirow{2}{*}{$\begin{array}{l}\text { N Rate } \\
\left(\mathrm{kg} \mathrm{ha}^{-1}\right)\end{array}$} & \multirow[b]{2}{*}{ Source of $\mathbf{N}$} & \multicolumn{2}{|c|}{ Variables Affecting Nitrogen Use Efficiency } \\
\hline & & & Timing of Application & $\begin{array}{l}\text { Metod of Fertilizer } \\
\text { Application }\end{array}$ \\
\hline 1 & 0 & Not applicable & Not applicable & Not applicable \\
\hline 2 & 150 & Urea & At planting & Top-dress \\
\hline 3 & 150 & Urea & At planting & Incorporadted at furrows \\
\hline 4 & 150 & Urea & At planting & Incorporadted at beds \\
\hline 5 & 150 & Urea & 50 at planting +100 before first post-plant irrigation & Top-dress \\
\hline 6 & 150 & Urea & 50 at planting +100 before first post-plant irrigation & Incorporadted at furrows \\
\hline 7 & 150 & Urea & 50 at planting +100 before first post-plant irrigation & Incorporadted at beds \\
\hline 8 & 150 & Urea & 100 at planting +50 before first post-plant irrigation & Incorporadted at furrows \\
\hline 9 & 150 & Urea & 100 at planting +50 before first post-plant irrigation & Incorporadted at beds \\
\hline 10 & 150 & NBPT-urea & At planting & Top-dress \\
\hline 11 & 150 & NBPT-urea & At planting & Incorporadted at furrows \\
\hline 12 & 150 & NBPT-urea & At planting & Incorporadted at beds \\
\hline 13 & 150 & NBPT-urea & 50 at planting +100 before first post-plant irrigation & Top-dress \\
\hline 14 & 150 & NBPT-urea & 50 at planting +100 before first post-plant irrigation & Incorporadted at furrows \\
\hline 15 & 150 & NBPT-urea & 50 at planting +100 before first post-plant irrigation & Incorporadted at beds \\
\hline 16 & 150 & NBPT-urea & 100 at planting +50 before first post-plant irrigation & Incorporadted at furrows \\
\hline 17 & 150 & NBPT-urea & 100 at planting +50 before first post-plant irrigation & Incorporadted at beds \\
\hline
\end{tabular}

\subsection{Response Variables}

Response variables were; grain yield, wheat grain and straw $\mathrm{N}$ concentration; agronomic efficiency of $\mathrm{N}\left(\mathrm{AE_{N }}\right), \mathrm{N}$ recovery efficiency $\left(\mathrm{RE}_{\mathrm{N}}\right)$, and $\mathrm{N}$ physiological efficiency $\left(\mathrm{PE}_{\mathrm{N}}\right)$. Grain was harvested at or after physiological maturity and adjusted to $12 \%$ moisture. Grain and straw N concentration was determined during the first four cycles and were estimated by oven drying samples at $70{ }^{\circ} \mathrm{C}$ for $48 \mathrm{~h}$, ground with rotor mill to pass a $2 \mathrm{~mm}$ sieve for straw and $0.5 \mathrm{~mm}$ sieve for grain. Nitrogen content was determined by taking $0.25 \mathrm{~g}$ grain flour and $0.50 \mathrm{~g}$ for straw by micro-Kjeldahl method. NUE and NUE components were computed as described by Dobermann (2005) [17] and by Ladha et al. (2005) [18]: $\mathrm{AE}_{\mathrm{N}}=$ (grain yield from fertilized plots - grain yield from unfertilized plots)/N fertilizer rate from fertilized plots; $R E_{N}=$ (total $\mathrm{N}$ in aboveground plant biomass from fertilized plots - total $\mathrm{N}$ aboveground plant biomass from unfertilized plots) $/ \mathrm{N}$ fertilizer rate from fertilized plots; and $\mathrm{PE}_{\mathrm{N}}=$ grain yield from fertilized plots - grain yield from unfertilized plots)/(total $\mathrm{N}$ in aboveground plant biomass from fertilized plots - total $\mathrm{N}$ aboveground plant biomass from unfertilized plots). The units for $\mathrm{AE}_{\mathrm{N}}, \mathrm{RE}_{\mathrm{N}}$, and $\mathrm{PE}_{\mathrm{N}}$ are: $\mathrm{kg}$ grain $\mathrm{kg}^{-1} \mathrm{~N}, \mathrm{~kg} \mathrm{~N}$ in total biomass $\mathrm{kg}^{-1} \mathrm{~N}$, and kg grain kg ${ }^{-1} \mathrm{~N}$, respectively. Variables $\mathrm{RE}_{\mathrm{N}}$ and $\mathrm{PE}_{\mathrm{N}}$ were computed for four cycles, from 2009-2010 to 2012-2013, since grain and straw $\mathrm{N}$ concentration were determined only during these cycles; while $\mathrm{AE}_{\mathrm{N}}$ was computed for all five cycles, since this variable do not require grain or straw $\mathrm{N}$ concentration data for its computation. 


\subsection{Experimental Design and Analyses}

Treatments were arranged on a completely randomized block design. Statistical analyses were made by analyses of variance first, to examine the significance of the interaction cycles $\times$ treatment, and secondly, orthogonal contrasts were performed on pooled data from cycles where this interaction was non-significant. A total of 17 contrasts were performed for each response variable (Table 3). From all contrasts performed, contrasts 1, 10, and 14 are of key relevance, since they compare the overall effects of sources, timing, and methods of fertilizer application, respectively. The rest of the contrasts, however, were planned to provide details for a better understanding about these overall comparisons. Proc GLM, statement: CONTRAST was used. Additionally, correlation and regression analyses were performed on yields, $\mathrm{AE}_{\mathrm{N}}$ and $\mathrm{AE}_{\mathrm{N}}$ components $\mathrm{RE}_{\mathrm{N}}$, and $\mathrm{PE}_{\mathrm{N}}$, using Proc Corr and Proc Reg, $\mathrm{SAS}$, version 9.0 was used (SAS Institute, Cary, CA, USA).

Table 3. Selected contrasts to compare the effects on wheat yield, grain and straw nitrogen concentration, agronomic efficiency of $\mathrm{N}\left(\mathrm{AE}_{\mathrm{N}}\right), \mathrm{N}$ recovery efficiency $\left(\mathrm{RE}_{\mathrm{N}}\right)$, and $\mathrm{N}$ physiological efficiency $\left(\mathrm{PE}_{\mathrm{N}}\right)$, as influenced by selected treatments composed of urea sources, timing and methods of fertilizer application at the International Maize and Wheat Improvement Center (CIMMYT), in the Yaqui valley, near Ciudad Obregon, Sonora, Mexico.

\begin{tabular}{cl}
\hline & \multicolumn{1}{c}{ Cycles 2010-2011 to 2013-2014 } \\
\hline & \multicolumn{1}{c}{ Contrasts } \\
\hline 1 & Urea vs. NBPT-urea \\
3 & Urea at planting vs. NBPT-urea at planting \\
4 & Urea all split vs. NBPT-urea all split \\
5 & Urea split 50 + 100 vs. NBPT-urea split 50 + 100 \\
6 & Urea split 100 + 50 vs. NBPT-urea split 100 + 50 \\
7 & Urea incorporated vs. NBPT-urea all treatments incorporated \\
8 & Urea incorporated at furrows vs. NBPT-urea incorportaed at furrows \\
9 & Urea incorporated at beds vs. NBPT-urea incorporated at beds \\
10 & At planting vs. all split \\
11 & At planting vs. split 50 + 100 \\
12 & At planting vs. split 100 + 50 \\
13 & Split 50+100 vs. split 100 + 50 \\
14 & Top-dress vs. All incorporated \\
15 & Top-dress vs. incorporated at furrows \\
16 & Top-dress vs. incorporated at beds \\
17 & Incorporated at furrows vs. incorporated at beds \\
\hline
\end{tabular}

\section{Results}

\subsection{Yields}

When analyzing all five cycles together, the interaction cycles $\times$ treatments was significant $(p=0.002)$. However, after excluding the first cycle (2009-2010) from the analysis, this interaction was non-significant $(p=0.051)$. The first cycle performed different from the following ones due to the presence of wheat leaf rust (Puccinia triticina Eriks.) that infected this experiment, due to its closeness to a contiguous experiment where wheat leaf rust had been inoculated for research purposes. Bolton et al. (2008) [20] revised the negative effects on crop production and characteristics of this pathogen. The yields of all five cycles are shown in Table 4. Yields decreased from the cycle 2010-2011 to 2012-2013, with mean yields of 6214,6201, and $5202 \mathrm{~kg} \mathrm{ha}^{-1}$, respectively; while cycles 2009-2010 and 2013-2014 yielded averages of 6083 and $5149 \mathrm{~kg} \mathrm{ha}^{-1}$, respectively. Within each cycle, there was a highly significant difference among $\mathrm{N}$ treatments $(p<0.0001)$. This was expected due to the inclusion of a control treatment, without $\mathrm{N}$ fertilizer, which yielded an average of $3242 \mathrm{~kg} \mathrm{ha}^{-1}$, while the fertilized treatments yielded an average of $5928 \mathrm{~kg} \mathrm{ha}^{-1}$. In order to avoid redundancy, because yields 
having a direct relationship with $\mathrm{AE}_{\mathrm{N}}$, contrasts for yields are presented in Appendix $\mathrm{A}$ (Table A1) and are addressed while discussing NUE variables. Contrast 1 , comparing both urea types was significant $(p=0.026)$ (Table A1), however, the absolute difference in yield was less than $200 \mathrm{~kg} \mathrm{ha}^{-1}$, in favor of urea over NBPT-urea. Contrast 12, the comparison of all $\mathrm{N}$ applied at planting vs a split application was also significant $(p=0.023)$ (Table A1), but the difference in yield was less than $250 \mathrm{~kg} \mathrm{ha}^{-1}$.

\subsection{Grain and Straw N Concentration}

Pooling together all four cycles of available data on grain and straw $\mathrm{N}$ concentration, or any combination of cycles, a significant interaction cycles $\times$ treatments was observed for grain $\mathrm{N}$ concentration and straw $\mathrm{N}$ concentration. Thus, mean grain and straw $\mathrm{N}$ concentrations are presented by individual cycles (Table 4). Although treatments performed differently across cycles in both grain and straw $\mathrm{N}$ concentration, results are shown and contrasts discussed emphasizing the effects of the main comparisons across cycles (contrasts 1, 10 and 14). Grain N concentration was not affected in any of the four cycles by $\mathrm{N}$ sources, but straw $\mathrm{N}$ concentration was affected in the first and last cycles (Table 5), with urea averaging $0.39 \%$ and NBPT-urea $0.37 \%$. N concentration in grain was influenced by timing of application in the first three cycles but not in the fourth cycle. A split application increased grain $\mathrm{N}$ concentration (1.91\%) compared to one application at planting (1.83\%). Straw $\mathrm{N}$ concentration was only affected $(p=0.021)$ by timing of fertilizer application in the 2010-2011 cycle, with $0.45 \%$ y $0.48 \%$ for treatments applied only once at planting and split applications, respectively. Method of fertilizer application was high to highly significant in all four cycles for grain $\mathrm{N}$ concentration. Treatments where the fertilizer was placed below the residue produced a mean $\mathrm{N}$ concentration of $1.89 \%$, compared with $1.73 \%$ recorded for the broadcasting treatment. With the exception of the first cycle (2009-2010), straw $\mathrm{N}$ concentration was also highly influenced by methods of fertilizer application; with incorporated treatments averaging $0.41 \%$, compared with $0.34 \%$ recorded for broadcasting treatments. 


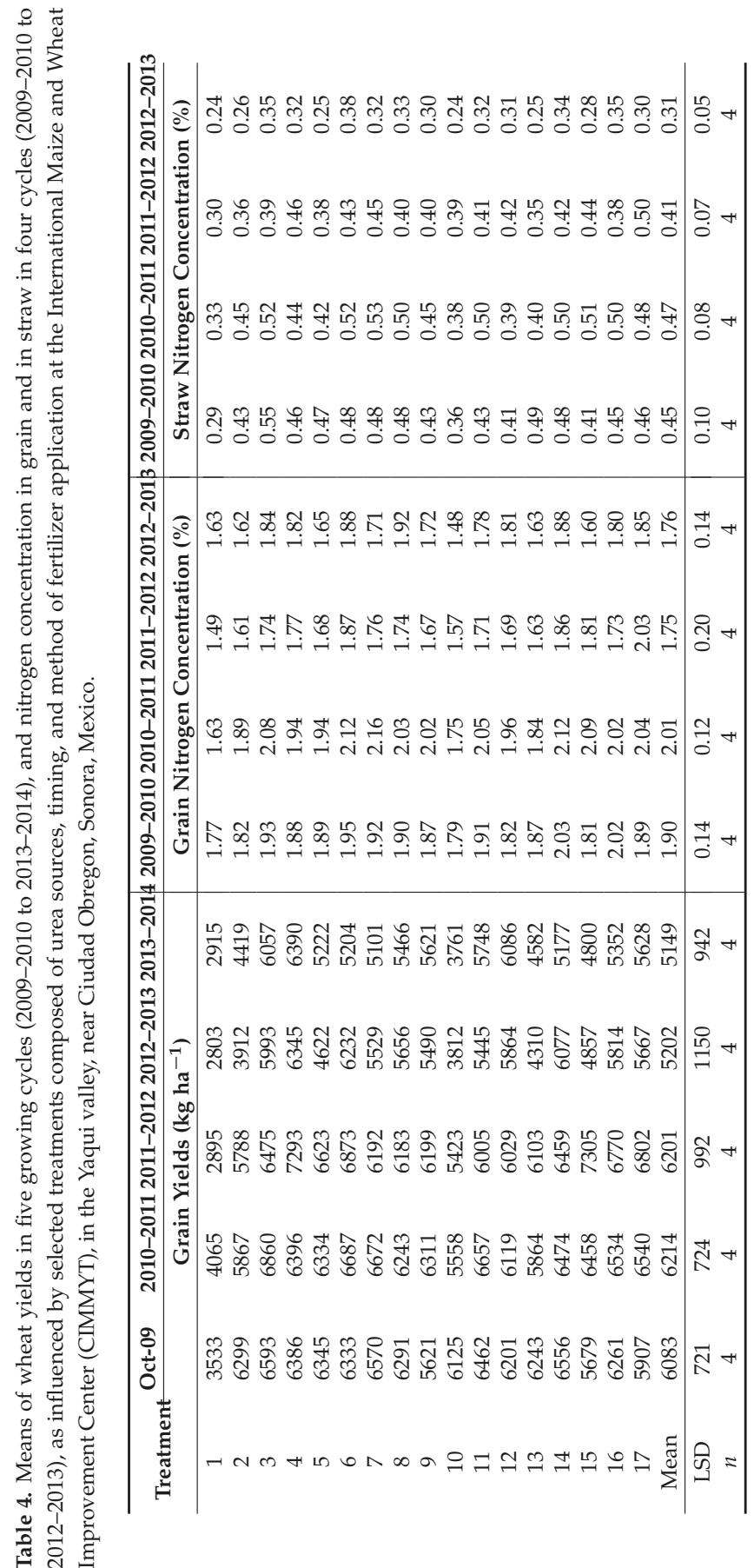


Table 5. $P$ values of contrasts to compare the effects on wheat nitrogen concentration in grain and in straw in four cycles (2009-2010 to 2012-2013), as influenced by selected treatments composed of urea sources, timing, and methods of fertilizer application at the International Maize and Wheat Improvement Center (CIMMYT), in the Yaqui valley, near Ciudad Obregon, Sonora, Mexico.

\begin{tabular}{|c|c|c|c|c|c|c|c|c|}
\hline \multirow{3}{*}{ Contrasts } & \multicolumn{4}{|c|}{$\%$ N Grain } & \multicolumn{4}{|c|}{$\%$ N Straw } \\
\hline & 2009-2010 & $2010-2011$ & 2011-2012 & 2012-2013 & $2009-2010$ & 2010-2011 & 2011-2012 & $2012-2013$ \\
\hline & \multicolumn{4}{|c|}{$p$-Values } & \multicolumn{4}{|c|}{$p$-Values } \\
\hline 1 & 0.939 & 0.077 & 0.456 & 0.087 & 0.050 & 0.127 & 0.634 & 0.044 \\
\hline 2 & 0.385 & 0.153 & 0.388 & 0.085 & 0.006 & 0.032 & 0.897 & 0.098 \\
\hline 3 & 0.564 & 0.250 & 0.111 & 0.401 & 0.747 & 0.799 & 0.616 & 0.198 \\
\hline 4 & 0.709 & 0.101 & 0.988 & 0.228 & 0.614 & 0.444 & 0.413 & 0.054 \\
\hline 5 & 0.174 & 0.836 & 0.014 & 0.876 & 0.913 & 0.592 & 0.077 & 0.723 \\
\hline 6 & 0.666 & 0.005 & 0.541 & 0.094 & 0.490 & 0.132 & 0.916 & 0.480 \\
\hline 7 & 0.872 & 0.695 & 0.228 & 0.308 & 0.060 & 0.368 & 0.542 & 0.054 \\
\hline 8 & 0.145 & 0.810 & 0.747 & 0.129 & 0.089 & 0.466 & 0.966 & 0.137 \\
\hline 9 & 0.217 & 0.754 & 0.046 & 0.932 & 0.329 & 0.584 & 0.366 & 0.207 \\
\hline 10 & 0.027 & 0.000 & 0.009 & 0.120 & 0.211 & 0.021 & 0.355 & 0.275 \\
\hline 11 & 0.061 & 0.000 & 0.035 & 0.964 & 0.176 & 0.046 & 0.583 & 0.775 \\
\hline 12 & 0.052 & 0.004 & 0.016 & 0.003 & 0.493 & 0.049 & 0.265 & 0.075 \\
\hline 13 & 0.783 & 0.589 & 0.581 & 0.004 & 0.592 & 0.853 & 0.530 & 0.125 \\
\hline 14 & 0.019 & $<0.0001$ & 0.000 & $<0.0001$ & 0.242 & $<0.0001$ & 0.000 & $<0.0001$ \\
\hline 15 & 0.001 & $<0.0001$ & 0.001 & $<0.0001$ & 0.069 & $<0.0001$ & 0.045 & $<0.0001$ \\
\hline 16 & 0.476 & $<0.0001$ & 0.001 & $<0.0001$ & 0.800 & 0.002 & $<0.0001$ & $<0.0001$ \\
\hline 17 & 0.002 & 0.161 & 0.763 & 0.001 & 0.079 & 0.025 & 0.002 & 0.000 \\
\hline
\end{tabular}

\subsection{Agronomic Efficiency $\left(A E_{N}\right), R E_{N}$, and $P E_{N}$ and Their Relationship with Yield}

\subsubsection{Agronomic Efficiency of Nitrogen $\left(\mathrm{AE}_{\mathrm{N}}\right)$}

The cycles $\times$ treatments interaction for $\mathrm{AE}_{\mathrm{N}}$ was no significant across all four cycles $(p=0.752)$. Means across these cycles are presented (Table 6) and only one set of contrasts was performed (Table 7). $\mathrm{AE}_{\mathrm{N}}$ averaged $19 \mathrm{~kg}$ grain kg-1 $\mathrm{N}$ (Table 6). The highest $\mathrm{AE}_{\mathrm{N}}$ was recorded for treatments 4 and 3 (with $\mathrm{AE}_{\mathrm{N}} \geq 21 \mathrm{~kg}_{\text {grain }} \mathrm{kg}^{-1} \mathrm{~N}$ ); while the lowest were treatments 10,2 , and 13 (with $\mathrm{AE}_{\mathrm{N}} \leq 16 \mathrm{~kg}$ grain $\mathrm{kg}^{-1} \mathrm{~N}$ ). The treatments with the highest $\mathrm{AE}_{\mathrm{N}}$ shared the characteristic of having urea as fertilizer source when this was incorporated. In contrast, the two treatments with the lowest $\mathrm{AE}_{\mathrm{N}}$ shared the characteristics of all the fertilizer being applied at planting and top-dressed. The three treatments with the lowest $\mathrm{AE}_{\mathrm{N}}$ were similar in that all three were top-dress treatments. Sources of urea or timing of fertilizer application did not influenced $\mathrm{AE}_{\mathrm{N}}$ (contrasts 1 and 10), with $p=0.513$ and $p=0.845$, respectively (Table 7). However, methods of application for $\mathrm{AE}_{\mathrm{N}}$ were highly significant $(p<0.0001)$

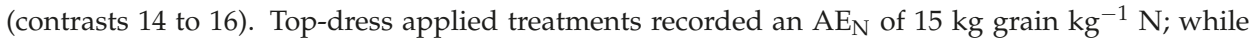
incorporated treatments reached an $\mathrm{AE}_{\mathrm{N}}$ of $20 \mathrm{~kg}_{\text {grain }} \mathrm{kg}^{-1} \mathrm{~N}$.

\subsubsection{Crop Recovery Efficiency of Applied N (REN)}

A highly significant cycles $\times$ treatments interaction $(p=0.008)$ was recorded when analyzing all four cycles together, or when making all possible combinations of cycles $(p<0.050)$. Thus, means and contrasts were performed for each individual cycle (Tables 6 and 7). In three out of four cycles (except for the last one, 2012-2013), treatments 14, 3, 7, and 6 recorded the highest $R E_{N}$ (with $R_{N}$ $\geq 0.60 \mathrm{~kg}$ in total aboveground biomass $\mathrm{kg}^{-1} \mathrm{~N}$ ) (Table 6). On the other hand, treatments 10 and 2 recorded the lowest $R E_{N}$ in all four cycles (with $R E_{N} \leq 0.50 \mathrm{~kg}$ in total aboveground biomass kg ${ }^{-1} \mathrm{~N}$ ); with treatment 10 consistently showing the lowest $R E_{N}$. Three out of four of the treatments with the highest $\operatorname{RE}_{\mathrm{N}}(6,7$, and 14) shared the characteristics of having been split applied, $50 \mathrm{~kg}$ of $\mathrm{N}$ at planting $+100 \mathrm{~kg}$ of $\mathrm{N}$ at late tillering, and also similar in that the fertilizer was incorporated (mechanically at planting and through irrigation by late tillering). In contrast, the treatments with the lowest $\mathrm{RE}_{\mathrm{N}}(10$ and 2) were all applied at planting and were top-dress applied. Nitrogen sources never influenced 
$\operatorname{RE}_{\mathrm{N}}(p>0.050)$ (Table 7). Timing of fertilizer application was highly significant in the two middle cycles $(p<0.050)$, but not in the first or last cycles $(p>0.050)$. The mean $\mathrm{RE}_{\mathrm{N}}$ for the two cycles where timing of fertilizer application was significant was $0.50 \mathrm{~kg} \mathrm{~N}$ in total aboveground biomass $\mathrm{kg}^{-1} \mathrm{~N}$, for fertilizer applied at planting and $0.62 \mathrm{~kg} \mathrm{~N}$ in total aboveground biomass $\mathrm{kg}^{-1} \mathrm{~N}$, for split applied treatments. Except for the first cycle, which showed just a trend $(p=0.095)$, for the rest of the cycles, method of fertilizer application was highly significant $(p<0.0001)$ for $\mathrm{RE}_{\mathrm{N}}$; with broadcasting and incorporated methods recording means across all cycles of 0.41 and $0.59 \mathrm{~kg} \mathrm{~N}$ in total aboveground biomass $\mathrm{kg}^{-1} \mathrm{~N}$, respectively.

\subsubsection{Physiological Efficiency of Applied N ( $\left.\mathrm{PE}_{\mathrm{N}}\right)$}

The cycles $\times$ treatments interaction for $\mathrm{PE}_{\mathrm{N}}$ was no significant across all four cycles $(p=0.288)$. Thus, means across all four cycles are presented (Table 6) and the results of only one set of contrasts are presented (Table 7). The most efficient treatments for converting existing $\mathrm{N}$ within the plants into grain $\left(\mathrm{PE}_{\mathrm{N}}\right.$ ) were 10 and 2 (with $\mathrm{PE}_{\mathrm{N}} \geq$ to $40 \mathrm{~kg}_{\text {grain }} \mathrm{kg}^{-1} \mathrm{~N}$ ); while the treatments with the lowest $P E_{N}$ were 14,6 , and 17 (with $P E_{N} \leq$ to $33 \mathrm{~kg} g r a i n ~ k g^{-1} \mathrm{~N}$ ). The highest $P E_{N}$ treatments were similar in that urea treatments were applied top-dress all at planting; while the lowest were similar in that the fertilizer was split applied and incorporated. $\mathrm{PE}_{\mathrm{N}}$ was not influenced by urea sources $(p=0.799)$, but was highly significant for timing and methods of fertilizer application $(p<0.0001$ for both variables) (Table 7). Split application treatments recorded a mean $P_{N}$ of 39 and $35 \mathrm{~kg} g r a i n ~ k g^{-1}$ $\mathrm{N}$ for incorporated treatments; while top-dress and incorporated methods of application recorded $\mathrm{PE}_{\mathrm{N}}$ of 42 and $35 \mathrm{~kg}_{\text {grain }} \mathrm{kg}^{-1} \mathrm{~N}$, respectively.

Table 6. Means of nitrogen $(\mathrm{N})$ agronomic efficiency $\left(\mathrm{AE}_{\mathrm{N}}\right)$, crop recovery efficiency of applied $\mathrm{N}$ $\left(R E_{N}\right)$, and physiological efficiency of applied $\mathrm{N}\left(\mathrm{PE}_{\mathrm{N}}\right)$, as influenced by selected treatments composed of urea sources, timing and method of fertilizer application at the International Maize and Wheat Improvement Center (CIMMYT), in the Yaqui valley, near Ciudad Obregon, Sonora, Mexico.

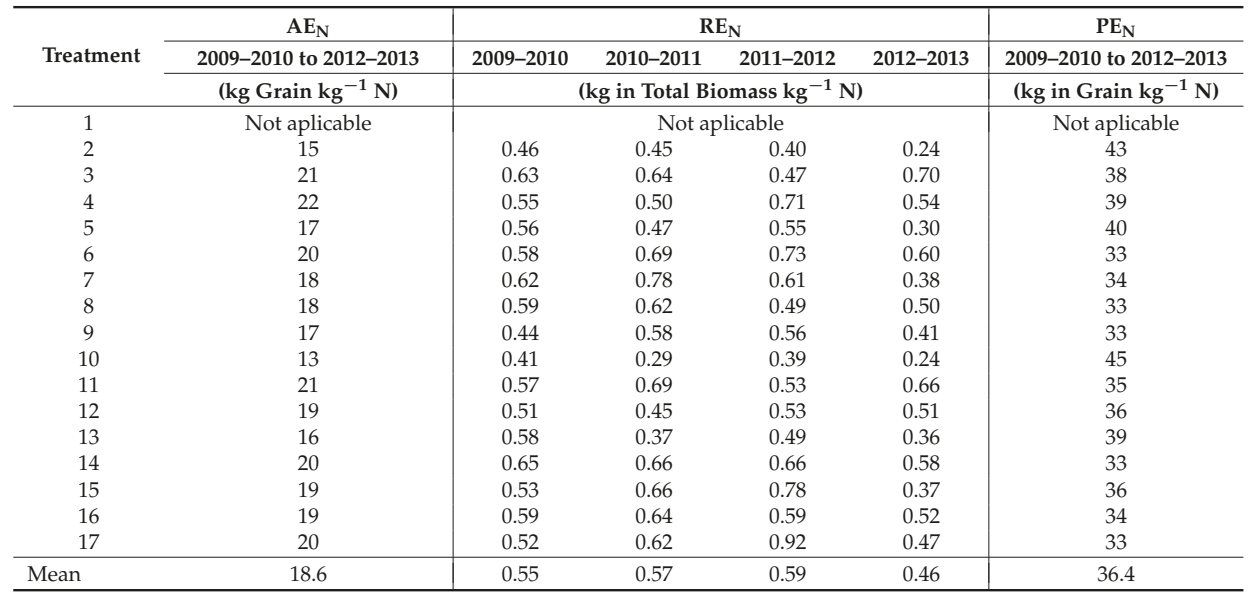


Table 7. $p$ values of contrasts on nitrogen $(\mathrm{N})$ agronomic efficiency $\left(\mathrm{AE}_{\mathrm{N}}\right)$, crop recovery efficiency of applied $\mathrm{N}\left(\mathrm{RE}_{\mathrm{N}}\right)$, and physiological efficiency of applied $\mathrm{N}\left(\mathrm{PE}_{\mathrm{N}}\right)$, as influenced by selected treatments composed of urea sources, timing and method of fertilizer application at the International Maize and Wheat Improvement Center (CIMMYT), in the Yaqui valley, near Ciudad Obregon, Sonora, Mexico.

\begin{tabular}{|c|c|c|c|c|c|c|}
\hline \multirow{3}{*}{ Contrasts } & \multirow{3}{*}{$\begin{array}{c}\mathrm{AE}_{\mathrm{N}} \\
2010-2011 \text { to } 2012-2013 \\
p \text {-Values }\end{array}$} & \multicolumn{4}{|c|}{$R E_{N}$} & \multirow{3}{*}{$\begin{array}{c}\mathrm{PE}_{\mathrm{N}} \\
\text { 2010-2011 to 2012-2013 } \\
p \text {-Values }\end{array}$} \\
\hline & & 2010-2011 & 2011-2012 & $2012-2013$ & 2013-2014 & \\
\hline & & \multicolumn{4}{|c|}{$p$-Values } & \\
\hline 2 & 0.057 & 0.317 & 0.254 & 0.385 & 0.613 & 0.473 \\
\hline 3 & 0.505 & 0.688 & 0.290 & 0.016 & 0.879 & 0.813 \\
\hline 4 & 0.623 & 0.996 & 0.074 & 0.769 & 0.427 & 0.772 \\
\hline 7 & 0.871 & 0.847 & 0.659 & 0.060 & 0.412 & 0.668 \\
\hline 8 & 0.659 & 0.909 & 0.793 & 0.597 & 0.725 & 0.676 \\
\hline 9 & 0.831 & 0.698 & 0.376 & 0.033 & 0.415 & 0.852 \\
\hline 10 & 0.845 & 0.158 & 0.001 & 0.000 & 0.774 & $<0.0001$ \\
\hline 11 & 0.976 & 0.073 & 0.002 & 0.001 & 0.293 & 0.005 \\
\hline 12 & 0.663 & 0.686 & 0.004 & 0.002 & 0.045 & $<0.0001$ \\
\hline 16 & $<0.0001$ & 0.555 & $<0.0001$ & $<0.0001$ & $<0.0001$ & $<0.0001$ \\
\hline 17 & 0.252 & 0.043 & 0.084 & 0.006 & $<0.0001$ & 0.421 \\
\hline
\end{tabular}

3.3.4. Correlation and Regression Analyses among Yields, $\mathrm{AE}_{\mathrm{N}}, \mathrm{RE}_{\mathrm{N}}$, and $\mathrm{PE}_{\mathrm{N}}$

Table 8 shows correlation coefficients between yields and NUE parameters and among NUE parameters, for each individual cycle. Although the magnitude of the correlation coefficients and significance levels varied to a certain degree across cycles, the overall consistency allows making some generalizations. Grain yields and $\mathrm{AE}_{\mathrm{N}}$ showed a positive and highly significant $(p<0.0001)$ correlation, varying from $r=0.50$ to 0.84 . Similarly, yields consistently and significantly $(p<0.0001)$ correlated with $R E_{N}$, ranging from $r=0.60$ to 0.75 . On the other hand, yields were poorly correlated with $P E_{N}$ and the correlations were non-significant $(p>0.050)$, with coefficients varying from $r=-0.24$ to 0.16 . Yields were higher as $A E_{N}$ and $R E_{N}$ increased, but inconsistently related with $P E_{N}$. From nine contrasts that were planned to compare wheat yields (contrasts not shown) in response to the effect of urea sources, three where significantly different $(p<0.050)$ (contrasts 1,2 , and 6). All three comparisons in favor of urea over NBPT-urea, but absolute differences among means were low, averaging only $193 \mathrm{~kg} \mathrm{ha}^{-1}$. Contrasts 10 to 13 were planned to compare timing of applications. Timing of application treatments were designed to test specifically whether applying $\mathrm{N}$ fertilizer all at planting vs split applications would make a difference. Contrast number 10 compared all treatments at planting versus all treatments with split applications and the difference was no significant $(p=0.121)$. Contrasts 14 to 17 were designed to test whether broadcasting (top-dressing) $\mathrm{N}$ fertilizers would make a difference with respect to incorporating the fertilizer into the soil. The overall difference between top-dress treatments and both incorporated treatments (at furrows or at beds) was highly significant $(p<0.0001)$ (contrast 14). The difference between incorporated at furrows versus incorporated at beds was not significant $(p=0.753)$ (contrast 17). 
Table 8. Correlation coefficients between wheat yields and NUE parameters: $A E_{N}, R E_{N}$, and $P E_{N}$ in four cycles, as influenced by selected treatments composed of urea sources, timing and methods of fertilizer application at the International Maize and Wheat Improvement Center (CIMMYT), in the Yaqui valley, near Ciudad Obregon, Sonora, Mexico.

\begin{tabular}{|c|c|c|c|c|}
\hline & Grain Yield & $\mathrm{AE}_{\mathrm{N}}$ & $R E_{N}$ & $P E_{N}$ \\
\hline \multicolumn{5}{|c|}{ 2009-2010 } \\
\hline Grain Yield & 1 & & & \\
\hline $\mathrm{AE}_{\mathrm{N}}$ & $0.71^{* * *}$ & 1 & & \\
\hline $\mathrm{RE}_{\mathrm{N}}$ & $0.60 * * *$ & $0.76^{* * *}$ & 1 & \\
\hline$P E_{N}$ & $0.15 \mathrm{~ns}$ & $0.24 \mathrm{~ns}$ & $-0.40^{* * *}$ & 1 \\
\hline \multicolumn{5}{|c|}{ 2010-2011 } \\
\hline Grain Yield & 1 & & & \\
\hline$A E_{N}$ & $0.65^{* * *}$ & 1 & & \\
\hline $\mathrm{RE}_{\mathrm{N}}$ & $0.68^{* * *}$ & $0.85^{* * *}$ & 1 & \\
\hline $\mathrm{PE}_{\mathrm{N}}$ & $-0.10 \mathrm{~ns}$ & $0.11 \mathrm{~ns}$ & $-0.39^{* *}$ & 1 \\
\hline \multicolumn{5}{|c|}{ 2011-2012 } \\
\hline Grain yield & 1 & & & \\
\hline $\mathrm{AE}_{\mathrm{N}}$ & $0.84^{* * * *}$ & 1 & & \\
\hline $\mathrm{RE}_{\mathrm{N}}$ & $0.75^{* * *}$ & $0.75^{* * *}$ & 1 & \\
\hline $\mathrm{PE}_{\mathrm{N}}$ & $0.16 \mathrm{~ns}$ & 0.30 * & $-0.35^{* *}$ & 1 \\
\hline \multicolumn{5}{|c|}{ 2012-2013 } \\
\hline Grain yield & 1 & & & \\
\hline $\mathrm{AE}_{\mathrm{N}}$ & $0.50 * * *$ & 1 & & \\
\hline $\mathrm{RE}_{\mathrm{N}}$ & $0.60^{* * *}$ & $0.93^{* * *}$ & 1 & \\
\hline $\mathrm{PE}_{\mathrm{N}}$ & $-0.24 \mathrm{~ns}$ & $0.16 \mathrm{~ns}$ & $-0.15 \mathrm{~ns}$ & 1 \\
\hline
\end{tabular}

$\mathrm{ns},{ }^{* *}$, and ${ }^{* * *}=$ non significant, significant at $p \leq 0.01$, and significant at $p \leq 0.001$ level, respectively.

$\mathrm{AE}_{\mathrm{N}}$ had a positive and highly significant $(p<0.0001)$ correlation with $\mathrm{RE}_{\mathrm{N}}$, ranging from $\mathrm{r}=0.75$ to 0.93 . In contrast, the correlations between $\mathrm{AE}_{\mathrm{N}}$ and $\mathrm{PE}_{\mathrm{N}}$ were much lower and generally non-significant $(p>0.050)$, ranging from $r=0.11$ to 0.30 . The correlations between $R_{N}$ and $\mathrm{PE}_{\mathrm{N}}$ were negative and, with the exception of the cycle 2012-2013, when this correlation was non-significant $(p>0.050)$, the other three were highly significant $(p<0.01)$, ranging from $r=-0.35$ to -0.40 .

Regression analysis showed that the total variation on $\mathrm{AE}_{\mathrm{N}}$ on each cycle was explained by $\mathrm{RE}_{\mathrm{N}}$ and $\mathrm{PE}_{\mathrm{N}}$, respectively, as follows: $57 \%$ and $36 \%$, explaining a total of $93 \%$ (cycle 2009-2010); $72 \%$ and $24 \%$, explaining a total of $96 \%$ (cycle $2010-2011$ ); $56 \%$ and $35 \%$, explaining a total of $91 \%$ (cycle 2011-2012); and 85\% and 9\%, explaining a total of 94\% (cycle 2012-2013).

\section{Discussion}

In the present study mean $\mathrm{AE}_{\mathrm{N}}$ was $18.6 \mathrm{~kg}_{\text {grain }} \mathrm{kg}^{-1} \mathrm{~N}$, with associated mean yields of $5925 \mathrm{~kg} \mathrm{ha}^{-1}$ (cycles 2009-2010 to 2012-2013). Ayadi et al. (2016) [21] reported a mean yield of $5000 \mathrm{~kg} \mathrm{ha}^{-1}$ for the $150 \mathrm{~kg} \mathrm{~N} \mathrm{ha}^{-1}$ treatment and an associated $\mathrm{AE}_{\mathrm{N}}$ of $13.97 \mathrm{~kg}_{\text {grain kg }}{ }^{-1} \mathrm{~N}$; slightly lower yields but substantially lower $\mathrm{N}$ use efficiency, as compared with the results reported in this study. Gupta et al. (2009) [22] found a mean $\mathrm{AE}_{\mathrm{N}}$ for the $150 \mathrm{~kg} \mathrm{~N}^{-1}$ of $16.4 \mathrm{~kg}_{\text {grain kg }}{ }^{-1} \mathrm{~N}$ with a mean yield associated with that treatment of $4545 \mathrm{~kg} \mathrm{ha}^{-1}$, across three growing cycles and two soil types, with comparable $\mathrm{N}$ use efficiency, but lower yields than those recorded in this study. In a study conducted in Arizona, U. S. A., Mon et al. (2016) [23] reported mean $\mathrm{AE}_{\mathrm{N}}$ and associated grain wheat yields during two years (2013 and 2014), for the treatment of $168 \mathrm{~kg} \mathrm{~N} \mathrm{ha}^{-1}$ (their highest yielding treatment), across five irrigation levels, of $17 \mathrm{~kg}_{\text {grain }} \mathrm{kg}^{-1} \mathrm{~N}$ and approximately, $4300 \mathrm{~kg} \mathrm{ha}^{-1}$, respectively (in 2013) and $9 \mathrm{~kg} \mathrm{~N} \mathrm{ha}^{-1}$ and approximately $3400 \mathrm{~kg} \mathrm{ha}^{-1}$, respectively (in 2014). In this same study [23], much lower $\mathrm{AE}_{\mathrm{N}}$ and yield levels were reported as $\mathrm{N}$ rates increased. Duan et al. (2014) [24] reported a robust paper about NUE across four wheat production regions in China over 
a 15 year period and across several fertilizer treatments. They reported a mean $\mathrm{AE}_{\mathrm{N}}$ of $15 \mathrm{~kg}$ grain $\mathrm{kg}^{-1} \mathrm{~N}$, associated with a mean yield of $3300 \mathrm{~kg} \mathrm{ha}^{-1}$.

The point of this discussion is to suggest that, while the NUE parameters recorded in this study were average, the productivity associated to these levels of $\mathrm{N}$ use efficiency is high. Thus, representing a net advance for the overall balance between the need of producing food and the environmental footprint of its production. The $\mathrm{N}$ use efficiency and yield levels in the present study may be associated with; (1) the adoption of long known strategies to increase $N$ use efficiency, (2) a non-critically limiting $\mathrm{N}$ supply for the crop, provided in part by soil mineralization under a mature conservation agriculture system, and a possible synergy among these two factors. Grahmann et al. (2013) [12] suggested an initial short-term $\mathrm{N}$ immobilization period under conservation agriculture, but steady $\mathrm{N}$ mineralization rates afterward. In support of the hypothesis that wheat in this study grew on a relatively $\mathrm{N}$ rich environment, not only through applied fertilizers, the following evidence is presented.

A soil analysis made before the beginning of the third cycle (2011-2012) showed organic matter concentrations of $0.87 \%, 0.62 \%, 0.40 \%$, and $0.25 \%$ in the $0-15,15-30,30-60$, and $60-90 \mathrm{~cm}$, soil profiles, respectively, with a $\mathrm{pH}$ of 8.8 . Furthermore, in the same experiment station also under conservation agriculture Grahmann et al. (2016) [25] reported organic matter concentrations of $1.2 \%, 0.9 \%, 0.7 \%$, and $0.3 \%$ for soil profiles $0-15,15-40,40-70$, and $70-120 \mathrm{~cm}$, respectively, with a pH of 8.0. From the organic matter concentrations recorded for this study, it is estimated that around $80 \mathrm{~kg} \mathrm{ha}^{-1}$ of mineral $\mathrm{N}$ could be made available for wheat each cycle in the $0-0.9 \mathrm{~m}$ soil profile. This estimation based on the assumptions of $50 \%$ organic carbon from total organic matter, a $10 \%$ of organic $\mathrm{N}$ from total organic carbon, and $2 \%$ mineralization rate year ${ }^{-1}$ (personal communication from Dr. William Raun, from the Plant and Soil Department, Oklahoma State University). In an early study, comparing conventional tillage versus conservation tillage, Franzluebbers et al. (1995) [26] estimated that, under adequate temperature and moisture conditions, $\mathrm{NO}^{3-}$ accumulated at a rate of $\approx 0.03 \mathrm{~g} \mathrm{~N} \mathrm{~m}^{-2} \mathrm{~d}^{-1}$, which equals to $110 \mathrm{~kg} \mathrm{~N}^{-1}$ year $^{-1}$. If $30 \mathrm{~kg} \mathrm{~N}(\mathrm{PFPN}=30 \mathrm{~kg}$ grain kg-1 N) are required to produce $1000 \mathrm{~kg}$ of wheat grain [27], $80 \mathrm{~kg} \mathrm{~N}$ would support yields of around $2600 \mathrm{~kg} \mathrm{ha}^{-1}$, which is close to the mean yields recorded in the control plots in this study during the last three cycles $\left(2870 \mathrm{~kg} \mathrm{ha}^{-1}\right)$. For the fertilized plots, because mineralization rates would be expected to be higher in fertilized than in the control plots [28], it is estimated that they received a rate of about $230 \mathrm{~kg} \mathrm{~N}^{-1} \mathrm{cycle}^{-1}$ (150 from applied fertilizer +80 from soil mineralization). Thus, if the response of yields to $\mathrm{N}$ fertilization was linear, yields would be around $7600 \mathrm{~kg} \mathrm{ha}^{-1}$, but in reality, this response is well known to increase less as $\mathrm{N}$ availability is increased $[23,29]$. In addition to mineral $\mathrm{N}$ resulting from $\mathrm{OM}$ mineralization in the present study, another contributing factor could have been related with reduced ammonia losses under CA. Yang et al. (2015) [30] and Sanz-Cobena et al. (2017) [31] reported that when N was applied as a deep band, the ammonia volatilization was lower under CA than under conventional tillage systems and concluded that reduced tillage and crop residues management show a large potential for reducing net greenhouse gas emissions.

Grain N concentration in the control plots in this study recorded a mean of $1.6 \%$ across the four cycles where this variable was determined. This grain $\mathrm{N}$ concentration, although was the lowest in every cycle (except in the last cycle), compared with the rest of the treatments, was not low, as compared with literature reports. Grahmann et al. (2016) [25] reported mean crude protein concentrations for the control treatment of $2 \%$ to $4 \%$ across four cycles, equivalent to about $0.4 \%$ to $0.7 \% \mathrm{~N}$ concentration $(\mathrm{N} \times 5.70)$, and for the $120 \mathrm{~kg} \mathrm{ha}^{-1}$ treatments, $6 \%$ to $9 \%$ crude protein, equivalent to about $1.1 \%$ to $1.7 \% \mathrm{~N}$ concentrations, comparable to the control treatment $(0 \mathrm{~N})$ in the present study. As an additional argument to support the hypothesis of recording relatively high yields and NUE in this study due to a sufficient (but not excessive) $\mathrm{N}$ supply, $R E_{\mathrm{N}}$ consistently explained more of the variability of $\mathrm{AE}_{\mathrm{N}}$ than $P E_{N}$, and these findings coincide with literature reports. Moll et al. (1982) [14] suggested that under relatively high $\mathrm{N}$ availability, $\mathrm{N}$ uptake efficiency accounted more than $\mathrm{N}$ utilization efficiency for explaining the variability of $N$ use efficiency. Similarly, Tian et al. (2016) [32] indicated that $P_{N}$ 
increased during cultivar genetic improvement in China, and that genetic improvement of NUE was mainly related to the increase in $\mathrm{AE}_{\mathrm{N}}$, under relatively high $\mathrm{N}$ supply.

There is a common assumption that wheat (as well as for other crops) yields and quality are irreconcilable objectives $[28,33,34]$, i.e., that one of them has to decrease for the other to increase. This negative relationship was not present in this study, as the highest yielding treatments were also the highest in grain N concentrations, and vice versa. According with Fischer et al. (1993) [35], Grant et al. (1985) [36], and Brown et al. (2005) [37], grain $\mathrm{N}$ decreases when $\mathrm{N}$ fertilizers are applied to a highly yielding responsive environment (low soil $\mathrm{N}$ supply) because yields increase and an increased accumulation of carbohydrates dilutes the $\mathrm{N}$ concentration in grain. On the other hand, the same authors indicate that $\mathrm{N}$ applications to environments with low yielding response probability due to high soil $\mathrm{N}$ supply, would not increase yields but only $\mathrm{N}$ concentration. In the present study, in general, both yields and grain $\mathrm{N}$ concentrations increased or decreased together across all treatments (Figure 2). Averaging the cycles 2010-2011 to 2012-2013, the seven lowest yielding treatments were also the lowest in grain $\mathrm{N}$ concentration, being, from the lowest to the highest, 1 (the control), 10, $2,13,5,9$, and 12 . On the other hand, treatment number 6 was the second highest yielding of all treatments with a mean of $6597 \mathrm{~kg} \mathrm{ha}^{-1}$ and also the second with the highest grain $\mathrm{N}$ concentration, with $1.95 \%$. Treatment number 3 was the third highest yielding, with $6442 \mathrm{~kg} \mathrm{ha}^{-1}$ and the fifth highest in grain $\mathrm{N}$ concentration, with $1.90 \%$. One exception to this pattern was observed for treatment number 4, which was the highest yielding treatment of all, with $6678 \mathrm{~kg} \mathrm{ha}^{-1}$ but the ninth in grain $\mathrm{N}$ concentration. This suggests that wheat under this treatment may have promoted conditions for high yields, experiencing a dilution of $\mathrm{N}$ concentration, as high yields imply large carbohydrate accumulation, as has been stated [35-37].

$a$

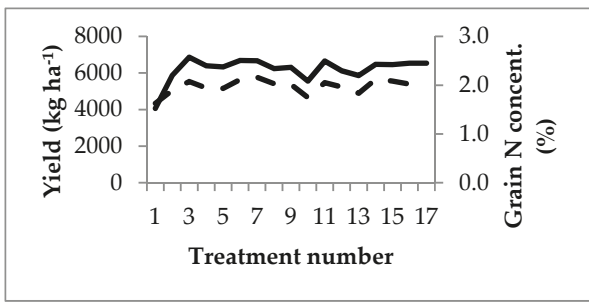

$c$

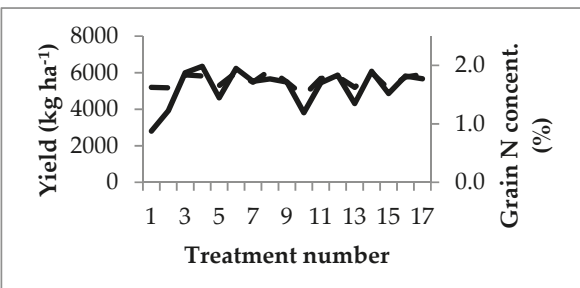

$b$

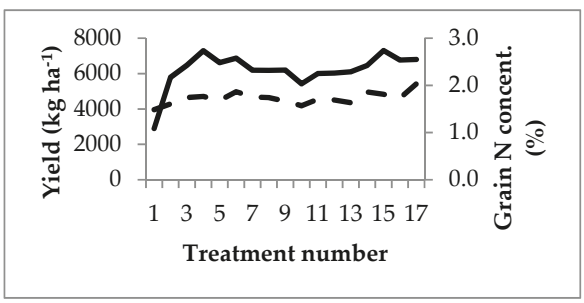

$d$

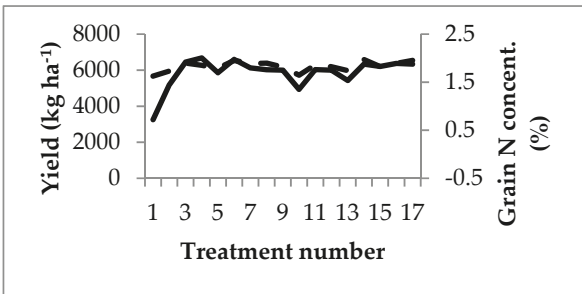

Figure 2. Relationship between wheat yields and grain nitrogen concentrations during the growing cycles of (a) 2010-2011, (b) 2011-2012, (c) 2011-2012, and (d) the average of the three cycles at the International Maize and Wheat Improvement Center (CIMMYT) experimental station, near Ciudad Obregon, Sonora in northwestern Mexico. The Solid lines represent yields and the dashed lines represent grain $\mathrm{N}$ concentration. 


\section{Conclusions}

The use of effective fertilizer management practices on a mature conservation agriculture system, under irrigation and under mild temperatures, like in these experiments, allowed relatively high wheat yields while recording average or slightly above average $\mathrm{N}$ use efficiency. Apparently, stable, mature conservation agriculture systems seem to provide a buffer capacity against $\mathrm{N}$ fertilizer management practices, due to their stability in releasing mineral N. From the three tested fertilizer management strategies: N sources, timing (or splitting), and methods of fertilizer application were the only factors that realistically showed potential for increasing the profitability for farmers (because of the increases in yields), as well as in environmental terms (because of the increase in $\mathrm{N}$ use efficiency) was method of application. Incorporation of $\mathrm{N}$ fertilizers in conservation agriculture had been identified in past research studies [25], as the most important variable for both wheat productivity and $\mathrm{N}$ use efficiency. From the results of this study, we hypothesize that the combination of CA and smart fertilizer management practices could contribute to increasing food production levels and quality, and, at the same time, improve the degree of sustainability of the current crop production systems. In view of the paramount importance of incorporating $\mathrm{N}$ fertilizers under $\mathrm{CA}$ in this study, future research interests would focus about testing the most effective disk harrow designs for optimum $\mathrm{N}$ fertilizers incorporation.

Author Contributions: I.O.-M. was responsible for finding the funding for conducting the present study. I.O.-M. designed the experiments, supervised the field works and data collection, and was responsible for producing the databases used in the present study. F.N.-R. contributed with reviewing and editing the manuscript and was the responsible for formatting the references as required by this journal (Agronomy). M.E.C.-C. was the foreman in establishing the experiments and on the process of data collection in the field, and helped I.O.-M. in several other ways. C.R.-A. thoroughly reviewed this manuscript and significantly contributed with it. J.S.-C. was the responsible of running the statistical analyses and of writing the full manuscript.

funding: This research received no external funding.

Acknowledgments: The authors thank the International Maize and Wheat Improvement Center (CIMMYT) and the Mexican Government throughout the Secretaría de Agricultura, Ganadería, Desarrollo Rural, Pesca y Alimentación (SAGARPA) and the Sustainable Modernization of Traditional Agriculture Program (MasAgro) (MasAgro; http:/ / masagro.mx) for financing part of the work presented in this study.

Conflicts of Interest: The authors declare no conflict of interest. The funders had no role in the design of the study, in the collection, analyses, or interpretation of data; in the writing of the manuscript, and in the decision to publish the results. 


\section{Appendix A}

Table A1. Orthogonal contrasts to compare the effects of selected treatments composed of urea sources, timing and methods of fertilizer application on wheat yields in four growing cycles (2010-2011 to 2013-2014), at the International Maize and Wheat Improvement Center (CIMMYT), in the Yaqui valley, near Ciudad Obregon, Sonora, Mexico.

\begin{tabular}{clc}
\hline & \multicolumn{1}{c}{ Contrasts } & $p$ Value \\
\hline 1 & Urea vs. NBPT-urea & 0.026 \\
2 & Urea at planting vs. NBPT-urea at planting & 0.002 \\
3 & Urea all split vs. NBPT-urea all split & 0.685 \\
4 & Urea split 50 + 100 vs. NBPT-urea split 50+100 & 0.095 \\
5 & Urea split 100 + 50 vs. NBPT-urea split 100 + 50 & 0.160 \\
6 & Urea top-dress vs. NBPT-urea top-dress & 0.015 \\
7 & Urea incorporated vs. NBPT-urea all treatments incorporated & 0.242 \\
8 & Urea incorporated at furrows vs. NBPT-urea incorportaed at furrows & 0.402 \\
9 & Urea incorporated at beds vs. NBPT-urea incorporated at beds & 0.413 \\
10 & At planting vs. all split & 0.121 \\
11 & At planting vs. split 50 + 100 & 0.542 \\
12 & At planting vs. split 100 + 50 & 0.023 \\
13 & Split 50+100 vs. split 100 + 50 & 0.082 \\
14 & Top-dress vs. All incorporated & $<0.0001$ \\
15 & Top-dress vs. incorporated at furrows & $<0.0001$ \\
16 & Top-dress vs. incorporated at beds & $<0.0001$ \\
17 & Incorporated at furrows vs. incorporated at beds & 0.753 \\
\hline
\end{tabular}

\section{References}

1. Gardner, F.P.; Pearce, R.B.; Mitchell, R.L. Physiology of Crop Plants; Scientific Publishers: Jodhpur, India, 2017.

2. Padilla, F.M.; Gallardo, M.; Manzano-Agugliaro, F. Global Trends in Nitrate Leaching Research in the 1960-2017 Period. Sci. Total Environ. 2018, 643, 400-413. [CrossRef] [PubMed]

3. Smith, P.; House, J.I.; Bustamante, M.; Sobocká, J.; Harper, R.; Pan, G.; West, P.C.; Clark, J.M.; Adhya, T.; Rumpel, C. Global Change Pressures on Soils from Land Use and Management. Glob. Chang. Biol. 2016, 22, 1008-1028. [CrossRef] [PubMed]

4. Ercoli, L.; Masoni, A.; Mariotti, M.; Pampana, S.; Pellegrino, E.; Arduini, I. Effect of Preceding Crop on the Agronomic and Economic Performance of Durum Wheat in the Transition from Conventional to Reduced Tillage. Eur. J. Agron. 2017, 82, 125-133. [CrossRef]

5. Rathore, V.S.; Nathawat, N.S.; Bhardwaj, S.; Sasidharan, R.P.; Yadav, B.M.; Kumar, M.; Santra, P.; Yadava, N.D.; Yadav, O.P. Yield, Water and Nitrogen Use Efficiencies of Sprinkler Irrigated Wheat Grown under Different Irrigation and Nitrogen Levels in an Arid Region. Agric. Water Manag. 2017, 187, 232-245. [CrossRef]

6. Pourazari, F.; Vico, G.; Båth, B.; Weih, M. Nitrogen Use Efficiency and Energy Harvest in Wheat, Maize and Grassland Ley Used for Biofuel-Implications for Sustainability. Procedia Environ. Sci. 2015, 29, 22-23. [CrossRef]

7. $\quad$ Meng, Q.; Yue, S.; Hou, P.; Cui, Z.; Chen, X. Improving Yield and Nitrogen Use Efficiency Simultaneously for Maize and Wheat in China: A Review. Pedosphere 2016, 26, 137-147. [CrossRef]

8. Yadav, M.R.; Kumar, R.; Parihar, C.M.; Yadav, R.K.; Jat, S.L.; Ram, H.; Meena, R.K.; Singh, M.; Birbal; Verma, A.P.; et al. Strategies for Improving Nitrogen Use Efficiency: A Review. Agric. Rev. 2017, 38, $29-40$.

9. Raun, W.; Johnson, G. Improving Nitrogen Use Efficiency for Cereal Production. Agron. J. 1999, 91, 357-363. [CrossRef]

10. Yang, X.; Lu, Y.; Ding, Y.; Yin, X.; Raza, S.; Tong, Y. Optimising Nitrogen Fertilisation: A Key to Improving Nitrogen-Use Efficiency and Minimising Nitrate Leaching Losses in an Intensive Wheat/Maize Rotation (2008-2014). Field Crops Res. 2017, 206, 1-10. [CrossRef]

11. Guttieri, M.J.; Frels, K.; Regassa, T.; Waters, B.M.; Baenziger, P.S. Variation for Nitrogen Use Efficiency Traits in Current and Historical Great Plains Hard Winter Wheat. Euphytica 2017, 213. [CrossRef] 
12. Grahmann, K.; Verhulst, N.; Buerkert, A.; Ortiz-Monasterio, I.; Govaerts, B. Nitrogen Use Efficiency and Optimization of Nitrogen Fertilization in Conservation Agriculture. CAB Rev. 2013, 8, 1-19. [CrossRef]

13. Hawkesford, M.J. Genetic Variation in Traits for Nitrogen Use Efficiency in Wheat. J. Exp. Bot. 2017, 68, 2627-2632. [CrossRef] [PubMed]

14. Moll, R.H.; Kamprath, E.J.; Jackson, W.A. Analysis and Interpretation of Factors Which Contribute to Efficiency of Nitrogen Utilization1. Agron. J. 1982, 74, 562-564. [CrossRef]

15. Ortiz-Monasterio, R.; Sayre, K.D.; Rajaram, S.; McMahon, M. Genetic Progress in Wheat Yield and Nitrogen Use Efficiency under Four Nitrogen Rates. Crop Sci. 1997, 37, 898-904. [CrossRef]

16. Rakotoson, T.; Dusserre, J.; Letourmy, P.; Ramonta, I.R.; Cao, T.-V.; Ramanantsoanirina, A.; Roumet, P.; Ahmadi, N.; Raboin, L.-M. Genetic Variability of Nitrogen Use Efficiency in Rainfed Upland Rice. Field Crops Res. 2017, 213, 194-203. [CrossRef]

17. Dobermann, A.R. Nitrogen Use Efficiency-State of the Art. In IFA International Workshop on Enhanced-Efficiency Fertilizers; Agronomy-Faculty Publications: Frankfurt, Germany, 28-30 June 2005; p. 316.

18. Ladha, J.K.; Pathak, H.; Krupnik, T.J.; Six, J.; van Kessel, C. Efficiency of Fertilizer Nitrogen in Cereal Production: Retrospects and Prospects. Adv. Agron. 2005, 87, 85-156. [CrossRef]

19. Malhi, S.S.; Grant, C.A.; Johnston, A.M.; Gill, K.S. Nitrogen Fertilization Management for No-till Cereal Production in the Canadian Great Plains: A Review. Soil Tillage Res. 2001, 60, 101-122. [CrossRef]

20. Bolton, M.D.; Kolmer, J.A.; Garvin, D.F. Wheat Leaf Rust Caused by Puccinia Triticina. Mol. Plant Pathol. 2008, 9, 563-575. [CrossRef]

21. Ayadi, S.; Karmous, C.; Chamekh, Z.; Hammami, Z.; Baraket, M.; Esposito, S.; Rezgui, S.; Trifa, Y. Effects of Nitrogen Rates on Grain Yield and Nitrogen Agronomic Efficiency of Durum Wheat Genotypes under Different Environments. Ann. Appl. Boil. 2016, 168, 264-273. [CrossRef]

22. Gupta, R.K.; Sidhu, H.S. Nitrogen and Residue Management Effects on Agronomic Productivity and Nitrogen Use Efficiency in Rice-Wheat System in Indian Punjab. Nutr. Cycl. Agroecosyst. 2009, 84, 141-154.

23. Mon, J.; Bronson, K.F.; Hunsaker, D.J.; Thorp, K.R.; White, J.W.; French, A.N. Interactive Effects of Nitrogen Fertilization and Irrigation on Grain Yield, Canopy Temperature, and Nitrogen Use Efficiency in Overhead Sprinkler-Irrigated Durum Wheat. Field Crops Res. 2016, 191, 54-65. [CrossRef]

24. Duan, Y.; Xu, M.; Gao, S.; Yang, X.; Huang, S.; Liu, H.; Wang, B. Nitrogen Use Efficiency in a Wheat-Corn Cropping System from 15 Years of Manure and Fertilizer Applications. Field Crops Res. 2014, 157, 47-56. [CrossRef]

25. Grahmann, K.; Govaerts, B.; Fonteyne, S.; Guzmán, C.; Soto, A.P.G.; Buerkert, A.; Verhulst, N. Nitrogen Fertilizer Placement and Timing Affects Bread Wheat (Triticum aestivum) Quality and Yield in an Irrigated Bed Planting System. Nutr. Cycl. Agroecosyst. 2016, 106, 185-199. [CrossRef]

26. Franzluebbers, A.J.; Hons, F.M.; Zuberer, D.A. Tillage and Crop Effects on Seasonal Soil Carbon and Nitrogen Dynamics. Soil Sci. Soc. Am. J. 1995, 59, 1618-1624. [CrossRef]

27. Li, S.; He, P.; Jin, J. Nitrogen Use Efficiency in Grain Production and the Estimated Nitrogen Input/Output Balance in China Agriculture. J. Sci. Food Agric. 2013, 93, 1191-1197. [CrossRef] [PubMed]

28. Rial-Lovera, K.; Davies, W.P.; Cannon, N.D.; Conway, J.S. Influence of Tillage Systems and Nitrogen Management on Grain Yield, Grain Protein and Nitrogen-Use Efficiency in UK Spring Wheat. J. Agric. Sci. 2016, 154, 1437-1452. [CrossRef]

29. Namvar, A.; Khandan, T. Response of Wheat to Mineral Nitrogen Fertilizer and Biofertilizer (Azotobacter Sp. and Azospirillum sp.) Inoculation under Different Levels of Weed Interference. Ekologija 2013, 59. [CrossRef]

30. Yang, Y.; Zhou, C.; Li, N.; Han, K.; Meng, Y.; Tian, X.; Wang, L. Effects of Conservation Tillage Practices on Ammonia Emissions from Loess Plateau Rain-Fed Winter Wheat Fields. Atmos. Environ. 2015, 104, 59-68. [CrossRef]

31. Sanz-Cobena, A.; Lassaletta, L.; Aguilera, E.; del Prado, A.; Garnier, J.; Billen, G.; Iglesias, A.; Sánchez, B.; Guardia, G.; Abalos, D.; et al. Strategies for Greenhouse Gas Emissions Mitigation in Mediterranean Agriculture: A Review. Agric. Ecosyst. Environ. 2017, 238, 5-24. [CrossRef]

32. Tian, Z.; Li, Y.; Liang, Z.; Guo, H.; Cai, J.; Jiang, D.; Cao, W.; Dai, T. Genetic Improvement of Nitrogen Uptake and Utilization of Winter Wheat in the Yangtze River Basin of China. Field Crops Res. 2016, 196, 251-260. [CrossRef] 
33. Taulemesse, F.; Le Gouis, J.; Gouache, D.; Gibon, Y.; Allard, V. Bread Wheat (Triticum Aestivum L.) Grain Protein Concentration Is Related to Early Post-Flowering Nitrate Uptake under Putative Control of Plant Satiety Level. PLoS ONE 2016, 11, e0149668. [CrossRef] [PubMed]

34. Fischer, R.A.; Howe, G.N.; Ibrahim, Z. Irrigated Spring Wheat and Timing and Amount of Nitrogen Fertilizer. I. Grain Yield and Protein Content. Field Crops Res. 1993, 33, 37-56. [CrossRef]

35. Fischer, R.A. Irrigated Spring Wheat and Timing and Amount of Nitrogen Fertilizer. II. Physiology of Grain Yield Response. Field Crops Res. 1993, 33, 57-80. [CrossRef]

36. Grant, C.A.; Stobbe, E.H.; Racz, G.J. The Effect of Fall-Applied N and P Fertilizer and Timing of N Application on Yield and Protein Content of Winter Wheat Grown on Zero-Tilled Land in Manitoba. Can. J. Soil Sci. 1985, 65, 621-628. [CrossRef]

37. Brown, B.; Westcott, M.; Christensen, N.; Pan, B.; Stark, J. Nitrogen Management for Hard Wheat Protein Enhancement. Pac. Northwest Ext. Publ. 2005, 578, 1-14.

(C) 2018 by the authors. Licensee MDPI, Basel, Switzerland. This article is an open access article distributed under the terms and conditions of the Creative Commons Attribution (CC BY) license (http:/ / creativecommons.org/licenses/by/4.0/). 

MDPI

St. Alban-Anlage 66

4052 Basel

Switzerland

Tel. +41616837734

Fax +41 613028918

www.mdpi.com

Agronomy Editorial Office

E-mail: agronomy@mdpi.com

www.mdpi.com/journal/agronomy

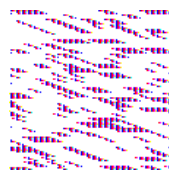



MDPI

St. Alban-Anlage 66

4052 Basel

Switzerland

Tel: +41 616837734

Fax: +41 613028918

www.mdpi.com 